\title{
LOAD DISTRIBUTION IN PRECAST WIDE-FLANGE CPCI GIRDER BRIDGES
}

BY

Magued W. Ibrahim, P.Eng.

B.Sc., Cairo University, Egypt, 1982

A Thesis

Presented to Ryerson University

In partial fulfillment of the

Requirement for the degree of

Master of Applied Science

In the program of

Civil Engineering

Toronto, Ontario, Canada, 2005

Magued Ibrahim 2005@ 


\title{
UMI Number: EC53024
}

\author{
All rights reserved \\ INFORMATION TO USERS
}

The quality of this reproduction is dependent upon the quality of the copy submitted. Broken or indistinct print, colored or poor quality illustrations and photographs, print bleed-through, substandard margins, and improper alignment can adversely affect reproduction.

In the unlikely event that the author did not send a complete manuscript and there are missing pages, these will be noted. Also, if unauthorized copyright material had to be removed, a note will indicate the deletion.

\section{$\mathrm{UMI}^{\circ}$}

UMI Microform EC53024

Copyright 2008 by ProQuest LLC

All rights reserved. This microform edition is protected against unauthorized copying under Title 17, United States Code.

ProQuest LLC

789 East Elsenhower Parkway

P.O. Box 1346

Ann Arbor, MI 48106-1346 


\section{Author's Declaration}

I hereby declare that I am the sole author of this thesis.

I authorize Ryerson to lend this document to other institutions or individuals for the purpose of scholarly research.

Magued Ib́rahim

I further authorize Ryerson University to reproduce the document by photocopying or by other means, in total or part, at the request of other institutions or individuals for the purpose of scholarly research.

IVlagucw ivianses 
Ryerson University requires the signatures of all persons using or photocopying this thesis.

Please sign below, and give address and date.

\begin{tabular}{|c|c|c|c|}
\hline Name & Address & Signature & Date \\
\hline & & & \\
\hline & & & \\
\hline & & & \\
\hline & & & \\
\hline & & & \\
\hline & & & \\
\hline & & & \\
\hline & & & \\
\hline & & & \\
\hline & & & \\
\hline & & & \\
\hline & & & \\
\hline & & & \\
\hline & & & \\
\hline & & & \\
\hline & & & \\
\hline & & & \\
\hline & & & \\
\hline & & & \\
\hline & & & \\
\hline & & & \\
\hline & & & \\
\hline & & & \\
\hline & & & \\
\hline & & & \\
\hline & & & \\
\hline & & & \\
\hline & & & \\
\hline & & & \\
\hline & & & \\
\hline & & & \\
\hline & & & \\
\hline & & & \\
\hline & & & \\
\hline
\end{tabular}




\section{ABSTRACT}

\section{LOAD DISTRIBUTION IN PRECAST WIDE-FLANGE CPCI GIRDER BRIDGES}

By Magued W. Ibrahim, B.Sc., P.Eng., for the degree of Master of Applied Science

Civil Engineering, Ryerson University, Toronto, Ontario, Canada, 2005

As Ontario bridge infrastructure enters the era of maintenance, rehabilitation and replacement, prefabricated bridge systems will certainly have many advantages as compared to the conventional systems. Prefabricated systems can be quickly assembled and the traffic can be opened in a very short period of time, minimizing the lane closure time, reducing the cost and design time, and minimizing forming and labour work. The Canadian Highway Bridge Design Code specifies simplified design method for slab-ongirder bridges in the form of moment and shear distribution factors. This thesis presents a parametric study, using the finite-element method, on a series of precast Wide-Flange $\mathrm{CPCI}$ girder bridges to examine the applicability of the CHBDC load distribution factors to this prefabricated bridge system. The parameters considered in this study include span length, number of lanes, number of girders, live load conditions, presence of intermediate diaphragms, and type of connections between individual girders. This study revealed that CHBDC load distribution factors generally overestimate the structural response of such bridges. As a result, a refined set of load distribution factor equations were developed. 


\section{ACKNOWLEDGEMENTS}

I would like to express my sincere thanks to GOD who helped and blessed me during my study.

I wish to express my deep appreciation to my advisor Dr. K. Sennah at Ryerson University, for his constant support and valuable input during the development of this research. Dr. Sennah devoted his time and effort to make this study a success. His most helpful guidance is greatly appreciated.

I wish to thank Marshall Macklin Monaghan Limited for their financial support and encouragement. I also acknowledge the support of the Ministry of Transportation of Ontario.

I am also very grateful to my late father, mother, wife, family and friends for their great support, understanding and encouragement. 


\section{TO MY FAMILY}




\section{TABLE OF CONTENTS}

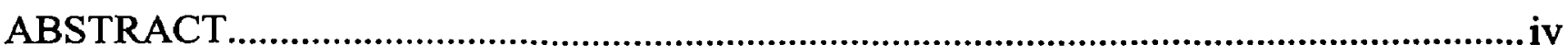

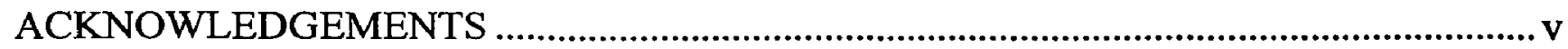

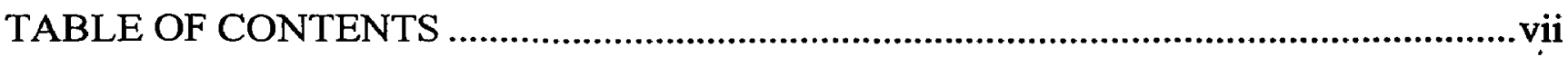

NOTATIONS

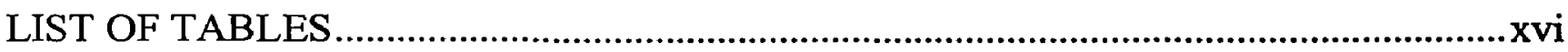

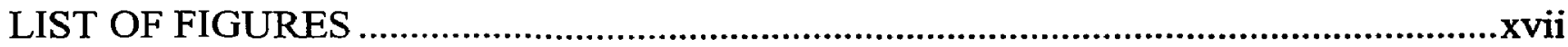

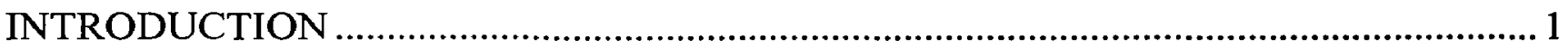

1.1 General 1

1.2 The Problem 2

1.3 Objectives 3

1.4 Scope 4

1.5 Contents and Arrangement of this Study 4

LITERATURE REVIEW

2.1 General 6

$\begin{array}{lll}2.2 & \text { Bridge Types } & 7\end{array}$

2.3 History of Prestressed Concrete Girders $\quad 8$

$2.4 \quad$ Fabrication of Prestressed Concrete Girders 9

$\begin{array}{ll}2.5 & \text { Previous Research Work } \\ 2.6 & 11\end{array}$

2.6 Simplified Methods of Analysis 20

2.7 Load Distribution and Codes of Practice for Precast Girders 23

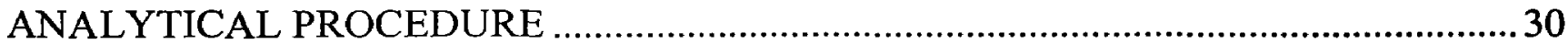

3.1 General 30

3.2 Finite Element Approach 31

3.3 SAP2000 Software 34

3.4 Finite Element Modeling of WF-CPCI Girder Bridges 35

3.4.1 Geometric Modeling 36

3.4.1.1 Modeling of Deck Slab, Webs, Bottom Flange, and Diaphragms 36

$\begin{array}{ll}\text { 3.4.1.2 Modeling of Connections } & 37\end{array}$

3.4.1.3 Modeling of Moving Load Paths $\quad 37$

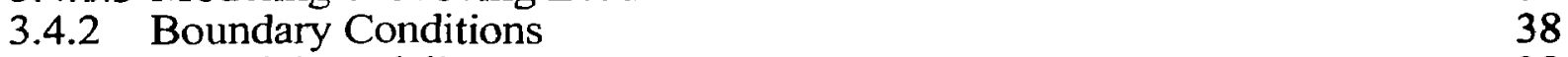

$\begin{array}{lll}\text { 3.4.3 Material Modeling } & 38\end{array}$ 
3.5 Bridge Configurations 40

3.6 CHBDC Specifications for Truck Loading 42

3.7 Loading Conditions 43

3.8 Load Distribution Factors 44

3.8.1 Load Distribution Factor for Longitudinal Bending Moments 44

3.8.2 Load Distribution Factor for Deflections 46

3.8.3 Load Distribution Factor for Vertical Shear 48

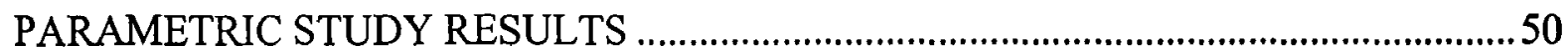

4.1 General 50

4.2 Effect of the Type of Connection between Girder Flanges 50

4.2.1 Moment Distribution Factor $\quad 52$

4.2.2 Deflection Distribution Factor $\quad 54$

4.2.3 Shear Distribution Factor $\quad 54$

4.3 Effect of Intermediate Diaphragms $\quad 55$

4.4 Effect of Span Length 56

4.4.1 Moment Distribution Factors $\quad 56$

4.4.2 Shear Distribution Factors $\quad 57$

4.4.3 Deflection Distribution Factors $\quad 58$

4.5 Effect of Number of Design Lanes $\quad 58$

4.6 Effect of Number of Girders 59

4.7 Evaluation of CHBDC Distribution Factors 60

4.8 Proposed Expressions for the Load Distribution Factors for WideFlange CPCI Girder Bridges 63

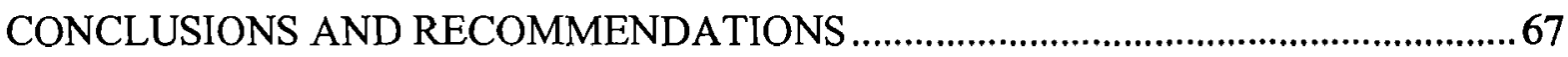

$\begin{array}{lll}5.1 \quad \text { General } & 67\end{array}$

$\begin{array}{lll}5.2 & \text { Conclusions } & 67\end{array}$

5.3 Recommendations for Future Research 69

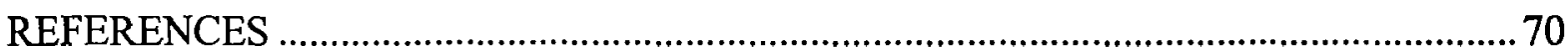

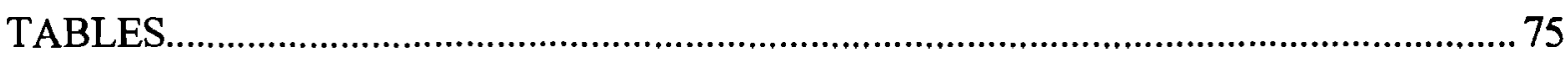

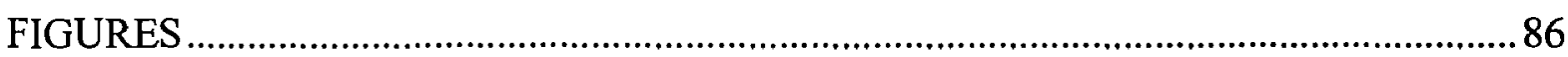

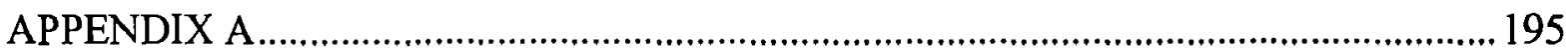

A - I. Input File For WF-CPCI 1600 Girder 30 m Span Bridge 195

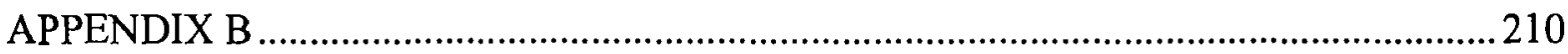

B - I. Distribution Factors for Bending Moment at Serviceability, Ultimate and Fatigue Limit States

B - II. Distribution Factors for Shear at Serviceability, Ultimate and Fatigue Limit States

B - III. Distribution Factors for Deflection at Serviceability, Ultimate and Fatigue Limit States 
B - IV. Moment Distribution Factors for $13.2 \mathrm{~m}$ Width, 6-Girder, Bridges with Various Joint Spacing

B - V. Deflection Lateral Distribution Factors for $13.2 \mathrm{~m}$ Width, 6-Girder, Bridges with Various Joint Spacing

B - VI. Shear Distribution Factors for 13.2 $\mathrm{m}$ Width, 6-Girder, Bridges with Various Joint Spacing

APPENDIX C

C - I. Accuracy factors of Bending Moment, Deflection and Shear for Various Number of Elements in The Finite Element Model 
transformation matrix from local to global coordinates

$A$

area of girder

$[B(x, y)]$

strain-displacement matrix

$b$

bridge width

C

stiffness parameter

$C_{e}$

correction factor for vehicle edge distance

$C_{f}$

correction factor

$[D]$

elasticity matrix

D

width of distribution per lane

$D_{l}$

coupling rigidity per unit width

$D_{2}$

coupling rigidity per unit length

$d_{e}$ edge distance between the centre of exterior girder and interior edge of curb or traffic barrier

$D_{f}$

distribution factor

$D_{x}$

longitudinal flexural rigidity

$D_{x y}$

longitudinal torsional rigidity per unit width

$D_{y}$

transverse flexural rigidity

$D_{y x}$

transverse torsional rigidity per unit length

E

factor depending on $d_{e}$

$E$

Young's modulus

$E_{B}$

modulus of elasticity of girder material in $\mathrm{MPa}$

$E_{c}$

Young's modulus for concrete

$E_{D}$

modulus of elasticity of deck material in MPa 
$e_{g}$

$E_{G}$

$E_{s}$

F

$f$

$f_{c}^{\prime}$

$F_{\text {fm ext }}$

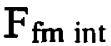

$F_{\text {fv ext }}$

$F_{\text {fvint }}$

$F_{f \delta}$ ext

$F_{f \delta}$ int

$F_{m}$

$F_{\text {mext }}$

$F_{m i n t}$

$F_{v}$

$\mathrm{F}_{\mathrm{v}}$

$F_{\text {vext }}$

$F_{v \text { int }}$

$F_{\delta}$

$\mathrm{F}_{\delta \text { ext }}$

$\mathrm{F}_{\delta \text { int }}$

G distance between the centers of gravity of the basic girder and deck in $\mathrm{mm}$

Young's modulus for girder cross section

modulus of elasticity of steel

width dimension that characterizes the load distribution for the bridge

conversion factor between metric and imperial systems

compressive strength of concrete

distribution factor for bending moment at exterior girders for fatigue

distribution factor for bending moment at interior girders for fatigue

distribution factor for shear at exterior girders for fatigue

distribution factor for shear at interior girders for fatigue

distribution factor for deflection at exterior girders for fatigue

distribution factor for deflection at interior girders for fatigue

amplification factor for the transverse variation in maximum longitudinal moment intensity (Distribution Factor)

distribution factor for bending moment at exterior girders

distribution factor for bending moment at interior girders

amplification factor for the transverse variation in maximum longitudinal vertical shear intensity (Distribution Factor)

load distribution factor for shear

distribution factor for shear at exterior girders

distribution factor for shear at interior girders

load distribution factor for deflection

distribution factor for deflection at exterior girders

distribution factor for deflection at interior girders

shear modulus 


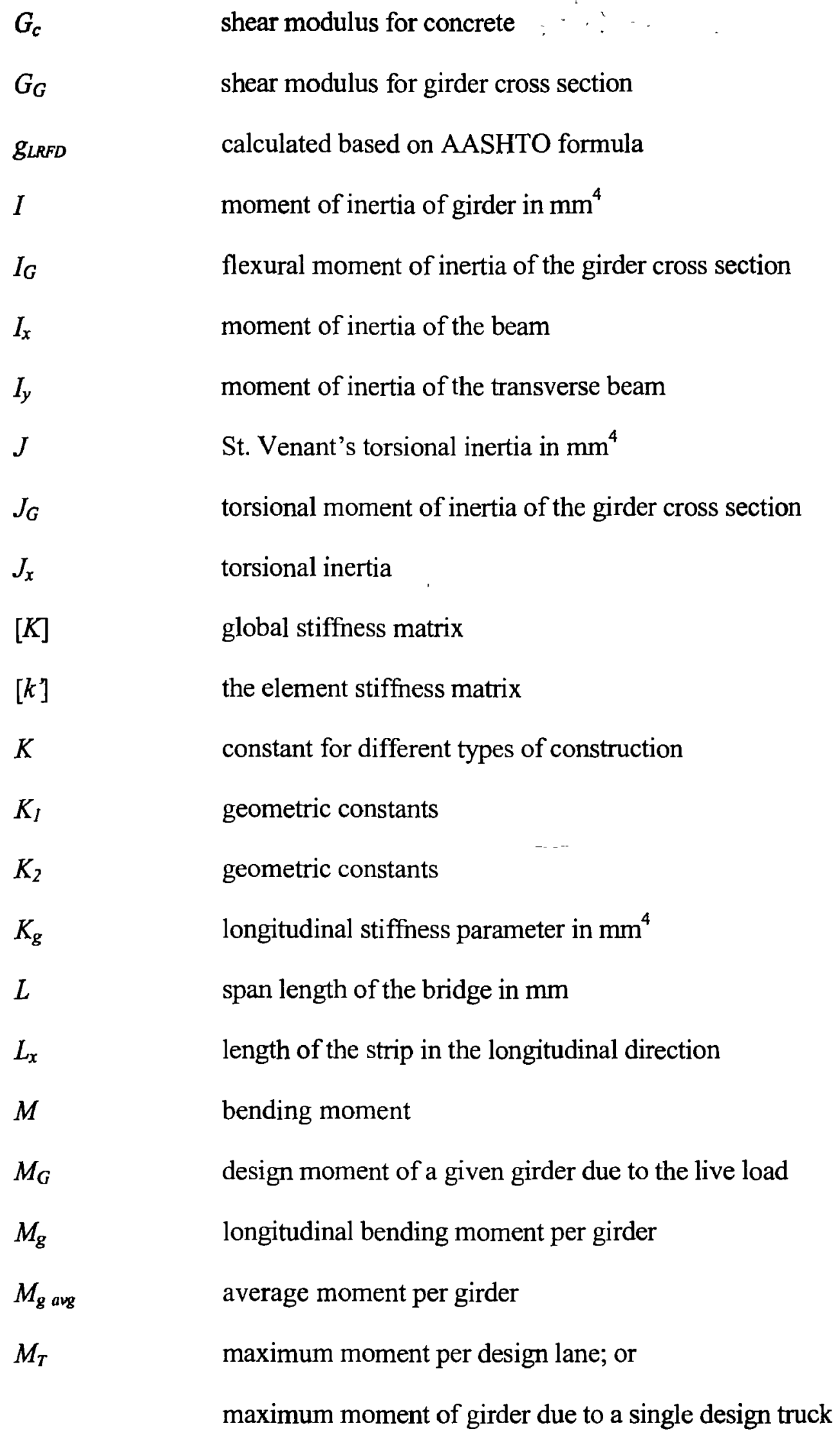


number of longitudinal girders; or

number of design lanes; or

constant

$n$

number of design lanes; or

modular ratio between girder and deck

$N_{B}$

number of girders

$N_{d}$

number of intermediate diaphragms

$N_{L}$

number of traffic lanes

$[P]$

nodal load vector

$R_{L}$

modification factor for multilane loading

$S$

centre-to-centre girder spacing; or

spacing between connections

$T$

slab/strip thickness

$t_{s}$

thickness of the concrete slab

$[U]$

nodal displacement vector

[u]

the vector of virtual displacement

$\mathrm{Ui}$

the displacement in the global axis i

$V$

$V_{\text {ext }}$

the maximum shear at the constrained joints resulting from the bridge analysis

maximum reaction at exterior girder

$V_{\text {f-ext }}$

maximum reaction at exterior girder due to fatigue loading

$V_{\text {f-int }}$ maximum reaction at interior girder due to fatigue loading

$V_{g}$ longitudinal vertical shear per girder

$V_{g \text { avg }}$

average moment per girder

$V_{\text {int }}$

maximum reaction at interior girder 


\begin{tabular}{|c|c|}
\hline$V_{o}$ & $\begin{array}{l}\text { shear for the corresponding single girder, resulting from the analysis } \\
\text { at the corresponding constrained joints of the bridge }\end{array}$ \\
\hline$V_{T}$ & maximum vertical shear \\
\hline$W$ & edge-to-edge width of the bridge in $\mathrm{mm}$ \\
\hline$W_{c}$ & deck width of the bridge between the inner face of the barrier walls \\
\hline$W_{E}$ & external virtual work \\
\hline$W_{e}$ & width of the design lane in meter \\
\hline$W_{l}$ & internal virtual work \\
\hline$y_{b}$ & distance from neutral axis to the bottom surface of the section \\
\hline$\Phi \mathrm{i}$ & the rotation around the global axis $\mathrm{i}$ \\
\hline$[\alpha]$ & generalized coordinates matrix. \\
\hline$\alpha$ & torsional parameter \\
\hline$\delta$ & deflection of girders resulting from the bridge analysis \\
\hline$\delta_{\text {ext }}$ & maximum average deflection at exterior girders \\
\hline$\delta_{\text {fext }}$ & $\begin{array}{l}\text { maximum average deflection at exterior girders due to fatigue } \\
\text { loading }\end{array}$ \\
\hline$\delta_{\text {f-int }}$ & $\begin{array}{l}\text { maximum average deflection at interior girders due to fatigue } \\
\text { loading }\end{array}$ \\
\hline$\delta_{\text {int }}$ & maximum average deflection at interior girders \\
\hline$\delta_{0}$ & deflection for single girder \\
\hline$[\varepsilon(x, y)]$ & strain matrix \\
\hline$\varepsilon$ & skew parameter \\
\hline$[\phi(x, y)]$ & displacement function matrix \\
\hline$\phi, \phi_{1}, \phi_{2}$ & parameters \\
\hline$\gamma_{c}$ & weight density \\
\hline
\end{tabular}


factor depending on $W_{e}:$

$v(x, y)$

internal displacement vector of the element

$\mathbf{v}$

Poisson's ratio

$v_{c}$

Poisson's ratio for concrete

$\theta$

flexural parameter

$\sigma$

longitudinal stresses resulting from the bridge analysis

$\sigma_{b}$

$\sigma_{\text {ext }}$

$\sigma_{\text {f-ext }}$

$\sigma_{\text {f-int }}$

$\sigma_{1 \mathrm{nt}}$

$\sigma_{\mathrm{o}}$

$\omega$

maximum average flexure stress at bottom surface of the exterior girders

maximum average flexure stress at bottom surface of the exterior girders due to fatigue loading

maximum average flexure stress at bottom surface of the interior girders due to fatigue loading

maximum average flexure stress at bottom surface of the interior girders

longitudinal stresses for single girder

skew angle in degree 


\section{LIST OF TABLES}

Table

Table 2.1 Section Properties for WF-CPCI girders

Page

Table 2.2 CHBDC expressions for $F, C_{f}$ and $C_{e}$ Factors for Slab-on-Girder

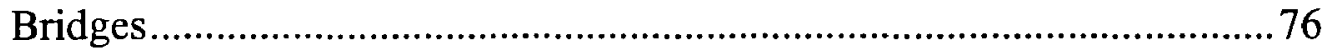

Table 3.1 Bridge Deck Configurations ......................................................................77

Table 3.2 Bridge Configurations Considered in This Study.....................................78

Table 3.3 Bridge Configurations considered to study the effect of the type of flange-to-flange connection on load distribution........................................84

Table 3.4 Modification Factors for Multilane Loading (CHBDC, 2000)...................85

Table 3.5 Number of Design Lanes (CHBDC 2000)................................................. 85

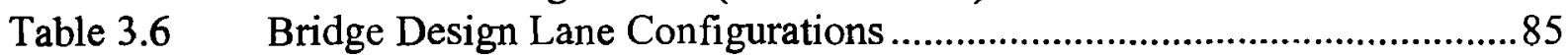




\section{LIST OF FIGURES}

Figure

Figure 1.2

Figure 2.1

Figure 2.2

Figure 2.3

Figure 2.4

Figure 2.5

Figure 3.1

Figure 3.2

Figure 3.3

Figure 3.4

Typical cross-section of WF-CPCI girder bridge system

Page

Typical section for WF-CPCI 1200 depth girders

Typical section for WF-CPCI 1400 depth girders

Typical section for WF-CPCI 1600 depth girders

89

Typical section for WF-CPCI 1900 depth girders

90

Possible connections between girder flanges

91

Shell element used in the analysis (SAP2000)

92

93

Schematic view of the SAP2000 model with continuous connections between girder flanges

Schematic view of the SAP2000 model showing the intermittent connections between girder flanges

Plan view of SAP2000 model for 6-girder bridge with no intermediate diaphragm and continuous connections between girders

Figure 3.5 View of SAP2000 model for 6-girder bridge with one intermediate diaphragm and continuous connections between girders

Figure 3.6 View of SAP2000 model for 6-girder bridge with two intermediate diaphragm and continuous connections between girders

Figure 3.7 CL-W truck and lane loading, CHBDC

Figure 3.9

Location of wheel loads for maximum bending moment on various spans

Figure 3.10 Location of wheel loads for maximum shear force on various spans

Figure 3.11.a Loading cases for three-design-lane, seven-girder, bridge with 2000 mm girder spacing

Figure 3.11.b Loading cases for three-design-lane, seven-girder, bridge with 2000 mm girder spacing

Figure 3.11.c Loading cases for three-design-lane, seven-girder bridge, with 2000 mm girder spacing

Figure 3.12.a Loading cases for four-design-lane, eight-girder, bridge with 2000 mm girder spacing

Figure 3.12.b Loading cases for four-design-lane, eight-girder, brıdge with 2000 mm girder spacing

Figure 3.12.c Loading cases for four-design-lane, eight-girder, bridge with 2000 mm girder spacing

Figure 3.13.a Loading cases for five-design-lane, nine-girder, bridge with 2000 mm girder spacing

Figure 3.13.b Loading cases for five-design-lane, nine-girder, bridge with 2000 $\mathrm{mm}$ girder spacing

Figure 3.13.c Loading cases for five-design-lane, nine-girder, bridge with 2000 $\mathrm{mm}$ girder spacing

Figure 3.14.a Loading cases for three-design-lane, six-girder, bridge with 2200 $\mathrm{mm}$ girder spacing 
Figure 3.14.b Loading cases for three-design-lane, six-girder, bridge with 2200 mm girder spacing

Figure 3.14.c Loading cases for three-design-lane, six-girder, bridge with 2200 mm girder spacing

Figure 3.15.a Loading cases for four-design-lane, seven-girder, bridge with 2200 mm girder spacing

Figure 3.15.b Loading cases for four-design-lane, seven-girder, bridge with 2200 mm girder spacing

Figure 3.15.c Loading cases for four-design-lane, seven-girder, bridge with 2200 mm girder spacing

Figure 3.16.a Loading cases for five-design-lane, eight-girder, bridge with 2200 mm girder spacing

Figure 3.16.b Loading cases for five-design-lane, eight-girder, bridge with 2200 $\mathrm{mm}$ girder spacing

Figure 3.16.c Loading cases for five-design-lane, eight-girder, bridge with 2200 $\mathrm{mm}$ girder spacing

Figure 3.17.a Loading cases for three-design-lane, five-girder, bridge with 2400 mm girder spacing

Figure 3.17.b Loading cases for three-design-lane, five-girder, bridge with 2400 $\mathrm{mm}$ girder spacing

Figure 3.17.c Loading cases for three-design-lane, five-girder, bridge with 2400 mm girder spacing

Figure 3.18.a Loading cases for four-design-lane, seven-girder, bridge with 2400 mm girder spacing

Figure 3.18.b Loading cases for four-design-lane, seven-girder, bridge with 2400 $\mathrm{mm}$ girder spacing

Figure 3.18.c Loading cases for four-design-lane, seven-girder, bridge with 2400 $\mathrm{mm}$ girder spacing

Figure 3.19.a Loading cases for five-design-lane, eight-girder, bridge with 2400 $\mathrm{mm}$ girder spacing

Figure 3.19.b Loading cases for five-design-lane, eight-girder, bridge with 2400 mm girder spacing

Figure 3.19.c Loading cases for five-design-lane, eight-girder, bridge with 2400 $\mathrm{mm}$ girder spacing

Figure 3.20 Loading cases of truck loading at the center of the design lane(s) for WF-CPCI 6-girder bridge

Figure 3.21 Longitudinal flexural stiffness $\left(D_{x}\right)$ of the WF-CPCI girder bridges

Figure 4.1 Schematic view of the intermittent connections between girder flanges

Figure 4.2 Moment distribution factors of $30 \mathrm{~m}$ span bridge eccentrically loaded with one truck

Figure 4.3 Moment distribution factors of $30 \mathrm{~m}$ span bridge eccentrically loaded with two trucks

Figure 4.4 Moment distribution factors of $30 \mathrm{~m}$ span bridge centrically loaded with three trucks

Figure 4.5 Deflection distribution factors of $30 \mathrm{~m}$ span bridge eccentrically 
loaded with one truck

Figure 4.6 Deflection distribution factors of $30 \mathrm{~m}$ span bridge eccentrically loaded with two trucks

Figure 4.7 Displacement distribution factors of $30 \mathrm{~m}$ span bridge centrically loaded with three trucks

Figure 4.8 Shear distribution factors of $30 \mathrm{~m}$ span bridge eccentrically loaded with one truck

Figure 4.9 Shear distribution factors of $30 \mathrm{~m}$ span bridge eccentrically loaded with two trucks

Figure 4.10 Shear distribution factors of $30 \mathrm{~m}$ span bridge centrically loaded with three trucks

Figure 4.11 Distribution factor for bending moment in G2 for various spacing between connections

Figure 4.12 Distribution factor for bending moment in G3 for various spacing between connections

Figure 4.13 Maximum bending moment in connections for various spacing between connections

Figure 4.14 Maximum shear force in connections for various spacing between connections

Figure 4.15 Effect of the presence of intermediate diaphragms on distribution factors for bending moment for one lane eccentrically loaded

Figure 4.16 Effect of the presence of intermediate diaphragms on distribution factors for bending moment for two-lane eccentrically loaded

Figure 4.17 Effect of the presence of intermediate diaphragms on distribution factors for bending moment for three lanes centrically loaded

Figure 4.18 Effect of the presence of intermediate diaphragms on distribution factors for deflection for one lane eccentrically loaded

Figure 4.19 Effect of the presence of intermediate diaphragms on distribution factors for deflection for two lanes eccentrically loaded

Figure 4.20 Effect of the presence of intermediate diaphragms on distribution factors for deflection for three lanes centrically loaded

Figure 4.21 Effect of the presence of intermediate diaphragms on distribution factor for shear for one lane eccentrically loaded

Figure 4.22 Effect of the presence of intermediate diaphragms on distribution factors for shear for two lanes eccentrically loaded

Figure 4.23 Effect of the presence of intermediate diaphragms on distribution factors for shear for three lanes centrically loaded

Figure 4.24 Effect of span length on moment distribution factor for exterior girder of bridges with $2000 \mathrm{~mm}$ girder spacing

Figure 4.25 Effect of span length on fatigue moment distribution factor for exterior girder of bridges with $2000 \mathrm{~mm}$ girder spacing

Figure 4.26 Effect of span length on moment distribution factor for interior girder of bridges with $2000 \mathrm{~mm}$ girder spacing

Figure 4.27 Effect of span length on fatigue moment distribution factor for interior girder of bridges with $2000 \mathrm{~mm}$ girder spacing

Figure 4.28 Effect of span length on shear distribution factor for exterior girder 
of bridges with $2000 \mathrm{~mm}$ girder spacing

Figure 4.29 Effect of span length on fatigue shear distribution factor for exterior girder of bridges with $2000 \mathrm{~mm}$ girder spacing

Figure 4.30 Effect of span length on shear distribution factor for interior girder of bridges with $2000 \mathrm{~mm}$ girder spacing

Figure 4.31 Effect of span length on fatigue shear distribution factor for interior girder of bridges with $2000 \mathrm{~mm}$ girder spacing

Figure 4.32 Effect of span length on deflection distribution factor for exterior girder of bridges with $2000 \mathrm{~mm}$ girder spacing

Figure 4.33 Effect of span length on fatigue deflection distribution factor for exterior girder of bridges with $2000 \mathrm{~mm}$ girder spacing

Figure 4.34 Effect of span length on deflection distribution factor for interior girder of bridges with $2000 \mathrm{~mm}$ girder spacing

Figure 4.35 Effect of span length on fatigue deflection distribution factor for interior girder of bridges with $2000 \mathrm{~mm}$ girder spacing

Figure 4.36 Effect of number of design lanes on bending moment distribution factor for exterior girder of $25 \mathrm{~m}$ span bridges

Figure 4.37 Effect of number of design lanes on fatigue bending moment distribution factor for exterior girder of $25 \mathrm{~m}$ span bridges

Figure 4.38 Effect of number of design lanes on bending moment distribution factor for interior girder of $25 \mathrm{~m}$ span bridges

Figure 4.39 Effect of number of design lanes on fatigue bending moment distribution factor for interior girder of $25 \mathrm{~m}$ span bridges

Figure 4.40 Effect of number of design lanes on shear distribution factor for exterior girder of $25 \mathrm{~m}$ span bridges

Figure 4.41 Effect of number of design lanes on fatigue shear distribution factor for exterior girder of $25 \mathrm{~m}$ span bridges

Figure 4.42 Effect of number of design lanes on shear distribution factor for interior girder of $25 \mathrm{~m}$ span bridges

Figure 4.43 Effect of number of design lanes on fatigue shear distribution factor for interior girder of $25 \mathrm{~m}$ span spans

Figure 4.44 Effect of number of design lanes on deflection distribution factor for exterior girder of $25 \mathrm{~m}$ span bridges

Figure 4.45 Effect of number of design lanes on fatigue deflection distribution factor for exterior girder of $25 \mathrm{~m}$ span bridges

Figure 4.46 Effect of number of design lanes on deflection distribution factor for interior girder of $25 \mathrm{~m}$ span bridges

Figure 4.47 Effect of number of design lanes on fatigue deflection distribution factor for interior girder of $25 \mathrm{~m}$ span bridges

Figure 4.48 Effect of number of girders on bending moment distribution factor for exterior girder of $25 \mathrm{~m}$ span bridges

Figure 4.49 Effect of number of girders on fatigue bending moment distribution factor for exterior girder of $25 \mathrm{~m}$ span

Figure 4.50 Effect of number of girders on bending moment distribution factor for interior girder of $25 \mathrm{~m}$ span bridges

Figure 4.51 Effect of number of girders on fatigue bending moment distribution 
factor for interior girder of $25 \mathrm{~m}$ span bridges

Figure 4.52 Effect of number of girders on shear distribution factor for exterior girder of $25 \mathrm{~m}$ span bridges

Figure 4.53 Effect of number of girders on fatigue shear distribution factor for exterior girder (for $25 \mathrm{~m}$ span)

Figure 4.54 Effect of number of girders on shear distribution factor for interior girder of $25 \mathrm{~m}$ span bridges

Figure 4.55 Effect of number of girders on fatigue shear distribution factor for interior girder of $25 \mathrm{~m}$ span bridges

Figure 4.56 Effect of number of girders on deflection distribution factor for exterior girder of $25 \mathrm{~m}$ span bridges

Figure 4.57 Effect of number of girders on fatigue deflection distribution factor for exterior girder of $25 \mathrm{~m}$ span bridges

Figure 4.58 Effect of number of girders on deflection distribution factor for interior girder of $25 \mathrm{~m}$ span bridges

Figure 4.59 Effect of number of girders on fatigue deflection distribution factor for interior girder of $25 \mathrm{~m}$ span bridges

Figure 4.60 Comparison between deflection distribution factors vs. bending moment distribution factors for exterior girder

Figure 4.61 Comparison between deflection distribution factors vs. bending moment distribution factors for interior girder

Figure 4.62 Comparison between deflection distribution factors vs. bending moment distribution factors for exterior girder for FLS

Figure 4.63 Comparison between deflection distribution factors vs. bending moment distribution factors for interior girder for FLS

Figure 4.64 Comparison between moment distribution factors of the exterior girder as obtained from FEA and CHBDC

Figure 4.65 Comparison between moment distribution factors of the exterior girder for FLS as obtained from FEA and CHBDC

Figure 4.66 Comparison between moment distribution factors of the interior girder as obtained from FEA and CHBDC

Figure 4.67 Comparison between moment distribution factors of the interior girder for FLS as obtained from FEA and CHBDC

Figure 4.68 Comparison between shear distribution factors of the exterior girder as obtained from FEA and CHBDC

Figure 4.69 Comparison between shear distribution factors of the exterior girder for FLS as obtained from FEA and CHBDC

Figure 4.70 Comparison between shear distribution factors of the interior girder as obtained from FEA and CHBDC

Figure 4.71 Comparison between shear distribution factors of the interior girder for FLS as obtained from FEA and CHBDC

Figure 4.72 Comparison between deflection distribution factors of the exterior girder as obtained from FEA and CHBDC

Figure 4.73 Comparison between deflection distribution factors of the exterior girder for FLS as obtained from FEA and CHBDC

Figure 4.74 Comparison between deflection distribution factors of the interior 
girder as obtained from FEA and CHBDC

Figure 4.75 Comparison between deflection distribution factors of the interior girder for FLS as obtained from FEA and CHBDC

Figure 4.76 Comparison between moment distribution factors of the exterior girder as obtained from FEA and CHBDC

Figure 4.77 Comparison between moment distribution factors of the exterior girder for FLS as obtained from FEA and CHBDC

Figure 4.78 Comparison between moment distribution factors of the interior girder as obtained from FEA and CHBDC

Figure 4.79 Comparison between moment distribution factors of the interior girder for FLS as obtained from FEA and CHBDC

Figure 4.80 Comparison between shear distribution factors of the exterior girder as obtained from FEA and CHBDC

Figure 4.81 Comparison between shear distribution factors of the exterior girder for FLS as obtained from FEA and CHBDC

Figure 4.82 Comparison between shear distribution factors of the interior girder as obtained from FEA and CHBDC

Figure 4.83 Comparison between fatigue shear distribution factors of the interior girder for FLS as obtained from FEA and CHBDC

Figure 4.84 Comparison between deflection distribution factors of the exterior girder as obtained from FEA and CHBDC

Figure 4.85 Comparison between deflection distribution factors of the exterior girder for FLS as obtained from FEA and CHBDC

Figure 4.86 Comparison between deflection distribution factor of the interior girder as obtained from FEA and CHBDC

Figure 4.87 Comparison between deflection distribution factors of the interior girder for FLS as obtained from FEA and CHBDC

Figure 4.88 Comparison between moment distribution factors of the exterior girder as obtained from FEA and CHBDC

Figure 4.89 Comparison between moment distribution factors of the exterior girder for FLS as obtained from FEA and CHBDC

Figure 4.90 Comparison between moment distribution factors of the interior girder as obtained from FEA and CHBDC

Figure 4.91 Comparison between moment distribution factors of the interior girder for FLS as obtained from FEA and CHBDC

Figure 4.92 Comparison between shear distribution factors of the exterior girder as obtained from FEA and CHBDC

Figure 4.93 Comparison between shear distribution factors of the exterior girder for FLS as obtained from FEA and CHBDC

Figure 4.94 Comparison between shear distribution factors of the interior girder as obtained from FEA and CHBDC

Figure 4.95 Comparison between shear distribution factors of the interior girder for FLS as obtained from FEA and CHBDC

Figure 4.96 Comparison between deflection distribution factors of the exterior girder as obtained from FEA and CHBDC

Figure 4.97 Comparison between deflection distribution factors of the exterior 
girder for FLS as obtained from FEA and CHBDC

Figure 4.98 Comparison between deflection distribution factors of the interior girder as obtained from FEA and CHBDC

Figure 4.99 Comparison between deflection distribution factors of the interior girder for FLS as obtained from FEA and CHBDC

Figure 4.100 Comparison between moment distribution factors of the exterior girder as obtained from FEA and CHBDC

Figure 4.101 Comparison between moment distribution factors of the exterior girder for FLS as obtained from FEA and CHBDC

Figure 4.102 Comparison between moment distribution factors of the interior girder as obtained from FEA and CHBDC

Figure 4.103 Comparison between moment distribution factors of the interior girder for FLS as obtained from FEA and CHBDC

Figure 4.104 Comparison between shear distribution factors of the exterior girder as obtained from FEA and CHBDC

Figure 4.105 Comparison between shear distribution factors of the exterior girder for FLS as obtained from FEA and CHBDC

Figure 4.106 Comparison between shear distribution factors of the interior girder as obtained from FEA and CHBDC

Figure 4.107 Comparison between shear distribution factors of the interior girder for FLS as obtained from FEA and CHBDC

Figure 4.108 Comparison between deflection distribution factors of the exterior girder as obtained from FEA and CHBDC

Figure 4.109 Comparison between deflection distribution factors of the exterior girder for FLS as obtained from FEA and CHBDC

Figure 4.110 Comparison between deflection distribution factors of the interior girder as obtained from FEA and CHBDC

Figure 4.111 Comparison between deflection distribution factors of the interior girder for FLS as obtained from FEA and CHBDC

Figure 4.112 FEA results versus proposed equation for moment distribution factor of exterior girder

Figure 4.114 FEA results versus proposed equation for moment distribution factor of interior girder

Figure 4.115 FEA results versus proposed equation for moment distribution factor of interior girder for FLS

Figure 4.116 FEA results versus proposed equation for shear distribution factor of exterior girder

Figure 4.117 FEA results versus proposed equation for shear distribution factor of exterior girder for FLS

Figure 4.118 FEA results versus proposed equation for shear distribution factor of interior girder

Figure 4.119 FEA results versus proposed equation for shear distribution factor of interior girder for FLS 


\section{CHAPTER I}

\section{INTRODUCTION}

\subsection{General}

In bridge design it is necessary to obtain an appropriate geometric layout for the structure so that it can safely and economically carry the loads imposed on it. In densely populated cities, elevated freeways and multi-level interchange structures are necessary. Nowadays, precast bridges have become an important component in highway bridges, especially when construction time and staging restrictions are often encountered. Precast prestressed bridges allow for rapid construction, less disturbance to the traffic flow and significant improvement in the quality and the durability of the structure with less environmental effect.

Precast prestressed concrete bridges have become increasingly popular. Approximately two-third of the bridges, with span length from 18 to $36 \mathrm{~m}$, are constructed using prestressed girders [41]. According to the National Bridge Inventory during the 1990s in the United States of America, it was observed that the precast prestressed concrete I-girder systems form about 50 percent of the prestressed concrete bridges built in the last 40 years [41].

Precast prestressed Wide-Flange girder technology, with the elimination of the castin-place concrete slab, is currently being investigated by the Ministry of Transportation of Ontario (MTO) as an innovative approach to the construction and rehabilitation of bridges that can potentially yield substantial economic benefits to the bridge authorities [19]. 
Figure 1.1 shows views of the Wide-Flange CPCI girders with longitudinal connections between them, while, Figure 1.2 shows typical cross section of such bridge system. Also, in 2001, the American Association of State Highway and Transportation Officials' Technology Implementation Group (TIG) selected prefabricated bridge elements and systems as one of their focus technologies, which are innovative technologies that are targeted for rapid implementation due to their high pay-off potential [36]. However, highway administrators, bridge designers and researchers face problems for which information already exists, either in documented form or as undocumented experience and practice. This information may be fragmented, scattered, and unevaluated for a specific use. As a consequence, full knowledge of what has been learned about a problem may not be brought to bear on its solution. Costly research findings may be gone unused, valuable experience may be overlooked, and due consideration may not be given to recommend practices for solving or alleviating the problem. An extensive literature review to assemble and evaluate such information and make it useful for type of innovative bridge systems is urgently required.

\subsection{The Problem}

Currently, the Canadian Highway Bridge Design Code (CHBDC), CAN/CSA-S600 [11], provides simplified method of analysis in the form of load distribution factors for slab-on-girder bridges. As per CHBDC, simplified methods of analysis for the live load are based upon the analysis resulting from many bridge structures using grillage, semicontinuum and finite element methods for which the idealized structure was essentially an orthotropic plate [11]. MTO developed a software program called "CANBAS" which designs the bridges based on two-dimensional analyses, in accordance with the simplified 
methods of analysis specified in the CHBDC. Recent software programs available in the market, based on finite element method, provide more powerful tools to analyze the structure using three-dimensional shell-element models for bridges.

Despite the general availability of computers and computer software programs for the bridge analysis, bridge designers in North America strongly prefer simplified methods of analysis to reduce the time spent in the design that will be reflected on a considerable reduction in design cost [7]. Since CHBDC load distribution factors were based on an equivalent orthotropic plate approach for general slab-on-girder bridges, a parametric study is required to investigate the applicability of these factors on the precast system considered in this thesis, especially when modelled using the three-dimensional finite element approach. If CHBDC is proved highly conservative, simplified expressions for load distribution factors for bending moment, shear, and deflection for ultimate, serviceability and fatigue limit states, focused on precast prestressed wide-flange CPCI girder bridges based on results from this study, are needed.

\subsection{Objectives}

The objectives of this study are:

1. To conduct a sensitivity study, using the three-dimensional finite-element modeling, on the effect of the type of joints between the precast wide-flange CPCI girders (intermittent connection or continuous connection) on the load distribution among girders.

2. To carry out a practical-design-oriented parametric study, using the threedimensional finite-element modeling, on the structural response of prefabricated 
, $=$ bridge system when subjected to CHBDC truck loading condition, and correlate the results with the specified CHBDC load distribution factor for slab-on-girder bridges.

3. To develop refined expressions of the load distribution factors for the studied prefabricated bridges.

\subsection{Scope}

The scope of this study includes the following:

1. A literature review of the types of bridges, theoretical research work, types of connections between girders along their longitudinal edges, and the available simplified methods of analysis for slab-on-girder bridges.

2. Parametric study on 24 WF-CPCI girder bridge superstructures to examine the change in the load distribution among girders for fully moment-transferring longitudinal connections between the precast girders or for intermittent connections with various spacing.

3. Parametric study on $189 \mathrm{WF}-\mathrm{CPCl}$ girder bridge superstructures to evaluate their load distribution factors for longitudinal bending stresses, shear force and deflection for ultimate, serviceability and fatigue limit states under CHBDC truck loading.

\subsection{Contents and Arrangement of this Study}

In chapter 2, previous work and literature review pertained to precast prestressed girder bridges are presented. Chapter 3 describes the procedure of parametric study conducted on various types of WF-CPCI girder bridges of different geometries and loading 
conditions. This chapter includes the principals of the finite element analysis and the details of the finite element model developed using SAP2000 software. Chapter 4 includes the results from the parametric study. Also, this chapter presents comparisons between the results from the finite element analysis and those calculated from the expressions specified in the CHBDC simplified methods of analysis for bending moment, shear and deflection for ultimate, serviceability and fatigue limit states. Finally, Chapter 5 summarizes the findings of this research, outlines conclusions reached and provides recommendations for future researches. 


\section{CHAPTER II}

\section{LITERATURE REVIEW}

\subsection{General}

Studying the structural response of a bridge to live loads is a complex task. The design values for bending moment, deflection or shear force for interior and exterior girders depend on the location and the number of moving trucks on the bridge deck, boundary conditions and the cross section properties of the bridge components. The design values of bending moment, deflection and shear force in the girder vary with the change in girder spacing, girder span, flexural and torsional stiffness and the number of intermediate diaphragms. The presence of curvature, skew and continuity of spans further complicate the task of estimating these design parameters. To simplify the design process, North American bridge codes, such as CAN/CSA-S6-00 (CHBDC) [11], AASHTO Load and Resistance Factor Design (LRFD) Specifications (2004, 2000 and 1998) [1, 2 and 3], and AASHTO Standard Specifications (1996) [4], treat the longitudinal and transverse effects of wheel loads as uncoupled phenomena [9]. Based on these codes, to obtain the design moment, deflection and shear force, the maximum moment, deflection, and shear force caused by a single truck live load are obtained using a single girder. Then, the values are to be amplified by a factor, which is usually referred to as the live load distribution factor.

The literature survey conducted is presented as follows: (1) Bridge types, (2) History of prestressed concrete girders, (3) Fabrication of prestressed concrete girders, (4) Previous research work, (5) Simplified methods of analysis, and (6) Load distribution and codes of 
practice for precast girders.

\section{$2.2 \quad$ Bridge Types}

Generally, bridges can be constructed entirely from reinforced concrete, pre-stressed, post-tensioned concrete, steel, wood or composite concrete deck-steel girders. These bridges may be comprised of a wood deck, concrete slab or steel deck on wood, concrete or steel girders. Many types of bridges have been used significantly on highway and road to facilitate the traffic flow. The bridge types covered by the simplified methods of analysis in the CHBDC [11] are as follows:

1. Reinforced / post-tensioned solid slab

2. Post-tensioned circular / trapezoidal voided deck

3. Deck-on-girders, including concrete slab-on-girder, steel grid deck on girder and wood deck on girder

4. Truss and arch

5. Rigid frame and integral abutment types

6. Bridges incorporating wood beams

7. Box girder single cell, multicell and multispine

8. Cable Stayed

9. Suspension

One of the most common types of bridges in Canada is the concrete slab on precast prestressed girders. As commonly known, precast prestressed can be defined as short spans 
for bridges up to $20 \mathrm{~m}$ spans, medium from 20 to $35 \mathrm{~m}$ spans and long for over $35 \mathrm{~m}$ spans [41]. The current study deals with concrete slab cast monolithically with CPCI girder bridges, as shown in Figures 2.1 to 2.4. While Table 2.1 summarizes section properties of these bridge cross-sections.

\subsection{History of Prestressed Concrete Girders}

The concept of prestressed concrete was discovered by the engineer P.H. Jackson, San Francisco, California, who patented the concept in 1872 and used it for tightening concrete blocks for floor slabs. The German Engineer C.E.W Doehring obtained a patent for prestressed concrete slab using metal wires concept about 1888 [32]. All these attempts were unsuccessful, because the prestressing force, in low strength steel, was lost due to the losses at early age of concrete. In 1927, the French engineer E. Fressynet (1879-1962) demonstrated the usefulness of prestressing using high-strength steel to control prestress losses [41]. In 1950, prestressed concrete bridge construction evolved with a two-span bridge of $6.1 \mathrm{~m}$ and $9.1 \mathrm{~m}$ span lengths [41]. Since the 1950 's, various configurations of precast prestressed concrete girders have been developed in many countries around the world for short-span bridges between $20 \mathrm{~m}$ and $36 \mathrm{~m}$. In 1956, three types of these girders; I-, U-, and box-girders, were adopted in North America Standards which became known as AASHTO/PCI girders [17]. As demand for longer-span and continuous bridges grew with time, new sections and modifications of existing sections were developed. These include several sections of so-called bulb-T and NU girders, which composed of I-girders with wider top flanges $[21,20,27]$. Currently, the NU girder types are widely used in western Canada [15]. In 1983, Chelak introduced the improvement of the Deck Bulb T girders used 
by Alberta Transportation. One of the major improvements is to make the web thickness $160 \mathrm{~mm}$ to meet the minimum requirements for the concrete cover to the stirrups [12]. In 1994, Yamane et al. presented the state-of-the-art of precast pretensioned beams section configurations for short-span bridges, using cast-in-place top slab and diaphragms, constructed in the United States and Japan [43].

Composite concrete deck slabs with precast prestressed girders have been extensively used in Canadian highways. This type of bridges has proven to be economical in North America and other parts of the world [18]. In Ontario, the most frequently used precast prestressed girders for bridges are the CPCI and box-girder types, as specified by the Canadian Precast/Prestressed Concrete Institute manuals.

In 2003, MTO started a project to investigate the feasibility of constructing/rehabilitating bridges using prefabricated beam elements. This resulted in using $22 \mathrm{~m}$ single-span integral abutment bridge type using CPCI girders cast monolithically with the concrete slab in replacing a bridge in Northern Ontario [19].

\subsection{Fabrication of Prestressed Concrete Girders}

Precast prestressed girders are constructed with constant dimensions in a steel form. Strands are placed after the reinforcing steel and pre-tensioned using jacks from out side the form. Hold-down points at defined locations are used to allow bending the strands from bottom layers at the middle of the girder to the upper surface at both ends.

$\mathrm{CPCI}$ girder types are the most commonly used prefabricated girders for bridges in Ontario. These girders comprise of $660 \mathrm{~mm}$ wide bottom flange, $160 \mathrm{~mm}$ thick web and $910 \mathrm{~mm}$ top flange [35]. Also, Bulb-T girder types, with a thin top flange using cast- 
in-place concrete slab, are widely used in New Brunswick [40]. New girders are used in the current research and comprised of, identical bottom flange and web thickness, to CPCI girders but with wider top flange to form the concrete slab. Therefore, the abbreviation WF-CPCI for this newly adopted girder types will be used in the course of the current study for simplicity. This abbreviation stands for Wide Flange-Canadian Precast Concrete Institute girder. The top flange width varies from 2.0 to $2.4 \mathrm{~m}$ with a constant thickness of $225 \mathrm{~mm}$ to accommodate the minimum required thickness for using the simplified design method outlined in the CHBDC. The minimum width of the flange was chosen $2.0 \mathrm{~m}$ to provide a reasonable spacing between girders and provide economical structures. The maximum width of the top flange is limited to $2.4 \mathrm{~m}$ to reduce the total weight of the girder for the ease of fabrication, transportation and construction. This type of girders will be used with no additional cast-in-place top slab for the bridge deck, or concrete overlay, as the top flanges with different connection types will form the final deck surface. This will enhance the durability of the top surface of the structure and will significantly reduce the cost by reducing the in-situ construction period of the structure. The main difference between the WF-CPCI and the AASHTO/PCI Deck Bulb-Tee girders is the constant $225 \mathrm{~mm}$ thickness of the top flange that allows for the design using the simplified method of analysis in CHBDC without using cast-in-place overlay or top slab. Also, the thickness of the top flange allows for two layers of reinforcing steel and a full connection between girders using the required standard splices. The major advantage of the monolithic section is that the centre of gravity of the section becomes higher resulting in larger eccentricity of the strands to the neutral axis with more efficient prestressing system. The advantage of this type of girders in the design of the 
superstructure is that the self-weight of the slab will be applied to the entire section rather than to the naked girder, without top slab, in slab-on-girder bridges. Details of different WF-CPCI girder types are presented in Figures 2.1 to 2.4. Possible examples for the types of longitudinal intermittent and continuous connections between the girders are provided in Figure 2.5. However, more details on the type of connections and their structural performance up to complete collapse were reported by Sennah et al. [38].

\subsection{Previous Research Work}

This section summarizes previous research work pertained to load distribution in slab-on-girder bridges. An analytical procedure for determining shear and moment due to live load for both composite and non-composite bridges was developed by Newmark et al. [33]. Newmark et al. analyzed a number of bridges using simplified assumptions based on elastic theory. They recommended the following relationship for the transverse distribution of total longitudinal moment at a cross section in multi-girder bridges and presented the result of their work in a series of tables containing the fixed-end moments, distribution factors, and the carryover factors for both non-composite and composite slab-on-girder bridges.

$$
\begin{aligned}
M_{G} & =D_{f} M_{T} \\
D_{f} & =\frac{S}{K}
\end{aligned}
$$

where $M_{G}$ is the design moment of a given girder due to the live load at the section of interest, $M_{T}$ is the maximum moment of the same girder due to a single design truck, $D_{f}$ is the distribution factor, $S$ is the girder spacing in meter and $K$ is a constant in meter. 
Newmark et al. [33] suggested $K$ of $1.676 \mathrm{~m}$. The 1996 version of AASHTO standard [4] uses the same formula for girder spacing up to $1.829 \mathrm{~m}$ in order to determine the design moment for each girder in composite bridges. Experimental research work was carried out by Newmark et al. at the University of Illinois to verify the above equations [33]. The Ontario Highway Bridge Design Code (OHBDC), (1983 and 1991) [31, 30] and Canadian Highway Bridge Design Code (CHBDC, 2000) [11] adopted the basic approach of Newmark et al. for calculating the live load design moment for girders. The maximum live load moment in each girder is obtained by multiplying the maximum moment due to the design live load by distribution factor $D_{f}[9]$.

In the early fifties, to better assess the live load distribution in slab-girder bridges, more rigorous analyses were performed based on the orthotropic plate theory. In this approach, an equivalent orthotropic plate is analyzed instead of the actual bridge. This transformation, however, in many cases cannot fully simulate the real bridge behaviour. With the introduction of computers into engineering calculations, bridge engineers could use refined numerical techniques to study load distribution problems. Different bridge responses were analyzed and evaluated for various loading conditions. Researchers started to develop simplified methods for bridge design, implementing distribution factors for the bending moment in the longitudinal direction as a factor of the calculated longitudinal moment resulted from single girder. In 1994, Dorton [16] studied and addressed the significant improvement to the Canadian design codes since 1950 to the draft of the CHBDC that was supposed to be issued in 1996.

In 1979, Bakht et al. [6] used the concept of orthotropic plate to develop a simplified method for calculating the design live load longitudinal moments. In their research, they 
conducted extensive parametric studies, which led them to find out that the distribution factor of bridges is related to a torsional parameter $\alpha$ and a flexural parameter $\theta$, which are functions of geometry and material properties of the bridge. These parameters are given by:

$$
\begin{aligned}
& \alpha=\frac{D_{x y}+D_{y x}+D_{1}+D_{2}}{2\left(D_{x} D_{y}\right)^{55}} \\
& \theta=\frac{b}{2 L}\left(\frac{D_{x}}{D_{y}}\right)^{025}
\end{aligned}
$$

where $b$ is the bridge width, $L$ is the span length of the bridge and the various rigidities are given by:

$$
\begin{aligned}
& D_{x}=\frac{E_{G} I_{G}}{S}+\frac{E_{c} t^{3}}{12} \\
& D_{y}=\frac{E_{c} t^{3}}{12\left(1-v_{c}^{2}\right)} \\
& D_{x y}=\frac{G_{G} J_{G}}{S}+\frac{G_{c} t^{3}}{6} \\
& D_{y x}=\frac{G_{c} t^{3}}{6} \\
& D_{1}=D_{2}=v_{c} D_{y}
\end{aligned}
$$

where $E_{c}, G_{c}$ and $v_{c}$ are the Young's modulus, the shear modulus and the Poisson's ratio, respectively, $t$ is the concrete slab thickness, $S$ is the girder spacing, $I_{G}$ and $J_{G}$ are the flexural and torsional moment of inertia of the girder cross section, respectively. The subscript $G$ refers to girder and $c$ refers to the concrete slab. This method gives better results than the AASHTO recommendations [4] that assume the girder spacing $S$ is the only 
parameter that affects load distribution in slab-on-girder bridges. This method formed the basis of the 1991 version of the OHBDC [30] as well as the CHBDC provisions [11].

In 1982, Jaeger and Bakht [24] used the grillage analogy method for the idealization of slab and beam bridges. In grillage analogy method, the longitudinal members were positioned to coincide with the actual girders centerlines and were given the properties of the composite section [22]. The transverse members were considered as beams replacing the strips of the top slab. The moment of inertia, $I_{y}$, of the transverse beam is considered as follows:

$$
I_{y}=\frac{L_{x} t^{3}}{12} I_{x}
$$

And the torsional inertia, $J_{x}$, is given by the relationship:

$$
G_{c} J_{x}=E_{c} I_{y}
$$

In which results to:

$$
J_{x}=\left(\frac{E_{c}}{G_{c}}\right)\left(\frac{L_{x} t^{3}}{12}\right)
$$

where $L_{x}$ is the length of the strip in the longitudinal direction, $t$ is the thickness of the strip, $E_{c}$ and $G_{c}$ are the concrete material modulus of elasticity and the shear modulus respectively. Details of simplified methods of analysis, which are also applicable for AASHTO loading, are given by Bakht and Jaeger [8].

In 1984, Kostem [25] used the finite element method to determine the transverse distribution of moments in composite bridges. He examined the distribution factors provided in 1977 version of the AASHTO standard. His research on eight simple-span prestressed concrete bridges indicated that the design parameters that govern the load 
distribution are beam spacing, span length, width of the bridge and the number of beams. He proposed the following equation for load distribution factor in concrete slab-on-girder bridges:

$$
D_{f}=\left(2 \frac{N_{L}}{N_{B}}\right)+K_{1}\left(\frac{S}{L}\right)^{n}+K_{2}
$$

where $N_{L}, N_{B}, S$, and $L$ are the number of traffic lanes, number of girders, girder spacing and span length of the bridge, respectively. $K_{I}$ and $K_{2}$ are geometric constants that depend on bridge width, number of girders, and number of traffic lanes, while $n$ is a constant.

In 1986, other investigation was carried out by Kuzmanovic and Sanchez [26], using the finite element method, to study the response of three types of structures, namely: beam and slab, multi-girder and box girder bridges. They concluded that the accuracy of the transverse load distribution factor is the key to make a really economical design.

In 1989, Ho et al. [23] performed Analysis on slab-on-girder bridges using finite strip method and checked the results with those obtained from the grillage analogy method. They provided design curves to obtain a distribution factor for the design moment. They believed that the accuracy of these curves is much higher than those factors obtained from the simplified method specified in the 1983 version of OHBDC.

In 1988, Nut et al. [34] presented a study on the distribution of wheel loads on highway bridges. A most recent version of the elastic load distribution factor for bridges was introduced by Zokaie, et al. [45]. This new distribution factor formed the basis of the AASHTO standard of 1996. According to their study, the distribution factors of the longitudinal bending moment to interior girders for slab-on-girder bridges are given by the - following equations: 
For one traffic lane:

$$
D_{f}=0.1+\left(\frac{S}{4}\right)^{0.4}\left(\frac{S}{L}\right)^{0.3}\left[\frac{K_{g}}{L t_{s}^{3}}\right]^{0.1}
$$

For two or more traffic lanes:

$$
D_{f}=0.15+\left(\frac{S}{3}\right)^{0.6}\left(\frac{S}{L}\right)^{02}\left[\frac{K_{g}}{L t_{s}^{3}}\right]^{01}
$$

The transverse distribution factor of the longitudinal shear for slab-on-girder bridges is given by the following equations:

For one traffic lane:

$$
D_{f}=0.6+\left(\frac{S}{15}\right)
$$

For two or more traffic lanes:

$$
D_{f}=0.4+\left(\frac{S}{6}\right)-\left(\frac{S}{25}\right)^{2}
$$

where $S, L, K_{\mathrm{g}}$ and $t_{s}$ are the spacing between girders in feet, the span length in feet, the longitudinal stiffness parameter and the slab thickness in feet, respectively. For exterior girders, they introduced correction factors to the previous equations of the interior girders for moment and shear.

In 1999, Chen performed a finite element analysis, using ADINA software program, on simple span precast prestressed concrete bridges using three types of AASHTO I-girders [13], to evaluate the live load distribution factors for bending moments used in AASHTO and AASHTO-LRFD. The finite element model includes shell elements for the top slab, 
frame elements representing the precast concrete girders and rigid links to link between the shell and the frame elements. She concluded that the factors derived from the finite element analysis were lower than the factors from AASHTO and AASHTO-LRFD. Also, Chen recommended that the finite element method should be used for future bridge projects [13].

In 2000, Zokaie [44] carried out extensive analysis using grillage and finite element analysis to verify and evaluate the formulas, developed earlier in 1991 [45]. In the finite element model, shell elements were used to represent the deck slab and frame elements to represent the precast girders [44]. In his study, Zokaie calibrated the developed formulas for moment and shear distribution factors to the interior and the exterior girders for bridges that are designed for one, two or more traffic lanes. According to this study, the distribution factor of longitudinal bending moment for slab-on-girder bridges for interior girders was given by the following equations:

For one traffic lane:

$$
D_{f}=0.1+\left(\frac{S}{4 f}\right)^{04}\left(\frac{S}{L}\right)^{03}\left[\frac{K_{g}}{L t_{s}^{3}}\right]^{0.1}
$$

For two or more traffic lanes:

$$
D_{f}=0.15+\left(\frac{S}{3 f}\right)^{06}\left(\frac{S}{L}\right)^{02}\left[\frac{K_{g}}{L t_{s}^{3}}\right]^{0.1}
$$

The distribution factor of the longitudinal shear for slab-on-girder bridges for interior was given by the following equations: 
For one traffic lane:

$$
D_{f}=0.6+\left(\frac{S}{15 f}\right)
$$

For two or more traffic lanes:

$$
D_{f}=0.4+\left(\frac{S}{6 f}\right)-\left(\frac{S}{25 f}\right)^{2}
$$

where $S, L, K_{g}$ and $t_{s}$ are the spacing between girders, the span length, the longitudinal stiffness parameter, and the slab thickness, respectively. The factor $f$ is a conversion factor between metric and imperial systems equal to $304.8 \mathrm{~mm}$ and $1.0 \mathrm{ft}$.

For exterior girders for one traffic lane, the factor 1.0 was provided for moment and shear related to the single beam distribution. For exterior girders for two or more traffic lanes, multiplication factors to the factors provided for interior girders are given as follows:

For bending moment for two or more traffic lanes:

$$
e=\frac{7 f+d_{e}}{9.1 f} \geq 1.0
$$

For shear for two or more traffic lanes:

$$
e=\frac{6 f+d_{e}}{10 f}
$$

where $d_{e}$ is the edge distance. The factor $f$ is a conversion factor between metric and imperial systems which equal to $304.8 \mathrm{~mm}$.

Zokaie [44] concluded that the results from the formulas previously provided in 1991 were within $5 \%$ of the results from the finite element analysis that he performed in his 
study in the year 2000 .

In 2001, Shahawy and Huang [39] performed an extensive theoretical analysis with field testing and proposed some modifications to the load distribution formulas of the AASHTO code in the case of concrete slab-girder bridges. According to their investigation, the AASHTO code provisions were found accurate enough for one design lane load but for two or more design lanes loaded some modifications should be applied as follows:

For interior girder:

$$
g_{\text {interor }}=g_{L F R D}(1-\phi)
$$

For exterior girder:

$$
g_{\text {exteror }}=g_{\text {LFRD }}(e)
$$

where $g_{L F R D}$ is calculated based on AASHTO formula and $\phi=\phi_{1} \times \phi_{2}$. Parameters $\phi_{1}$ and $\phi_{2}$ were derived and given in charts, $\mathrm{e}=0.77+d_{e} / 2800 \geq 1.0$, where $d_{e}$ is the overhang distance, i.e. is the distance between the centre of exterior girder and interior edge of curb or traffic barrier.

In 2001, Schwarz and Laman carried out experimental program on three bridges, slab on concrete-I-girders type for one lane and two lane truck loadings for the comparison to the AASHTO-LRFD and to assess the numerical grillage model used in the analysis [37]. They performed tests on three bridges of 10.3, 23.3 and $31.1 \mathrm{~m}$ span lengths. For one loaded lane, the comparison between the load tests and the grillage model indicated that the results from grillage analysis are higher than those obtained from load tests by $32 \%$ to $38 \%$ for the interior girder under the load and less than $10 \%$ for exterior girder for the shortest 
span. For the other two bridges with longer spans, the results obtained from the grillage model exceeded the results obtained from load tests by less than $30 \%$ for the interior girder and 10 to $20 \%$ for the exterior girder. Furthermore, the load distribution factors obtained from grillage analysis were higher than the calculated factors from AASHTO-LRFD by at least $17 \%$. They concluded that results form grillage model were in close agreement with the measured results, neglecting the transverse diaphragm in the grillage analysis model.

In 2001, Barr et al. used the finite element analysis to study live load distribution factors for bending moment for three-span skew prestressed concrete girder bridge [9]. They used shell elements for the top cast-in-place slab and frame elements for the precast prestressed girders. Rigid links were used to connect the shell elements with the frame elements that located at the neutral axes of the girders. They compared the results with the expressions for distribution factors for bending moment specified in AASHTO-LRFD Specifications of 1998, the AASHTO Standard Specifications of 1996, and the OHBDC of 1991. They observed that the distribution factors from the finite element model were $6 \%$ to $28 \%$ lower than those calculated from AASHTO-LRFD Specifications and AASHTO Standard. However, the distribution factors obtained from the finite element analysis were observed to be close, in some models, to those calculated from OHBDC and were unconservative in other models.

\subsection{Simplified Methods of Analysis}

The CHBDC, 2000 [11], as well as the 1991 version of the OHBDC [30], specifies simplified method of analysis for live load using load distribution factors for slab-on-girder bridges. For OHBDC, the simplified method of analysis for the live load is based on 
considering the bridge as a rectangular orthotropic plate that was simply supported at two opposite ends on unyielding line supports which were continuous across the width of the plate and did not impose moment restraint. For CHBDC, the simplified method of analysis for the live load is based on the results from many bridge structures using grillage, semi-continuum and finite element methods for which the idealized structure was essentially an orthotropic plate. There are conditions and limitations for the use of simplified method of analysis. Two specified requirements for the concrete deck on precast girders are specified (the longitudinal moment is to be resisted by a composite section comprised of the girder and the effective part of the deck slab, and the transverse moment is to be taken by the deck slab). The conditions, specified in the CHBDC for applying simplified methods of analysis on straight bridges, are as follows:

1. The bridge width is constant;

2. The support conditions are closely equivalent to line support;

3. The skew Parameter $(\varepsilon=S \tan \omega / L)$ does not exceed $1 / 18$ where $S$ is the spacing between girders, $\omega$ is the skew angle and $L$ is the span length;

4. There shall be at least three longitudinal girders that are of equal flexural rigidity and equally spaced or with variation from the mean of not more than $10 \%$ in each case; and

5. The overhang does not exceed $60 \%$ of the mean spacing between longitudinal girders and not more than $1.80 \mathrm{~m}$.

These restrictions have been provided for the consistency between the methods of analysis in CHBDC and OHBDC. Shear-connected beam bridges are analyzed by the 
methods applicable to shallow superstructure provided that continuity of transverse flexural rigidity across the cross-section is present. If not, analysis for longitudinal moments and shears is by the same method as for multispine box girders.

When the skew angle, $\omega$, of a bridge is less than $20^{\circ}$, it has usually been considered safe to ignore the skew angle and analyze the bridge as a right bridge whose span is equal to the skew span. The implication of this practice is that the angle of skew is considered to be the only necessary measure of the skewness of the bridge with respect to its load distribution characteristics. Extensive comparative analyses of skew and equivalent right bridges conducted by Jaeger and Bakht [24] showed that the angle of skew of the bridge is not the only necessary measure of its skewness, which is also affected by its span, width and girder spacing, if present. In particular, it has been shown that a dimensionless parameter characterizing the skewness of a slab-on-girder bridge is $S \tan \omega / L$. For permitting the analysis of a skew bridge as an equivalent right bridge, the Code has imposed the upper limit of $1 / 18$ for this parameter to ensure that the shear values in particular are not in unsafe error by more than $5 \%$. CHBDC noted that the force effects in skewed, slab-on-girder type bridges may be analyzed by the simplified methods presented, if the other conditions of the simplified method are met. The simplified method presented in the Code enable the designer to calculate the increased shear effects that occur with increase in skewness.

CHBDC stated that the two limitations pertaining to an overhanging deck slab, noted in condition 5, relate to the need to have the structure remain such that the orthotropic plate approximation is closely applicable. For a slab-on-girder bridge with equally spaced girders a distance $S$ apart, a cantilever overhang of $S / 2$ on either side is the desired condition, since each longitudinal girder can then be associated in a width $S / 2$ of deck on either side of its 
centreline; a uniformly distributed load over the entire deck area would then result in the girders sharing equally in accepting the total longitudinal responses. If the overhang is permitted to be a maximum of $0.6 S$, the outer girders then accept rather more bending moment and shear force than the interior ones, but the departure from uniformity is still acceptable. So far as the limitation on the deck overhang of $1.80 \mathrm{~m}$ is concerned, when due allowance is made for barrier walls, curbs, etc. this limitation means that when a vehicle is travelling as far over in the outside lane as possible, its centre of gravity will not be significantly outside the centreline of the outermost girder. This limitation is necessary if the orthotropic plate representation is to be realistic. The bridges selected for establishing analysis results for the simplified methods in this Code had the same limitations for the deck slab overhang, being equal to or less than $60 \%$ of the girder spacing, $\mathrm{S}$, with a maximum overhang equal to $1.8 \mathrm{~m}$.

\subsection{Load Distribution and Codes of Practice for Precast Girders}

The CHBDC, 2000, specifies equations for the simplified method of analysis to determine the longitudinal bending moments and vertical shear in slab-on-girder bridges due to live load for ultimate, serviceability and fatigue limit states using load distribution factors. The CHBDC distribution factor equations used for slab-on-prestressed-girders are as follows:

For the longitudinal bending moment per girder, $M_{g}$, for ultimate and serviceability limit states:

$$
M_{g}=F_{n t} M_{g a v g}
$$


where $M_{\text {gavg }}$ is the average moment per girder and $F_{m}$ is an amplification factor for the transverse variation in maximum longitudinal moment intensity (Distribution Factor).

$$
\begin{aligned}
& M_{\text {gavg }}=\frac{n M_{T} R_{L}}{N} \\
& F_{m}=\frac{S N}{F\left(1+\frac{\mu C_{f}}{100}\right)} \geq 1.05 \\
& \mu \quad=\frac{W_{e}-3.3}{0.6} \leq 1.0
\end{aligned}
$$

where $M_{T}$ is the maximum moment.per design lane, $n$ is the number of design lanes, $R_{L}$ is a modification factor for multilane loading, $N$ is the number of longitudinal girders, $S$ is centre-to-centre girder spacing in meter, $W_{e}$ is the width of the design lane in meter, $C_{f}$ is a correction factor obtained from tables and $F$ is the width dimension that characterizes the load distribution for the bridge. Expressions for $F$ and $C_{f}$ for slab-on-girder bridges are shown in Table 2.2 .

For the longitudinal bending moment per girder, $M_{g}$, for Fatigue Limit State:

$$
M_{g}=F_{m} M_{g \text { avg }}
$$

where $M_{\text {gavg }}$ is the average moment per girder and $F_{m}$ is an amplification factor for the transverse variation in maximum longitudinal moment intensity (Distribution Factor).

$$
M_{\text {gavg }}=\frac{M_{T}}{N}
$$




$$
\begin{aligned}
& F_{m}=\frac{S N}{F\left(1+\frac{\mu C_{f}}{100}+\frac{C_{e}}{100}\right)} \geq 1.05 \\
& \mu \quad=\frac{\dot{W}_{e}-3.3}{0.6} \quad \leq 1.0
\end{aligned}
$$

where $M_{T}$ is the maximum moment per design lane, $n$ is the number of design lanes, $R_{L}$ is a modification factor for multilane loading, $N$ is the number of longitudinal girders, $S$ is centre-to-centre girder spacing in meter, $W_{e}$ is the width of the design lane in meter, $C_{f}$ is a correction factor obtained from tables, $C_{e}$ is a correction factor for vehicle edge distance obtained from tables and $F$ is the width dimension that characterizes the load distribution for the bridge. Expressions for $F, C_{f}$ and $C_{e}$ for slab-on-girder bridges are shown in Table 2.2.

For the longitudinal vertical shear per girder, $V_{g}$, for ultimate, serviceability and fatigue limit states:

$$
V_{g}=F_{v} V_{g a v g}
$$

where $V_{\text {gavg }}$ is the average shear per girder and $F_{v}$ is an amplification factor for the transverse variation in maximum longitudinal vertical shear intensity (Distribution Factor).

$$
\begin{aligned}
& V_{\text {gavg }}=\frac{n V_{T} R_{L}}{N} \\
& F_{v}=\frac{S N}{F}
\end{aligned}
$$

where $V_{T}$ is the maximum vertical shear per design lane, $n$ is the number of design lanes, $R_{L}$ is a modification factor for multilane loading, $N$ is the number of longitudinal girders, $S$ is centre-to-centre girder spacing in meter, $W_{e}$ is the width of the design lane in meter and 
$F$ is the width dimension that characterizes the load distribution for the bridge and can be obtained from provided tables.

The AASHTO LRFD Bridge Design Specifications [1] specify equations for the simplified method of analysis to determine the flexural moment and shear force in concrete slab-on-multi girder bridges due to live load for one design lane and two or more design lanes using distribution factors. The AASHTO LRFD specifies different equations for precast concrete tee section sufficiently connected to act as a unit or connected enough to prevent relative vertical displacement. The AASHTO LRFD distribution factor equations used for precast concrete tee sections are as follows:

For the longitudinal bending moment distribution factor for girders sufficiently connected to act as one unit:

1) For interior girder with one design lane:

$$
g_{\text {nnterior }}=0.06+\left(\frac{S}{4300}\right)^{0.4}\left(\frac{S}{L}\right)^{0.3}\left(\frac{K_{g}}{L t_{s}^{3}}\right)^{0.1}
$$

2) For interior girder with two or more design lanes:

$$
g_{\text {nterior }}=0.075+\left(\frac{S}{2900}\right)^{0.6}\left(\frac{S}{L}\right)^{0.2}\left(\frac{K_{g}}{L t_{s}^{3}}\right)^{0.1}
$$

and $K_{g}$ is taken as:

$$
K_{g}=n\left(I+A e_{g}^{2}\right)
$$

in which: 


$$
n=\frac{E_{B}}{E_{D}}
$$

where $S$ is centre-to-centre girder spacing in $\mathrm{mm}, L$ is the span length in $\mathrm{mm}, K_{\mathrm{g}}$ is the longitudinal stiffness parameter in $\mathrm{mm}^{4}, t_{s}$ is the thickness of the concrete slab, $n$ is the modular ratio between girder and deck, $I$ is the moment of inertia of girder in $\mathrm{mm}^{4}, A$ is the area of girder in $\mathrm{mm}^{2}, e_{\mathrm{g}}$ is the distance between the centers of gravity of the basic girder and deck in mm, $E_{B}$ is the modulus of elasticity of girder material in $\mathrm{MPa}$, and $E_{D}$ is the modulus of elasticity of deck material in MPa.

Also, AASHTO LRFD specifies the range of applicability for these distribution factor equations as follows: $1100 \leq S \leq 4900,110 \leq t_{\mathrm{s}} \leq 300,6000 \leq L \leq 73000$, $N_{b} \geq 4$, and $4 \times 10^{9} \leq K_{g} \leq 3 \times 10^{12}$, where $N_{b}$ is the number of girders.

3) For exterior girder with one design lane loaded, the lever rule is specified to be used.

4) For exterior girder with two or more design lane loaded:

$$
g_{\text {exteriol }}=\left(0.77+\frac{d_{e}}{2800}\right) g_{\text {mterior }}
$$

where $d_{e}$ is the distance from the web of the exterior girder to the interior edge of curb or traffic barrier.

For $N_{b}=3$, the lesser values obtained from the previous equations or the lever rule are to be used.

For the shear distribution factor for girders sufficiently connected to act as one unit:

1) For interior girder with one design lane loaded: 


$$
g_{\text {interior }}=0.36+\left(\frac{S}{7600}\right)
$$

2) For interior girder with two or more design lane loaded:

$$
g_{\text {Interior }}=0.20+\left(\frac{S}{3600}\right)-\left(\frac{\dot{S}}{10700}\right)^{2.0}
$$

For $N_{b}=3$, the lever rule is to be used.

For the longitudinal bending moment distribution factor for girders connected only enough to prevent relative vertical displacement at the interface:

1) For interior girder regardless of the number of loaded lanes:

$$
g_{\text {internor }}=\frac{S}{D}
$$

where: $D=300\left(11.5-N_{L}+1.4 N_{L}(1-0.2 C)^{2}\right) \quad$ For $C>5$

and:

$$
D=300\left(11.5-N_{L}\right) \quad \text { For } C \leq 5
$$

in which:

$$
C=K\left(\frac{W}{L}\right) \leq K
$$

and:

$$
K=\sqrt{\frac{(1+\mu) I}{J}}
$$

where $S$ is centre-to-centre girder spacing in mm, $D$ is the width of distribution per lane in 
$\mathrm{mm}, N_{L}$ is the number of design lanes, and $C$ is a stiffness parameter, $K$ is a constant for different types of construction, $W$ is the edge-to-edge width of the bridge in $\mathrm{mm}, L$ is the bridge span in mm, $v$ is the Poisson's ratio, $I$ is the moment of inertia in $\mathrm{mm}^{4}$, and $J$ is St. Venant's torsional inertia in $\mathrm{mm}^{4}$.

2) For exterior girder, the lever rule is specified to be used.

Also, AASHTO-LRFD specifies the range of applicability for these distribution factor equations such that the skew angle is not more than $45^{\circ}$ and $N_{L}$ is not more than 6 . A preliminary value for $K$ is specified to be equal 2 for these types of bridges.

For the shear distribution factor for girders connected only enough to prevent relative vertical displacement at the interface, the lever rule is specified for both interior and exterior girders. 


\section{Chapter III}

\section{ANALYTICAL PROCEDURE}

\subsection{General}

The finite element method is considered as the most powerful and versatile method of analysis available nowadays [10]. In early 1980 s, the grillage analogy method was extensively used and was very popular [24]. Because of the recent development in finite element method, and the large capacities of high-speed computers, it is possible to model a bridge in a very realistic manner and to provide a full description of its structural response due to different loading conditions. One of the most important advantages of the finite element method is the ability to deal with problems that have arbitrary arrangements of structural elements, material properties, and boundary conditions. Also, it allows the analysis using combination of various structural elements such as plates, beams, and shells. Therefore, the finite element method is very suitable for the analysis of precast prestressed concrete girder bridges. This chapter includes descriptions of modeling the different components of the precast prestressed concrete WF-CPCI girders. The finite element model includes the concrete deck slab, web, bottom flange, end-diaphragms, intermediate diaphragms and the connections between girder flanges as described in subsequent sections in this chapter. The finite element analysis software "SAP2000" version 8 [14] was used throughout this study to determine the structural behaviour of the precast prestressed concrete girder bridges under truck loads. A general description of this software is presented further in this chapter. The finite element method described herein was used to perform extensive parametric study on the structural response of both partially 
and fully connected precast prestressed concrete WF-CPCI girder bridges due to CHBDC truck loading conditions.

\subsection{Finite Element Approach}

The finite element method is a numerical method for solving problems in fields of engineering and mathematical physics. In structural engineering problems, the solution is typically concerned with determining stresses and displacements and will yield approximate values of the unknowns at discrete number of points in a continuum. This numerical method of analysis starts by discretizing a model. Discretization is the process where a body is divided into an equivalent system of smaller bodies or units, expressed as elements, and interconnected at points, expressed as nodes, common to two or more elements and/or boundary lines and/or surface. All elements are combined in formulated equations to obtain the solution for the entire structure. Using a displacement formulation, the stiffness matrix of each element is derived and the global stiffness matrix of the entire structure can be formulated by the direct stiffness method. This global stiffness matrix, along with the given displacement boundary conditions and applied loads is then solved, thus the displacements and stresses for the entire system are determined. The global stiffness matrix represents the nodal force-displacement relationships and is expressed in a matrix equation form as follows $[10,5]:$

$$
[P]=[K][U]
$$

where: $[P] \quad=\quad$ nodal load vector;

$[K]=$ global stiffness matrix; and 
$[U]=$ nodal displacement vector

The steps for deriving the above equation can be summarized in the following basic relationships:

a) $\quad v(x, y)=[\phi(x, y)][\alpha]$

where:

$v(x, y)=\quad$ the internal displacement vector of the element;

$[\phi(x, y)]=\quad$ the displacement function matrix; and

$[\alpha]=$ the generalized coordinates matrix.

b) $\quad[U]=[A][\alpha] \quad$ then, $[\alpha]=[A]^{-1}[U]$

where $[A]$ is the transformation matrix from local to global coordinates,

c) $\quad[\varepsilon(x, y)]=[B(x, y)][\alpha]=[B(x, y)][A]^{-1}[U]$

where:

$[B(x, y)]=$ the strain-displacement matrix; and $[\varepsilon(x, y)]=\quad$ the strain matrix.

d) $\quad[\sigma(x, y)]=[D][\varepsilon(x, y)]=[D][B(x, y)][A]^{-1}[U]$

where: $[D]=$ the constitutive matrix or the elasticity matrix.

From the principle of minimization of the local potential energy, the total external work is equal to $\frac{1}{2}[U]^{T}[P]$ 
e) I - $W_{E}=\left[U^{\prime}\right]^{T}[P]$

II - $\quad W_{I}=\int_{o l}[\varepsilon]^{T}[\sigma]=\left[u^{\prime}\right]^{T}[A]^{-1}\left[k^{\prime}\right][A]^{-1}[U]$

$$
\left[k^{\prime}\right]=\int_{o l}[B(x, y)]^{T}[D][B(x ; y)]
$$

where:

$W_{E}=$ the external virtual work;

$W_{l}=$ the internal virtual work;

$[u]=$ the vector of virtual displacement; and

$[k]=$ the element stiffness matrix.

f) From the principle of virtual work, $W_{E}=W_{l}$. By taking one element of virtual nodal displacement vector $[u]$ equal to unity, the solution becomes:

$[P]=[K][U]$

where $[K]=\Sigma[k]$, so the global structural stiffness matrix is an assemblage of the element stiffness matrix $[k]$.

g) The solution of the resulting system of equations yields the values of nodal displacement $[U]$ and the internal forces for each element can be obtained from equation (3.4).

In the case of a linear (elastic) structural problem, loads are first applied on a model and the solution is obtained directly. In a non-linear case, the analysis follows a different numerical method to obtain a solution. However, such analysis is beyond the scope of this thesis and is not discussed. 


\subsection{SAP2000 Software}

SAP2000 software [14] is a structural analysis program that uses the finite element method and has a range of capabilities depending on the version used. Widespread use across many countries during the 1980 s and 1990s made SAP2000 software a popular choice for finite element analysis. The program is used worldwide to estimate structural responses of structures due to various applied loads. It is also capable of analyzing structures in static and/or dynamic modes using the following type of elements that are available in the program:

- FRAME Element: The Frame element is a two-node three-dimensional element, which includes the effect of biaxial bending, tension, axial deformation, and biaxial shear deformation.

- Shell Element: The Shell element is a three- or four-node three-dimensional element, which combines separate membrane and plate-bending behaviour. The membrane behaviour includes translational in-plane stiffness components and rotational stiffness component in the direction normal to the plane of the element. The plate bending behaviour includes two-way, out of plane, plate rotational stiffness components and translational stiffness component in the direction normal to the plane of the element. The program allows using pure membrane, pure plate, or full shell behaviour.

- Plane Element: The Plane element is a three- to nine-node two-dimensional element, which contributes stiffness only in the two translational degrees of freedom at each of its connected joints. Plane element is used for modeling thin 
plane stress structures and long plane strain structures.

- Solid Element: The Solid element is an eight-node three-dimensional element, which includes nine optional incompatible bending modes. The solid element contributes stiffness in all three translational degrees of freedom at each of its connected joints.

- Asolid Element: The Asolid element is a three- to nine-node two-dimensional element, which contributes stiffness only in the two translational degrees of freedom at each of its connected joints. Asolid element is used for modeling axisymmetric structures under axisymmetric loading.

- Nllink Element: The Nllink element is a one joint grounded spring or two joint link which is composed of six separate springs, one of each of the six deformational degrees of freedom. The Nllink element is used for modeling linear or nonlinear structural behaviour. The nonlinear behaviour is used only for the time-history analysis.

In addition, subsets of these elements with varying degrees of freedom are available in the form of truss, frame, membrane, beam, strain, gap, and hook elements.

\subsection{Finite Element Modeling of WF-CPCI Girder Bridges}

A three dimensional finite element model was used to analyze the WF-CPCI girder bridges considered in this study. A convergence study was conducted to choose the finite element mesh. The finite element mesh is usually chosen based on pilot runs and is a compromise between economy and accuracy. In the finite modeling process, the structure is 
first divided into several components. In this case, the bridges were divided into: concrete deck slab, webs, bottom flanges, concrete diaphragms and steel connections.

\subsubsection{Geometric Modeling}

\subsubsection{Modeling of Deck Slab, Webs, Bottom Flange, and Diaphragms}

From many types of shell elements available in SAP2000 library, the four-node shell element was chosen to model deck slabs (top flanges), webs, bottom flanges and diaphragms. The four-node shell element has six degrees of freedom at each node that are three displacements (U1, U2, U3) and three rotations (Ф1, $22, \Phi 3)$. A detailed diagram of the shell element is presented in Figure 3.1. Four horizontal elements were used to model each top flange between webs; while two vertical elements were used to model the web. Two horizontal elements, in the transverse direction, were used to model the bottom flange of each girder. The diaphragms between the webs were modeled with a total of eight elements comprised of four elements in the lateral direction and two elements in the vertical direction. In the longitudinal direction of the bridge, 62 elements were considered. These elements comprised of one element at each end representing the longitudinal overhang beyond the bearing locations for future studies and 60 elements between the two supports. Figures 3.2 to 3.6 show views of the SAP2000 finite-element model for a bridge of six WFCPCI girders, of $2000 \mathrm{~mm}$ girder spacing, $30 \mathrm{~m}$ length and $1400 \mathrm{~mm}$ girder depth, with no intermediate diaphragms, and one or two intermediate diaphragms.

A conversion study has been carried out to investigate the accuracy of the results from the finite element analysis. In this study, various numbers of elements, in the longitudinal, vertical and transverse directions of the bridge model, have been considered. In the longitudinal direction of the bridge, 20,30, 40, 60 and 120 elements were considered 
between the two supports of the bridge. In the transverse direction, 2, 3, 4 and 6 elements were considered for each top flange between webs, while 1, 2, 3 and 4 elements were considered in the vertical direction for each web. In modelling diaphragms, $1,2,3$ and 4 elements were considered in the lateral direction. The accuracy factors of maximum bending moment, deflection and shear force is presented in Appendix C. The reference values used in this comparison were highlighted in Table C-1 shown in Appendix C. Thus, the accuracy factors are considered as the ratios between the moment, shear and deflection for a certain number of elements and those for highlighted number of elements. The number of elements used in conducting the parametric study is also presented in bold in Table C-1, Appendix C. The results indicate that the proposed finite element model for this parametric study provides results within $\underline{2} 2.5 \%$ differences from those obtained with higher or lower number of elements.

\subsubsection{Modeling of Connections}

To model the intermittent connection between girder flanges in the longitudinal direction, two-node three-dimensional frame element was used. This frame element has two nodes with six degrees of freedom at each node that are three displacements (U1, U2, U3) and three rotations $(\Phi 1, \Phi 2, \Phi 3)$. Schematic view of the bridge model showing the intermittent connections between girder flanges is presented in Figure 3.3.

\subsubsection{Modeling of Moving Load Paths}

SAP2000 software has the ability to run a moving load along a defined frame element path. The program shifts a group of loads, previously defined as static loads, certain interval along a defined path and provides the extreme straining actions at each node.

Therefore, frame elements are provided in the longitudinal direction at the top of the shell 
elements for the paths of the moving loads. These frame elements are modeled with a very small section dimensions so that they do not affect the finite element model of the structure. Static loads on frame elements were used to reduce the time of computer runs and placed to provide equivalent maximum bending moment, deflection and shear force resulted from SAP2000 moving loads runs.

\subsubsection{Boundary Conditions}

Nodal constraints were used in the analysis as boundary conditions to represent the supports of the bridge. First, the roller support at the right end of the bridge restricted both vertical and lateral displacements at the three nodes of the bottom flange of the middle girder. Second, the hinged support at the left end of the bridge restricted all three displacements at the three nodes of the bottom flange of the middle girder. Roller support, at the three nodes of the bottom flange of other girders at the right end of the bridge restricted the vertical displacement only. Hinged support, at three nodes of the bottom flange of the other girders at the left end of the bridge restricted the vertical and longitudinal displacements only and released the displacement in the lateral direction. In case of even number of girders, one of the most inner girders is considered the middle girder.

\subsubsection{Material Modeling}

The material properties can highly affect the results of the analysis. Therefore, it is important that the material properties are defined so that SAP2000 software can provide suitable properties for the elements. Material properties, for concrete and steel, are considered linear elastic and isotropic for these structures. The required properties for SAP2000 software are the elastic modulus, Poisson's ratio, the weight density, the mass density and the coefficient of the thermal expansion in three directions. In SAP2000 
software, the shear modulus is defined in terms of Young's modulus and Poisson's ratio as per the following equation:

$$
G=\frac{E}{2(1+v)}
$$

where: $G=$ the shear modulus;

$$
\begin{aligned}
& E=\text { Young's modulus; and } \\
& u=\text { Poisson's ratio. }
\end{aligned}
$$

Materials and their properties are chosen based on the CHBDC and the common materials available in Ontario. The compressive strength of concrete $\left(f_{c}^{\prime}\right)$ is considered $35 \mathrm{MPa}$. As per CHBDC, the weight density $\left(\gamma_{c}\right)$ for normal prestressed concrete is considered $24.5 \mathrm{kN} / \mathrm{m}^{3}$. The modulus of elasticity of concrete $\left(E_{c}\right)$ is calculated from the following equation [11]:

$$
\begin{aligned}
& E_{c}=\left(3000 \sqrt{f_{c}^{\prime}}+6900\right)\left(\gamma_{c} / 2300\right)^{15} \\
& E_{c}=27,900 \mathrm{MPa}
\end{aligned}
$$

The Poisson's ratio for elastic strains of concrete is taken as 0.2 and the mass density for concrete is taken as $2500 \mathrm{~kg} / \mathrm{m}^{3}$.

The modulus of elasticity of steel $\left(E_{s}\right)$ is taken as $200,000 \mathrm{MPa}$ and the Poisson's ratio for elastic strains of steel is taken as 0.3 .

Samples of the resulting input files are given in Appendix A. The individual steps involved in creating the input data files are outlined in the SAP2000 Users Manual [14]. 


\subsection{Bridge Configurations}

Hundred and eighty nine (189) straight WF-CPCI bridges with different configurations were considered in the parametric study. WF-CPCI girders with top flange width of 2.0, 2.2 and $2.4 \mathrm{~m}$ width were considered. Four different girder depths were considered in forming the bridge prototypes, namely: 1200, 1400,1600, and $1900 \mathrm{~mm}$. The following bridge parameters were considered in this study:

1. Girder span length $(L)$ was taken as $20,25,30$ and $35 \mathrm{~m}$.

2. Spacing between girders $(S)$ was taken as the same width as the top flange of the girder $(2.0,2.2$, and $2.4 \mathrm{~m})$.

3. Number of girders $(N)$ was taken $5,6,7,8$, and 9 .

4. Three cases for intermediate diaphragm were considered, namely: no intermediate diaphragm, one intermediate diaphragm, and two intermediate diaphragms.

5. The Spacing for the lateral connection between girders in the longitudinal direction of the bridge was taken $500,1000,1500,2000,2500,3000$, $3500 \mathrm{~mm}$ and fully connected along the length of the girder.

The number of girders, considered for each bridge cross-section, was based on the bridge width required for 2,3 , or 4 lanes, shoulders on both sides with barrier walls type Performance Level 3 (PL3) of $570 \mathrm{~mm}$ width in accordance with the Structural Manual of MTO [28]. The shoulder width considered in this study satisfies the minimum side clearances provided in the MTO Revision Information Sheet for Geometric Design Standards for Ontario Highways [29], (Table D7-1, Minimum Side Clearances at Bridges, dated August 30, 2002). Table 3.1 summarizes the bridge deck configurations considered 
in this study and the associated shoulder width. The number of girders chosen herein satisfied the number of design lanes (n) of 3,4 , and 5 according to CHBDC requirements [11] as shown in Table 3.5. The width of the design lane $\left(W_{e}\right)$, shown in Table 3.6, was calculated in accordance with CHBDC, Section 3.8.2, from the following equation:

$$
W_{e}=\frac{W_{c}}{n}
$$

where: $W_{c} \quad$ is the deck width from the inner face of the barrier wall to the inner face of the other barrier wall.

Details of the 189 WF-CPCI girder bridges used in this study are summarized in Table 3.2. The deck cross slopes and the longitudinal grade were ignored in the analysis. No sidewalks were considered as the bridge configurations were based on PL3. Table 3.3 summarizes the bridge configurations used to conduct the parametric study on the effect of the change in type and configuration of the connection between the WF-CPCI girder flanges.

For all WF-CPCI girder bridges considered in this study, the longitudinal flexural stiffness $\left(D_{x}\right)$ was calculated and provided in Table 2.1 based on the following equation that is presented in the CHBDC:

$$
D_{x}=\frac{E_{c} I}{S}
$$

where: $E_{c} \quad$ is the modulus of elasticity for concrete;

$I \quad$ is the moment of inertia of the girder; and

$S \quad$ is center-to-center spacing between girders.

The moment of inertia was determined for each girder shown in Figures 2.2 to 2.5. 
According to CHBDC, a database of composite steel and prestressed slab-on-girder bridges from the Province of New Brunswick was examined and an average longitudinal flexural stiffness parameter, $D_{x}$, was determined to be presented by the following empirical equation:

$$
D_{x}=3350 L^{2}+66000 L
$$

Also, the flexural stiffnesses for the studied WF-CPCI girder bridges were determined based on Eq. 3.14. Figure 3.21 presents a comparison between both results. It can be observed that all bridge configurations provided flexural stiffness less than those obtained from Eq. 3.15 except WF-CPCI girders with $1600 \mathrm{~mm}$ depth and $20 \mathrm{~m}$ span. However, the $1600 \mathrm{~mm}$ depth girders are not practical for $20 \mathrm{~m}$ span bridges, but these were considered in this study to broaden the range of the applicability of the research work.

\subsection{CHBDC Specifications for Truck Loading}

The live load, specified in the CHBDC, consists of CL-W Truck or CL-W Lane Load. The CL-W Truck consists of idealized five axles with total load of $625 \mathrm{kN}$ as shown in Figure 3.7. The CL-625-ONT Truck load, shown in Figure 3.8, specified for the province of Ontario is different from CL-W Truck, provided for all other provinces, in the axle loads. Both CL-W and CL-625-ONT trucks are placed centrally in a space of $3.0 \mathrm{~m}$ wide that represents the clearance envelope for each truck. Dynamic load allowance is applied to both CL-W and CL-625-ONT Trucks. The CL-W Lane Load consists of $80 \%$ of the value given for each axle of the CL-W Truck superimposed within a uniformly distributed load of $9 \mathrm{kN} / \mathrm{m}$ and a space of $3.0 \mathrm{~m}$ wide (Figure 3.7). The CL-625-ONT Lane Load is similar to 
the CL-W Lane Load but using the CL-625-ONT Truck instead of using the CL-W Truck (Figure 3.8). No dynamic load allowance is considered for both CL-W and CL-625-ONT Lane Loads. For multilane loading, the live load, specified above, should be multiplied by a modification factor as shown in Table 3.4. The uniformly distributed portion of the lane load, which decreases the load effect, shall not be applied to the structure. For serviceability and ultimate limit states, the traffic loads can be the truckload with the dynamic allowance or the lane load, which ever produces the maximum load effect. This load is positioned within each design lane.

For fatigue analysis, an equivalent static load is specified in the CHBDC. Only one truck, either CL-W Truck or CL-625-ONT Truck, can be placed at the centre of one travelling lane. The lane load is not considered for the fatigue limit state and no dynamic allowance is considered. The CHBDC states that for longitudinal bending moments and associated deflections for fatigue limit state and superstructure vibration, the vehicle edge distance (the distance from the centre of the outer wheel load to the edge of the bridge) shall not be greater than $3.0 \mathrm{~m}$.

In studying the bending moment and deflection distribution factors, live loading was applied on the bridge in such a way to produce maximum mid-span longitudinal stresses, (Figure 3.9). For shear force distribution factors, the loading was applied on the bridge in such a way to produce maximum reaction on the supports at one side of the bridge, (Figure 3.10).

\subsection{Loading Conditions}

A preliminary study on a single girder for both CL-625-ONT Truck and CL-625- 
ONT Lane Load indicated that the CL-625-ONT Truck provides the maximum load effect for simple spans of $20 \mathrm{~m}$ to $35 \mathrm{~m}$ long. As a result, the CL-625-ONT Truck is considered in this study to obtain the design parameters. Based on the CHBDC, the design of the bridge is characterized by three limit states, namely: the Serviceability Limit State (SLS), the Ultimate Limit State (ULS), and the Fatigue Limit State (FLS). As such, loading conditions considered herein include truck-loading cases for each of the three limit states of design. Since, bridge configurations considered in this study include two- to four-lane bridges which reflect three to five design lanes, three to five different sets of loading cases were considered for the mid-span bending moment and deflection. Another three to five different sets of loading cases, based on the number of the design lanes, were considered for the end span shear distribution. Figures 3.11 to 3.19 schematically indicate all possible live load cases considered for the bending moment, deflection and shear at both exterior and interior girders. In this study, the exterior girder is the one closest to bridge barrier location while, the interior girder is any girder between both exterior girders.

\subsection{Load Distribution Factors}

\subsubsection{Load Distribution Factor for Longitudinal Bending Moments}

In order to determine the load distribution factor for longitudinal bending moment $\left(\mathrm{F}_{\mathrm{m}}\right)$ for the exterior and the interior girders, the longitudinal stresses in girders at the bottom surface of the bottom flange, resulting from the bridge analysis at the critical section $(\sigma)$, due to truck loadings were identified. Also, the longitudinal stresses for the corresponding single girder, resulting from the analysis at the corresponding critical section of the bridge $\left(\sigma_{0}\right)$, due to a single truck loading were identified. The maximum 
stress at the bottom surface of the bottom flange was identified from the average stress results for the 4 elements adjacent to the chosen section. Thus, the girder bending moment can be calculated from the obtained stresses using the following equation:

$$
\sigma_{b}=M \times \frac{y_{b}}{I}
$$

where: $\sigma_{b}=$ the average flexure stress at the bottom surface of the bottom flange;

$M=$ the bending moment corresponding to $\sigma_{b}$;

$y_{b}=$ the distance from the neutral axis of the section to the bottom surface of the bottom flange; and

$I=$ the moment of inertia of the section.

Based on the concept shown in Chapter 2, the distribution factors for the longitudinal bending moment $\left(\mathrm{F}_{\mathrm{m}}\right)$ were calculated in accordance with CHBDC as follows:

a) For longitudinal bending moment at exterior girders $\left(\mathrm{F}_{\mathrm{m} \text { ext }}\right)$ :

$$
\mathrm{F}_{\mathrm{mext}}=N\left(\sigma_{\mathrm{ext}}\right) /\left(n \sigma_{\mathrm{o}} R_{L}\right)
$$

b) For longitudinal bending moment at interior girders $\left(\mathrm{F}_{\mathrm{m} n \mathrm{nt}}\right)$ :

$$
\mathrm{F}_{\mathrm{m} \mathrm{ntt}}=N\left(\sigma_{\mathrm{mt}}\right) /\left(n \sigma_{\mathrm{o}} R_{L}\right)
$$

c) For longitudinal bending moment at exterior girders for fatigue $\left(F_{f m ~ e x t}\right)$ :

$$
\mathrm{F}_{\text {fm ext }}=N\left(\sigma_{\text {f-ext }}\right) /\left(n \sigma_{\mathrm{o}} R_{L}\right)
$$

d) For longitudinal bending moment at interior girders for fatigue $\left(\mathrm{F}_{\mathrm{fm} \mathrm{int}}\right)$ :

$$
\mathrm{F}_{\mathrm{fm} \mathrm{int}}=N\left(\sigma_{\mathrm{f} \text {-int }}\right) /\left(n \sigma_{\mathrm{o}} R_{L}\right)
$$

where:

$N \quad=$ number of girders; 
$n=$ number of design lanes;

$R_{L}=$ modification factor for multilane loading in accordance with CHBDC, shown in Table 3.4;

$\sigma_{\text {ext }}=$ the maximum average flexure stress, resulting from bridge analysis, at the bottom surface of the bottom flange of the exterior girders;

$\sigma_{\text {int }}=$ the maximum average flexure stress, resulting from bridge analysis, at the bottom surface of the bottom flange of the interior girder;

$\sigma_{\text {f-ext }}=$ the maximum average flexure stress, resulting from bridge analysis, at the bottom surface of the bottom flange of the exterior girder due to fatigue loadings; and

$\sigma_{\mathrm{f}-\mathrm{nt}}=$ the maximum average flexure stress, resulting from bridge analysis, at the bottom surface of the bottom flange of the interior girder due to fatigue loadings.

\subsubsection{Load Distribution Factor for Deflections}

In order to determine the load distribution factor for deflections $\left(F_{\delta}\right)$ for the exterior and the interior girders, the deflection of girders, resulting from bridge analysis at the critical section $(\delta)$, due to truck loadings was identified. Also, the deflection for the corresponding single girder, resulting from the analysis at the corresponding critical section of the bridge $\left(\delta_{0}\right)$, due to single truck loading was identified. The maximum deflection at the bottom flange was identified from the average vertical displacements for the three nodal joints adjacent to the chosen section. The distribution factors for deflections $\left(\mathrm{F}_{\delta}\right)$ were calculated in accordance with $\mathrm{CHBDC}$ as follows:

a) For deflection of the exterior girders $\left(\mathrm{F}_{\delta \text { ext }}\right)$ : 


$$
\mathrm{F}_{\delta \text { ext }}=N\left(\delta_{\text {ext }}\right) /\left(n \delta_{0} R_{L}\right)
$$

b) For deflection of the interior girders $\left(\mathrm{F}_{\delta} \mathrm{int}\right)$ :

$$
\mathrm{F}_{\delta \text { int }}=N\left(\delta_{\mathrm{mt}}\right) /\left(n \delta_{\circ} R_{L}\right)
$$

c) For deflection at exterior girders for fatigue $\left(F_{f \delta \text { ext }}\right)$ :

$$
\mathrm{F}_{\text {fo ext }}=N\left(\delta_{\text {fext }}\right) /\left(n \delta_{\mathrm{o}} R_{L}\right)
$$

d) For deflection at interior girders for fatigue $\left(\mathrm{F}_{\mathrm{f} \delta \text { int }}\right)$ :

$$
F_{\mathrm{f \delta} \text { int }}=N\left(\delta_{\mathrm{f}-\mathrm{int}}\right) /\left(n \delta_{\mathrm{o}} R_{L}\right)
$$

where:

$$
\begin{aligned}
& N \quad=\text { number of girders; } \\
& n \quad=\text { number of design lanes; }
\end{aligned}
$$

$R_{L}=$ modification factor for multilane loading in accordance with CHBDC, shown in Table 3.4;

$\delta_{\mathrm{ext}}=$ the maximum average deflection, resulting from bridge analysis, at the bottom surface of the bottom flange of the exterior girder;

$\delta_{\text {int }}=$ the maximum average deflection, resulting from bridge analysis, at the bottom surface of the bottom flange of the interior girder;

$\delta_{\mathrm{fext}}=$ the maximum average deflection, resulting from bridge analysis, at the bottom surface of the bottom flange of the exterior girder due to fatigue loadings; and

$\delta_{\text {fint }}=$ the maximum average deflection, resulting from bridge analysis, at the bottom surface of the bottom flange of the interior girders due to fatigue loadings. 


\subsubsection{Load Distribution Factor for Vertical Shear}

In order to determine the load distribution factor for shear $\left(\mathrm{F}_{\mathrm{v}}\right)$ for the exterior and the interior girders, the maximum shear force at the constrained joints resulting from bridge analysis $(V)$, due to truck loadings, were identified. Also, the shear forces for the corresponding single girder, resulting from the analysis at the corresponding constrained joints of the bridge $\left(V_{o}\right)$, due to single truck loading, were identified. The maximum shear force at supports was identified from the total reaction forces at the three joints of the bottom flange that were vertically restricted. The distribution factors for shear $\left(F_{v}\right)$ were calculated in accordance with CHBDC as follows:

a) For shear at exterior girders $\left(F_{v e x t}\right)$ :

$\mathrm{F}_{\mathrm{vext}}=N\left(V_{\mathrm{ext}}\right) /\left(n V_{o} R_{L}\right)$

b) For shear at interior girders $\left(F_{v_{\mathrm{nt}}}\right)$ :

$$
\mathrm{F}_{\mathrm{v} \mathrm{nt}}=N\left(V_{\mathrm{Int}}\right) /\left(n V_{o} R_{L}\right)
$$

c) For shear at exterior girders for fatigue $\left(\mathrm{F}_{\mathrm{fv}}\right.$ ext $)$ :

$$
\mathrm{F}_{\text {fvext }}=N\left(V_{\mathrm{f} \text {-ext }}\right) /\left(n V_{o} R_{L}\right)
$$

d) For shear at interior girders for fatigue $\left(\mathrm{F}_{\mathrm{fv} \text {, nt }}\right)$ :

$$
\mathrm{F}_{\mathrm{fv} \text { int }}=N\left(V_{\mathrm{f} \text {-int }}\right) /\left(n V_{o} R_{L}\right)
$$

where: $N \quad=\quad$ number of girders;

$n \quad=\quad$ number of design lanes;

$R_{L}=$ modification factor for multilane loading in accordance with CHBDC, shown in Table 3.4;

$V_{\mathrm{ext}}=$ the maximum total reaction, resulting from bridge analysis, at the exterior girder supports; 


$$
\begin{aligned}
V_{\text {int }}= & \text { the maximum total reaction, resulting from bridge analysis, at the } \\
& \text { interior girder supports; } \\
V_{\mathrm{f} \text {-ext }}= & \text { the maximum total reaction, resulting from bridge analysis, at the } \\
& \text { exterior girder supports due to fatigue loadings; and } \\
V_{\mathrm{f}-\mathrm{int}}= & \text { the maximum total reaction, resulting from bridge analysis, at the } \\
& \text { interior girders due to fatigue loadings. }
\end{aligned}
$$

It should be noted that the stresses, deflections or shear forces obtained from the finite element analysis were modified by taking into account the modification factor for multiple lane loading as shown in Table 3.4. This is in addition to the $\mathrm{RL}$ value shown in the denominator in Equations 3.17 to 3.28. 


\section{CHAPTER IV}

\section{PARAMETRIC STUDY RESULTS}

\subsection{General}

This chapter presents the results from a practical-design-oriented parametric study on 189 simply-supported straight concrete WF-CPCI girder bridge prototypes, using the finite-element method. The bridges were analyzed to evaluate their structural responses when subjected to CL-625-ONT truck loading conditions. The parametric study included the investigation of the distribution factors for longitudinal bending moment, deflection and shear force at the ultimate, serviceability and fatigue limit states. The key parameters considered in this study included spacing of the lateral connection between girders in the longitudinal direction of the bridge $(s)$, span length $(L)$, number of longitudinal girders $(N)$, girder spacing $(S)$, number of intermediate diaphragms $\left(N_{d}\right)$, number of design lanes $(n)$, and truck loading conditions. Comparison between the results from the finite element modelling and the corresponding factors from the simplified method of analysis specified in the CHBDC for slab-on-girder bridges was conducted. Based on the

results generated from this parametric study, refined equations are proposed to adjust the results obtained from the CHBDC simplified methods of analysis for slab-on-girder bridges.

\subsection{Effect of the Type of Connection between Girder Flanges}

The connection between the flanges of the WF-CPCI girders can take two forms, namely: continuous connection joint and intermittent connection joint. In continuous 
connection, reinforcing steel rebars are extended beyond the sides of the flanges and overlapped to form moment-transferring joint as shown in joint (1, 2 and 3) in Figure 2.5. In this joint, moment continuity is achieved along the length of the joint in the direction of the girders. On the other hand, these girder flange ends can be joint together using steel plates dowelled into the flange ends at equal intervals in the direction of the girders. Once these girders are placed in their positions over the abutments or piers, these steel plates are either welded as shown in joint (4) in Figure 2.5 or bolted as shown in joint (5) in Figure 2.5. Figure 4.1 shows schematic view of a WF-CPCI girder bridge with intermittent joints. The behaviour of these joints under CHBDC wheel loading was studied elsewhere [38]. In the current research, a parametric study is conducted to examine the effect of the type of connection between the ends of girder flanges in the direction of traffic.

A $30 \mathrm{~m}$ span two-lane bridge of $1600 \mathrm{~mm}$ depth was chosen to study the effect of the type of joint between the ends of girder flanges. In modelling continuity of moment at the line between the ends of girder flanges, one nodal line, with 62 nodal points in the longitudinal direction of the bridge, was considered to represent both ends of girder flanges as shown in Figure 3.2. At each node, three-translational and three-rotational degrees of freedom were assumed to provide full interaction between the two sides of the connections along the nodal line. However, to represent the intermittent connection between the ends of the girder flanges, two nodal lines were considered, one at each flange end as shown in Figure 3.3, with 62 nodal points in the longitudinal direction of the bridge. A frame element was utilized to link the nodes on the first nodal line to the corresponding nodes on the second nodal line, within each slab panel. This frame 
element was assumed to have a rectangular section of $12 \mathrm{~mm}$ height and $300 \mathrm{~mm}$ width representing the welding between a connecting rebar and each of the steel plates embedded on the vertical sides of the ends of the girder flanges.

\subsubsection{Moment Distribution Factor}

The results from the analysis of the $30 \mathrm{~m}$ span bridge are presented in the form of moment, deflection and shear distribution factors for eccentric and centric loading cases. Figures 4.2 to 4.4 show change in the moment distribution factors in each girder due to eccentric truck loading condition with one truck in the outer lane, eccentric loading with two trucks in the outer two lanes and centric loading with three trucks in the three lanes, with the change in the flange-to-flange connection from continuous type to intermittent one, with joint spacing of $0.5,1.0,1.5,2.0,2.5,3.0$, and $3.5 \mathrm{~m}$.

Comparing the results for the exterior girder in Figures 4.2 to 4.4, it can be observed that the eccentric loading case, with two trucks in the outer two lanes, provides the design moment distribution factor for the exterior girder. As such, the results shown in these figures are used to study the effect of connection type. It can be observed that the change in the flange-to-flange connection from continuous one to intermittent with any joint spacing between 0.5 to $3.5 \mathrm{~m}$ had insignificant effect on the moment distribution factor for the exterior girder.

Figure 4.4 shows the change of flange-to-flange connection from continuous type to intermittent one when all the lanes were loaded centrically. It can be observed that the moment distribution factor for the interior girder $G 2$ increased with the change from continuous connection to intermittent one. Further increase in moment distribution factor was observed with increase in joint spacing for girder G2. Also, Figure 4.4 shows opposite 
trend for girder G3 with respect to girder G2. However, in design process, all the interior girders are usually assigned for the maximum bending moment in any of these girders. It can also be observed, from Figure 4.4, that maximum moment distribution factor for all interior girders, G2 to G5, changed from 1.11 in case of continuous connection to 1.14 in case of intermittent connection with $3.5 \mathrm{~m}$ joint spacing (an increase of $2.5 \%$ ). Also, it can be observed that the moment distribution factor for the second girder changed from 1.02 in case of continuous connection to 1.14 in case of intermittent connection with $3.5 \mathrm{~m}$ spacing between joints (an increase of about 11\%). Comparing the results for the interior girders in Figures 4.2 to 4.4 , it can be observed that the centric loading case, with three trucks, provided the design moment distribution factor of the interior girder for intermittent connections at G2 and for continuous connections at G3. As such, Figures 4.11 and 4.12 show the moment distribution factor for G2 and G3 girders, respectively, when the three lanes were loaded for bridges with no intermediate diaphragm, one intermediate diaphragm and two intermediate diaphragms. It can be observed from Figure 4.11 that the moment carried by girder $\mathrm{G} 2$, in case of continuous connection, changed from 1.03 with no intermediate diaphragms to 0.97 in case of one intermediate diaphragm (a decrease of about $6 \%$ ). Also, It can be observed from Figure 4.12 that the moment carried by girder G3, in case of continuous connection, changed from 1.11 with no intermediate diaphragms to 0.97 in case of one intermediate diaphragm (a decrease of about $13 \%$ ). In case of bridges with no intermediate diaphragms, it can be observed that the change in flange-to-flange connection from continuous type to intermittent type with $3.5 \mathrm{~m}$ spacing between connections increases the moment distribution factor for girder G2 by $32 \%$. However, the moment distribution factor for G3 decreases by $3 \%$ when 
changing the flange-to-flange connection from continuous type to intermittent type.

\subsubsection{Deflection Distribution Factor}

Figures 4.5 to 4.7 show change in the deflection distribution factors in each girder due to eccentric truck loading condition with one truck in the outer lane, eccentric loading with two trucks in the outer two lanes and centric loading with a truck in each lane, with the change in the flange-to-flange connection from continuous type to intermittent one, with joint spacing of $0.5,1.0,1.5,2.0,2.5,3.0$, and $3.5 \mathrm{~m}$. Similar trend to that for moment distribution factors was observed in case of deflection distribution factor. For example, Figure 4.7 shows that the design deflection distribution factor (shown here for girder G2) changed from 1.016 in case of continuous connection to 1.084 in case of intermittent joint of $3.5 \mathrm{~m}$ spacing (an increase of about $7 \%$ ).

\subsubsection{Shear Distribution Factor}

Figures 4.8 to 4.10 show change in the shear distribution factors in each girder due to eccentric truck loading condition with one truck in the outer lane, eccentric loading with two trucks in the outer two lanes and centric loading with a truck in each lane, with the change in the flange-to-flange connection from continuous type to intermittent one, with joint spacing of $0.5,1.0,1.5,2.0,2.5,3.0$, and $3.5 \mathrm{~m}$. Similar trend to that for moment distribution factors was observed in case of shear distribution factor. For example, Figure 4.10 shows that the design shear distribution factor (shown here for girder G2) changed from 1.33 in case of continuous connection to 1.78 in case of intermittent connection of $3.0 \mathrm{~m}$ spacing (an increase of about $34 \%$ ).

Figures 4.13 and 4.14 show the maximum bending moment and shear force 
transferred through flange-to-flange connections, respectively for different loading conditions. It should be noted that the plotted values are the maximum from all flangeto-flange connections in this bridge. Figure 4.13 shows that the design bending moment, transferred through the intermittent connections, is negligible. However, it can be observed that the maximum shear force, transferred from a girder flange to the adjacent one through the connection element, increases with the increase in spacing between these connections in the longitudinal direction of the girder. For example, the shear force, presented in Figure 4.14, changes from $43 \mathrm{kN}$ in case of $500 \mathrm{~mm}$ spacing to $190 \mathrm{kN}$ in case of $3500 \mathrm{~mm}$ spacing (an increase of about 3.4 times the shear force). It can also be observed that the shear loading case of fully loaded lanes with CHBDC trucks provides the design force for such connections.

\subsection{Effect of Intermediate Diaphragms}

CHBDC specifies load distribution factors for slab-on-girder bridges assuming that there are no intermediate diaphragms between the support line and that end diaphragms exist only along the support lines. A sensitivity study was conducted herein to examine the effect of the presence of one or two intermediate diaphragms on load distribution factors among girders. Figures 4.15 to 4.17 show the effect of the number of intermediate diaphragms on the moment distribution factors due to one lane loaded eccentrically, two lanes loaded eccentrically and three lanes loaded centrically. In case of fully loaded lanes shown in Figure 4.17, it can be observed that the presence of intermediate diaphragms assisted in distributing the moments among girders more evenly and that the maximum moment distribution factor obtained from this load case decreased by about approximately $8 \%$ with 
the presence of intermediate diaphragms.

Figures 4.18 to 4.20 show the effect of the number of intermediate diaphragms on the deflection distribution factors due to one lane loaded eccentrically, two lanes loaded eccentrically and three lanes loaded centrically. Figure 4.19 shows a trend similar to that in case of moment distribution factor for fully loaded lanes. It can be observed that the design deflection distribution factor increased by about $8 \%$ for the exterior girder and decreased by about $6 \%$ for the interior girder in case of eccentrically loaded lanes. Figures 4.18 and 4.19 indicate slight change in the deflection profile.

Figures 4.21 to 4.23 show the effect of the number of intermediate diaphragms on the shear distribution factors due to one lane loaded eccentrically, two lanes loaded eccentrically and three lanes loaded centrically. In case of exterior girder, Figure 4.21, the shear distribution factor changed from 1.19 in case of no diaphragms to 1.25 in case of one diaphragms (an increase of about 5\%) and 1.31 in case of two diaphragms (an increase of about $10 \%$ ). However, for interior girders (as depicted from Figure 4.21), the shear distribution factor changed from 1.45 in case of no diaphragms to 1.4 in case of one diaphragms (a decrease of about 3\%) and 1.3 in case of two diaphragms (a decrease of about $10 \%$ ). In conclusion, the presence of intermediate diaphragms improves the distribution of

loads on girders by increasing the load distribution factor for the exterior girder and decreasing it for the interior girder.

\subsection{Effect of Span Length}

\subsubsection{Moment Distribution Factors}

Figures 4.24 and 4.25 show selected results for the effect of the bridge span length 
on the moment distribution factors at ultimate limit state (ULS) and fatigue limit state (FLS), respectively, for the exterior girder of bridges with girder spacing of $2000 \mathrm{~mm}$. It can be observed that the effect of bridge span length on the moment distribution factor is insignificant at ULS. However, the moment distribution factors for FLS increase with increase in span length. For example, the moment distribution factor for FLS for the exterior girder of $20 \mathrm{~m}$ span bridge with 7 girders is 1.02 , while it is 1.19 for a similar bridge but of $30 \mathrm{~m}$ span (an increase of 17\%). It is interesting to mention that Figures 4.24 and 4.25 show the moment distribution factors as obtained from CHBDC equation and that a similar trend is observed.

Figures 4.26 and 4.27 show selected results for the effect of the bridge span length on the moment distribution factors at ultimate limit state (ULS) and fatigue limit state (FLS), respectively, for the interior girder of bridges with girder spacing of $2000 \mathrm{~mm}$. It can be observed that moment distribution factors at ULS have no general trend with increase in bridge span. For example these factors slightly decrease with increase in span length in case of seven-girder and eight girder bridges, while they slightly increase with increase in span length in case of nine-girder bridges. In case of loading condition for fatigue limit state design, the moment distribution factors decrease with increase in span length.

\subsubsection{Shear Distribution Factors}

Figures 4.28 and 4.29 show selected results for the effect of the bridge span length on the shear distribution factor for ultimate limit state (ULS) and fatigue limit state (FLS) design, respectively, for the exterior girder of bndges of $2000 \mathrm{~mm}$ girder spacing. It can be observed that bridge span length has insignificant effect on the shear distribution factors at ULS design. However, these factors increase with increase in span length in case of FLS 
design. Figures 4.30 and 4.31 show similar graphs for the interior girder. It can be observed that no general trend is observed in the change in shear distribution factor at ULS with increase in span length, while it decreases with increase in span length at FLS.

\subsubsection{Deflection Distribution Factors}

Figures 4.32 and 4.33 show selected results for the effect of the bridge span length on the deflection distribution factor for ULS and FLS design, respectively, for the exterior girder of bridges of $2000 \mathrm{~mm}$ girder spacing. It can be observed that bridge span length has insignificant effect on the deflection distribution factors at ULS. However, these factors increase with increase in span length. Figures 4.34 and 4.35 show similar graphs for the interior girder. It can be observed that no general trend is observed in the change in deflection distribution factors at ULS with the increase in span length, while it decreases with increase in span length for FLS.

\subsection{Effect of Number of Design Lanes}

Figures 4.36 and 4.37 show selected results for the effect of the number of the design lanes $(N)$ on the moment distribution factor for ultimate limit state (ULS) and fatigue limit state designs (FLS), respectively, for the exterior girder of $25 \mathrm{~m}$ span bridges. Figures 4.38 and 4.39 show similar graphs for the interior girders. The figures include the distribution factors for bridges with $2.0,2.2$ and $2.4 \mathrm{~m}$ girder spacing for the sake of broadening the comparison. Generally, it can be observed that the moment distribution factor increases with increase in number of design lanes. Also, these figures show that the results obtained from the finite element analysis follow similar trend as those obtained from CHBDC equations. 
Figures 4.40 and 4.41 show shear distribution factors for ultimate limit state (ULS) and fatigue limit state (FLS) designs, respectively, for the exterior girder of $25 \mathrm{~m}$ span bridges. Figures 4.42 and 4.43 show similar graphs for the interior girders. Also, Figures 4.44 to 4.47 show similar graphs but for the deflection distribution factors. It can be observed that both the shear and deflection distribution factors at ULS and FLS generally increase with increase in number of design lanes. For example, the shear distribution factor for ULS for the exterior girder of $25 \mathrm{~m}$ span bridge with 3 design lanes is 1.32 , while it is 1.78 for a similar bridge but with 5 design lanes (an increase of about $35 \%$ ).

\subsection{Effect of Number of Girders}

Figures 4.48 and 4.49 show the change in number of girders on the moment distribution factor for ULS and FLS designs, respectively, for the exterior girder of bridges of $25 \mathrm{~m}$ spans and $2.2 \mathrm{~m}$ girder spacing. Figures 4.50 and 4.51 show similar graphs for the interior girders. It can be observed that the moment distribution factor for ULS design does not change significantly with the increase in number of girder in case of no presence of the intermediate diaphragms. However, a slight increase in the moment distribution factor is observed with the increase in number of girders in case of the presence of intermediate diaphragms. In case of FLS design, it can be observed that the moment distribution factor significantly increases with increase in number of girders.

Figures 4.52 and 4.53 depict the change in number of girders on the shear distribution factor for ULS and FLS designs, respectively, for the exterior girder of bridges of $25 \mathrm{~m}$ spans and $2.2 \mathrm{~m}$ girder spacing. Figures 4.54 and 4.55 show similar graphs for the interior girders. It can be observed that the shear distribution factor generally increases with 
increase in number of girders irrespective of the presence of the intermediate diaphragms. For example, the shear distribution factor for FLS for the interior girder of $25 \mathrm{~m}$ span bridge with 6 girders and 1 intermediate diaphragm is 3.35 , while it is 4.42 for a similar bridge but with 8 girders (an increase of about 32\%).

Figures 4.56 and 4.57 depict the change in the deflection distribution factor with the change in number of girders for ULS and FLS designs, for the exterior girder of bridges of $25 \mathrm{~m}$ span and 2.2 girder spacing. Figures 4.58 and 4.59 show similar results in case of the interior girder. It can be observed that the deflection distribution factor for FLS design significantly increases with increase in number for girders, with little effect in case of ULS design. For example, the deflection distribution factor for ULS for the exterior girder of $25 \mathrm{~m}$ span bridge with 6 girders and no intermediate diaphragm is 1.04 , while it is 1.09 for a similar bridge but with 8 girders (an increase of about $5 \%$ ).

\subsection{Evaluation of CHBDC Distribution Factors}

To evaluate the empincal formulas for load distribution factors specified for the simplified method of analysis in CHBDC for slab-on-girder bridges, the results from the finite-element analysis, and the corresponding values calculated in accordance with CHBDC equations are presented. It should be noted that CHBDC load distribution factors were developed based on slab-on-grrder bridges configuratıons with no intermediate diaphragms, but with only end diaphragms located along the support lines. It should be noted that the results presented earlier in this chapter indicate that the presence of intermediate diaphragms generally has a significant effect on the values of moment and shear distribution factors at ULS and FLS. As a result, three set of graphs are presented here for bridges with no 
intermediate diaphragms, bridges with one intermediate diaphragms and bridges with two intermediate diaphragms, respectively.

Since, the CHBDC simplified method of analysis provides one expression for both deflection and bending moment distribution factors at ULS and FLS, it is interesting to investigate the correlation between both factors resulted from the FEA. Figures 4.60 and 4.61 present the comparison between the deflection distribution factors and the corresponding bending moment factors for exterior and interior girders, respectively. It can be observed from Figure 4.60 that the deflection distribution factors for exterior girders, resulting from the FEA, are higher than those for the bending moment (within about 5\% difference). However for interior girders, it can be observed from Figure 4.61 that the deflection distribution factors, resulting from the FEA, are lower than those for the bending moment (within 5\% difference). Figures 4.62 and 4.63 are similar to Figures 4.60 and 4.61 but for load distribution factors at FLS. It can be observed that the deflection distribution factors for the exterior girders are higher than the corresponding moment distribution factors (with maximum difference of about 25\%). However, the deflection distribution factors for the interior girders are lower than the corresponding moment distribution factor at FLS (with a maximum of $20 \%$ ).

For bridges with no intermediate diaphragms, Figures 4.64 and 4.65 shows the correlation between the moment distribution factors for the exterior girder as obtained from the finite element analysis and the corresponding CHBDC moment distribution factors from the equations presented in chapter 2. Figures 4.66 and 4.67 depict similar graphs but for the interior girders. Also, Figures 4.68 to 4.71 presents the correlation between the shear distribution factors for the exterior and interior girders for both ULS and FLS design. While 
Figures 4.72 to 4.75 show the correlation between the deflection distribution factors for both the ULS and FLS designs of the exterior and interior girders. One may observe that CHBDC simplified method of analysis provide highly conservative values for moment, shear deflection distribution factors for the exterior girders. For example, for moment distribution, shear and deflection distribution factors for the exterior girder, of 8 girders of $2.2 \mathrm{~m}$ spacing and $25 \mathrm{~m}$ span bridge, are $1.68,1.73$ and 1.68 as obtained from CHBDC expressions shown in chapter 2 . The corresponding values as obtained from finite-element analysis are $1.05,1.36$ and 1.07, respectively (an overestimation of $38 \%, 21 \%$ and $36 \%$, respectively).

Similar trend is observed in the case of the interior girder except for the shear distribution factors for the interior girders. Figure 4.70 shows that in many cases, CHBDC expressions underestimate the shear distribution factor for the interior girder at ULS. For example, at a CHBDC shear distribution factor of 1.77 , for 9 girders and $20 \mathrm{~m}$ span bridge, the corresponding value obtained from the finite-element analysis is 1.92 (an underestimation of about $8 \%$ ). Also, Figure 4.71 shows a similar underestimation of the shear distribution factors of the internor girder for FLS design when using the CHBDC expressions. For example, for a fatigue shear distribution factor of the interior girder of 3.33, for 5 girders and $20 \mathrm{~m}$ span bridge, the corresponding value as obtained from the finite element analysis is 3.56 (an underestimation of about 7\%).

In case of bridges with one intermediate diaphragm, Figures 4.76 to 4.87 show the correlation between the moment, shear and deflection distribution factors for the exterior and interior girders as obtained from CHBDC simplified design method and the finite element analysis. One may observe that $\mathrm{CHBDC}$ expressions provide highly conservative 
values, when compared to those obtained from the finite element analysis, in many cases expect for moment distribution factors for FLS design shown in Figure 4.79. Figures 4.77 and 4.82 show few bridges with underestimated values. However, the differences between CHBDC values and the corresponding values from the finite element analysis are within $5 \%$ and considered acceptable from the engineerng point of view.

Figures 4.88 to 4.99 show the third sets of graphs representing bridges with two intermediate diaphragms. It can be observed that CHBDC simplified method of analysis provides load distribution factors that are highly conservative when compared to the corresponding values obtained from the finite element analysis. The only exception of this observation is the shear distribution factor values for the interior girder at ULS design shown in Figure 4.94. However, the underestimation is this particular case is within $5 \%$ as

7. depicted in Figure 4.94. Figures 4.100 to 4.111 combine all the results for the cases of no intermediate diaphragm, one intermediate diaphragm and two intermediate diaphragms for

1. the sake of visualizing the trend associated with the presence of diaphragms. However, for the sake of upgrading the CHDBC simplified method of analysis for slab-on-girder bridges based on the aforementioned findings, it was decided to develop a new set of load distribution factors for moment and shear at both the ULS and FLS levels for bridges with no intermediate diaphragms.

\subsection{Proposed Expressions for the Load Distribution Factors for Wide- Flange CPCI Girder Bridges}

Based in the data generated from the parametric study on wide-flange $\mathrm{CPCI}$ girder bridges with no intermediate diaphragms, a statistical package of curve fit was used to 
develop expressions for the moment and shear distribution factors at ULS and FLS levels for the exterior and interior girders. The following expressions were derived in the same format, as those originally exist in CHBDC for slab-on-girder bridges.

1) For moment distribution factor for the exterior girder at SLS and ULS:

$$
F_{n}=\frac{C(S N)}{F\left(1+\frac{\mu C_{f}}{100}\right)}
$$

where: $F=8.7+\frac{5.2}{L}$;

$\mu=\frac{W_{e}-3.3}{0.6} \leq 1.0$

$$
C_{f}=10-\frac{25}{L}
$$

$S$ is center-to-center girder spacing;

$N$ is the number of girders and

$C$ is a factor taking into consideration the number of design lanes and can be obtained from the following equation:

$$
C=1.3 n^{-046}
$$

2) For moment distribution factor for the interior girder at SLS and ULS:

$$
F_{m}=\frac{C(S N)}{F\left(1+\frac{\mu C_{f}}{100}\right)}
$$

where: $F=10.5-\frac{7.0}{L}$;

$$
\mu=\frac{W_{e}-3.3}{0.6} \leq 1.0
$$


$C_{f}=10-\frac{25}{L}$ and

$C$ is a factor taking into consideration the number of design lanes and can be obtained from the following equation:

$$
C=1.9 n^{-06}
$$

3) For moment distribution factor for the exterior girder at FLS:

$$
F_{m}=\frac{S N}{F\left(1+\frac{C_{e}}{100}\right)}
$$

where: $F=7.0+\frac{L}{140}$ and

$$
C_{e}=26\left(D_{V E}-1\right)\left[1+\frac{160\left(D_{V E}-1\right)^{2}}{L^{23}}\right]
$$

4) For moment distribution factor for the interior girder at FLS:

$$
F_{n t}=\frac{S N}{F\left(1+\frac{C_{e}}{100}\right)}
$$

where: $F=7.75-\frac{8}{L}$ and

$$
C_{e}=0
$$

5) For shear distribution factor for the exterior girder at SLS and ULS:

$$
F_{V}=\frac{S N n^{-025}}{F}
$$

where: $F=7.0$

6) For shear distribution factor for the interior girder at SLS and ULS: 


$$
F_{V}=\frac{S N n^{-0.334}}{F}
$$

where: $F=5.6$

7) For shear distribution factor for the exterior girder at FLS:

$$
F_{V}=\frac{S N n^{0.2}}{F}
$$

where: $F=26.0$

8) For shear distribution factor for the interior girder at FLS:

$$
F_{V}=\frac{S N n^{-01}}{F}
$$

where: $F=3.1$;

$F_{m}, F_{v}, F, S, N, L, C_{f}, C_{e}, \mu, W_{e}, n$ and $D_{V E}$ are previously defined in section 2.7.

Figures 4.112 to 4.119 show the correlation between the developed expressions and the corresponding values as obtained from the finite element analysis. It can be observed that the proposed expressions provide closer values to those obtained from finite element analysis than those obtained from the currently available CHBDC simplified method of analysis shown in Figures 4.64 to 4.71 . It should be noted that the above expressions are applicable only to wide-flange CPCI girder bridges with span length ranging from 20 to $35 \mathrm{~m}$, number of girders ranging from 5 to 9 , number of design lanes ranging from 3 to 5 , girder spacing ranging from 2.0 to $2.4 \mathrm{~m}$ and for CHBDC truck loading. 


\section{CHAPTER V \\ CONCLUSIONS AND RECOMMENDATIONS}

\subsection{General}

A practical-design-oriented parametric study, using finite element method, was conducted to investigate the statıc response of Wide-Flange CPCI girder bridges of different configurations and truck loading conditions. A literature review was provided in order to establish the bases of this study. The influence of several key parameters on the moment, deflection and shear distribution factors for ultimate, serviceability and fatigue limit states designs was examined with the commercially available finite-element computer program "SAP2000". The key parameters considered in this study included span length, number of lanes, number of girders, live load loading conditions, presence of intermediate diaphragms, and type of longitudinal joints between individual girders.

\subsection{Conclusions}

Based on the results from the parametric study, the following conclusions are drawn:

1- The type of the connection between flanges of the precast wide-flange girder is an important parameter that influences the distribution factors in WF-CPCI girder bridges. The sensitivity study for the type of connections indicated that the continuous connections provide better load distribution to the girders than the intermittent connections.

2- The connections between flanges of WF-CPCI exhibit high shear force with 
negligible bending moment. The shear force significantly increases with the increase in spacing between connections.

3- Bridge span length, number of girder and number of design lanes play a significant role on the value of the load distribution factors for the exterior and interior girders.

4- The presence of the intermediate diaphragms improves the distribution of loads on girders.

5- CHBDC load distribution factors generally overestimate the structural response of bridges, with a significant margin in many bridge geometries. A few cases were observed for the interior girders where CHBDC simplified method of analysis underestimates the shear distribution factors by a maximum of $8 \%$.

6- Deflection distribution factors are always higher than the corresponding moment distribution factors for exterior girders and vice versa in case of the interior girder,

7- The database generated from the parametric study was used to develop expressions for moment and shear distribution factors at ULS and FLS design for the exterior and interior girders of bridges without intermediate diaphragms. These proposed expressions can predict the design parameters more economically and reliably when compared to the available CHBDC simplified method of analysis. 


\subsection{Recommendations for Future Research}

It is recommended that further research efforts be directed towards the following aspects:

1- The study of load distribution factors for bridges with no shoulder conditions.

2- Investigation of end restraints on the load distribution factors of WF-CPCI girders if used for integral or semi-integral type bridges.

3- Investigate the effect of material and geometric nonlinearity on the load distribution factors of such bridges.

4- Study time-dependant effects on such bridges when span continuity is considered. 


\section{REFERENCES}

1. American Association of State Highway and Transportation Officials, AASHTO. 2004. AASHTO LRFD Bridge Design Specifications. Third Edition, Washington, DC.

2. American Association of State Highway and Transportation Officials, AASHTO. 2000. AASHTO LRFD Bridge Design Specifications. Second Edition, Washington, DC.

3. American Association for State Highway and Transportation Officials, AASHTO. 1994. AASHTO LRFD Bridge Design Specifications. First Edition, Washington, DC.

4. American Association of State Highway and Transportation Officials, AASHTO. 1996. Standard specifications for highway bridges. Sixteenth Edition, Washington, D.C.

5. Bakhoum, M. 1992. Structural Mechanics. Cairo University, Giza, Egypt.

6. Bakht, B., Cheung, M. S., and aziz, T. S. 1979. Application of Simplified Method of Calculating Longitudinal moments to the Ontario Highway Bridge Design Code. Canadian Journal of Civil Engineenng, 61(1): 36-50.

7. Bakht, B., and Jaegor, L. G. 1992. Simplified Methods of Bridge Analysis for the Third Edition of OHBDC. Canadian Journal of Civil Engineering, 19(4): 551-559.

8. Bakht, B. and Jaegor, L. G. 1985. Bridge Deck Simplified. McGraw-Hill, New York, N.Y.

9. Barr P. J., Ederhard M. O., and Stanton J. F. 2001. Live-Load Distribution Factors in Prestressed Concrete girder Bridges. ASCE Joumal of Bridge Engineering, 
6(5): 298-306.

10. Bathe, K. J. 1996. Finite Element Procedures. Prentice Hall, New Jersey, USA.

11. Canadian Standards Association. 2000. Canadian Highway Bridge Design Code (CHBDC and Commentary), CAN/CSA-S6-00. Toronto, Ontario, Canada.

12. Chelak, B. L. 1983. Development of The Alberta Deck Bulb Tee Girder. ThirtySixth Annual Conference of the Western Association of Canadian Highway Officials, Alberta Transportation, Winnipeg, Manitoba, pp: 1-6.

13. Chen, Y. 1999. Distribution of Vehicular Loads on Bridge Girders by the FEA Using ADINA: Modeling, Simulation, and Comparison. Journal of Computers and Structures, 72: 127-139.

14. Computers and Structures Inc. CSI. 2000. SAP2000, Integrated Finite Element Analysis and Design of Structures, version 8. Berkeley, California, USA.

15. Con-Force Structures Ltd. 2004. CF-AB- Technical Information/2004. Edmonton, Canada.

16. Dorton, A. R. 1994. Development of Canadian Bridge Codes. Conference on Developments in Short and Medium Span Bridge Engineering, Canada, pp:1-12.

17. Dunker, K. F., and Rabbat, B. G. 1990. Highway Bridge Type and Performance Patterns. ASCE, Journal of Performance of Constructional Facilities, 4(3): 161-173.

18. Fereig, S. 1996. Economic Preliminary Design of Bridges with Prestressed IGirders. ASCE Journal of bridge Engineering, 1(1): 18-25.

19. Fowler, J., 2004. Case Study 1- Moose Creek Bridge, Ontario. Technology Exchange Forum on Prefabricated Concrete Bridge Elements and Systems, Cement Association of Canada, Toronto, Ontario, Canada. 
20. Gracia, A. M. 1993. Florida's Long-Span Bridges: New Forms, New Horizons, PCI Journal, 38(4): 34-49.

21. Geren, K. Y. and Tadros, M. K. 1994. The NU Precast Prestressed Concrete Bridge I-Girder Series. PCI Journal, 39(3): 29-39.

22. Hambly, E. C. 1976. Bridge Deck Behaviour. John Wiley \& Sons Inc., New York.

23. Ho, S., Cheung, M. S., Ng, S. F., and Yu, T. 1989. Longitudinal Girder Moments in Simply Supported Bridges by the Finite Strip Method. Canadian Journal of Civil Engineering, 16(5): 698-703.

24. Jaeger, L. G., and Bakht B. 1982. The Grillage Analogy in Bridge Analysis. Canadian Journal of Civil Engineering, 9: 224-235.

25. Kostem, C. N. 1984. Lateral Live Load Distribution in Prestressed Concrete Highway Bridges. Lehigh University, Pennsylvania, USA.

26. Kuzmanovic, B. O., and Sanchez, M. R. 1986. Lateral Distribution of Live Loads on Highway Bridges. ASCE Journal of Structural Engineering, 112(8): 1847-1862.

27. Lin, T.Y. and Burns, N. H. 1981. Design of Prestressed Concrete Structures. Third Edition, John Wiley \& Sons, New York.

28. Ministry of Transportation Ontario, MTO. 2002. Structural Manual. St. Catharines, Ontario, Canada.

29. Ministry of Transportation Ontano, MTO. 2002. Geometric Design Standards for Ontario Highways, and Revisions. St Catharines, Ontario, Canada.

30. Ministry of Transportation Ontario, MTO. 1991. Ontario Highway Bridge Design Code, OHBDC. Third edition, Downsview, Ontario, Canada.

31. Ministry of Transportation and Communications Ontario (MTO). 1983. Ontario 
Highway Bridge Design Code, OHBDC. Second Edition, Downsview, Ontario, Canada.

32. Nawy, E. G. 2000. Prestressed Concrete: A Fundamental Approach. Prentice Hall, Upper Saddle River, New Jersey.

33. Newmark, N. M., Siess, C. P. and Beckham, R. R. 1948. Studies of Slab on Beam Highway Bridges. Part I: Test of Simple-Span Right I-Beam Bridges. Engrg. Experiment Station, University of Illinois, Urbana, III, Bulletin series No. 375.

34. Nutt., R. V., Schamber, R. A., and Zokaie, T. 1988. Distribution of wheel loads on highway bridges. Transportation Research Board, National Cooperative Highway Research Council, Imbsen \& Associates Inc., Sacramento, Calif.

35. Pre-Con Inc. 2004. Precast Prestressed Bridge Components. Brampron, Ontario, Canada.

36. Ralls, M. L., Medlock, R.D., and Slagle, S. 2002. Prefabricated Bridge National Implementation Initiative. Proceedings of the 2002 Concrete Bridge conference, USA,pp:1-13.

37. Schwarz, M., and Laman, J. A. 2001. Response of Prestressed Concrete I-Girder Bridges to Live Load. ASCE Journal of Bridge Engineering, 6(1): 1-8.

38. Sennah, K., Kianoush, R., Shah, B., Tu, S., and Al-Hashimy, M.. 2004. Innovative Precast/Prestressed Concrete Bridge Systems and Connection Technology: Experimental Study. Report submitted to MTO Highway Infrastructure Innovation : Funding Program, Ministry of Transportation of Ontario, pp. 232, July. Ryerson University, Toronto, Ontario.

39. Shahawy, M, Huang, D. 2001. Analytical and Field Investigation of Lateral Load 
Distribution in Concrete Slab-on-Girder Bridges. ACI Structural Journal, 98 (4): $590-599$.

40. STRESCON Limited. 2004. Precast and Prestressed Concrete Products. Saint Johns. N.B., Canada.

41. Taly, N. 1998. Design of Modern Highway Bridges. California State University, Los Angeles, CA.

42. Tarhini, K. M., and Fredrick, G. R. 1992. Wheel Load Distribution in I-Girder Highway Bridges. ASCE Journal of Structural Engineering, 118(5): 1285-1294.

43. Yamane, T., Tadros, M. K., and Arumugasaamy, P. 1994. Short-to-Medium-Span Prestressed Concrete Bridges in Japan. PCI Journal, 39(2): 74-100.

44. Zokaie, T. 2000. AASHTO-LRFD Live Load Distribution Specifications. ASCE Journal of Bridge Engineering, 5(2): 131-137.

45. Zokaie, T., Imbsen, R. A., and Osterkamp, T. A. 1991. Transportation Research Record, CA, 1290: 119-126. 


\section{TABLES}

Table 2.1 Section Properties for WF-CPCI girders

\begin{tabular}{|c|c|c|c|c|c|c|c|c|c|c|}
\hline \multicolumn{11}{|c|}{ SECTION PROPERTIES } \\
\hline Girder & Depth & Area & Weight & Stiffness & \multirow{2}{*}{$I_{x}$} & \multirow{2}{*}{$Y_{b}$} & \multirow{2}{*}{$Y_{t}$} & \multirow{2}{*}{$S_{b}$} & \multirow{2}{*}{$S_{t}$} & \multirow{2}{*}{$I_{y}$} \\
\hline Size & $D$ & $A$ & $W$ & $D_{\mathrm{r}}$ & & & & & & \\
\hline WF-CPCI & $\mathrm{mm}$ & $\mathrm{mm}^{2}$ & $\mathrm{kN} / \mathrm{m}$ & $\mathrm{kN} \cdot \mathrm{m}^{2} / \mathrm{m}$ & $m^{4}$ & $\mathrm{~mm}$ & $\mathrm{~mm}$ & $\mathrm{~m}^{3}$ & $\mathrm{~m}^{3}$ & $\mathrm{~m}^{4}$ \\
\hline \multicolumn{11}{|c|}{2000 mm Slab W1dth:- } \\
\hline 1200 & 1200 & 752875 & 18.45 & 1773573 & 0.1271 & 789 & 411 & 0.1611 & 0.3095 & 0.1563 \\
\hline 1400 & 1400 & 784875 & 19.23 & 2643759 & 0.1895 & 918 & 482 & 0.2064 & 0.3933 & 0.1563 \\
\hline 1600 & 1600 & 816875 & 20.01 & 3716108 & 0.2664 & 1045 & 555 & 0.2550 & 0.4797 & 0.1564 \\
\hline 1900 & 1900 & 864875 & 21.19 & 5727300 & 0.4106 & 1231 & 669 & 0.3335 & 0.6136 & 0.1565 \\
\hline \multicolumn{11}{|c|}{2200 mm Slab Width:- } \\
\hline 1200 & 1200 & 797875 & 19.55 & 1662645 & 0.1311 & 806 & 394 & 0.1626 & 0.3328 & 0.2059 \\
\hline 1400 & 1400 & 829875 & 20.33 & 2479466 & 0.1955 & 938 & 462 & 0.2084 & 0.4233 & 0.2060 \\
\hline 1600 & 1600 & 861875 & 21.12 & 3486727 & 0.2749 & 1068 & 532 & 0.2575 & 0.5167 & 0.2060 \\
\hline 1900 & 1900 & 909875 & 22.29 & 5377074 & 0.4240 & 1258 & 642 & 0.3369 & 0.6609 & 0.2061 \\
\hline \multicolumn{11}{|c|}{2400 mm Slab Wıdth:- } \\
\hline 1200 & 1200 & 842875 & 20.65 & 1565517 & 0.1347 & 821 & 379 & 0.1640 & 0.3554 & 0.2655 \\
\hline 1400 & 1400 & 874875 & 21.43 & 2335611 & 0.2009 & 956 & 444 & 0.2101 & 0.4526 & 0.2655 \\
\hline 1600 & 1600 & 906875 & 22.22 & 3285929 & 0.2827 & 1089 & 511 & 0.2596 & 0.5528 & 0.2656 \\
\hline 1900 & 1900 & 954875 & 23.39 & 5070701 & 0.4362 & 1283 & 617 & 0.3399 & 0.7074 & 0.2657 \\
\hline
\end{tabular}


Table 2.2 CHBDC expressions for $F, C_{r}$ and $C_{e}$ Factors for Slab-on-Girder Bridges

\begin{tabular}{|c|c|c|c|c|c|}
\hline & $\begin{array}{l}\text { Number } \\
\text { of } \\
\text { Design } \\
\text { Lanes }\end{array}$ & $\begin{array}{l}\text { Type of } \\
\text { Girder }\end{array}$ & $F, \mathrm{~m}$ & $C_{f}, \%$ & $C_{e}, \%$ \\
\hline \multirow{4}{*}{$\begin{array}{l}\text { Bending } \\
\text { Moments } \\
\text { and } \\
\text { Deflections } \\
\text { for SLS } \\
\text { and ULS }\end{array}$} & \multirow{2}{*}{3} & external & $8.7-\left(\frac{4}{L}\right)$ & $10-\left(\frac{25}{L}\right)$ & N. A. \\
\hline & & internal & $9.6-\left(\frac{21}{L}\right)$ & $10-\left(\frac{25}{L}\right)$ & N. A. \\
\hline & \multirow{2}{*}{4} & external & $10.0-\left(\frac{5}{L}\right)$ & $10-\left(\frac{25}{L}\right)$ & N. A. \\
\hline & & internal & $11.6-\left(\frac{22}{L}\right)$ & $10-\left(\frac{25}{L}\right)$ & N. A. \\
\hline \multirow{4}{*}{$\begin{array}{l}\text { Bending } \\
\text { Moments } \\
\text { and } \\
\text { Deflections } \\
\text { for FLS }\end{array}$} & \multirow{2}{*}{3} & external & $3.7+\frac{(L-10)}{140}$ & 0.0 & $26\left(D_{V E}-1\right)\left[1+\frac{160\left(D_{V E}-1\right)^{2}}{L^{2}}\right.$ \\
\hline & & internal & $4.80-\left(\frac{8}{L}\right)$ & 0.0 & 0.0 \\
\hline & \multirow{2}{*}{$\begin{array}{l}4 \text { or } \\
\text { more }\end{array}$} & external & $3.80+\frac{(L-10)}{140}$ & 0.0 & $26\left(D_{V E}-1\right)\left[1+\frac{160\left(D_{V E}-1\right)^{2}}{L^{2}}\right.$ \\
\hline & & internal & $5.00-\left(\frac{10}{L}\right)$ & 0.0 & 0.0 \\
\hline \multirow{2}{*}{$\begin{array}{l}\text { Vertical } \\
\text { Shear for } \\
\text { SLS and } \\
\text { ULS } \\
\end{array}$} & 3 & \multirow{2}{*}{$\begin{array}{l}\text { external } \\
\text { or } \\
\text { internal }\end{array}$} & 8.20 & N. A. & N. A. \\
\hline & $\begin{array}{l}4 \text { or } \\
\text { more }\end{array}$ & & 9.50 & N. A. & N. A. \\
\hline \multirow{2}{*}{$\begin{array}{l}\text { Vertical } \\
\text { Shear for } \\
\text { FLS }\end{array}$} & 3 & \multirow{2}{*}{$\begin{array}{l}\text { external } \\
\text { or } \\
\text { internal }\end{array}$} & 3.6 & N. A. & N. A. \\
\hline & $\begin{array}{l}4 \text { or } \\
\text { more }\end{array}$ & & 3.7 & N. A. & N. A. \\
\hline
\end{tabular}

Notes: 1- Bending moment and deflection $F$ expressions are for $L>10.0 \mathrm{~m}$. 2-Bending moment and deflection $C_{e}$ expressions are for $L \geq 20.0 \mathrm{~m}$. 
Table 3.1 Bridge Deck Configurations

\begin{tabular}{|c|c|c|c|c|c|c|}
\hline $\begin{array}{c}\text { Width of WF- } \\
\text { CPCI }\end{array}$ & No of Girders & No of Lanes & Lane Width & $\begin{array}{c}\text { Shoulder } \\
\text { Width }\end{array}$ & Barrier & Total Width \\
\hline $\mathrm{mm}$ & & & $\mathrm{mm}$ & $\mathrm{mm}$ & $\mathrm{mm}$ & $\mathrm{mm}$ \\
\hline 2000 & 7 & 2 & 3750 & 2680 & 570 & 14000 \\
\hline 2000 & 8 & 3 & 3750 & 1805 & 570 & 16000 \\
\hline 2000 & 9 & 3 & 3750 & 2805 & 570 & 18000 \\
\hline 2200 & 6 & 2 & 3750 & 2280 & 570 & 13200 \\
\hline 2200 & 7 & 3 & 3750 & 1505 & 570 & 15400 \\
\hline 2200 & 8 & 3 & 3750 & 2605 & 570 & 17600 \\
\hline 2400 & 5 & 2 & 3750 & 1680 & 570 & 12000 \\
\hline 2400 & 7 & 3 & 3750 & 2205 & 570 & 16800 \\
\hline 2400 & 8 & 4 & 3750 & 1530 & 570 & 19200 \\
\hline
\end{tabular}


Table 3.2 Bridge Configurations Considered in This Study

\begin{tabular}{|c|c|c|c|c|c|c|c|c|}
\hline $\begin{array}{c}\text { Bridge } \\
\text { Span }\end{array}$ & Type & Depth & $\begin{array}{l}\text { Width of } \\
\text { Girder }\end{array}$ & $\begin{array}{c}\text { No of } \\
\text { Intermediate } \\
\text { Diaphragms }\end{array}$ & $\begin{array}{l}\text { No of } \\
\text { Lanes }\end{array}$ & $\begin{array}{c}\text { Total } \\
\text { Width }\end{array}$ & $\begin{array}{l}\text { No of } \\
\text { Girders }\end{array}$ & $\begin{array}{l}\text { No of } \\
\text { Design } \\
\text { Lanes }\end{array}$ \\
\hline $\mathrm{m}$ & & $\mathrm{mm}$ & $\mathrm{mm}$ & & & $\mathrm{mm}$ & & \\
\hline \multirow[t]{9}{*}{20} & \multirow[t]{9}{*}{ WF-CPCI 1200} & \multirow[t]{9}{*}{1200} & \multirow[t]{3}{*}{2000} & \multirow[t]{3}{*}{0} & 2 & 14000 & 7 & 3 \\
\hline & & & & & 3 & 16000 & 8 & 4 \\
\hline & & & & & 3 & 18000 & 9 & 5 \\
\hline & & & \multirow[t]{3}{*}{2200} & \multirow[t]{3}{*}{0} & 2 & 13200 & 6 & 3 \\
\hline & & & & & 3 & 15400 & 7 & 4 \\
\hline & & & & & 3 & 17600 & 8 & 5 \\
\hline & & & \multirow[t]{3}{*}{2400} & \multirow[t]{3}{*}{0} & 2 & 12000 & 5 & 3 \\
\hline & & & & & 3 & 16800 & 7 & 4 \\
\hline & & & & & 4 & 19200 & 8 & 5 \\
\hline \multirow[t]{9}{*}{20} & \multirow[t]{9}{*}{ WF-CPCI 1200} & \multirow[t]{9}{*}{1200} & \multirow[t]{3}{*}{2000} & \multirow[t]{3}{*}{1} & 2 & 14000 & 7 & 3 \\
\hline & & & & & 3 & 16000 & 8 & 4 \\
\hline & & & & & 3 & 18000 & 9 & 5 \\
\hline & & & \multirow[t]{3}{*}{2200} & \multirow[t]{3}{*}{1} & 2 & 13200 & 6 & 3 \\
\hline & & & & & 3 & 15400 & 7 & 4 \\
\hline & & & & & 3 & 17600 & 8 & 5 \\
\hline & & & \multirow[t]{3}{*}{2400} & \multirow[t]{3}{*}{1} & 2 & 12000 & 5 & 3 \\
\hline & & & & & 3 & 16800 & 7 & 4 \\
\hline & & & & & 4 & 19200 & 8 & 5 \\
\hline \multirow[t]{9}{*}{20} & \multirow[t]{9}{*}{ WF-CPCI 1200} & \multirow[t]{9}{*}{1200} & \multirow[t]{3}{*}{2000} & \multirow[t]{3}{*}{2} & 2 & 14000 & 7 & 3 \\
\hline & & & & & 3 & 16000 & 8 & 4 \\
\hline & & & & & 3 & 18000 & 9 & 5 \\
\hline & & & \multirow[t]{3}{*}{2200} & \multirow[t]{3}{*}{2} & 2 & 13200 & 6 & 3 \\
\hline & & & & & 3 & 15400 & 7 & 4 \\
\hline & & & & & 3 & 17600 & 8 & 5 \\
\hline & & & \multirow[t]{3}{*}{2400} & 2 & 2 & 12000 & 5 & 3 \\
\hline & & & & & 3 & 16800 & 7 & 4 \\
\hline & & & & & 4 & 19200 & 8 & 5 \\
\hline 20 & WF-CPCI 1400 & 1400 & 2000 & 0 & 2 & 14000 & 7 & 3 \\
\hline & & & & & 3 & 16000 & 8 & 4 \\
\hline & & & & & 3 & 18000 & 9 & 5 \\
\hline & & & 2200 & 0 & 2 & 13200 & 6 & 3 \\
\hline & & & & & 3 & 15400 & 7 & 4 \\
\hline & & & & & 3 & 17600 & 8 & 5 \\
\hline & & & 2400 & 0 & 2 & 12000 & 5 & 3 \\
\hline & & & & & 3 & 16800 & 7 & 4 \\
\hline & & & & & 4 & 19200 & 8 & 5 \\
\hline
\end{tabular}


Cont.

\begin{tabular}{|c|c|c|c|c|c|c|c|c|}
\hline $\begin{array}{l}\text { Bridge } \\
\text { span }\end{array}$ & Type & Depth & $\begin{array}{l}\text { Width of } \\
\text { girder }\end{array}$ & $\begin{array}{c}\text { No of } \\
\text { Intermediate } \\
\text { Diaphragms }\end{array}$ & $\begin{array}{l}\text { No of } \\
\text { Lanes }\end{array}$ & $\begin{array}{c}\text { Total } \\
\text { Width }\end{array}$ & $\begin{array}{l}\text { No of } \\
\text { girders }\end{array}$ & $\begin{array}{l}\text { No of } \\
\text { Design } \\
\text { Lanes }\end{array}$ \\
\hline $\mathrm{m}$ & & $\mathrm{mm}$ & $\mathrm{mm}$ & & & $\mathrm{mm}$ & & \\
\hline \multirow[t]{9}{*}{20} & \multirow[t]{9}{*}{ WF-CPCI 1600} & \multirow[t]{9}{*}{1600} & \multirow[t]{3}{*}{2000} & \multirow[t]{3}{*}{0} & 2 & 14000 & 7 & 3 \\
\hline & & & & & 3 & 16000 & 8 & 4 \\
\hline & & & & & 3 & 18000 & 9 & 5 \\
\hline & & & \multirow[t]{3}{*}{2200} & \multirow[t]{3}{*}{0} & 2 & 13200 & 6 & 3 \\
\hline & & & & & 3 & 15400 & 7 & 4 \\
\hline & & & & & 3 & 17600 & 8 & 5 \\
\hline & & & \multirow[t]{3}{*}{2400} & \multirow[t]{3}{*}{0} & 2 & 12000 & 5 & 3 \\
\hline & & & & & 3 & 16800 & 7 & 4 \\
\hline & & & & & 4 & 19200 & 8 & 5 \\
\hline \multirow[t]{9}{*}{20} & \multirow[t]{9}{*}{ WF-CPCI 1600} & \multirow[t]{9}{*}{1600} & \multirow[t]{3}{*}{2000} & \multirow[t]{3}{*}{1} & 2 & 14000 & 7 & 3 \\
\hline & & & & & 3 & 16000 & 8 & 4 \\
\hline & & & & & 3 & 18000 & 9 & 5 \\
\hline & & & \multirow[t]{3}{*}{2200} & \multirow[t]{3}{*}{1} & 2 & 13200 & 6 & 3 \\
\hline & & & & & 3 & 15400 & 7 & 4 \\
\hline & & & & & 3 & 17600 & 8 & 5 \\
\hline & & & \multirow[t]{3}{*}{2400} & \multirow[t]{3}{*}{1} & 2 & 12000 & 5 & 3 \\
\hline & & & & & 3 & 16800 & 7 & 4 \\
\hline & & & & & 4 & 19200 & 8 & 5 \\
\hline \multirow[t]{9}{*}{20} & \multirow[t]{9}{*}{ WF-CPCI 1600} & \multirow[t]{9}{*}{1600} & \multirow[t]{3}{*}{2000} & \multirow[t]{3}{*}{2} & 2 & 14000 & 7 & 3 \\
\hline & & & & & 3 & 16000 & 8 & 4 \\
\hline & & & & & 3 & 18000 & 9 & 5 \\
\hline & & & \multirow[t]{3}{*}{2200} & \multirow[t]{3}{*}{2} & 2 & 13200 & 6 & 3 \\
\hline & & & & & 3 & 15400 & 7 & 4 \\
\hline & & & & & 3 & 17600 & 8 & 5 \\
\hline & & & \multirow[t]{3}{*}{2400} & 2 & 2 & 12000 & 5 & 3 \\
\hline & & & & & 3 & 16800 & 7 & 4 \\
\hline & & & & & 4 & 19200 & 8 & 5 \\
\hline 25 & WF-CPCI 1200 & 1200 & 2000 & 0 & 2 & 14000 & 7 & 3 \\
\hline & & & & 0 & 3 & 16000 & 8 & 4 \\
\hline & & & & 0 & 3 & 18000 & 9 & 5 \\
\hline & & & 2200 & 0 & 2 & 13200 & 6 & 3 \\
\hline & & & & 0 & 3 & 15400 & 7 & 4 \\
\hline & & & & 0 & 3 & 17600 & 8 & 5 \\
\hline & & & 2400 & 0 & 2 & 12000 & 5 & 3 \\
\hline & & & & 0 & 3 & 16800 & 7 & 4 \\
\hline & & & & 0 & 4 & 19200 & 8 & 5 \\
\hline
\end{tabular}


Cont.

\begin{tabular}{|c|c|c|c|c|c|c|c|c|}
\hline $\begin{array}{l}\text { Bridge } \\
\text { span }\end{array}$ & Type & Depth & $\begin{array}{l}\text { Width of } \\
\text { girder }\end{array}$ & $\begin{array}{c}\text { No of } \\
\text { Intermediate } \\
\text { Diaphragms }\end{array}$ & $\begin{array}{l}\text { No of } \\
\text { Lanes }\end{array}$ & $\begin{array}{l}\text { Total } \\
\text { Width }\end{array}$ & $\begin{array}{l}\text { No of } \\
\text { girders }\end{array}$ & $\begin{array}{l}\text { No of } \\
\text { Design } \\
\text { Lanes }\end{array}$ \\
\hline $\mathrm{m}$ & & $\mathrm{mm}$ & $\mathrm{mm}$ & & & $\mathrm{mm}$ & & \\
\hline \multirow[t]{9}{*}{25} & \multirow[t]{9}{*}{ WF-CPCI 1400} & \multirow[t]{9}{*}{1400} & \multirow[t]{3}{*}{2000} & 0 & 2 & 14000 & 7 & 3 \\
\hline & & & & 0 & 3 & 16000 & 8 & 4 \\
\hline & & & & 0 & 3 & 18000 & 9 & 5 \\
\hline & & & \multirow[t]{3}{*}{2200} & 0 & 2 & 13200 & 6 & 3 \\
\hline & & & & 0 & 3 & 15400 & 7 & 4 \\
\hline & & & & 0 & 3 & 17600 & 8 & 5 \\
\hline & & & \multirow[t]{3}{*}{2400} & 0 & 2 & 12000 & 5 & 3 \\
\hline & & & & 0 & 3 & 16800 & 7 & 4 \\
\hline & & & & 0 & 4 & 19200 & 8 & 5 \\
\hline \multirow[t]{9}{*}{25} & \multirow[t]{9}{*}{ WF-CPCI 1400} & \multirow[t]{9}{*}{1400} & \multirow[t]{3}{*}{2000} & 1 & 2 & 14000 & 7 & 3 \\
\hline & & & & 1 & 3 & 16000 & 8 & 4 \\
\hline & & & & 1 & 3 & 18000 & 9 & 5 \\
\hline & & & \multirow[t]{3}{*}{2200} & 1 & 2 & 13200 & 6 & 3 \\
\hline & & & & 1 & 3 & 15400 & 7 & 4 \\
\hline & & & & 1 & 3 & 17600 & 8 & 5 \\
\hline & & & \multirow[t]{3}{*}{2400} & 1 & 2 & 12000 & 5 & 3 \\
\hline & & & & 1 & 3 & 16800 & 7 & 4 \\
\hline & & & & 1 & 4 & 19200 & 8 & 5 \\
\hline \multirow[t]{9}{*}{25} & \multirow[t]{9}{*}{ WF-CPCI 1400} & \multirow[t]{9}{*}{1400} & \multirow[t]{3}{*}{2000} & 2 & 2 & 14000 & 7 & 3 \\
\hline & & & & 2 & 3 & 16000 & 8 & 4 \\
\hline & & & & 2 & 3 & 18000 & 9 & 5 \\
\hline & & & \multirow[t]{3}{*}{2200} & 2 & 2 & 13200 & 6 & 3 \\
\hline & & & & 2 & 3 & 15400 & 7 & 4 \\
\hline & & & & 2 & 3 & 17600 & 8 & 5 \\
\hline & & & \multirow[t]{3}{*}{2400} & 2 & 2 & 12000 & 5 & 3 \\
\hline & & & & 2 & 3 & 16800 & 7 & 4 \\
\hline & & & & 2 & 4 & 19200 & 8 & 5 \\
\hline \multirow[t]{9}{*}{25} & \multirow[t]{9}{*}{ WF-CPCI 1600} & \multirow[t]{9}{*}{1600} & \multirow[t]{3}{*}{2000} & 0 & 2 & 14000 & 7 & 3 \\
\hline & & & & 0 & 3 & 16000 & 8 & 4 \\
\hline & & & & 0 & 3 & 18000 & 9 & 5 \\
\hline & & & \multirow[t]{3}{*}{2200} & 0 & 2 & 13200 & 6 & 3 \\
\hline & & & & 0 & 3 & 15400 & 7 & 4 \\
\hline & & & & 0 & 3 & 17600 & 8 & 5 \\
\hline & & & \multirow[t]{3}{*}{2400} & 0 & 2 & 12000 & 5 & 3 \\
\hline & & & & 0 & 3 & 16800 & 7 & 4 \\
\hline & & & & 0 & 4 & 19200 & 8 & 5 \\
\hline
\end{tabular}


Cont.

\begin{tabular}{|c|c|c|c|c|c|c|c|c|}
\hline $\begin{array}{c}\text { Bridge } \\
\text { span }\end{array}$ & Type & Depth & $\begin{array}{l}\text { Width of } \\
\text { girder }\end{array}$ & $\begin{array}{c}\text { No of } \\
\text { Intermediate } \\
\text { Diaphragms }\end{array}$ & $\begin{array}{l}\text { No of } \\
\text { Lanes }\end{array}$ & $\begin{array}{c}\text { Total } \\
\text { Width }\end{array}$ & $\begin{array}{l}\text { No of } \\
\text { girders }\end{array}$ & $\begin{array}{c}\text { No of } \\
\text { Design } \\
\text { Lanes }\end{array}$ \\
\hline $\mathrm{m}$ & & $\mathrm{mm}$ & $\mathrm{mm}$ & & & $\mathrm{mm}$ & & \\
\hline \multirow{9}{*}{25} & \multirow[t]{9}{*}{ WF-CPCI 1600} & \multirow{9}{*}{1600} & \multirow{3}{*}{2000} & 1 & 2 & 14000 & 7 & 3 \\
\hline & & & & 1 & 3 & 16000 & 8 & 4 \\
\hline & & & & 1 & 3 & 18000 & 9 & 5 \\
\hline & & & \multirow[t]{3}{*}{2200} & 1 & 2 & 13200 & 6 & 3 \\
\hline & & & & 1 & 3 & 15400 & 7 & 4 \\
\hline & & & & 1 & 3 & 17600 & 8 & 5 \\
\hline & & & \multirow[t]{3}{*}{2400} & 1 & 2 & 12000 & 5 & 3 \\
\hline & & & & 1 & 3 & 16800 & 7 & 4 \\
\hline & & & & 1 & 4 & 19200 & 8 & 5 \\
\hline \multirow[t]{9}{*}{25} & \multirow[t]{9}{*}{ WF-CPCI 1600} & \multirow[t]{9}{*}{1600} & \multirow[t]{3}{*}{2000} & 2 & 2 & 14000 & 7 & 3 \\
\hline & & & & 2 & 3 & 16000 & 8 & 4 \\
\hline & & & & 2 & 3 & 18000 & 9 & 5 \\
\hline & & & \multirow[t]{3}{*}{2200} & 2 & 2 & 13200 & 6 & 3 \\
\hline & & & & 2 & 3 & 15400 & 7 & 4 \\
\hline & & & & 2 & 3 & 17600 & 8 & 5 \\
\hline & & & \multirow[t]{3}{*}{2400} & 2 & 2 & 12000 & 5 & 3 \\
\hline & & & & 2 & 3 & 16800 & 7 & 4 \\
\hline & & & & 2 & 4 & 19200 & 8 & 5 \\
\hline \multirow[t]{9}{*}{30} & \multirow[t]{9}{*}{ WF-CPCI 1600} & \multirow[t]{9}{*}{1600} & \multirow[t]{3}{*}{2000} & 0 & 2 & 14000 & 7 & 3 \\
\hline & & & & 0 & 3 & 16000 & 8 & 4 \\
\hline & & & & 0 & 3 & 18000 & 9 & 5 \\
\hline & & & \multirow[t]{3}{*}{2200} & 0 & 2 & 13200 & 6 & 3 \\
\hline & & & & 0 & 3 & 15400 & 7 & 4 \\
\hline & & & & 0 & 3 & 17600 & 8 & 5 \\
\hline & & & \multirow[t]{3}{*}{2400} & 0 & 2 & 12000 & 5 & 3 \\
\hline & & & & 0 & 3 & 16800 & 7 & 4 \\
\hline & & & & 0 & 4 & 19200 & 8 & 5 \\
\hline \multirow[t]{9}{*}{30} & \multirow[t]{9}{*}{ WF-CPCI 1600} & \multirow[t]{9}{*}{1600} & \multirow[t]{3}{*}{2000} & 1 & 2 & 14000 & 7 & 3 \\
\hline & & & & 1 & 3 & 16000 & 8 & 4 \\
\hline & & & & 1 & 3 & 18000 & 9 & 5 \\
\hline & & & \multirow[t]{3}{*}{2200} & 1 & 2 & 13200 & 6 & 3 \\
\hline & & & & 1 & 3 & 15400 & 7 & 4 \\
\hline & & & & 1 & 3 & 17600 & 8 & 5 \\
\hline & & & \multirow[t]{3}{*}{2400} & 1 & 2 & 12000 & 5 & 3 \\
\hline & & & & 1 & 3 & 16800 & 7 & 4 \\
\hline & & & & 1 & 4 & 19200 & 8 & 5 \\
\hline
\end{tabular}


Cont.

\begin{tabular}{|c|c|c|c|c|c|c|c|c|}
\hline $\begin{array}{l}\text { Bridge } \\
\text { span }\end{array}$ & Type & Depth & $\begin{array}{l}\text { Width of } \\
\text { girder }\end{array}$ & $\begin{array}{c}\text { No of } \\
\text { Intermediate } \\
\text { Diaphragms }\end{array}$ & $\begin{array}{l}\text { No of } \\
\text { Lanes }\end{array}$ & $\begin{array}{l}\text { Total } \\
\text { Width }\end{array}$ & $\begin{array}{l}\text { No of } \\
\text { girders }\end{array}$ & $\begin{array}{c}\text { No of } \\
\text { Design } \\
\text { Lanes }\end{array}$ \\
\hline $\mathrm{m}$ & & $\mathrm{mm}$ & $\mathrm{mm}$ & & & $\mathrm{mm}$ & & \\
\hline \multirow[t]{9}{*}{30} & \multirow[t]{9}{*}{ WF-CPCI 1600} & \multirow[t]{9}{*}{1600} & \multirow[t]{3}{*}{2000} & 2 & 2 & 14000 & 7 & 3 \\
\hline & & & & 2 & 3 & 16000 & 8 & 4 \\
\hline & & & & 2 & 3 & 18000 & 9 & 5 \\
\hline & & & \multirow[t]{3}{*}{2200} & 2 & 2 & 13200 & 6 & 3 \\
\hline & & & & 2 & 3 & 15400 & 7 & 4 \\
\hline & & & & 2 & 3 & 17600 & 8 & 5 \\
\hline & & & \multirow[t]{3}{*}{2400} & 2 & 2 & 12000 & 5 & 3 \\
\hline & & & & 2 & 3 & 16800 & 7 & 4 \\
\hline & & & & 2 & 4 & 19200 & 8 & 5 \\
\hline \multirow[t]{9}{*}{35} & \multirow[t]{9}{*}{ WF-CPCI 1600} & \multirow[t]{9}{*}{1600} & \multirow[t]{3}{*}{2000} & 0 & 2 & 14000 & 7 & 3 \\
\hline & & & & 0 & 3 & 16000 & 8 & 4 \\
\hline & & & & 0 & 3 & 18000 & 9 & 5 \\
\hline & & & \multirow[t]{3}{*}{2200} & 0 & 2 & 13200 & 6 & 3 \\
\hline & & & & 0 & 3 & 15400 & 7 & 4 \\
\hline & & & & 0 & 3 & 17600 & 8 & 5 \\
\hline & & & \multirow[t]{3}{*}{2400} & 0 & 2 & 12000 & 5 & 3 \\
\hline & & & & 0 & 3 & 16800 & 7 & 4 \\
\hline & & & & 0 & 4 & 19200 & 8 & 5 \\
\hline \multirow[t]{9}{*}{35} & \multirow[t]{9}{*}{ WF-CPCI 1600} & \multirow[t]{9}{*}{1600} & \multirow[t]{3}{*}{2000} & 1 & 2 & 14000 & 7 & 3 \\
\hline & & & & 1 & 3 & 16000 & 8 & 4 \\
\hline & & & & 1 & 3 & 18000 & 9 & 5 \\
\hline & & & \multirow[t]{3}{*}{2200} & 1 & 2 & 13200 & 6 & 3 \\
\hline & & & & 1 & 3 & 15400 & 7 & 4 \\
\hline & & & & 1 & 3 & 17600 & 8 & 5 \\
\hline & & & \multirow[t]{3}{*}{2400} & 1 & 2 & 12000 & 5 & 3 \\
\hline & & & & 1 & 3 & 16800 & 7 & 4 \\
\hline & & & & 1 & 4 & 19200 & 8 & 5 \\
\hline \multirow[t]{9}{*}{35} & \multirow[t]{9}{*}{ WF-CPCI 1600} & \multirow[t]{9}{*}{1600} & \multirow[t]{3}{*}{2000} & 2 & 2 & 14000 & 7 & 3 \\
\hline & & & & 2 & 3 & 16000 & 8 & 4 \\
\hline & & & & 2 & 3 & 18000 & 9 & 5 \\
\hline & & & \multirow[t]{3}{*}{2200} & 2 & 2 & 13200 & 6 & 3 \\
\hline & & & & 2 & 3 & 15400 & 7 & 4 \\
\hline & & & & 2 & 3 & 17600 & 8 & 5 \\
\hline & & & \multirow[t]{3}{*}{2400} & 2 & 2 & 12000 & 5 & 3 \\
\hline & & & & 2 & 3 & 16800 & 7 & 4 \\
\hline & & & & 2 & 4 & 19200 & 8 & 5 \\
\hline
\end{tabular}


Cont.

\begin{tabular}{|c|c|c|c|c|c|c|c|c|}
\hline $\begin{array}{c}\text { Bridge } \\
\text { span }\end{array}$ & Type & Depth & $\begin{array}{l}\text { Width of } \\
\text { girder }\end{array}$ & $\begin{array}{c}\text { No of } \\
\text { Intermediate } \\
\text { Diaphragms }\end{array}$ & $\begin{array}{l}\text { No of } \\
\text { Lanes }\end{array}$ & $\begin{array}{c}\text { Total } \\
\text { Width }\end{array}$ & $\begin{array}{l}\text { No of } \\
\text { girders }\end{array}$ & $\begin{array}{l}\text { No of } \\
\text { Design } \\
\text { Lanes }\end{array}$ \\
\hline $\mathrm{m}$ & & $\mathrm{mm}$ & $\mathrm{mm}$ & & & $\mathrm{mm}$ & & \\
\hline \multirow[t]{9}{*}{35} & \multirow[t]{9}{*}{ WF-CPCI 1900} & \multirow{9}{*}{1900} & \multirow[t]{3}{*}{2000} & 0 & 2 & 14000 & 7 & 3 \\
\hline & & & & 0 & 3 & 16000 & 8 & 4 \\
\hline & & & & 0 & 3 & 18000 & 9 & 5 \\
\hline & & & \multirow[t]{3}{*}{2200} & 0 & 2 & 13200 & 6 & 3 \\
\hline & & & & 0 & 3 & 15400 & 7 & 4 \\
\hline & & & & 0 & 3 & 17600 & 8 & 5 \\
\hline & & & \multirow[t]{3}{*}{2400} & 0 & 2 & 12000 & 5 & 3 \\
\hline & & & & 0 & 3 & 16800 & 7 & 4 \\
\hline & & & & 0 & 4 & 19200 & 8 & 5 \\
\hline
\end{tabular}


Table 3.3 Bridge Configurations considered to study the effect of the type of flangeto-flange connection on load distribution

\begin{tabular}{|c|c|c|c|c|c|c|c|c|}
\hline $\begin{array}{l}\text { Bridge } \\
\text { span }\end{array}$ & Type & Depth & $\begin{array}{c}\text { Spacing } \\
\text { between } \\
\text { Joints }\end{array}$ & $\begin{array}{c}\text { No of } \\
\text { Intermediate } \\
\text { Diaphragms }\end{array}$ & $\begin{array}{l}\text { No of } \\
\text { Lanes }\end{array}$ & $\begin{array}{l}\text { Total } \\
\text { Width }\end{array}$ & $\begin{array}{l}\text { No of } \\
\text { girders }\end{array}$ & $\begin{array}{l}\text { No of } \\
\text { Design } \\
\text { Lanes }\end{array}$ \\
\hline $\mathrm{m}$ & & $\mathrm{mm}$ & $\mathrm{mm}$ & & & $\mathrm{mm}$ & & \\
\hline \multirow[t]{8}{*}{30} & \multirow{8}{*}{ WF-CPCI 1600} & \multirow{8}{*}{1600} & Full & 0 & 2 & 13200 & 6 & 3 \\
\hline & & & 500 & 0 & 2 & 13200 & 6 & 3 \\
\hline & & & 1000 & 0 & 2 & 13200 & 6 & 3 \\
\hline & & & 1500 & 0 & 2 & 13200 & 6 & 3 \\
\hline & & & 2000 & 0 & 2 & 13200 & 6 & 3 \\
\hline & & & 2500 & 0 & 2 & 13200 & 6 & 3 \\
\hline & & & 3000 & 0 & 2 & 13200 & 6 & 3 \\
\hline & & & 3500 & 0 & 2 & 13200 & 6 & 3 \\
\hline \multirow[t]{8}{*}{30} & \multirow[t]{8}{*}{ WF-CPCI 1600} & \multirow[t]{8}{*}{1600} & Full & 1 & 2 & 13200 & 6 & 3 \\
\hline & & & 500 & 1 & 2 & 13200 & 6 & 3 \\
\hline & & & 1000 & 1 & 2 & 13200 & 6 & 3 \\
\hline & & & 1500 & 1 & 2 & 13200 & 6 & 3 \\
\hline & & & 2000 & 1 & 2 & 13200 & 6 & 3 \\
\hline & & & 2500 & 1 & 2 & 13200 & 6 & 3 \\
\hline & & & 3000 & 1 & 2 & 13200 & 6 & 3 \\
\hline & & & 3500 & 1 & 2 & 13200 & 6 & 3 \\
\hline \multirow[t]{8}{*}{30} & \multirow[t]{8}{*}{ WF-CPCI 1600} & \multirow[t]{8}{*}{1600} & Full & 2 & 2 & 13200 & 6 & 3 \\
\hline & & & 500 & 2 & 2 & 13200 & 6 & 3 \\
\hline & & & 1000 & 2 & 2 & 13200 & 6 & 3 \\
\hline & & & 1500 & 2 & 2 & 13200 & 6 & 3 \\
\hline & & & 2000 & 2 & 2 & 13200 & 6 & 3 \\
\hline & & & 2500 & 2 & 2 & 13200 & 6 & 3 \\
\hline & & & 3000 & 2 & 2 & 13200 & 6 & 3 \\
\hline & & & 3500 & 2 & 2 & 13200 & 6 & 3 \\
\hline
\end{tabular}


Table 3.4 Modification Factors for Multilane Loading (CHBDC, 2000)

\begin{tabular}{|c|c|}
\hline Number of loaded design lanes & Modification Factor \\
\hline 1 & 1.00 \\
\hline 2 & 0.90 \\
\hline 3 & 0.80 \\
\hline 4 & 0.70 \\
\hline 5 & 0.60 \\
\hline 6 or more & 0.55 \\
\hline
\end{tabular}

Table 3.5 Number of Design Lanes (CHBDC 2000)

\begin{tabular}{|c|c|}
\hline$W_{c}$ & $n$ \\
\hline $6.0 \mathrm{~m}$ or less & 1 \\
\hline Over $6.0 \mathrm{~m}$ to $10.0 \mathrm{~m}$ & 2 \\
\hline Over $10.0 \mathrm{~m}$ to $13.5 \mathrm{~m}$ & 2 or $3^{*}$ \\
\hline Over $13.5 \mathrm{~m}$ to $17.0 \mathrm{~m}$ & 4 \\
\hline Over $17.0 \mathrm{~m}$ to $20.5 \mathrm{~m}$ & 5 \\
\hline Over $20.5 \mathrm{~m}$ to $24.0 \mathrm{~m}$ & 6 \\
\hline Over $24.0 \mathrm{~m}$ to $27.5 \mathrm{~m}$ & 7 \\
\hline Over $27.5 \mathrm{~m}$ & 8 \\
\hline
\end{tabular}

* Both should be checked.

Table 3.6 Bridge Design Lane Configurations

\begin{tabular}{|c|c|c|c|c|c|}
\hline $\begin{array}{c}\text { Width of WF- } \\
\text { CPCI }\end{array}$ & $\begin{array}{c}\text { No of } \\
\text { girders }\end{array}$ & Total Width & $\begin{array}{c}\text { Roadway } \\
\text { Width }\end{array}$ & $\begin{array}{c}\text { No of Design } \\
\text { Lanes }\end{array}$ & $\begin{array}{c}\text { Design Lane } \\
\text { width }\end{array}$ \\
\hline $\mathrm{mm}$ & & $\mathrm{mm}$ & $\mathrm{mm}$ & & $\mathrm{mm}$ \\
\hline 2000 & 7 & 14000 & 12860 & 3 & 4287 \\
\hline 2000 & 8 & 16000 & 14860 & 4 & 3715 \\
\hline 2000 & 9 & 18000 & 16860 & 5 & 3372 \\
\hline 2200 & 6 & 13200 & 12060 & 3 & 4020 \\
\hline 2200 & 7 & 15400 & 14260 & 4 & 3565 \\
\hline 2200 & 8 & 17600 & 16460 & 5 & 3292 \\
\hline 2400 & 5 & 12000 & 10860 & 3 & 3620 \\
\hline 2400 & 7 & 16800 & 15660 & 4 & 3915 \\
\hline 2400 & 8 & 19200 & 18060 & 5 & 3612 \\
\hline
\end{tabular}




\section{FIGURES}

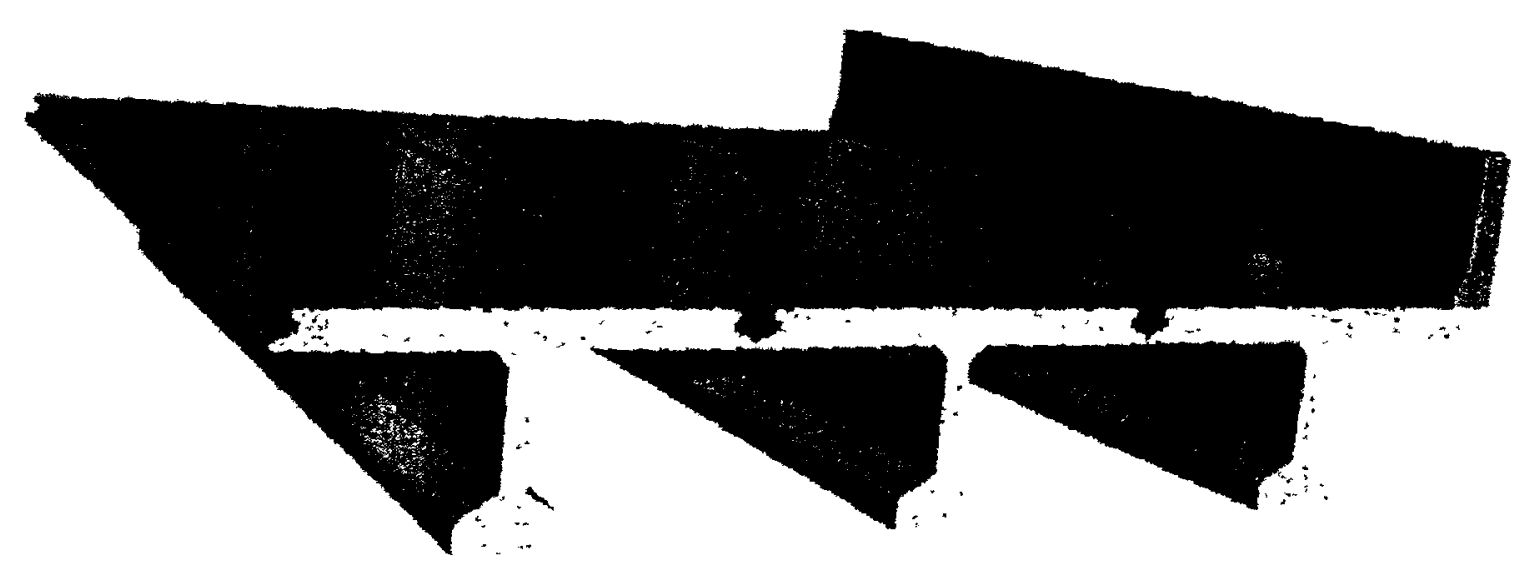

a) Continuous connection

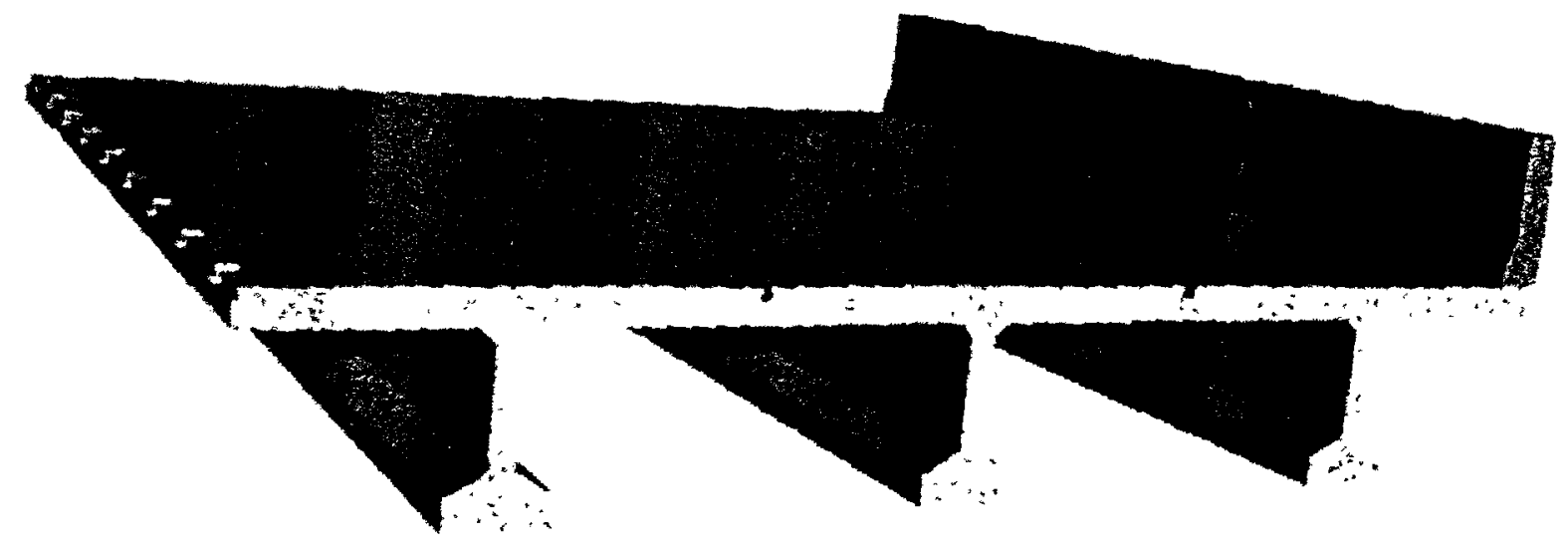

b) Intermittent connection

Figure 1.1

Views of WF-CPCI girder bridge
connections

cross-sections with longitudinal 


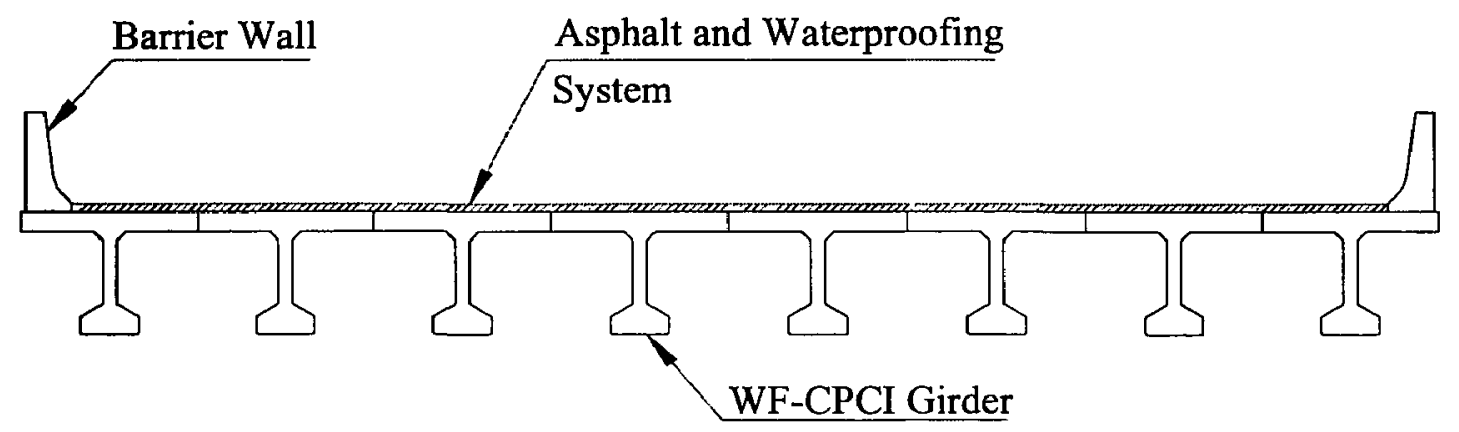

Figure 1.2 Typical cross-section of WF-CPCI girder bridge system 
$2000 \mathrm{~mm}$ WDE FLANGE

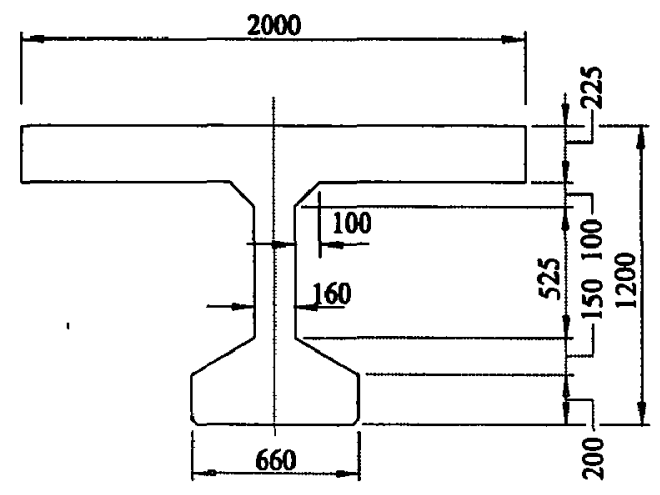

$2200 \mathrm{~mm}$ WIDE FLANGE

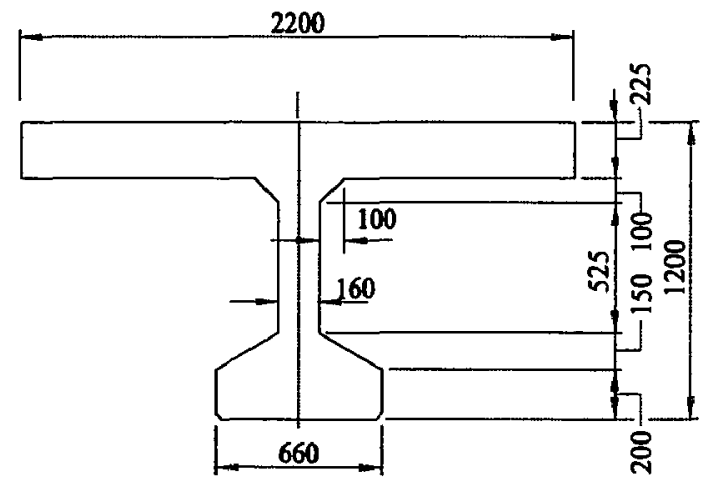

$2400 \mathrm{~mm}$ WIDE FLANGE

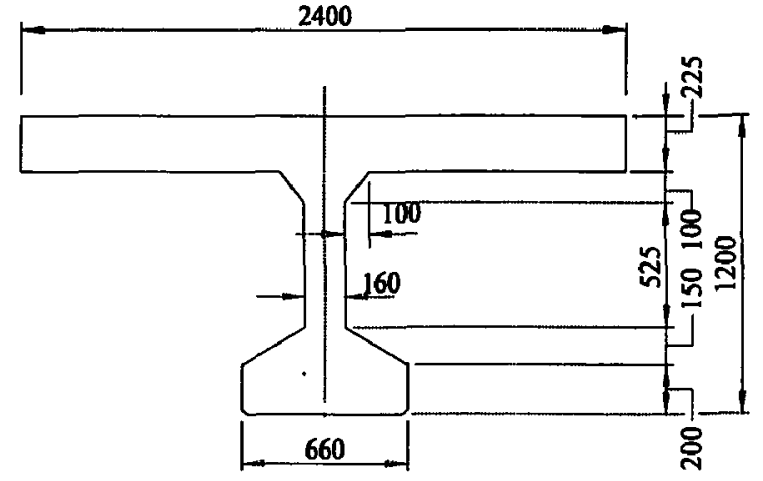

Figure 2.1 Typical section for WF-CPCI 1200 depth girders 
$2000 \mathrm{~mm}$ WIDE FLANGE

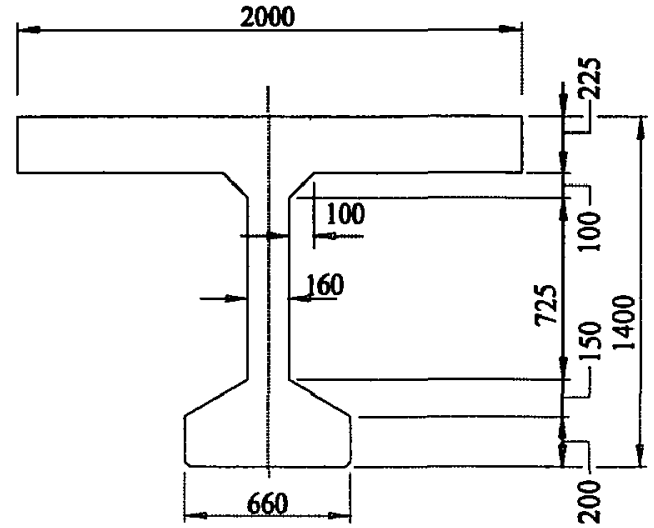

$2200 \mathrm{~mm}$ WIDE FLANGE

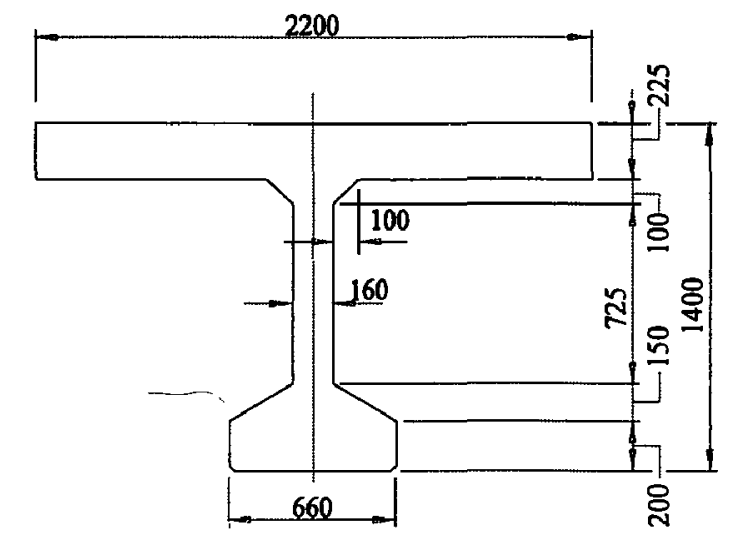

$2400 \mathrm{~mm}$ WIEE FLANGE

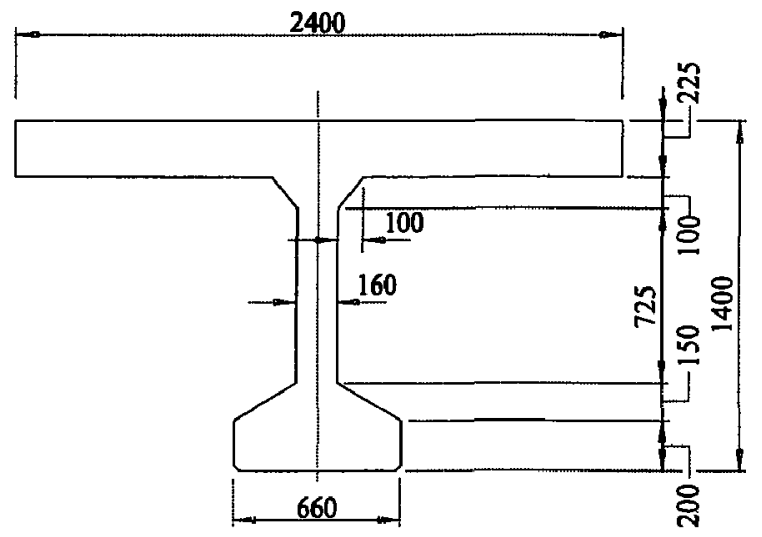

Figure 2.2 Typical section for WF-CPCI 1400 depth girders 


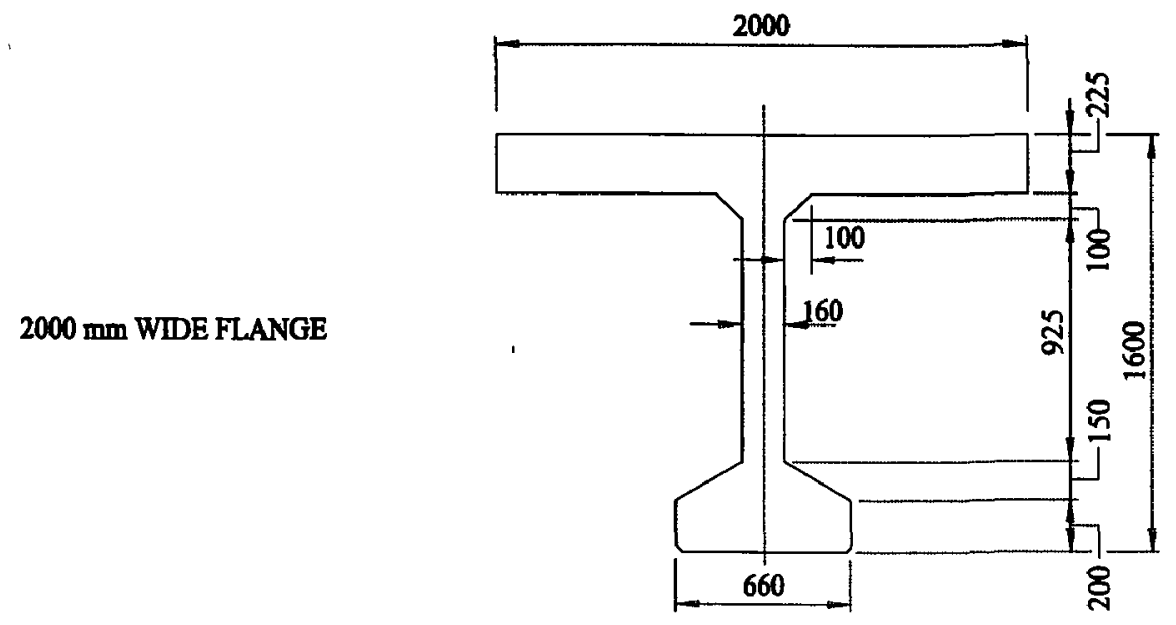

$2200 \mathrm{~mm}$ WIDE FLANGE

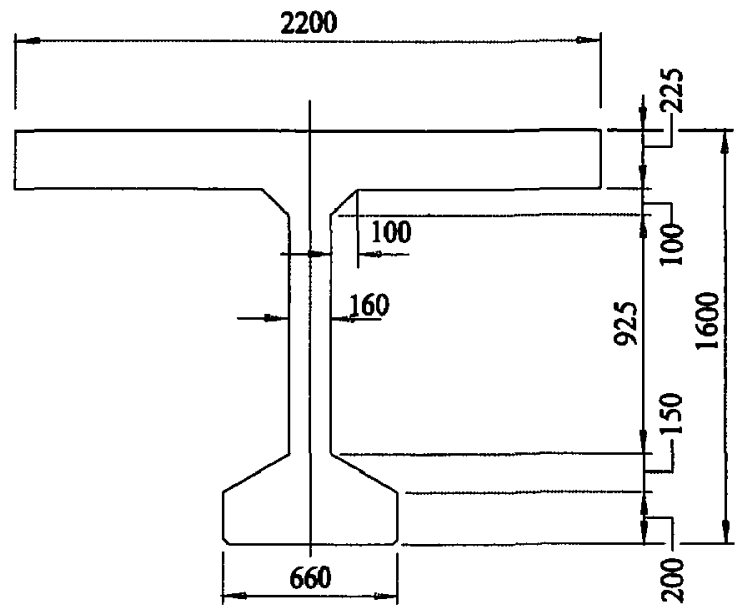

$2400 \mathrm{~mm}$ WIDE FLANGE

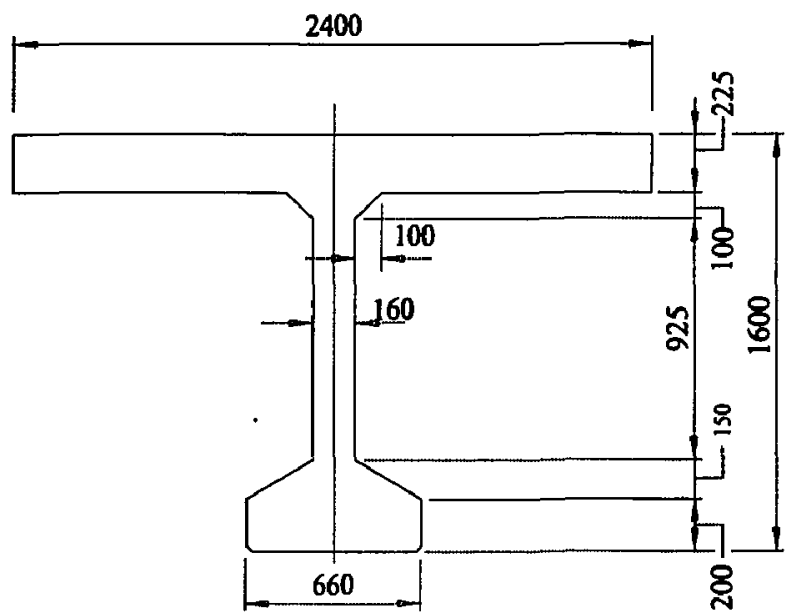

Figure 2.3 Typical section for WF-CPCI 1600 depth girders 
$2000 \mathrm{~mm}$ WIDE FLANGE

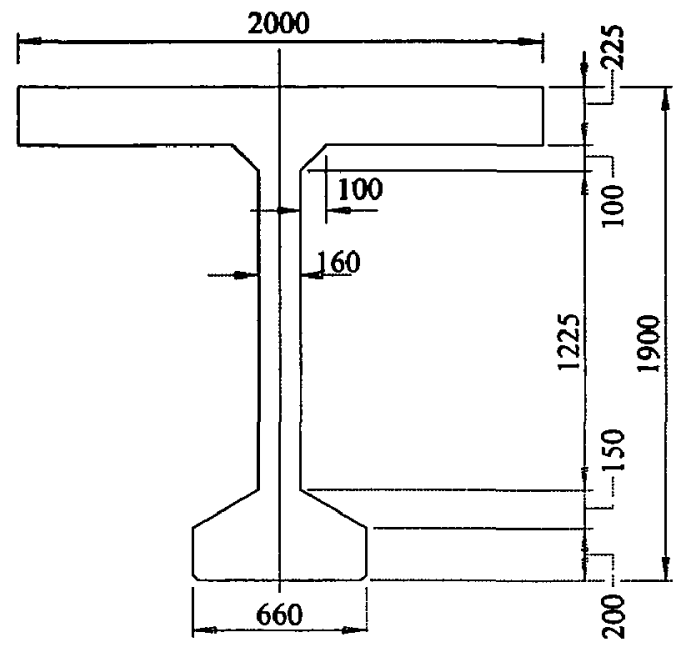

$2200 \mathrm{~mm}$ WIDE FLANGE

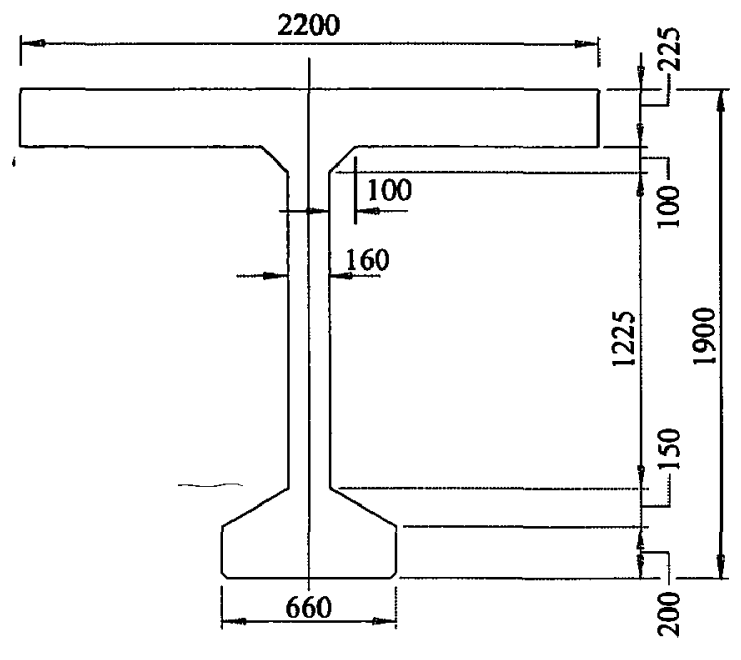

$2400 \mathrm{~mm}$ WIDE FLANGE

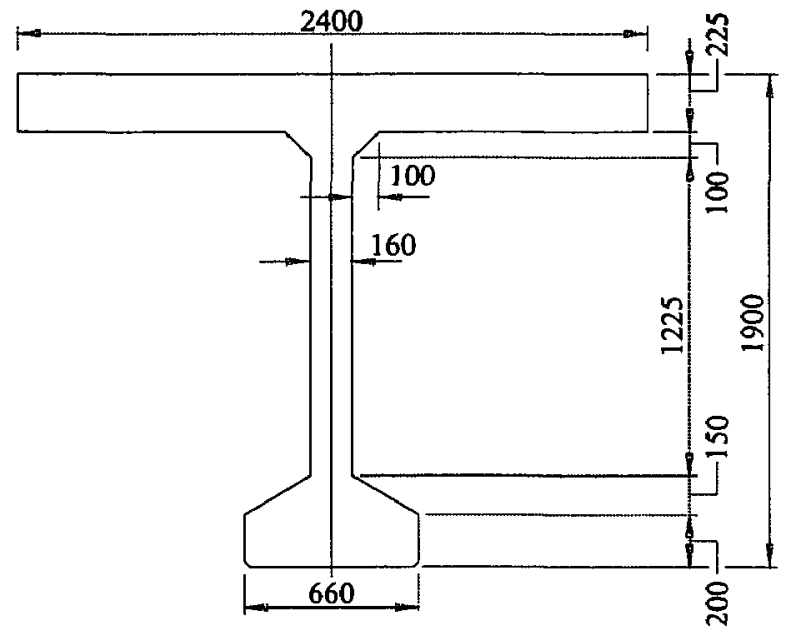

Figure 2.4 Typical section for WF-CPCI 1900 depth girders 


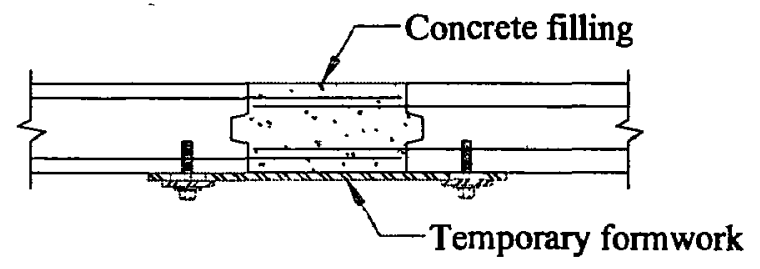

Joint 1

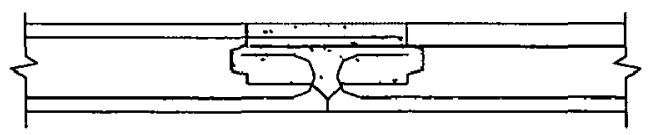

Joint 2

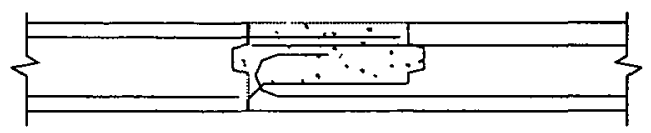

Joint 3

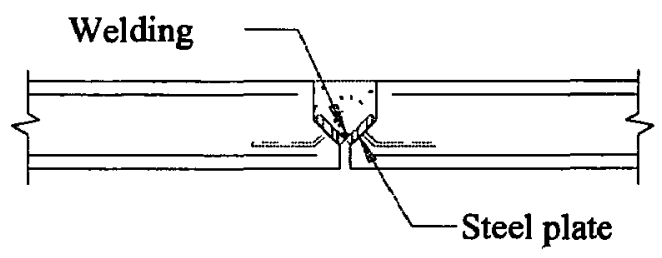

Joint 4

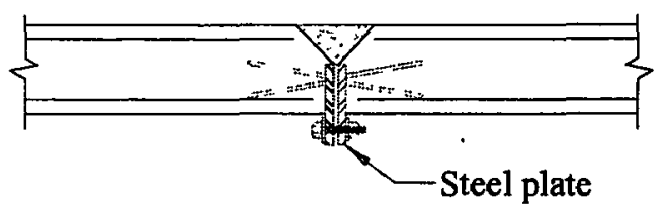

Joint 5

Figure 2.5 Possible connections between girder flanges 


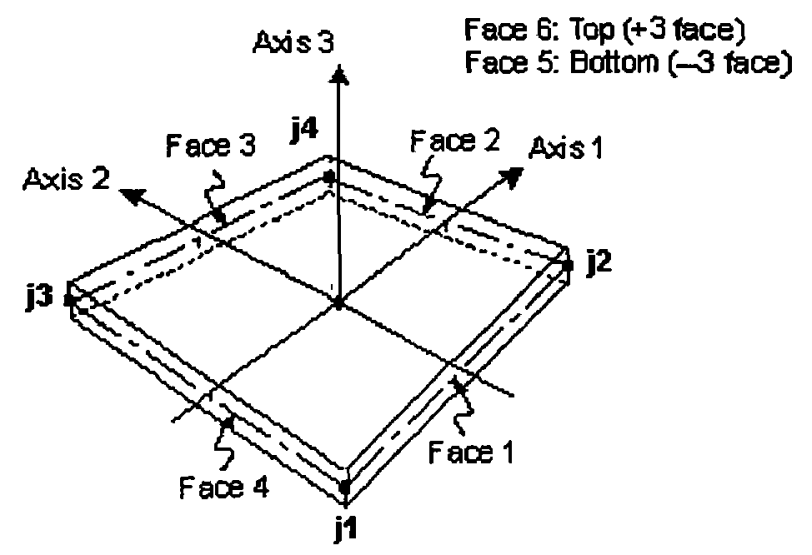

a) Four-node shell element

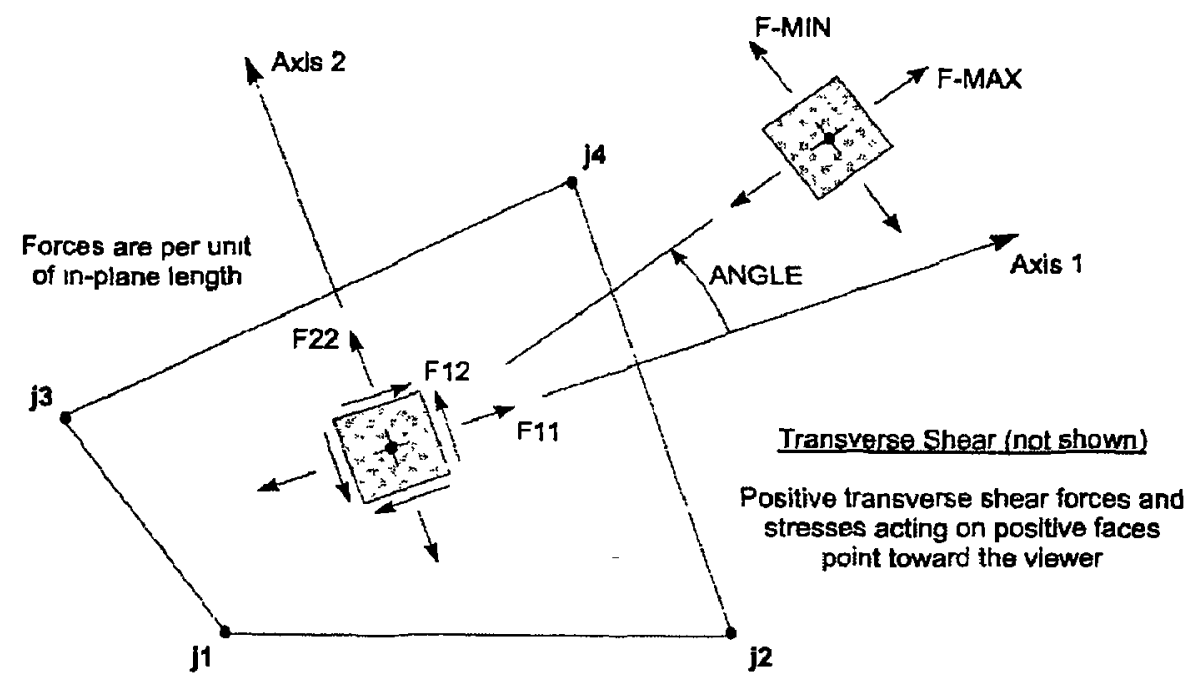

b) Stress and membrane forces

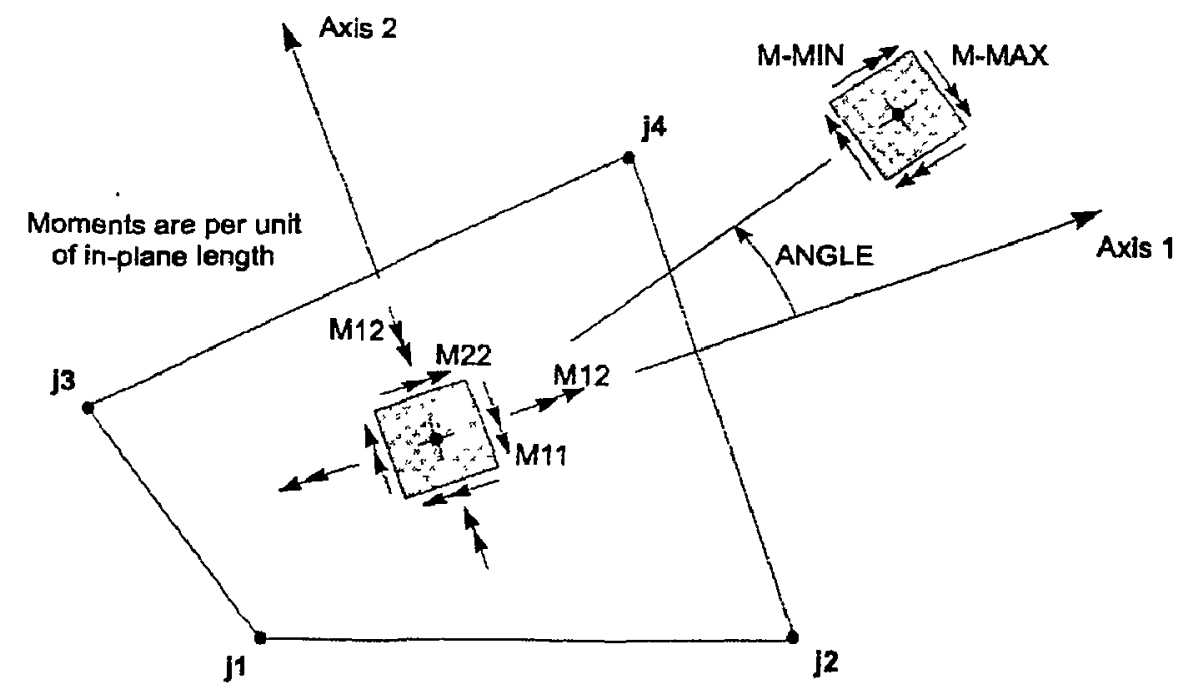

c) Plate bending moments

Figure 3.1 Shell element used in the analysis (SAP2000) 


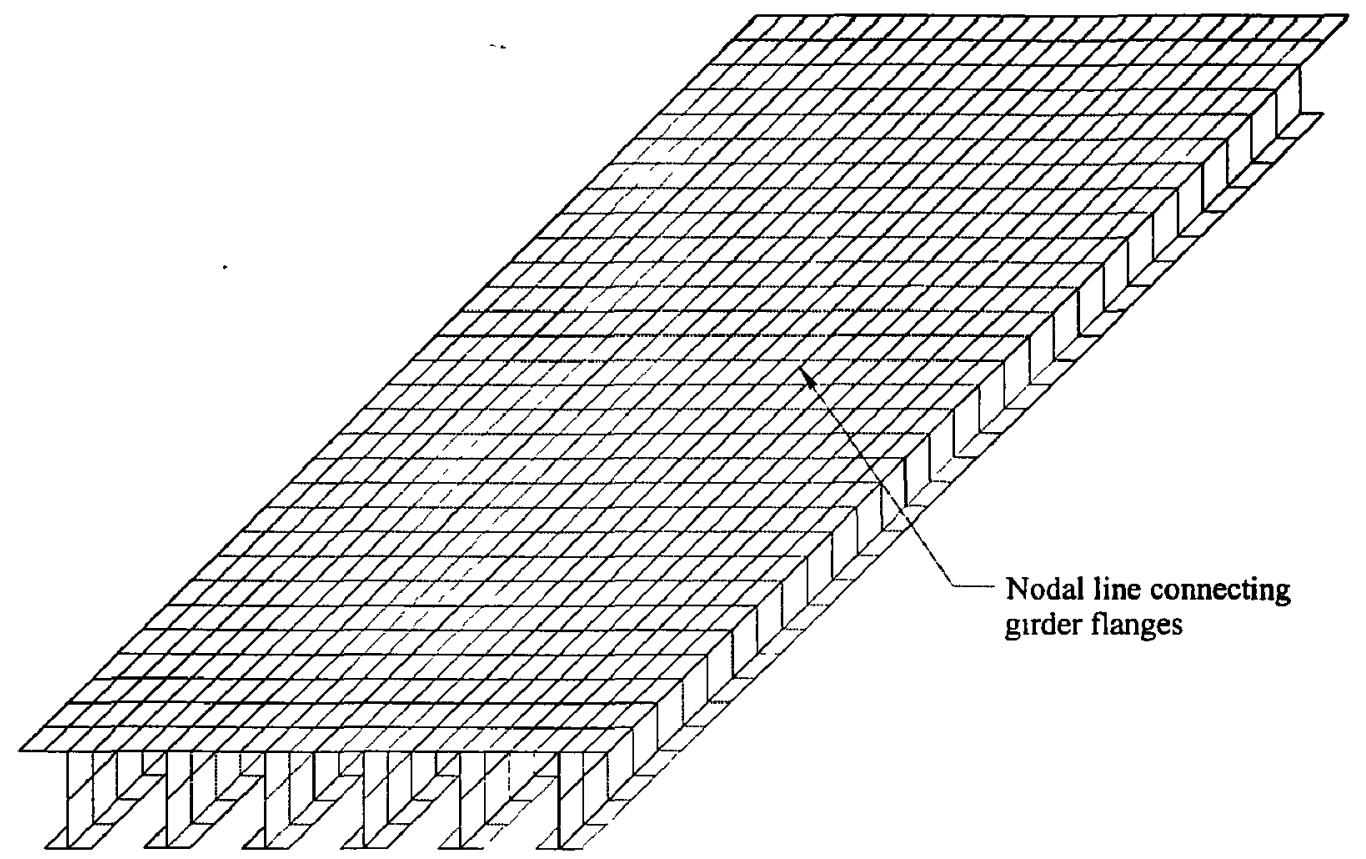

Figure 3.2 Schematic view of the SAP2000 model with continuous connections between girder flanges

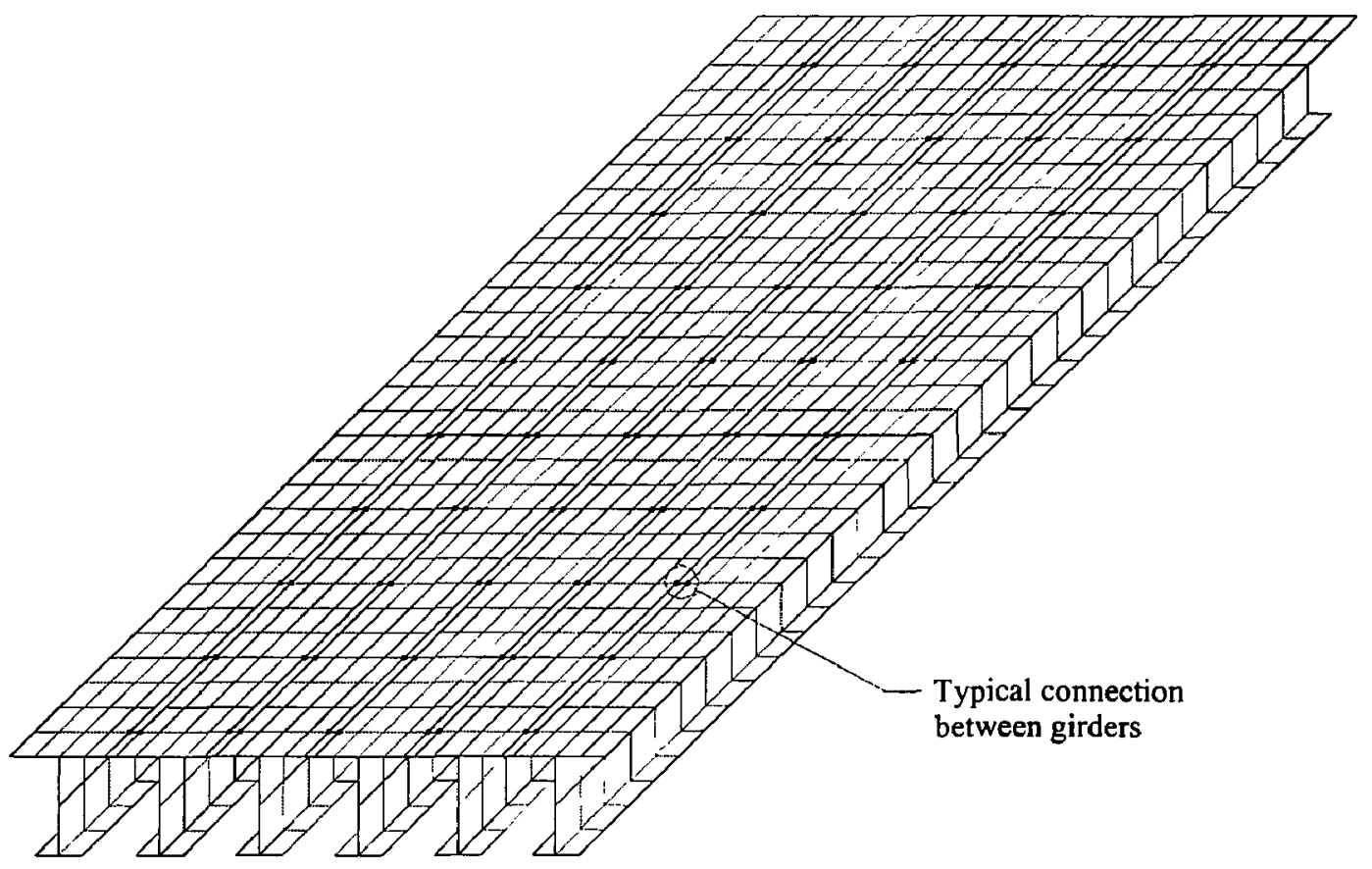

Figure 3.3 Schematic view of the SAP2000 model showing the intermittent connections between girder flanges 


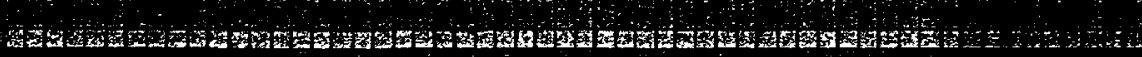

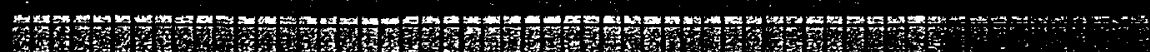

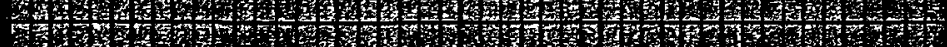

W6

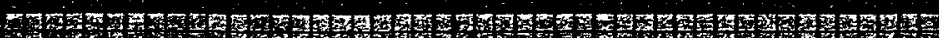

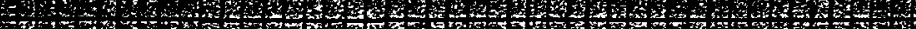

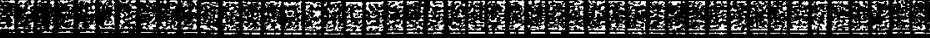

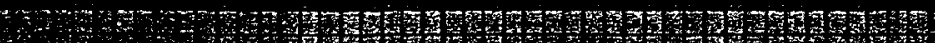

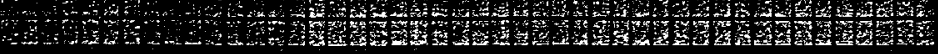

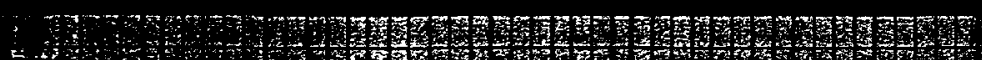

Figure 3.4 Plan view of SAP2000 model for 6-girder bridge with no intermediate diaphragm and continuous connections between girders

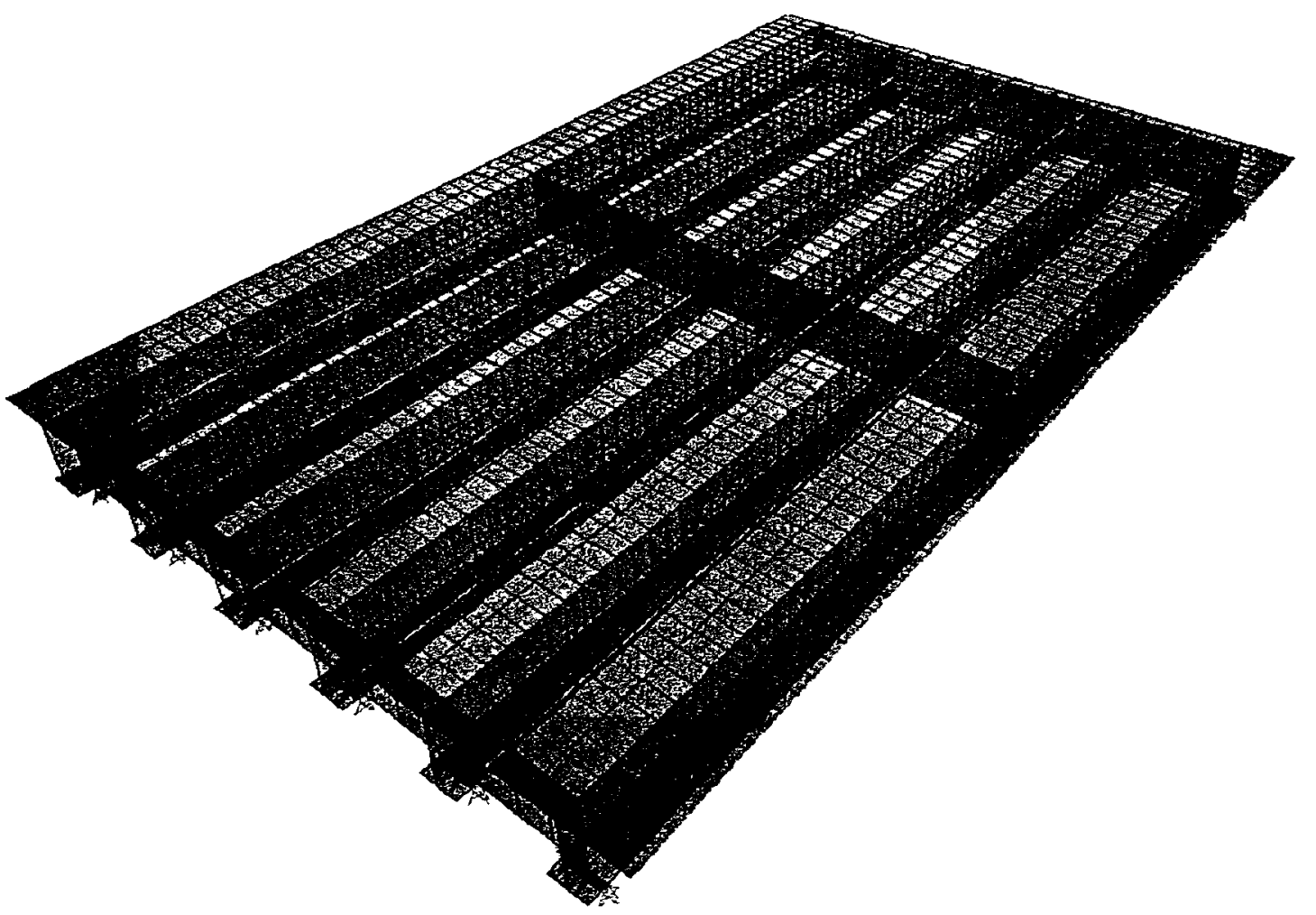

Figure 3.5 View of SAP2000 model for 6-girder bridge with one intermediate diaphragm and continuous connections between girders 


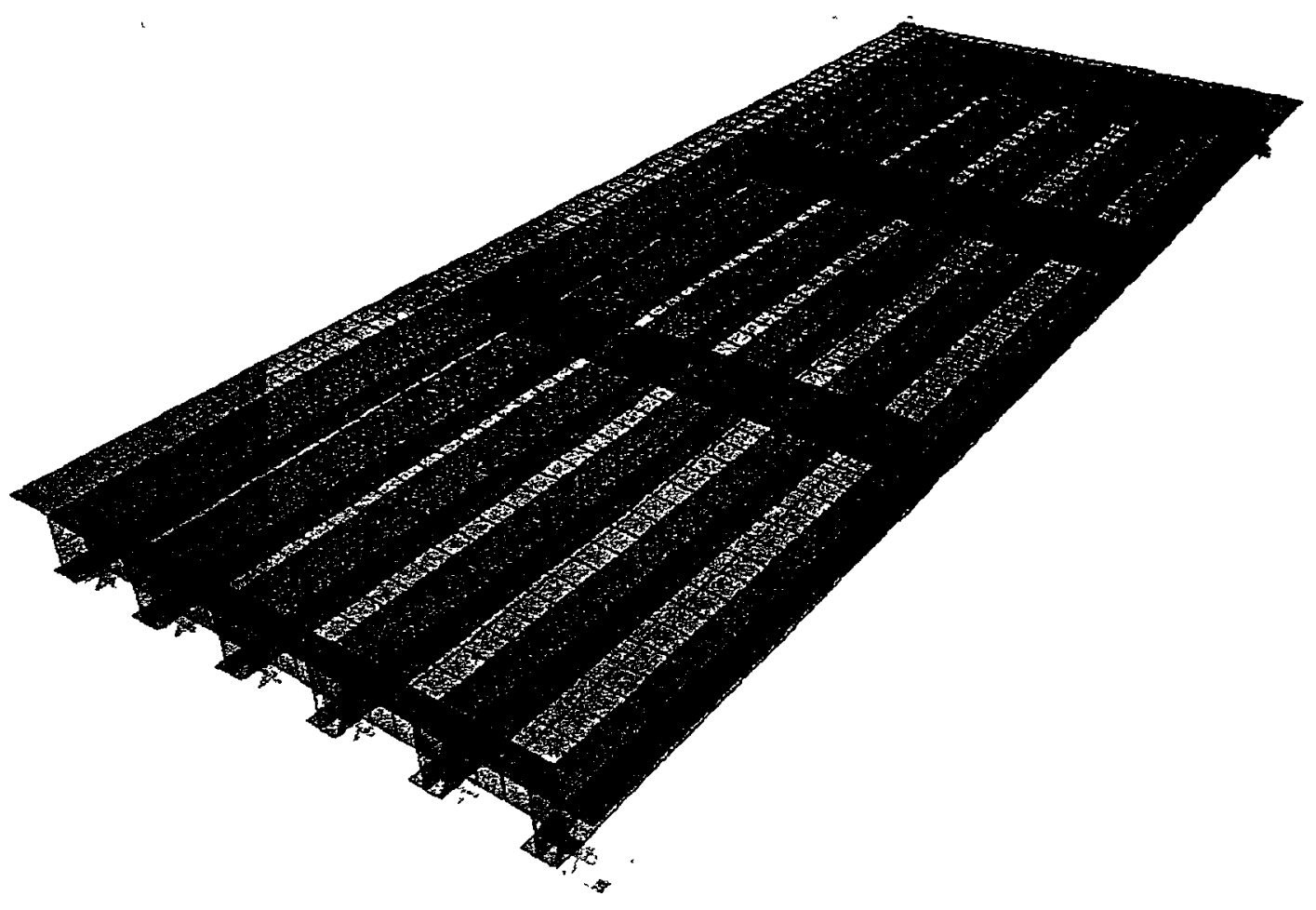

Figure 3.6 View of SAP2000 model for 6-girder bridge with two intermediate diaphragm and continuous connections between girders 


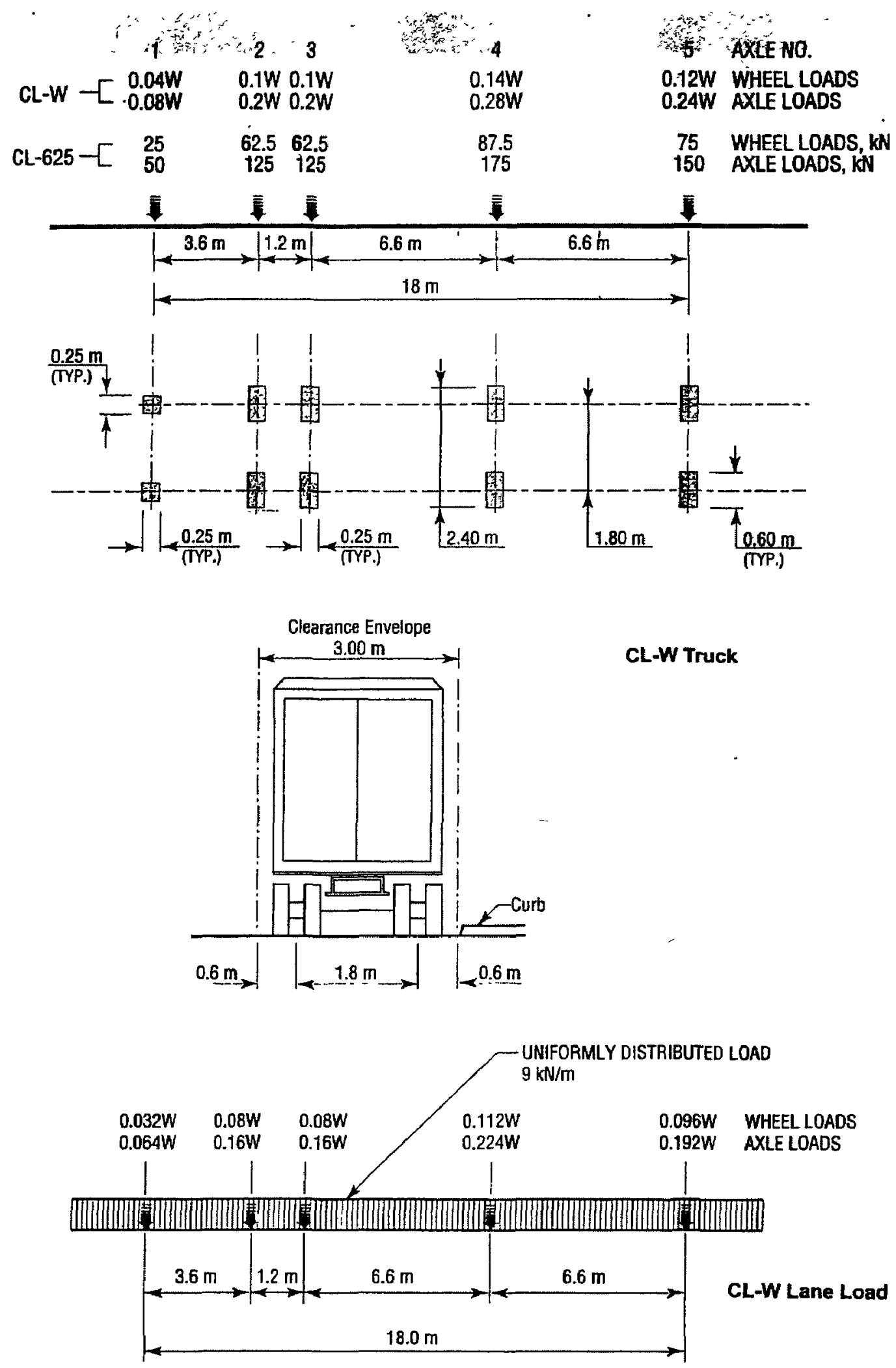

Figure 3.7 CL-W truck and lane loading, CHBDC 

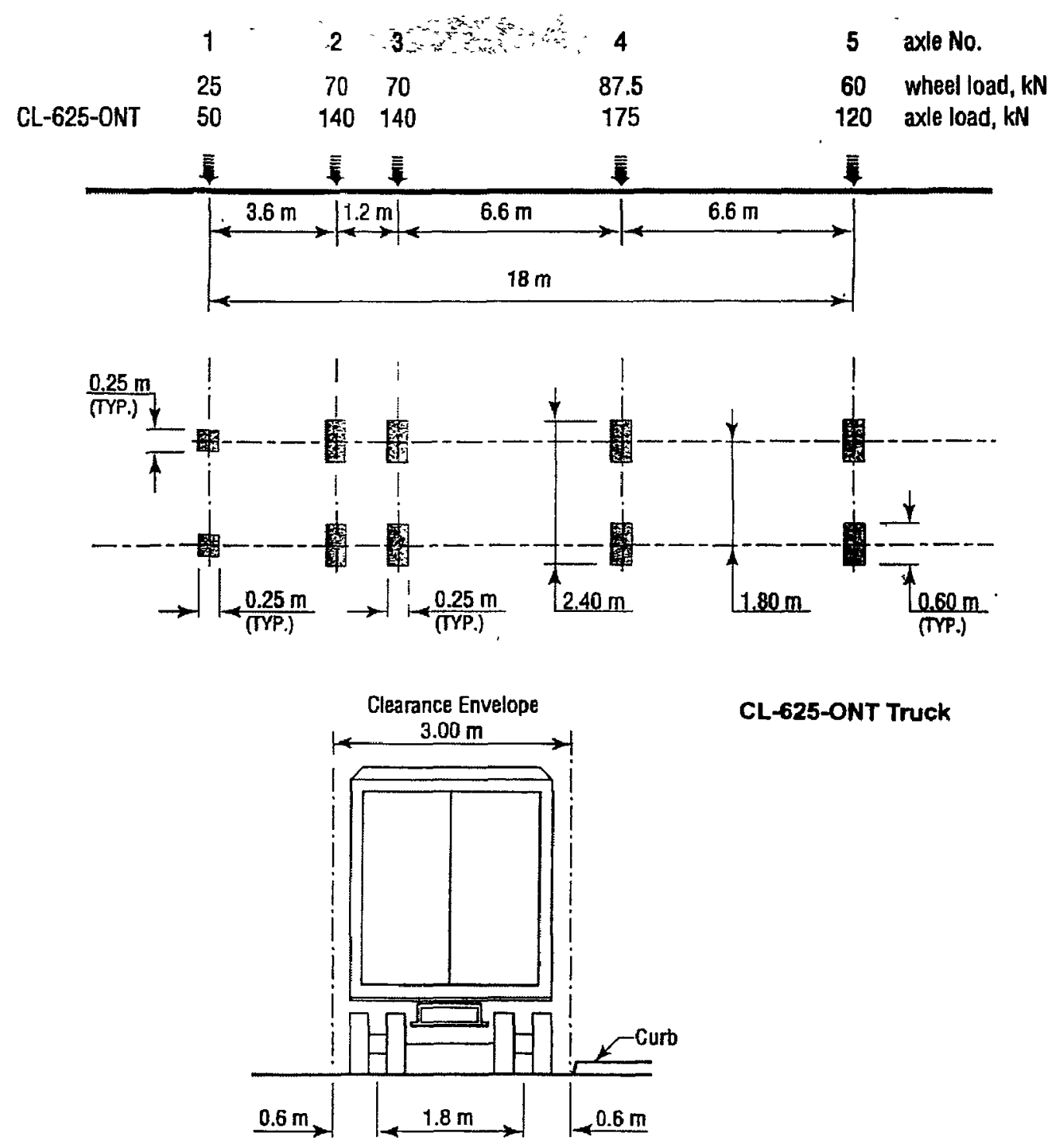

CL-625-ONT Truck

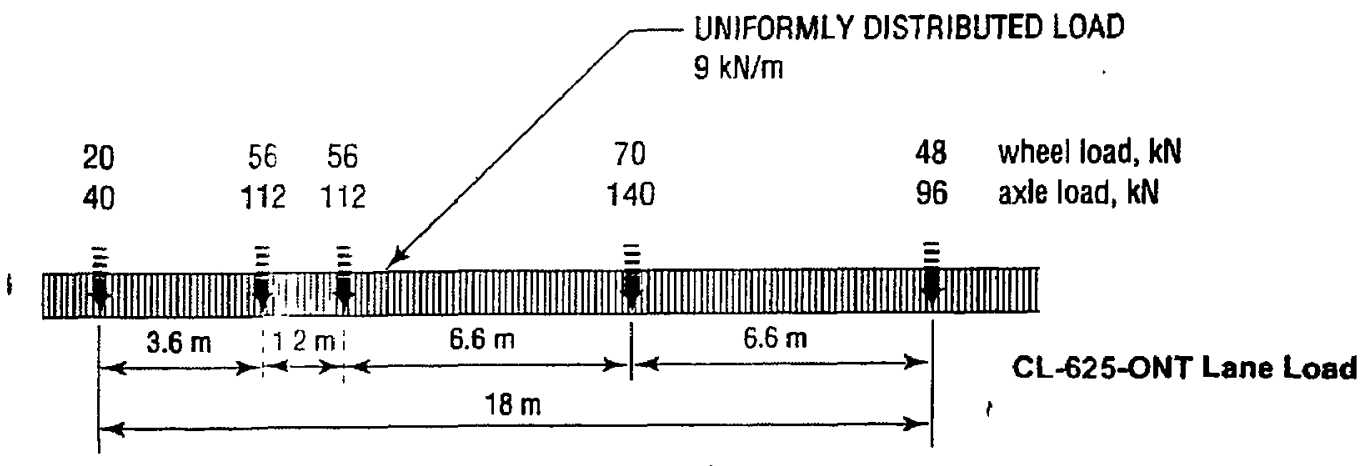

Figure 3.8 CL-625-ONT truck and lane loading, CHBDC 

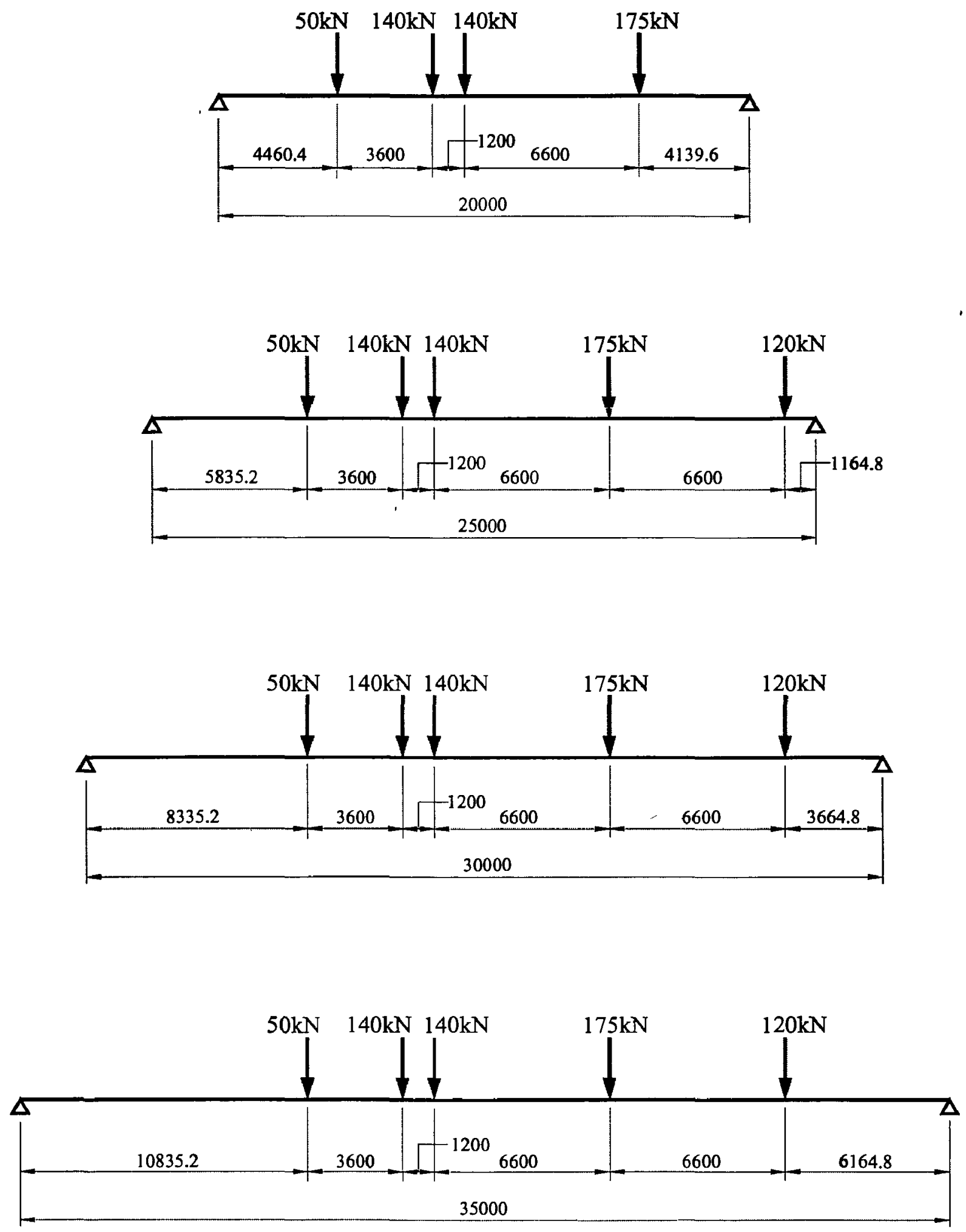

Figure 3.9 Location of wheel loads for maximum bending moment on various spans 

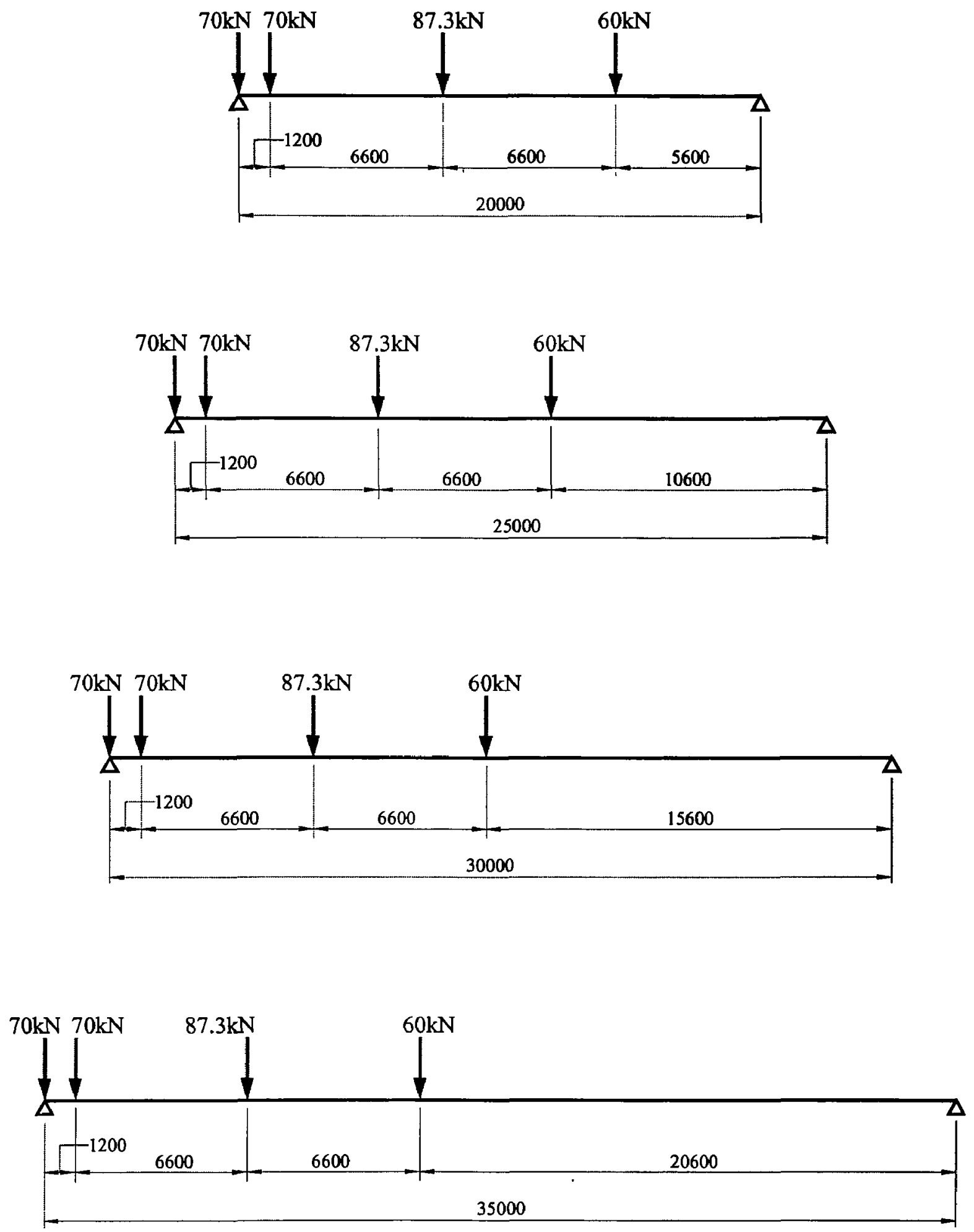

Figure 3.10 Location of wheel loads for maximum shear force on various spans 

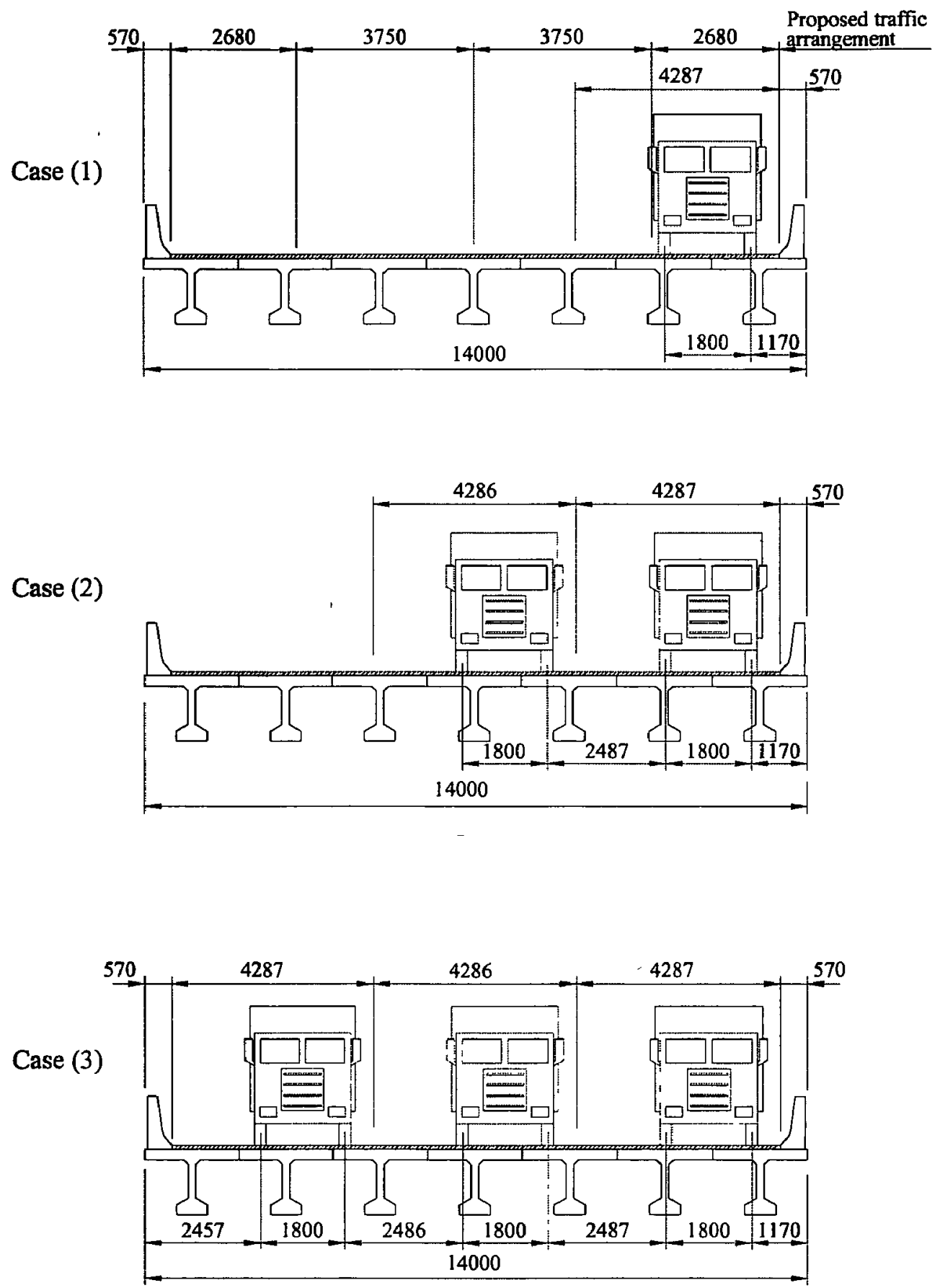

Figure 3.11.a Loading cases for three-design-lane, seven-girder, bridge with $2000 \mathrm{~mm}$ girder spacing 

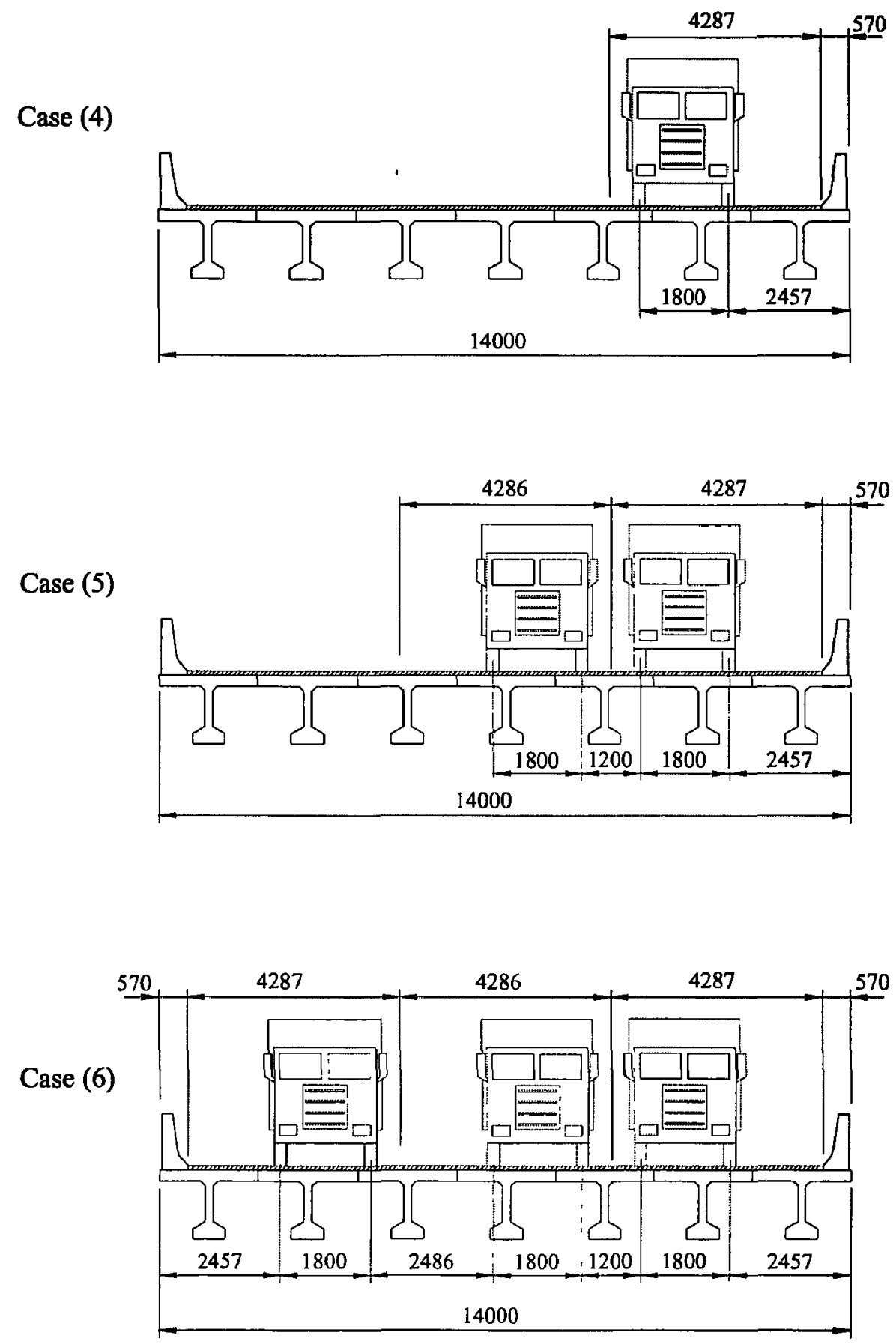

Figure 3.11.b Loading cases for three-design-lane, seven-girder, bridge with $2000 \mathrm{~mm}$ girder spacing 

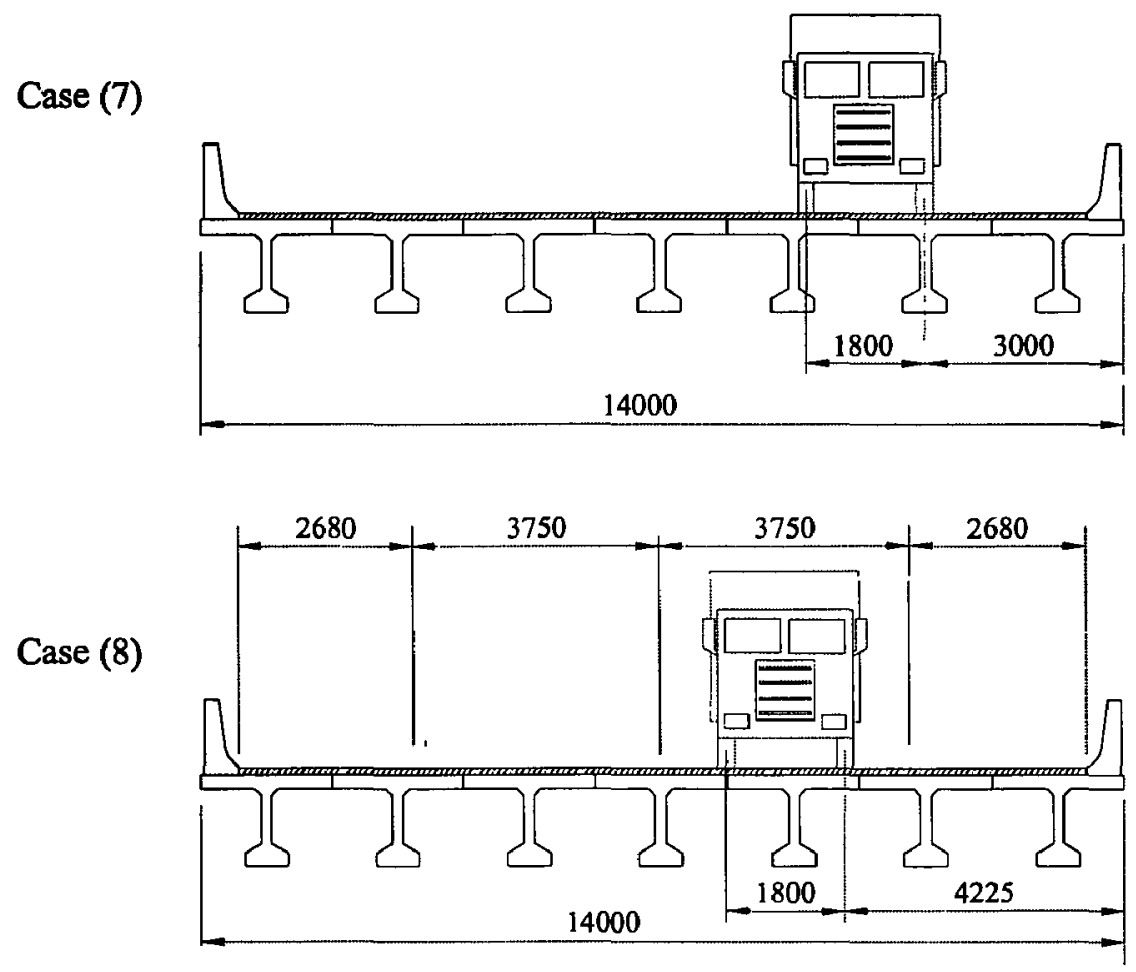

Figure 3.11.c Loading cases for three-design-lane, seven-girder bridge, with $2000 \mathrm{~mm}$ girder spacing 

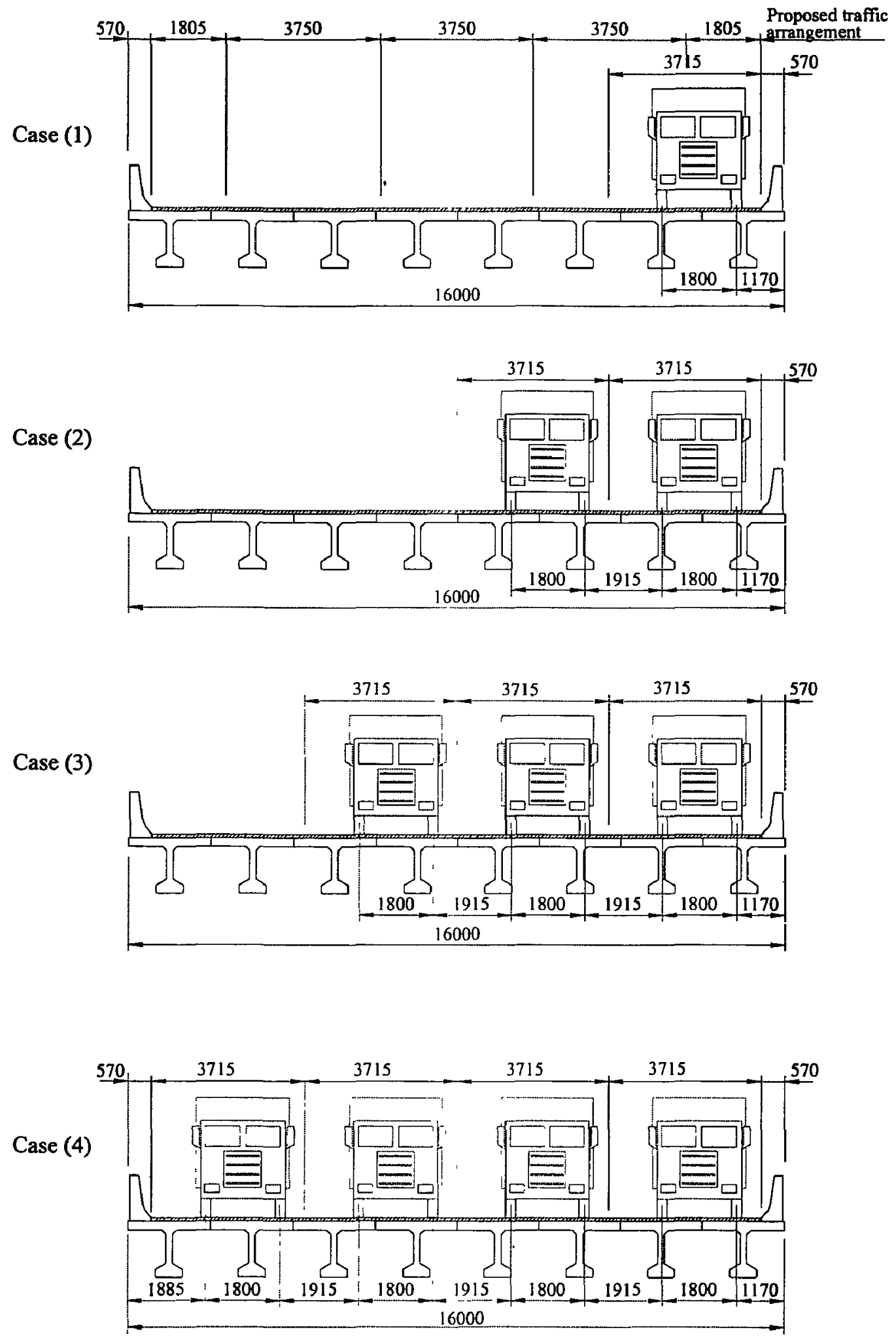

Figure 3.12.a Loading cases for four-design-lane, eight-girder, bridge with $2000 \mathrm{~mm}$ girder spacing 


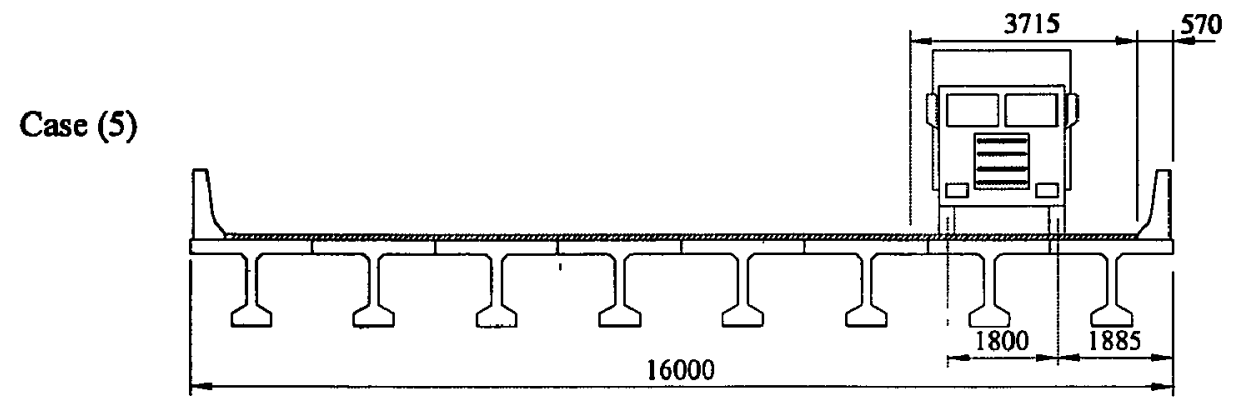

Case (6)
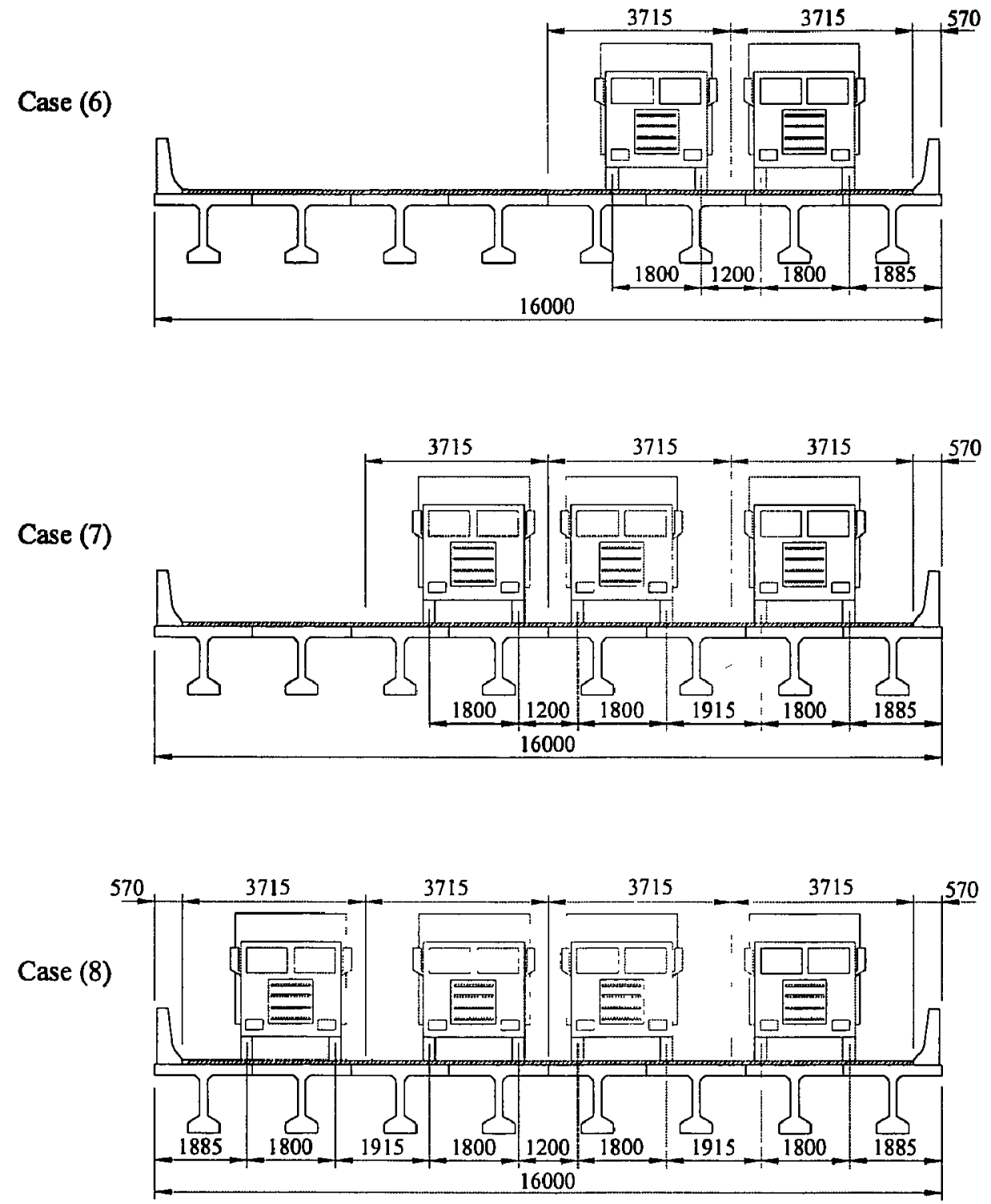

Figure 3.12.b Loading cases for four-design-lane, eight-girder, bridge with $2000 \mathrm{~mm}$ girder spacing 


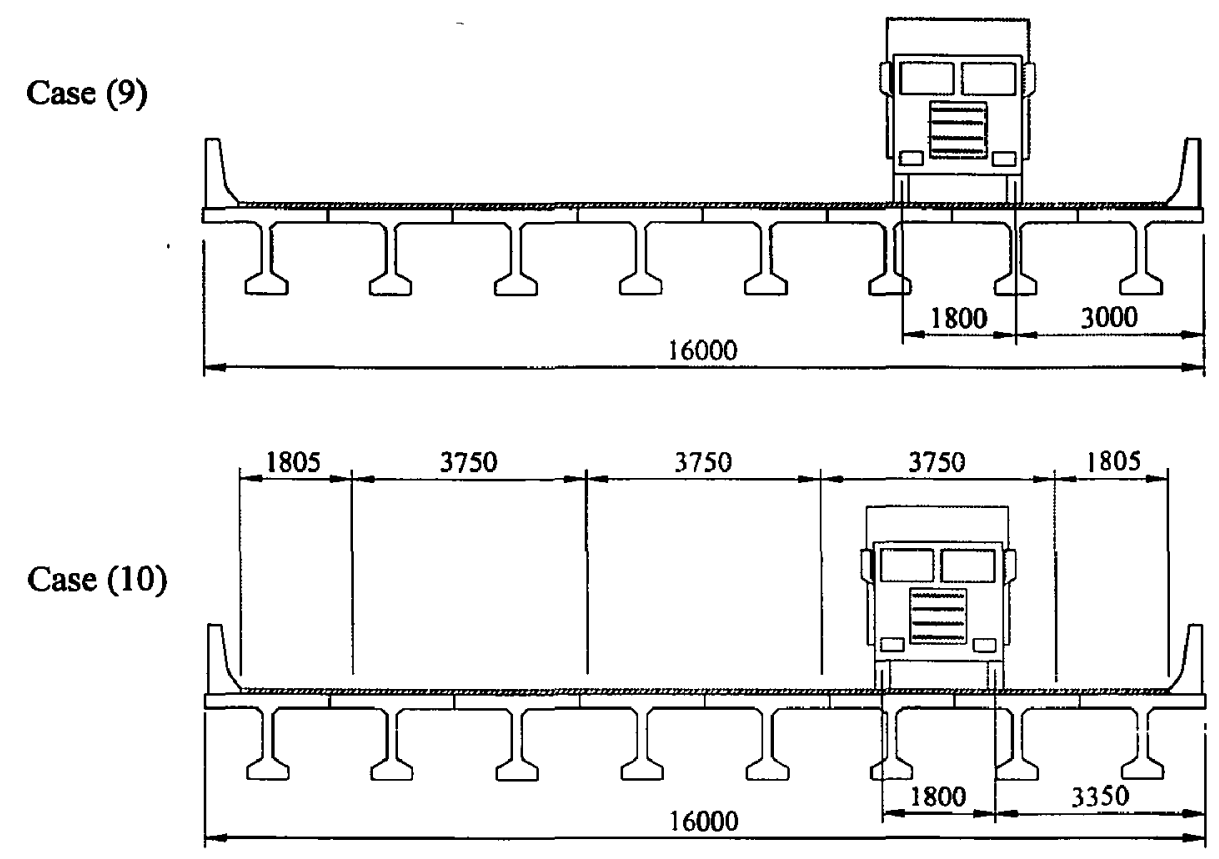

Figure 3.12.c Loading cases for four-design-lane, eight-girder, bridge with $2000 \mathrm{~mm}$ girder spacing 


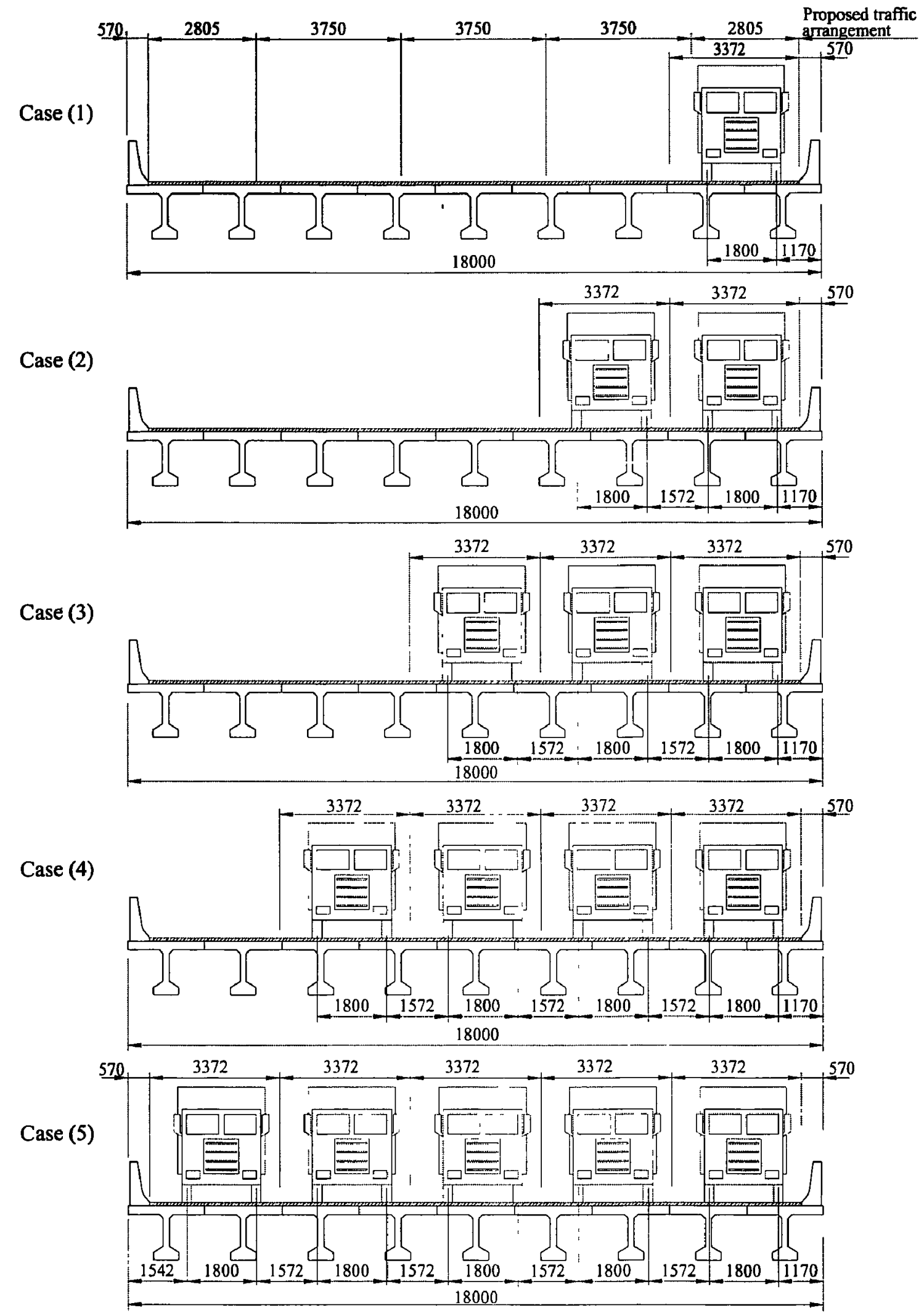

Figure 3.13.a Loading cases for five-design-lane, nine-girder, bridge with $2000 \mathrm{~mm}$ girder spacing 


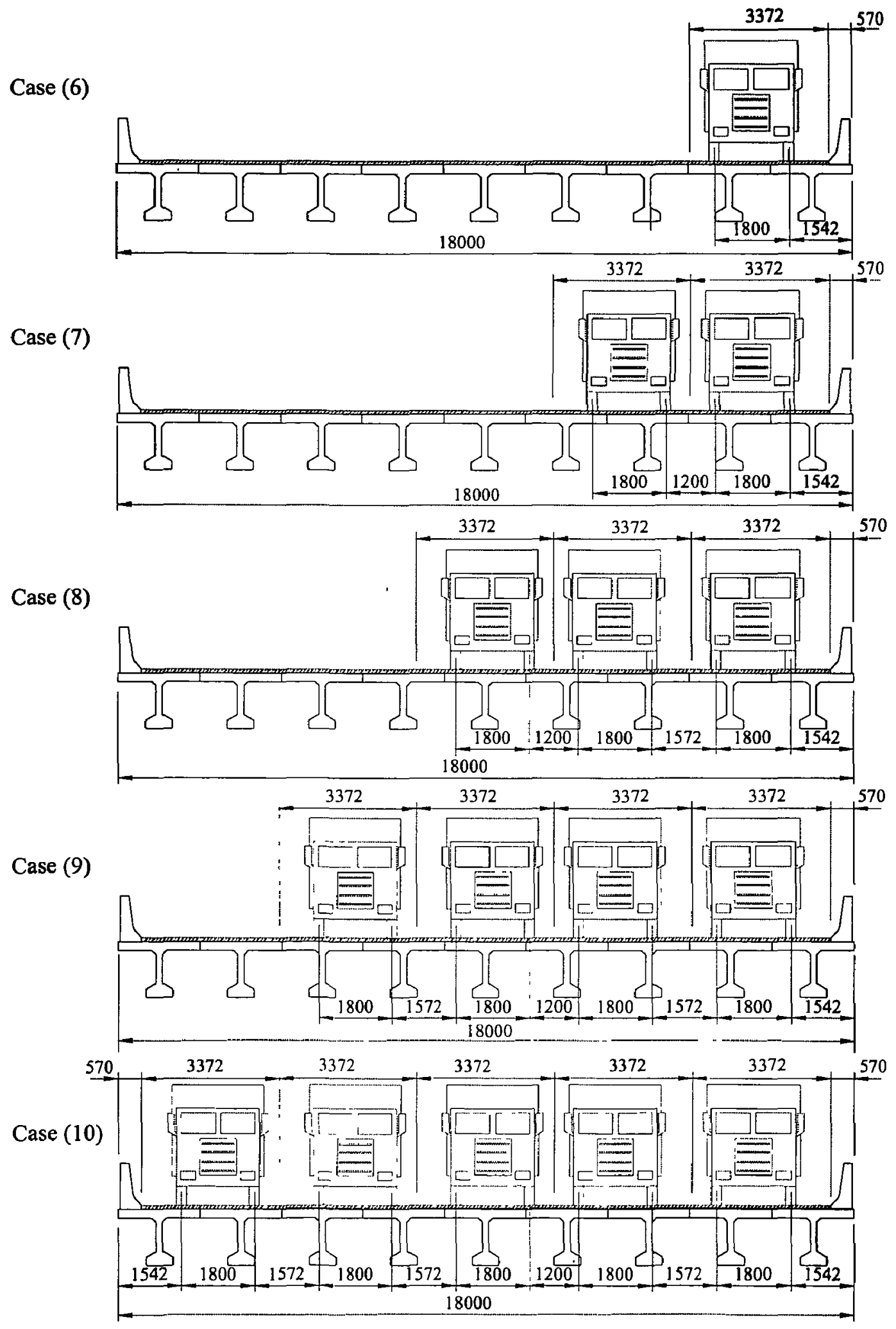

Figure 3.13.b Loading cases for five-design-lane, nine-girder, bridge with $2000 \mathrm{~mm}$ girder spacing 

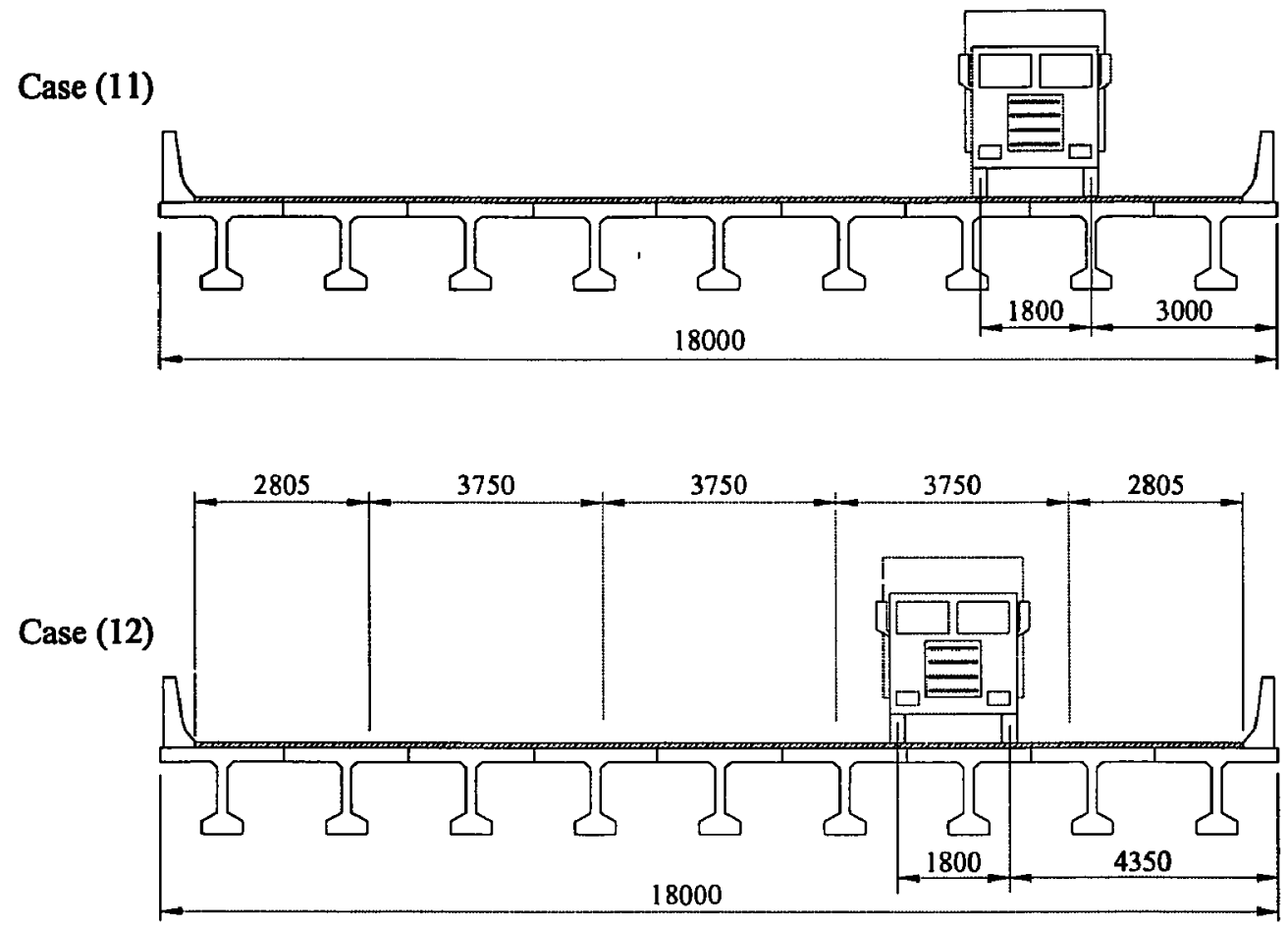

Figure 3.13.c Loading cases for five-design-lane, nine-girder, bridge with $2000 \mathrm{~mm}$ girder spacing 

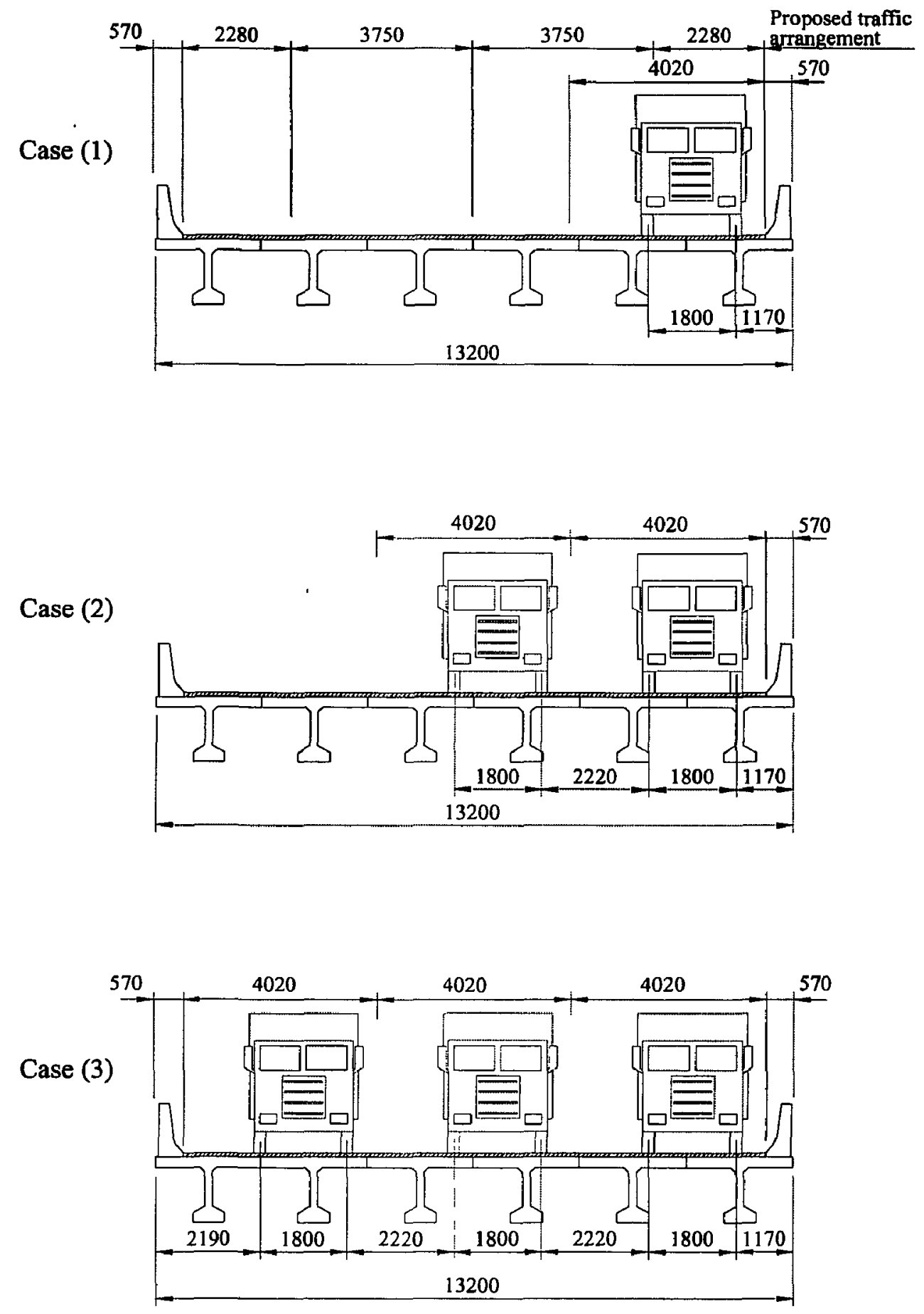

Figure 3.14.a Loading cases for three-design-lane, six-girder, bridge with $2200 \mathrm{~mm}$ girder spacing 

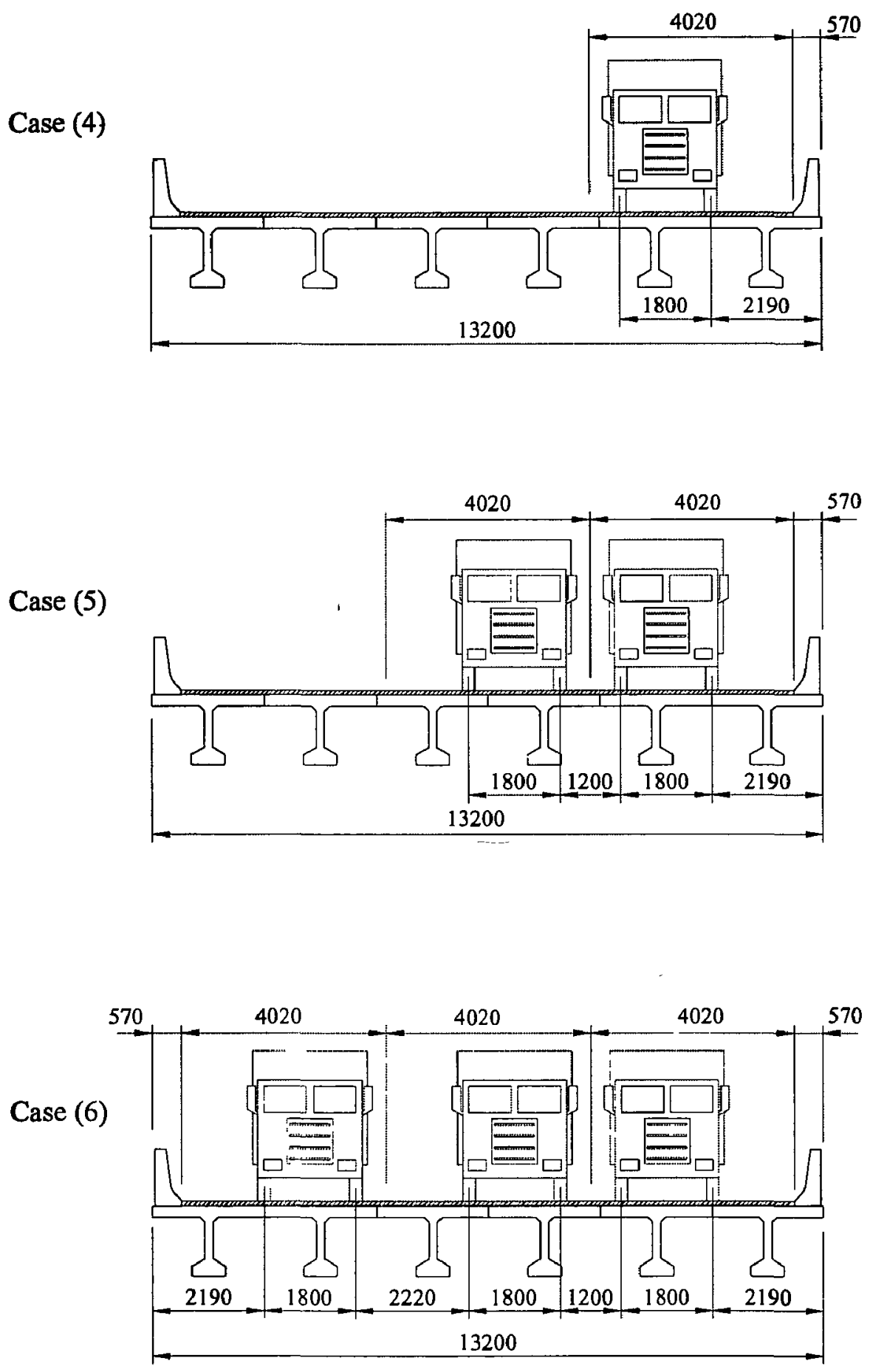

Figure 3.14.b Loading cases for three-design-lane, six-girder, bridge with $2200 \mathrm{~mm}$ girder spacing 

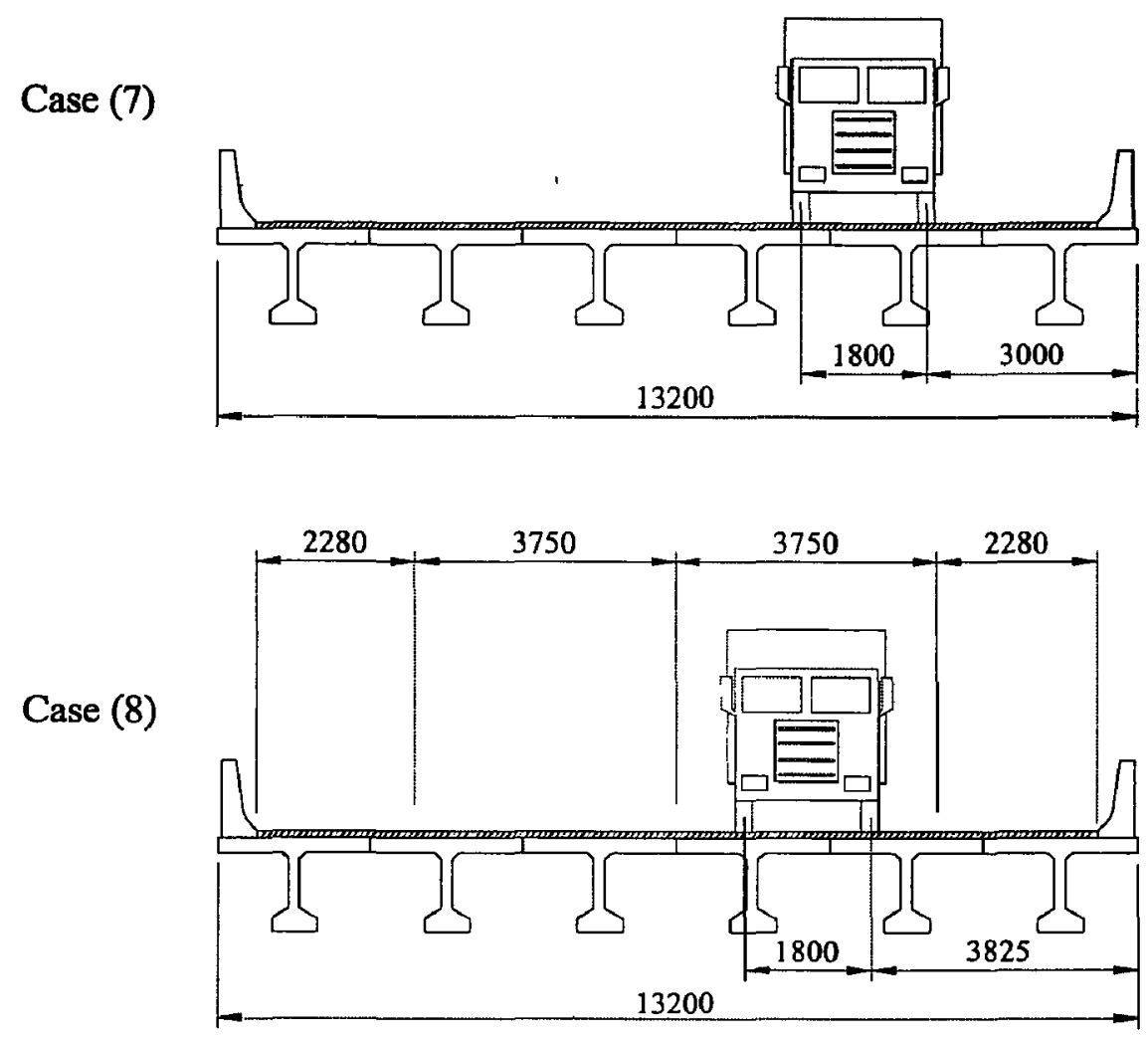

Figure 3.14.c Loading cases for three-design-lane, six-girder, bridge with $2200 \mathrm{~mm}$ girder spacing 


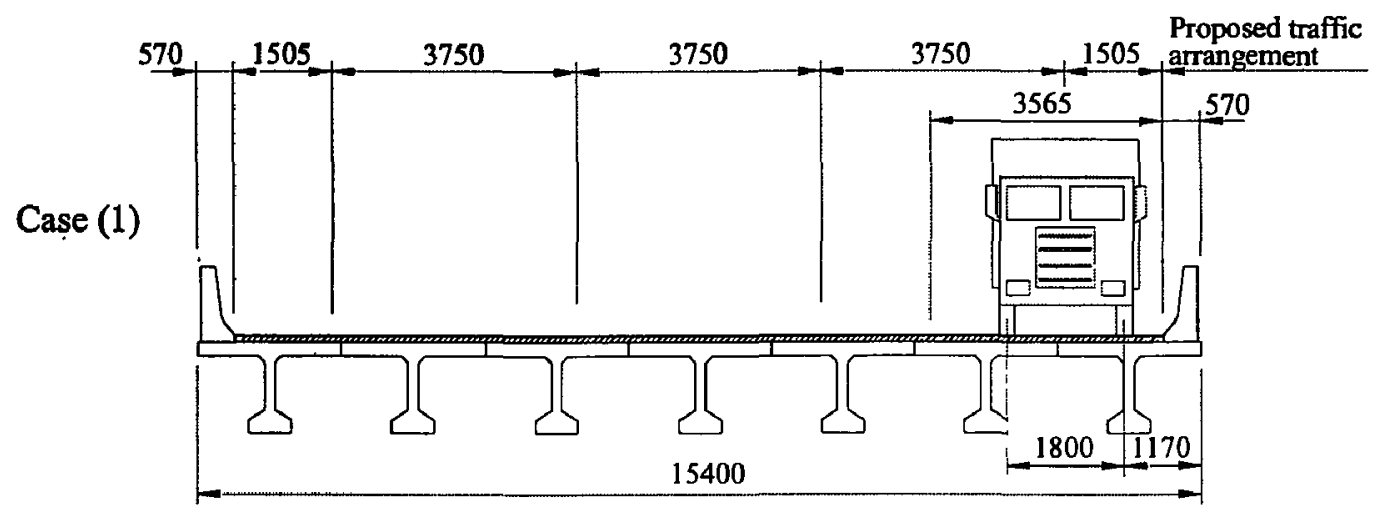

Case (2)

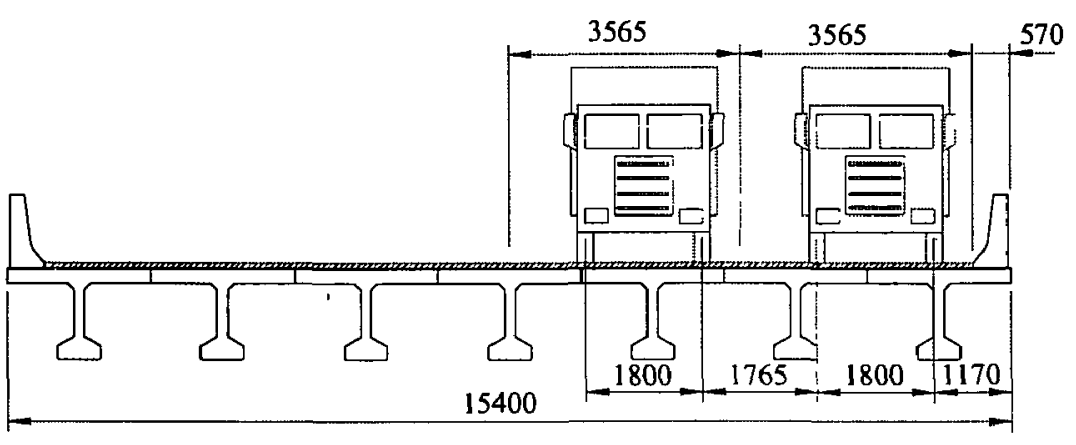

Case (3)
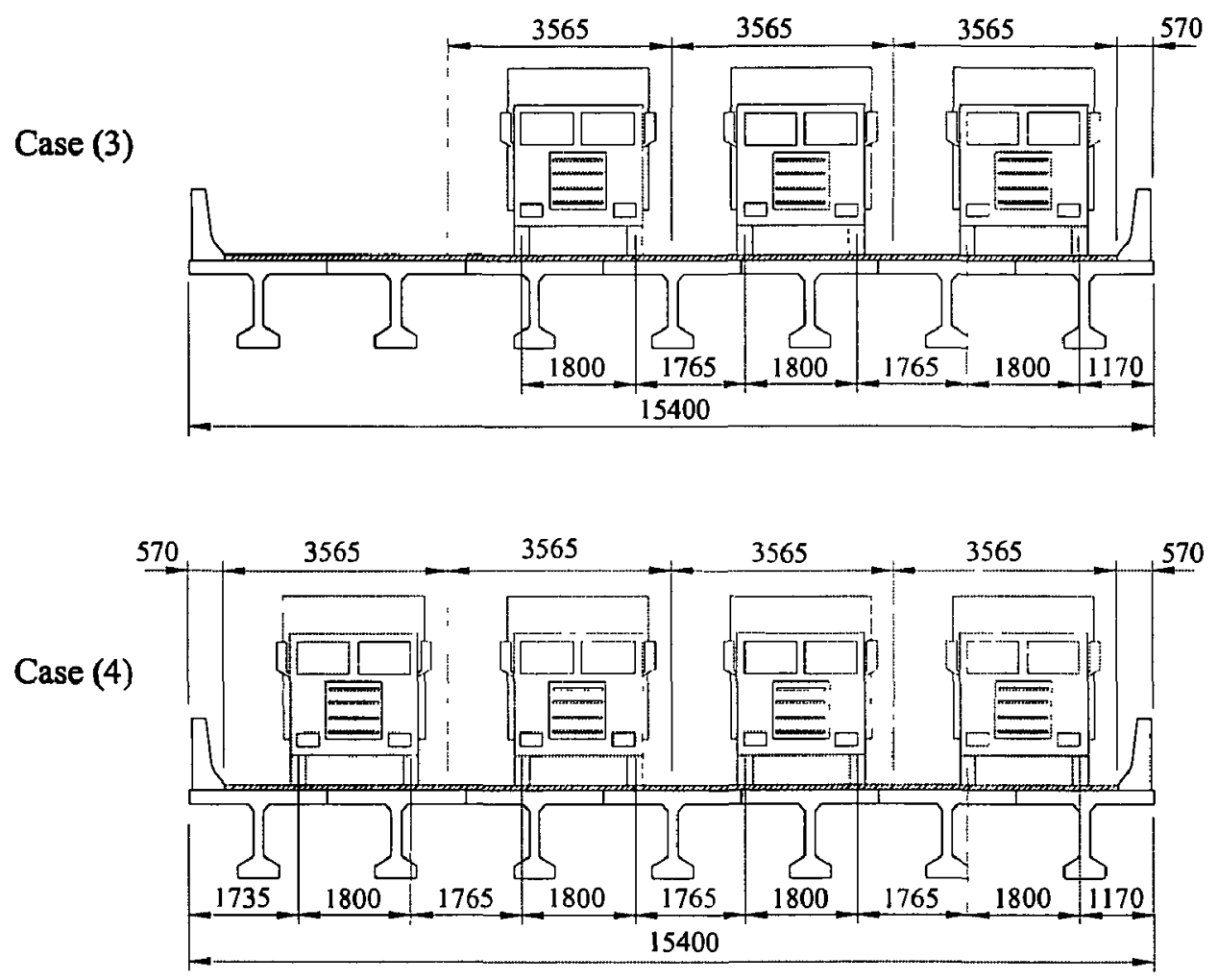

Figure 3.15.a Loading cases for four-design-lane, seven-girder, bridge with $2200 \mathrm{~mm}$ girder spacing 


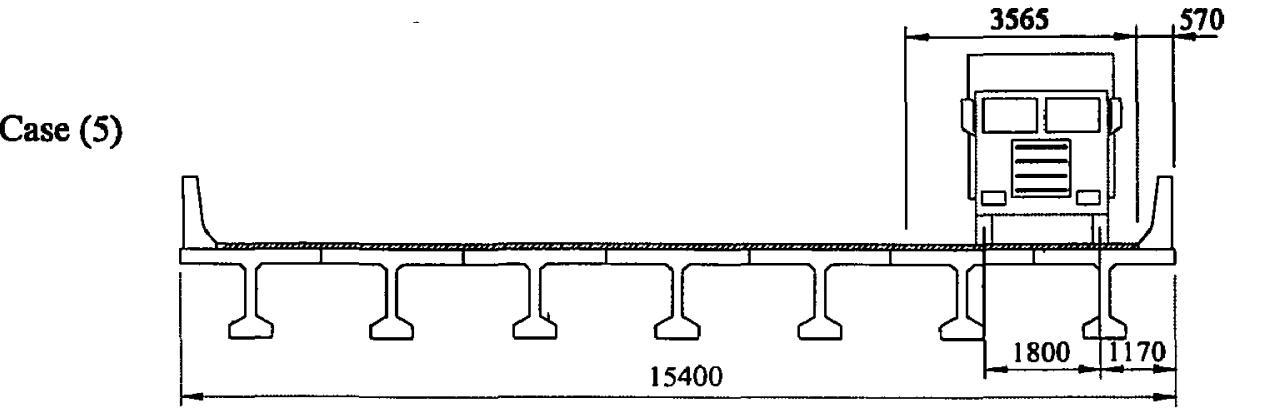

Case (6)

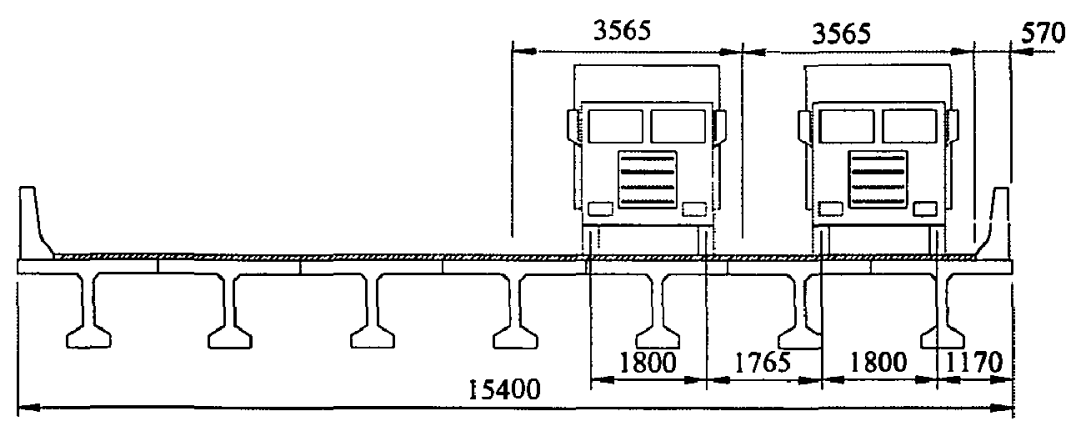

Case (7)
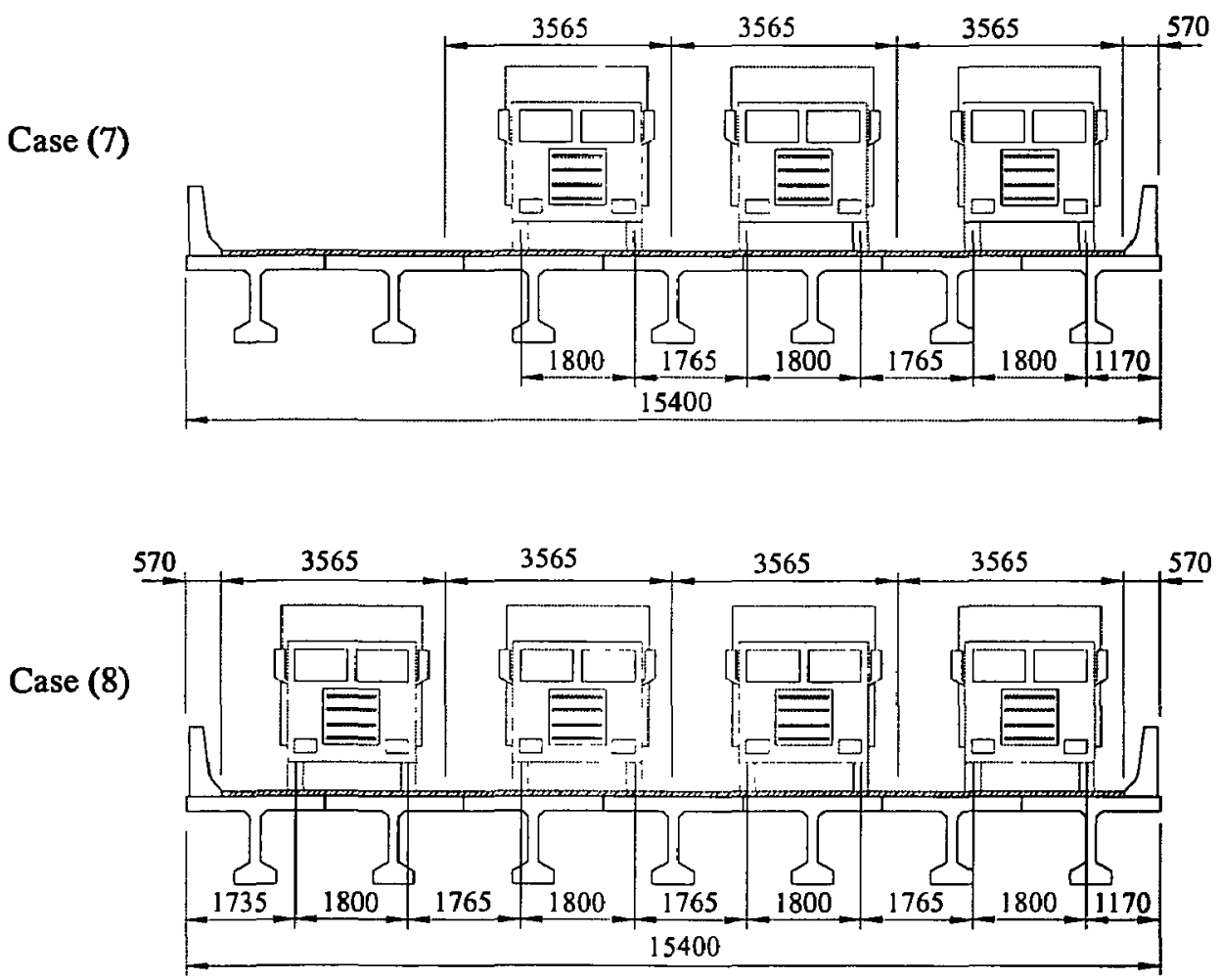

Figure 3.15.b Loading cases for four-design-lane, seven-girder, bridge with $2200 \mathrm{~mm}$ girder spacing 


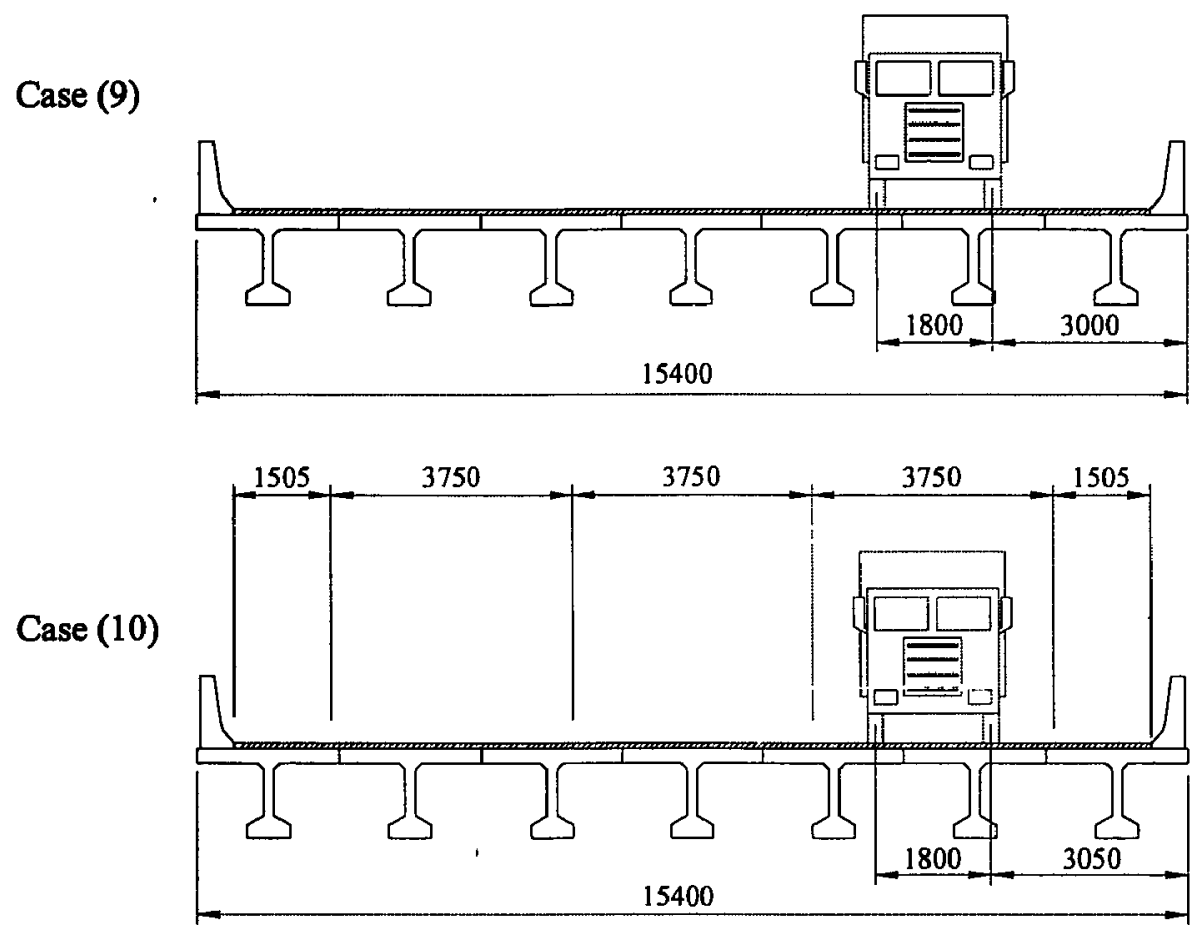

Figure 3.15.c Loading cases for four-design-lane, seven-girder, bridge with $2200 \mathrm{~mm}$ girder spacing 


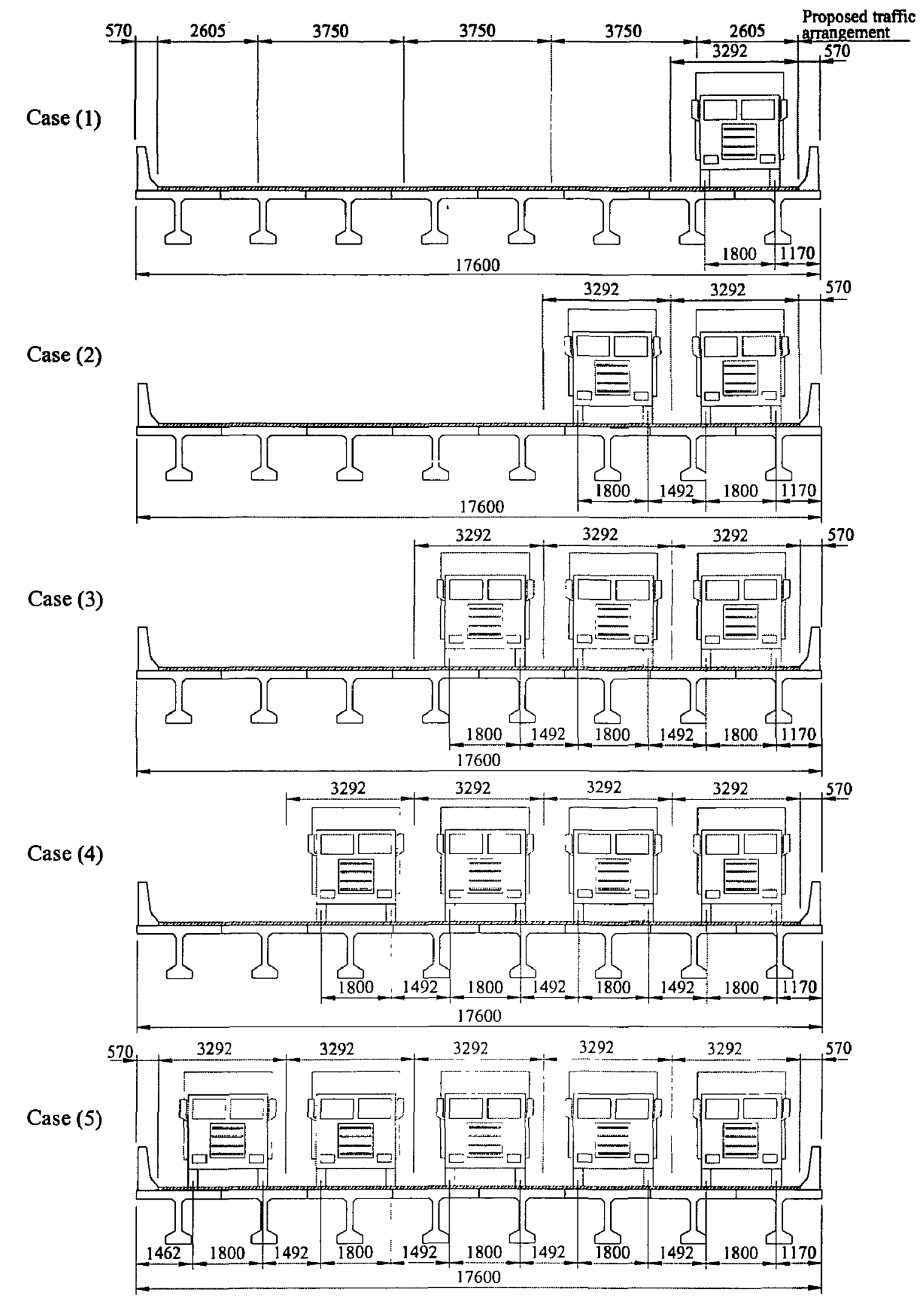

Figure 3.16.a Loading cases for five-design-lane, eight-girder, bridge with $2200 \mathrm{~mm}$ girder spacing 


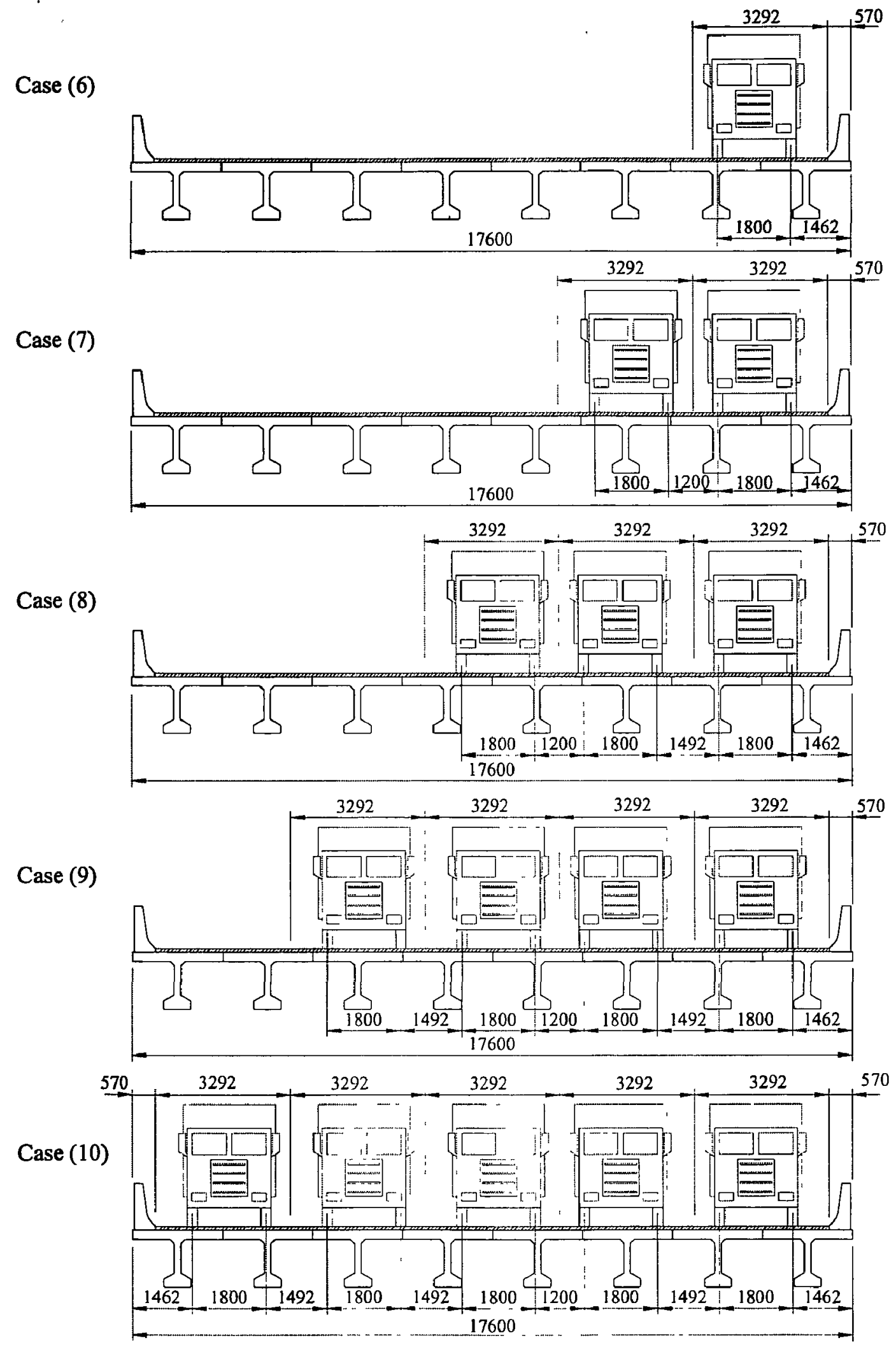

Figure 3.16.b Loading cases for five-design-lane, eight-girder, bridge with $2200 \mathrm{~mm}$ girder spacing 

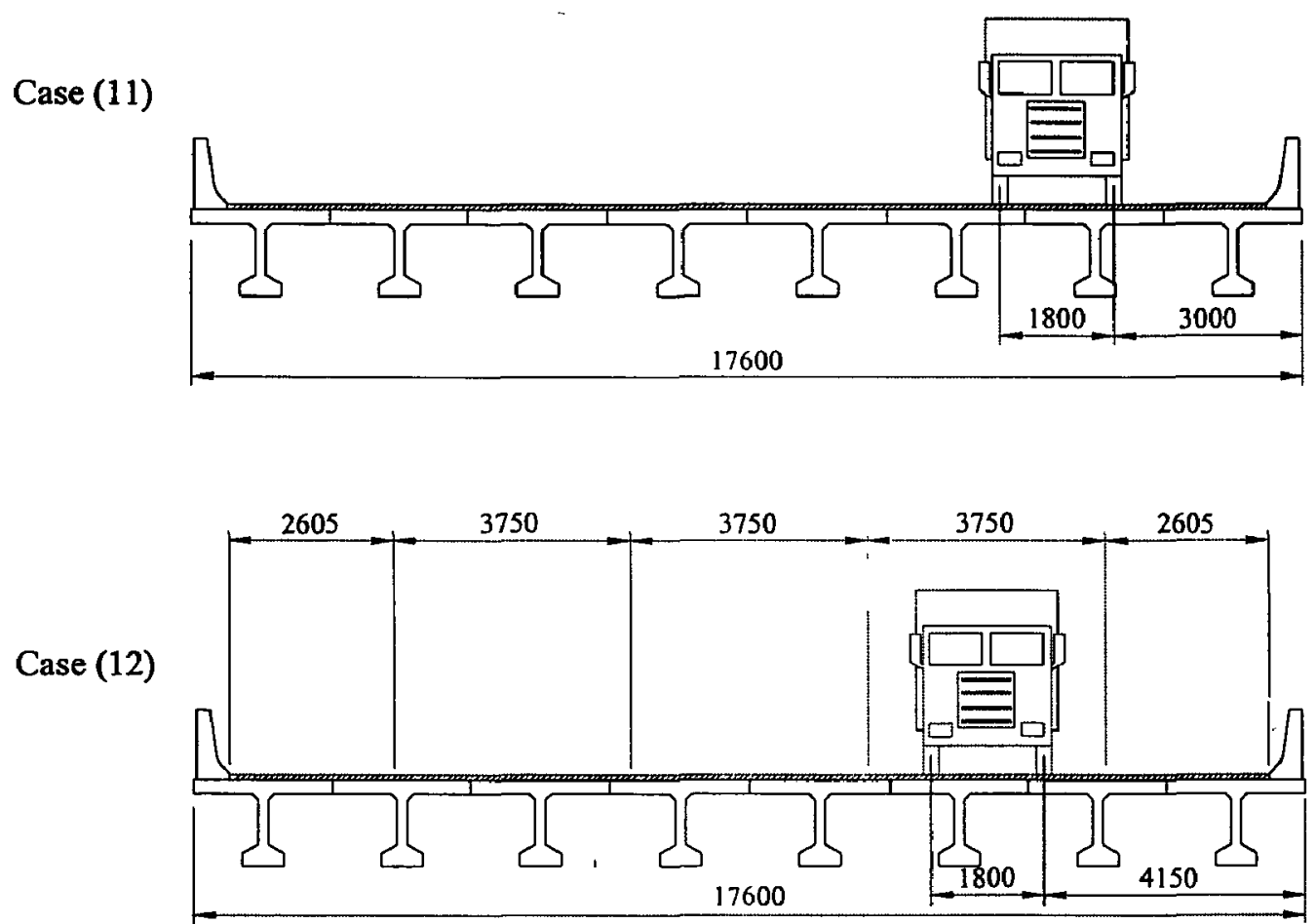

Figure 3.16.c Loading cases for five-design-lane, eight-girder, bridge with $2200 \mathrm{~mm}$ girder spacing 

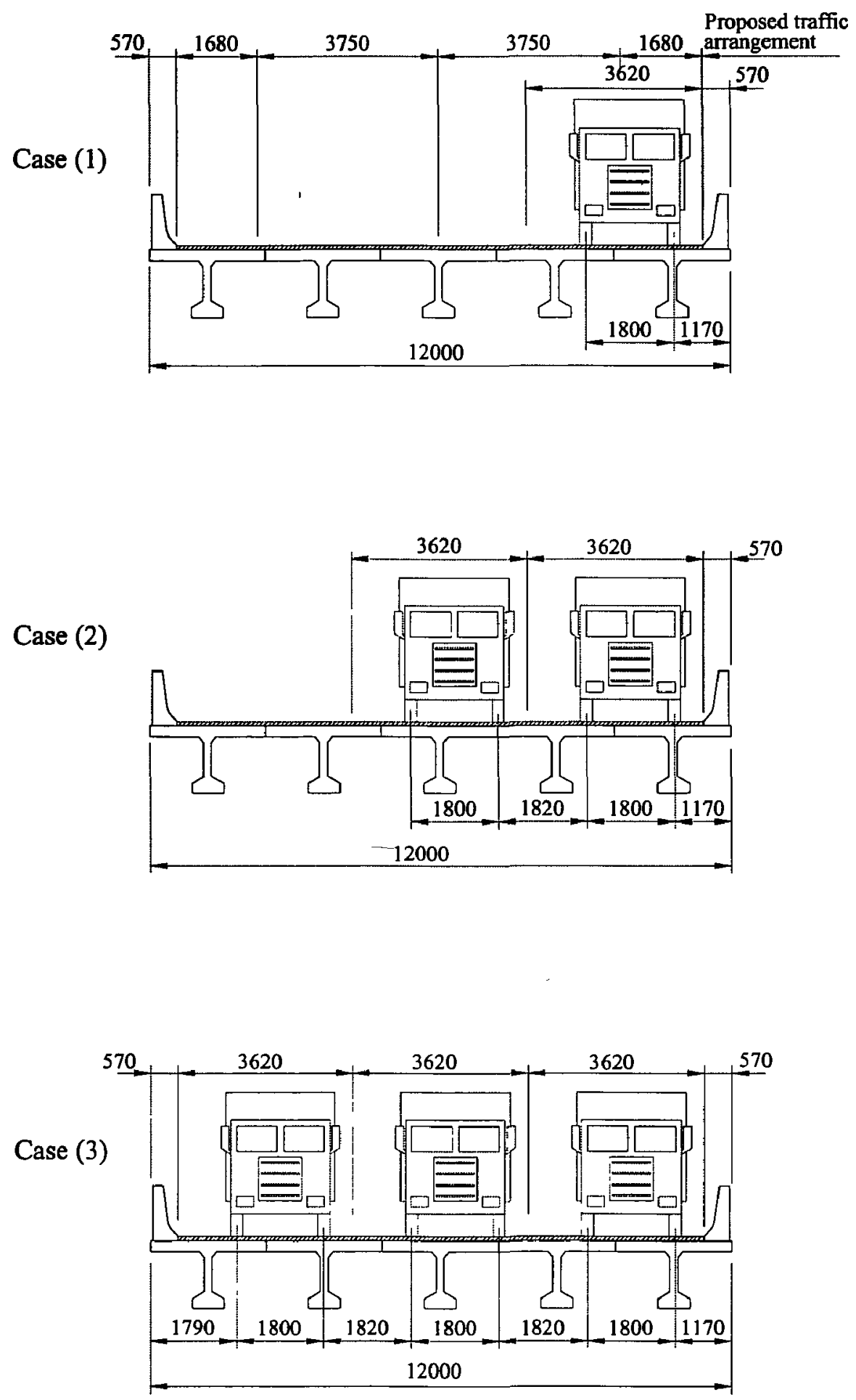

Figure 3.17.a Loading cases for three-design-lane, five-girder, bridge with $2400 \mathrm{~mm}$ girder spacing 

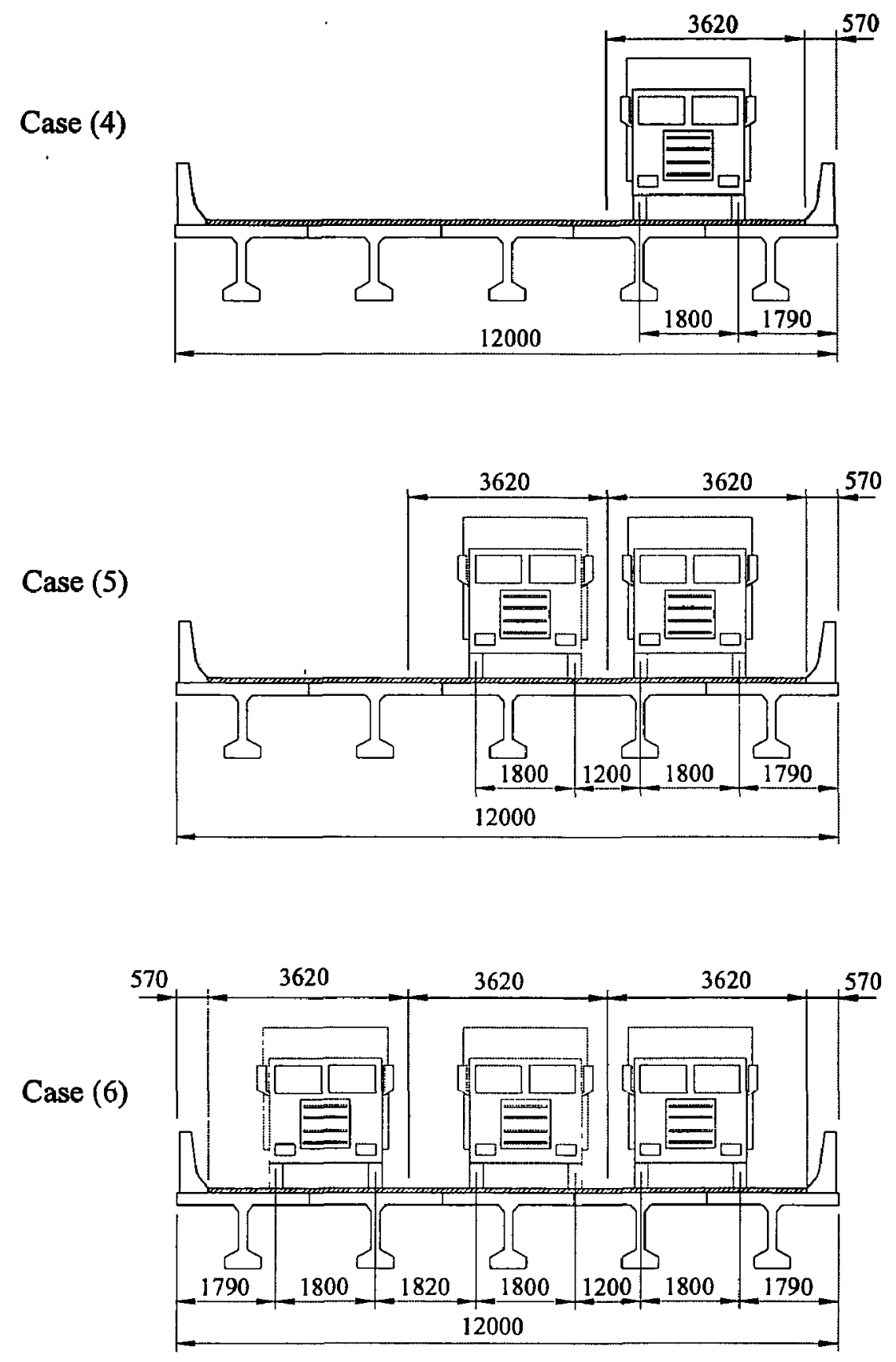

Figure 3.17.b Loading cases for three-design-lane, five-girder, bridge with $2400 \mathrm{~mm}$ girder spacing 


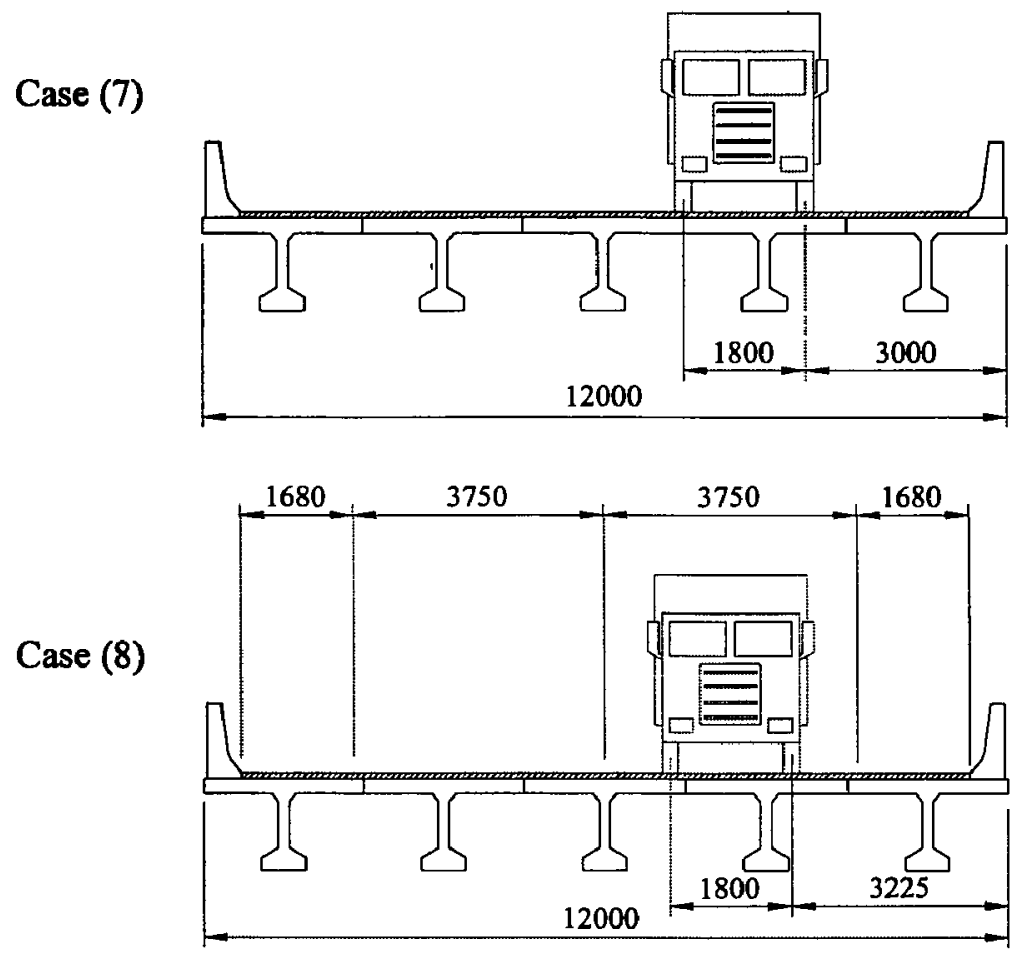

Figure 3.17.c Loading cases for three-design-lane, five-girder, bridge with $2400 \mathrm{~mm}$ girder spacing 


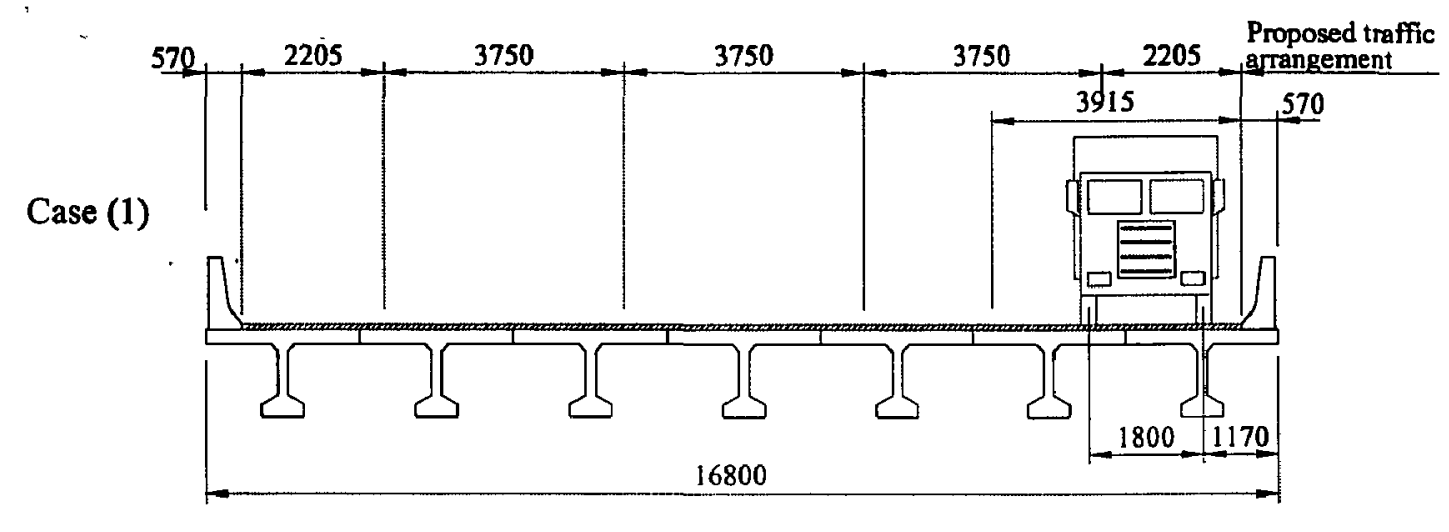

Case (2)
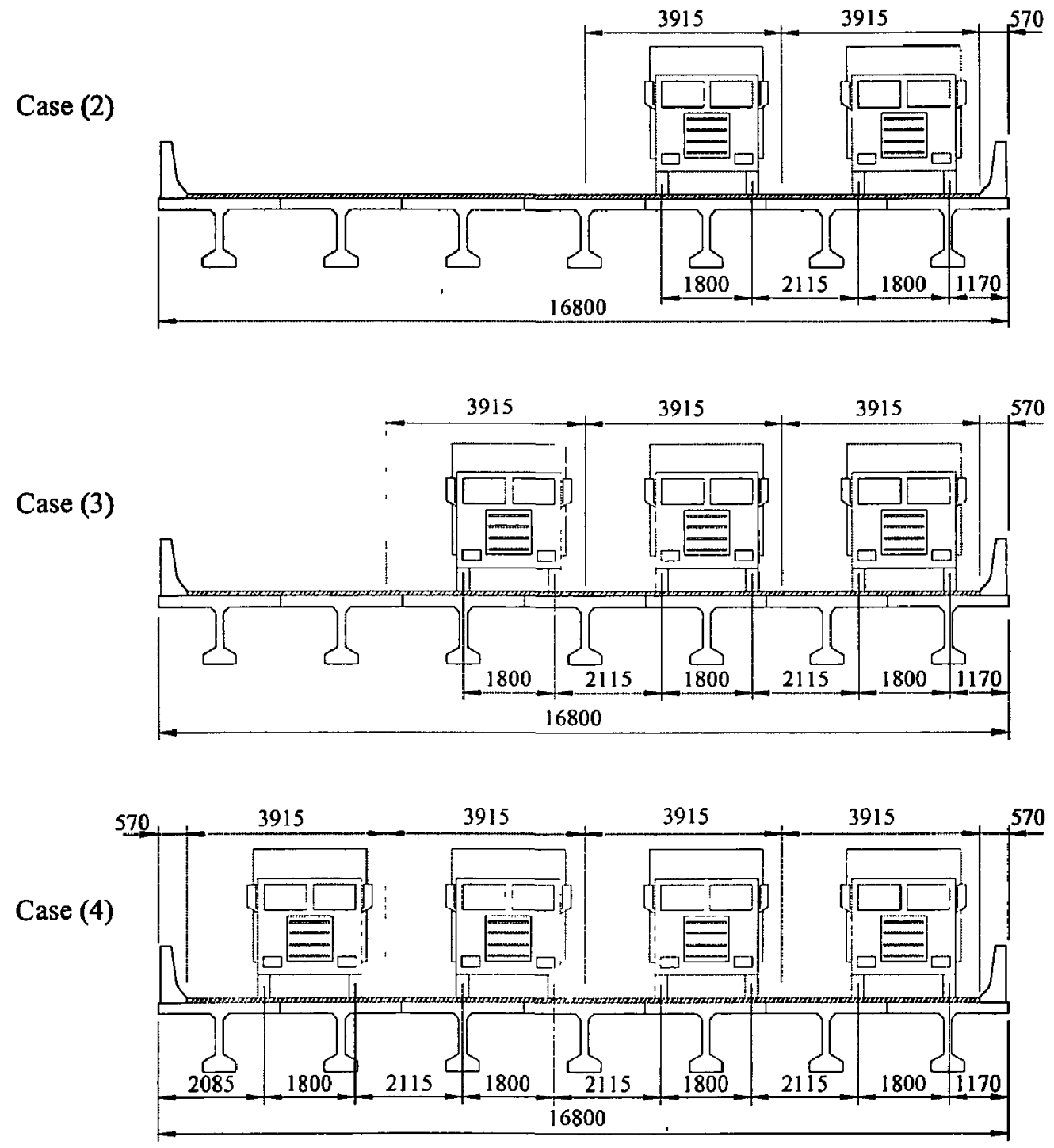

Figure 3.18.a Loading cases for four-design-lane, seven-girder, bridge with $2400 \mathrm{~mm}$ girder spacing 

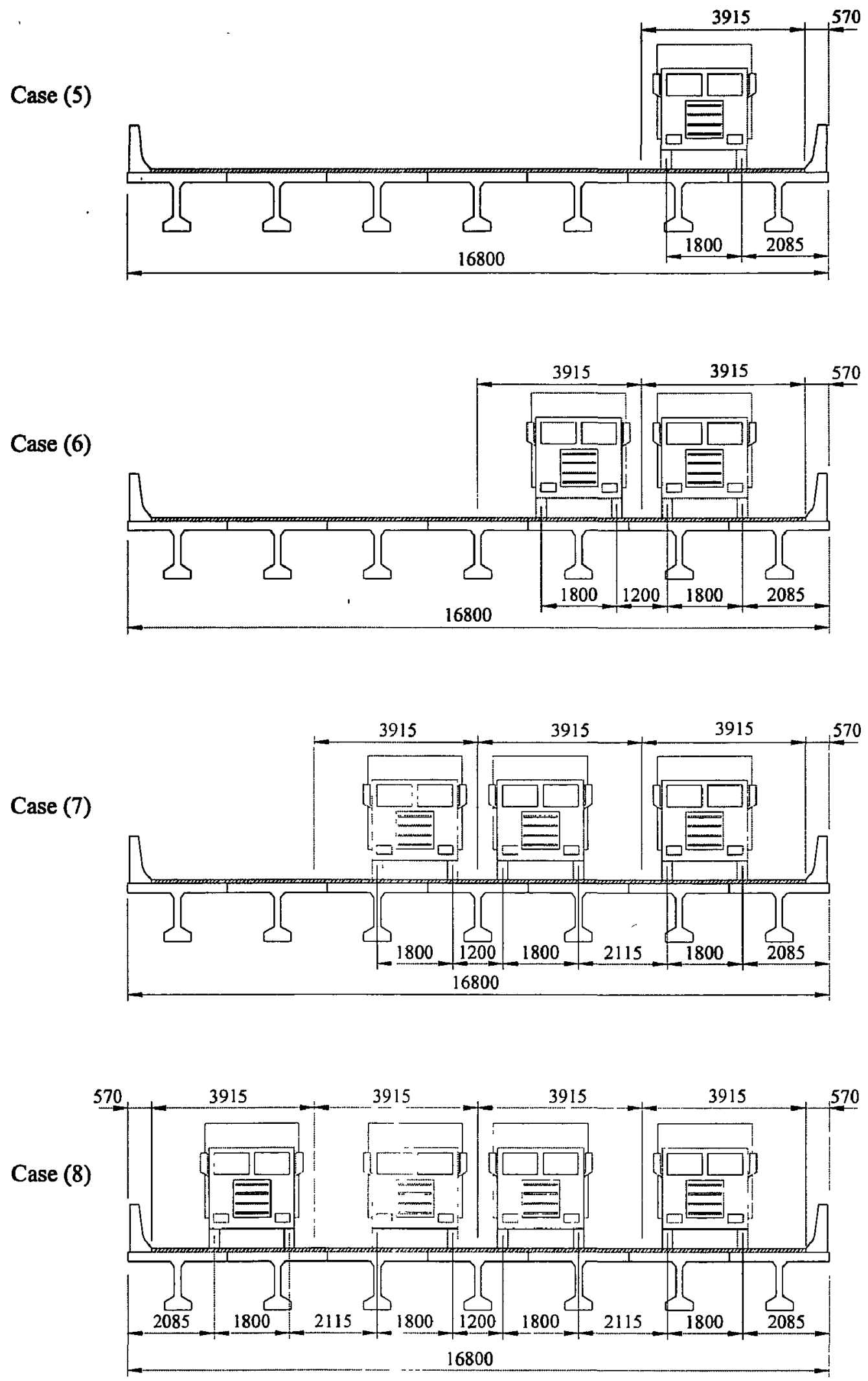

Figure 3.18.b Loading cases for four-design-lane, seven-girder, bridge with $2400 \mathrm{~mm}$ girder spacing 
$\therefore$

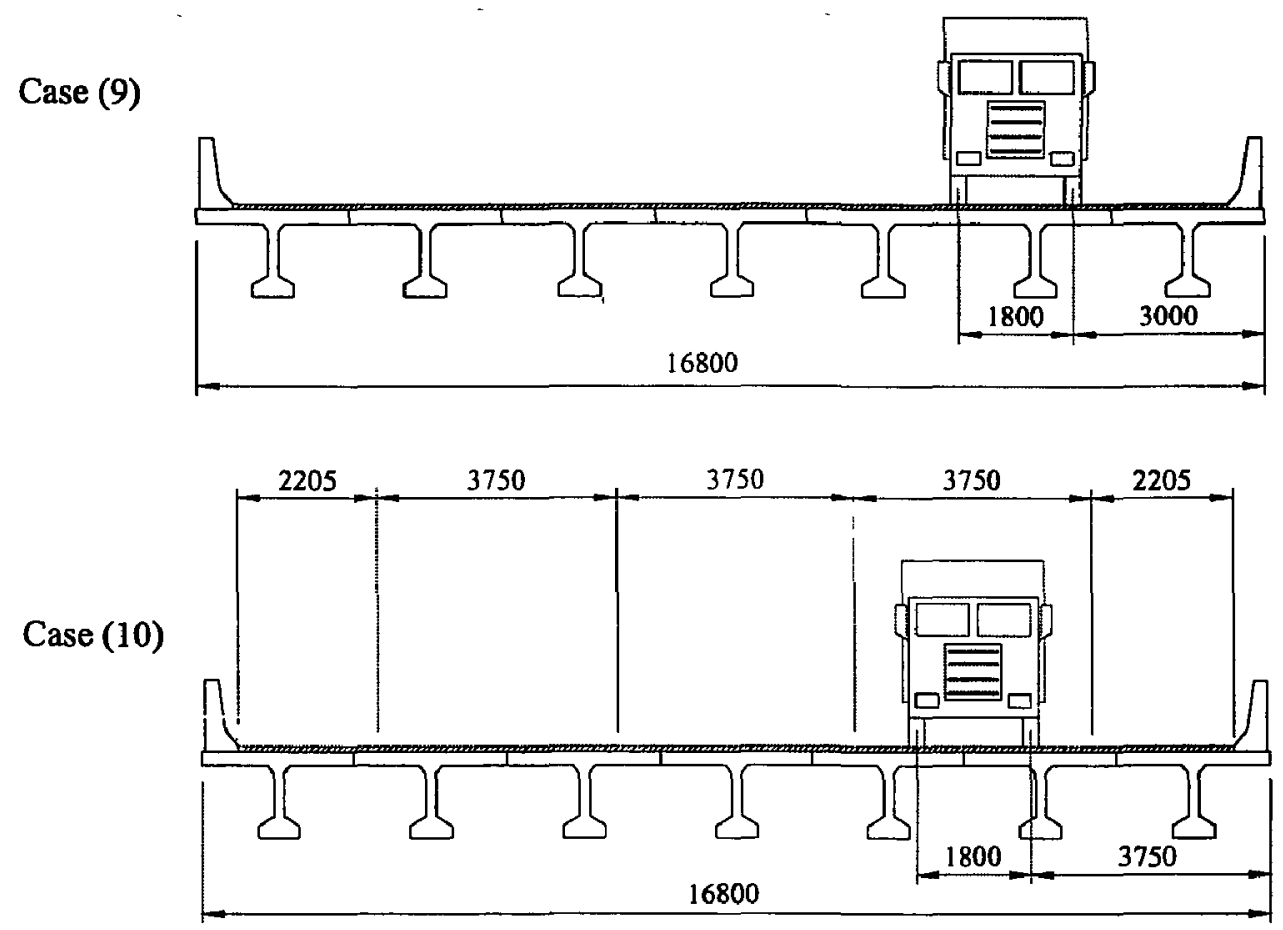

Figure 3.18.c Loading cases for four-design-lane, seven-girder, bridge with $2400 \mathrm{~mm}$ girder spacing 


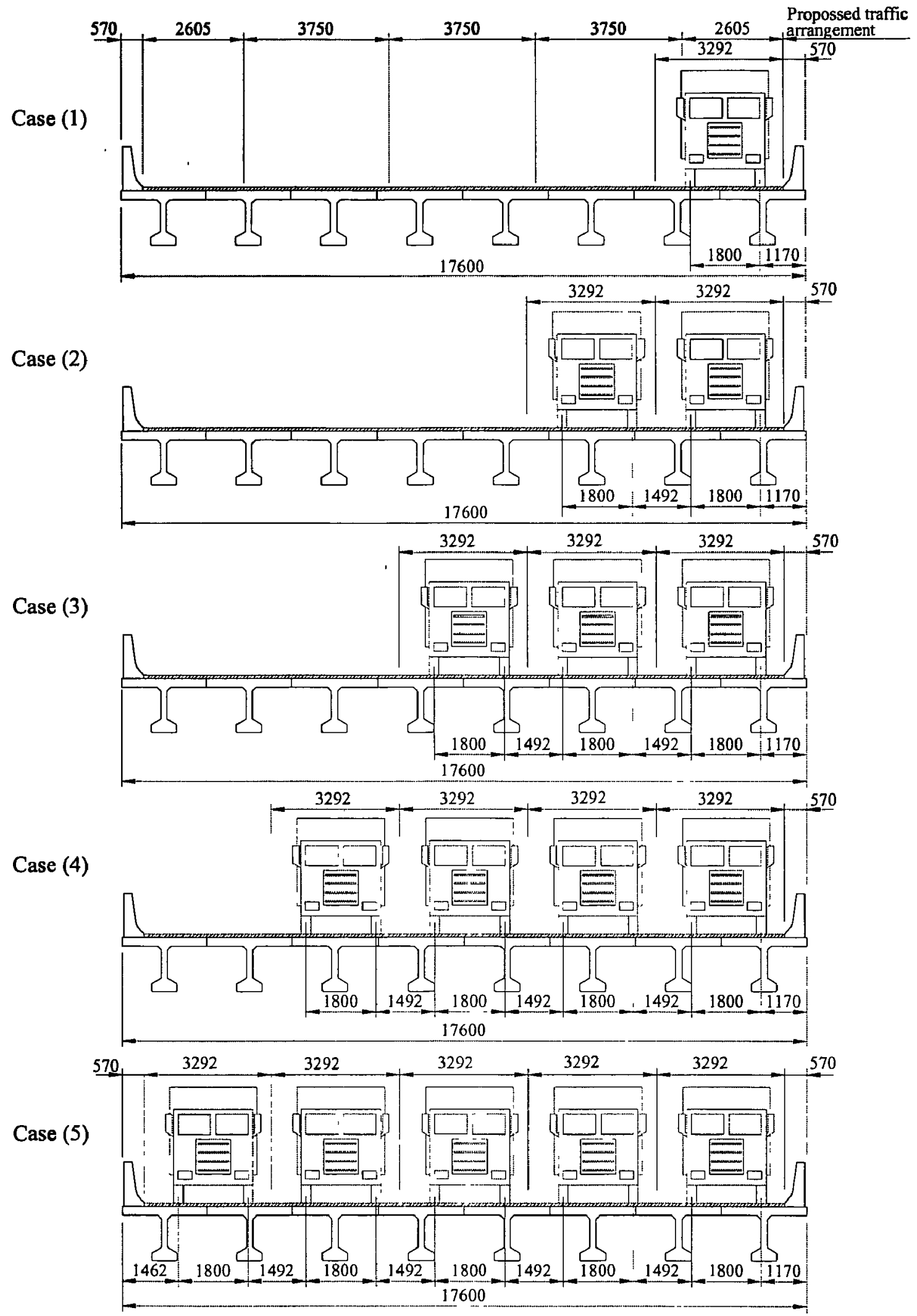

Figure 3.19.a Loading cases for five-design-lane, eight-girder, bridge with $2400 \mathrm{~mm}$ girder spacing 


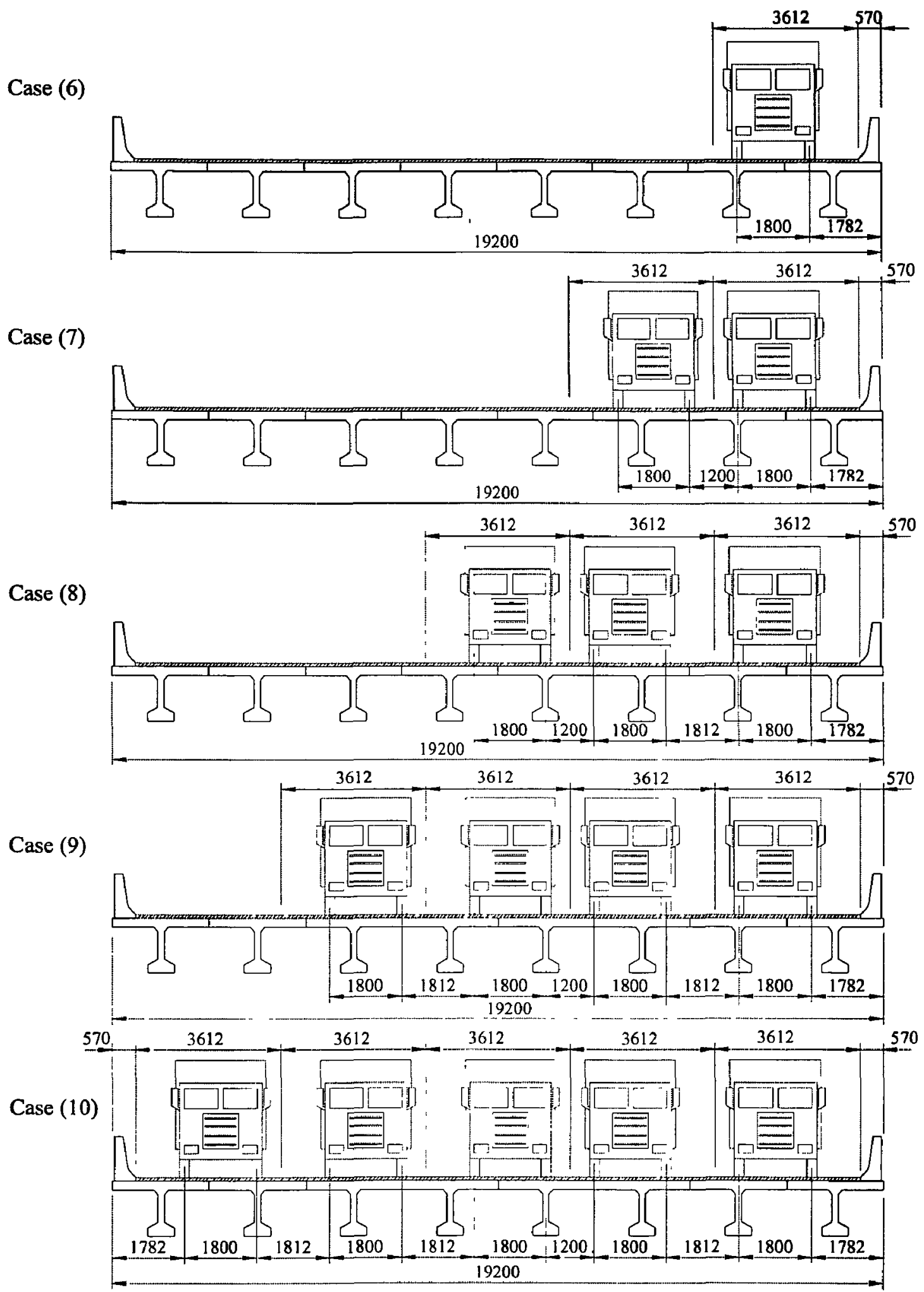

Figure 3.19.b Loading cases for five-design-lane, eight-girder, bridge with $2400 \mathrm{~mm}$ girder spacing 

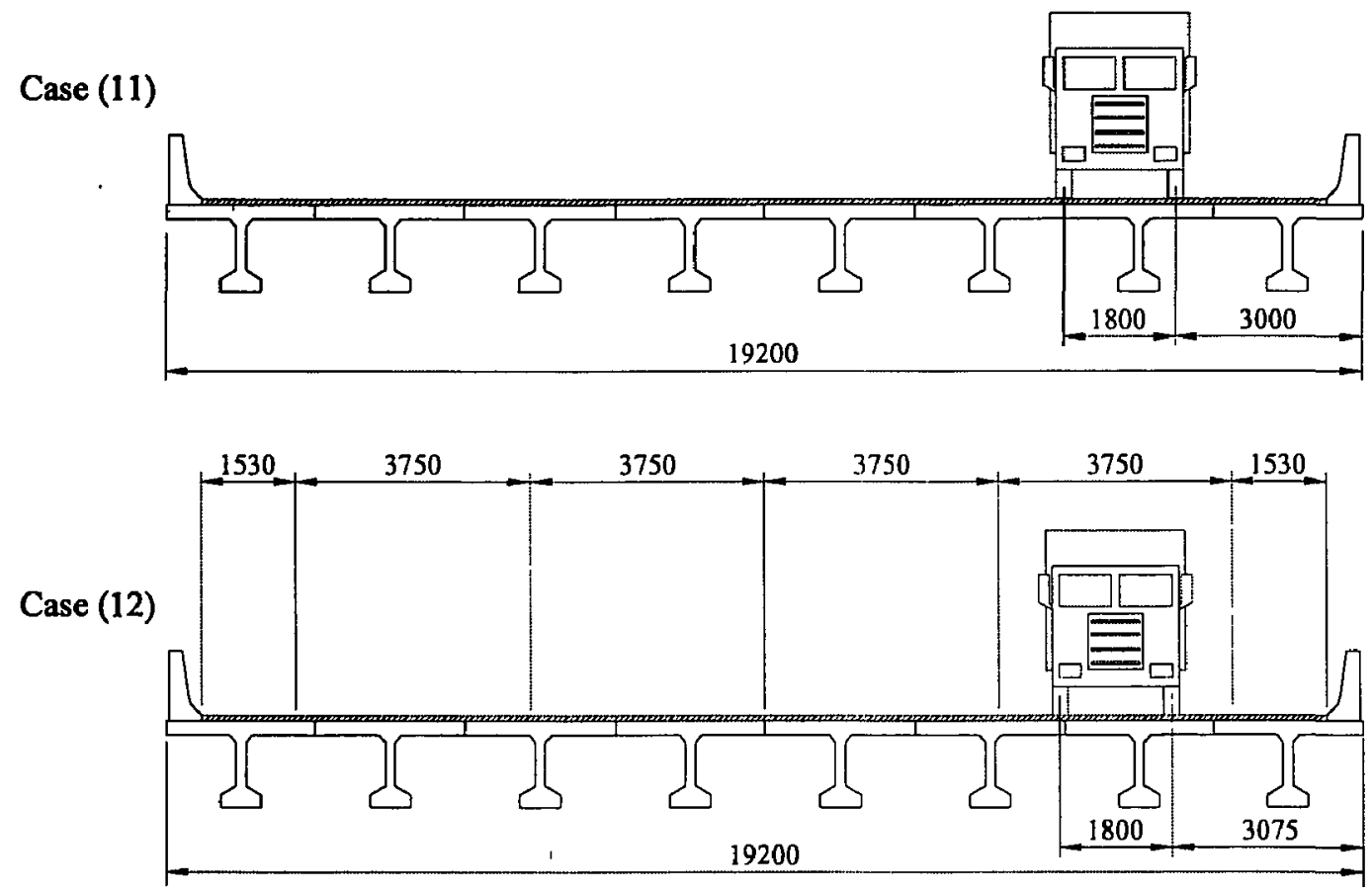

Figure 3.19.c Loading cases for five-design-lane, eight-girder, bridge with $2400 \mathrm{~mm}$ girder spacing 


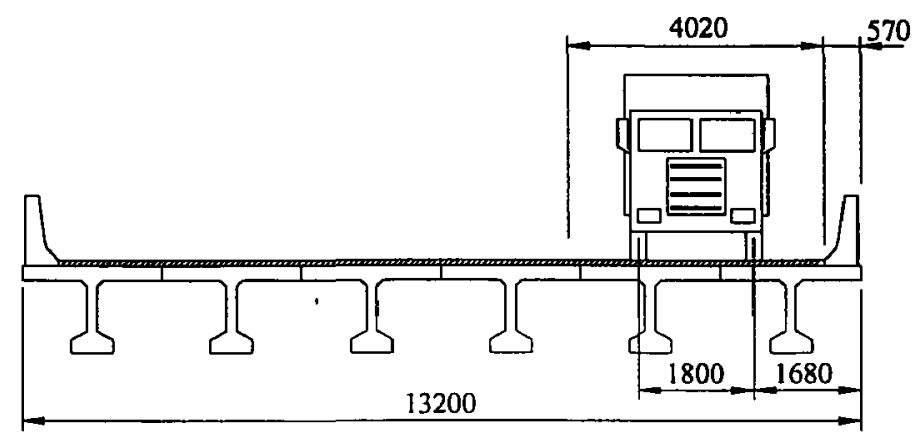

CASE 1: 1-Lane Eccentric

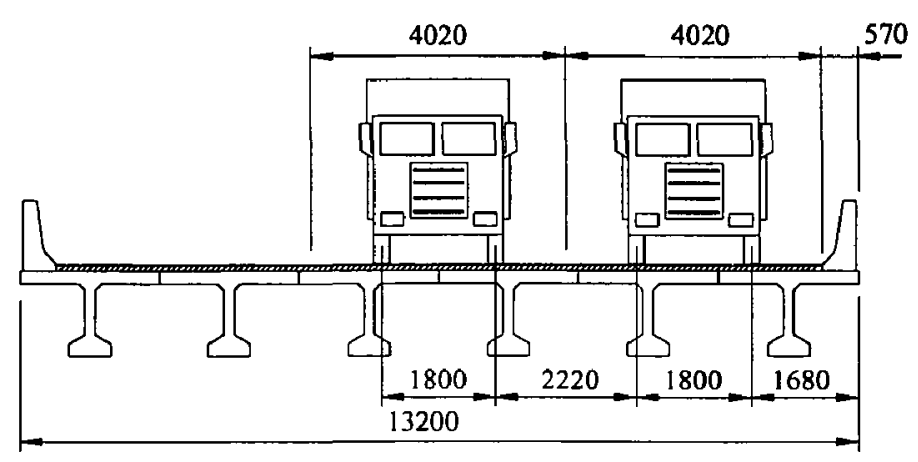

CASE 2- 2-Lane Eccentric

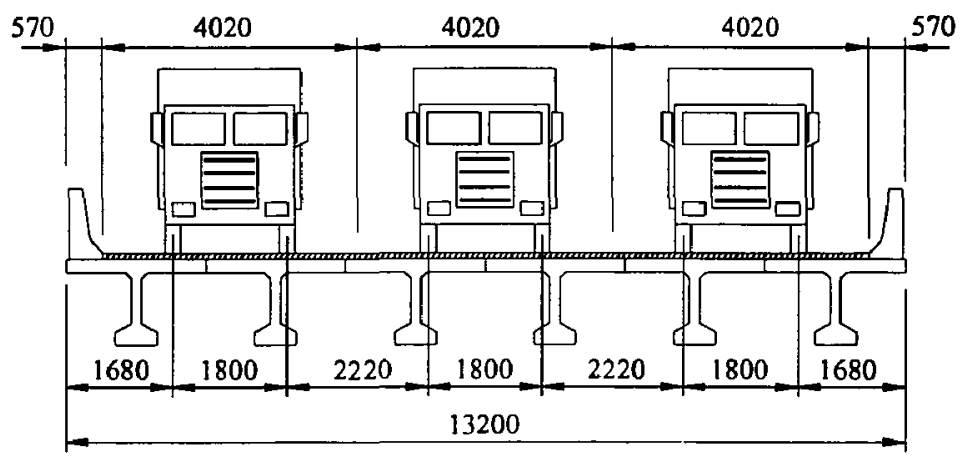

Case 3: 3-Lane Centric

Figure 3.20 Loading cases of truck loading at the center of the design lane(s) for WFCPCI 6-girder bridge 


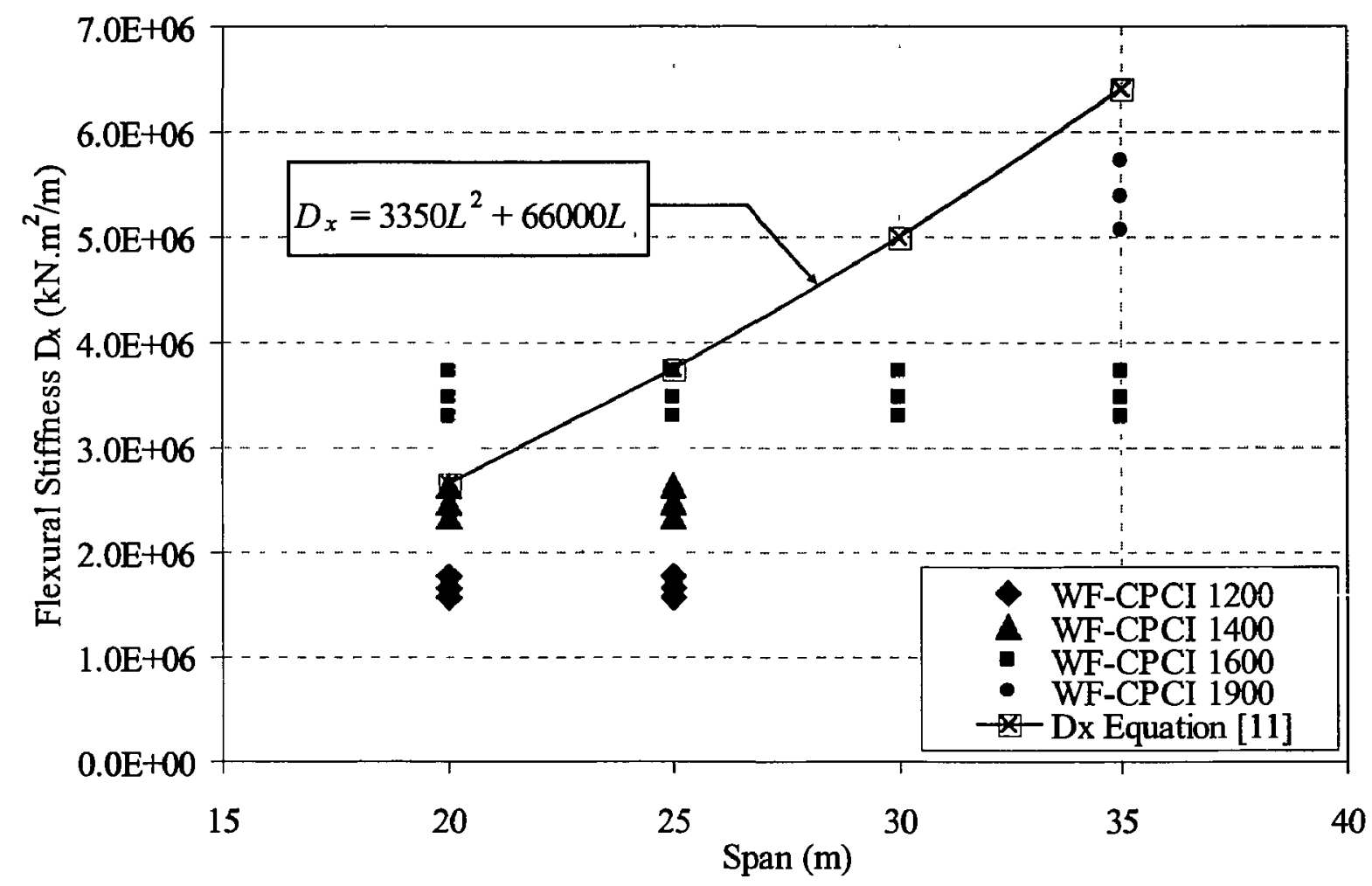

Figure 3.21 Longitudinal flexural stiffness $\left(D_{x}\right)$ of the WF-CPCI girder bridges 


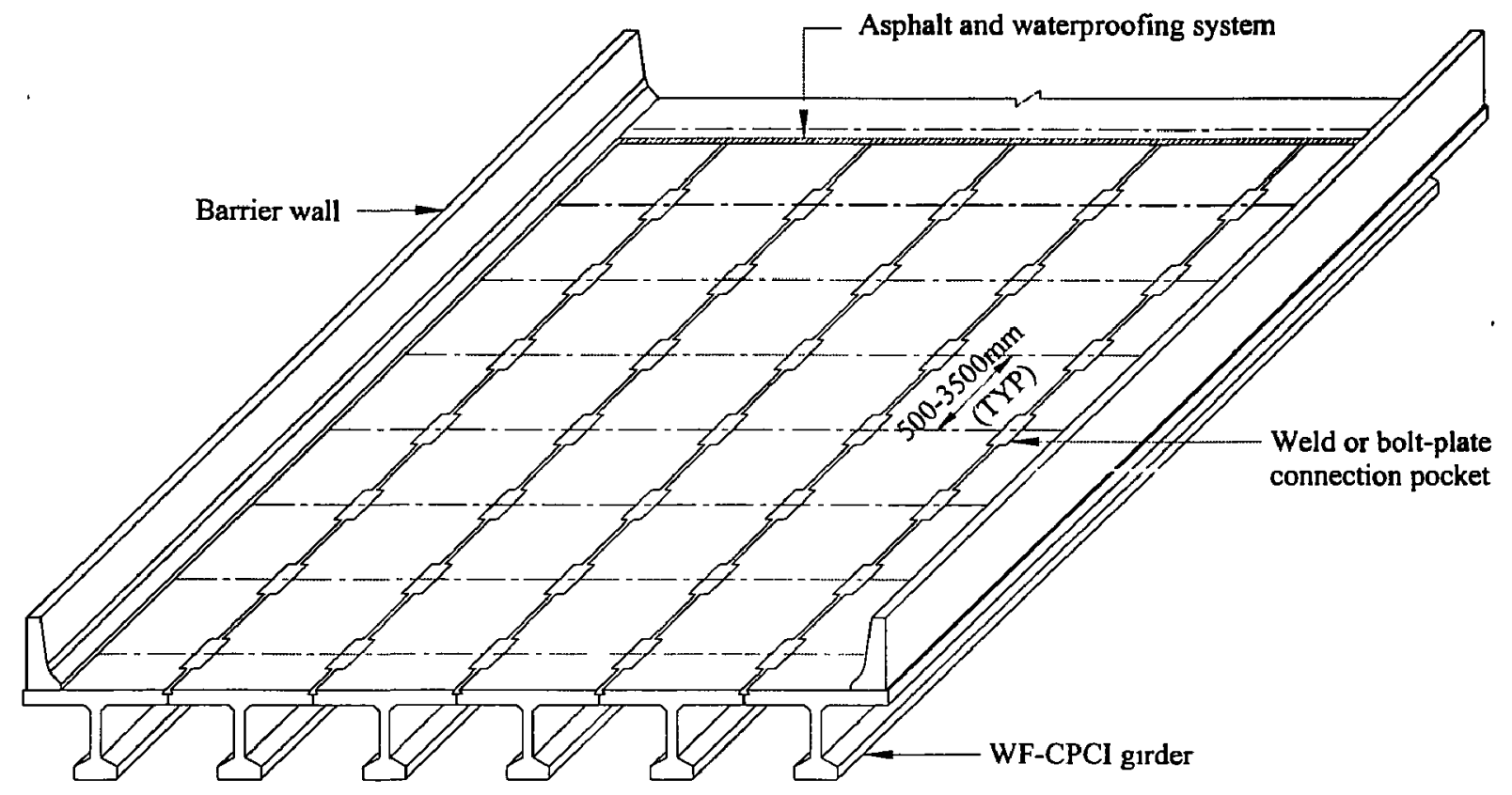

Figure 4.1 Schematic view of the intermittent connections between girder flanges 


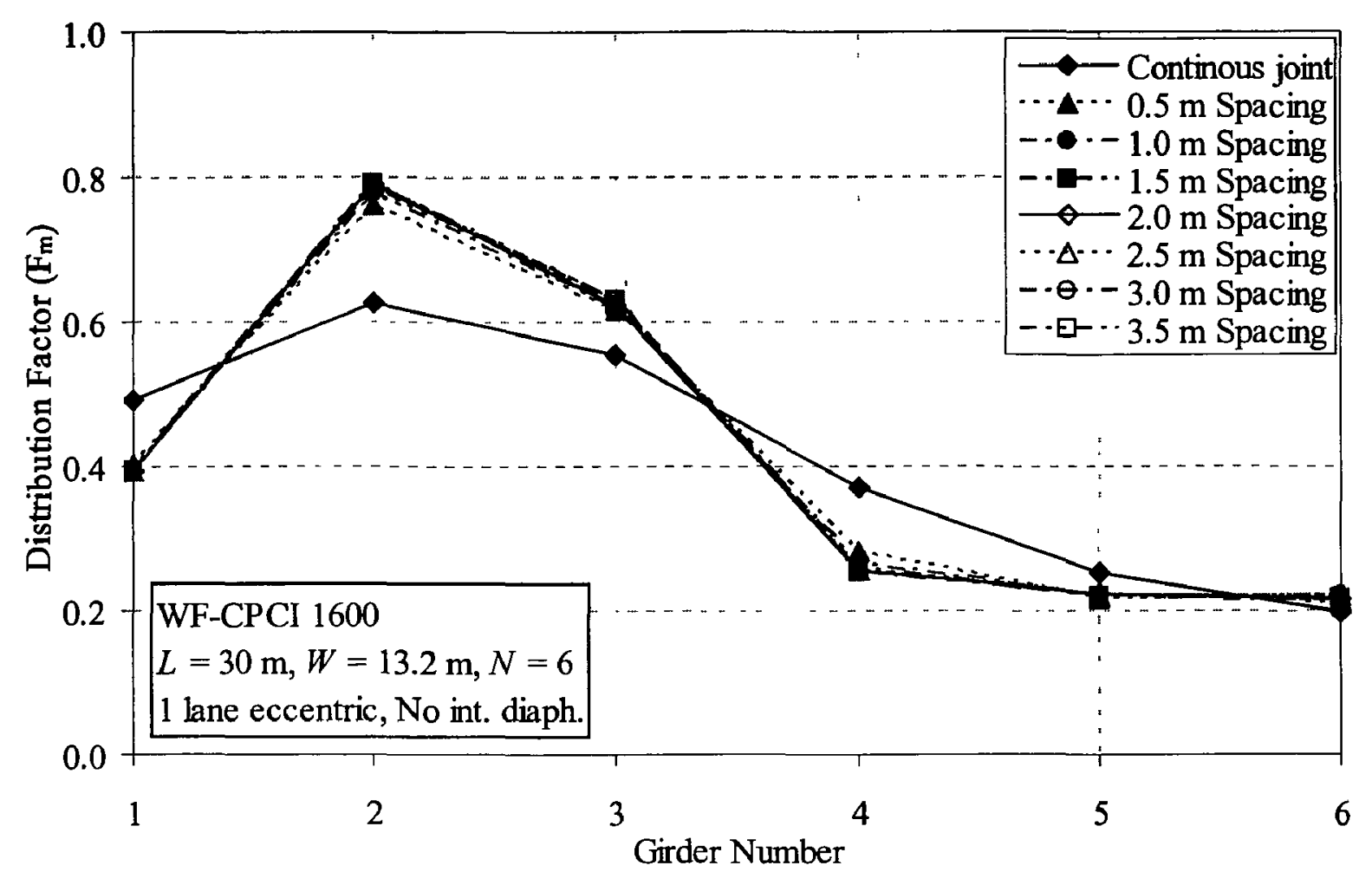

a) Moment distribution factor vs. girder location

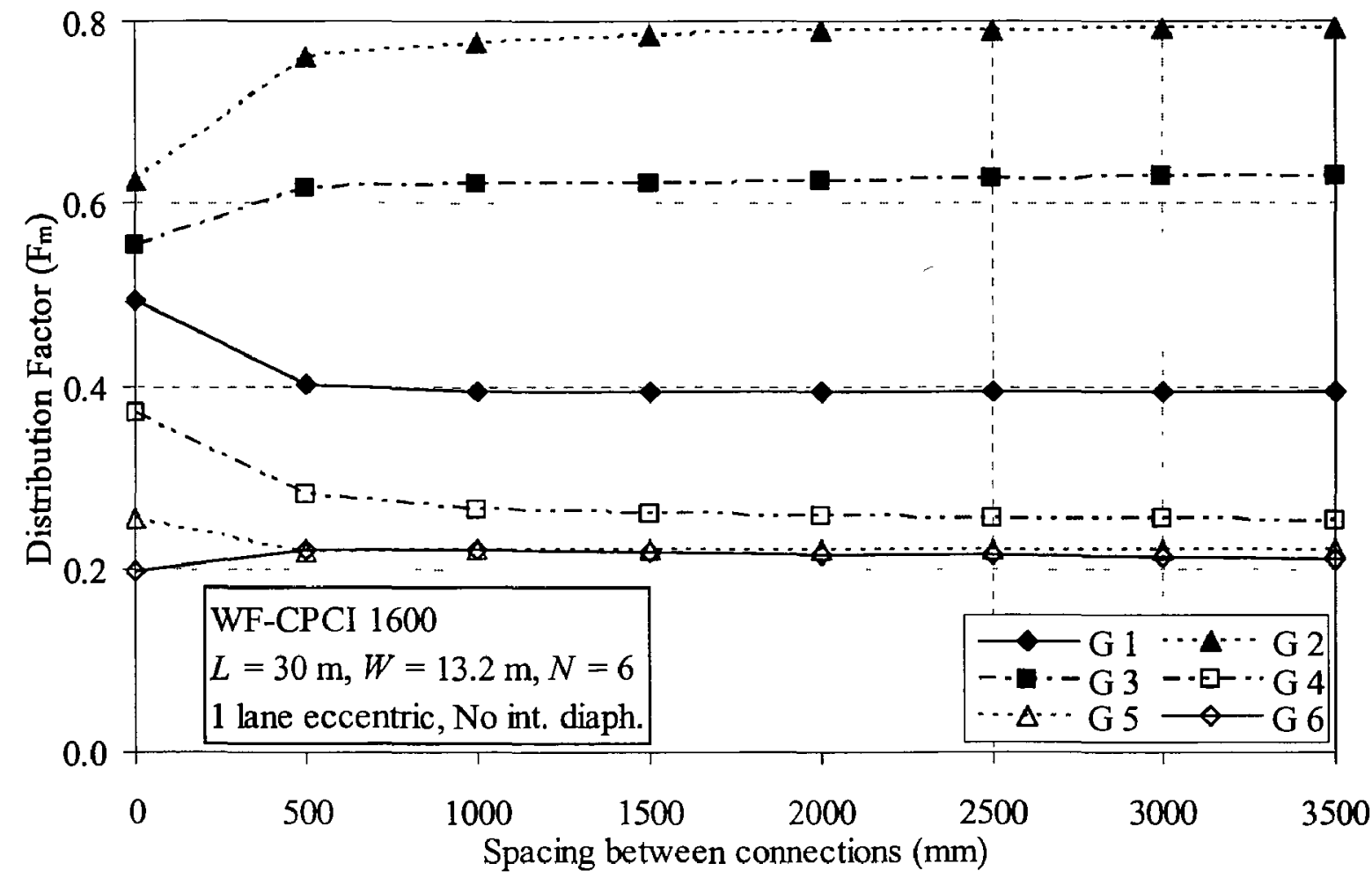

b) Moment distribution factor vs. spacing between connections

Figure 4.2 Moment distribution factors of $30 \mathrm{~m}$ span bridge eccentrically loaded with one truck 


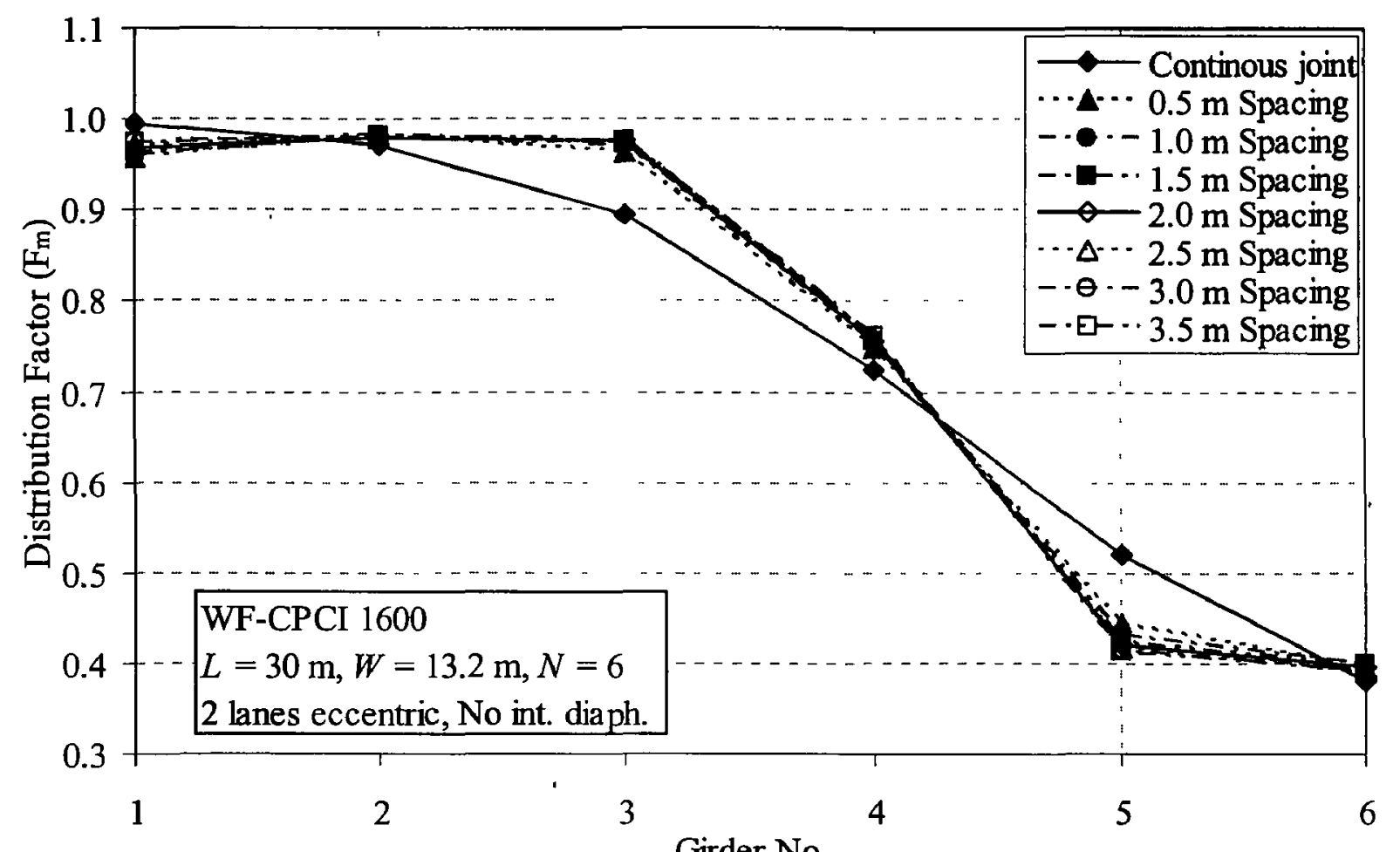

a) Moment distribution factor vs. girder location

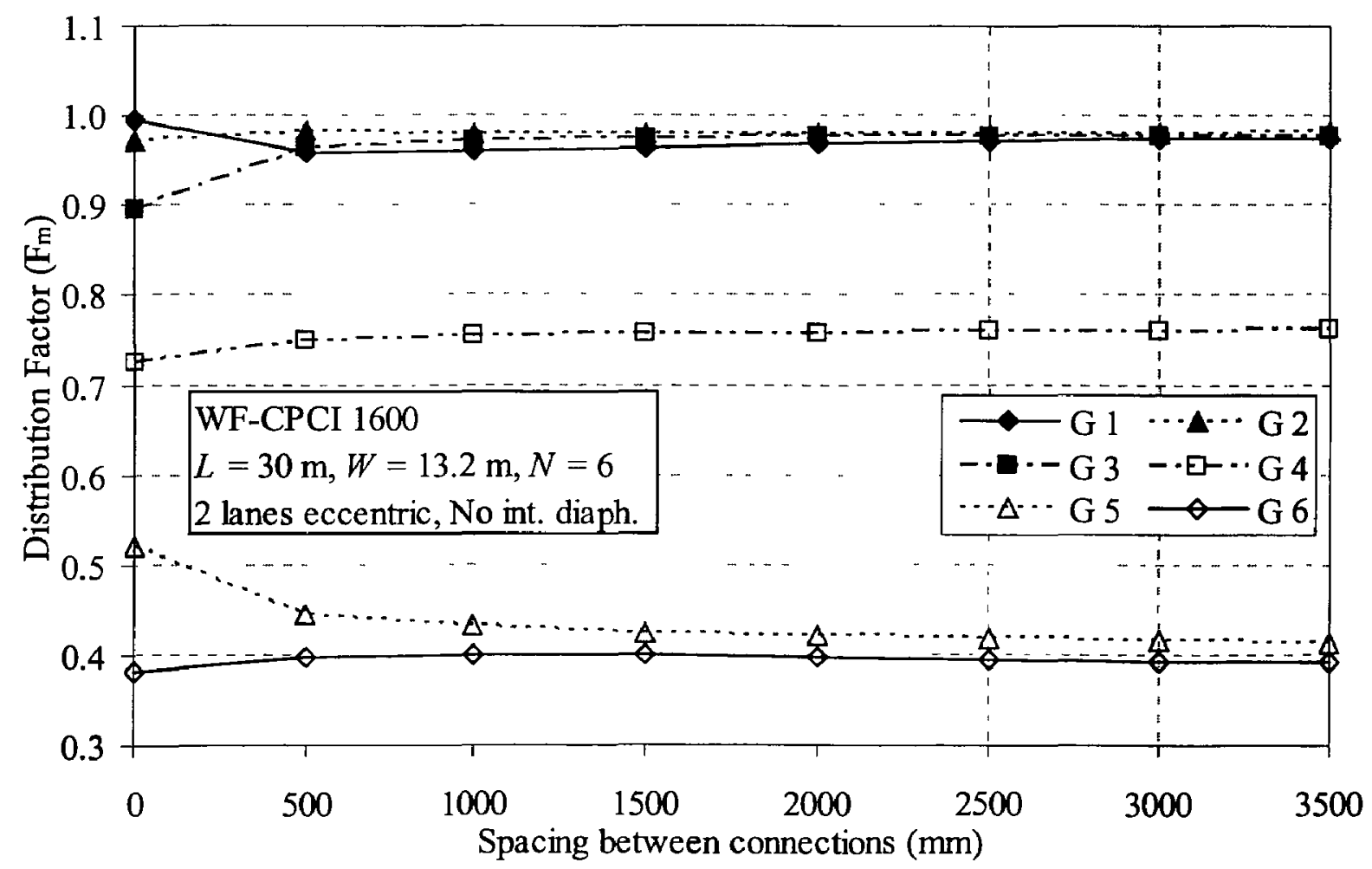

b) Moment distribution factor vs. spacing between connections

Figure 4.3 Moment distribution factors of $30 \mathrm{~m}$ span bridge eccentrically loaded with two trucks 


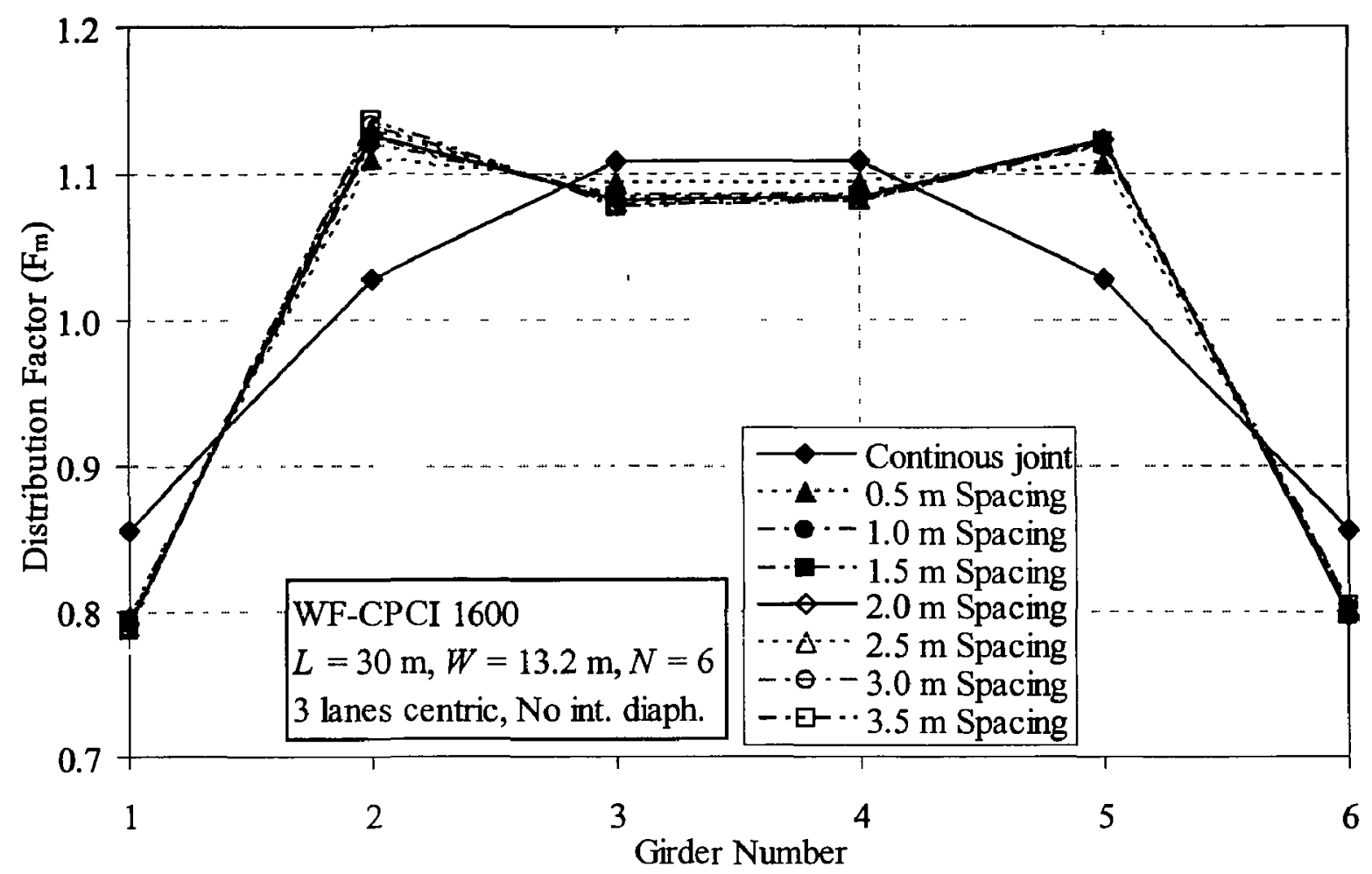

a) Moment distribution factor vs. girder location

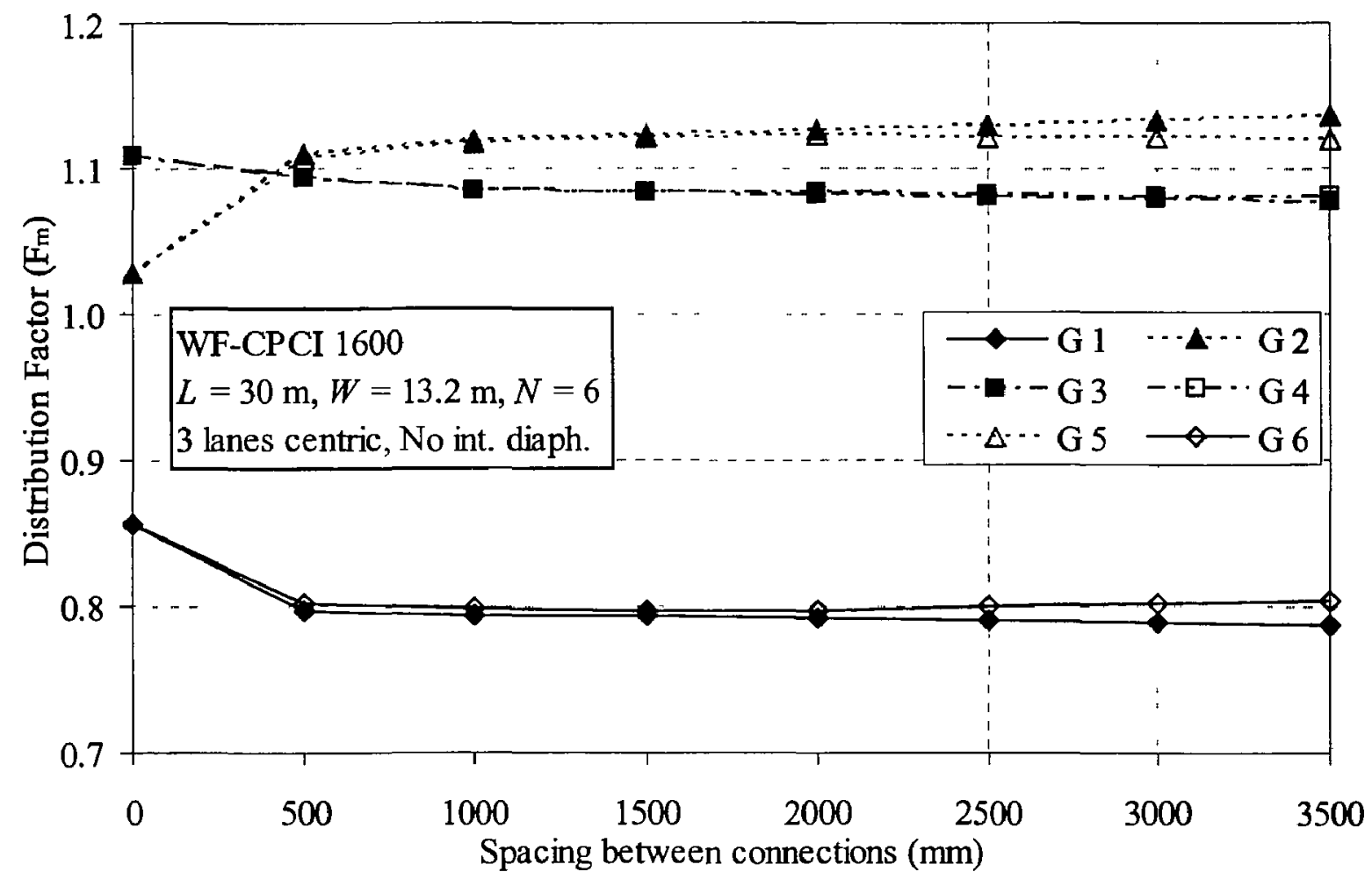

b) Moment distribution factor vs. spacing between connections

Figure 4.4 Moment distribution factors of $30 \mathrm{~m}$ span bridge centrically loaded with three trucks 


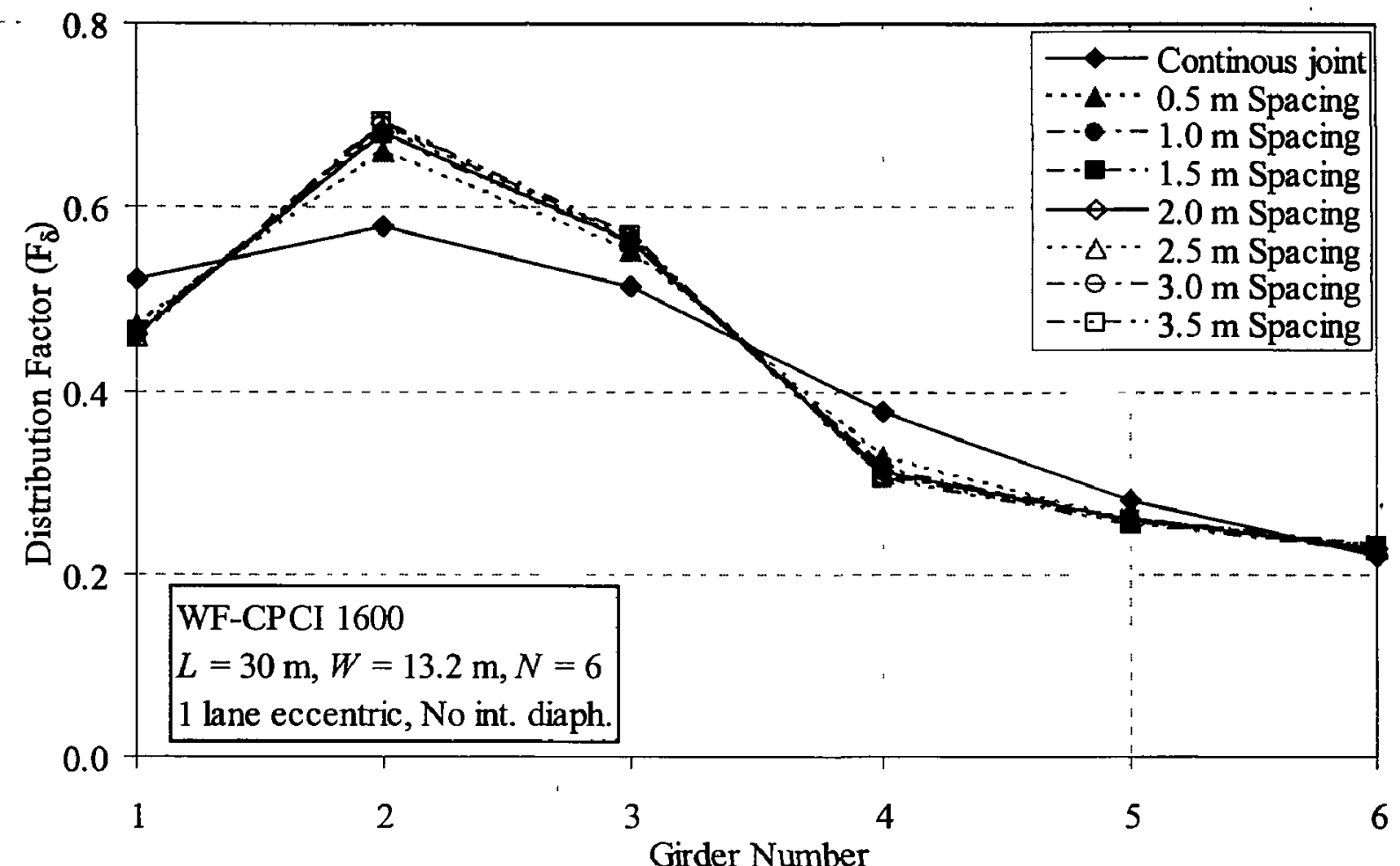

a) Deflection distribution factor vs. girder location

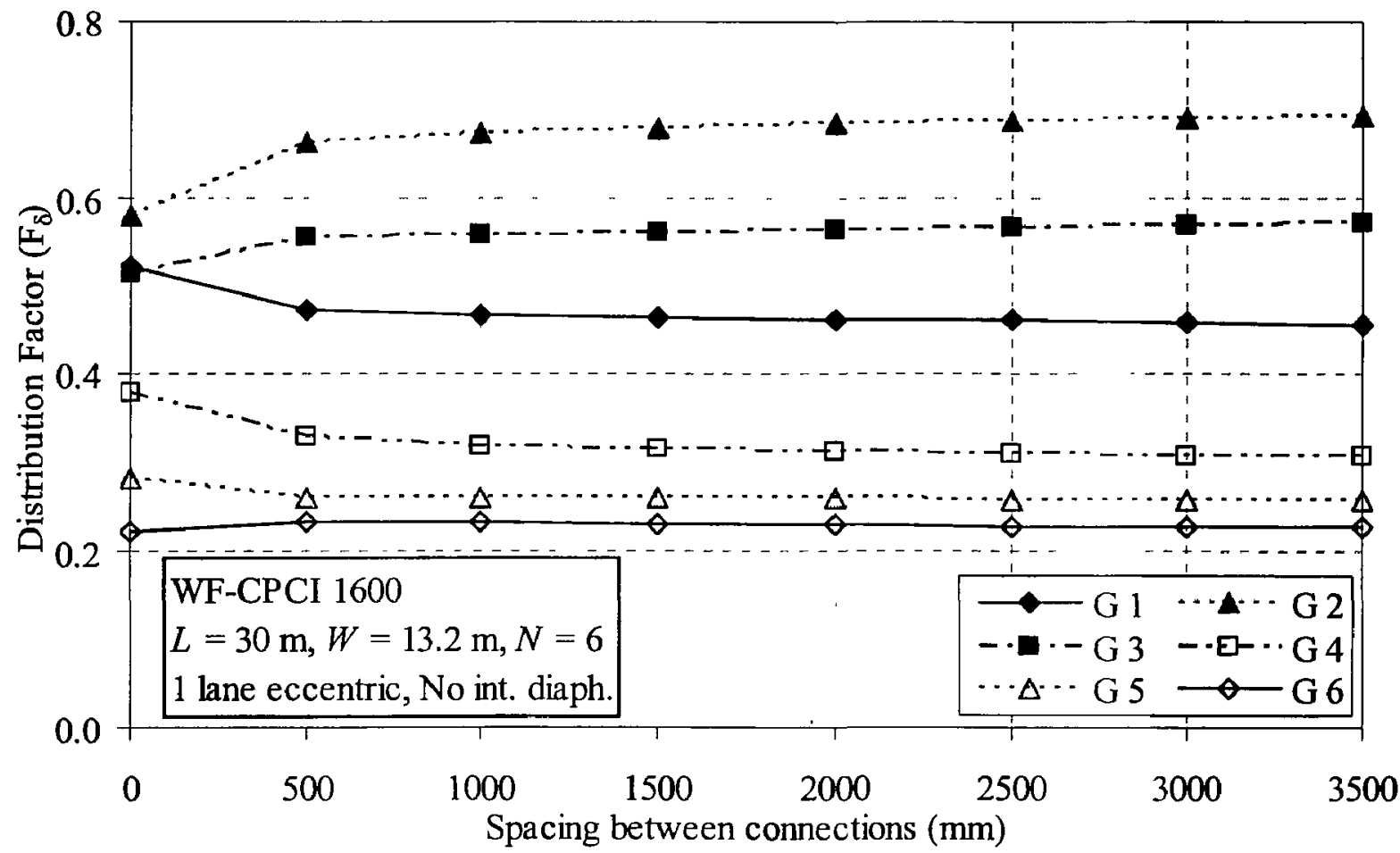

b) Deflection distribution factor vs. spacing between connections

Figure 4.5 Deflection distribution factors of $30 \mathrm{~m}$ span bridge eccentrically loaded with one truck 


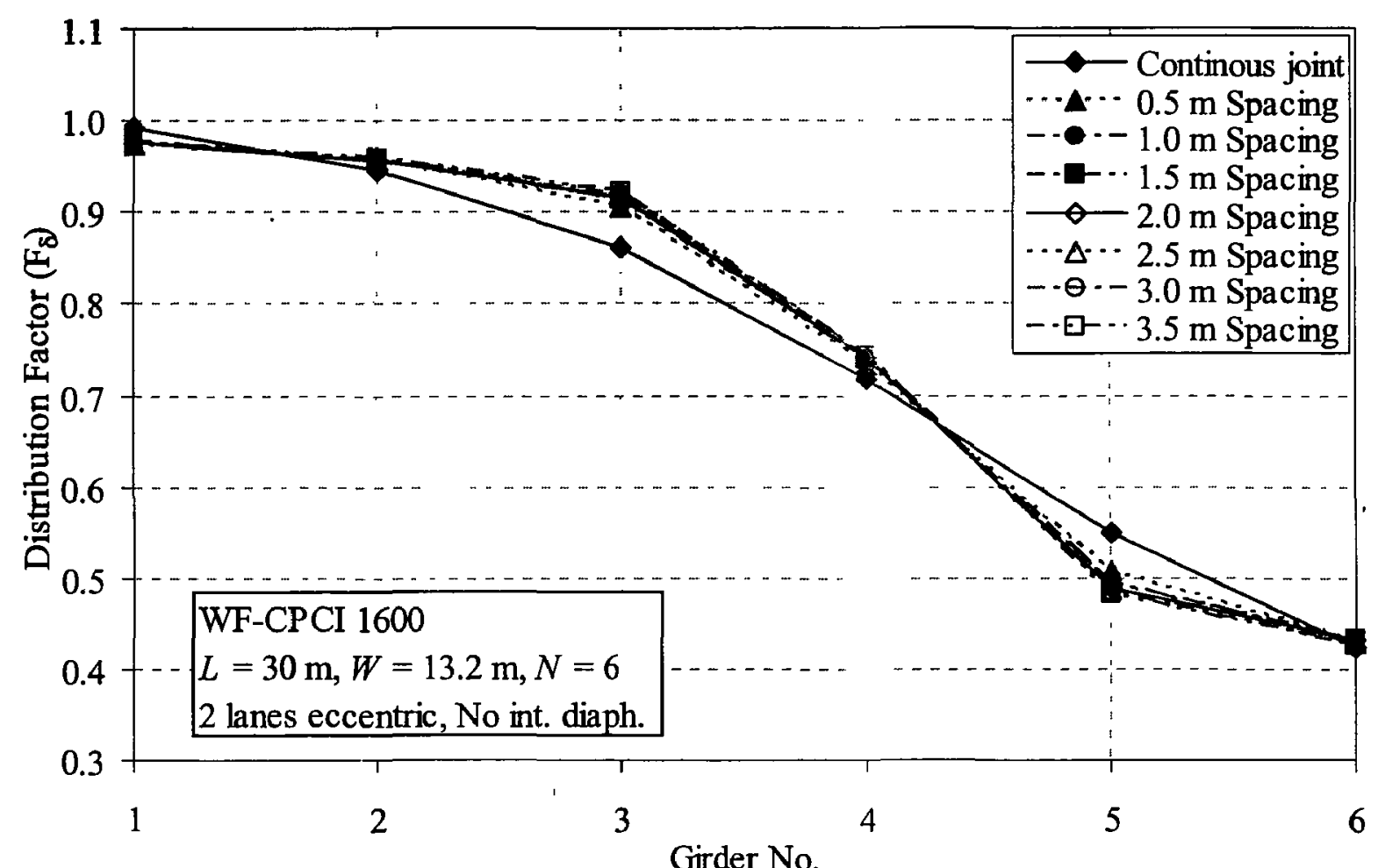

a) Deflection distribution factor vs. girder location

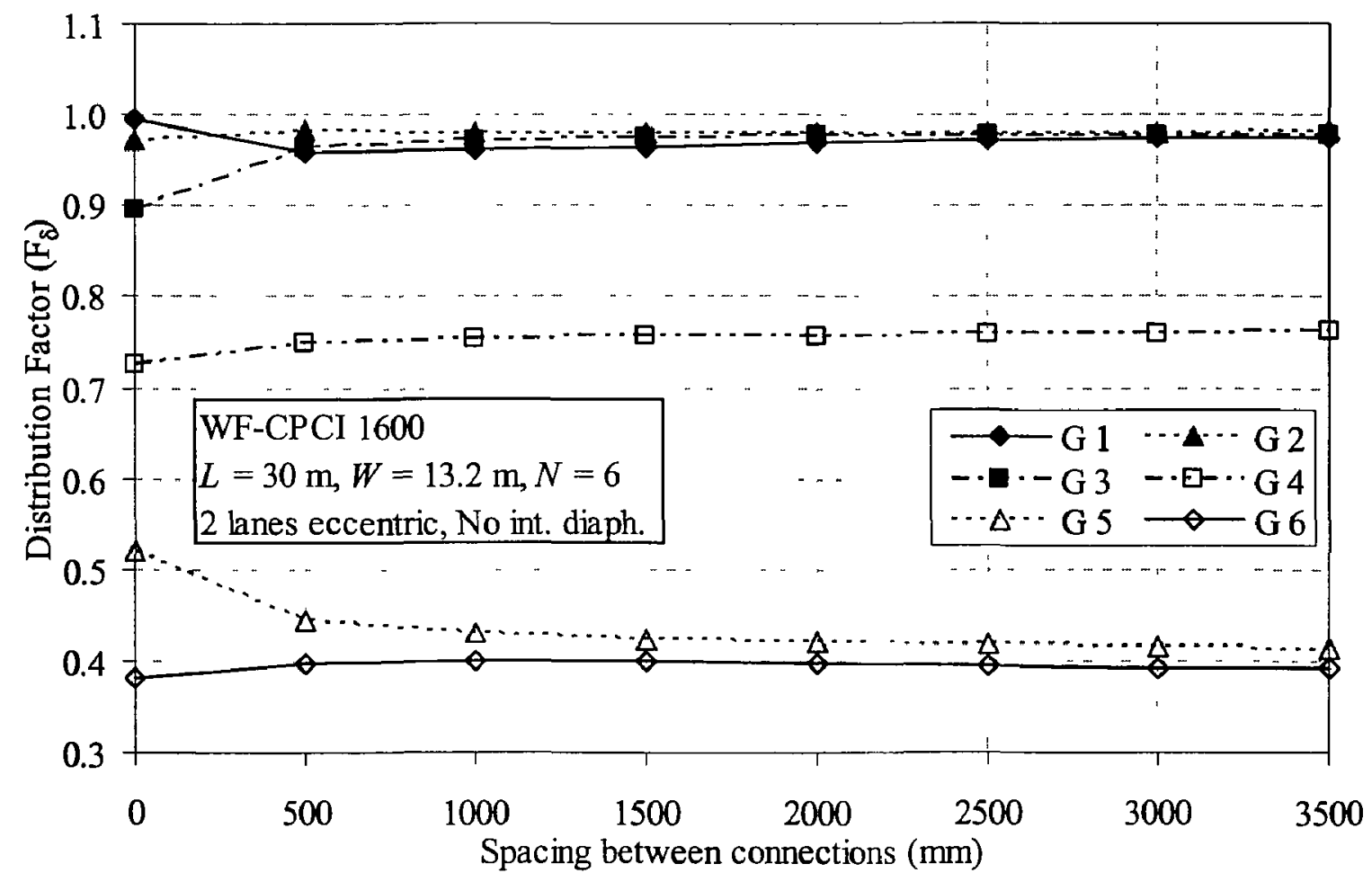

b) Deflection distribution factor vs. spacing between connections

Figure 4.6 Deflection distribution factors of $30 \mathrm{~m}$ span bridge eccentrically loaded with two trucks 


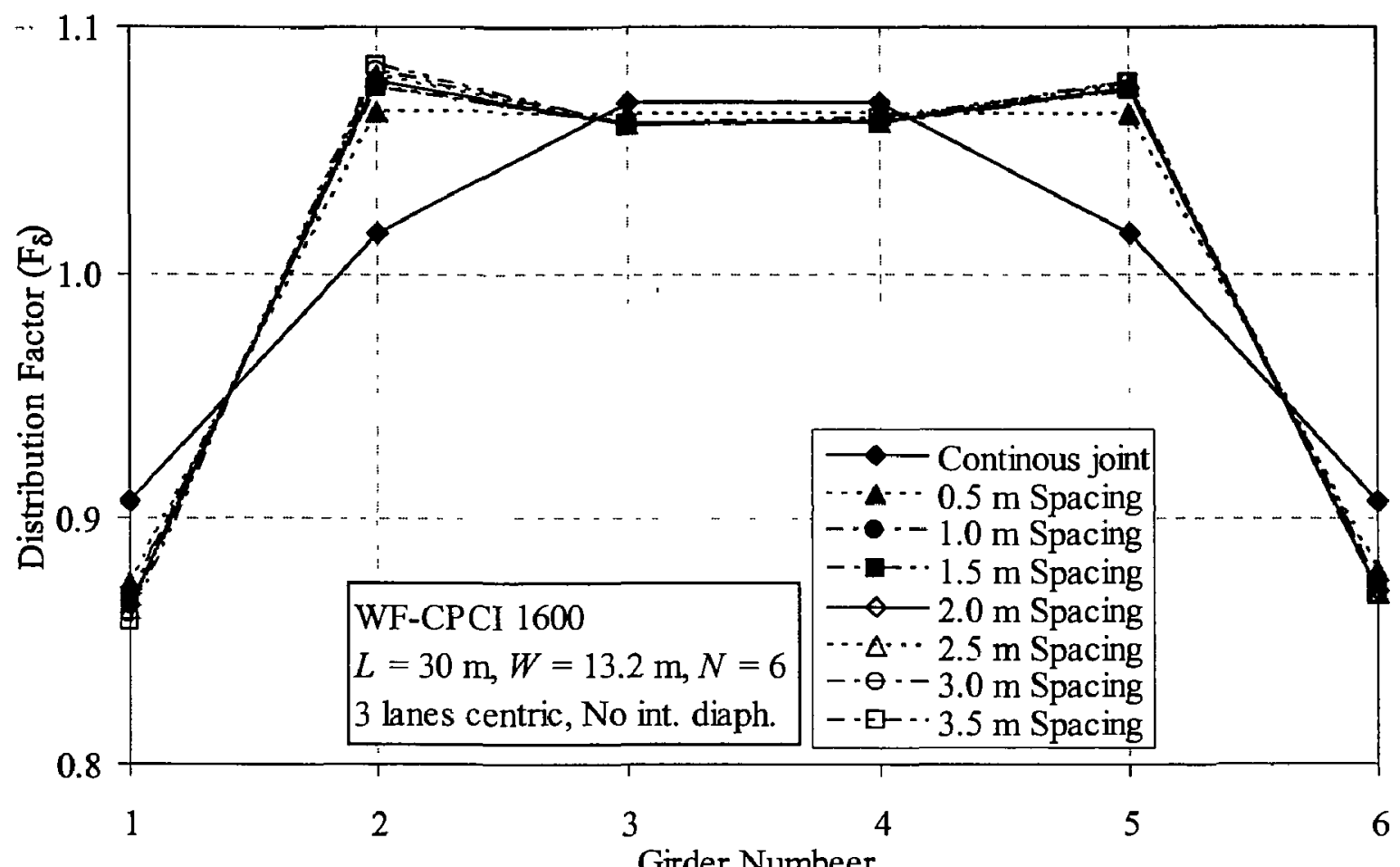

a) Deflection distribution factor vs. girder location

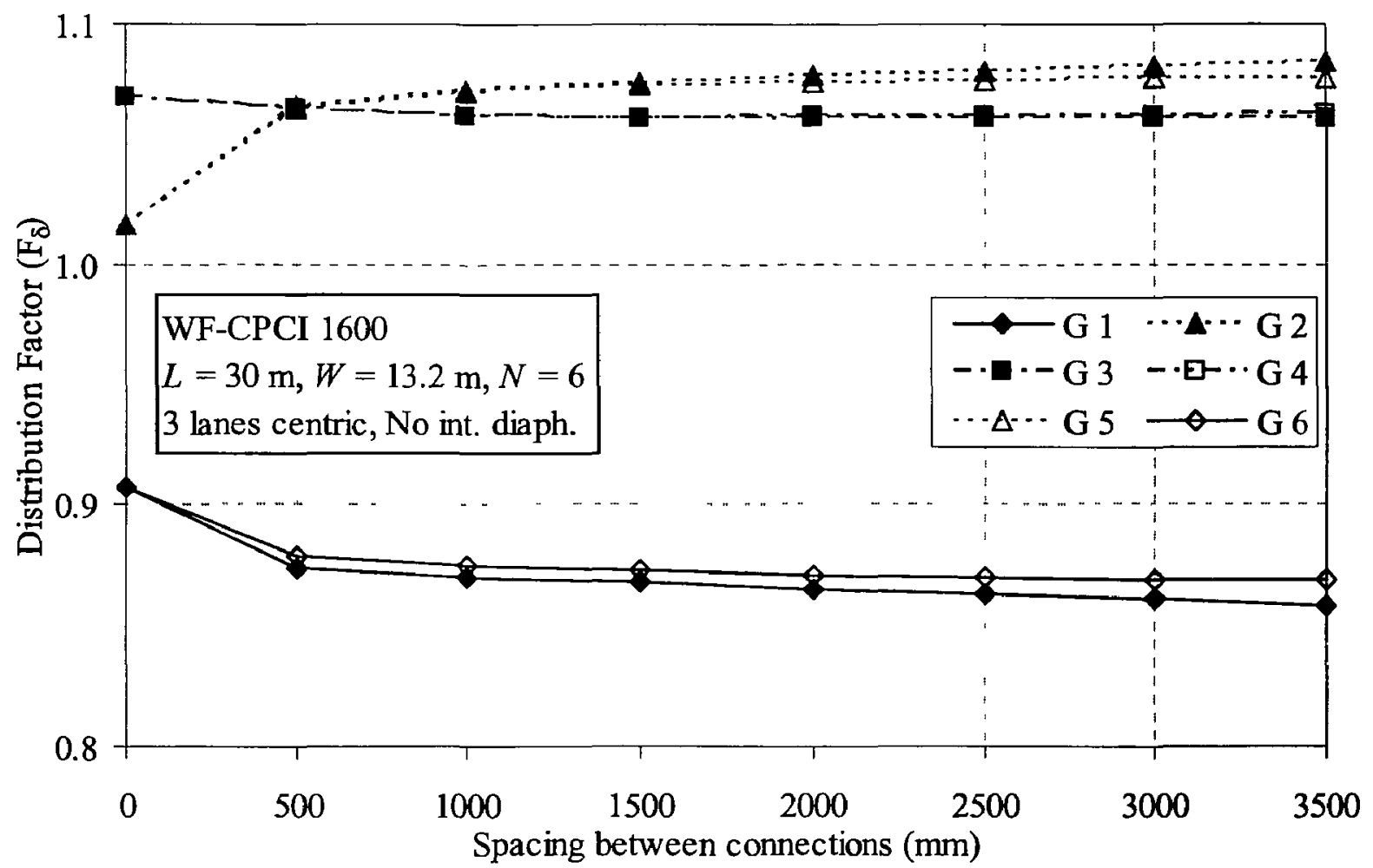

b) Deflection distribution factor vs. spacing between connections

Figure 4.7 Displacement distribution factors of $30 \mathrm{~m}$ span bridge centrically loaded with three trucks 


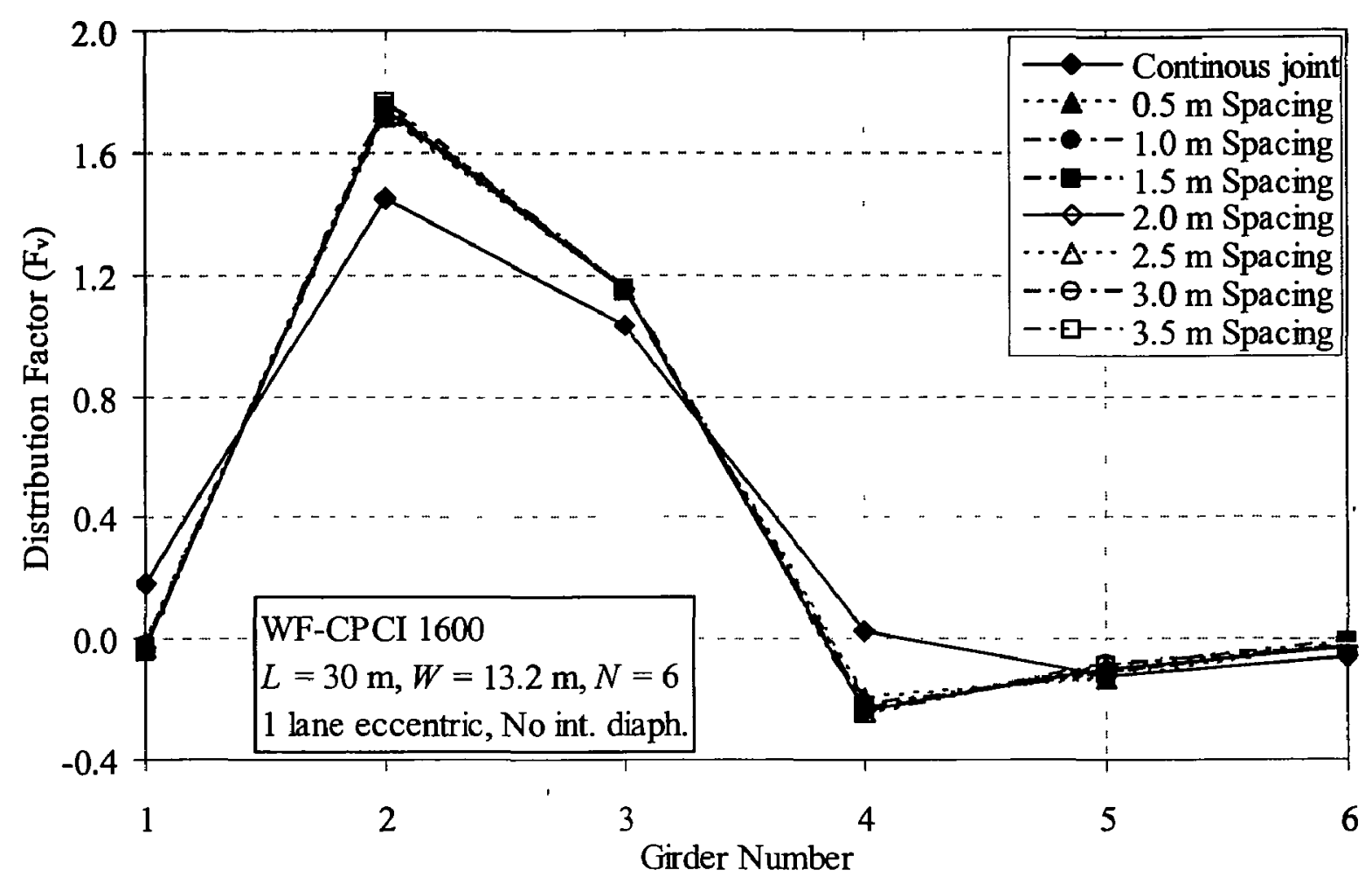

a) Shear distribution factor vs. girder location

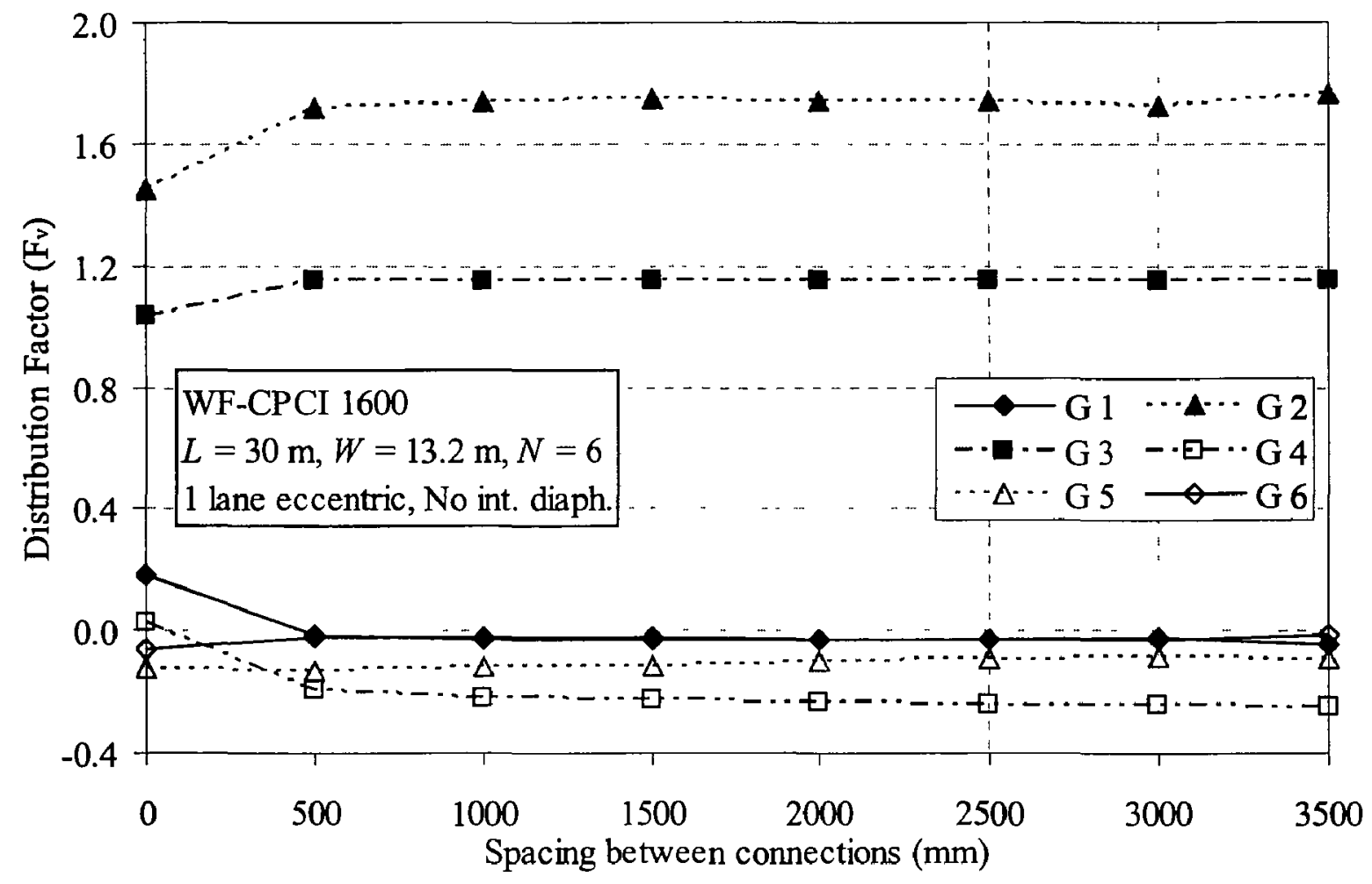

b) Shear distribution factor vs. spacing between connections

Figure 4.8 Shear distribution factors of $30 \mathrm{~m}$ span bridge eccentrically loaded with one truck 


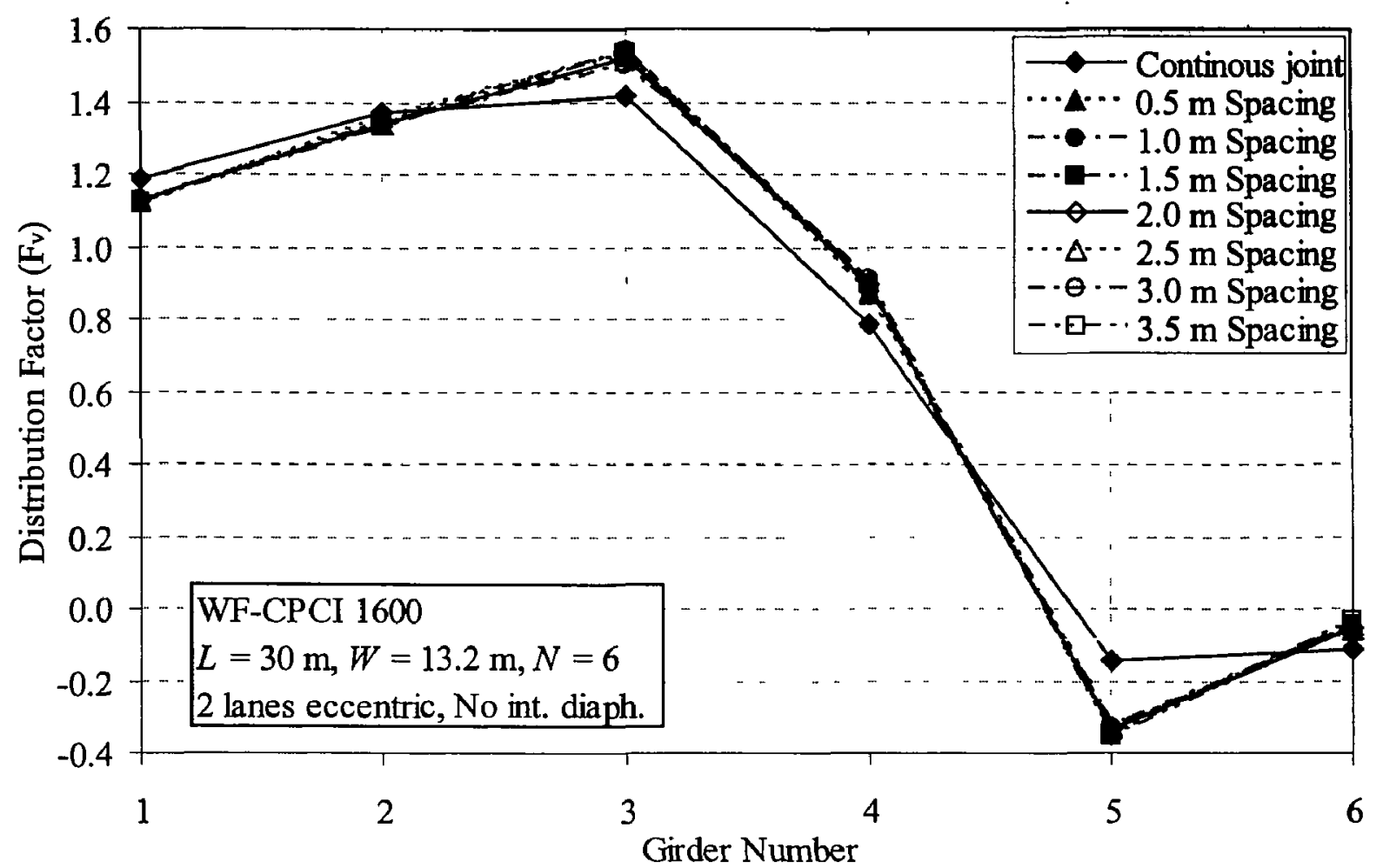

a) Shear distribution factor vs. girder location

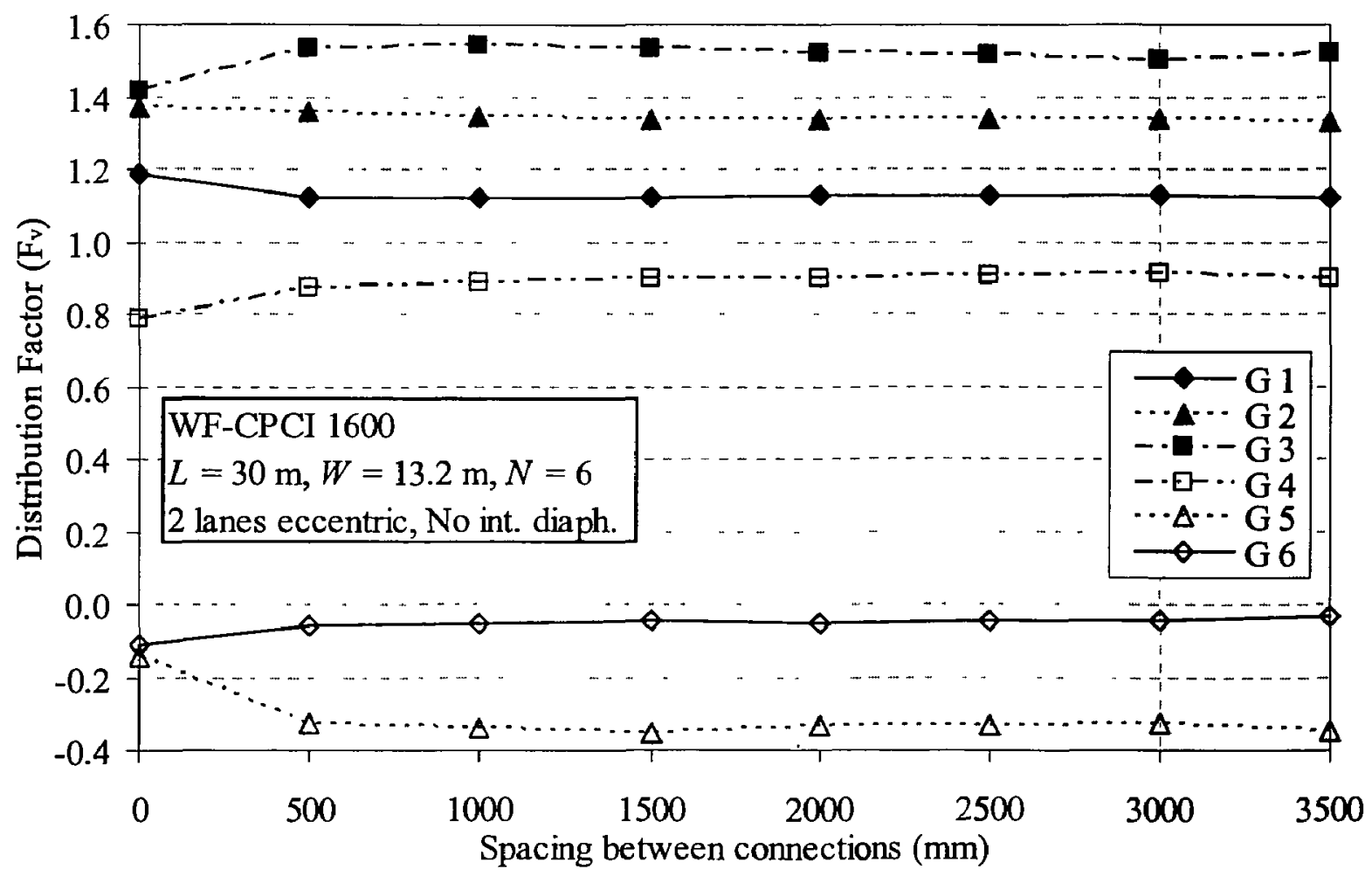

b) Shear distribution factor vs. spacing between connections

Figure 4.9 Shear distribution factors of $30 \mathrm{~m}$ span bridge eccentrically loaded with two trucks 


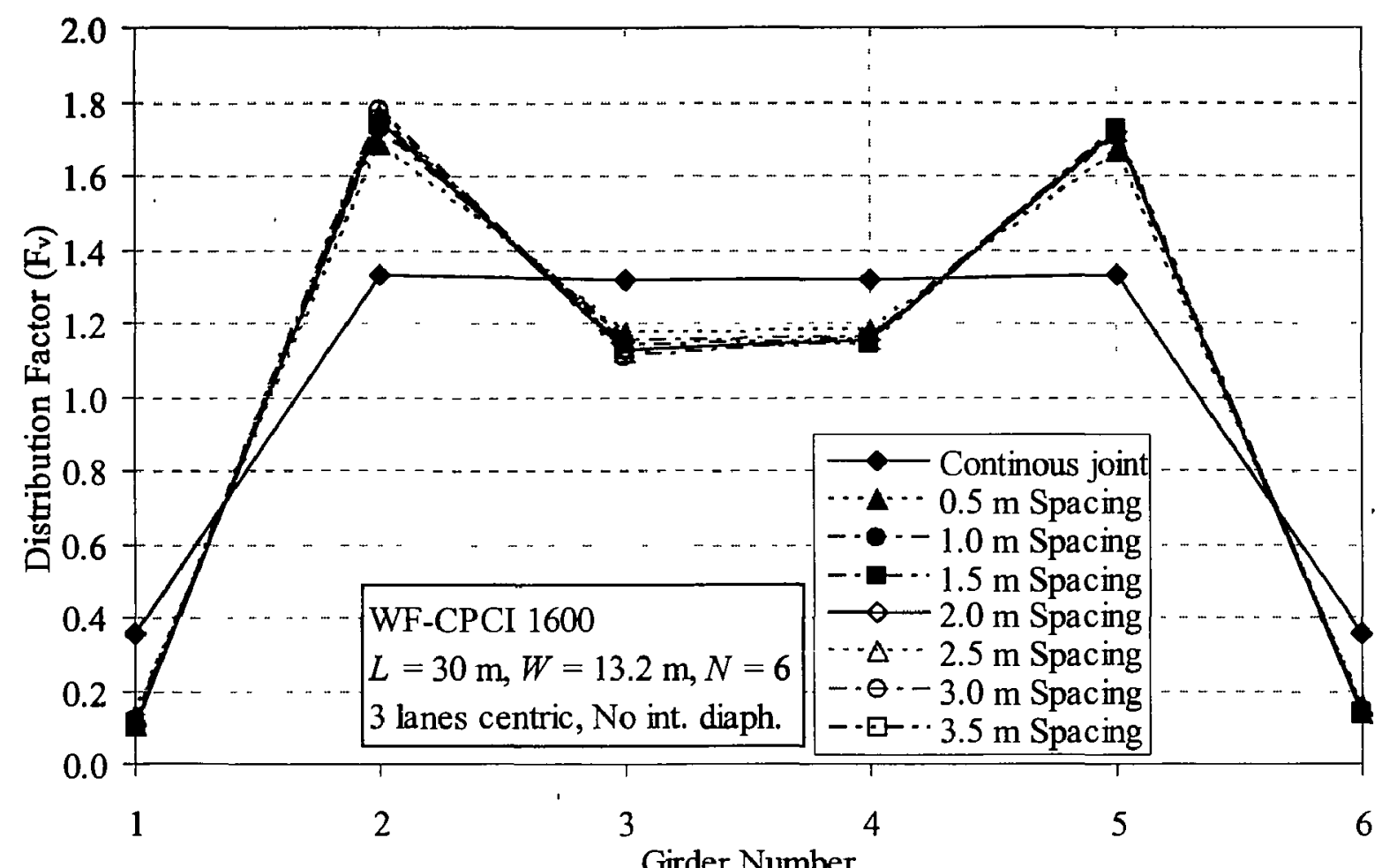

a) Shear distribution factor vs. girder location

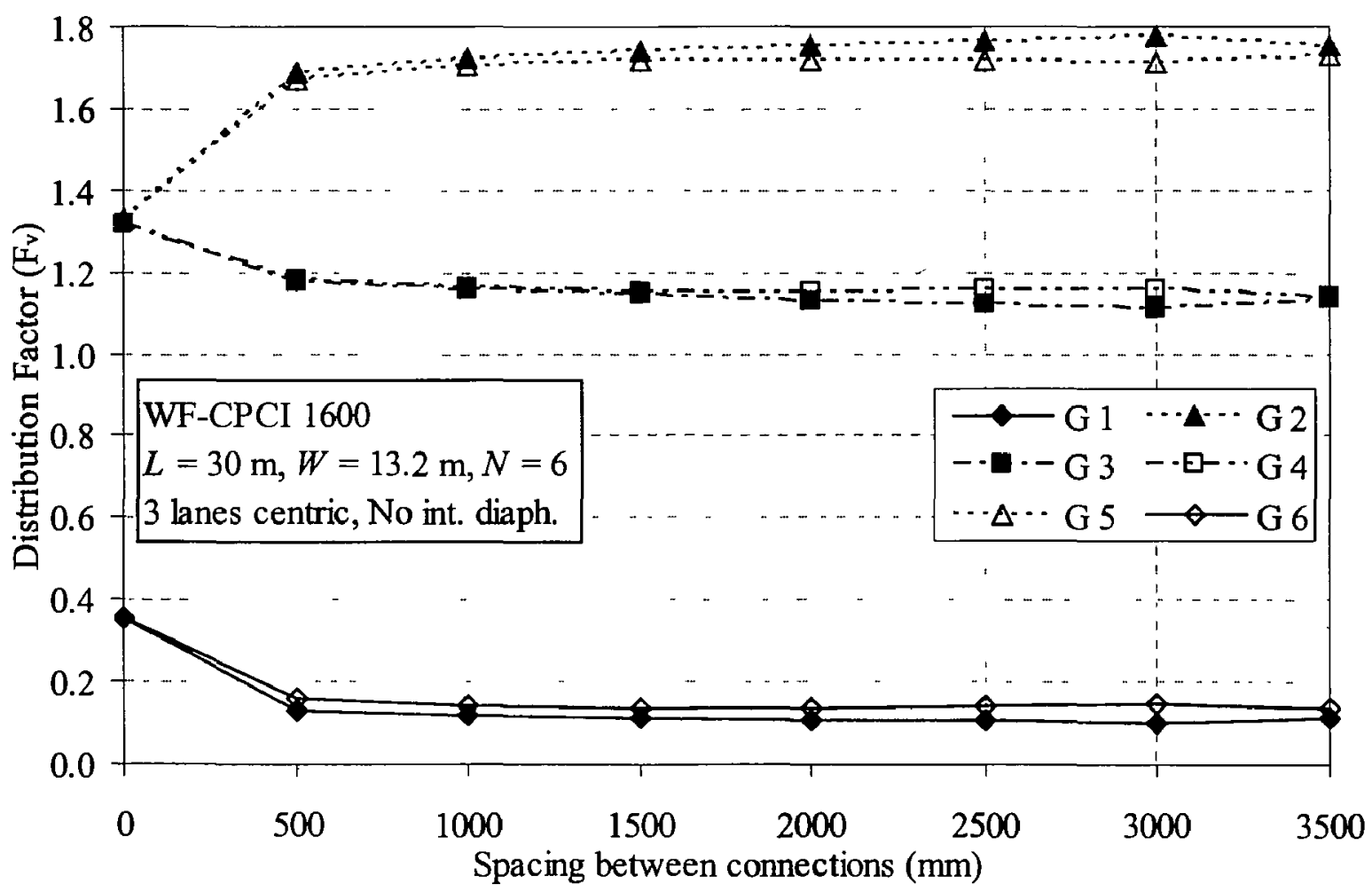

b) Shear distribution factor vs. spacing between connections

Figure 4.10 Shear distribution factors of $30 \mathrm{~m}$ span bridge centrically loaded with three trucks 


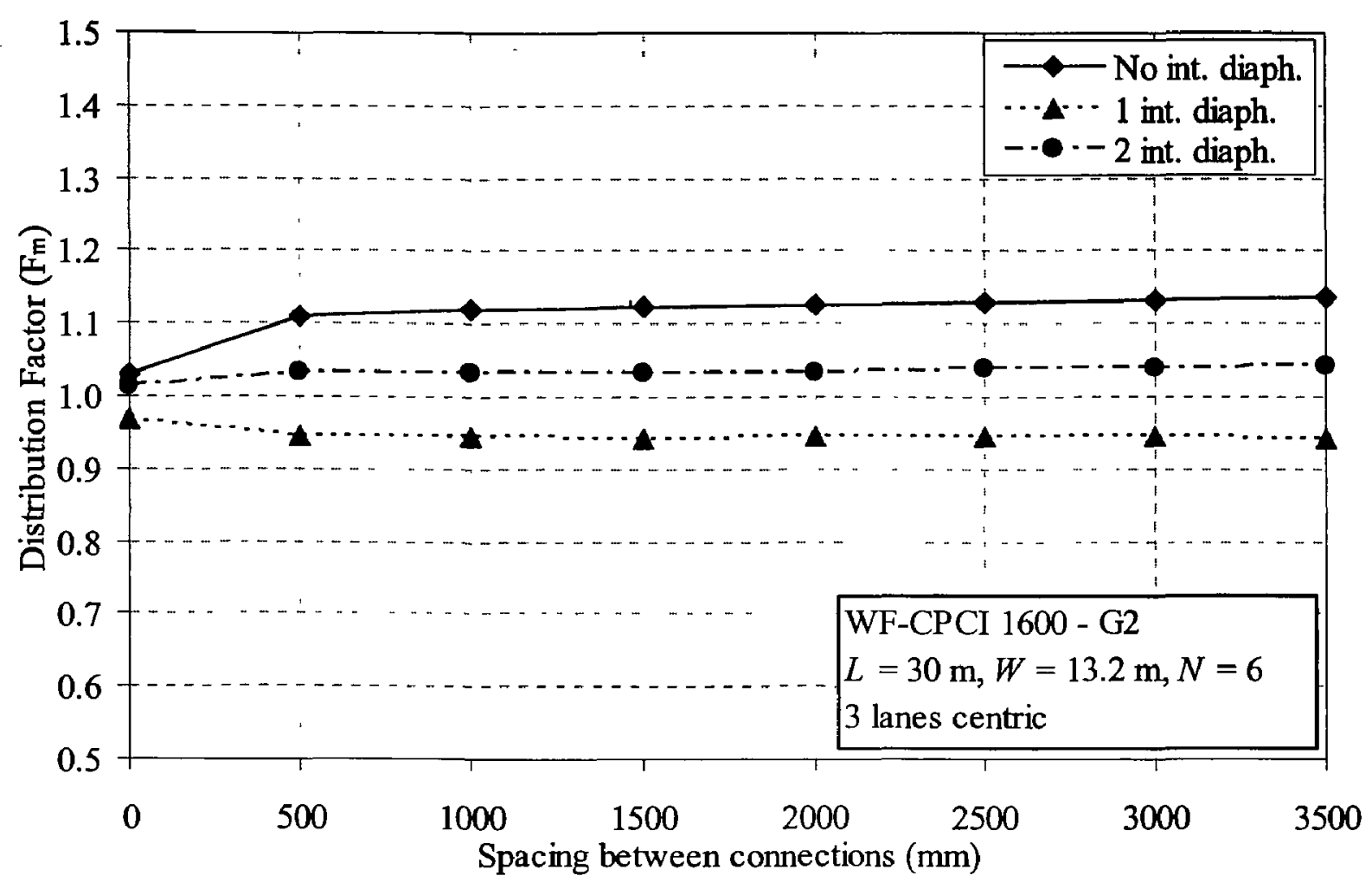

Figure 4.11 Distribution factor for bending moment in $\mathrm{G} 2$ for various spacing between connections

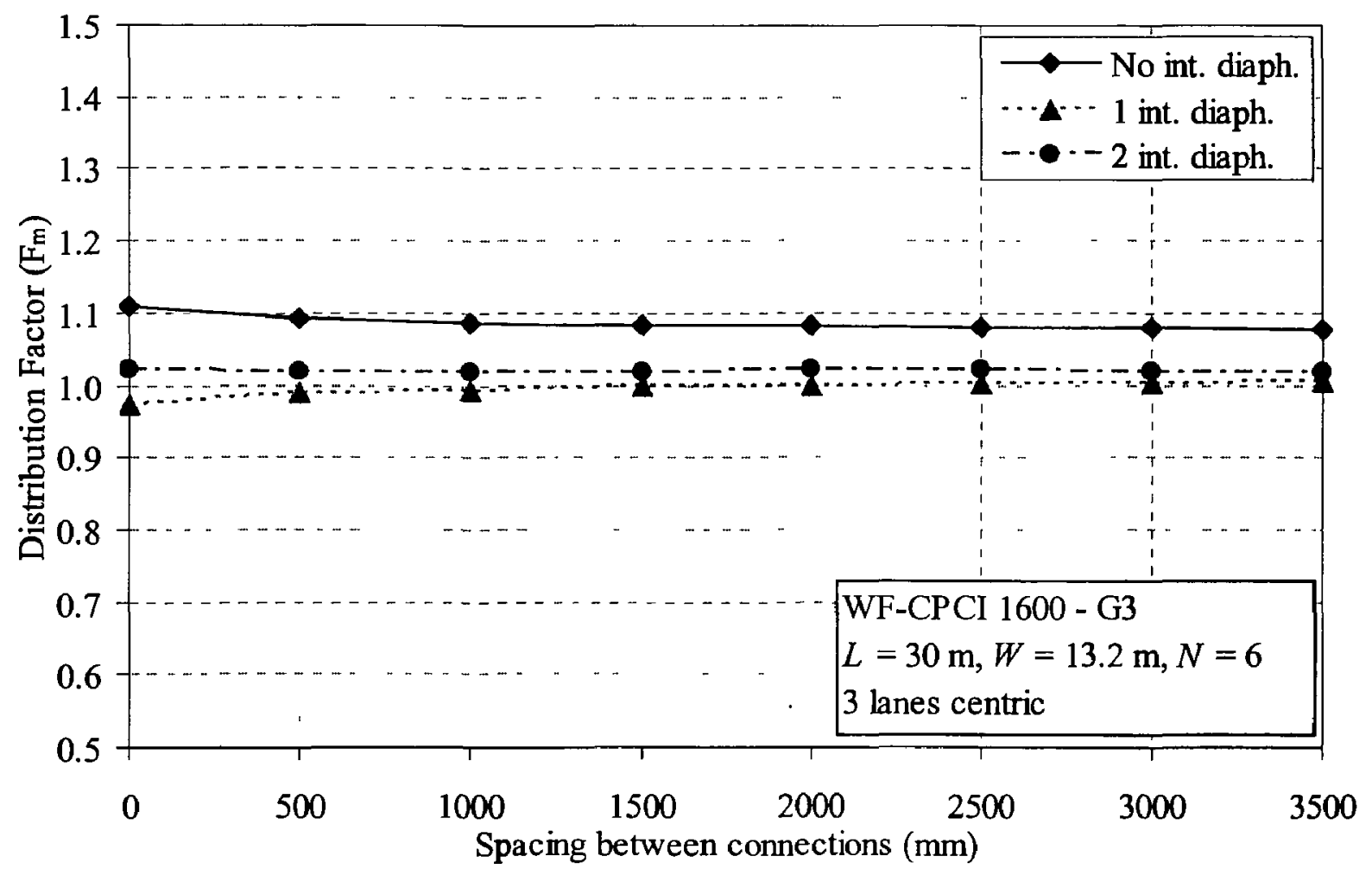

Figure 4.12 Distribution factor for bending moment in G3 for various spacing between connections 


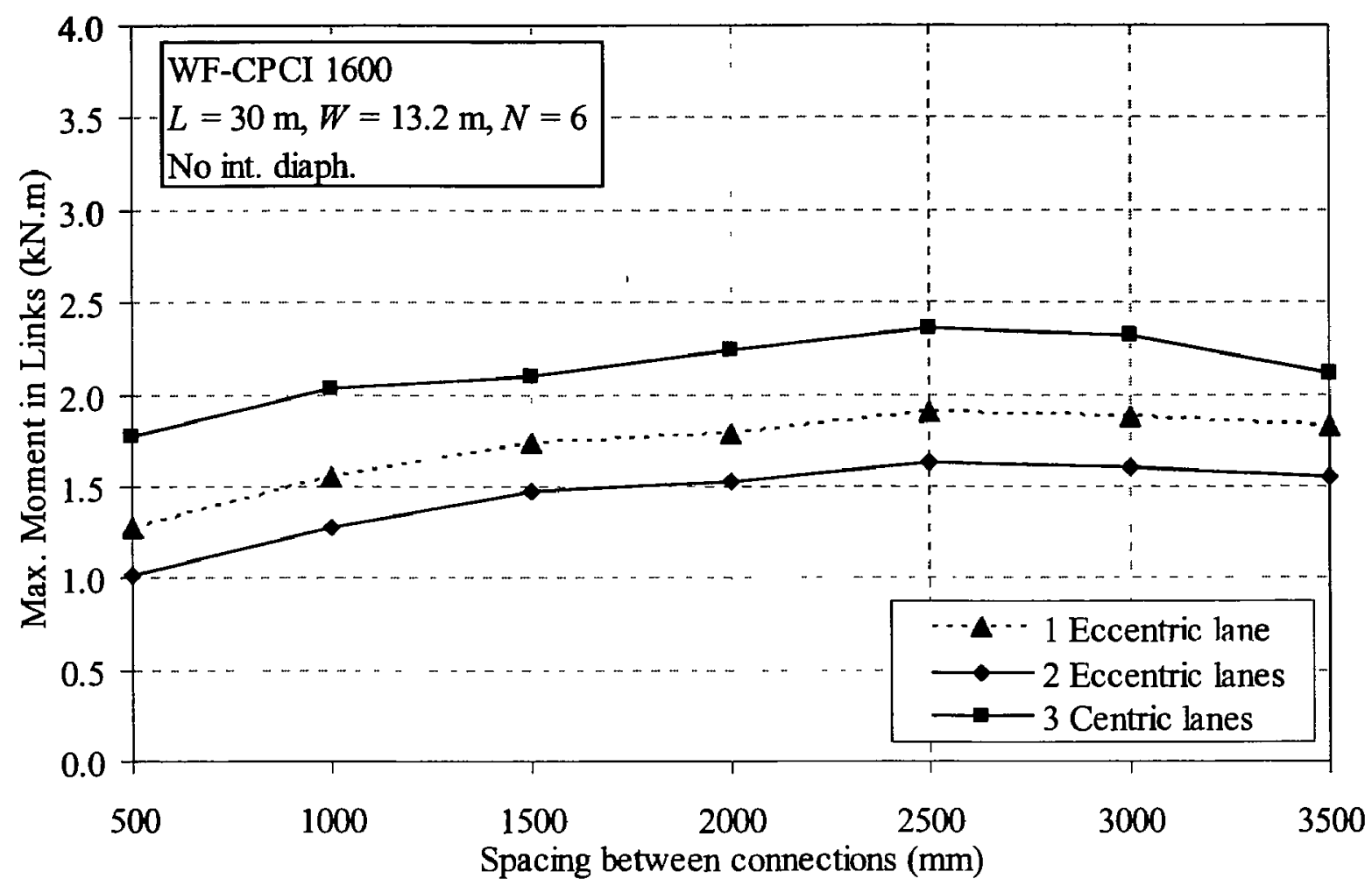

Figure 4.13 Maximum bending moment in connections for various spacing between connections

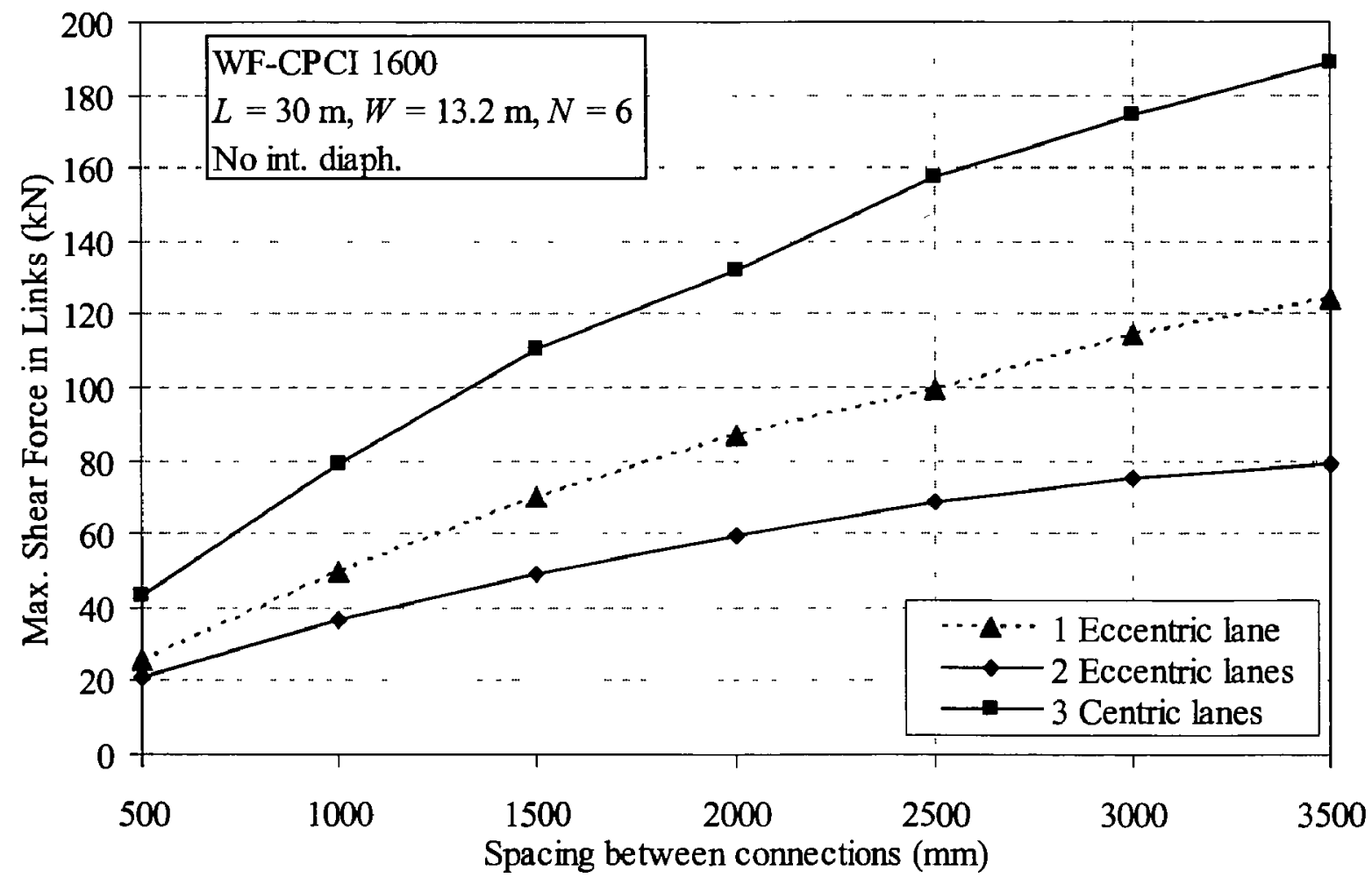

Figure 4.14 Maximum shear force in connections for various spacing between connections 


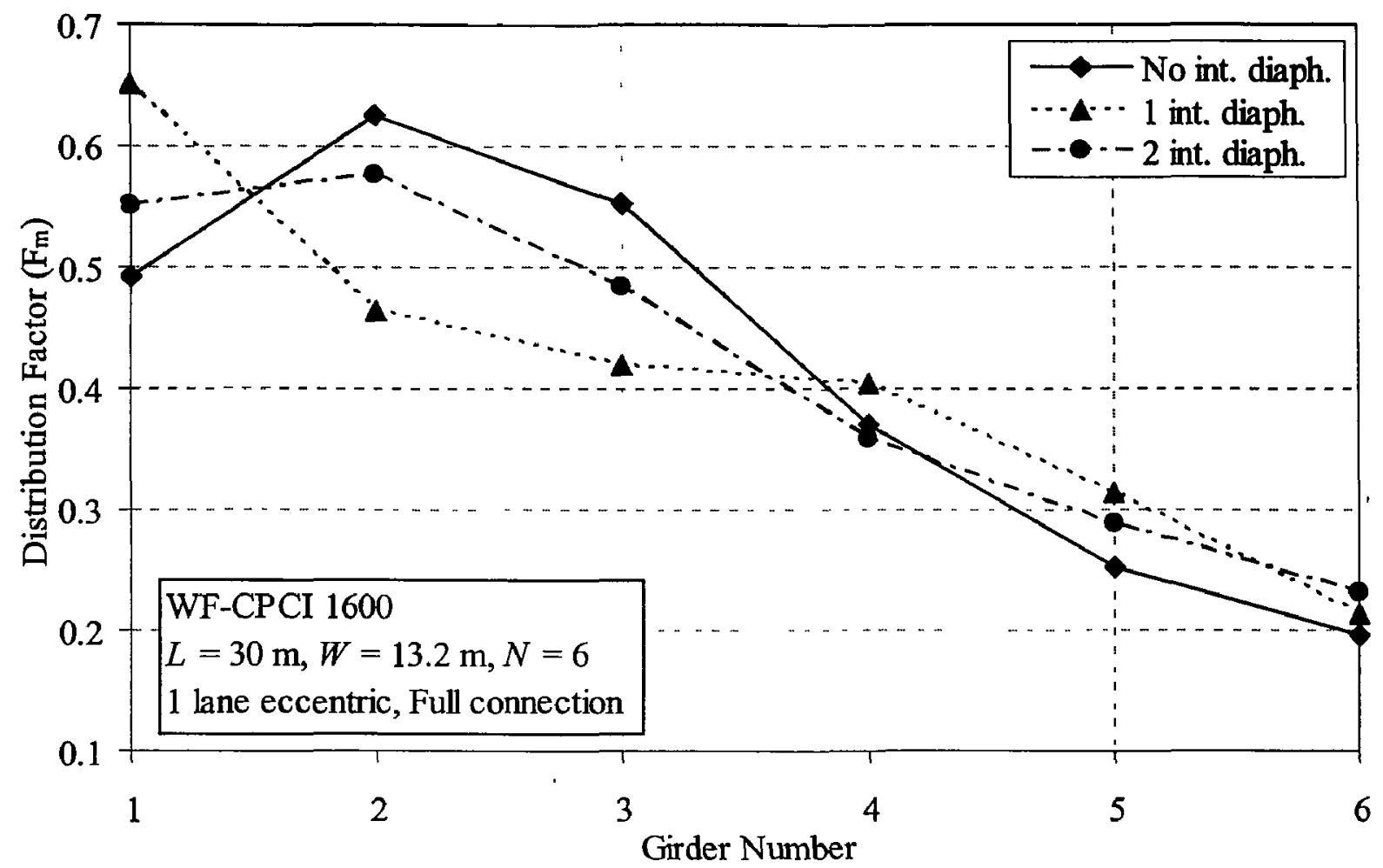

Figure 4.15 Effect of the presence of intermediate diaphragms on distribution factors for bending moment for one lane eccentrically loaded

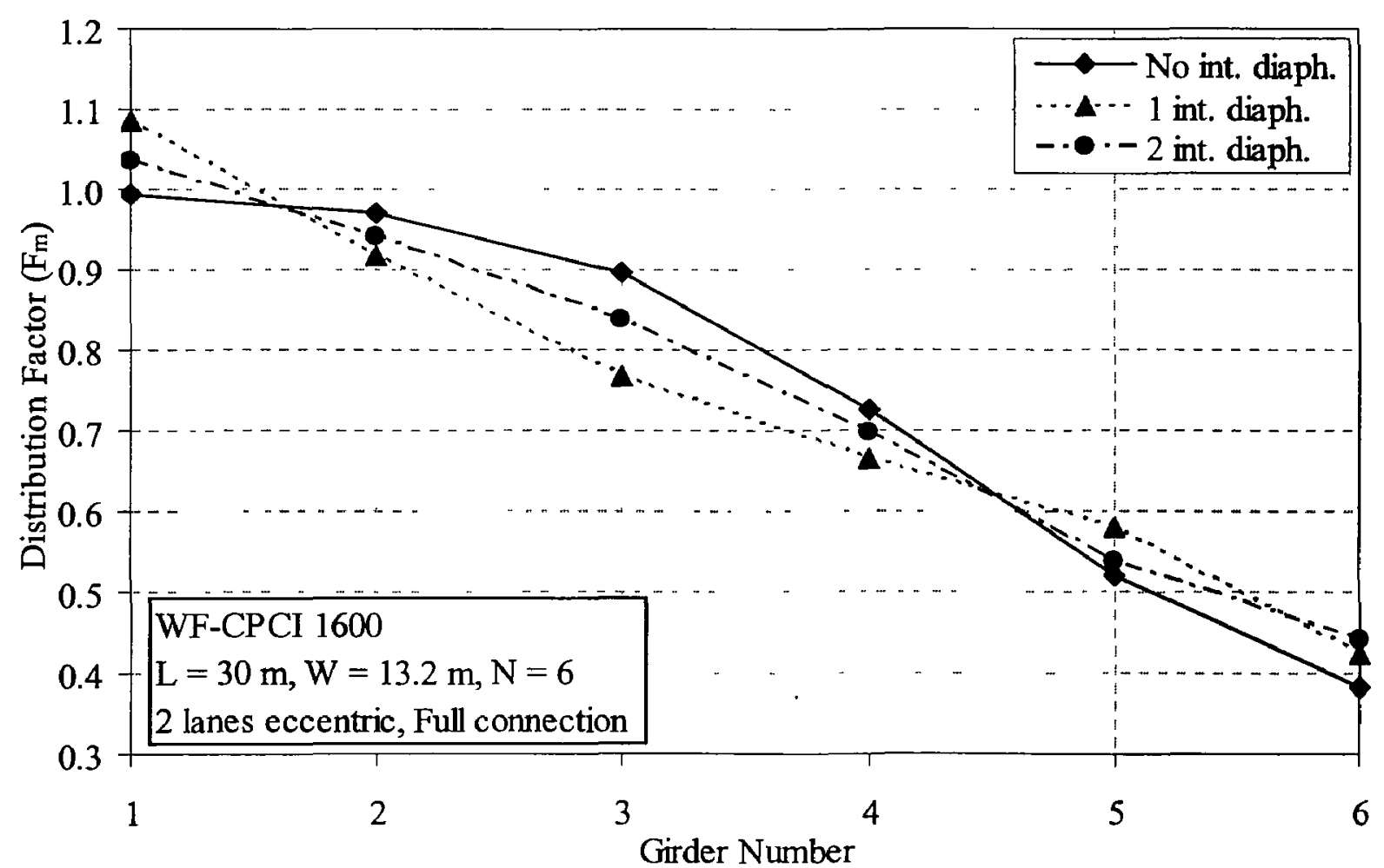

Figure 4.16 Effect of the presence of intermediate diaphragms on distribution factors for bending moment for two-lane eccentrically loaded 


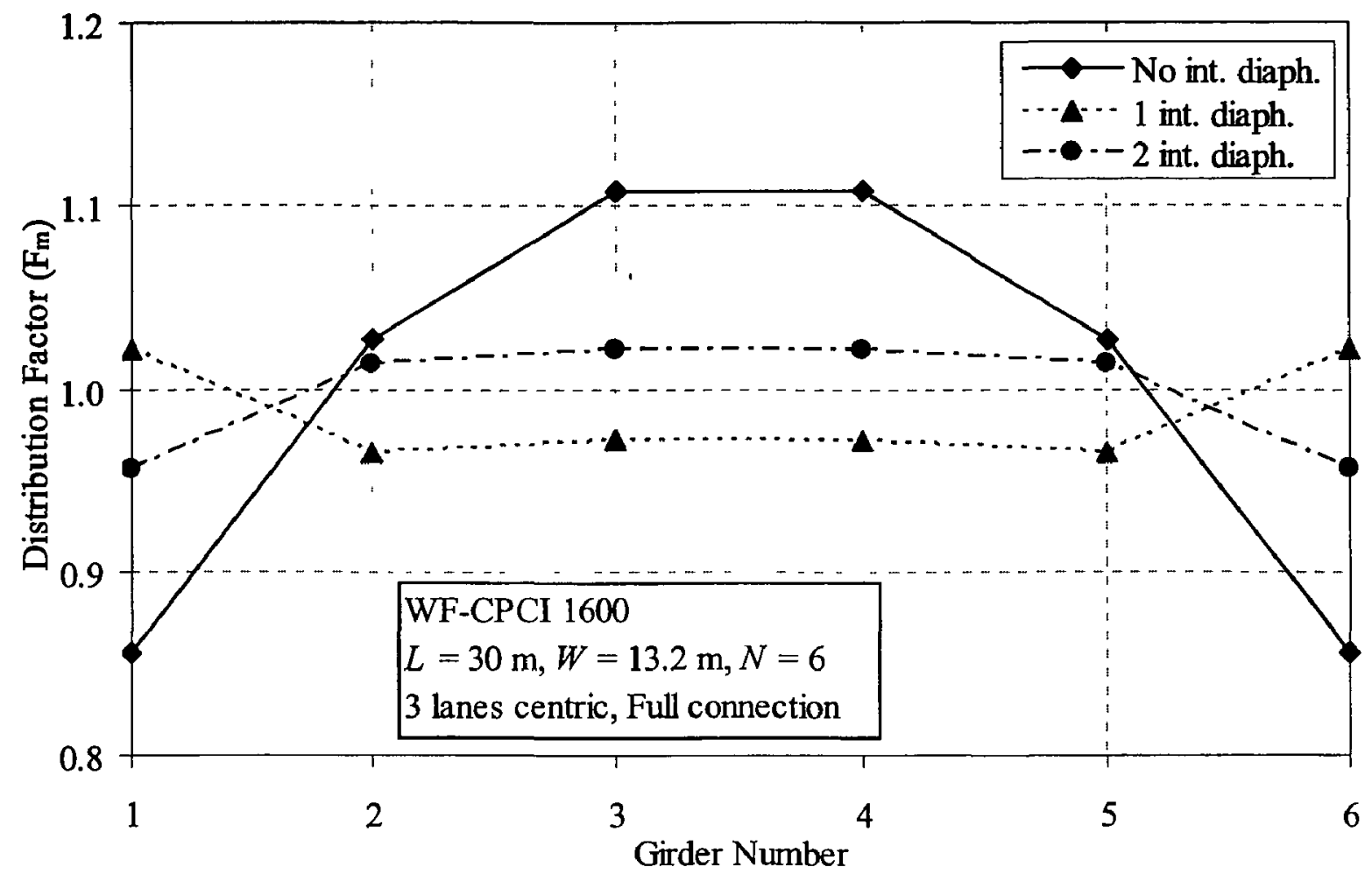

Figure 4.17 Effect of the presence of intermediate diaphragms on distribution factors for bending moment for three lanes centrically loaded

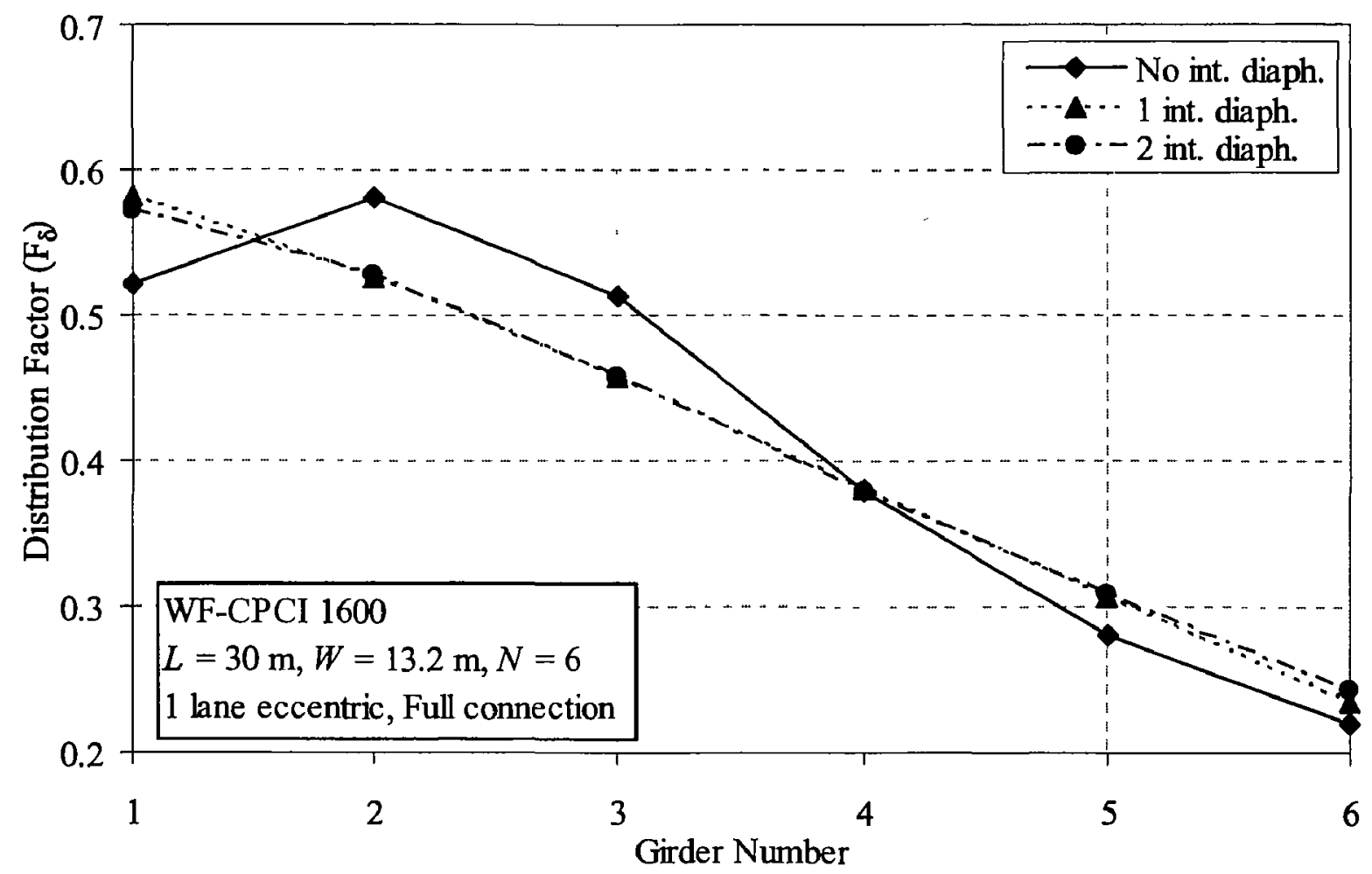

Figure 4.18 Effect of the presence of intermediate diaphragms on distribution factors for deflection for one lane eccentrically loaded 


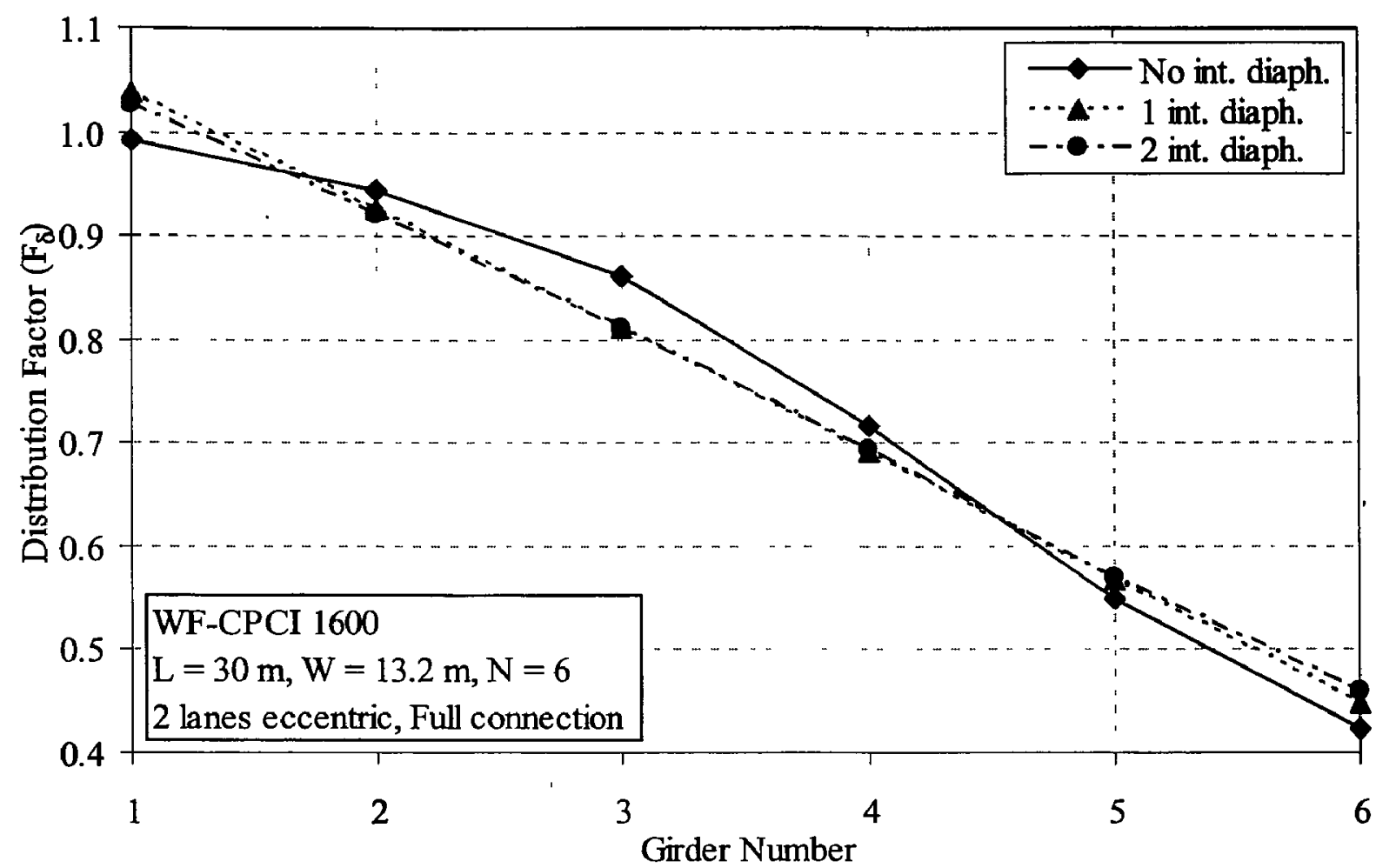

Figure 4.19 Effect of the presence of intermediate diaphragms on distribution factors for deflection for two lanes eccentrically loaded

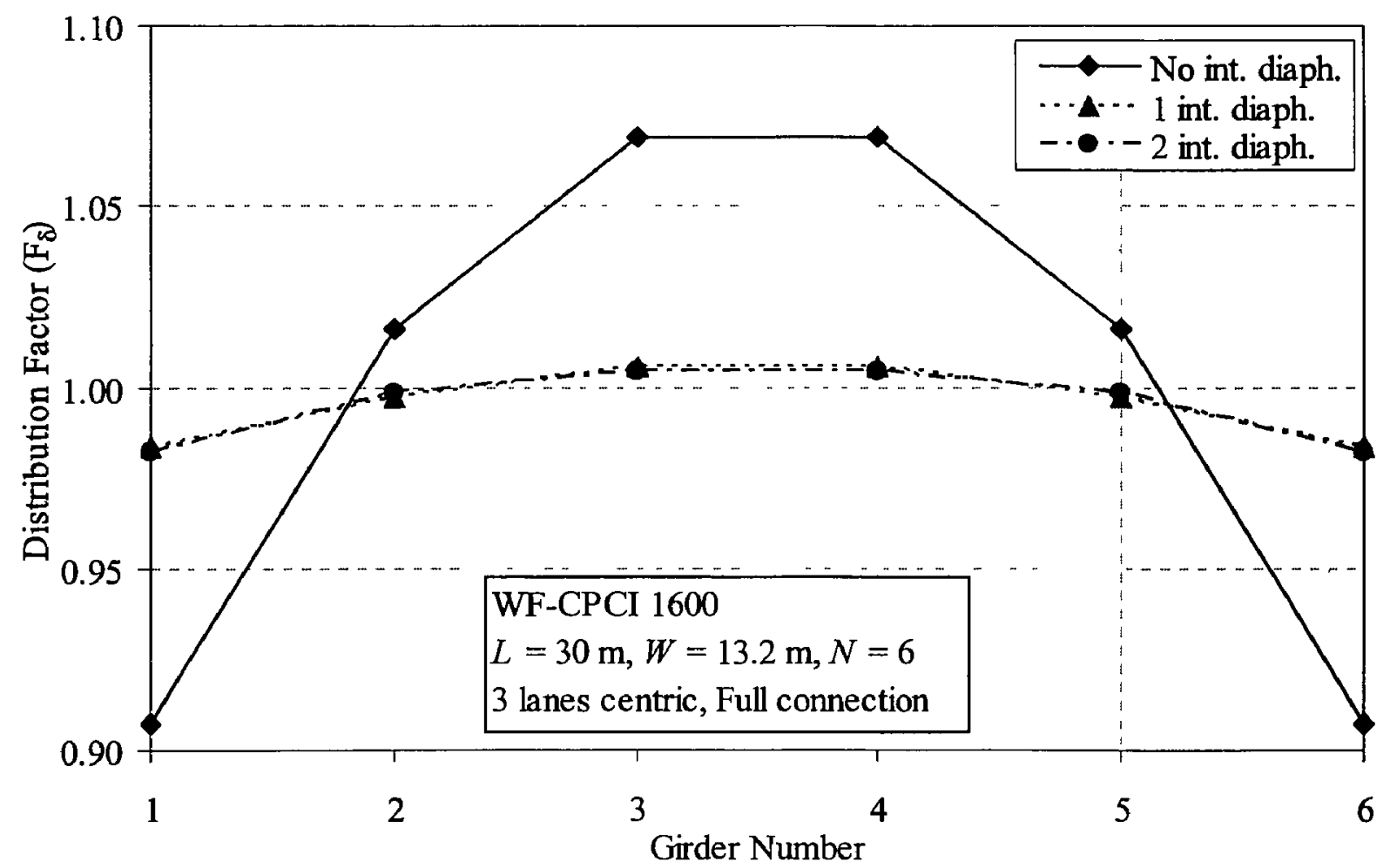

Figure 4.20 Effect of the presence of intermediate diaphragms on distribution factors for deflection for three lanes centrically loaded 


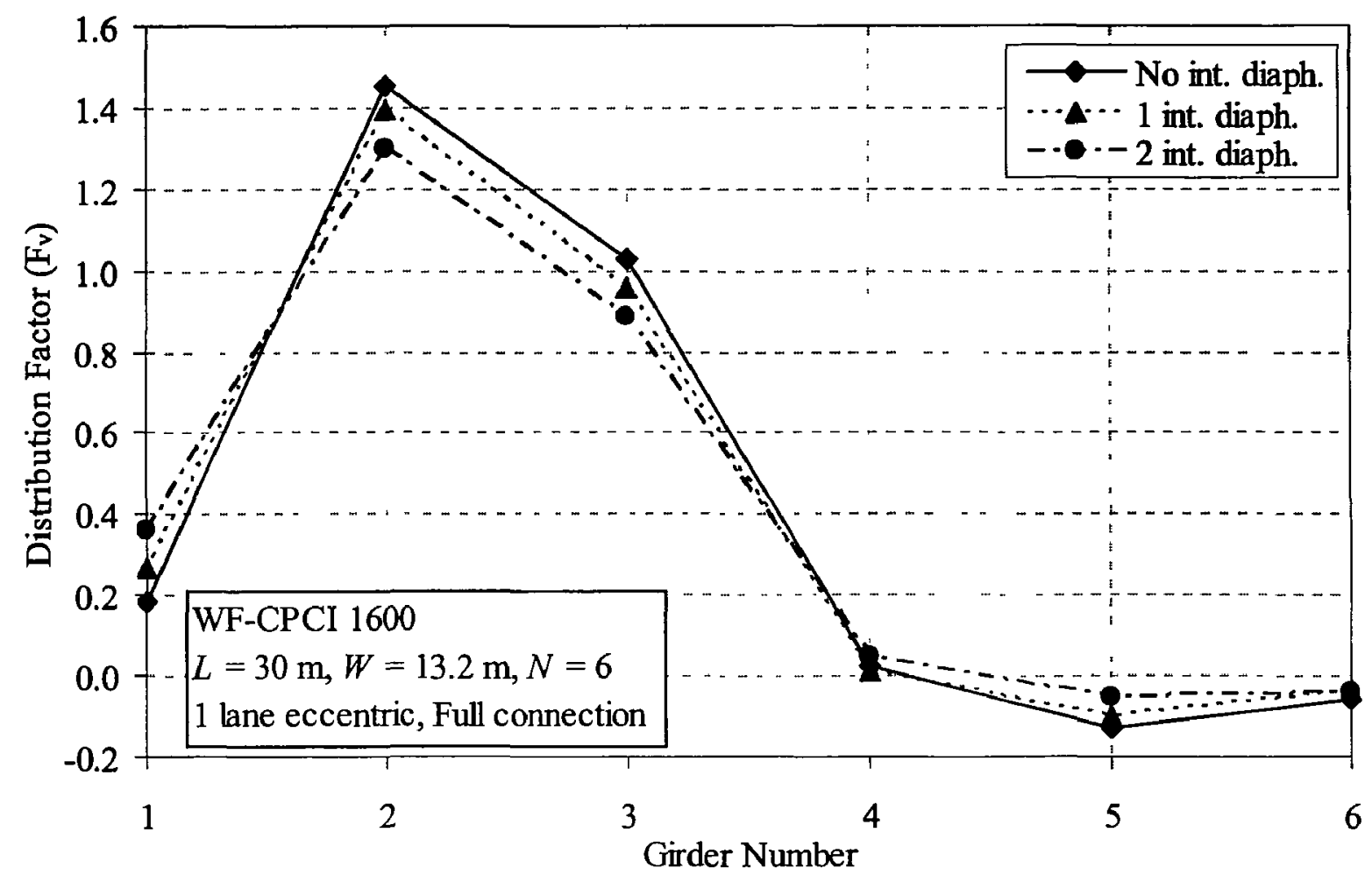

Figure 4.21 Effect of the presence of intermediate diaphragms on distribution factor for shear for one lane eccentrically loaded

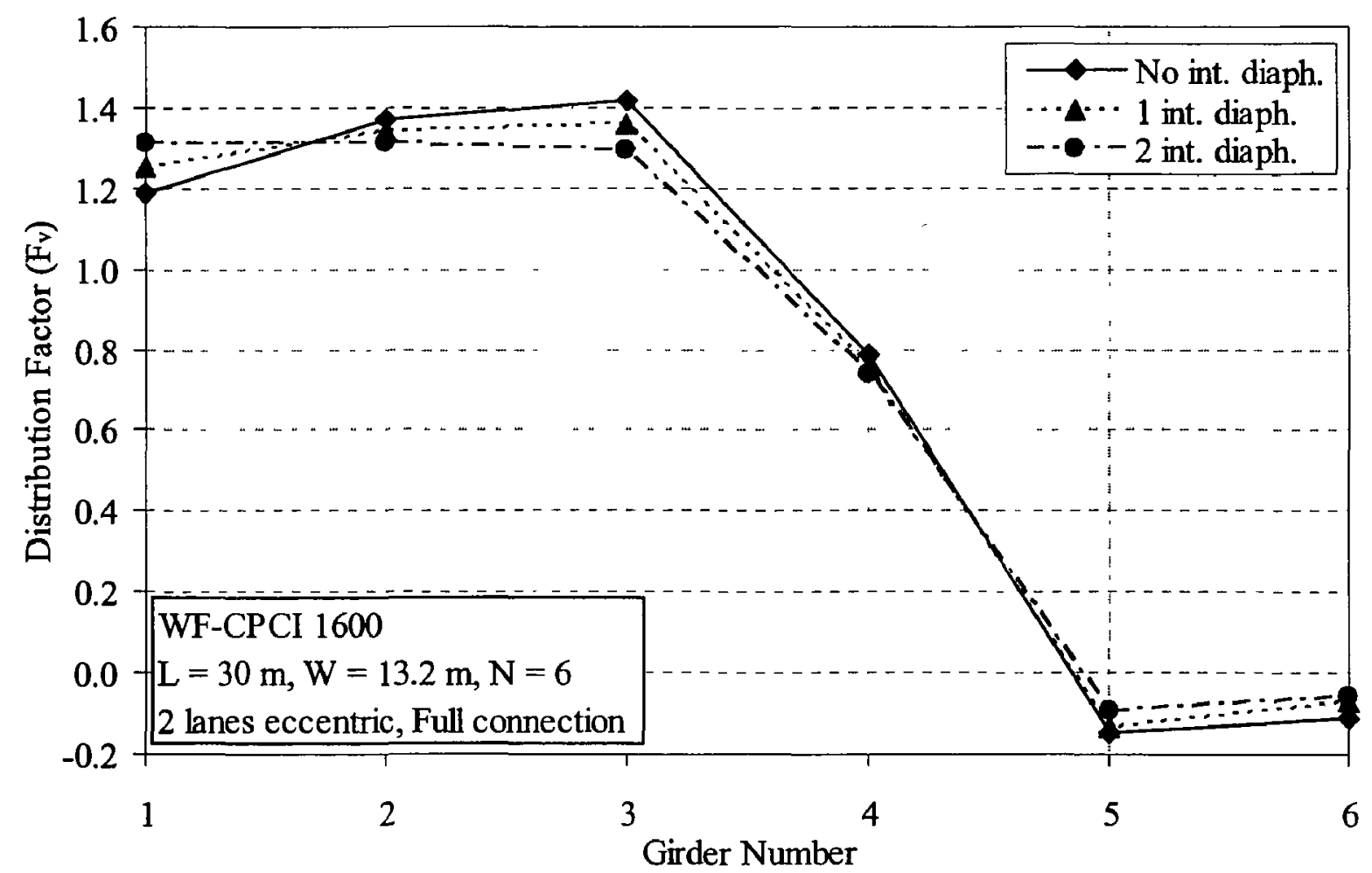

Figure 4.22 Effect of the presence of intermediate diaphragms on distribution factors for shear for two lanes eccentrically loaded 


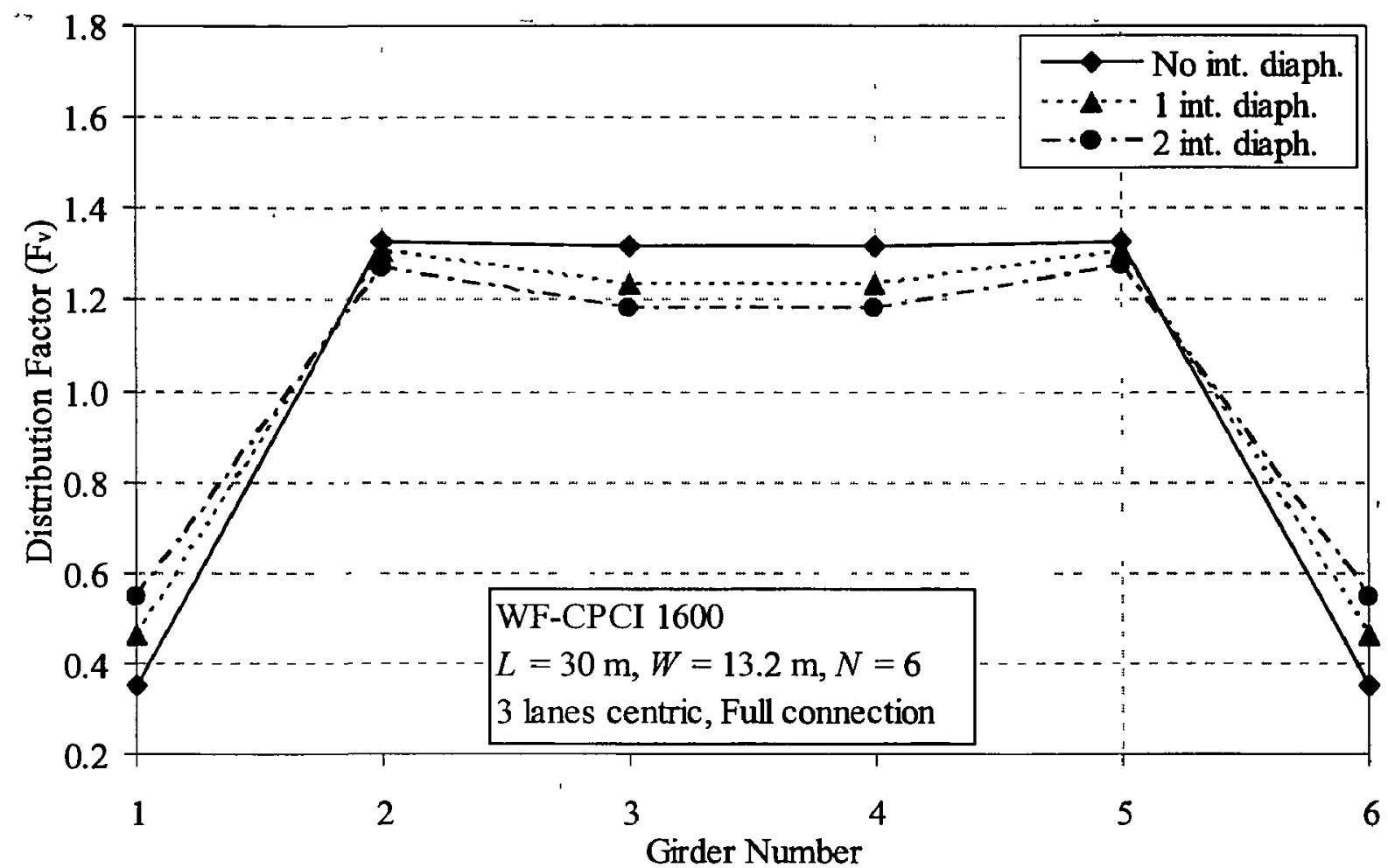

Figure 4.23 Effect of the presence of intermediate diaphragms on distribution factors for shear for three lanes centrically loaded 


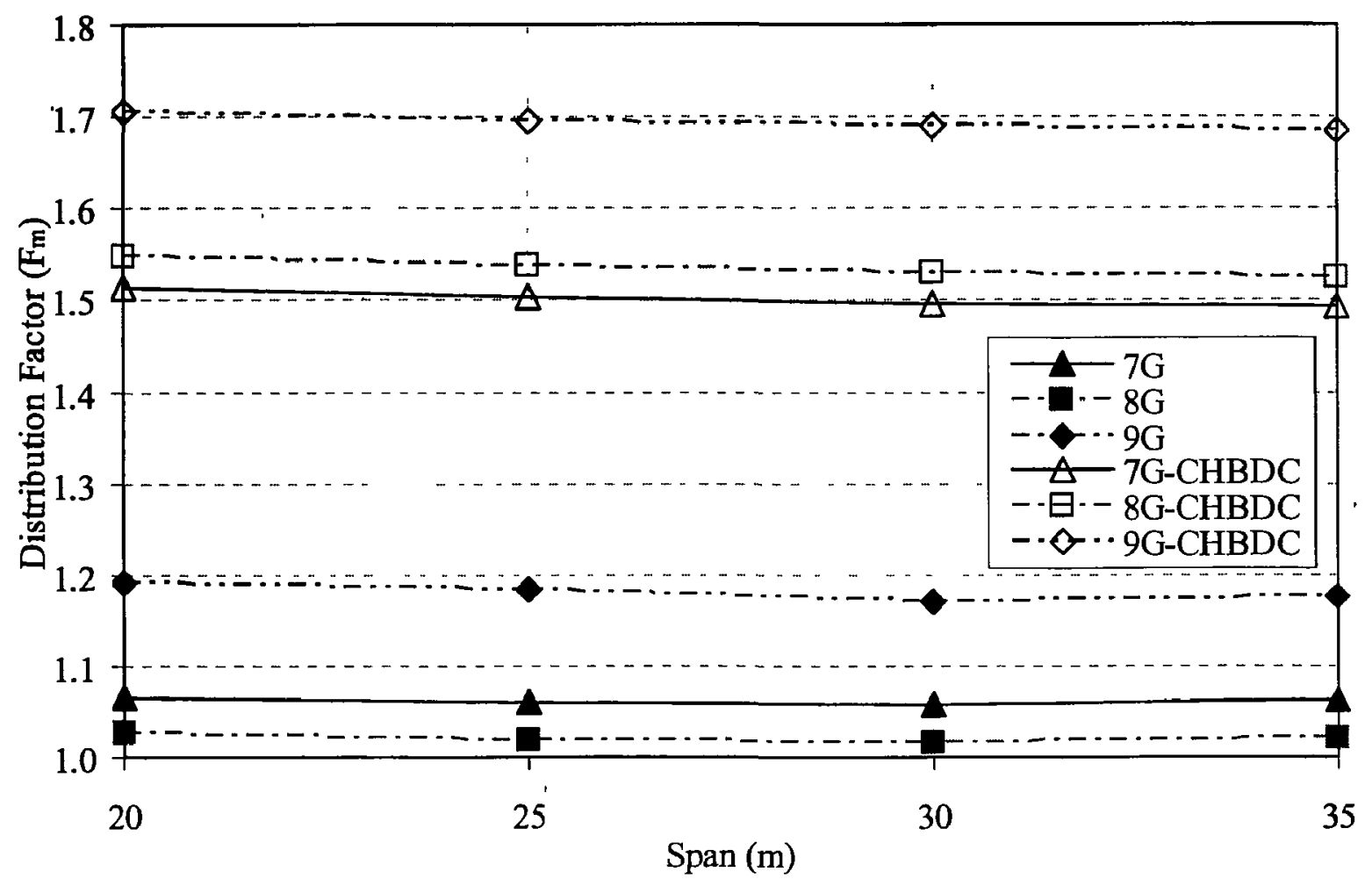

Figure 4.24 Effect of span length on moment distribution factor for exterior girder of bridges with $2000 \mathrm{~mm}$ girder spacing

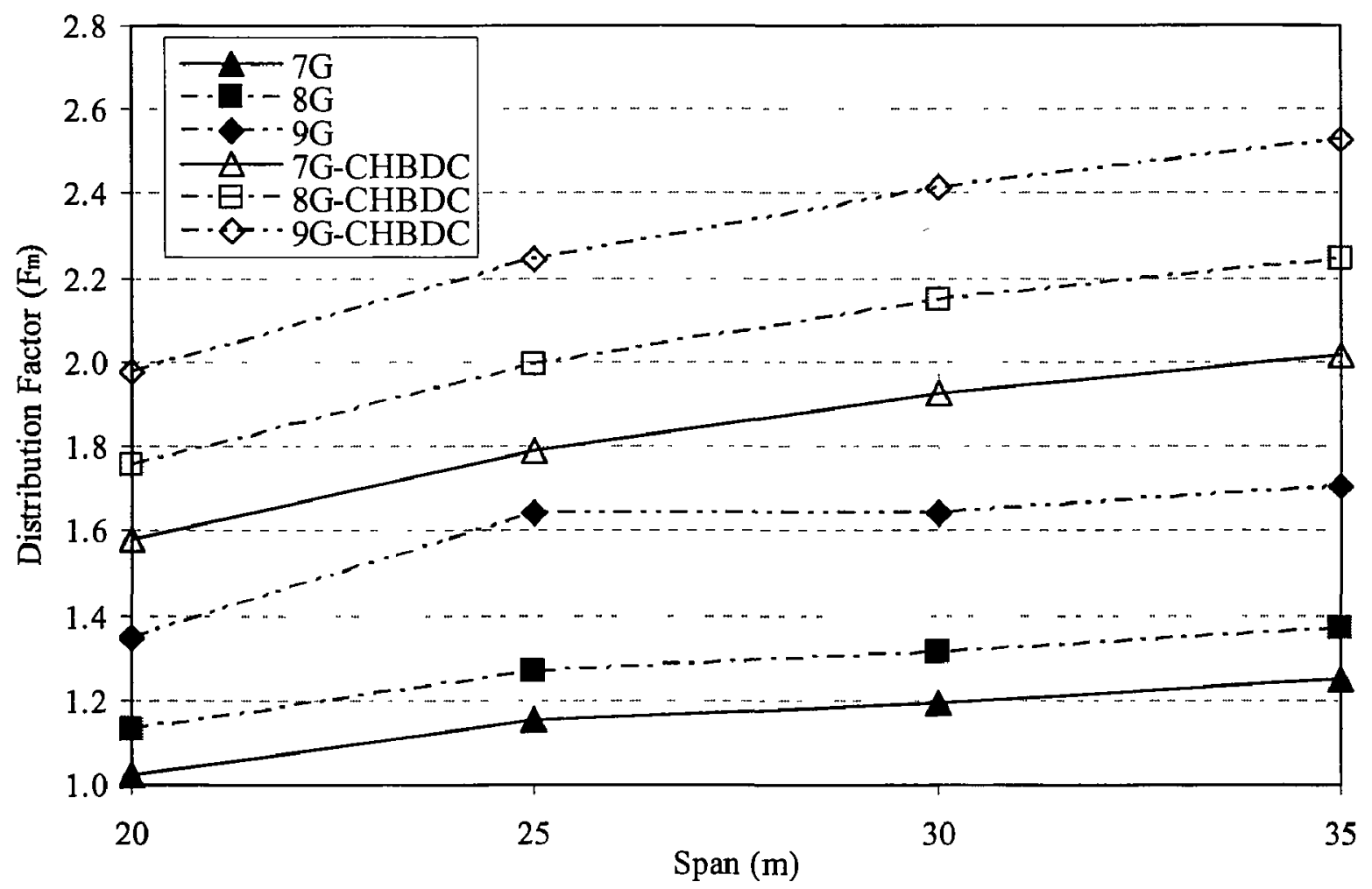

Figure 4.25 Effect of span length on fatigue moment distribution factor for exterior girder of bridges with $2000 \mathrm{~mm}$ girder spacing 


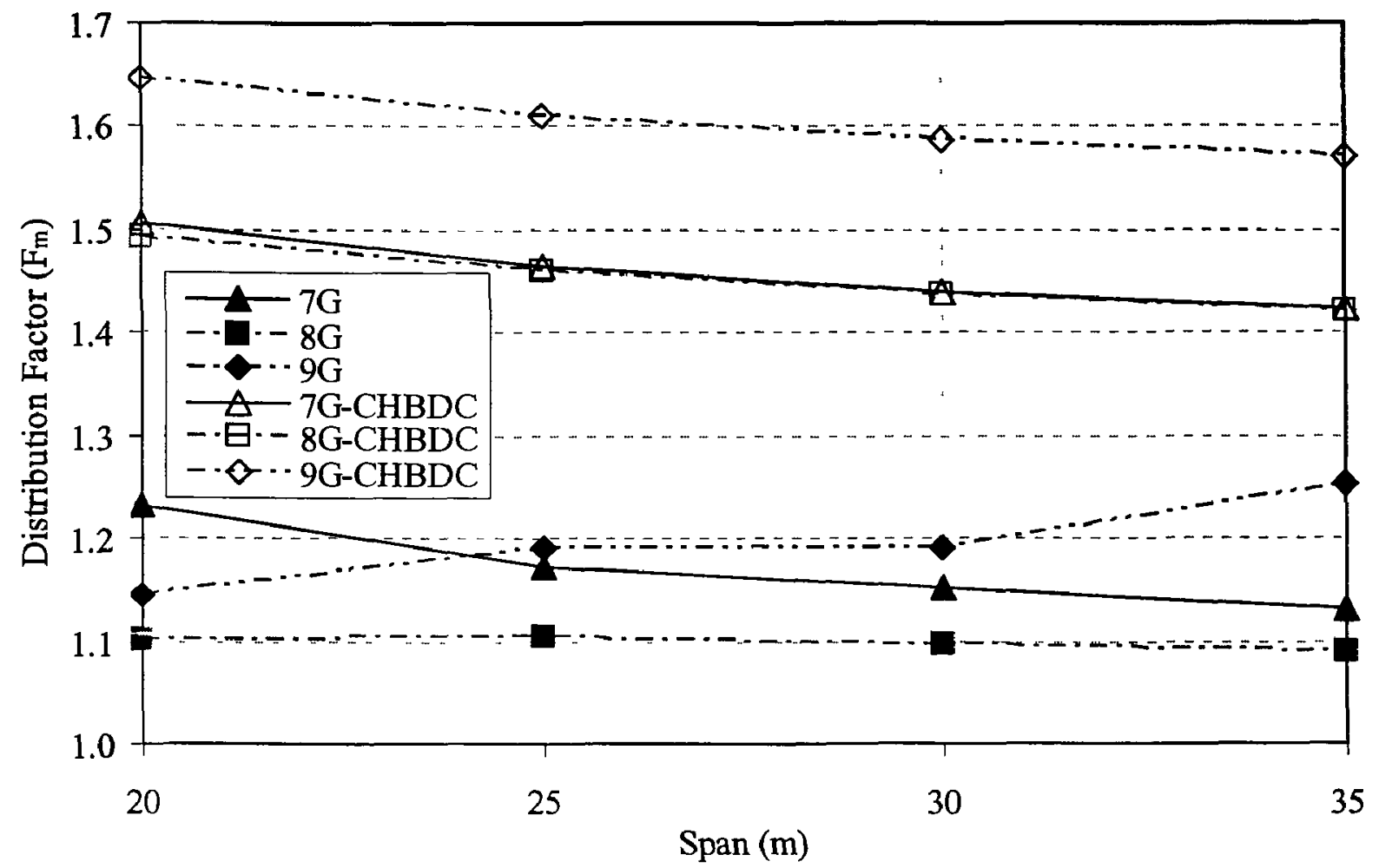

Figure 4.26 Effect of span length on moment distribution factor for interior girder of bridges with $2000 \mathrm{~mm}$ girder spacing

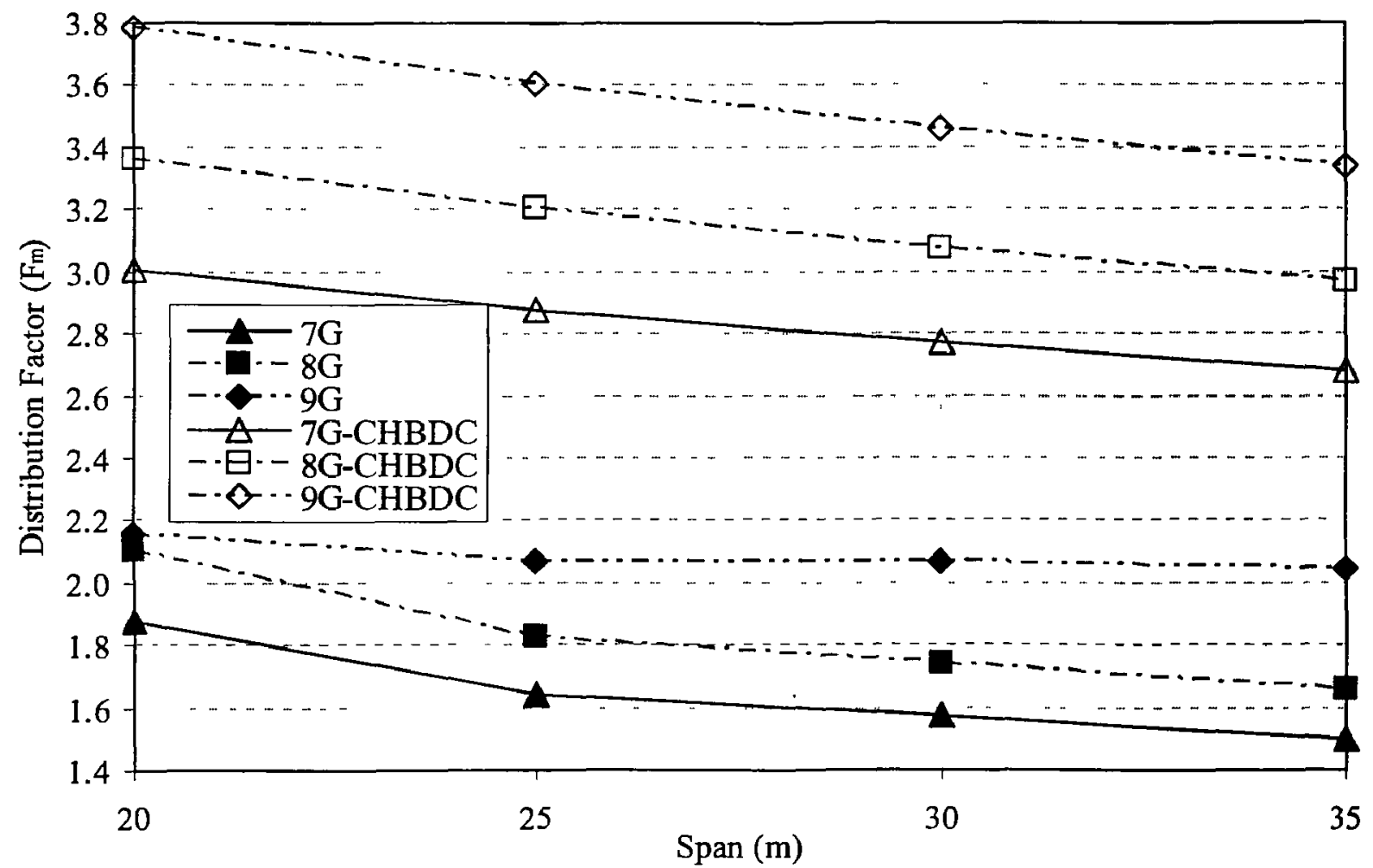

Figure 4.27 Effect of span length on fatigue moment distribution factor for interior girder of bridges with $2000 \mathrm{~mm}$ girder spacing 


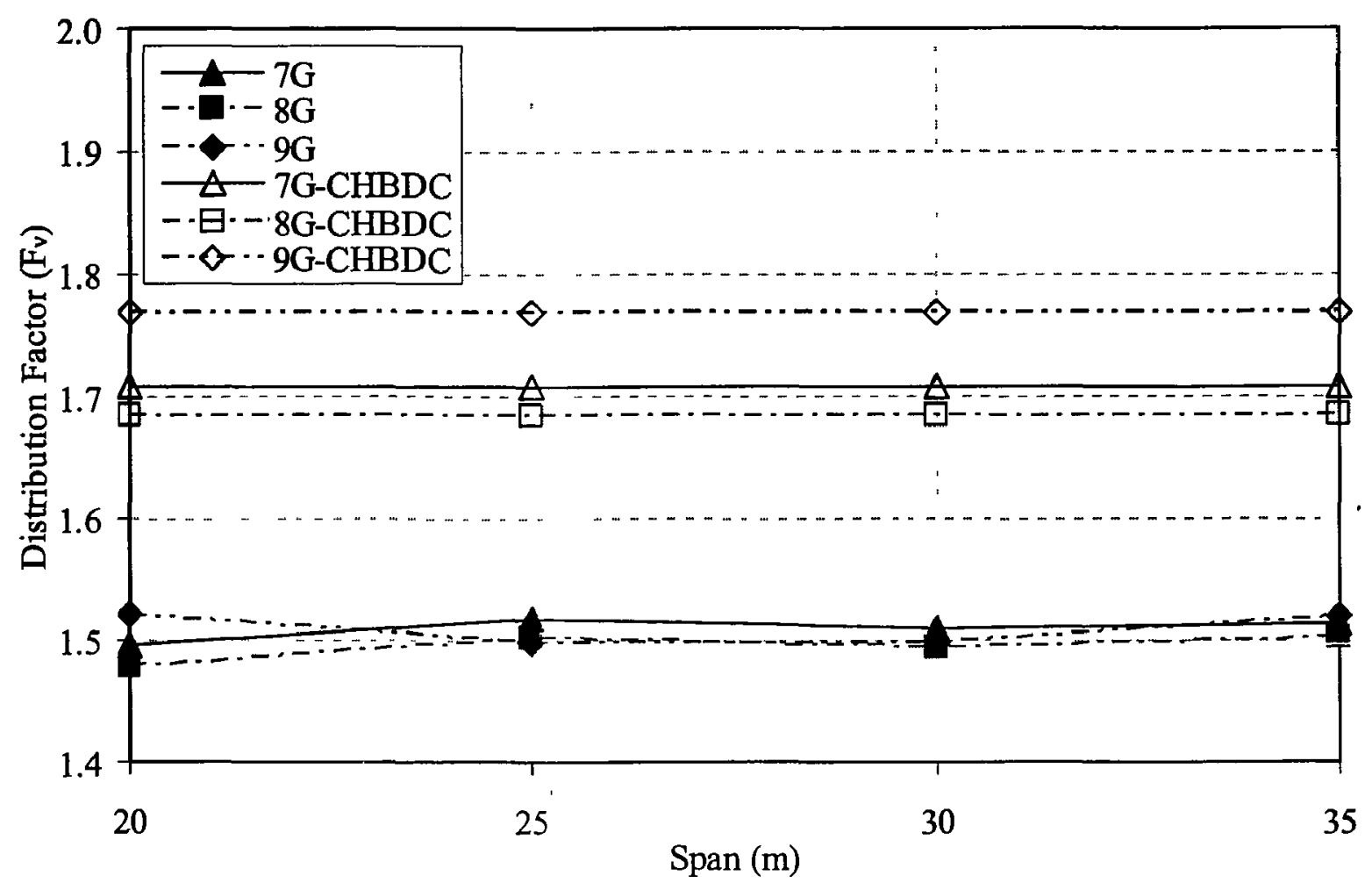

Figure 4.28 Effect of span length on shear distribution factor for exterior girder of bridges with $2000 \mathrm{~mm}$ girder spacing

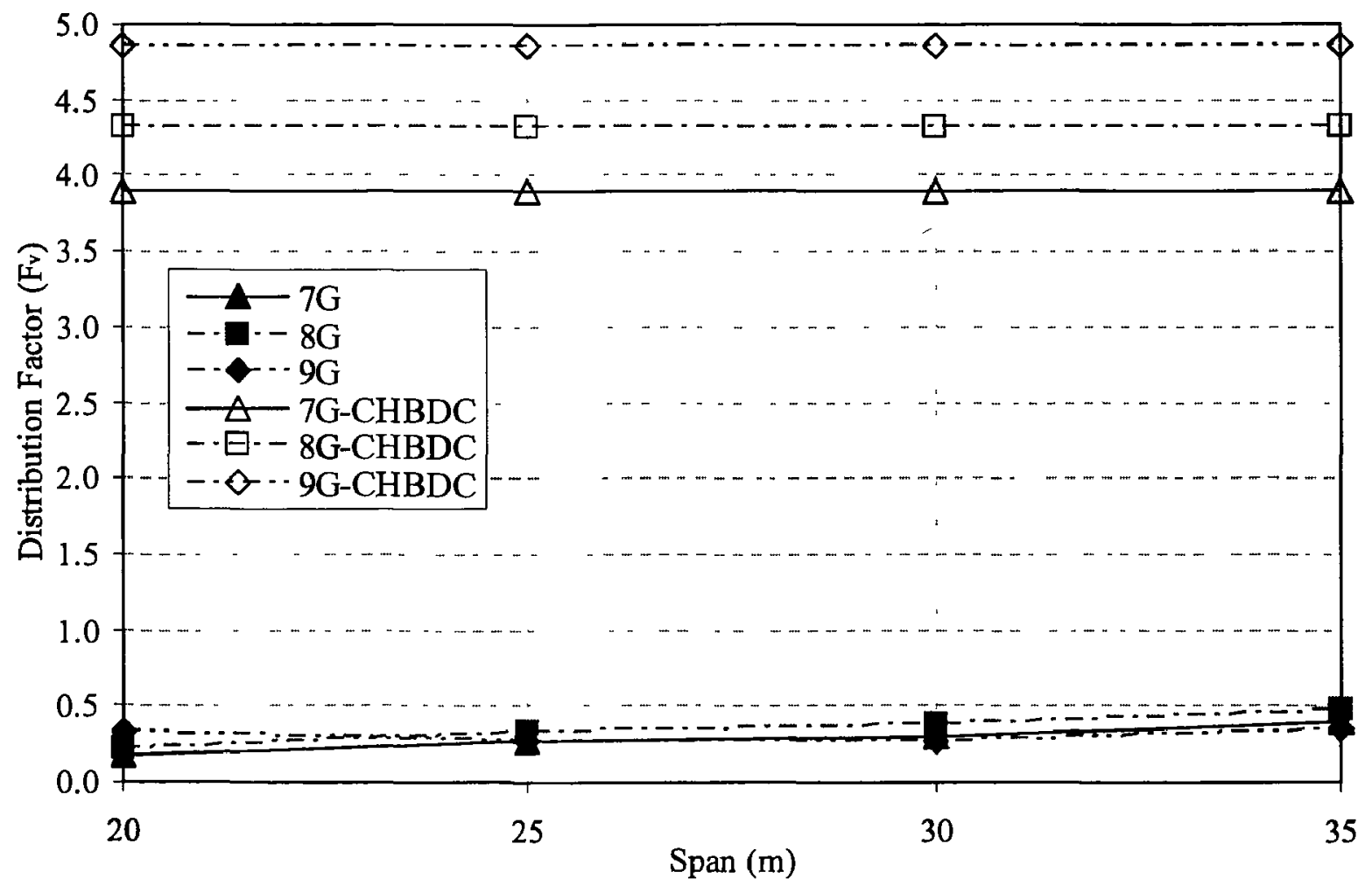

Figure 4.29 Effect of span length on fatigue shear distribution factor for exterior girder of bridges with $2000 \mathrm{~mm}$ girder spacing 


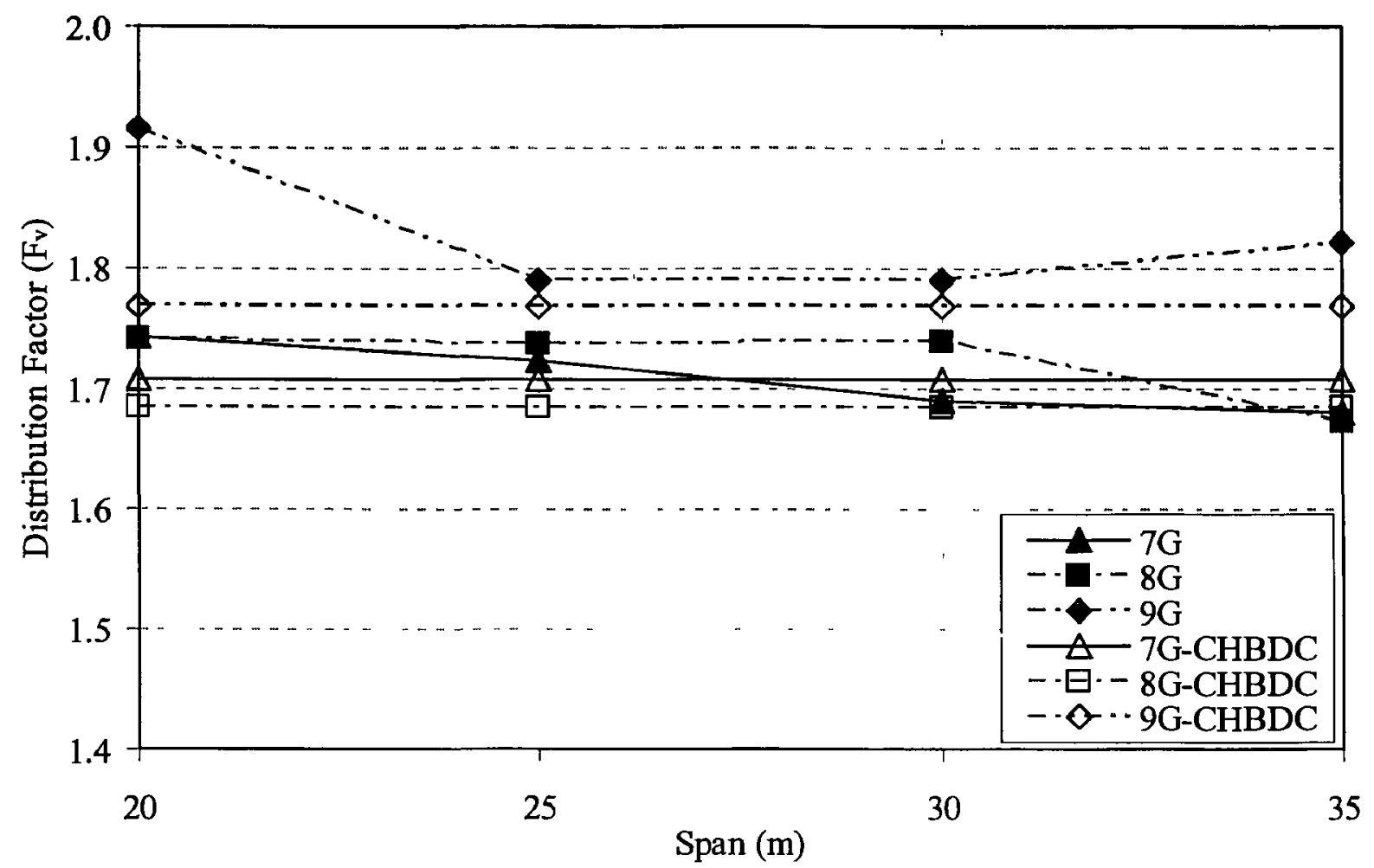

Figure 4.30 Effect of span length on shear distribution factor for interior girder of bridges with $2000 \mathrm{~mm}$ girder spacing

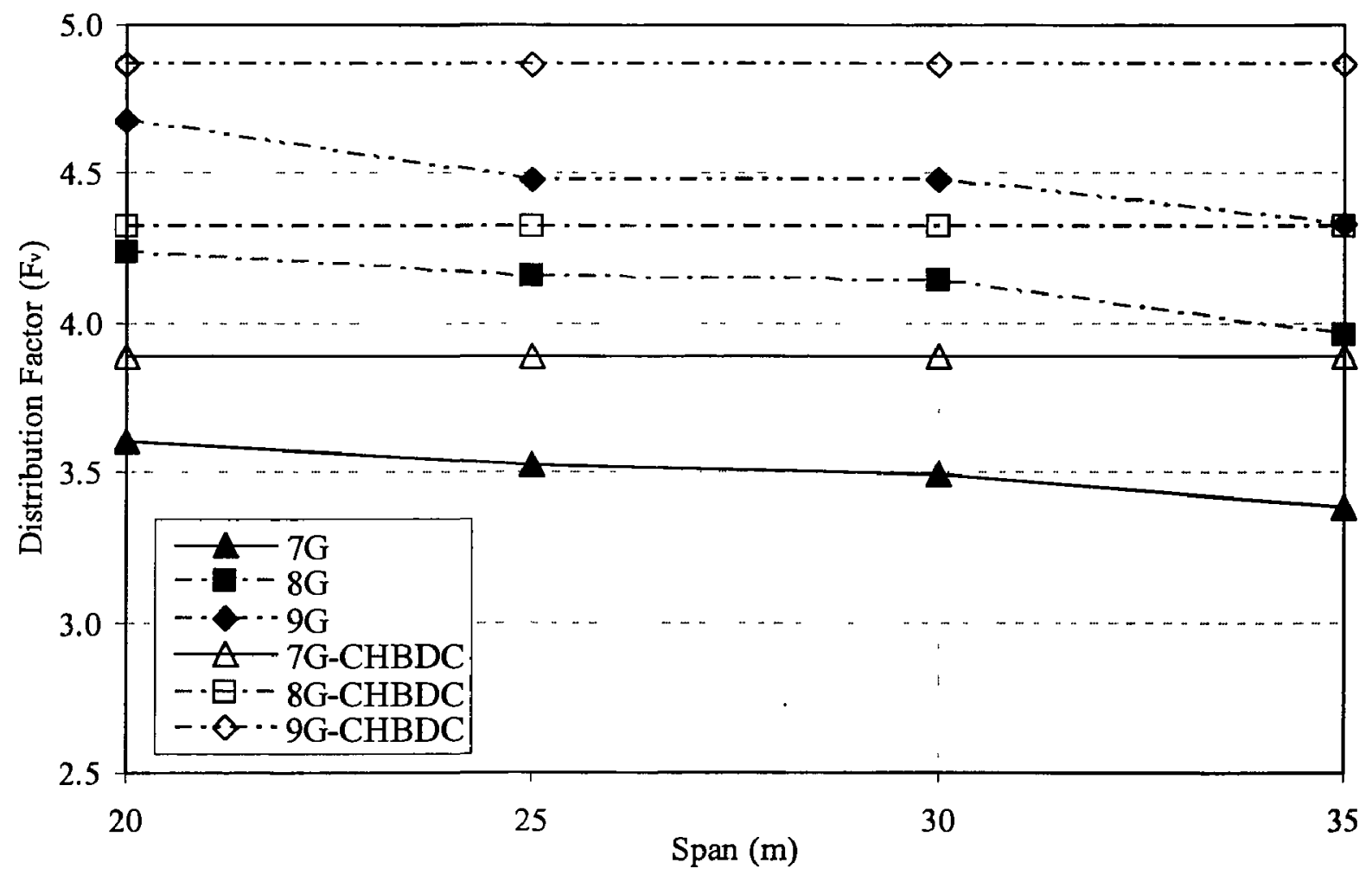

Figure 4.31 Effect of span length on fatigue shear distribution factor for interior girder of bridges with $2000 \mathrm{~mm}$ girder spacing 


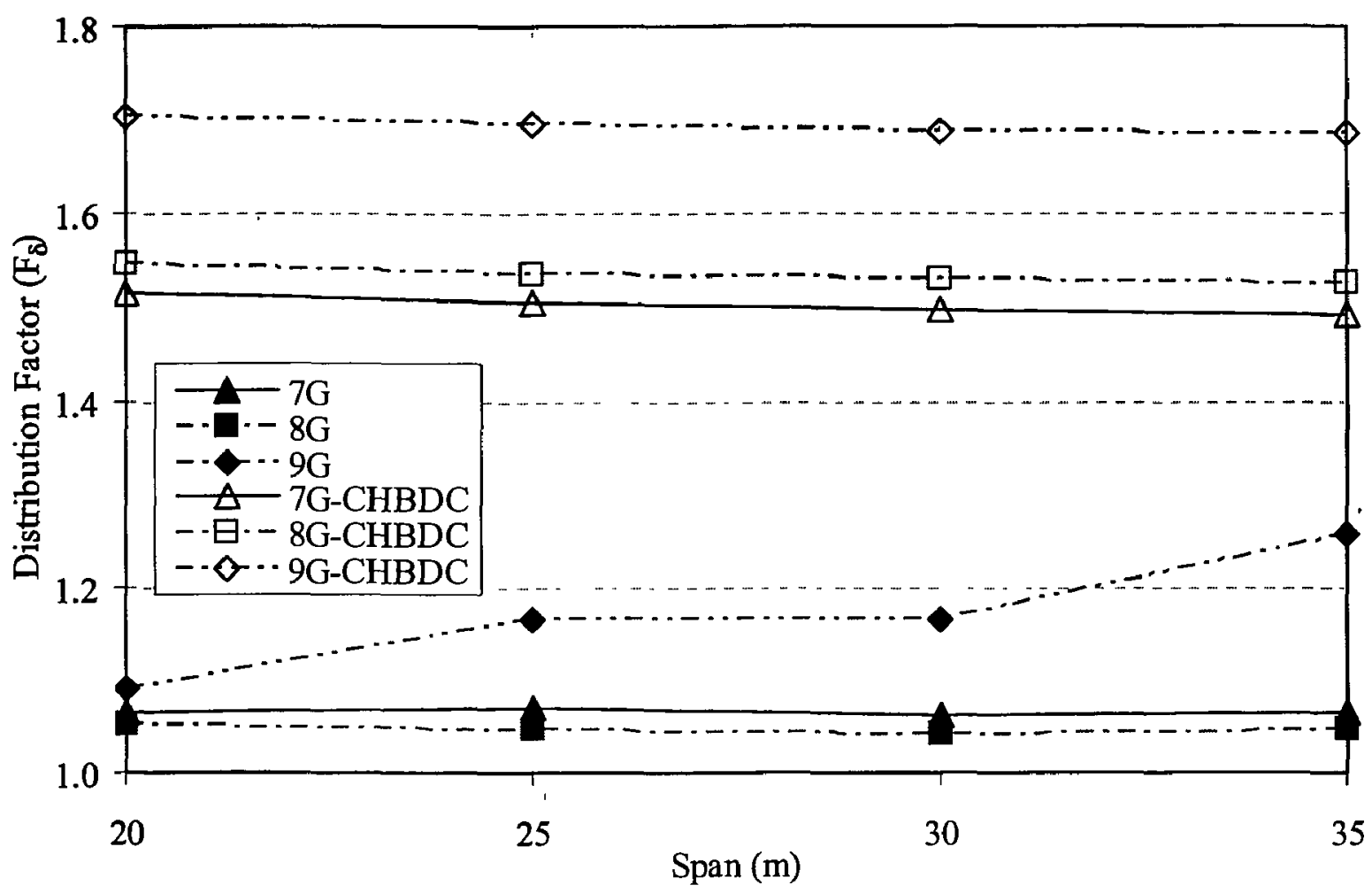

Figure 4.32 Effect of span length on deflection distribution factor for exterior girder of bridges with $2000 \mathrm{~mm}$ girder spacing

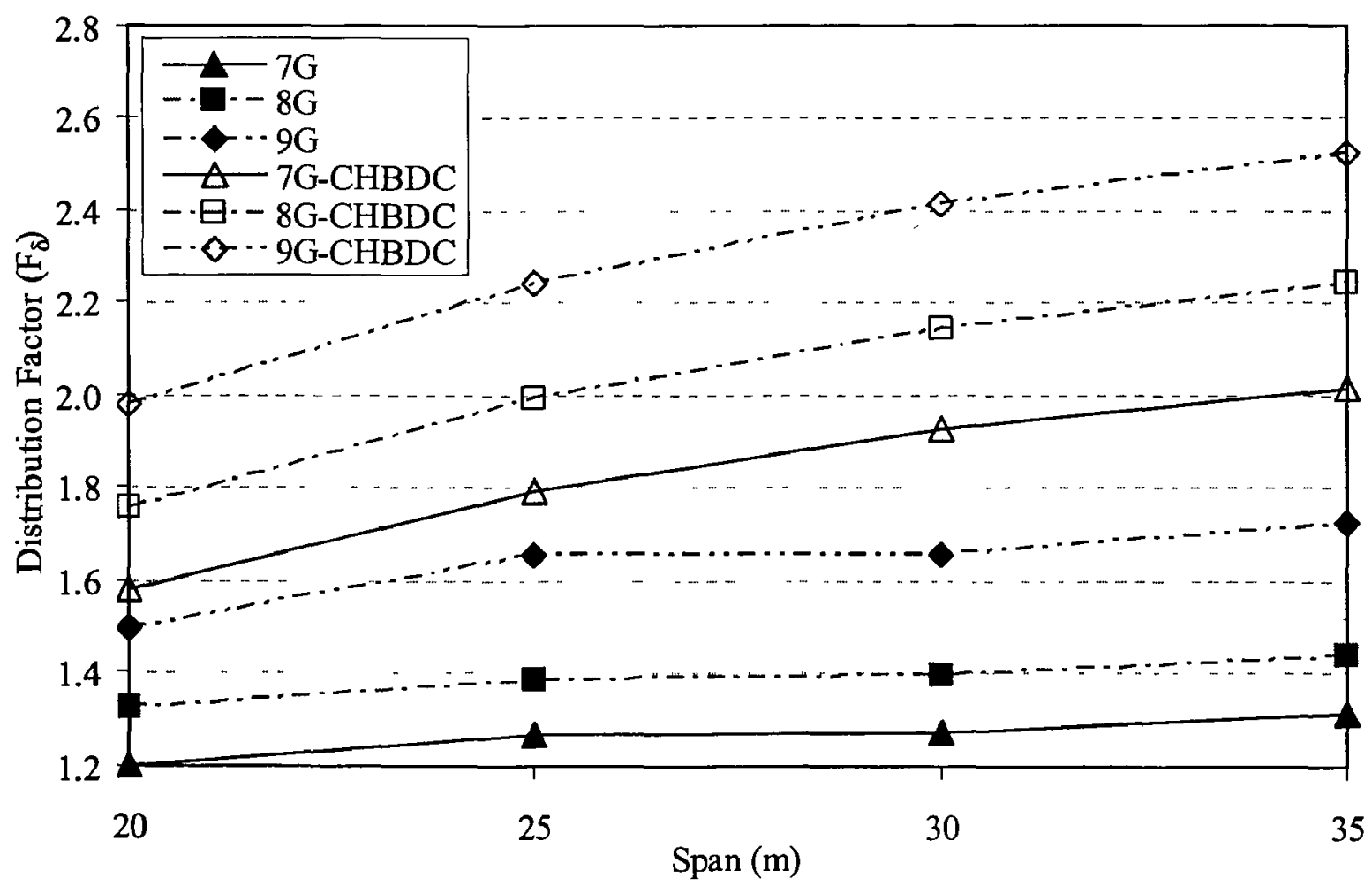

Figure 4.33 Effect of span length on fatigue deflection distribution factor for exterior girder of bridges with $2000 \mathrm{~mm}$ girder spacing 


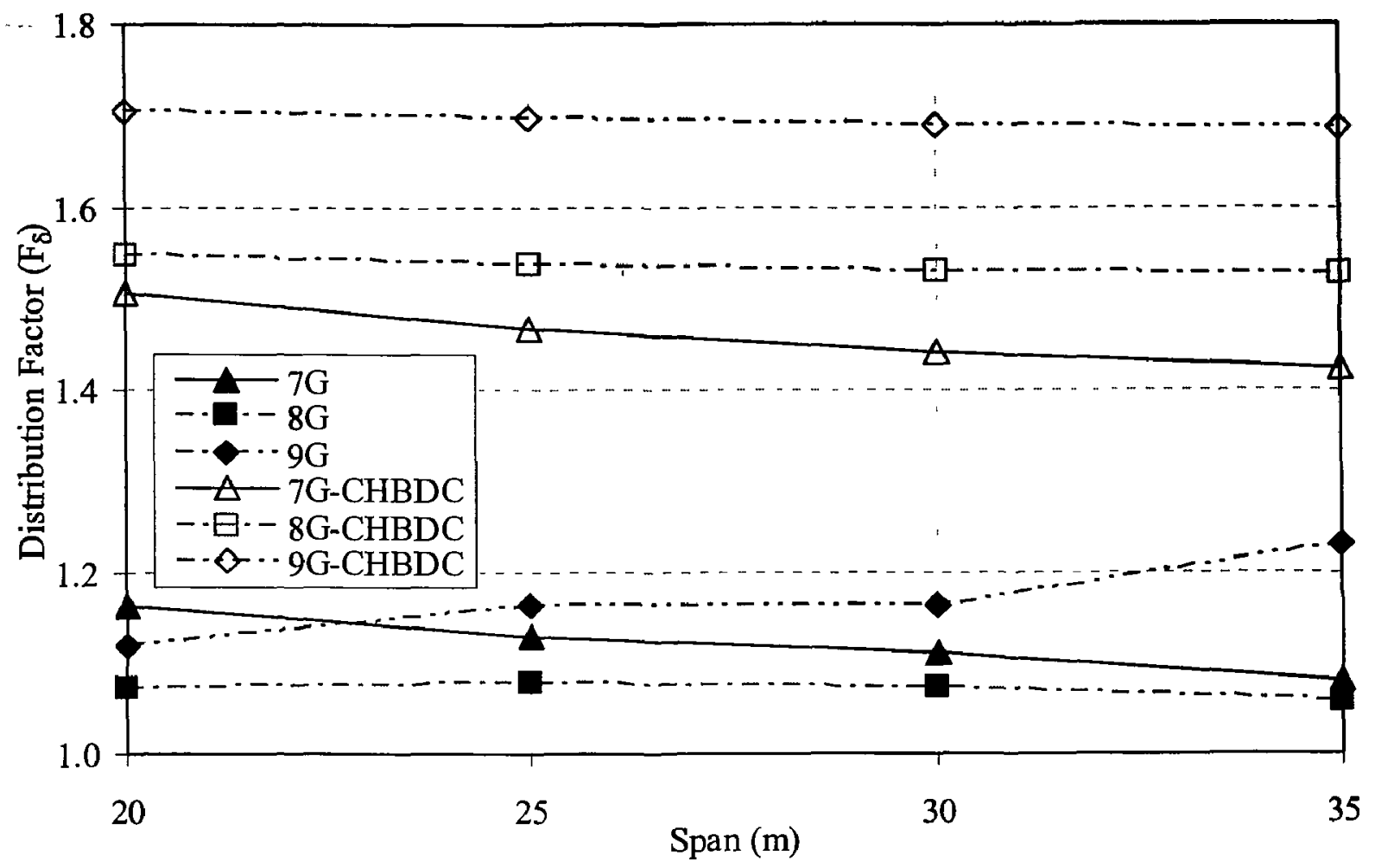

Figure 4.34 Effect of span length on deflection distribution factor for interior girder of bridges with $2000 \mathrm{~mm}$ girder spacing

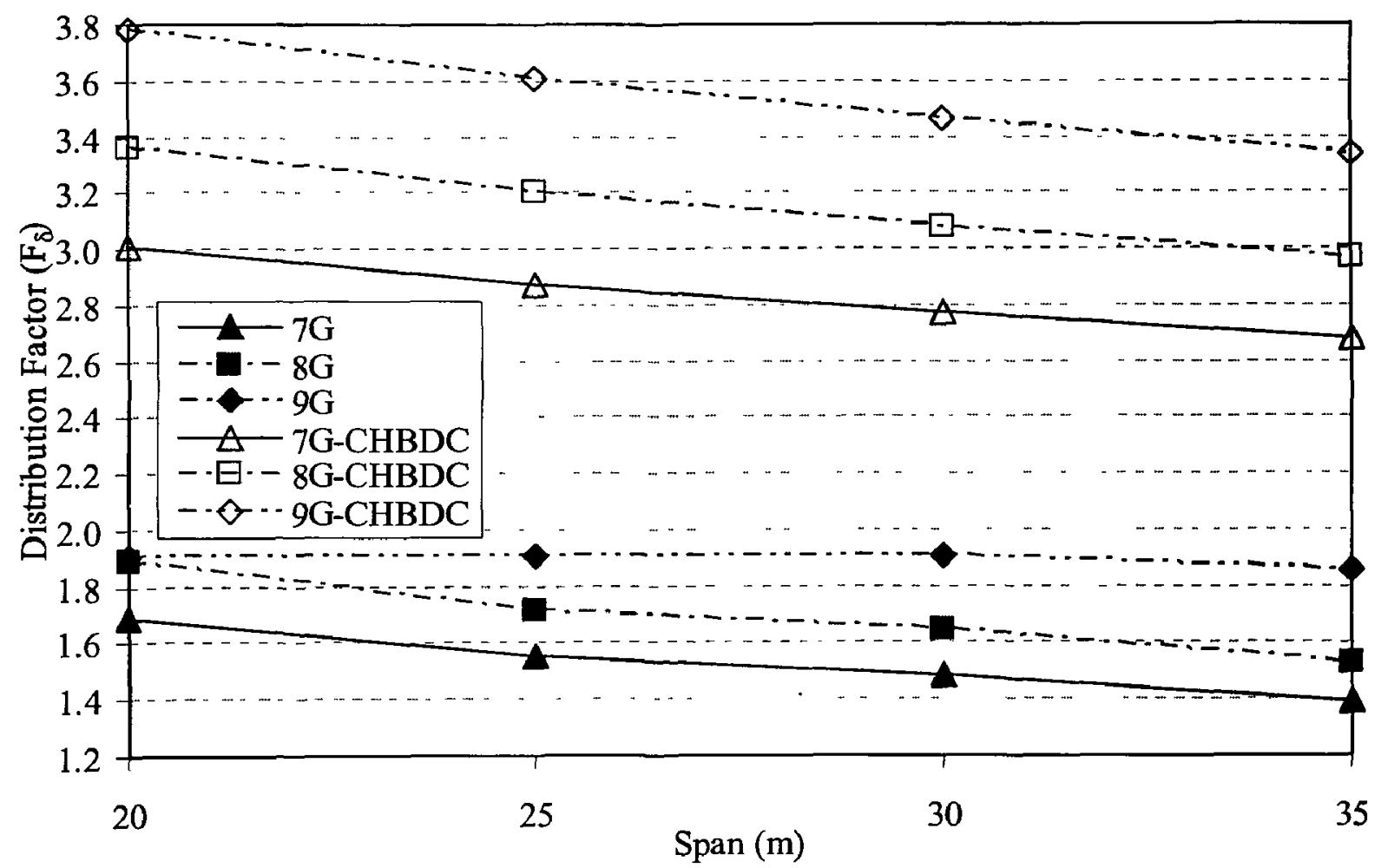

Figure 4.35 Effect of span length on fatigue deflection distribution factor for interior girder of bridges with $2000 \mathrm{~mm}$ girder spacing 


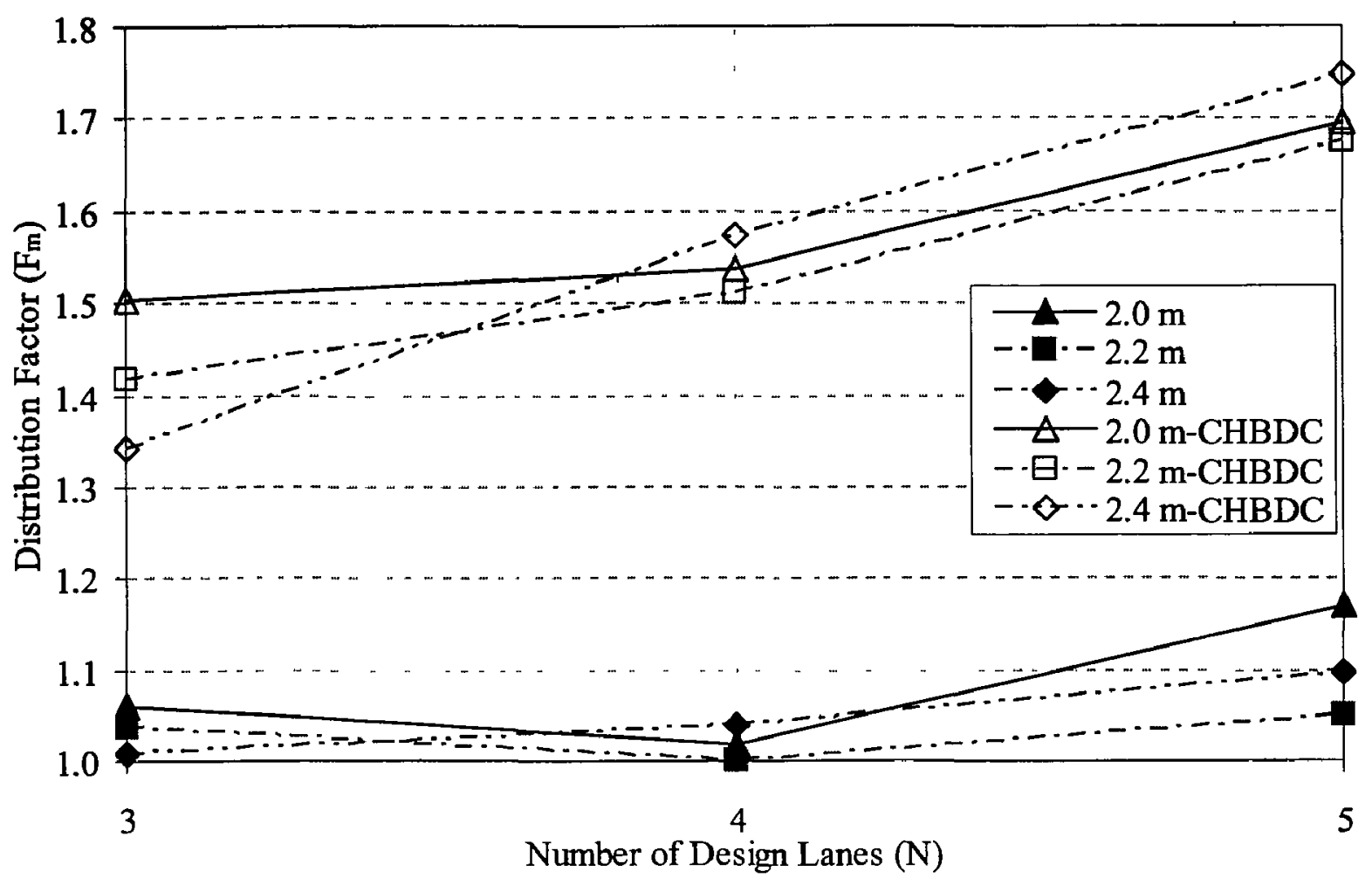

Figure 4.36 Effect of number of design lanes on bending moment distribution factor for exterior girder of $25 \mathrm{~m}$ span bridges

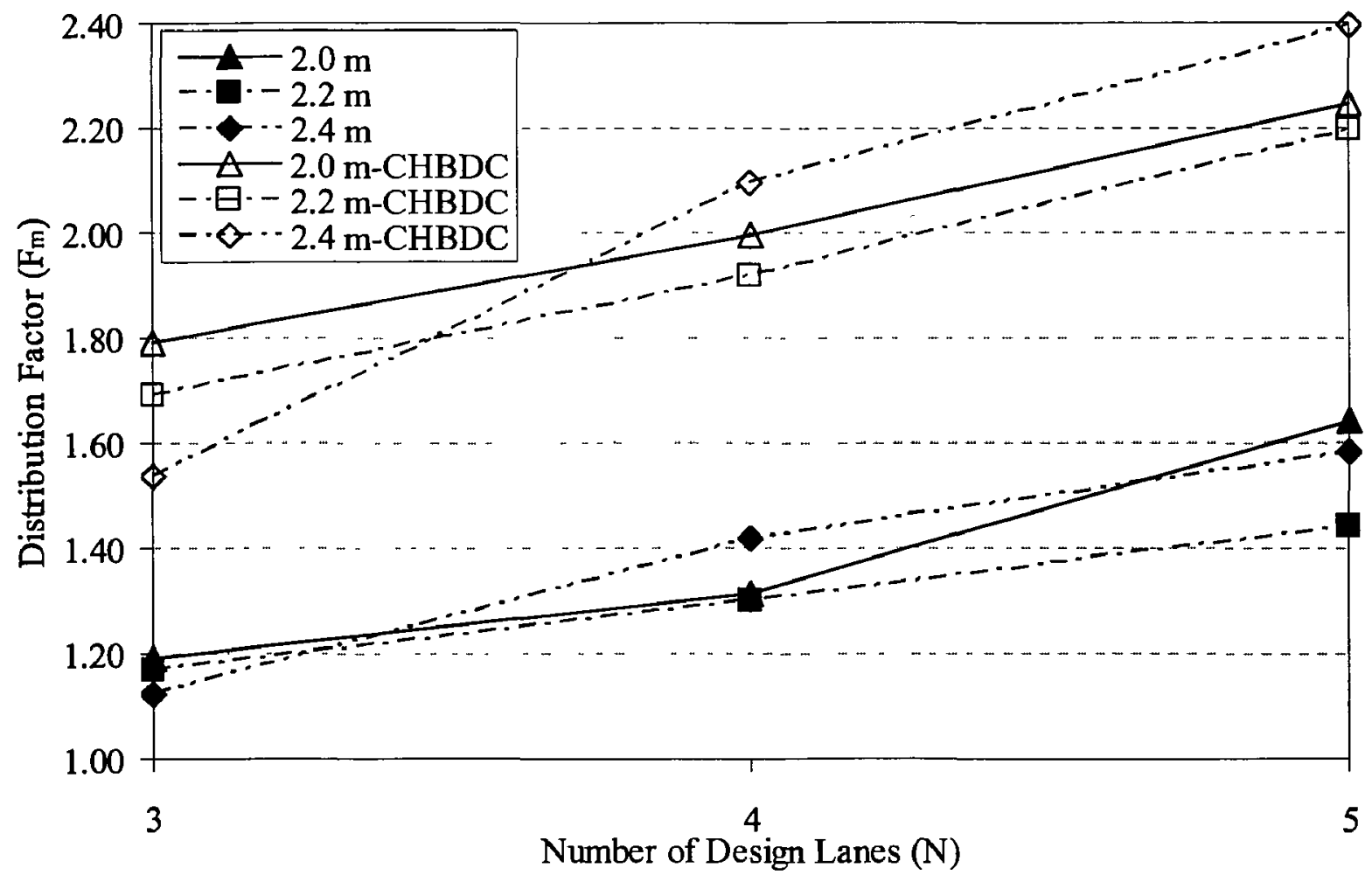

Figure 4.37 Effect of number of design lanes on fatigue bending moment distribution factor for exterior girder of $25 \mathrm{~m}$ span bridges 


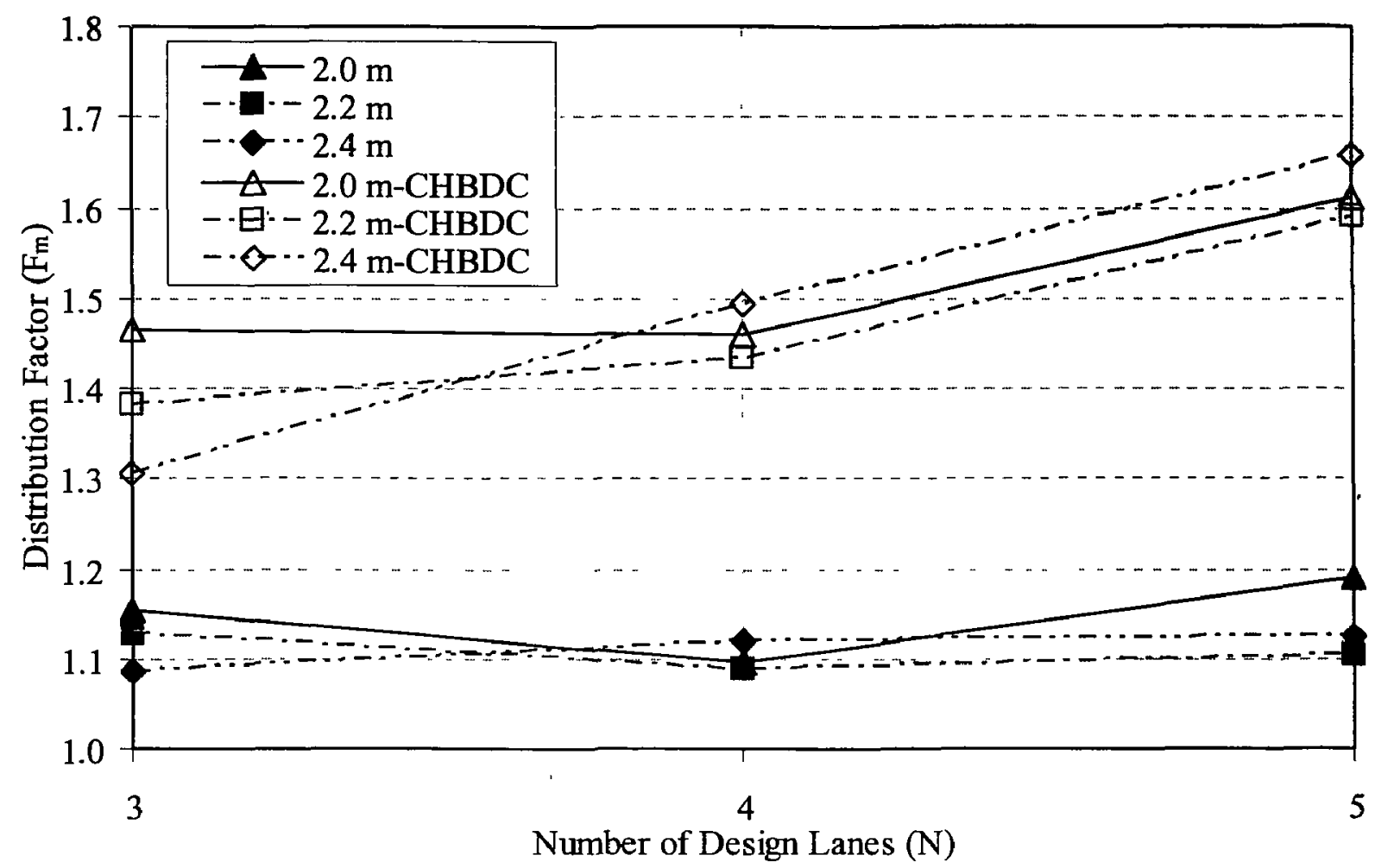

Figure 4.38 Effect of number of design lanes on bending moment distribution factor for interior girder of $25 \mathrm{~m}$ span bridges

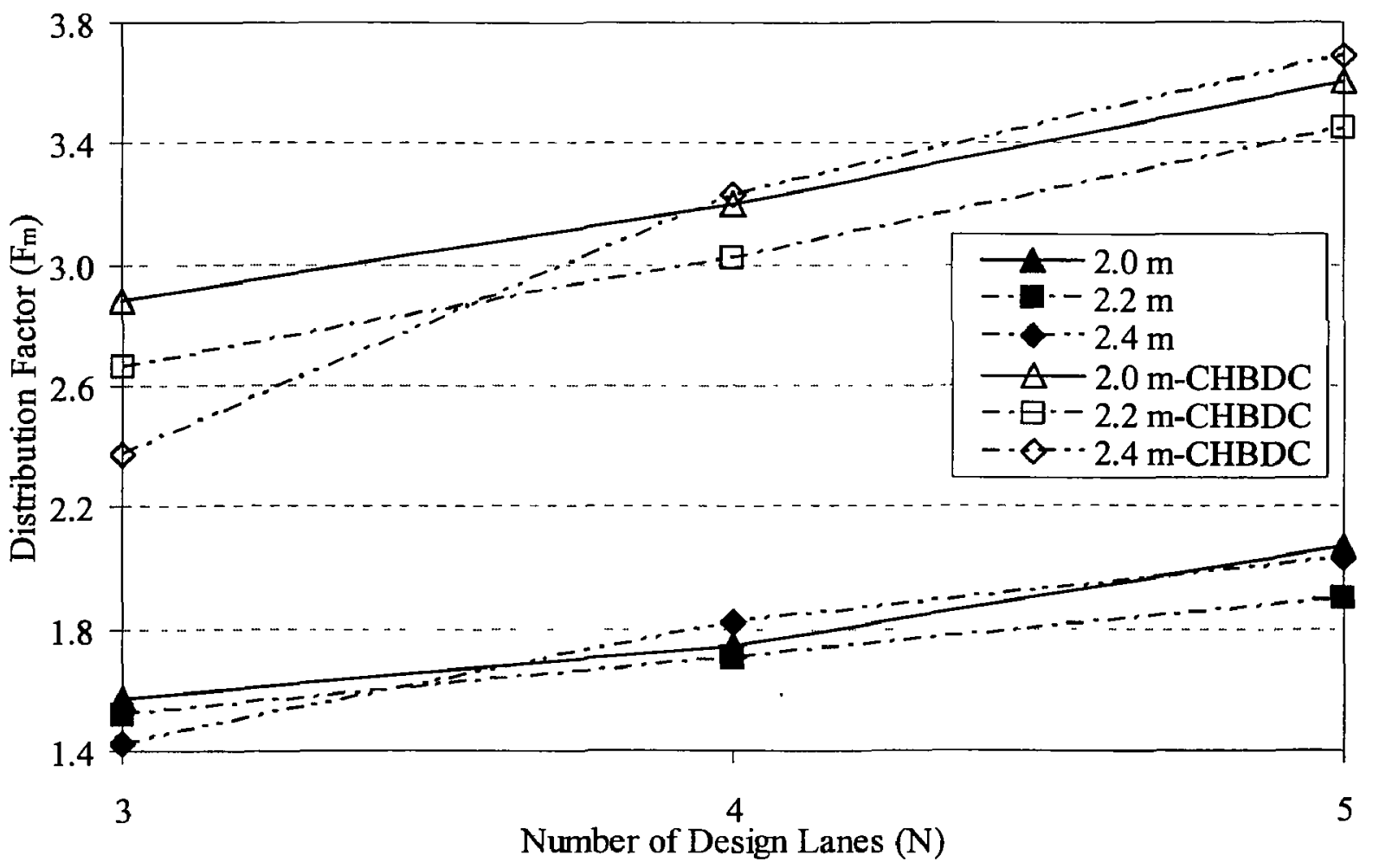

Figure 4.39 Effect of number of design lanes on fatigue bending moment distribution factor for interior girder of $25 \mathrm{~m}$ span bridges 


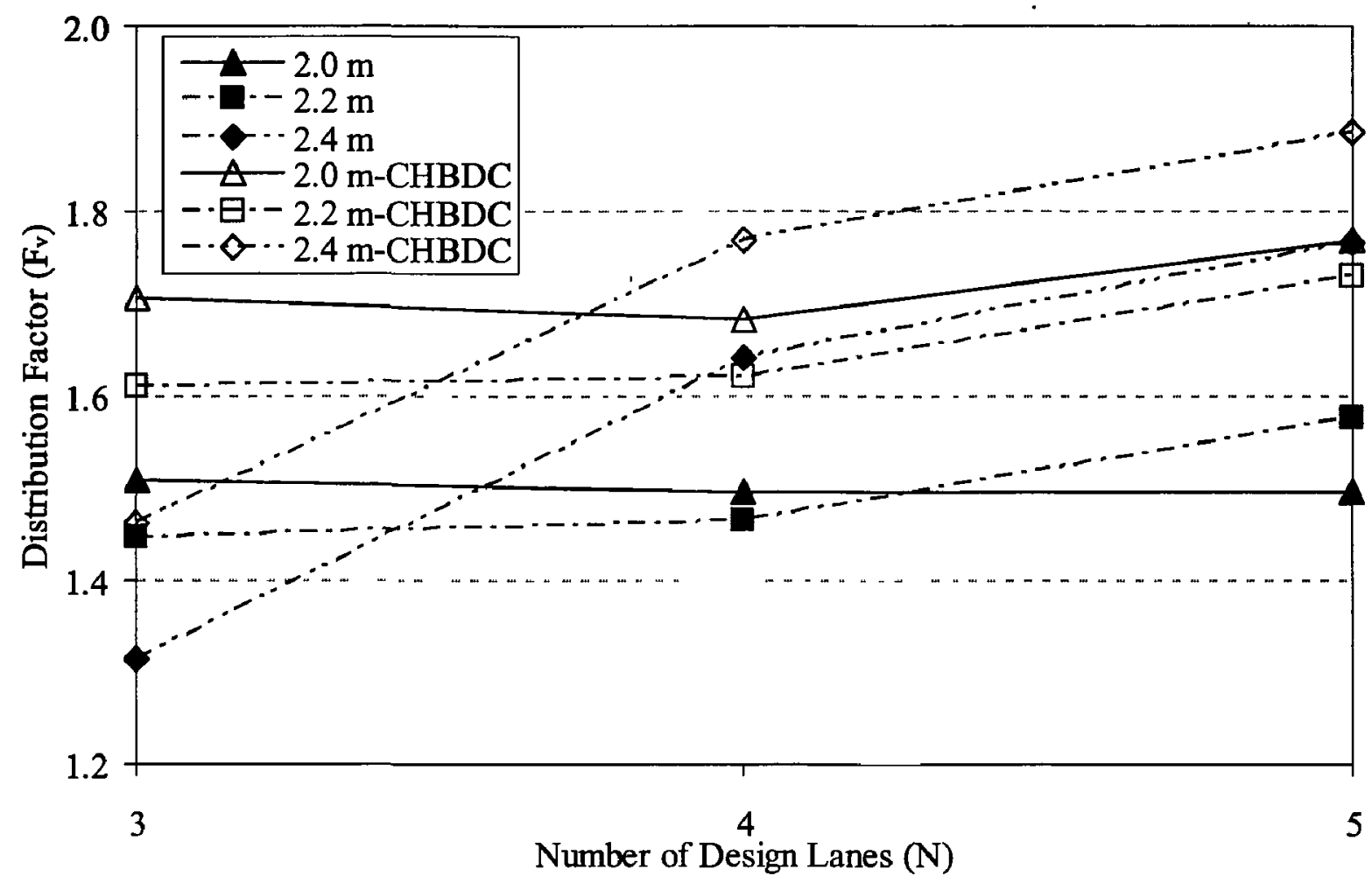

Figure 4.40 Effect of number of design lanes on shear distribution factor for exterior girder of $25 \mathrm{~m}$ span bridges

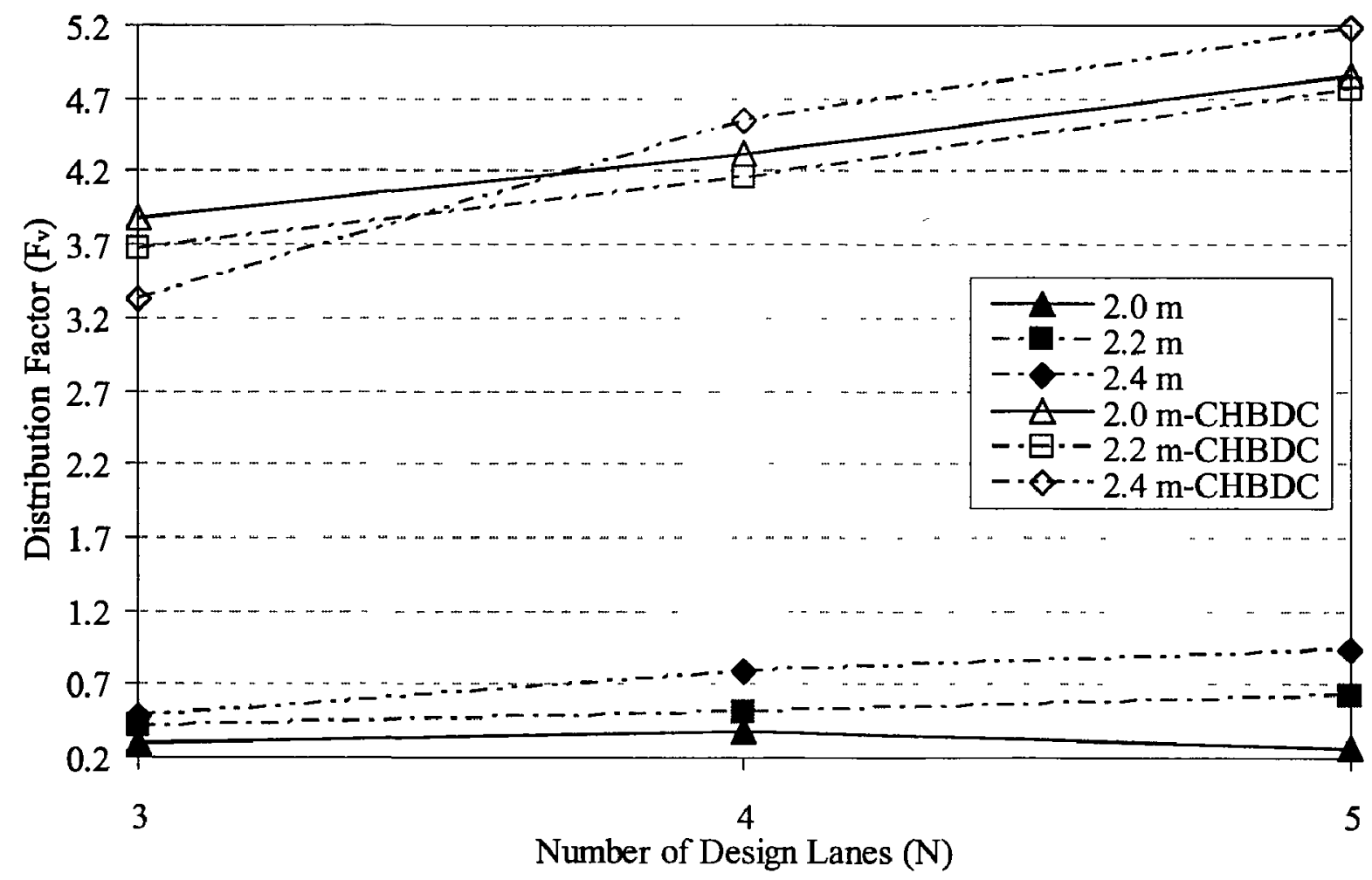

Figure 4.41 Effect of number of design lanes on fatigue shear distribution factor for exterior girder of $25 \mathrm{~m}$ span bridges 


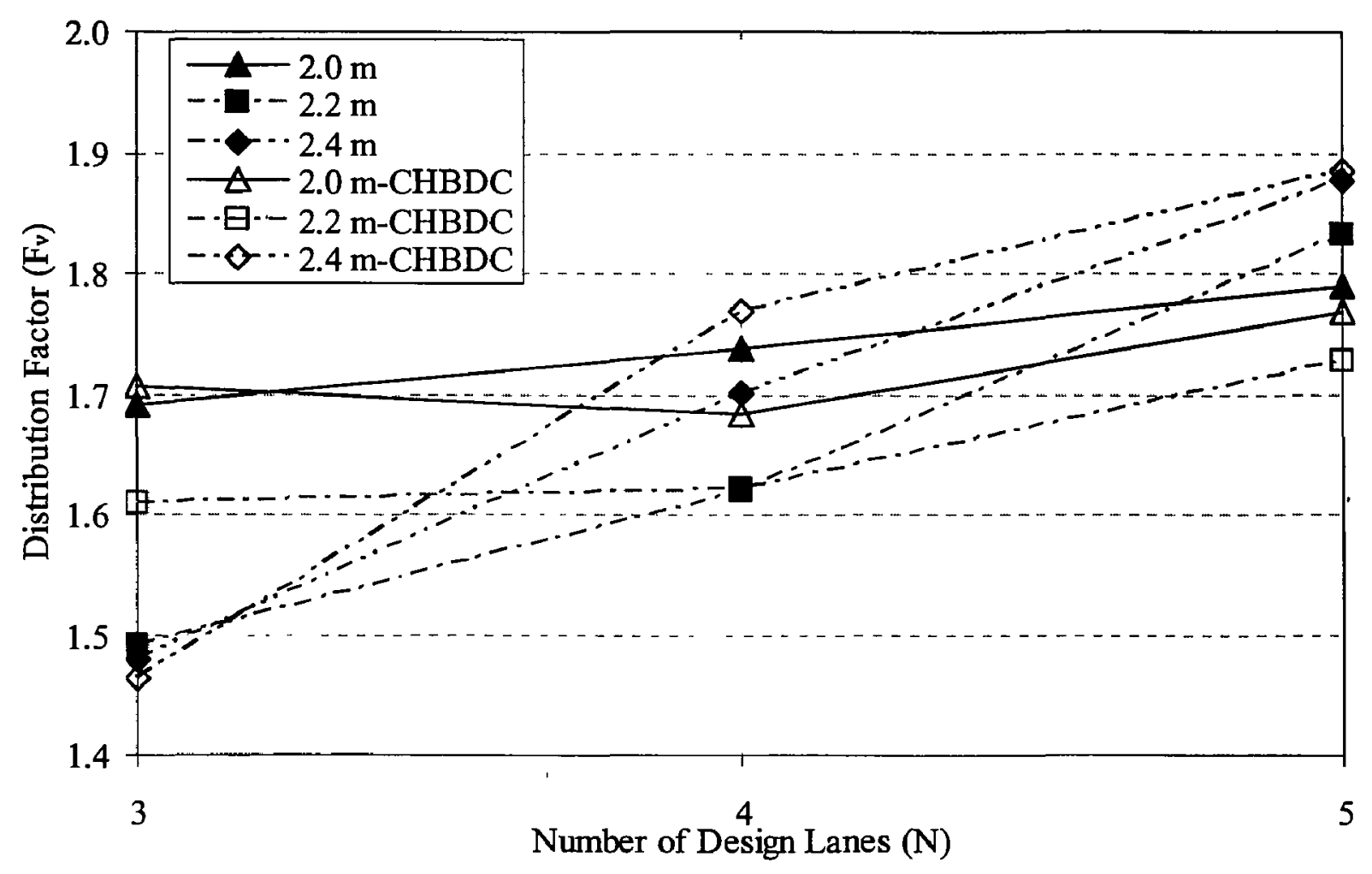

Figure 4.42 Effect of number of design lanes on shear distribution factor for interior girder of $25 \mathrm{~m}$ span bridges

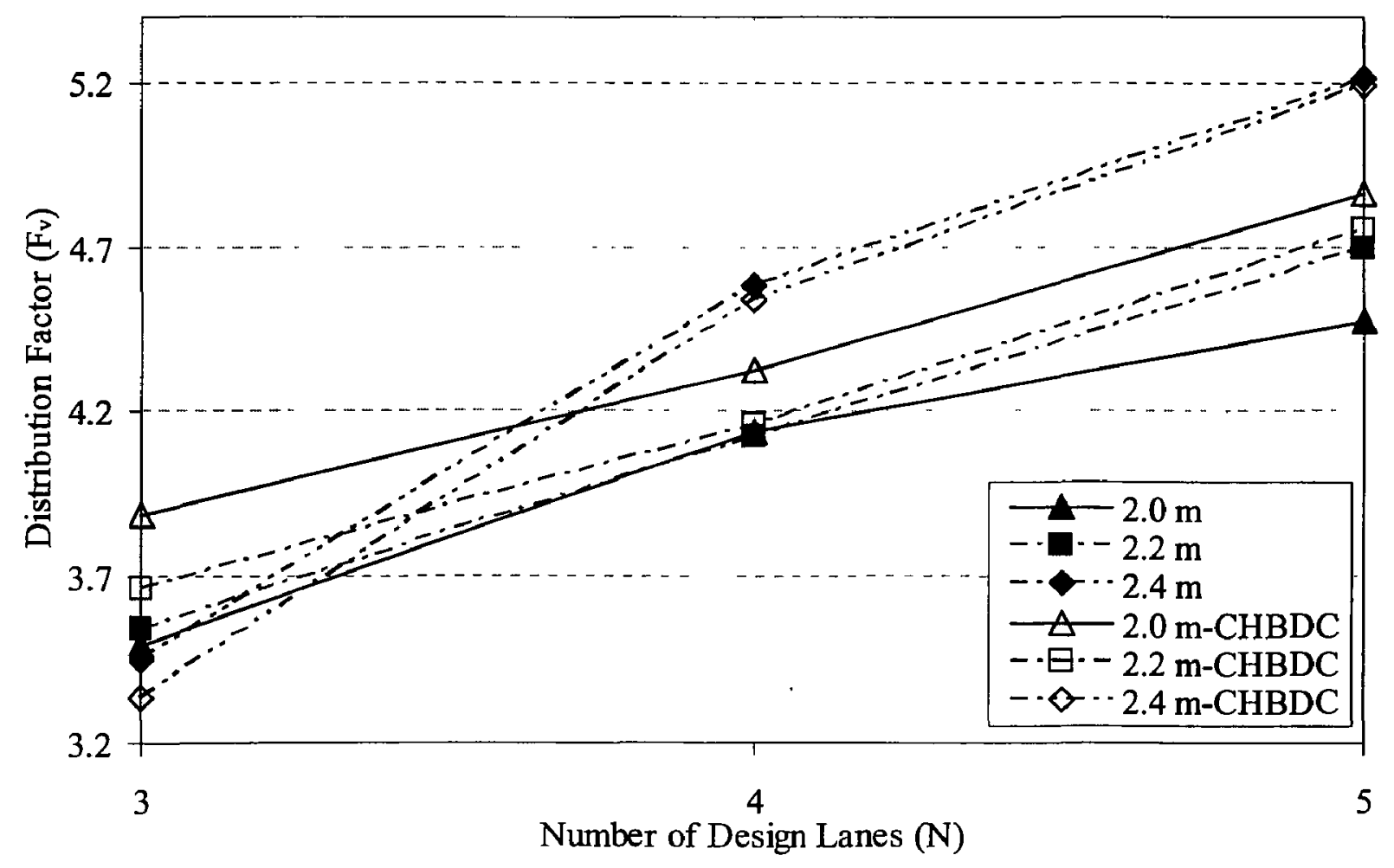

Figure 4.43 Effect of number of design lanes on fatigue shear distribution factor for interior girder of $25 \mathrm{~m}$ span spans 


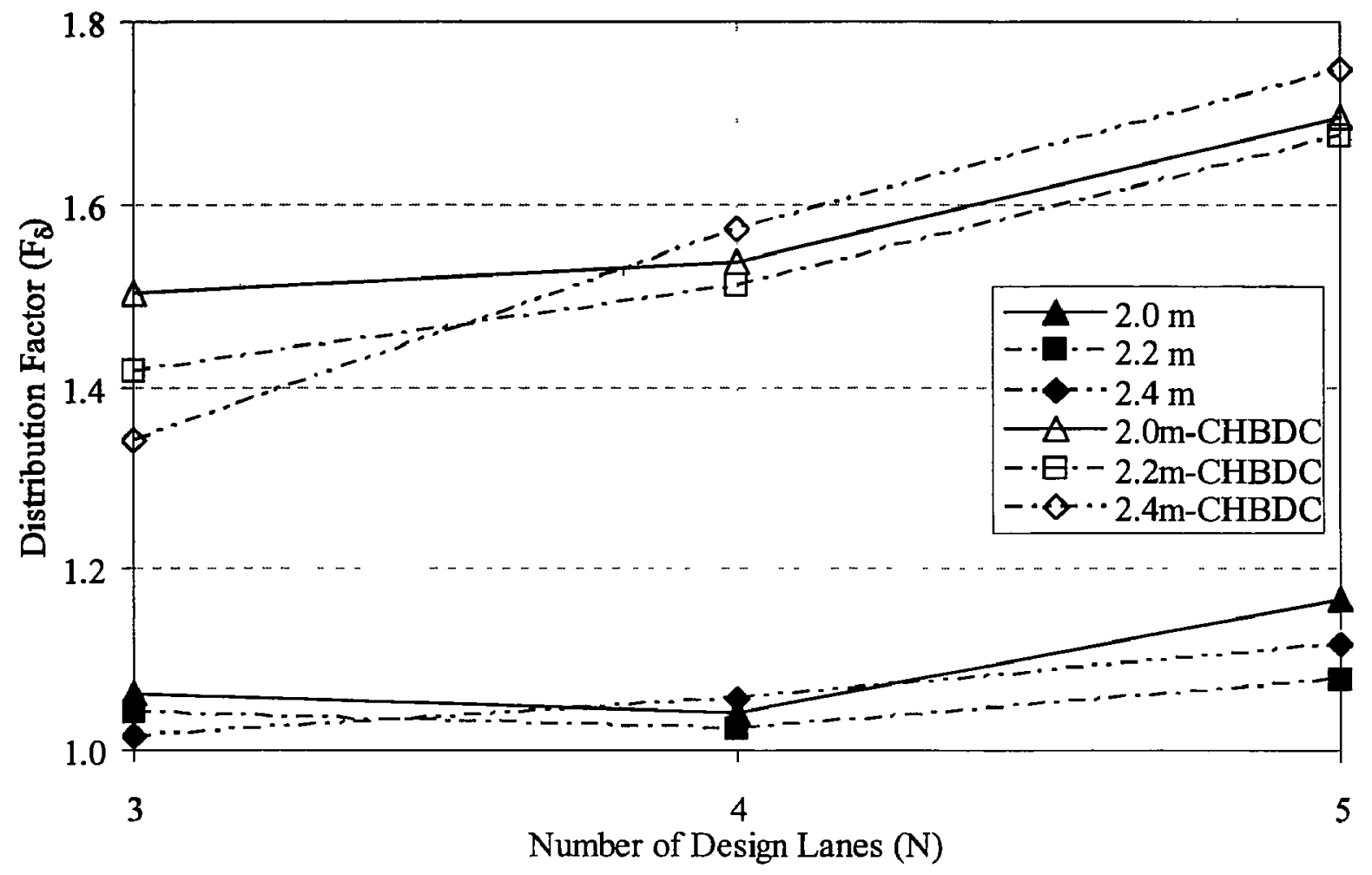

Figure 4.44 Effect of number of design lanes on deflection distribution factor for exterior girder of $25 \mathrm{~m}$ span bridges

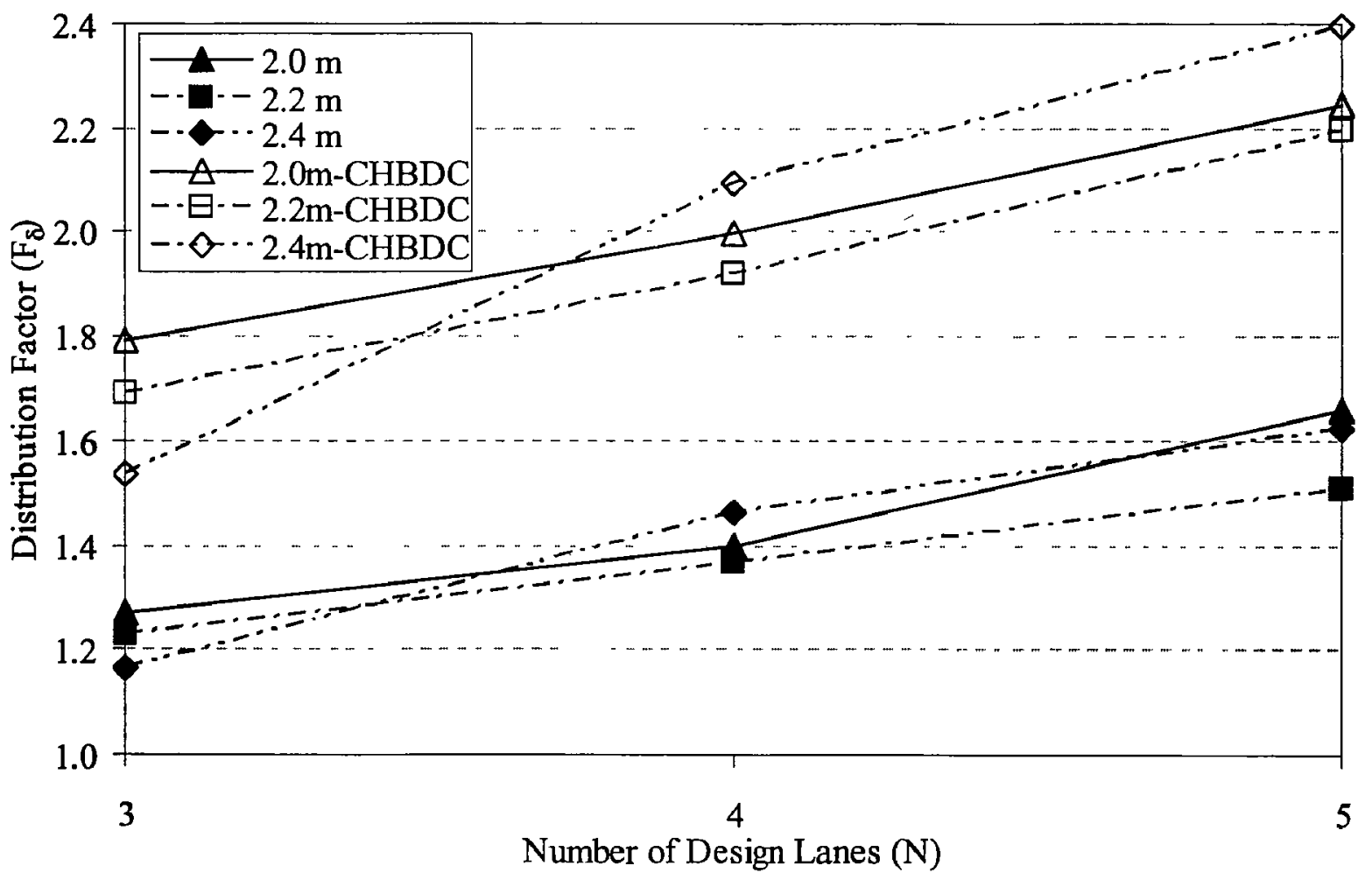

Figure 4.45 Effect of number of design lanes on fatigue deflection distribution factor for exterior girder of $25 \mathrm{~m}$ span bridges 


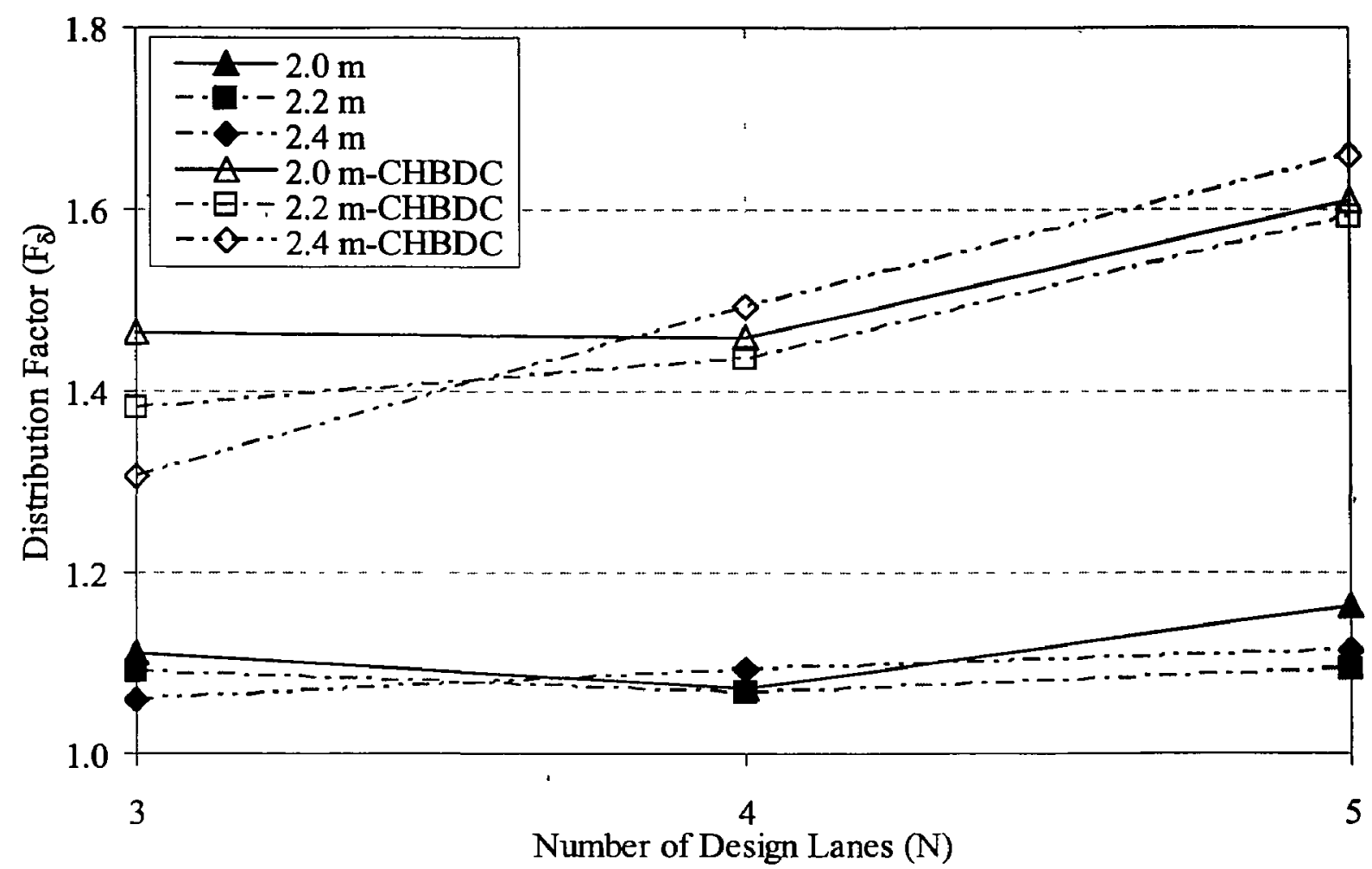

Figure 4.46 Effect of number of design lanes on deflection distribution factor for interior girder of $25 \mathrm{~m}$ span bridges

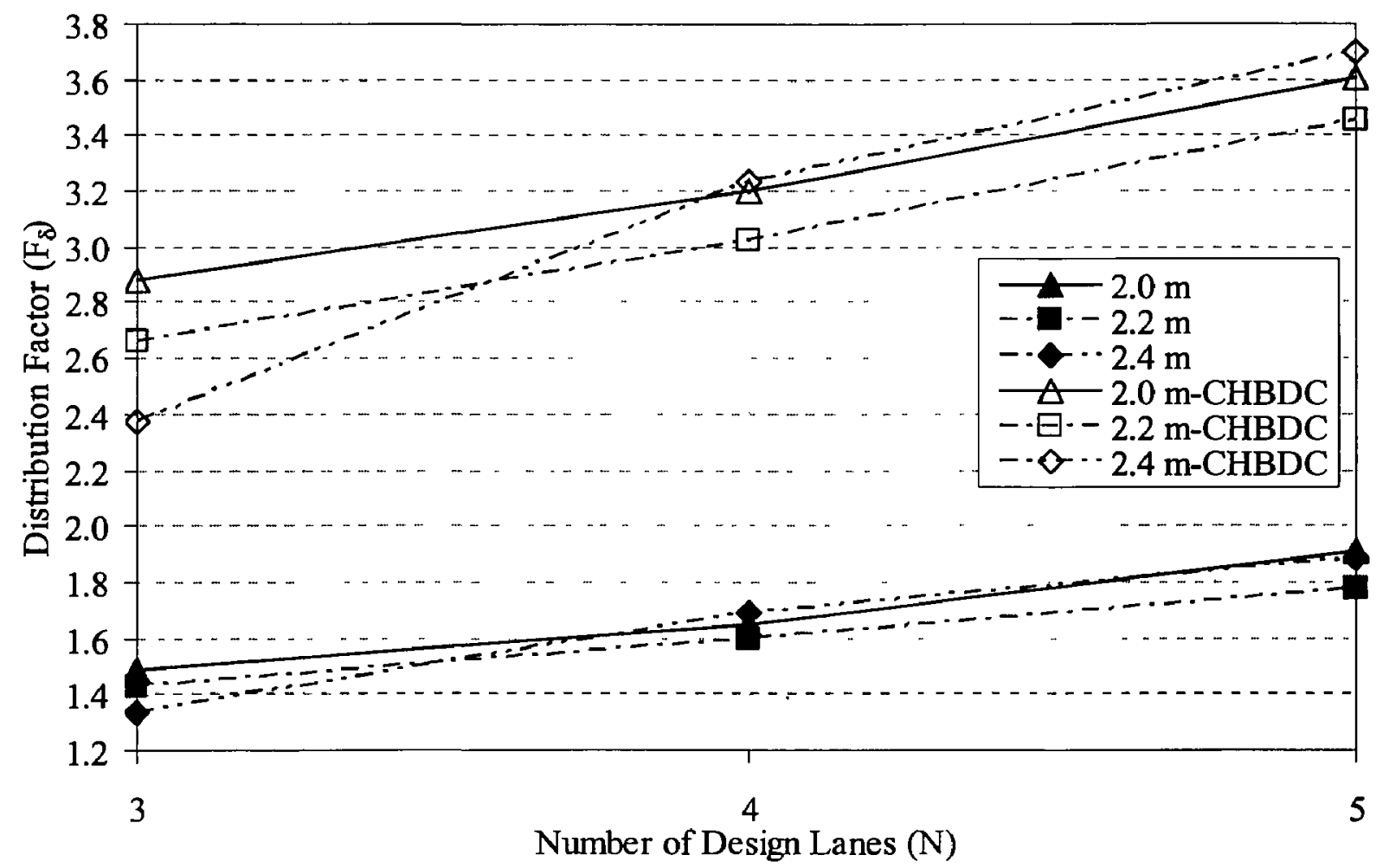

Figure 4.47 Effect of number of design lanes on fatigue deflection distribution factor for interior girder of $25 \mathrm{~m}$ span bridges 


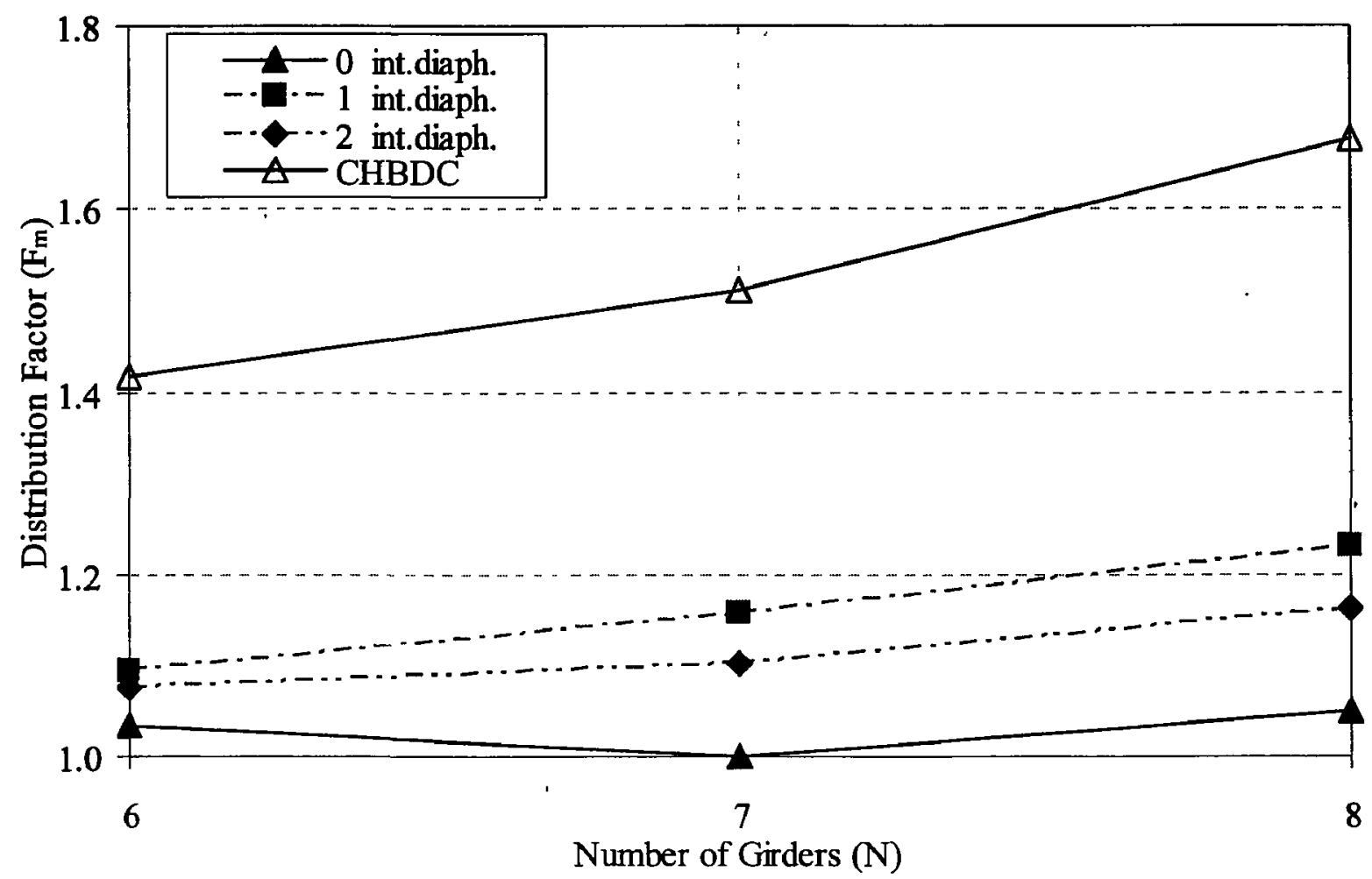

Figure 4.48 Effect of number of girders on bending moment distribution factor for exterior girder of $25 \mathrm{~m}$ span bridges

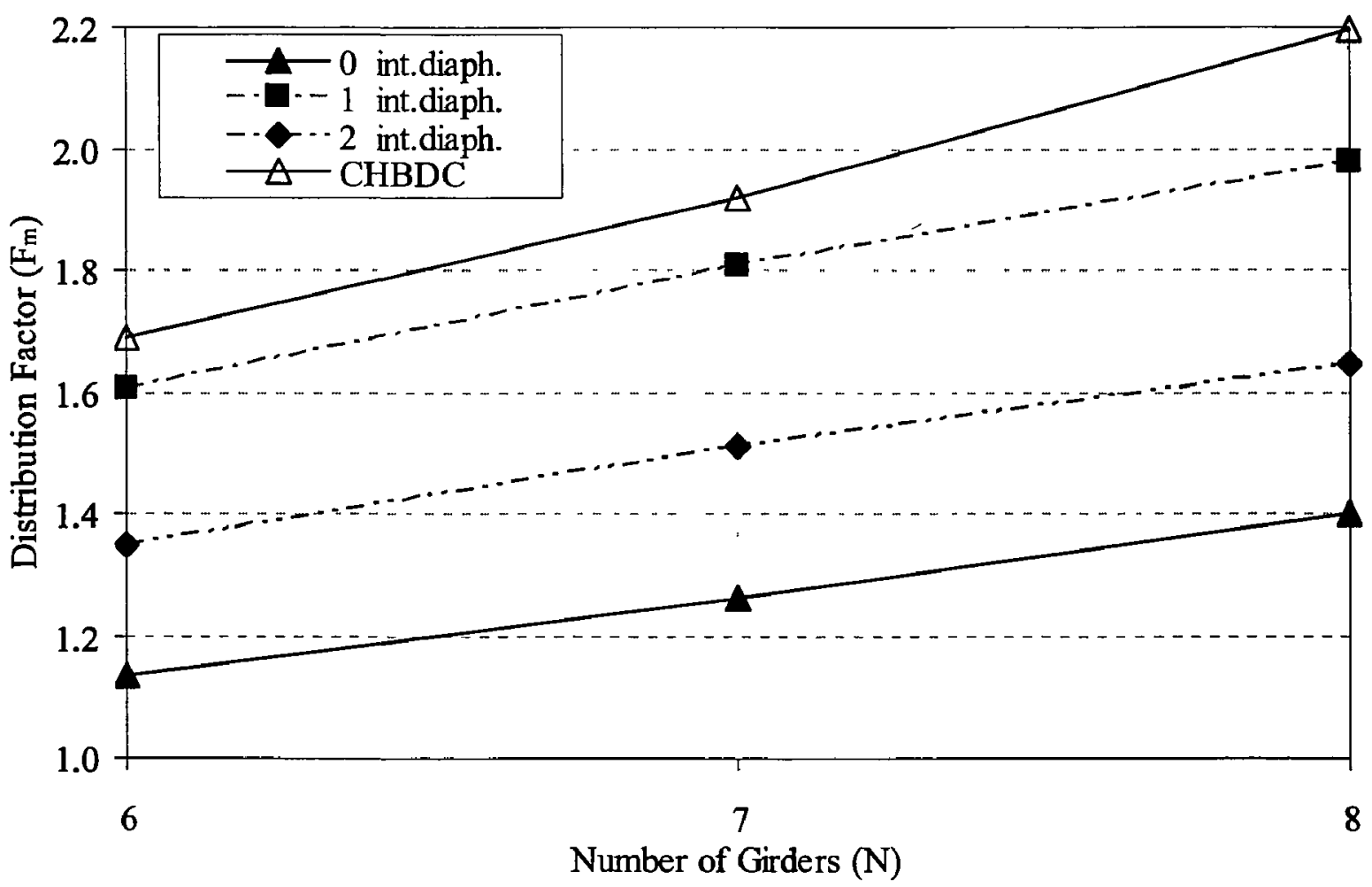

Figure 4.49 Effect of number of girders on fatigue bending moment distribution factor for exterior girder of $25 \mathrm{~m}$ span 


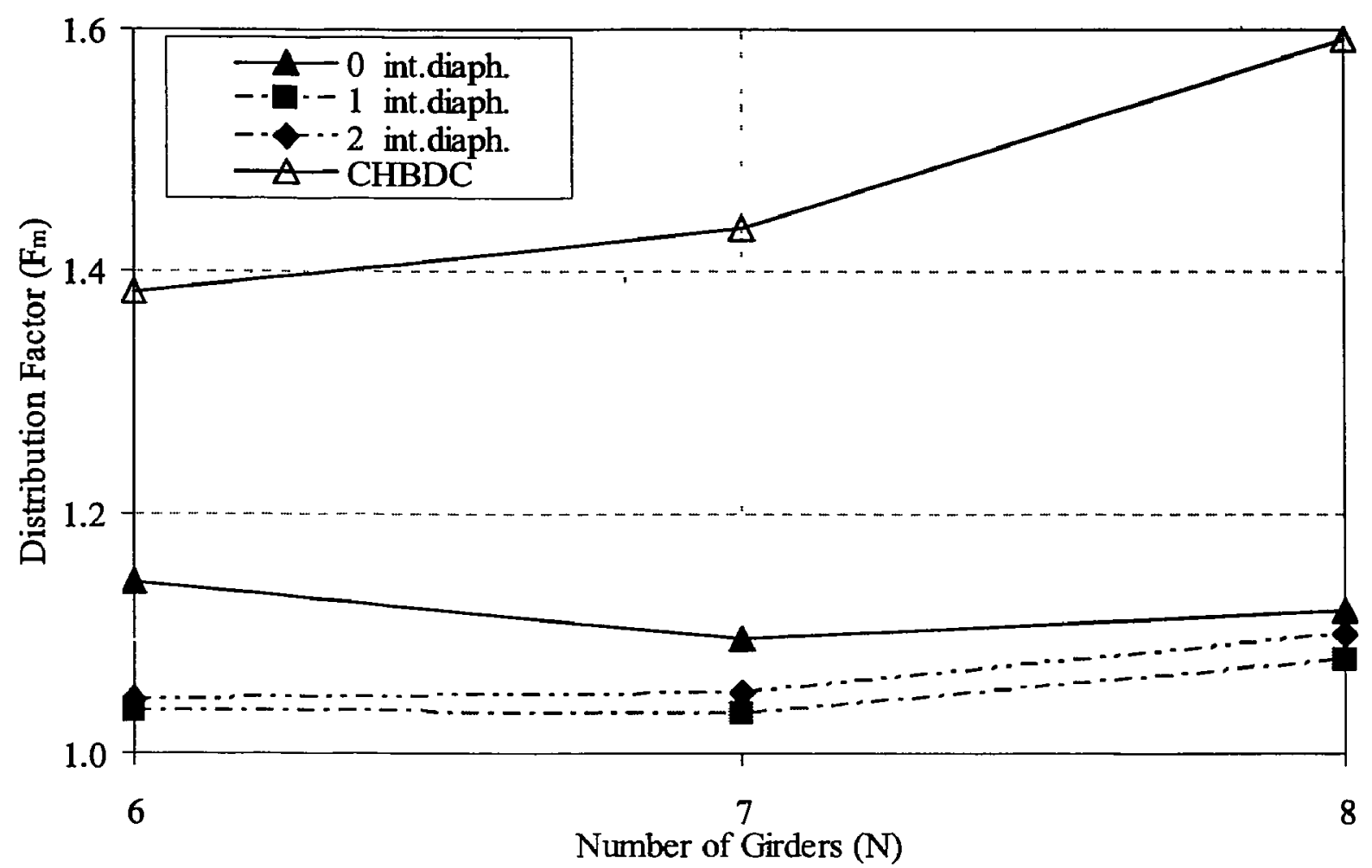

Figure 4.50 Effect of number of girders on bending moment distribution factor for interior girder of $25 \mathrm{~m}$ span bridges

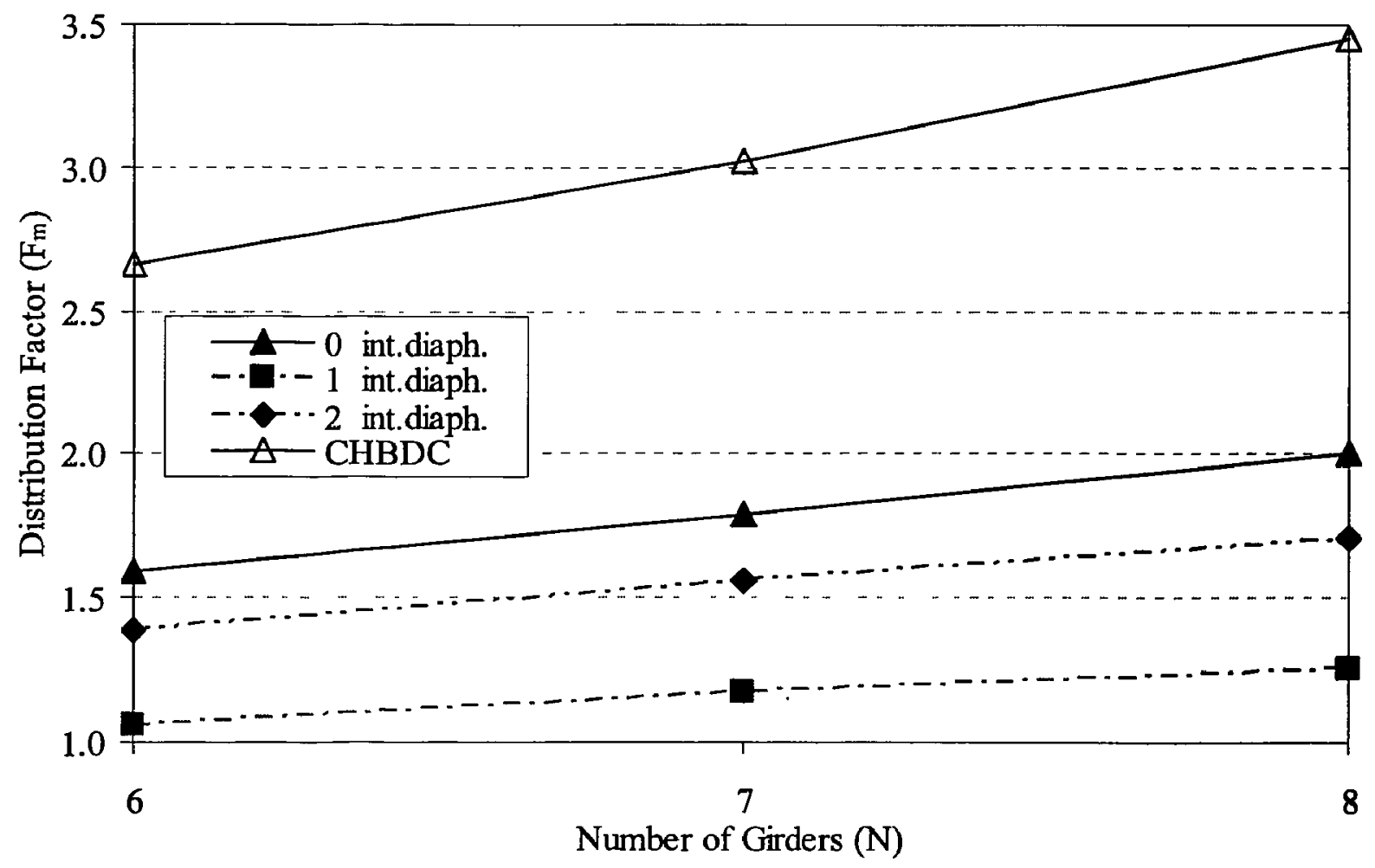

Figure 4.51 Effect of number of girders on fatigue bending moment distribution factor for interior girder of $25 \mathrm{~m}$ span bridges 


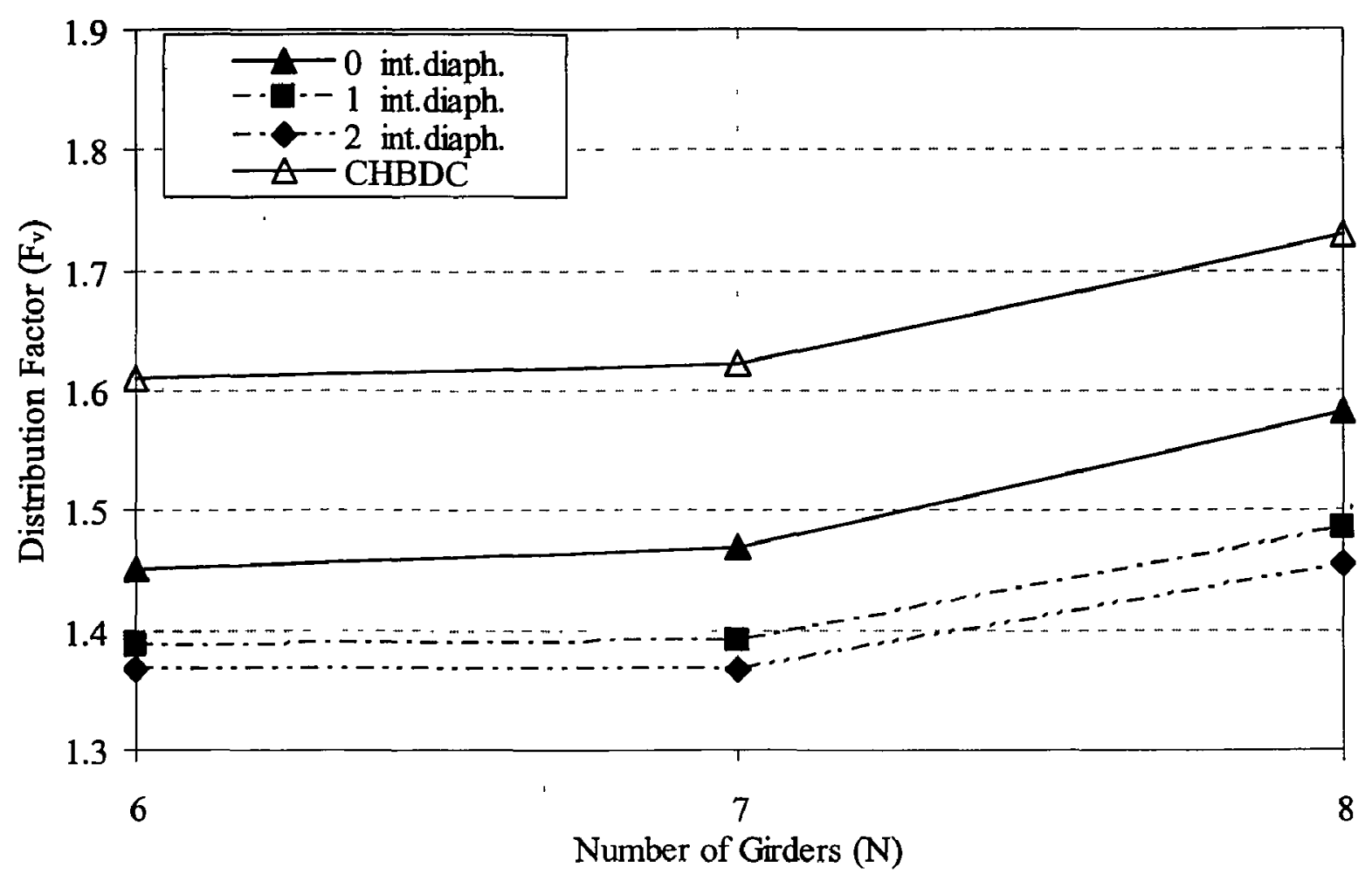

Figure 4.52 Effect of number of girders on shear distribution factor for exterior girder of $25 \mathrm{~m}$ span bridges

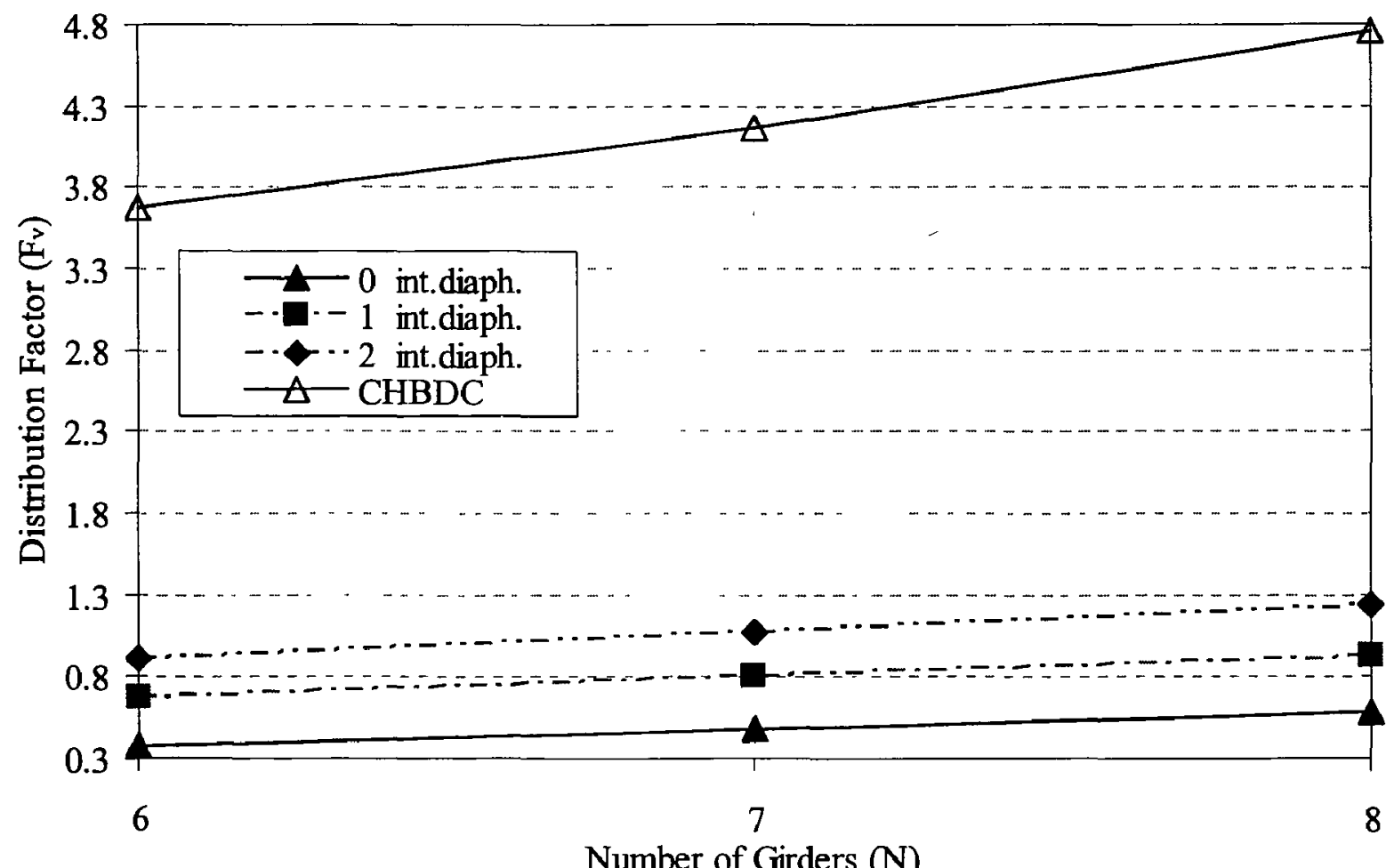

Figure 4.53 Effect of number of girders on fatigue shear distribution factor for exterior girder (for 25m span) 


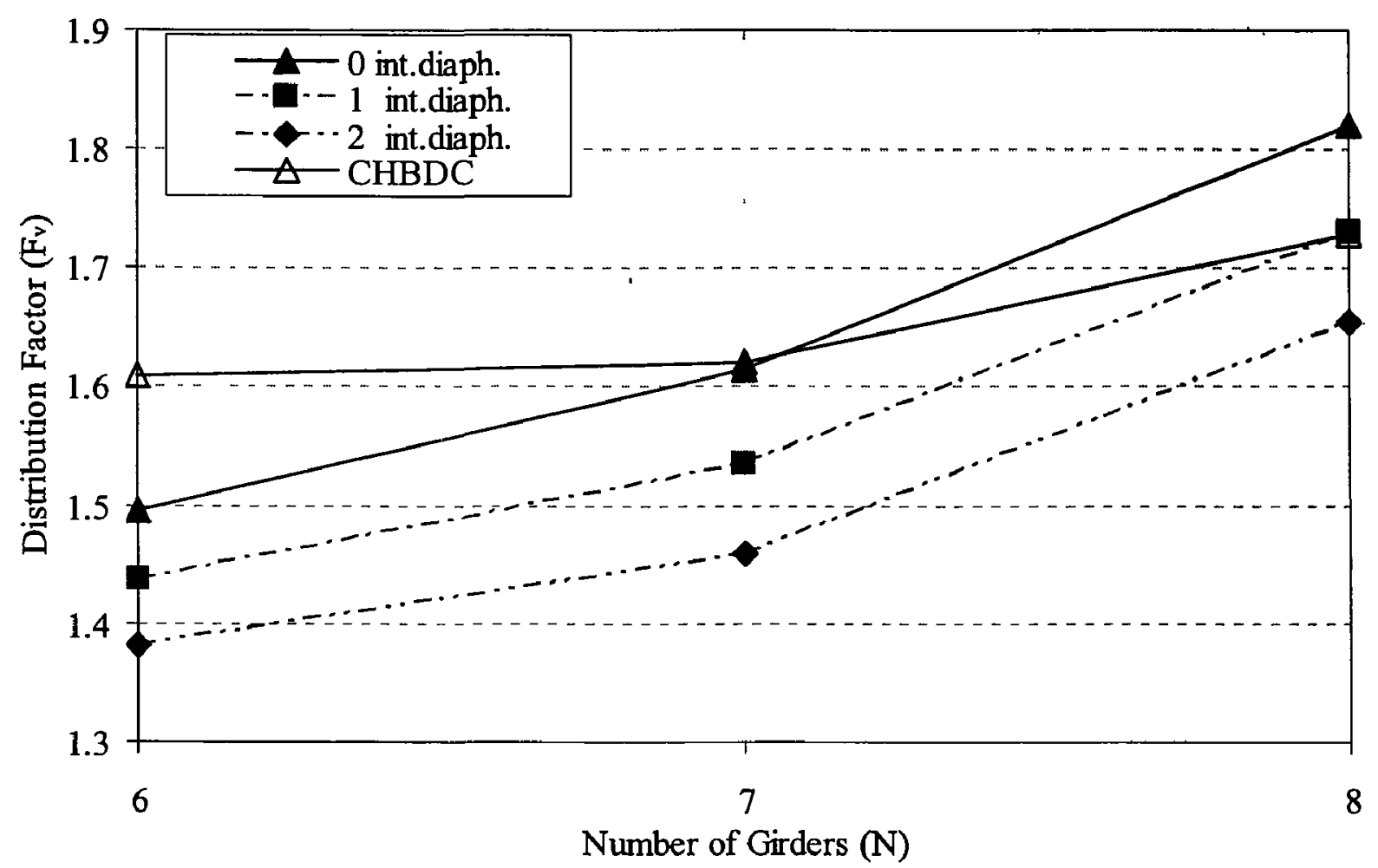

Figure 4.54 Effect of number of girders on shear distribution factor for interior girder of $25 \mathrm{~m}$ span bridges

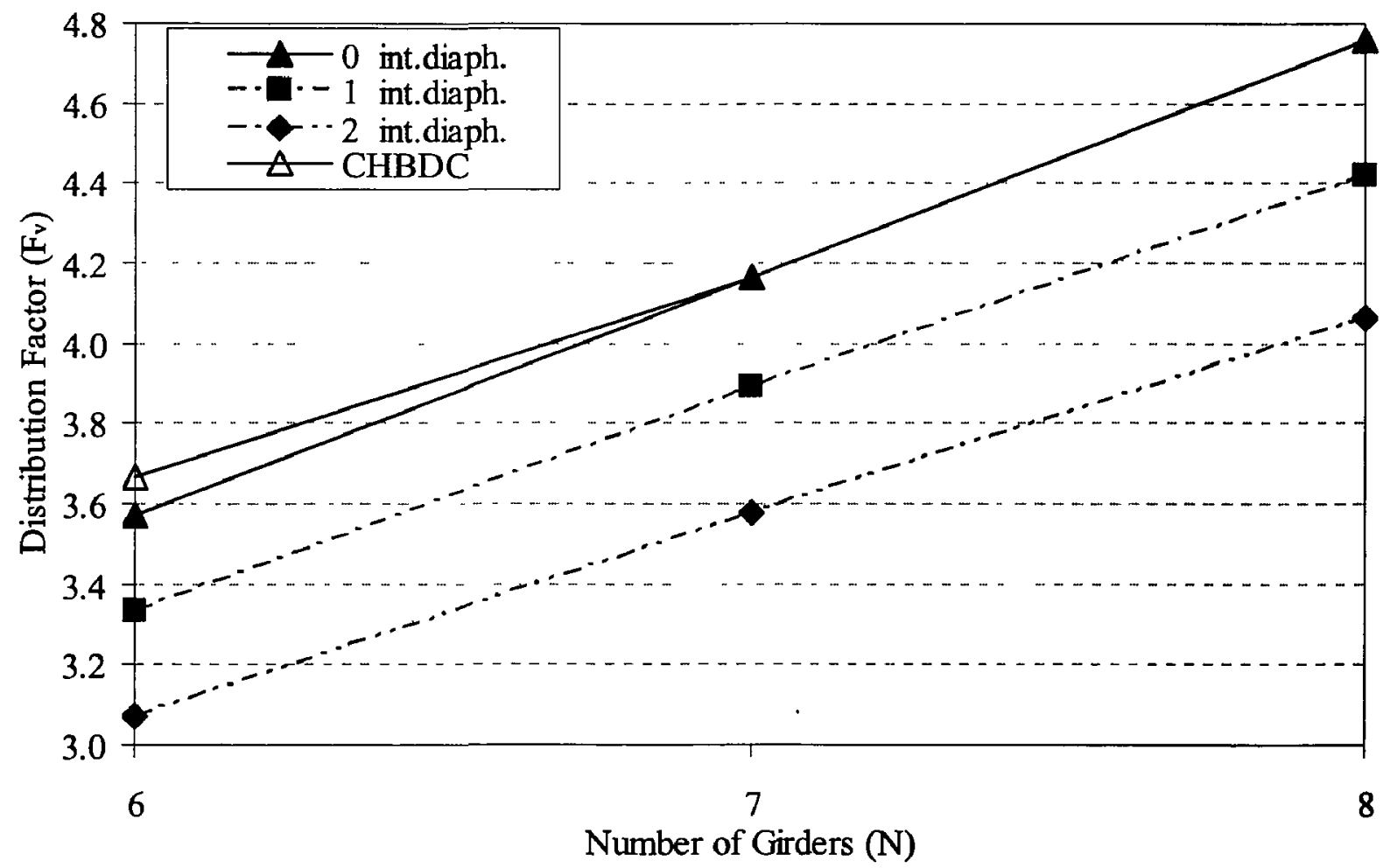

Figure 4.55 Effect of number of girders on fatigue shear distribution factor for interior girder of $25 \mathrm{~m}$ span bridges 


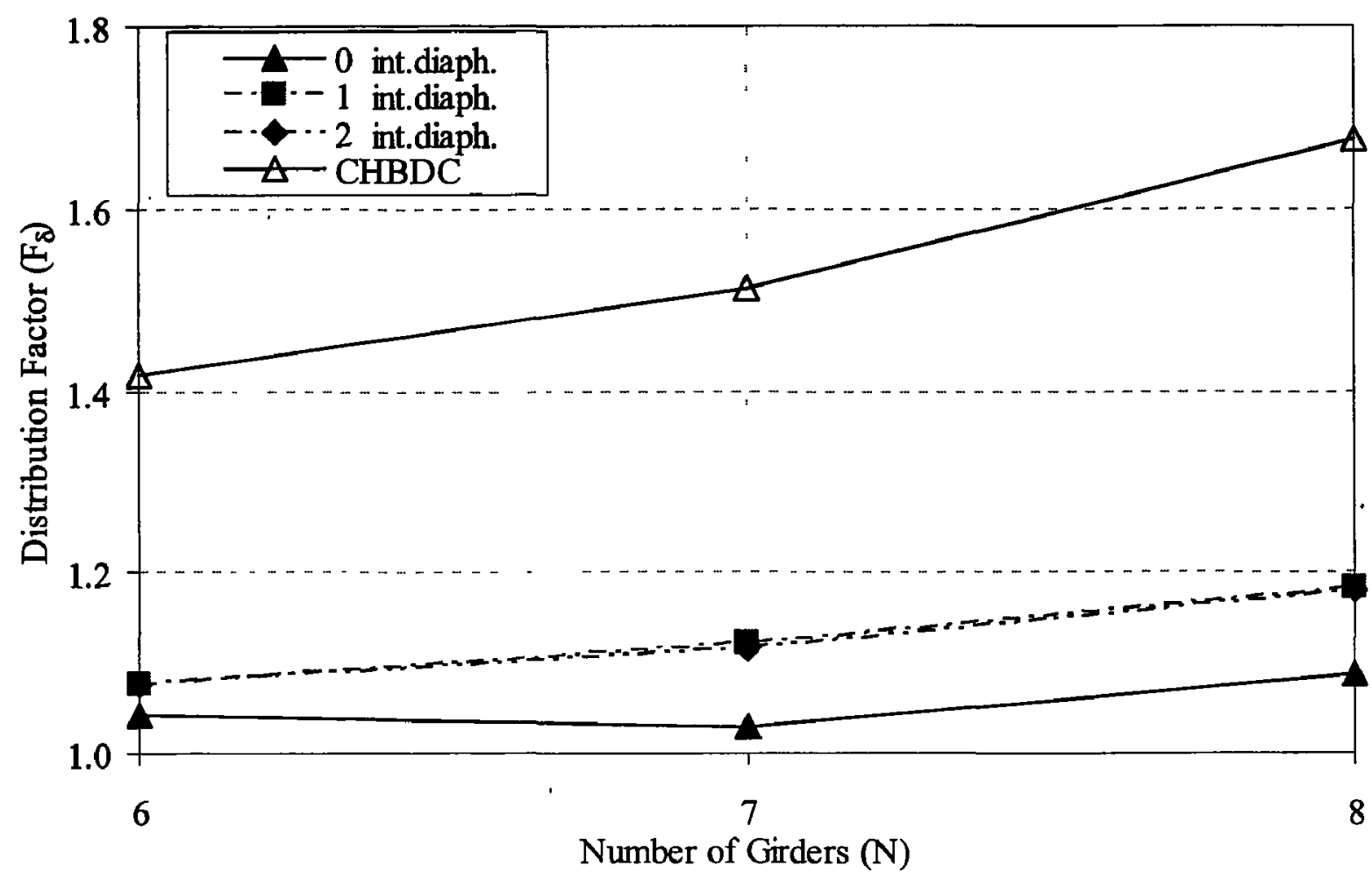

Figure 4.56 Effect of number of girders on deflection distribution factor for exterior girder of $25 \mathrm{~m}$ span bridges

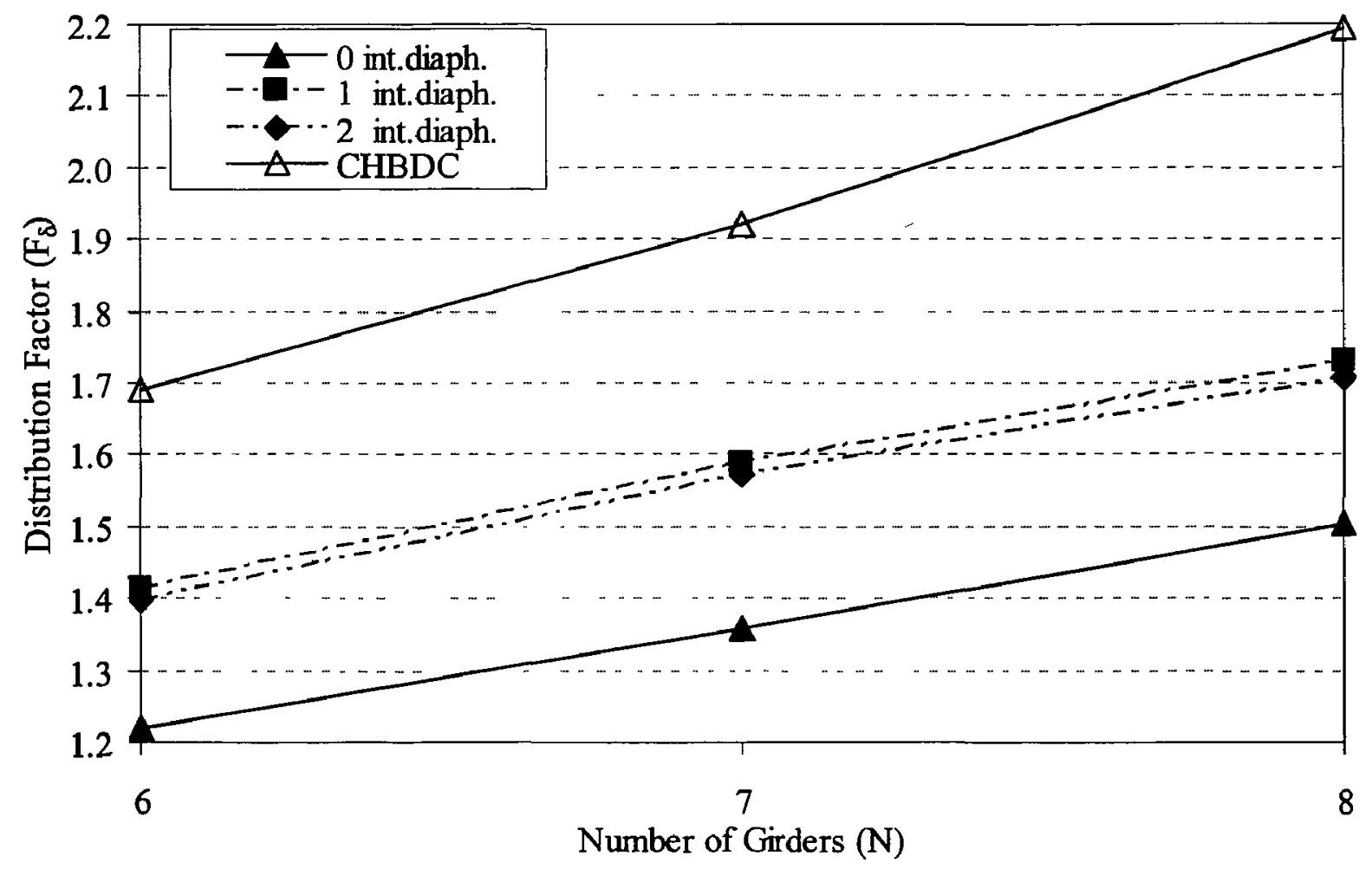

Figure 4.57 Effect of number of girders on fatigue deflection distribution factor for exterior girder of $25 \mathrm{~m}$ span bridges 


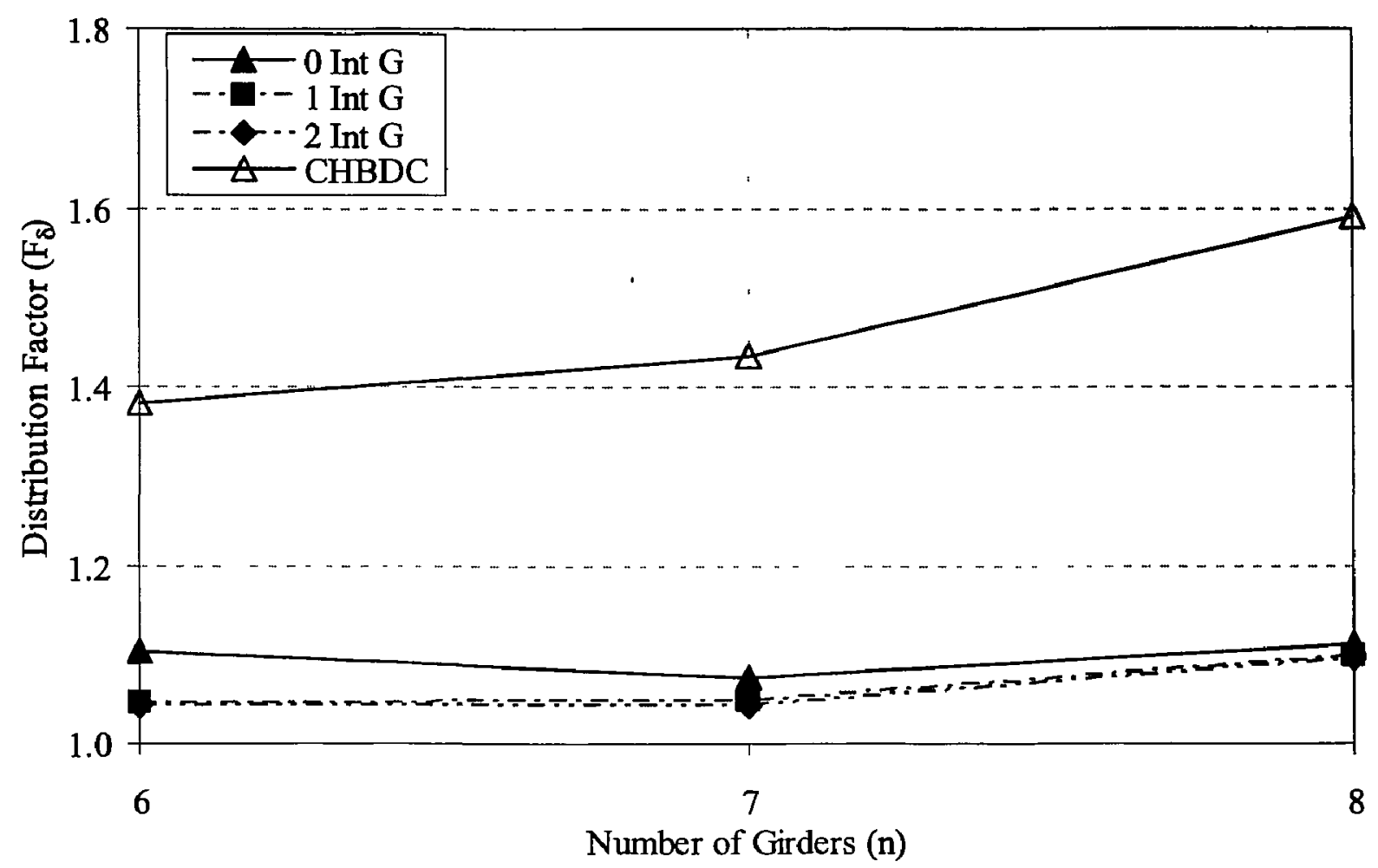

Figure 4.58 Effect of number of girders on deflection distribution factor for interior girder of $25 \mathrm{~m}$ span bridges

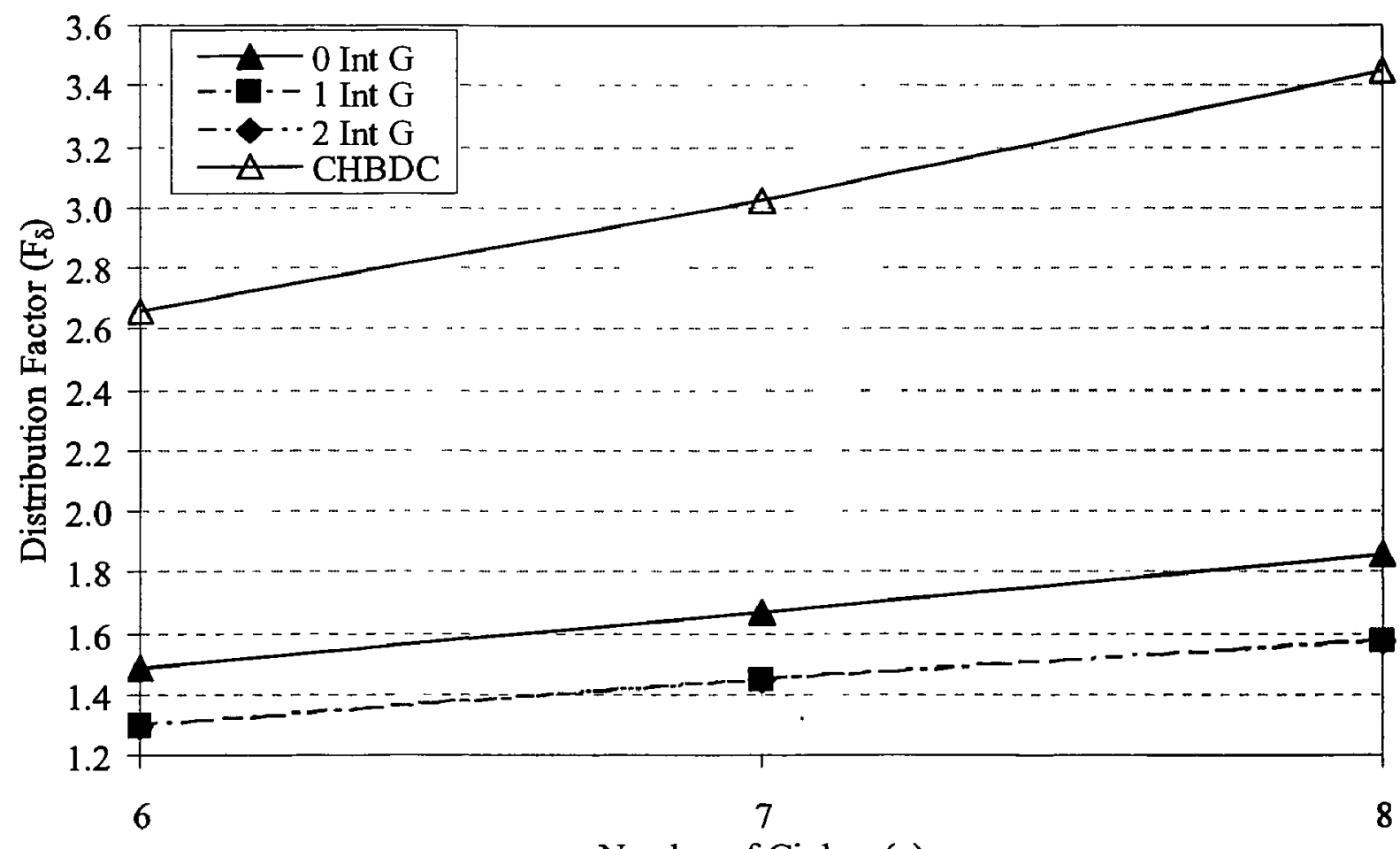

Figure 4.59 Effect of number of girders on fatigue deflection distribution factor for interior girder of $25 \mathrm{~m}$ span bridges 


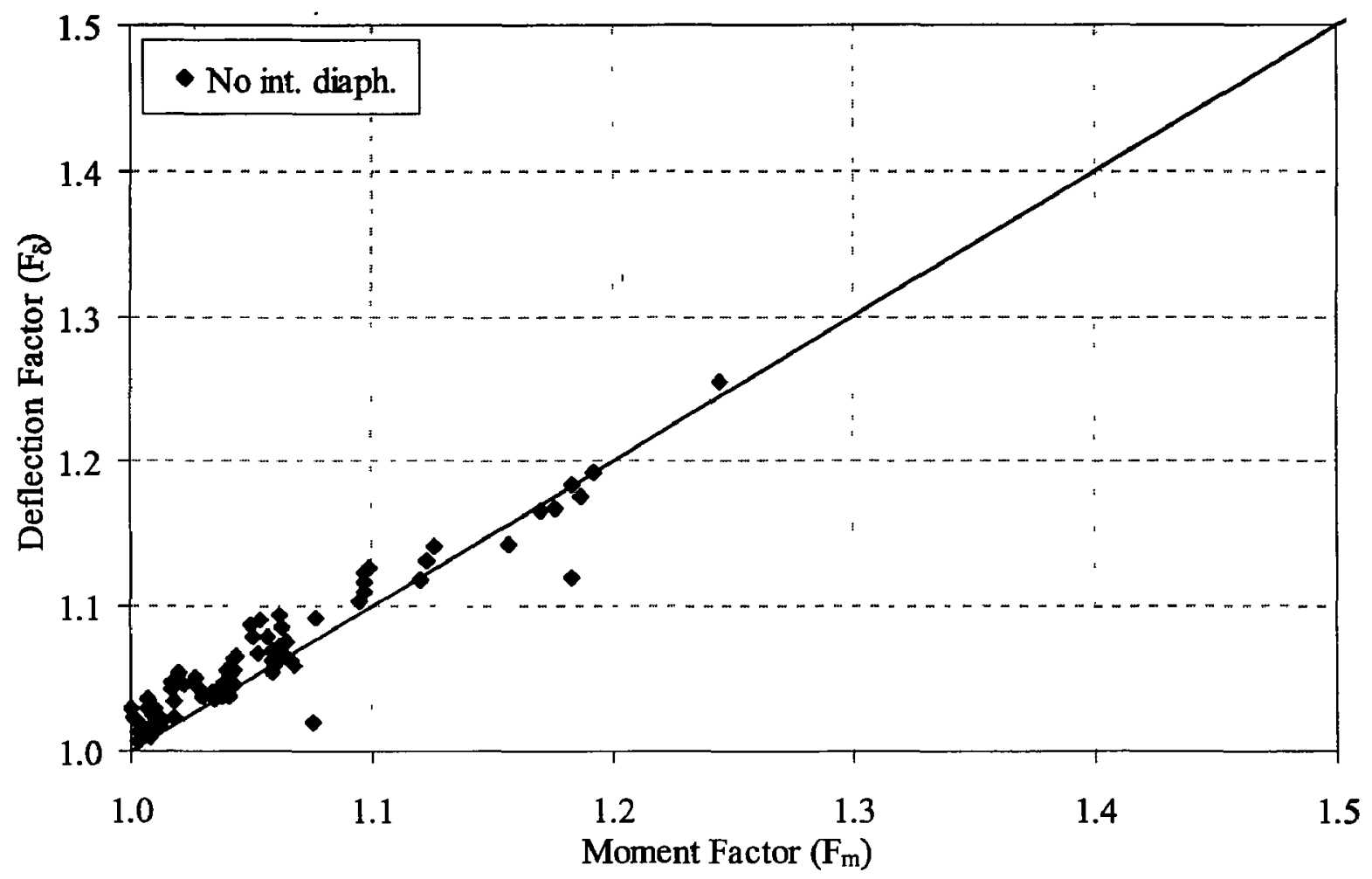

Figure 4.60 Comparison between deflection distribution factors vs. bending moment distribution factors for exterior girder

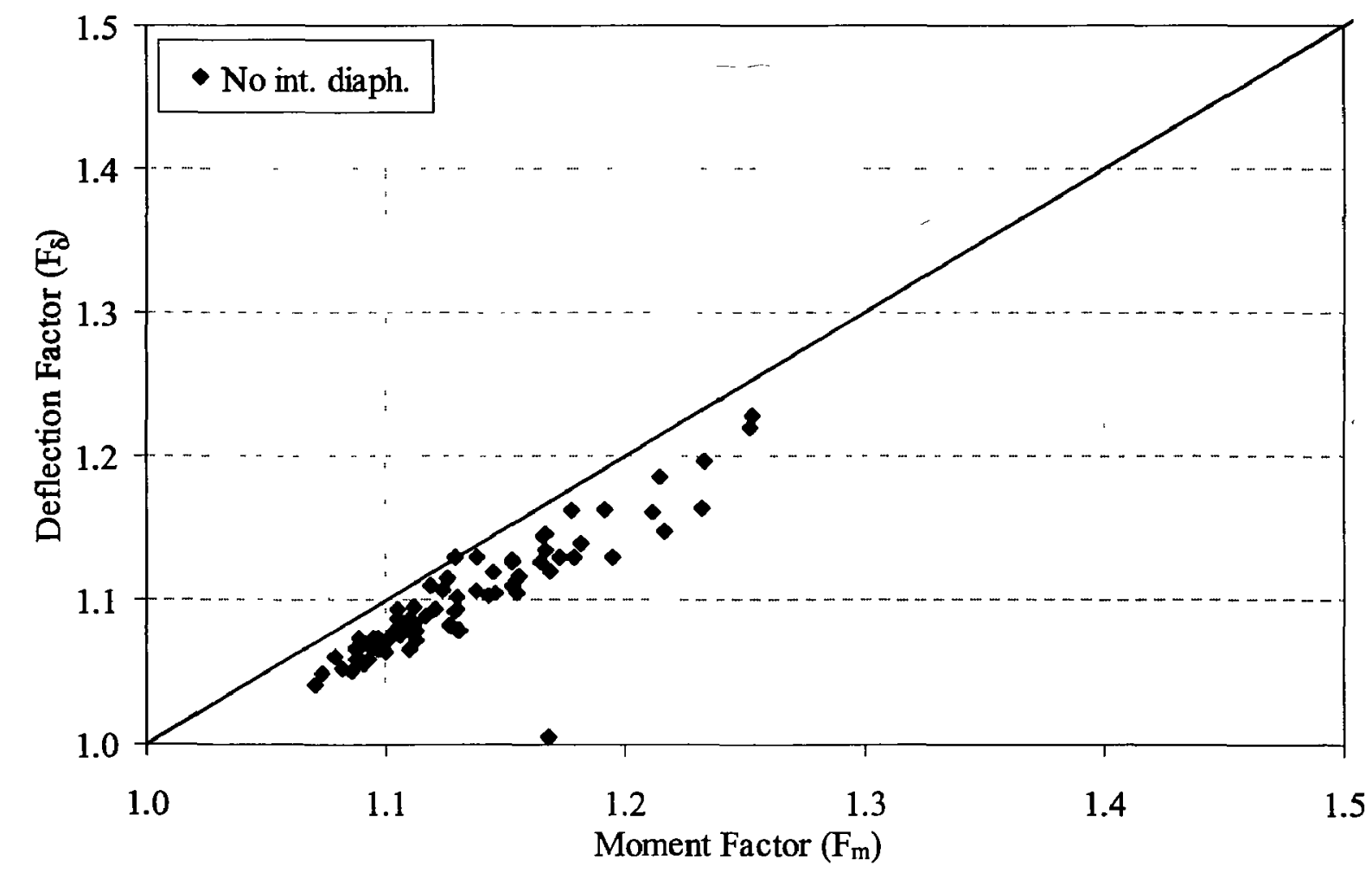

Figure 4.61 Comparison between deflection distribution factors vs. bending moment distribution factors for interior girder 


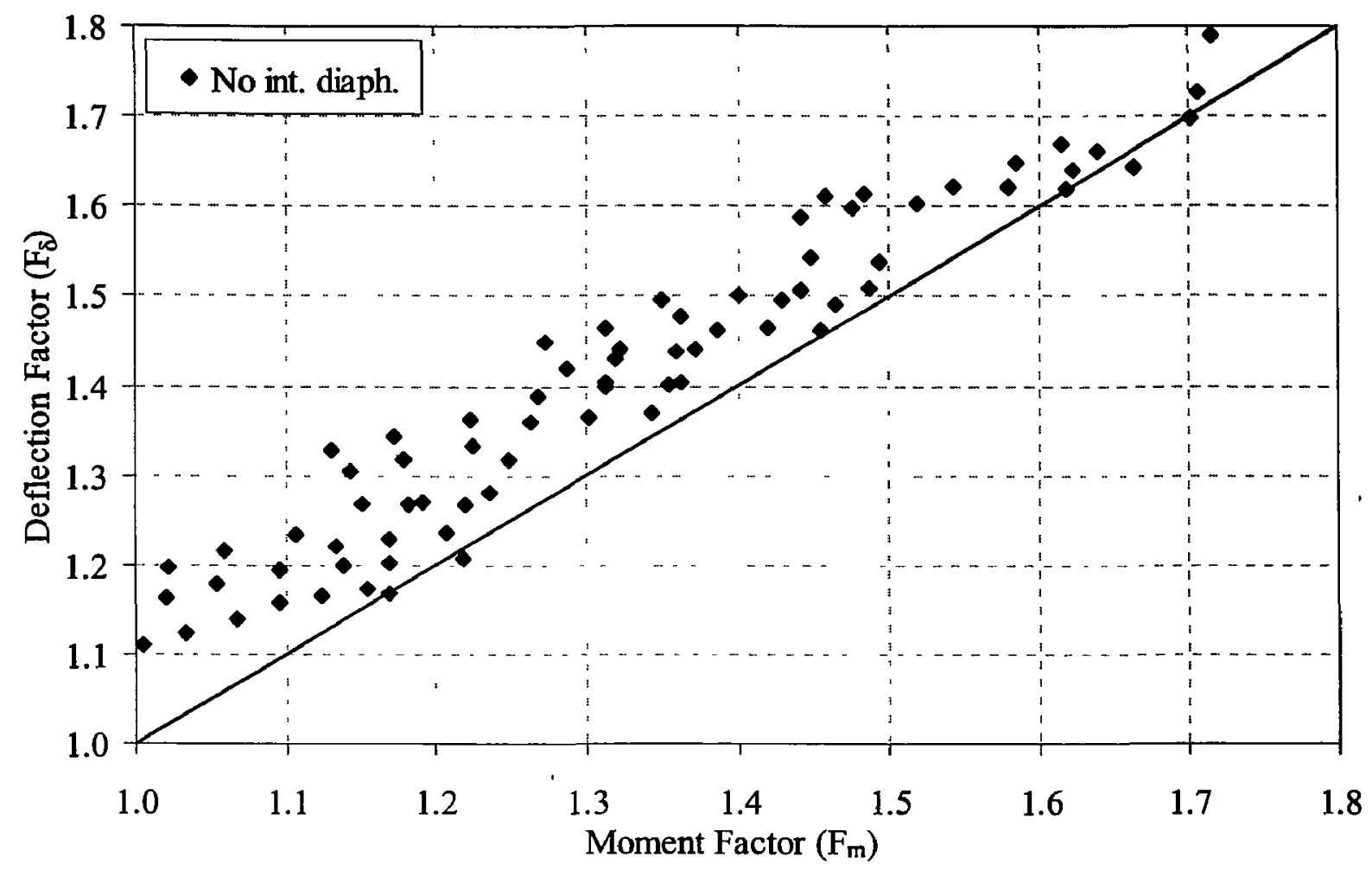

Figure 4.62 Comparison between deflection distribution factors vs. bending moment distribution factors for exterior girder for FLS

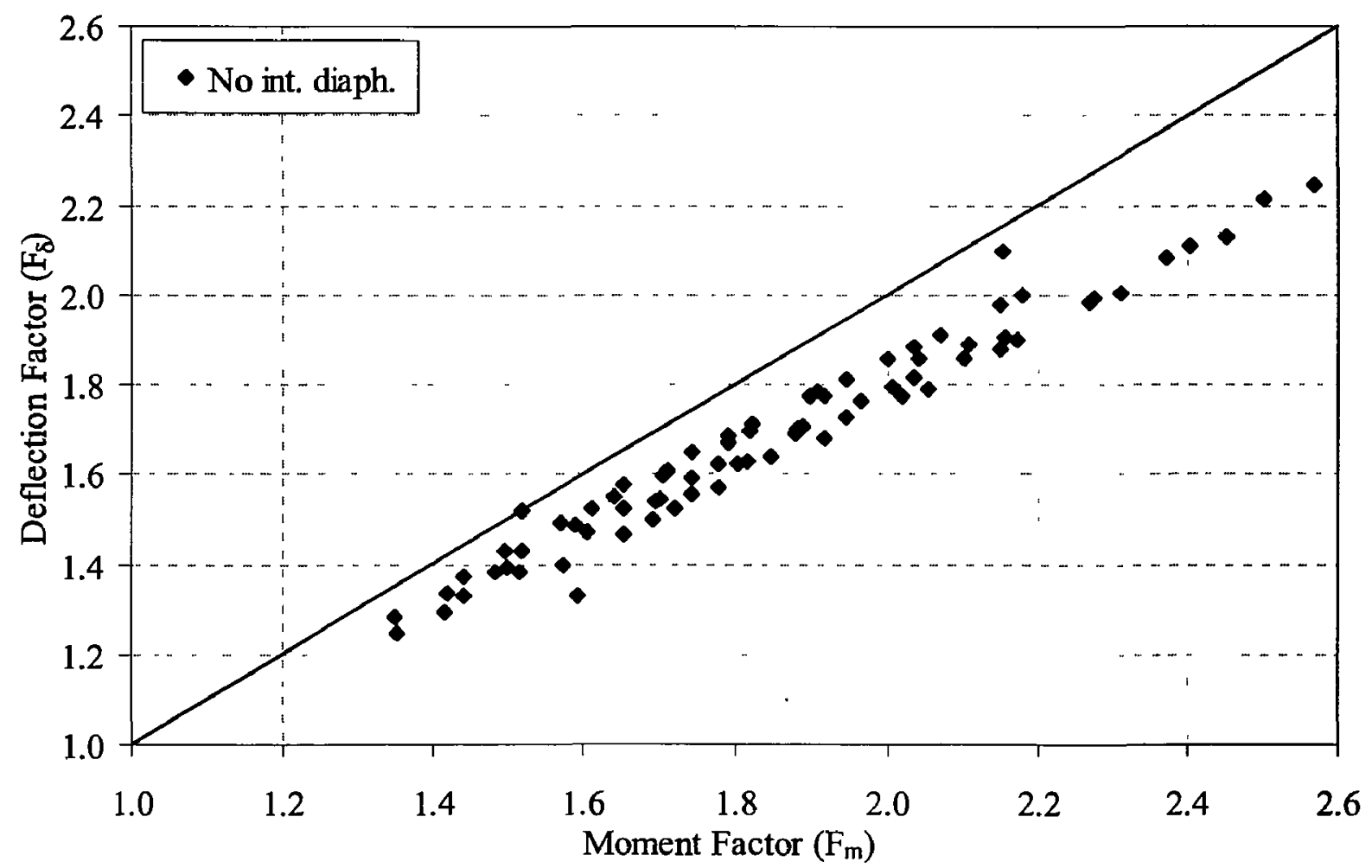

Figure 4.63 Comparison between deflection distribution factors vs. bending moment distribution factors for interior girder for FLS 


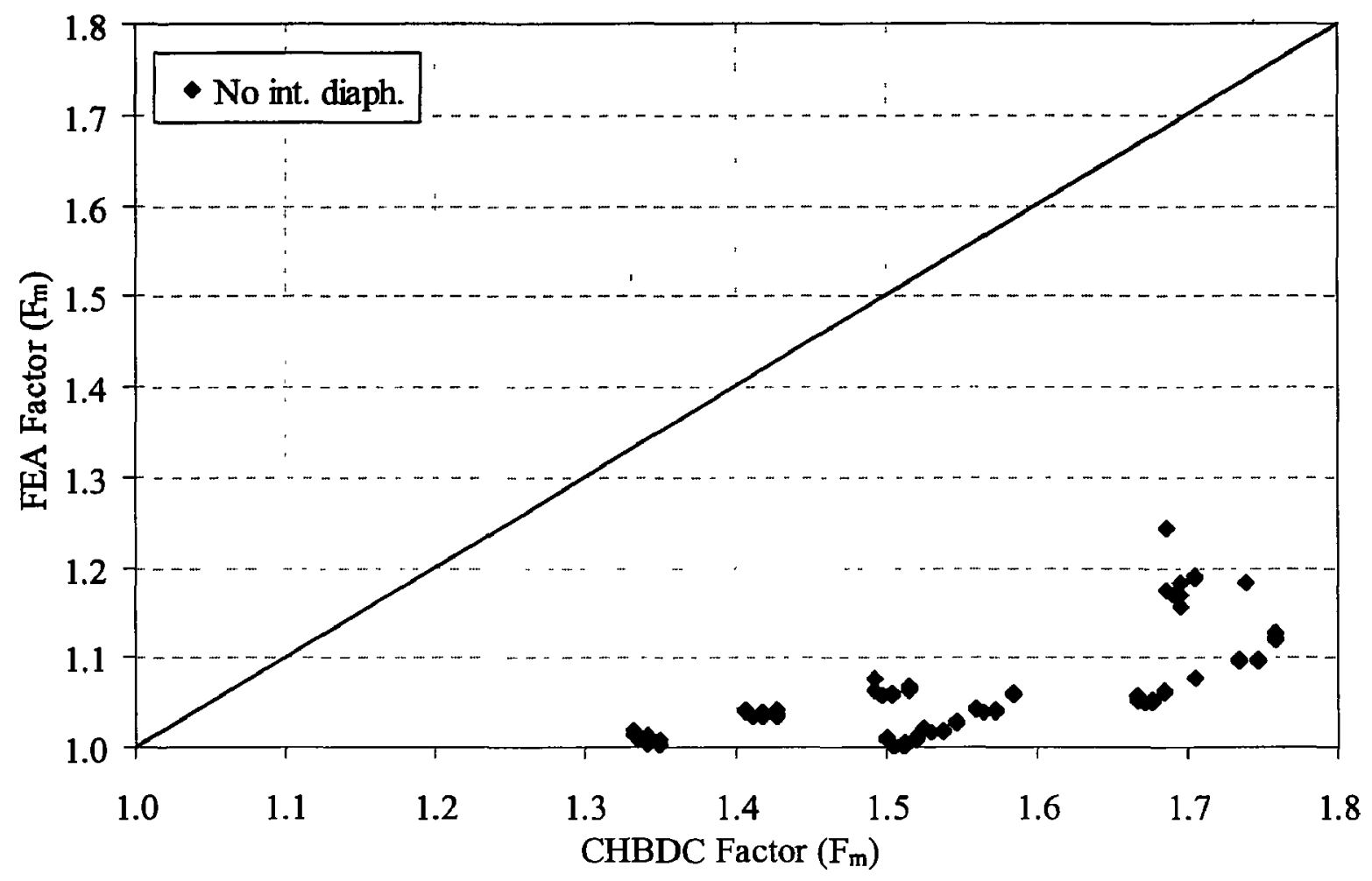

Figure 4.64 Comparison between moment distribution factors of the exterior girder as obtained from FEA and CHBDC

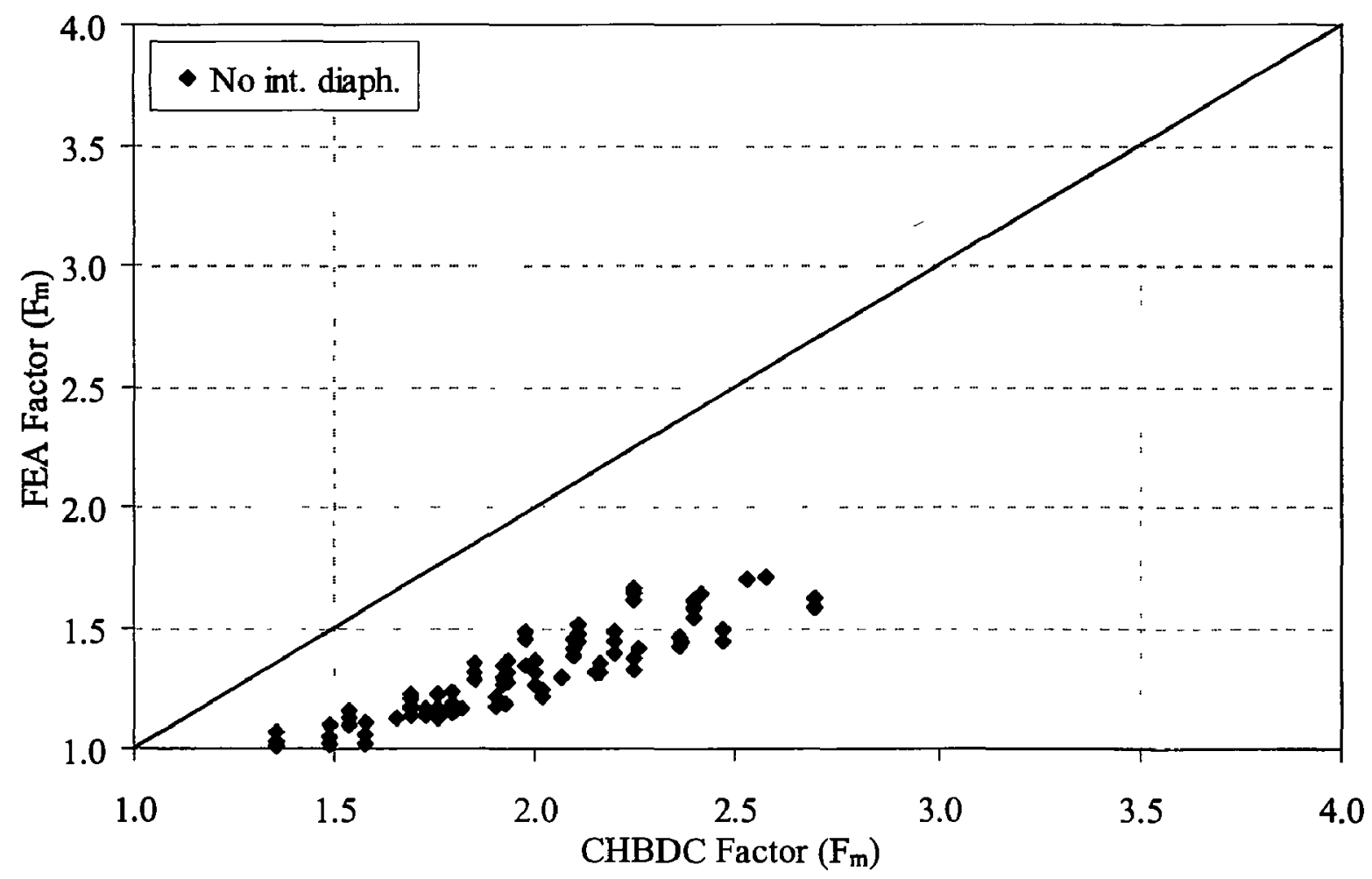

Figure 4.65 Comparison between moment distribution factors of the exterior girder for FLS as obtained from FEA and CHBDC 


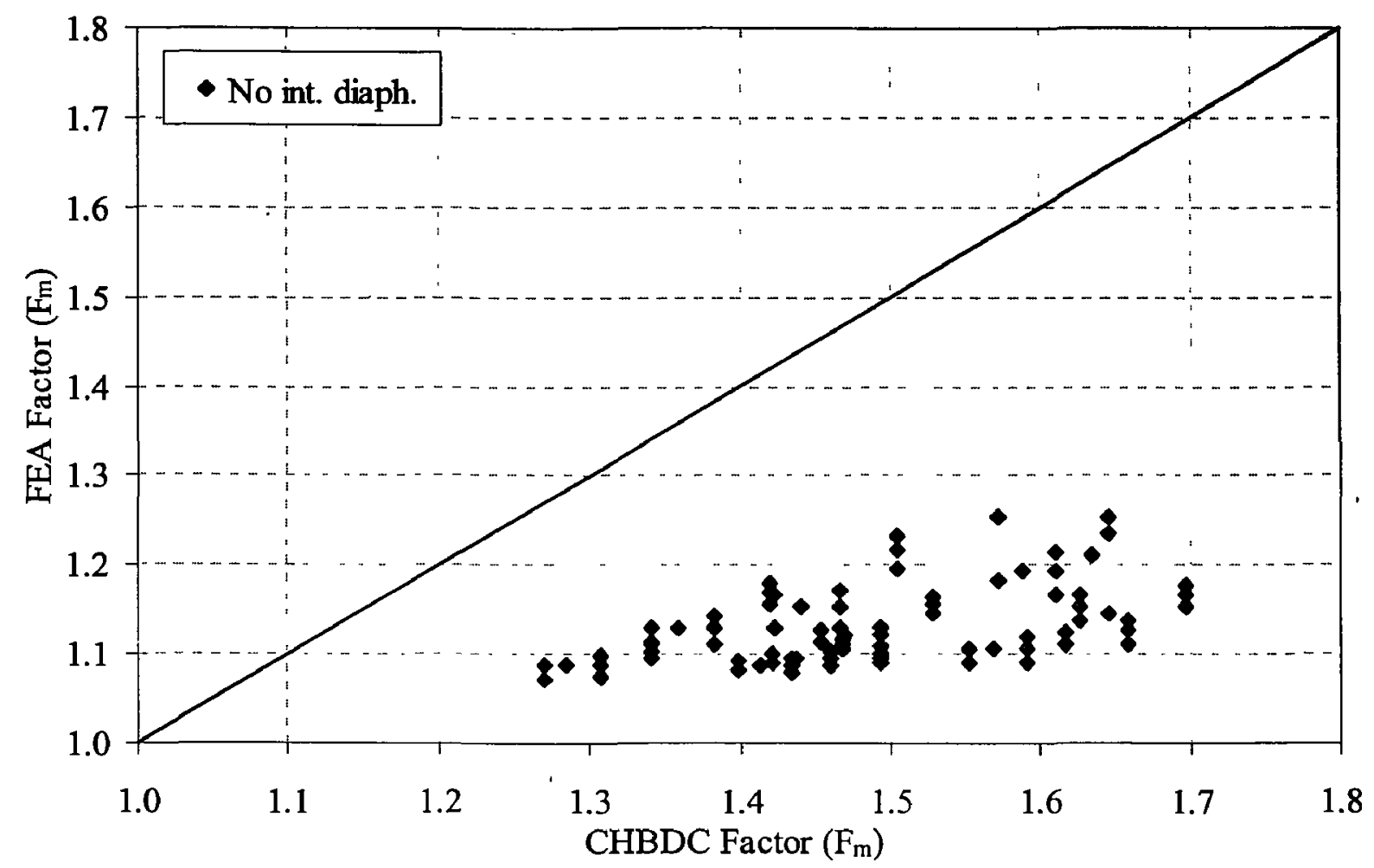

Figure 4.66 Comparison between moment distribution factors of the interior girder as obtained from FEA and CHBDC

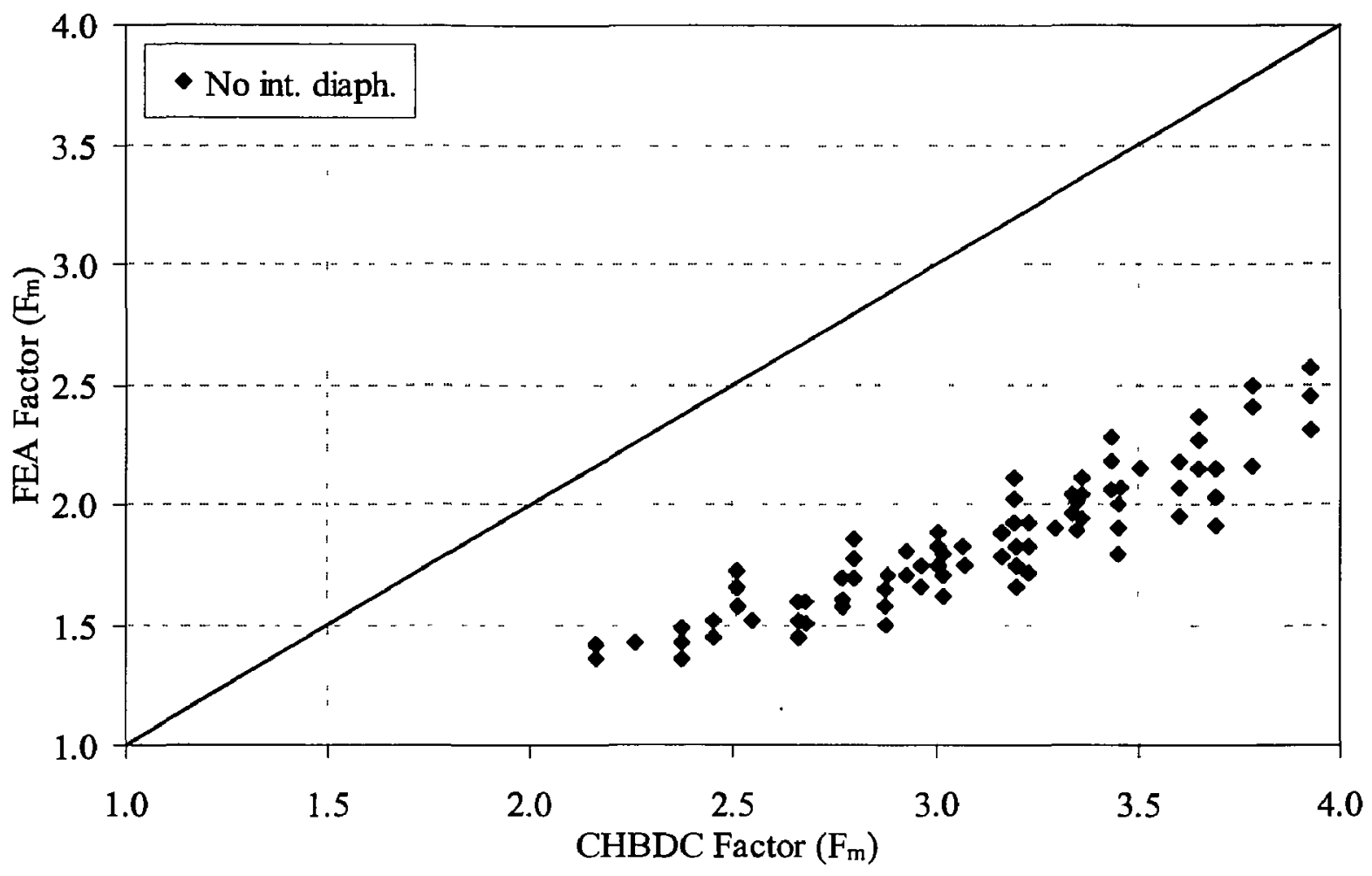

Figure 4.67 Comparison between moment distribution factors of the interior girder for FLS as obtained from FEA and CHBDC 


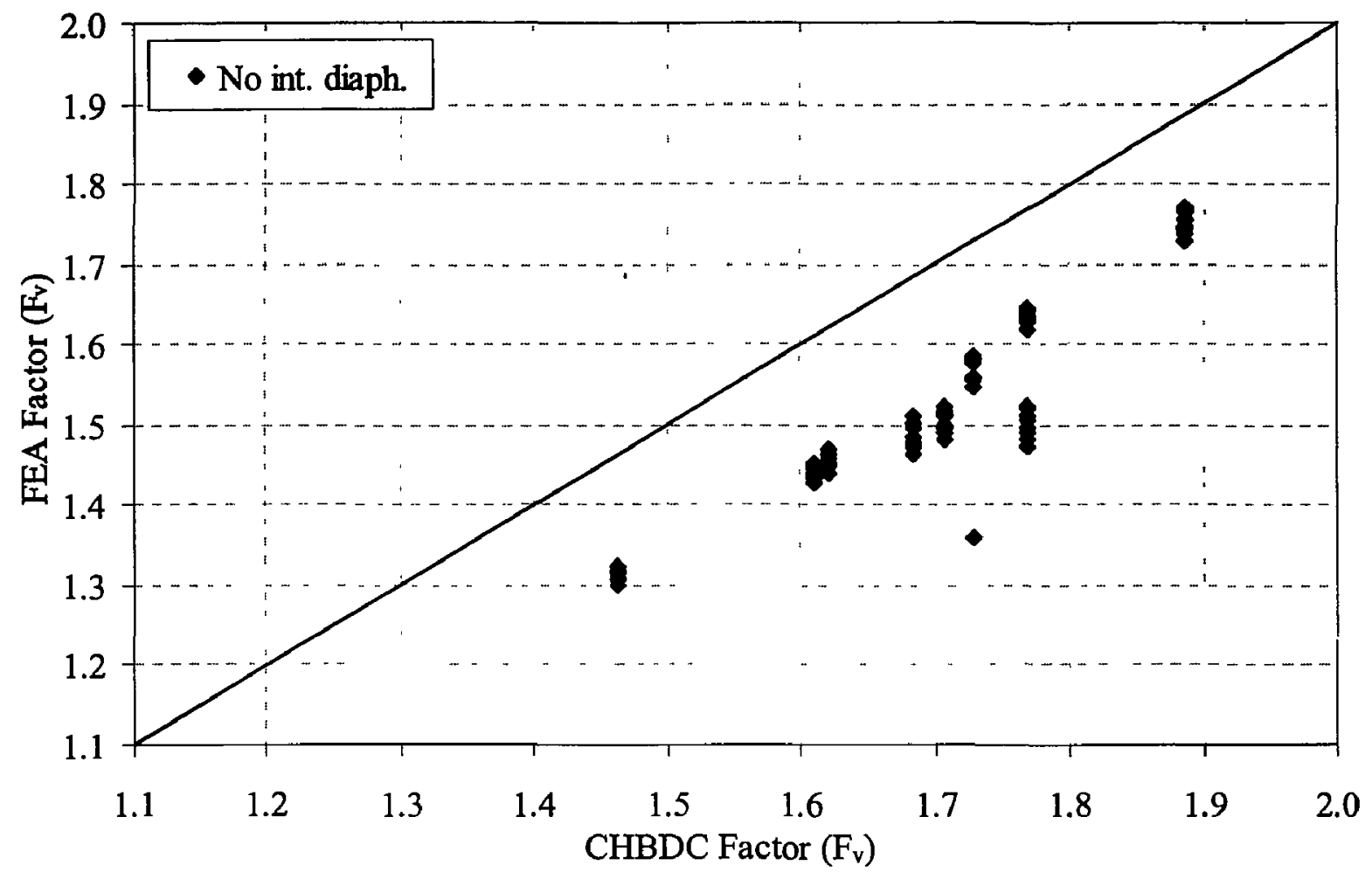

Figure 4.68 Comparison between shear distribution factors of the exterior girder as obtained from FEA and CHBDC

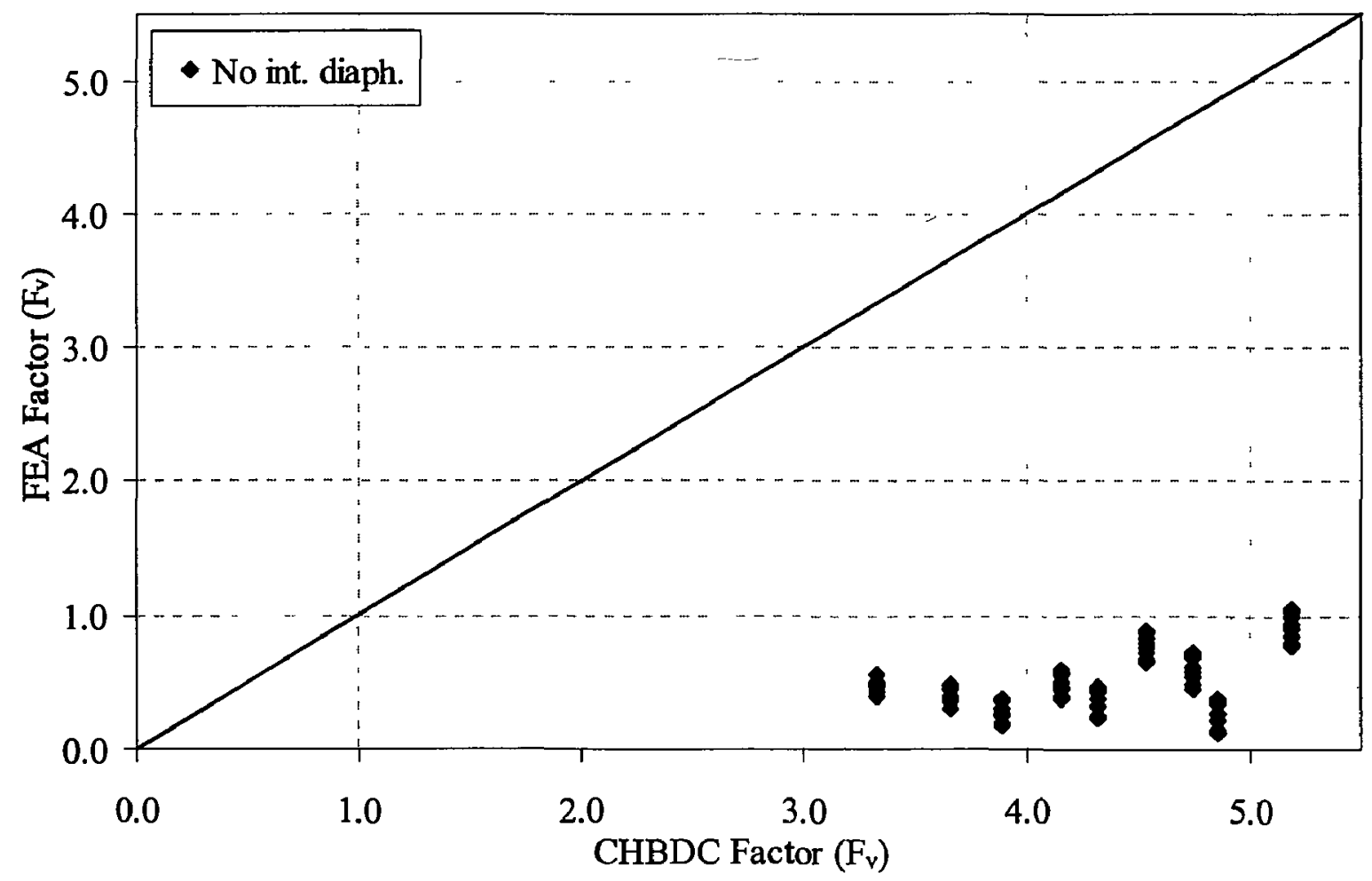

Figure 4.69 Comparison between shear distribution factors of the exterior girder for FLS as obtained from FEA and CHBDC 


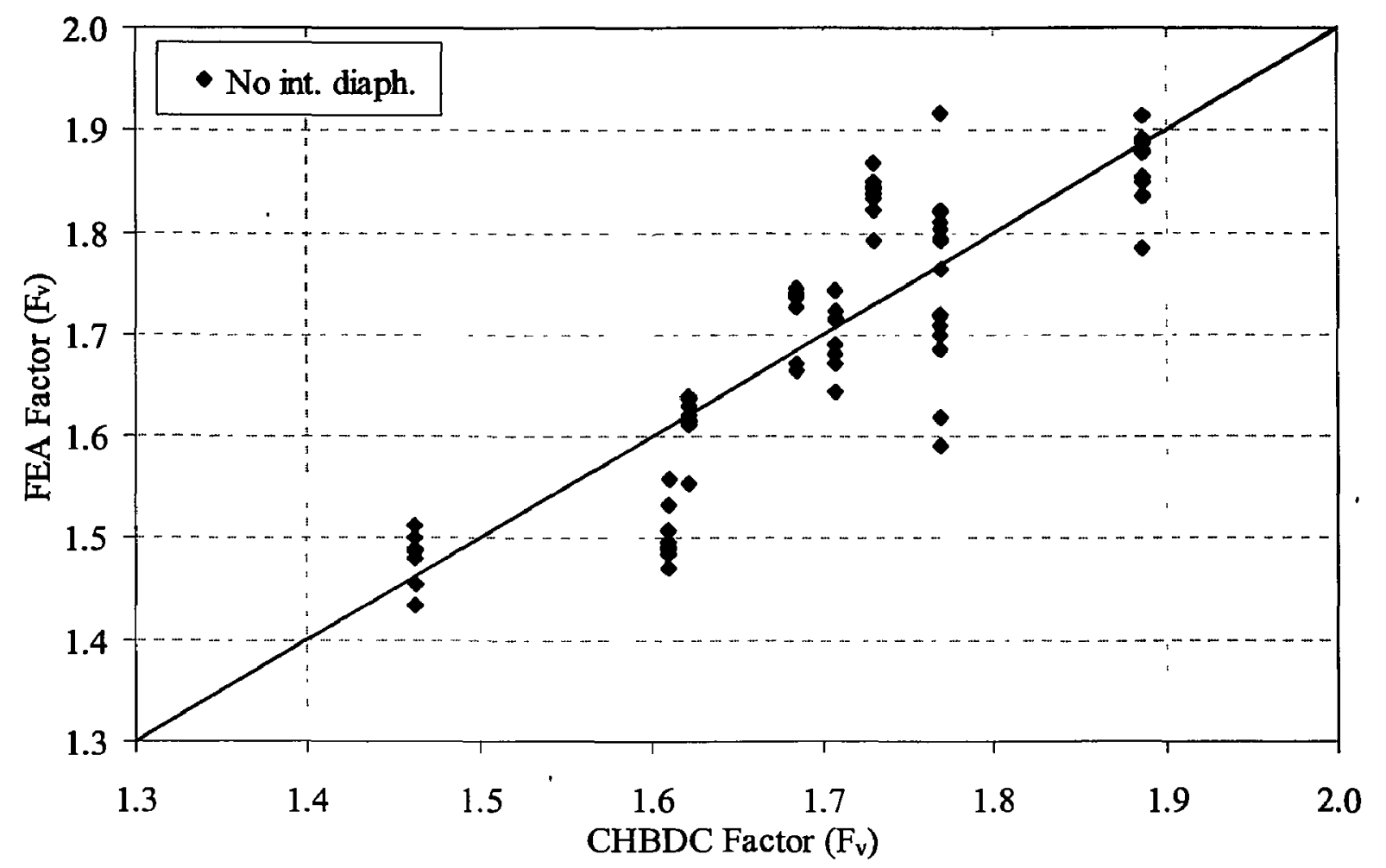

Figure 4.70 Comparison between shear distribution factors of the interior girder as obtained from FEA and CHBDC

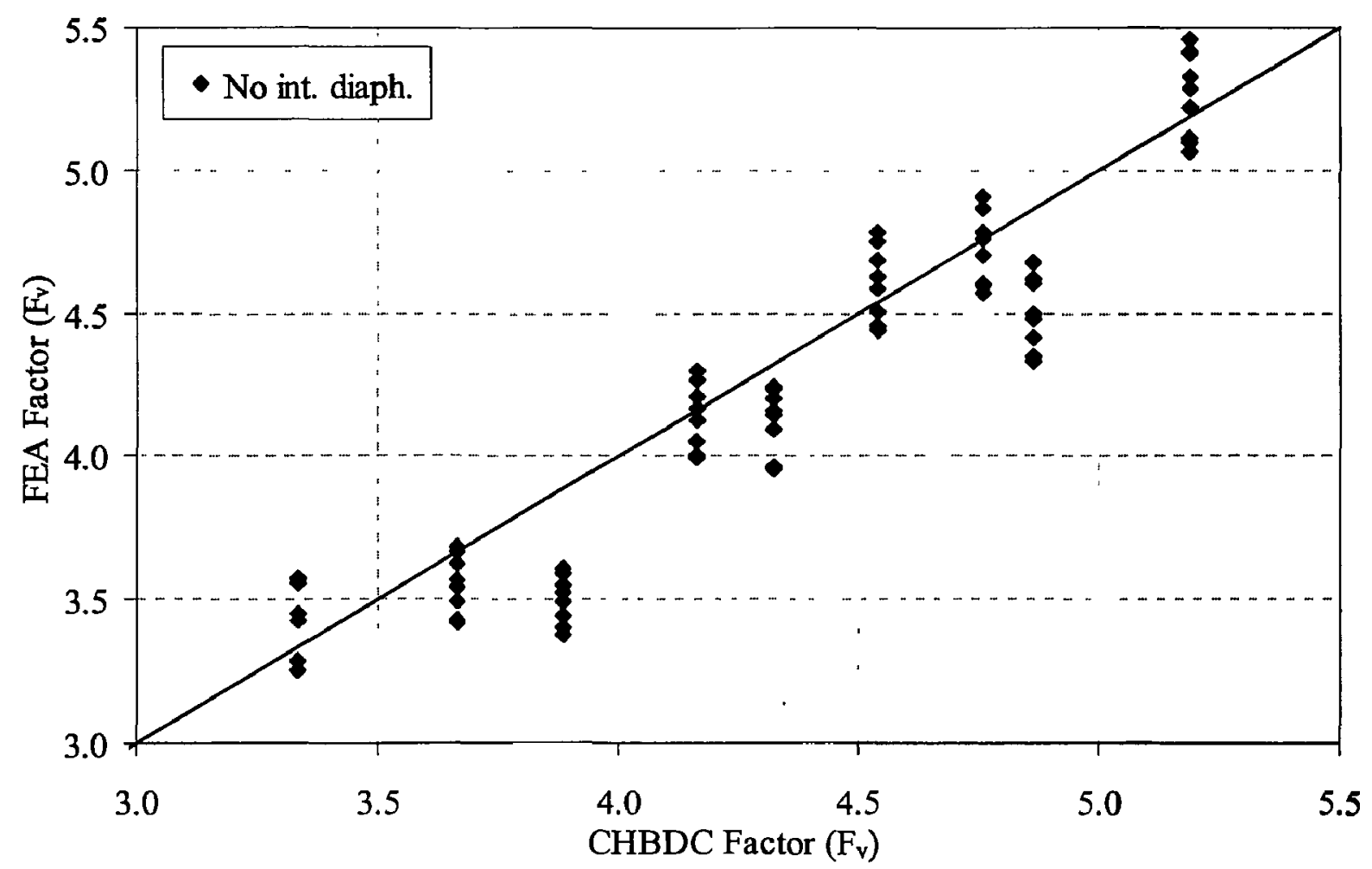

Figure 4.71 Comparison between shear distribution factors of the interior girder for FLS as obtained from FEA and CHBDC 


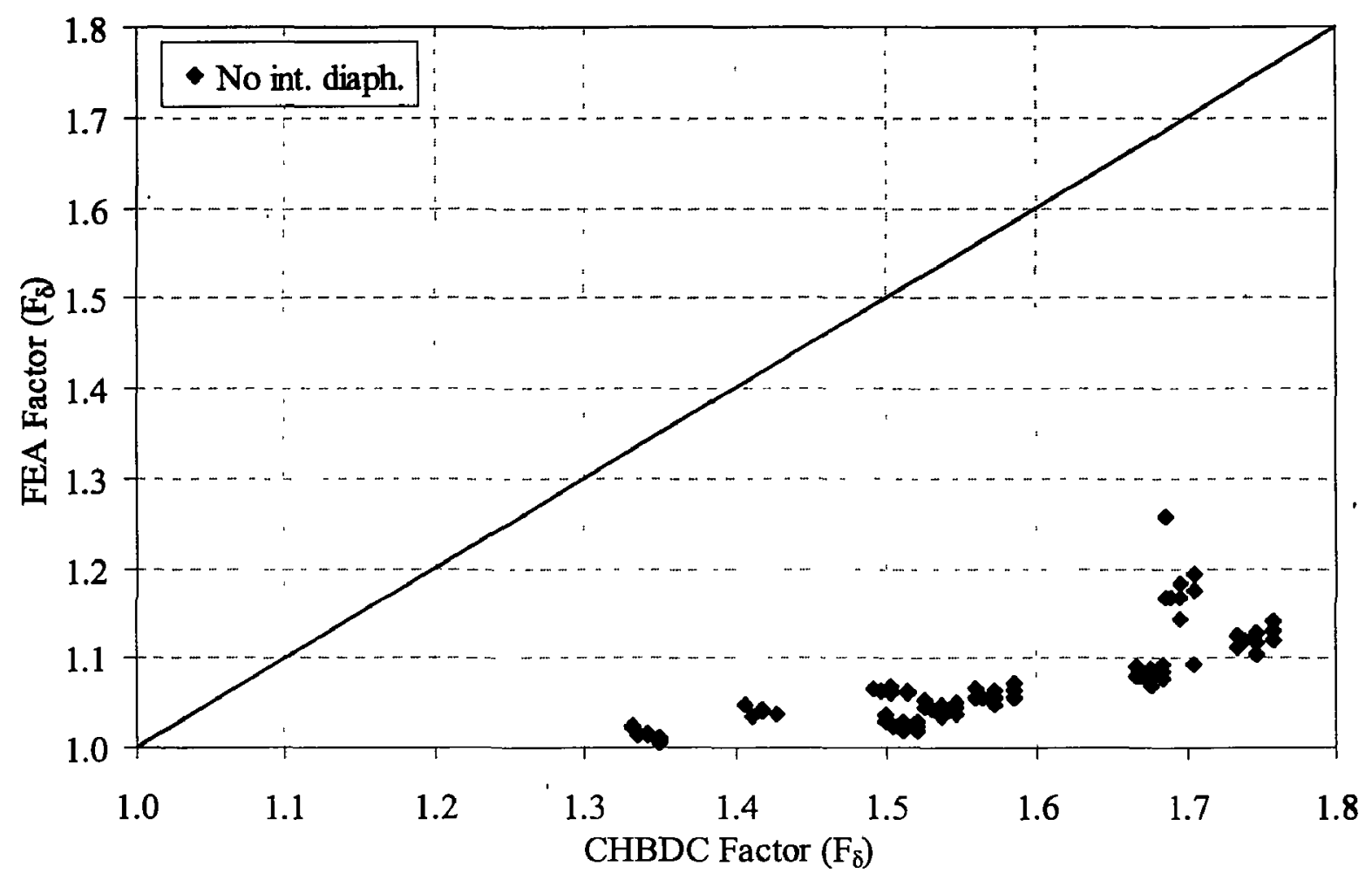

Figure 4.72 Comparison between deflection distribution factors of the exterior girder as obtained from FEA and CHBDC

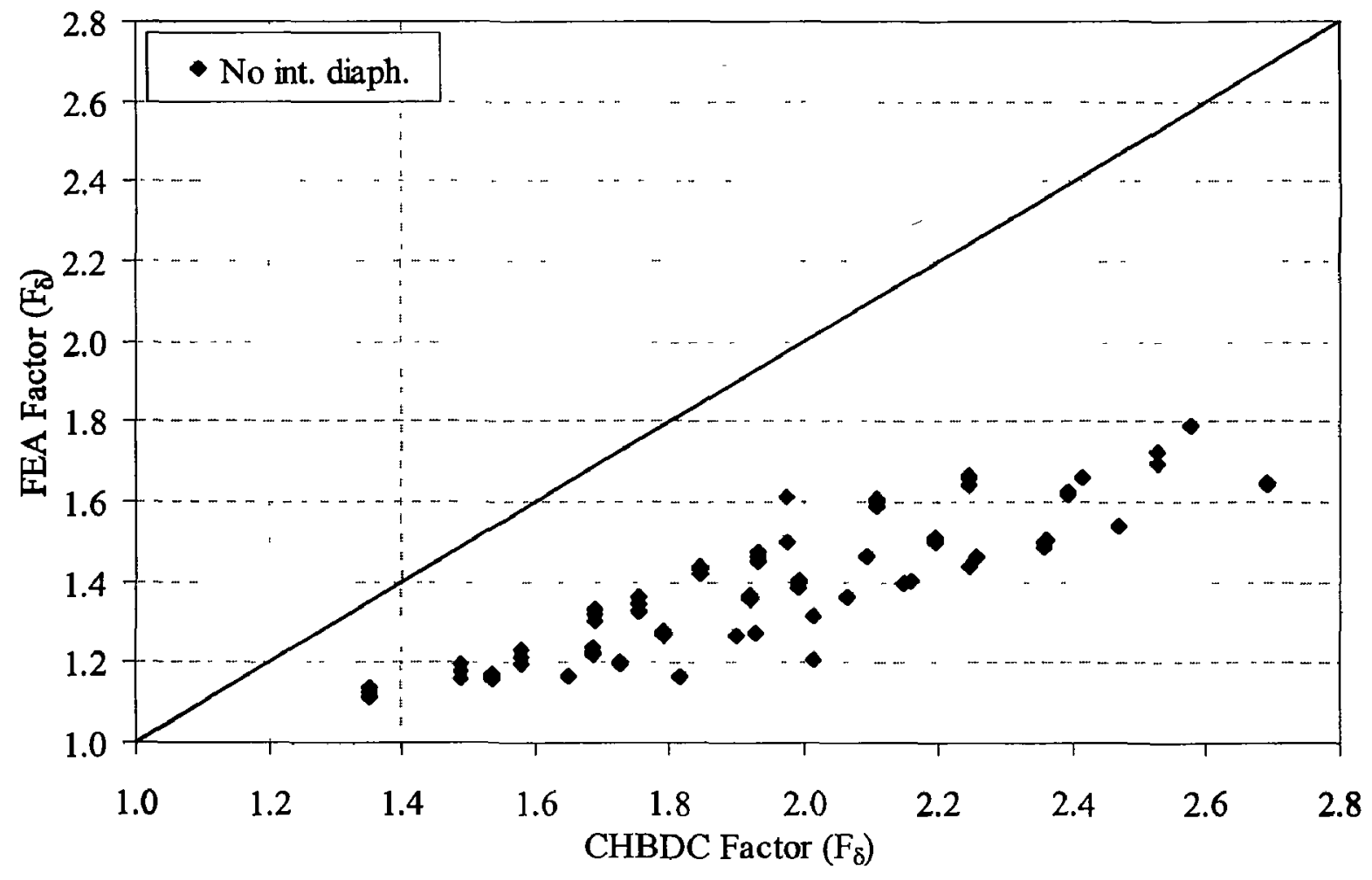

Figure 4.73 Comparison between deflection distribution factors of the exterior girder for FLS as obtained from FEA and CHBDC 


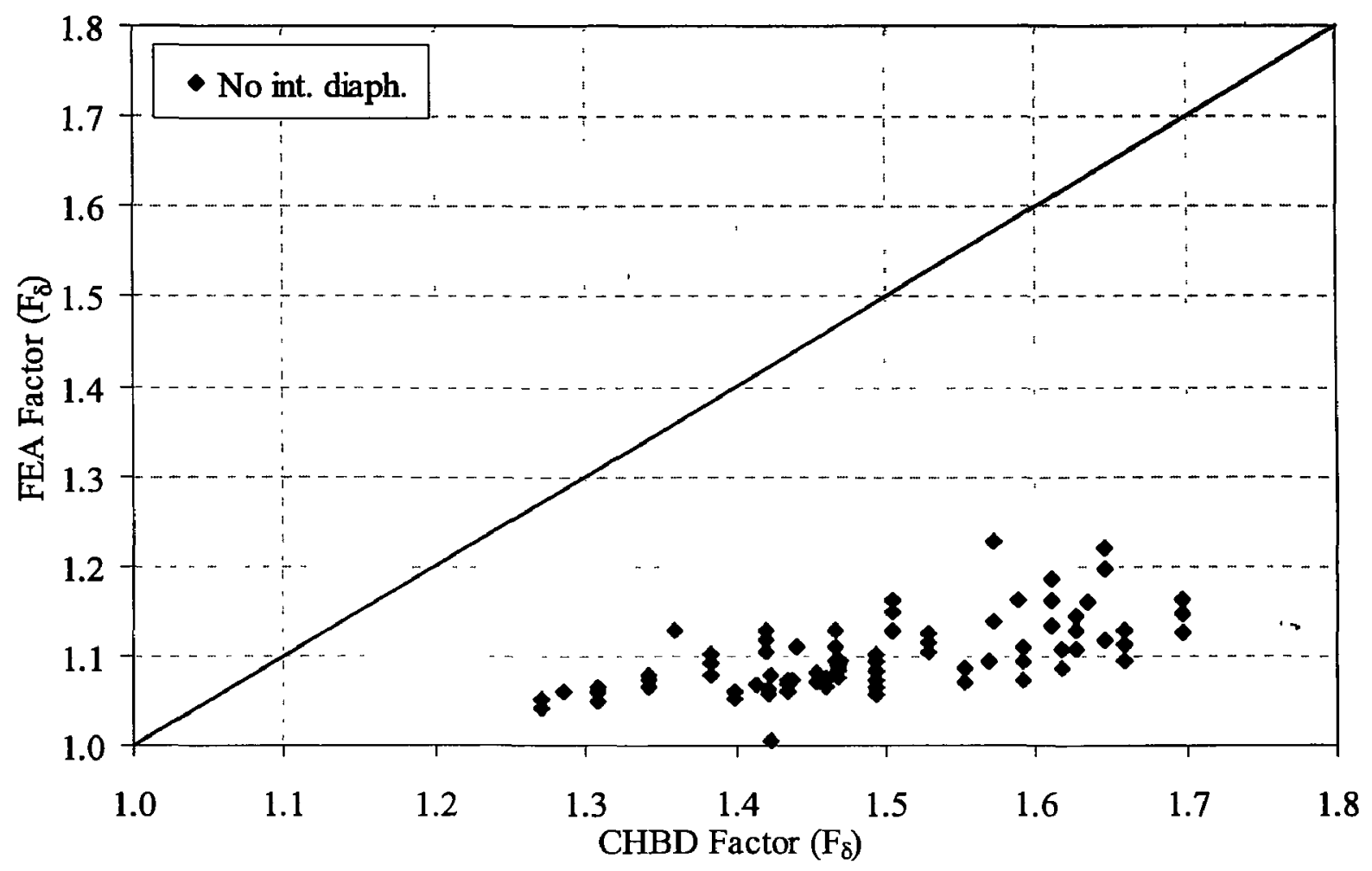

Figure 4.74 Comparison between deflection distribution factors of the interior girder as obtained from FEA and CHBDC

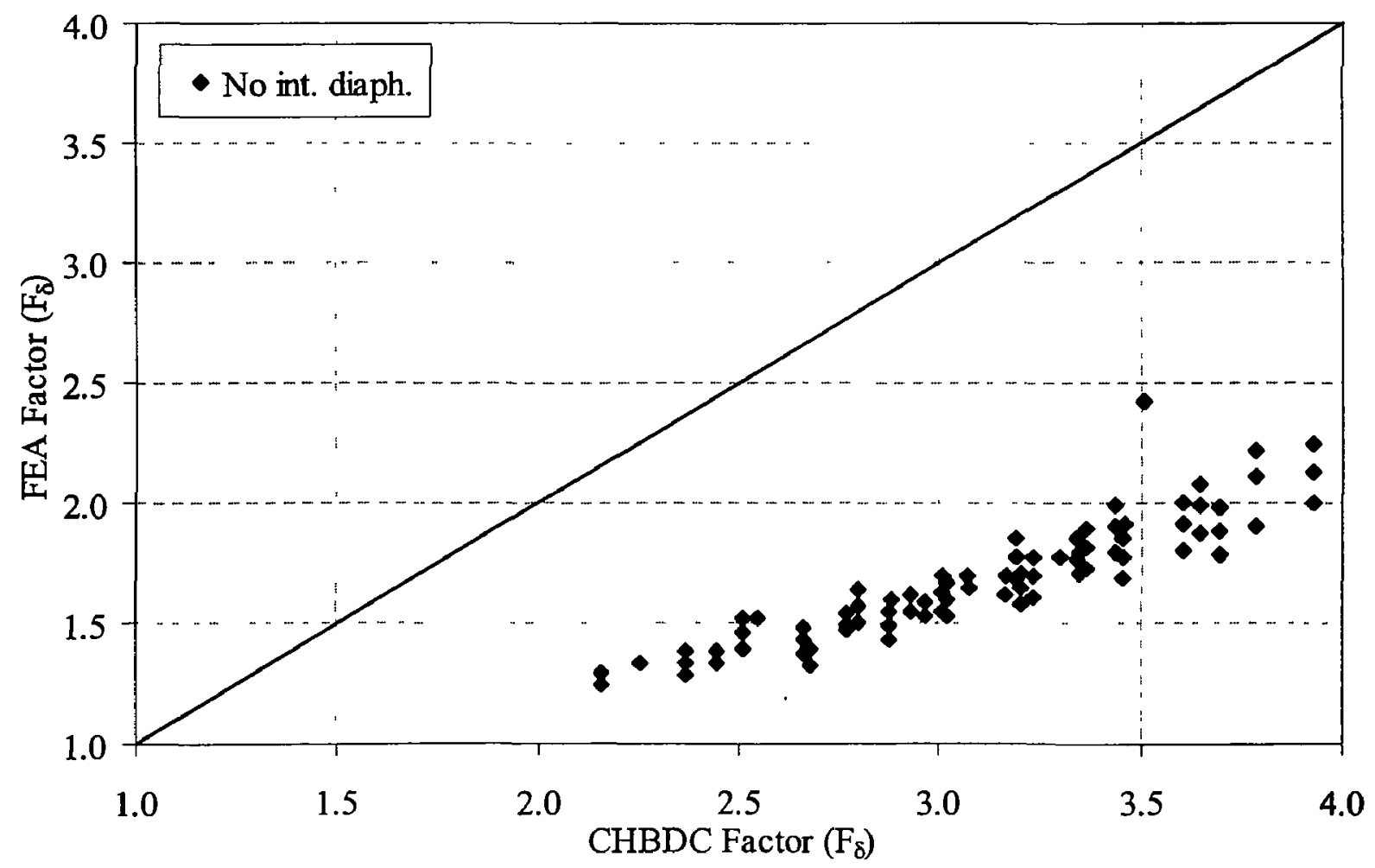

Figure 4.75 Comparison between deflection distribution factors of the interior girder for FLS as obtained from FEA and CHBDC 


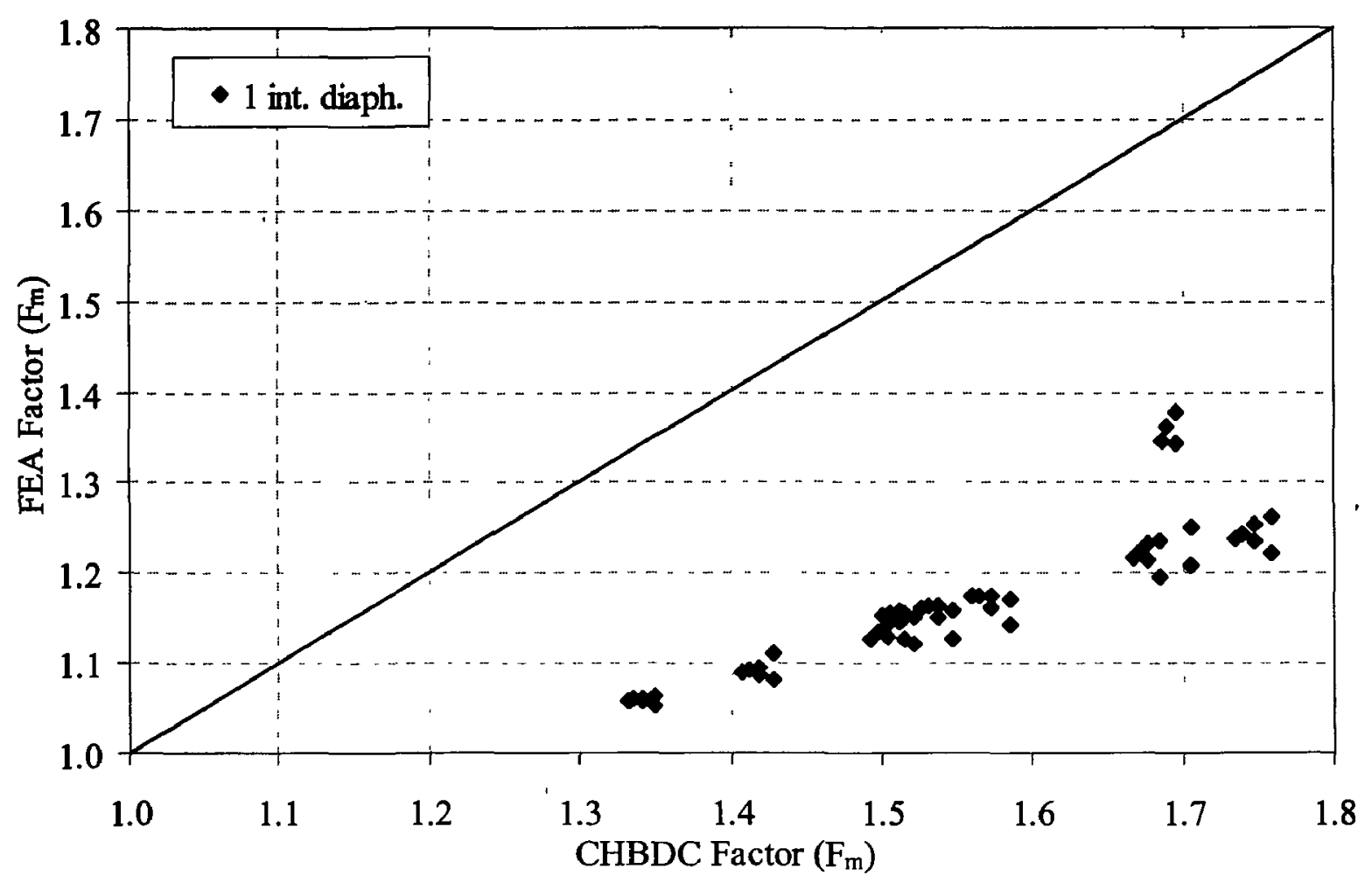

Figure 4.76 Comparison between moment distribution factors of the exterior girder as obtained from FEA and CHBDC

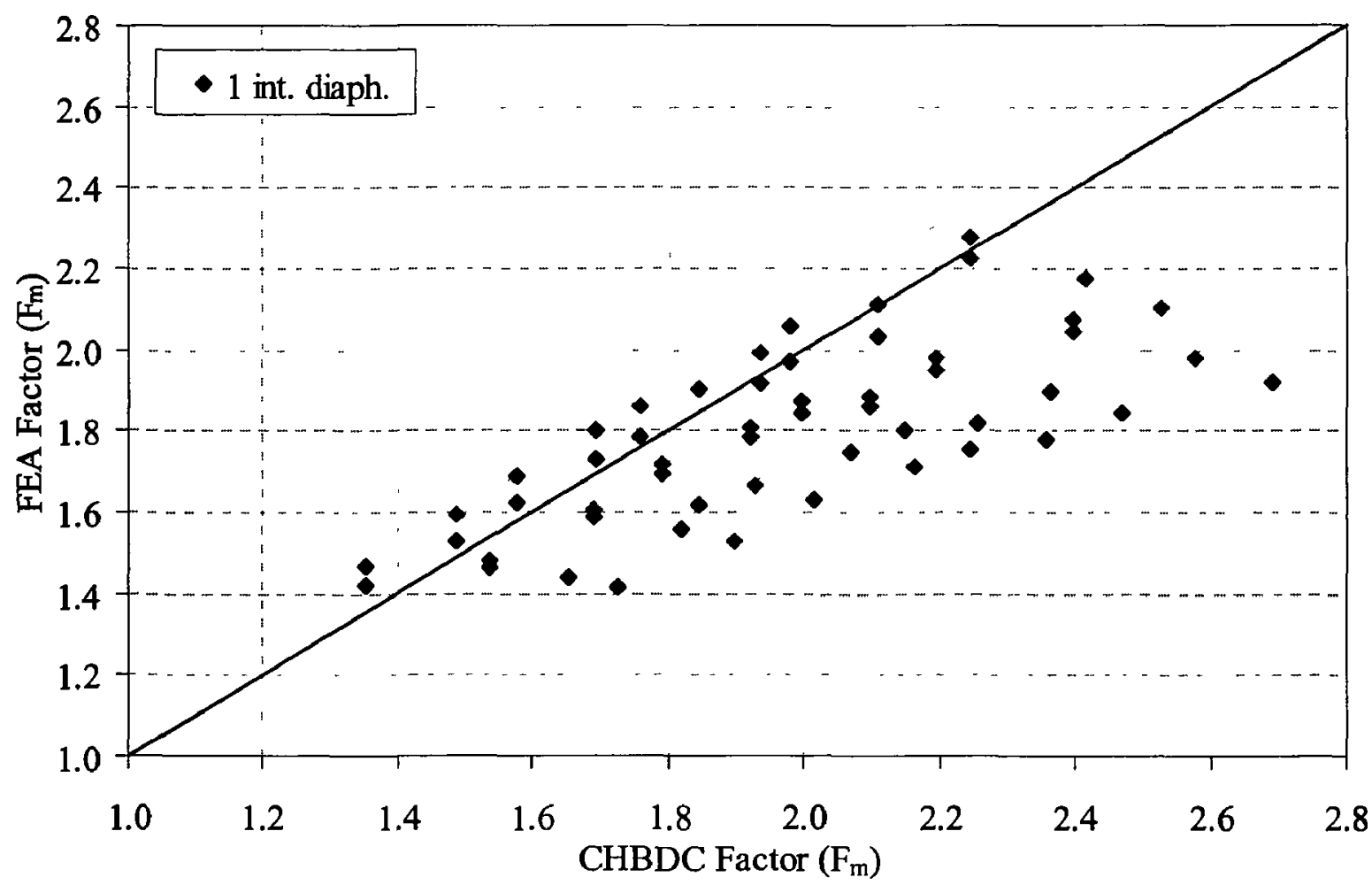

Figure 4.77 Comparison between moment distribution factors of the exterior girder for FLS as obtained from FEA and CHBDC 


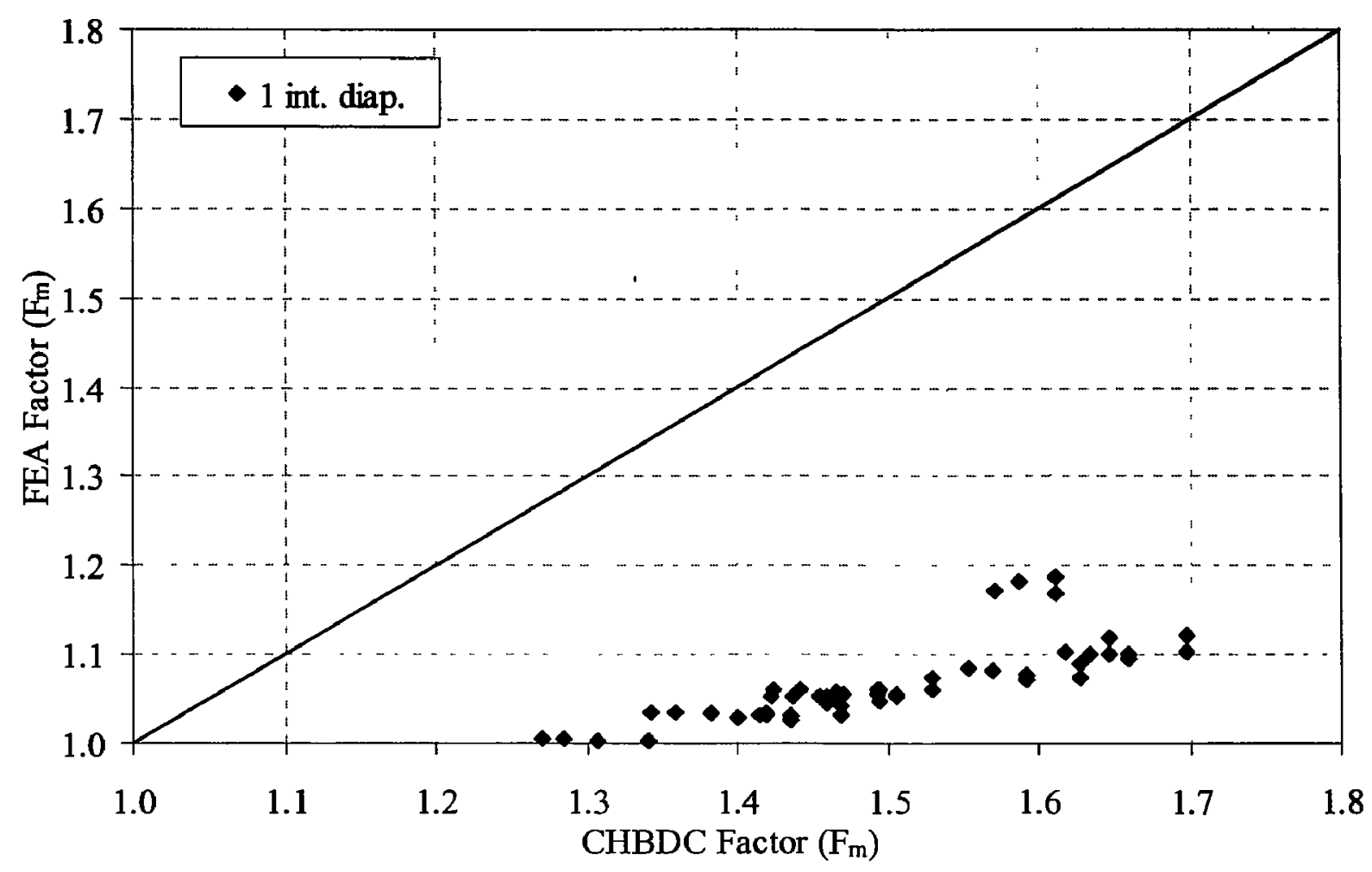

Figure 4.78 Comparison between moment distribution factors of the interior girder as obtained from FEA and CHBDC

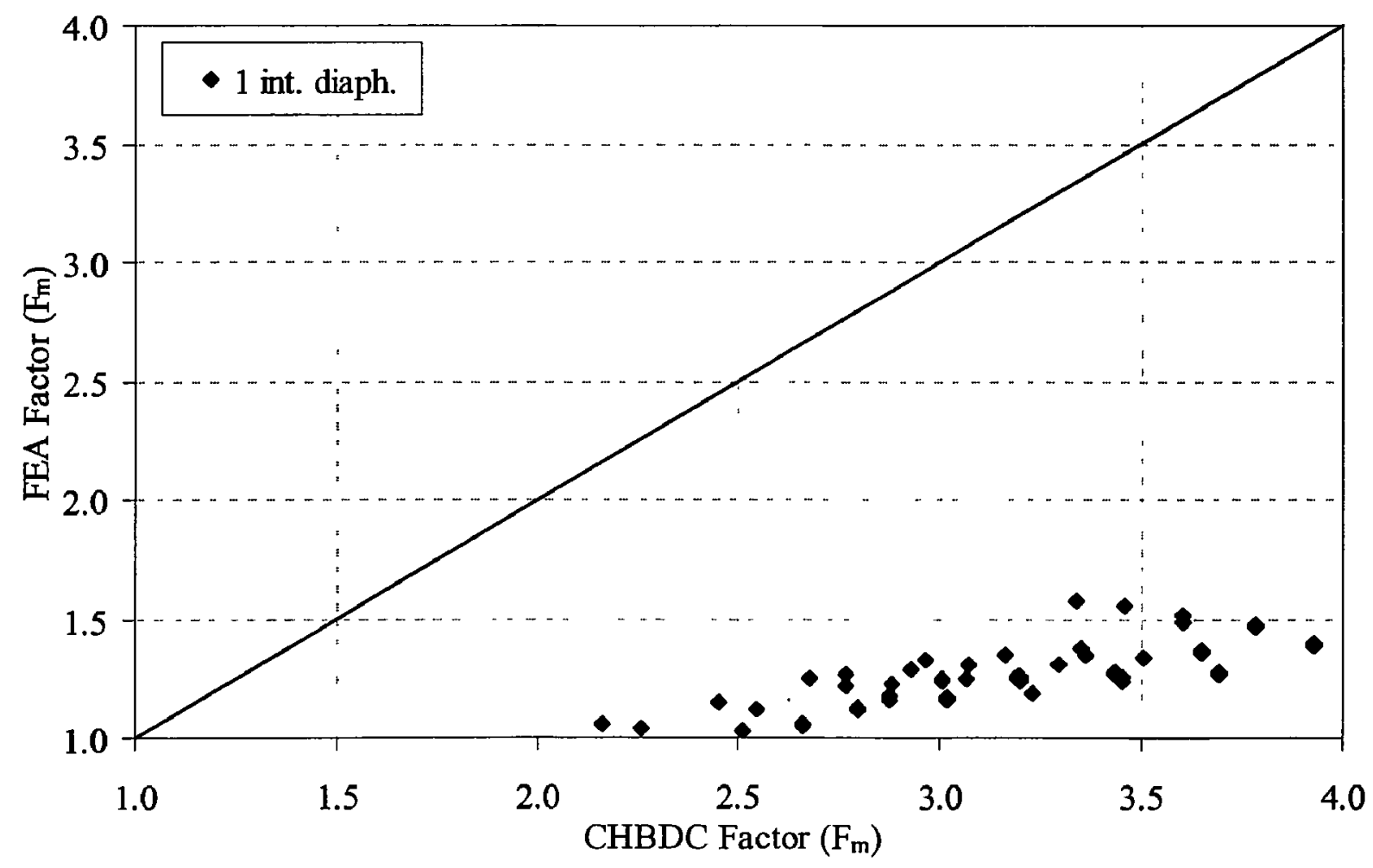

Figure 4.79 Comparison between moment distribution factors of the interior girder for FLS as obtained from FEA and CHBDC 


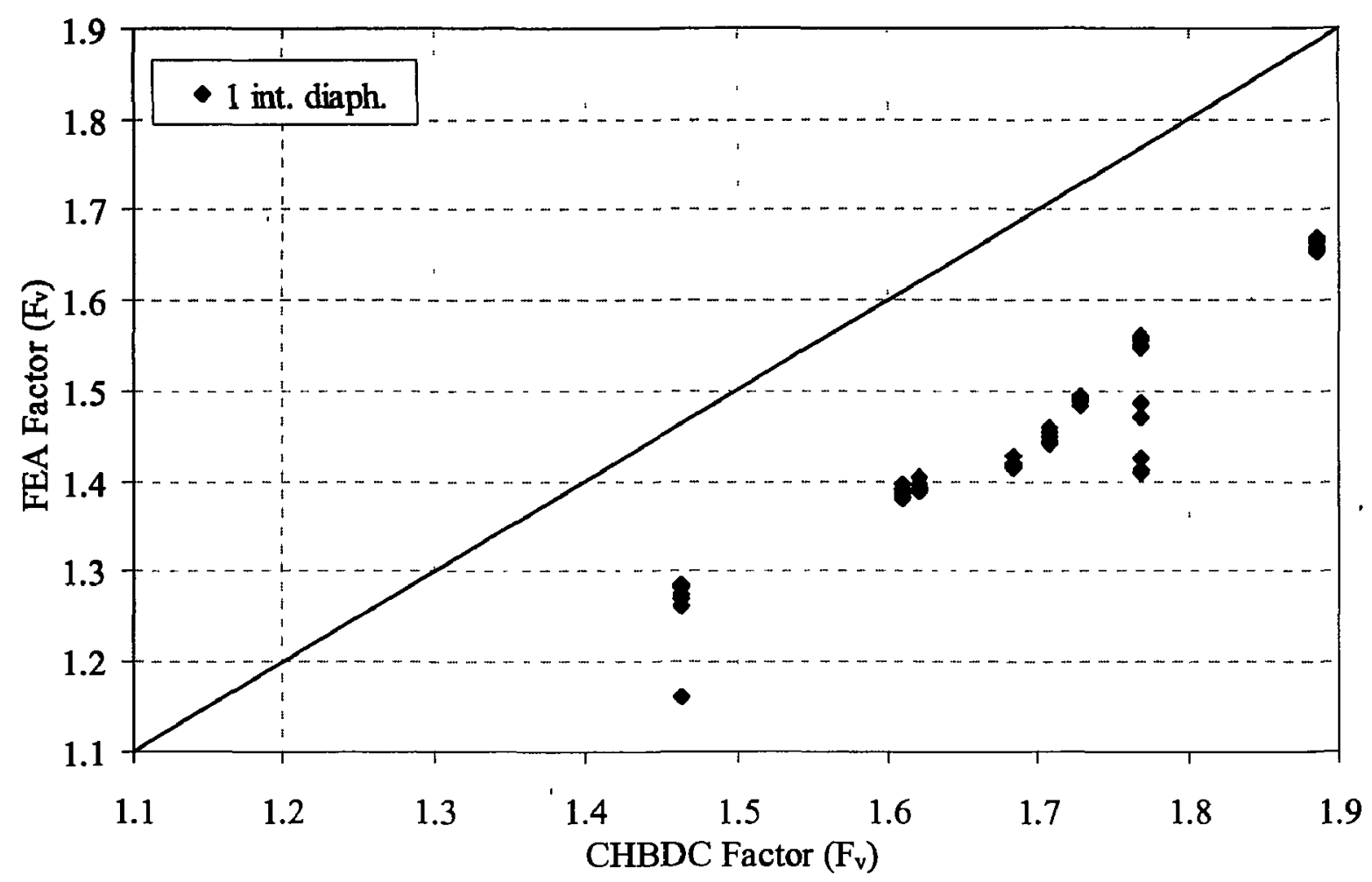

Figure 4.80 Comparison between shear distribution factors of the exterior girder as obtained from FEA and CHBDC

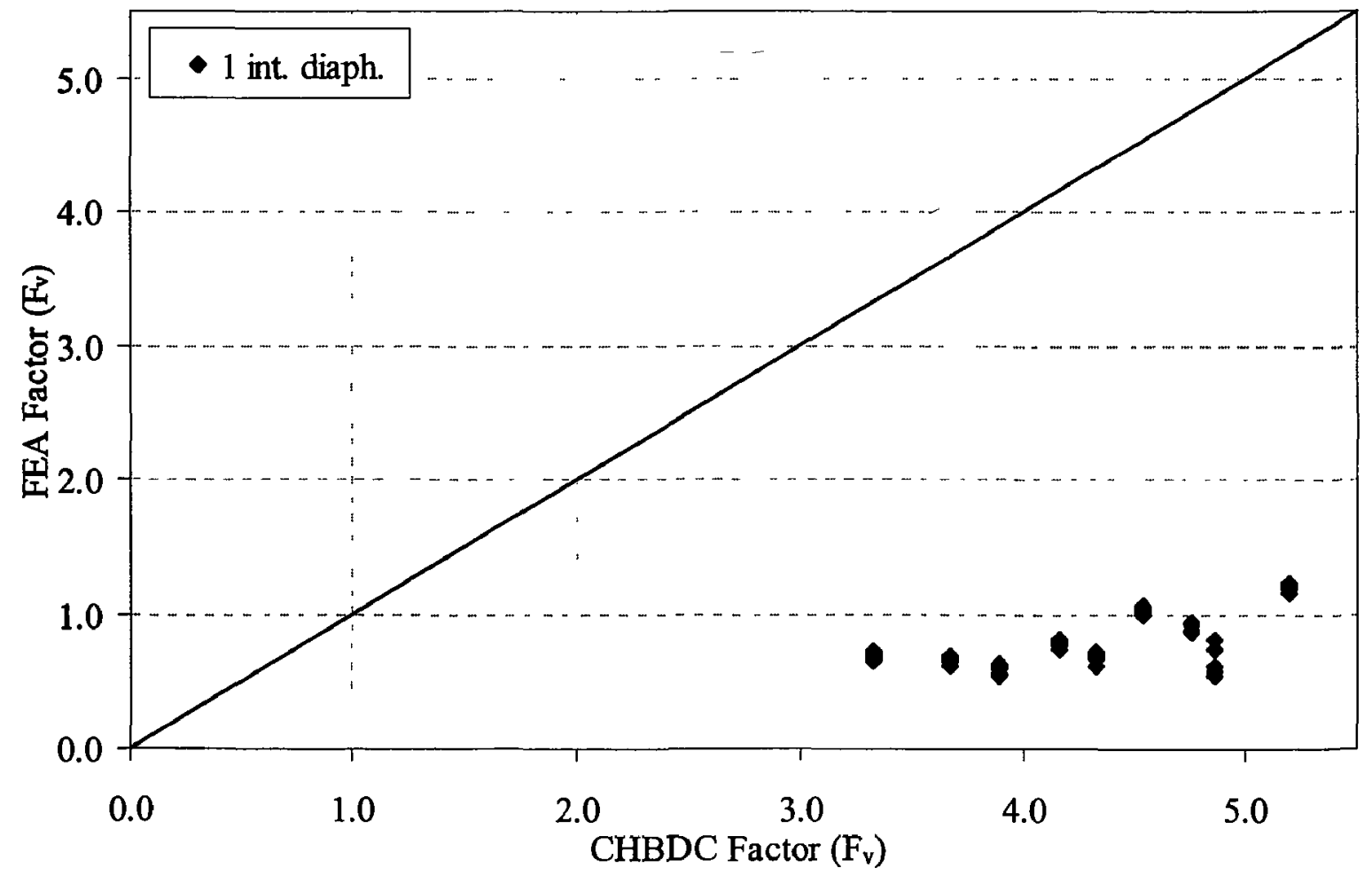

Figure 4.81 Comparison between shear distribution factors of the exterior girder for FLS as obtained from FEA and CHBDC 


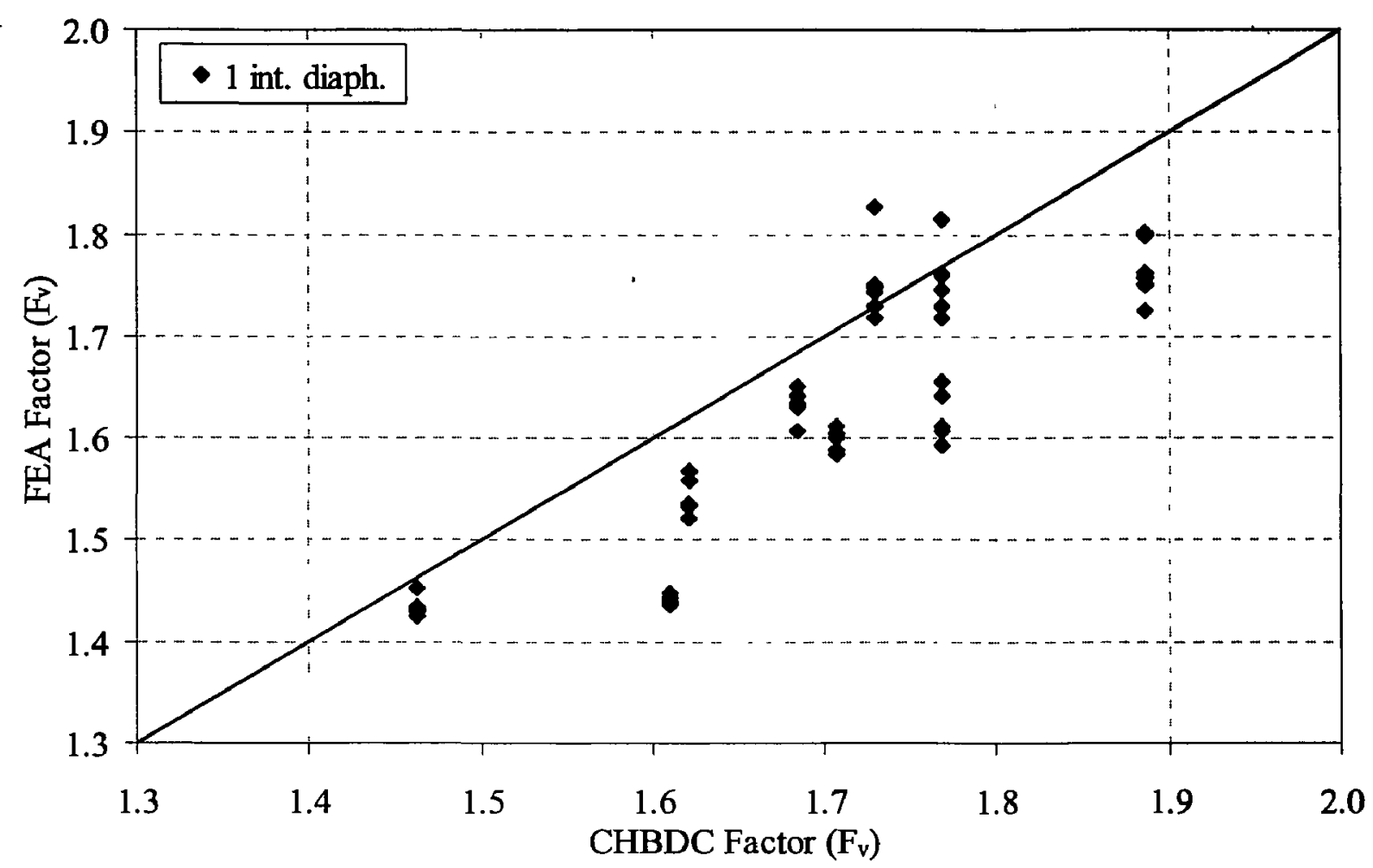

Figure 4.82 Comparison between shear distribution factors of the interior girder as obtained from FEA and CHBDC

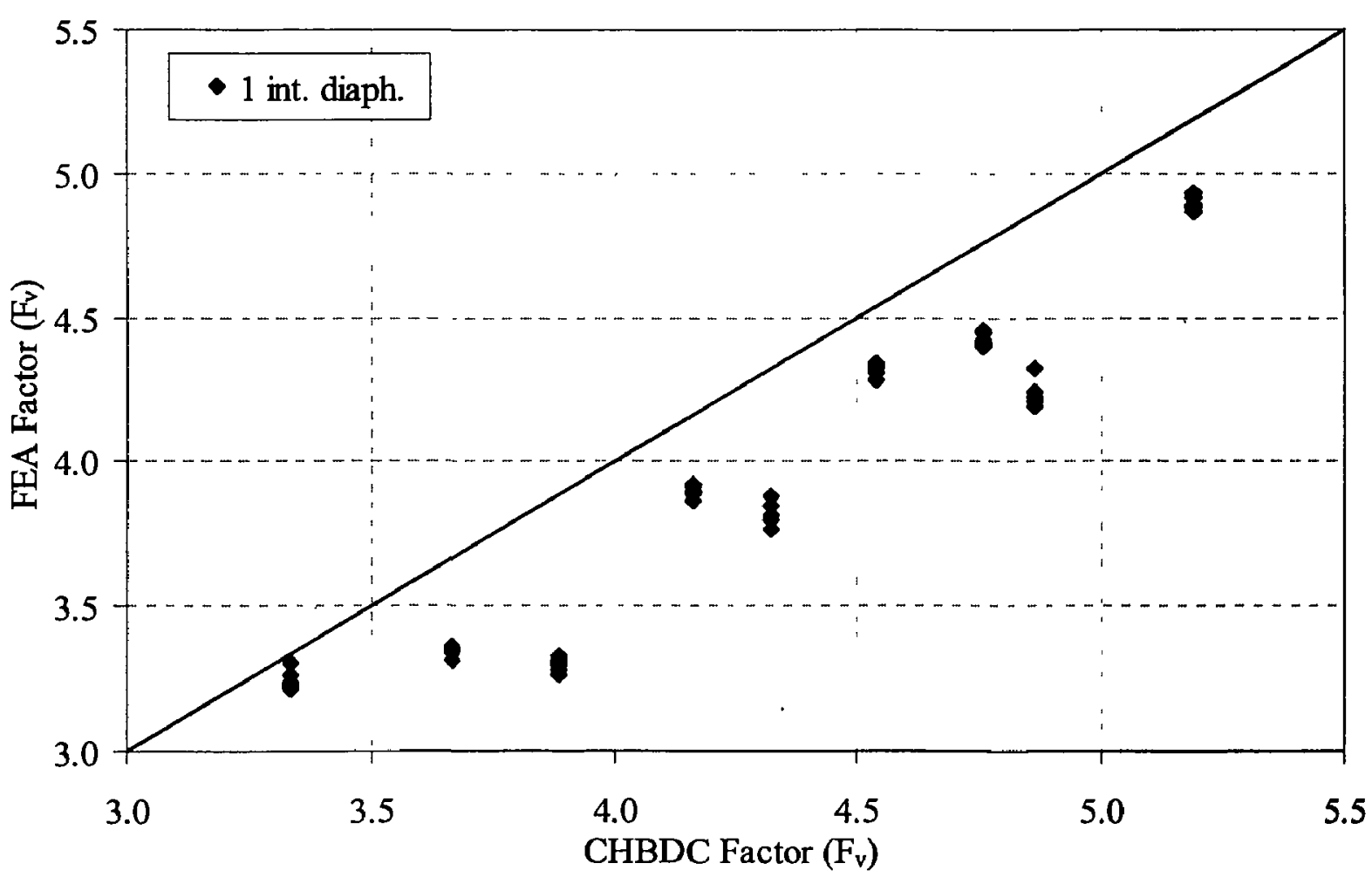

Figure 4.83 Comparison between fatigue shear distribution factors of the interior girder for FLS as obtained from FEA and CHBDC 


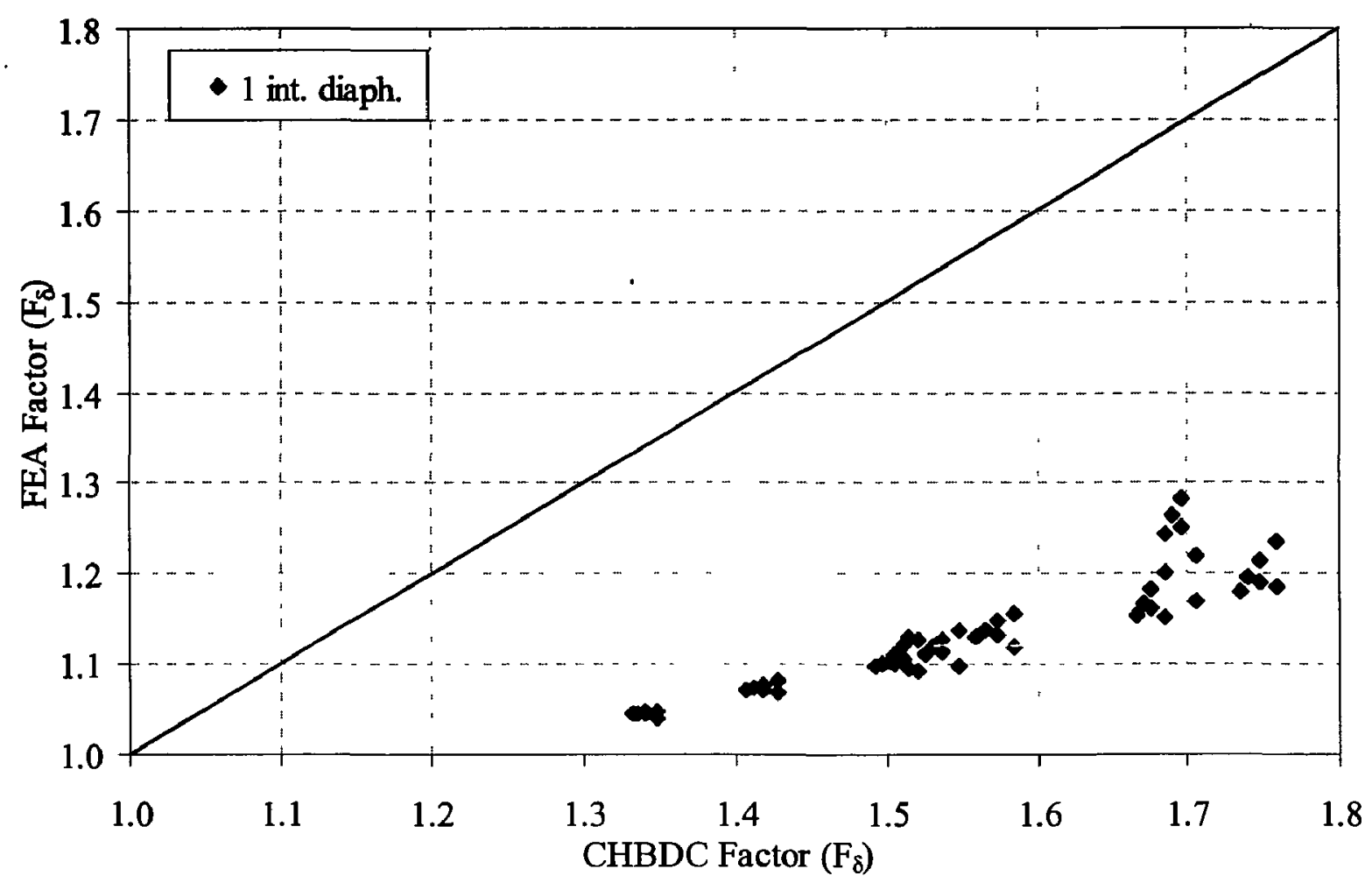

Figure 4.84 Comparison between deflection distribution factors of the exterior girder as obtained from FEA and CHBDC

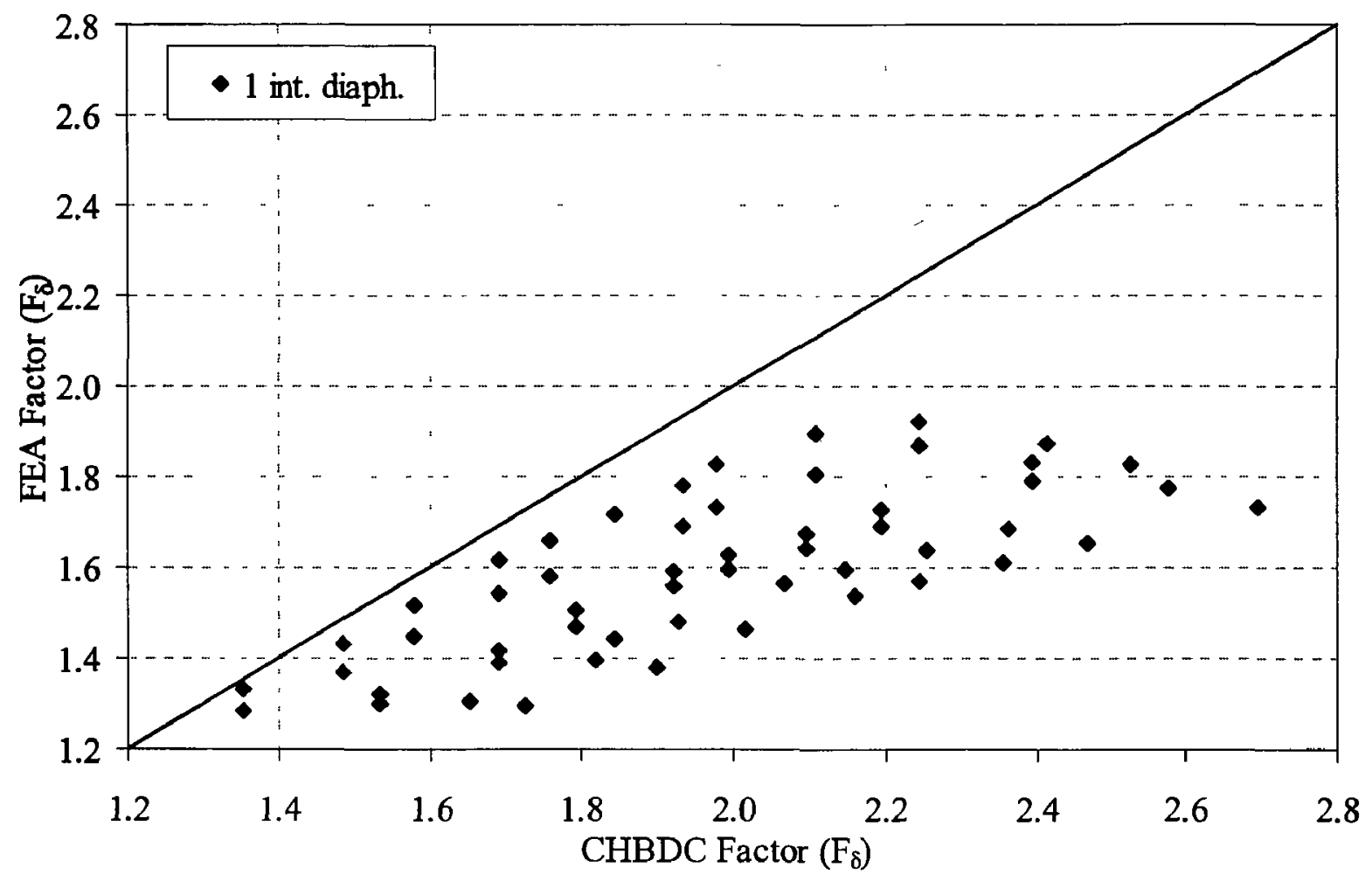

Figure 4.85 Comparison between deflection distribution factors of the exterior girder for FLS as obtained from FEA and CHBDC 


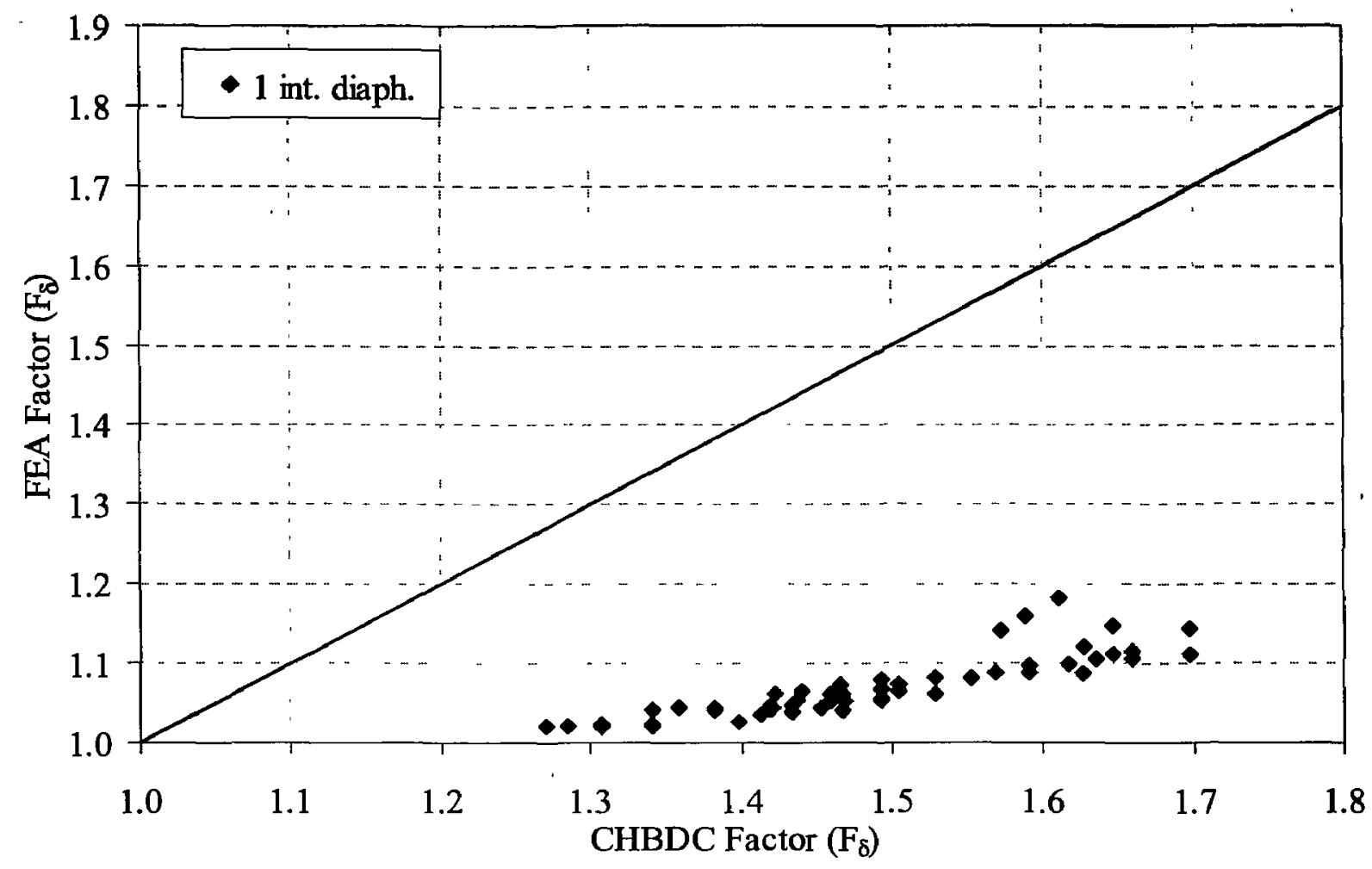

Figure 4.86 Comparison between deflection distribution factor of the interior girder as obtained from FEA and CHBDC

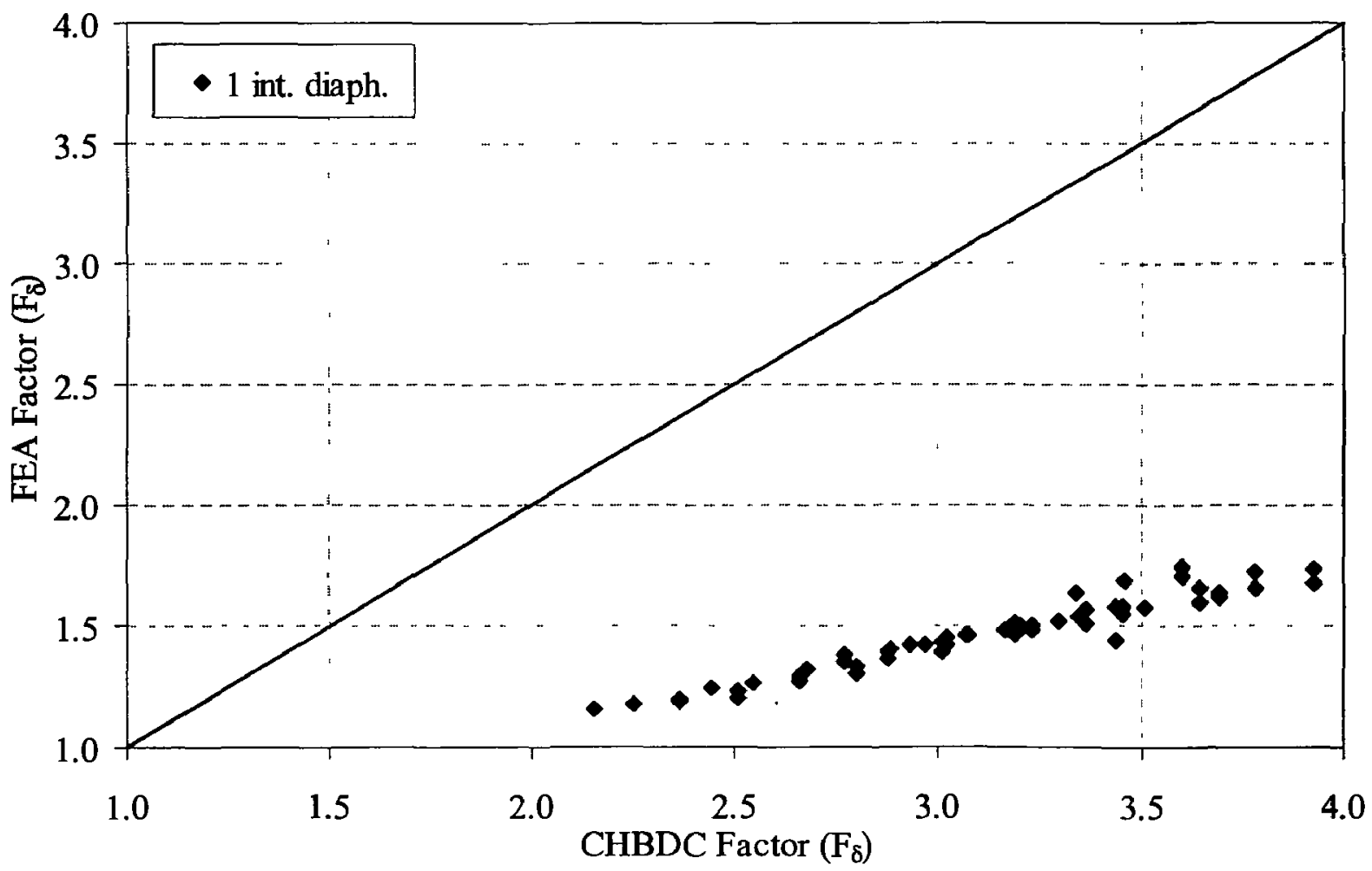

Figure 4.87 Comparison between deflection distribution factors of the interior girder for FLS as obtained from FEA and CHBDC 


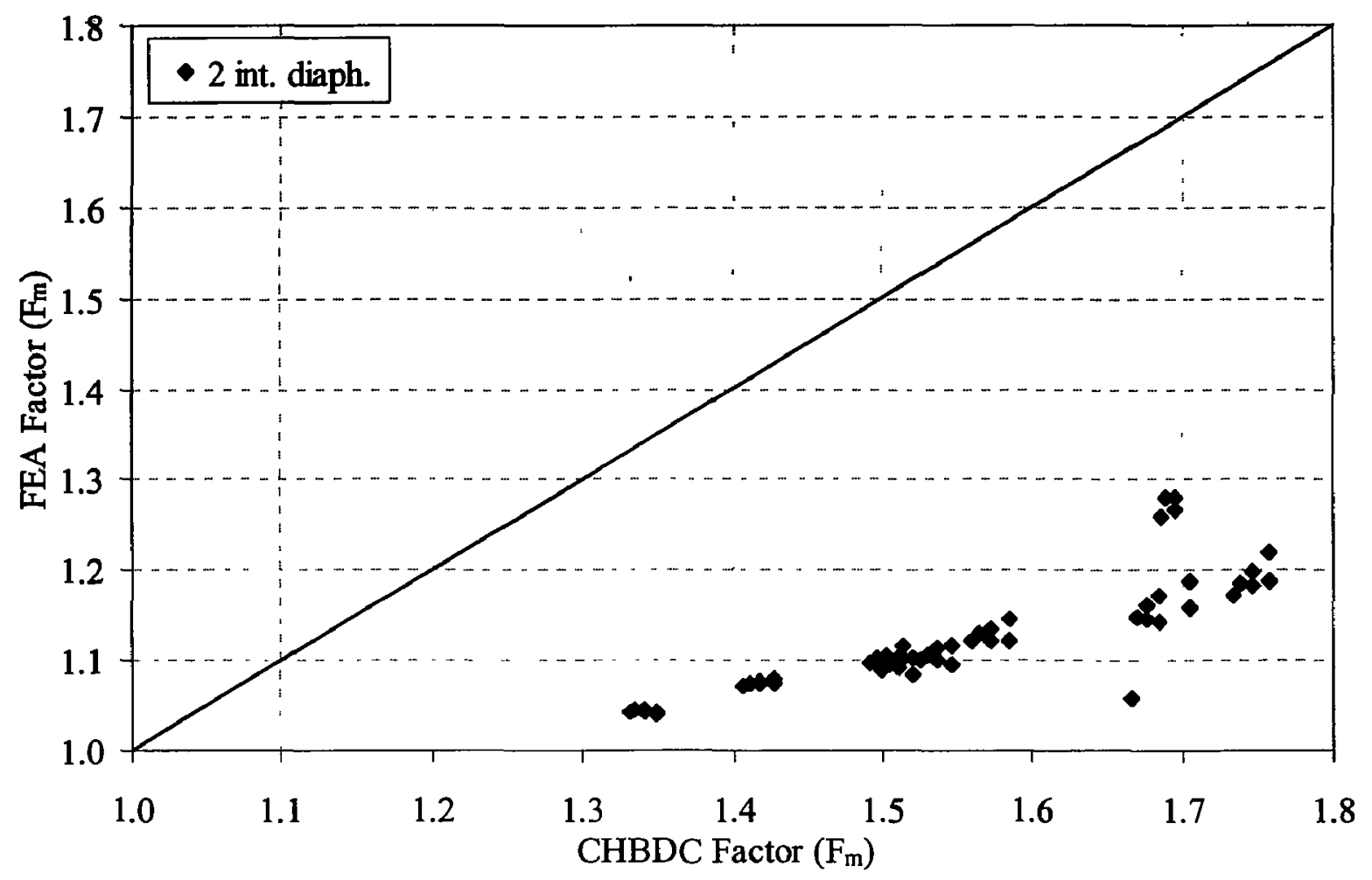

Figure 4.88 Comparison between moment distribution factors of the exterior girder as obtained from FEA and CHBDC

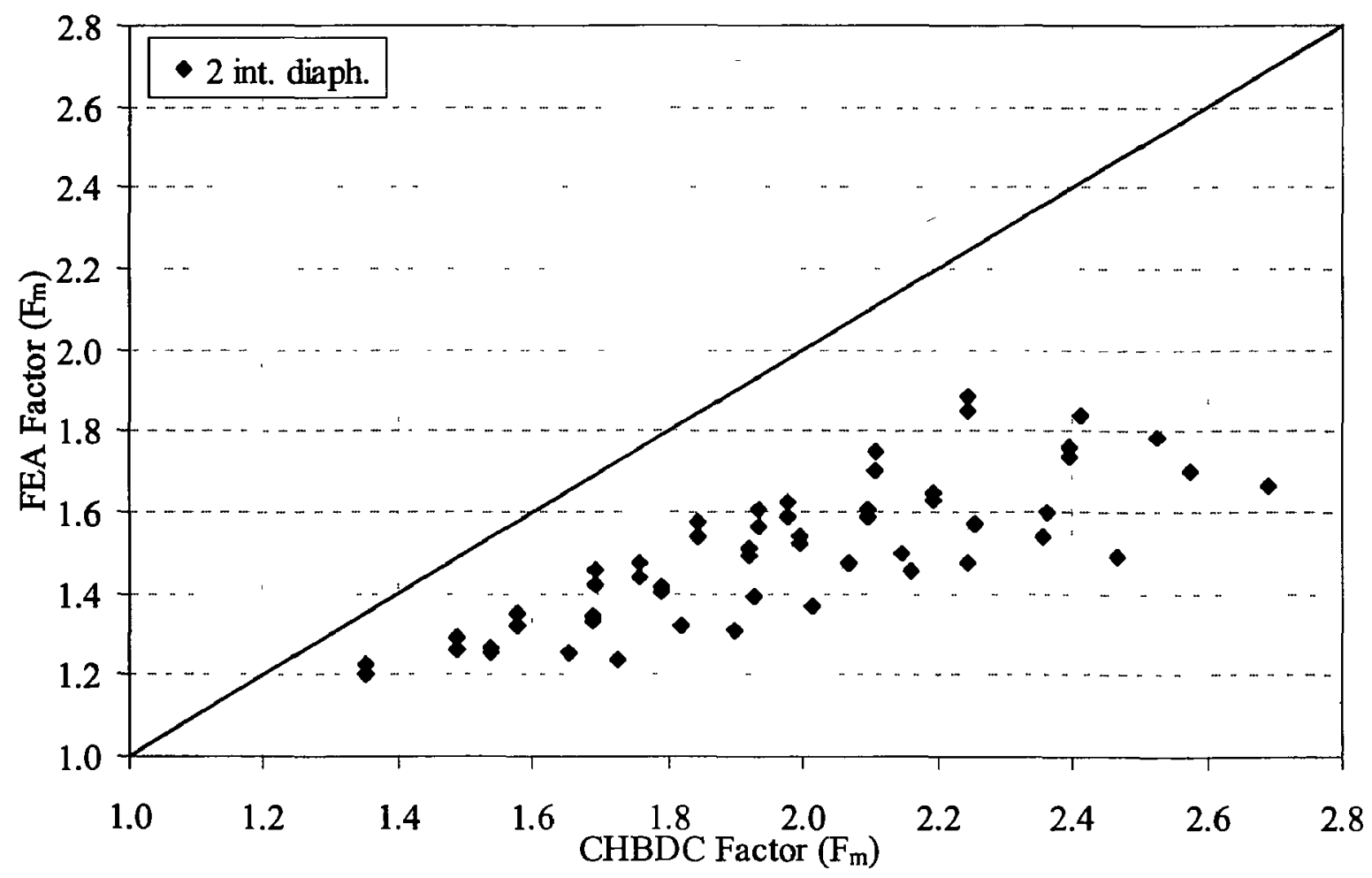

Figure 4.89 Comparison between moment distribution factors of the exterior girder for FLS as obtained from FEA and CHBDC 


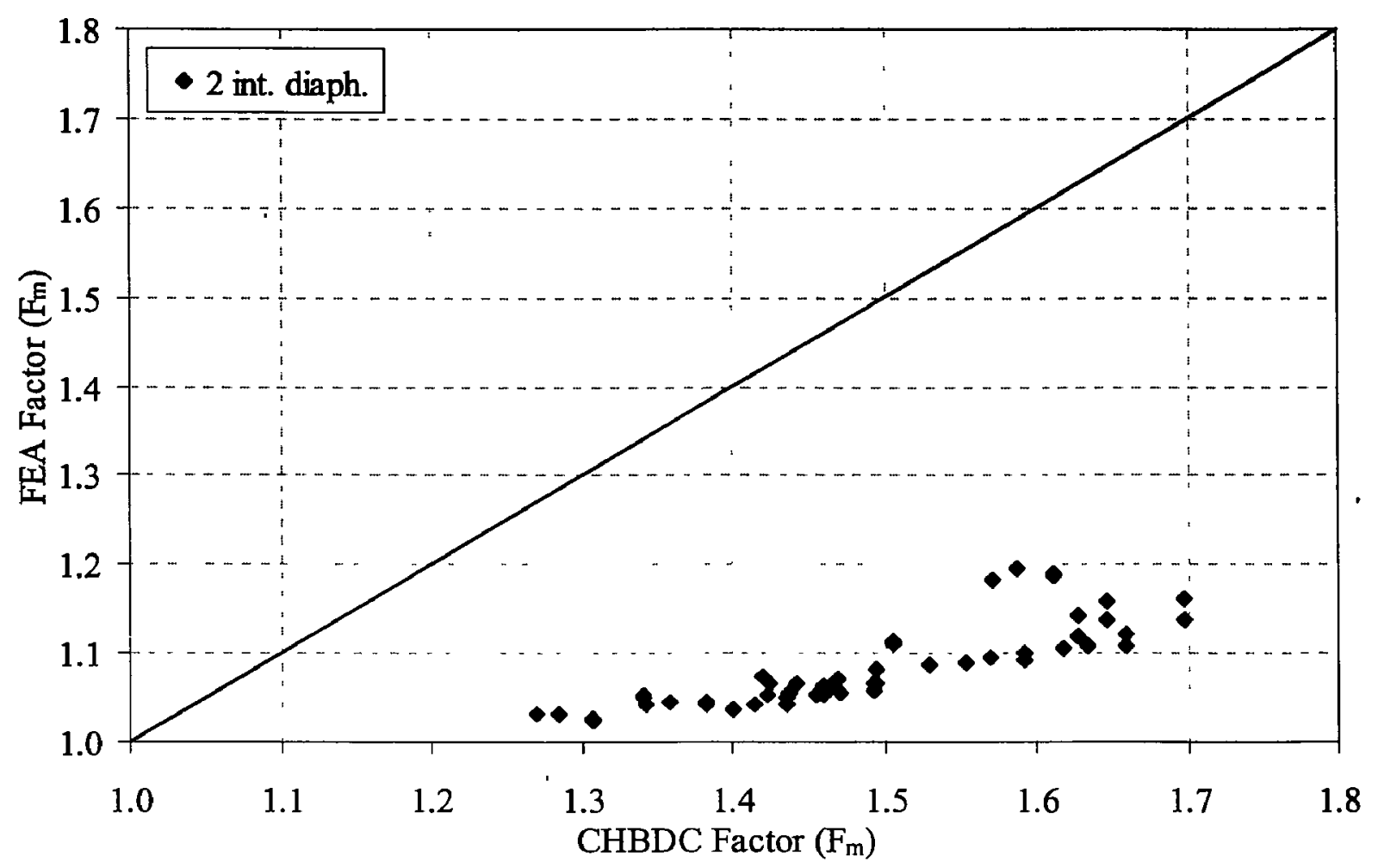

Figure 4.90 Comparison between moment distribution factors of the interior girder as obtained from FEA and CHBDC

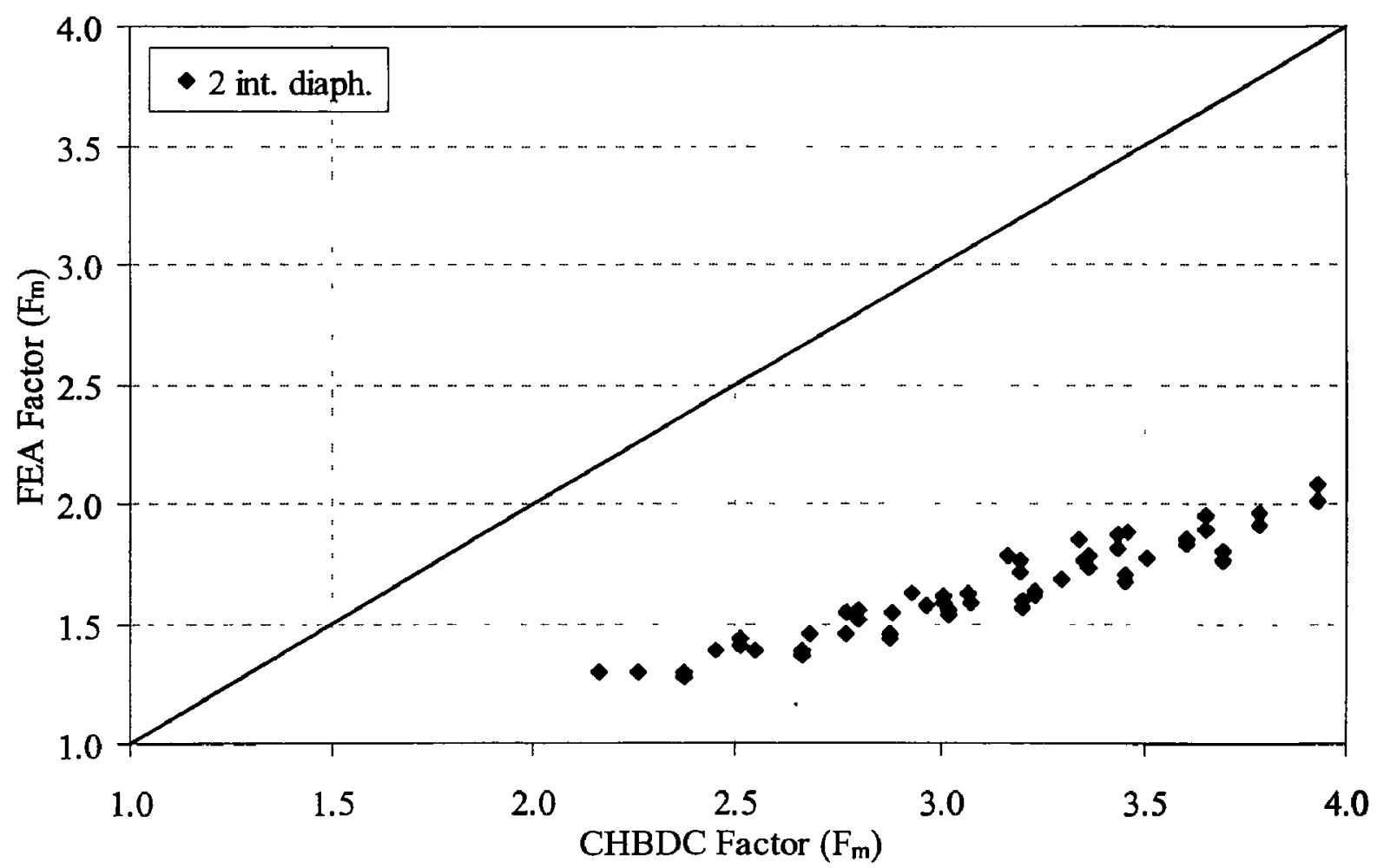

Figure 4.91 Comparison between moment distribution factors of the interior girder for FLS as obtained from FEA and CHBDC 


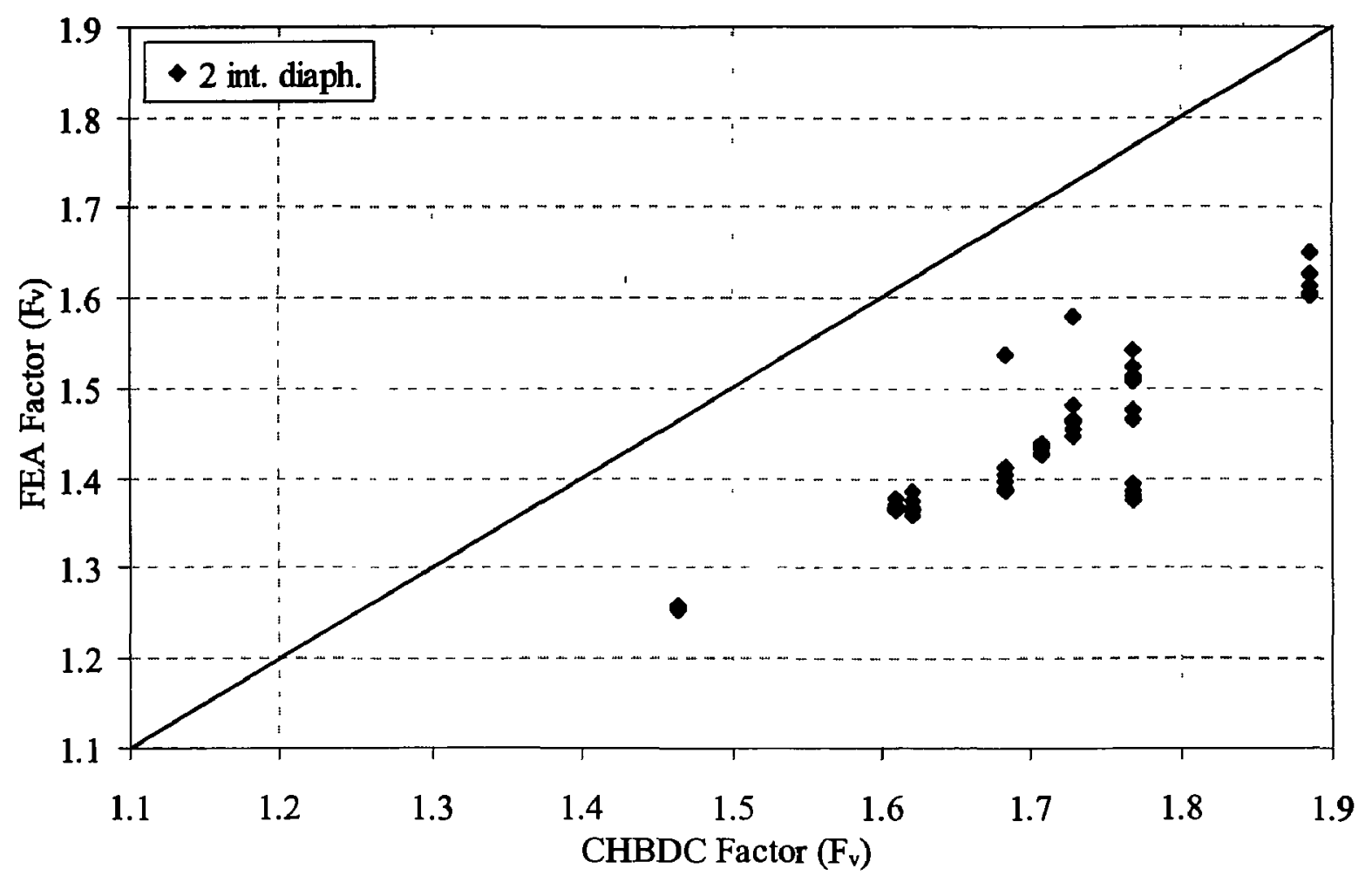

Figure 4.92 Comparison between shear distribution factors of the exterior girder as obtained from FEA and CHBDC

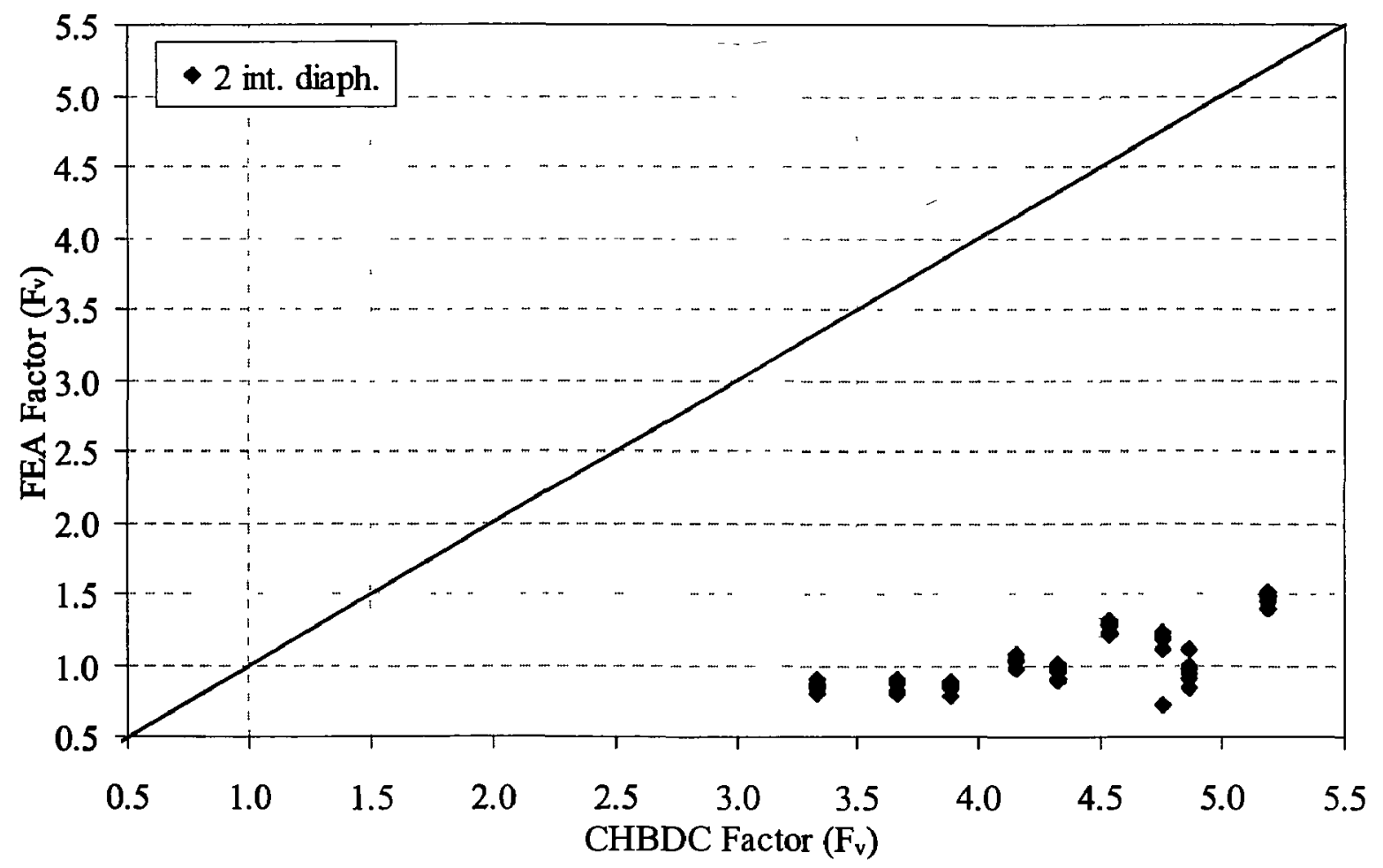

Figure 4.93 Comparison between shear distribution factors of the exterior girder for FLS as obtained from FEA and CHBDC 


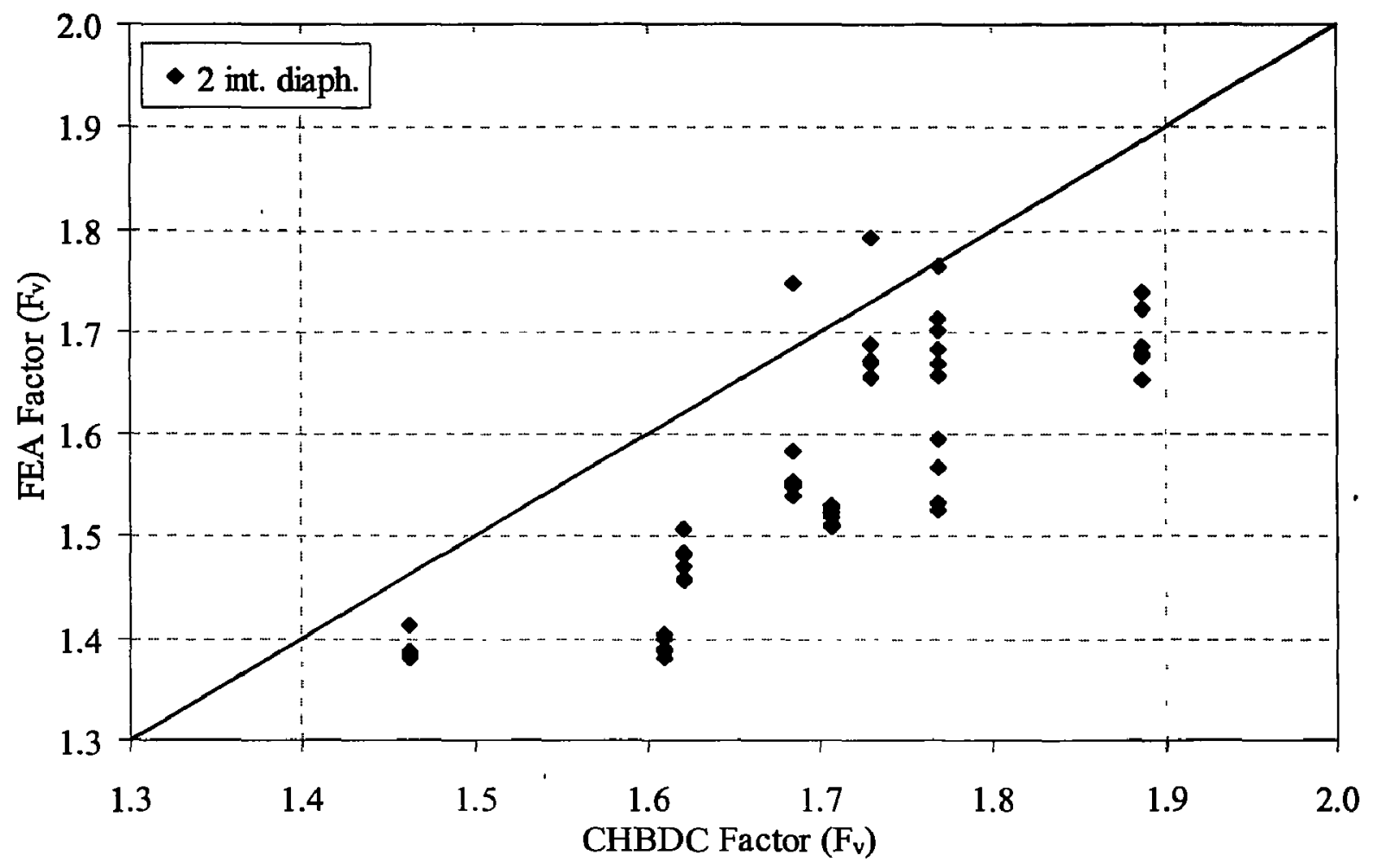

Figure 4.94 Comparison between shear distribution factors of the interior girder as obtained from FEA and CHBDC

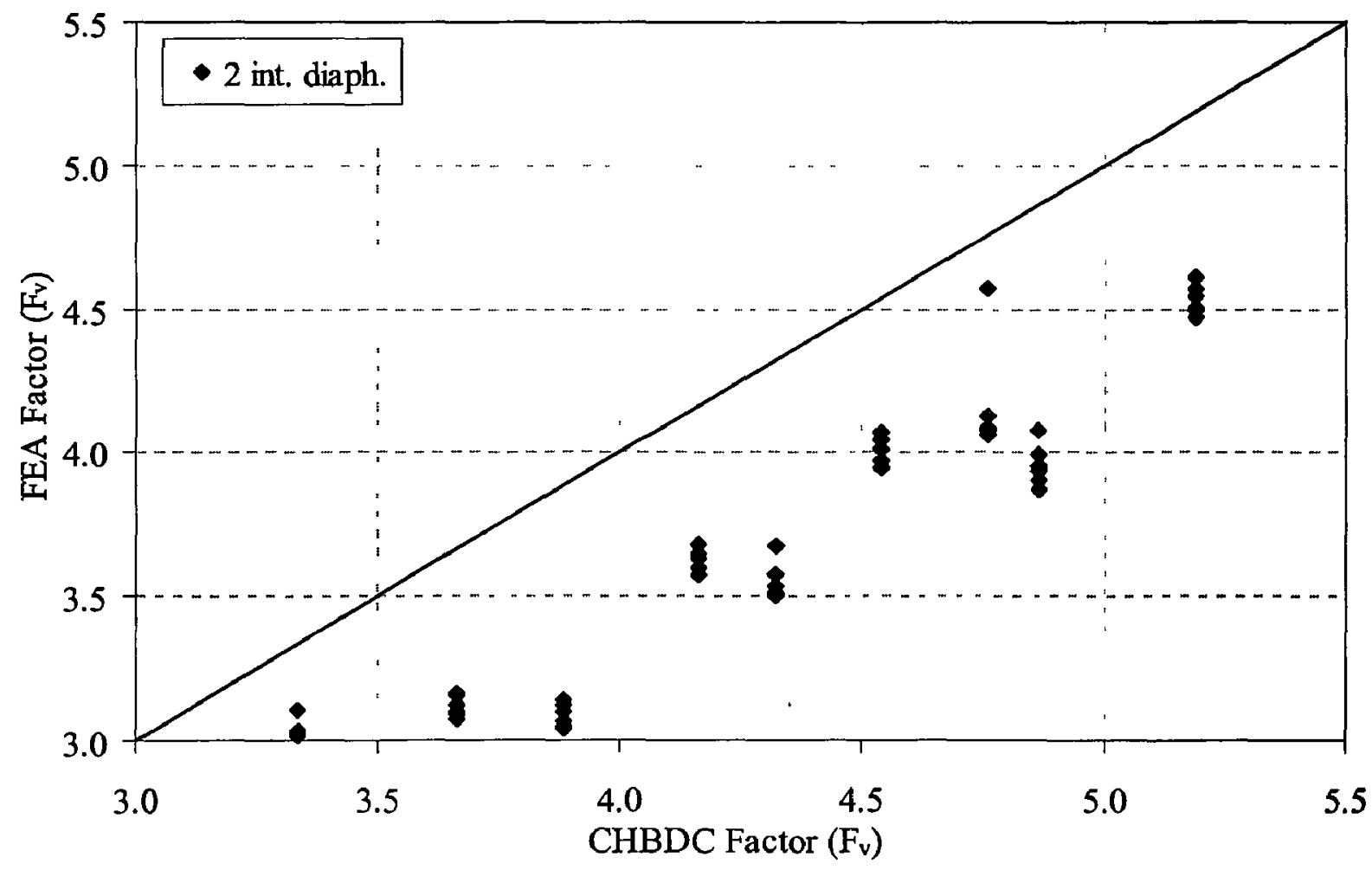

Figure 4.95 Comparison between shear distribution factors of the interior girder for FLS as obtained from FEA and CHBDC 


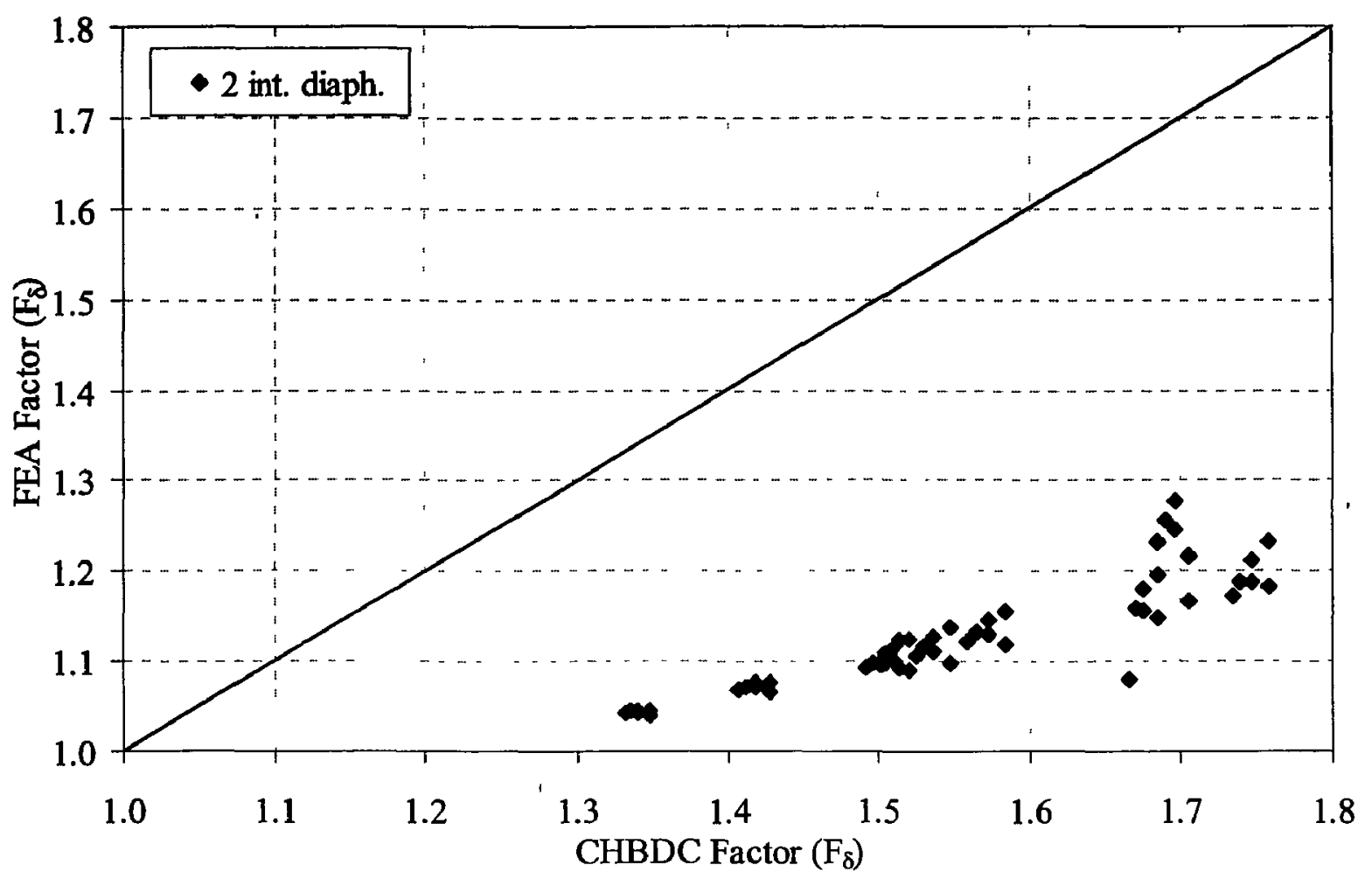

Figure 4.96 Comparison between deflection distribution factors of the exterior girder as obtained from FEA and CHBDC

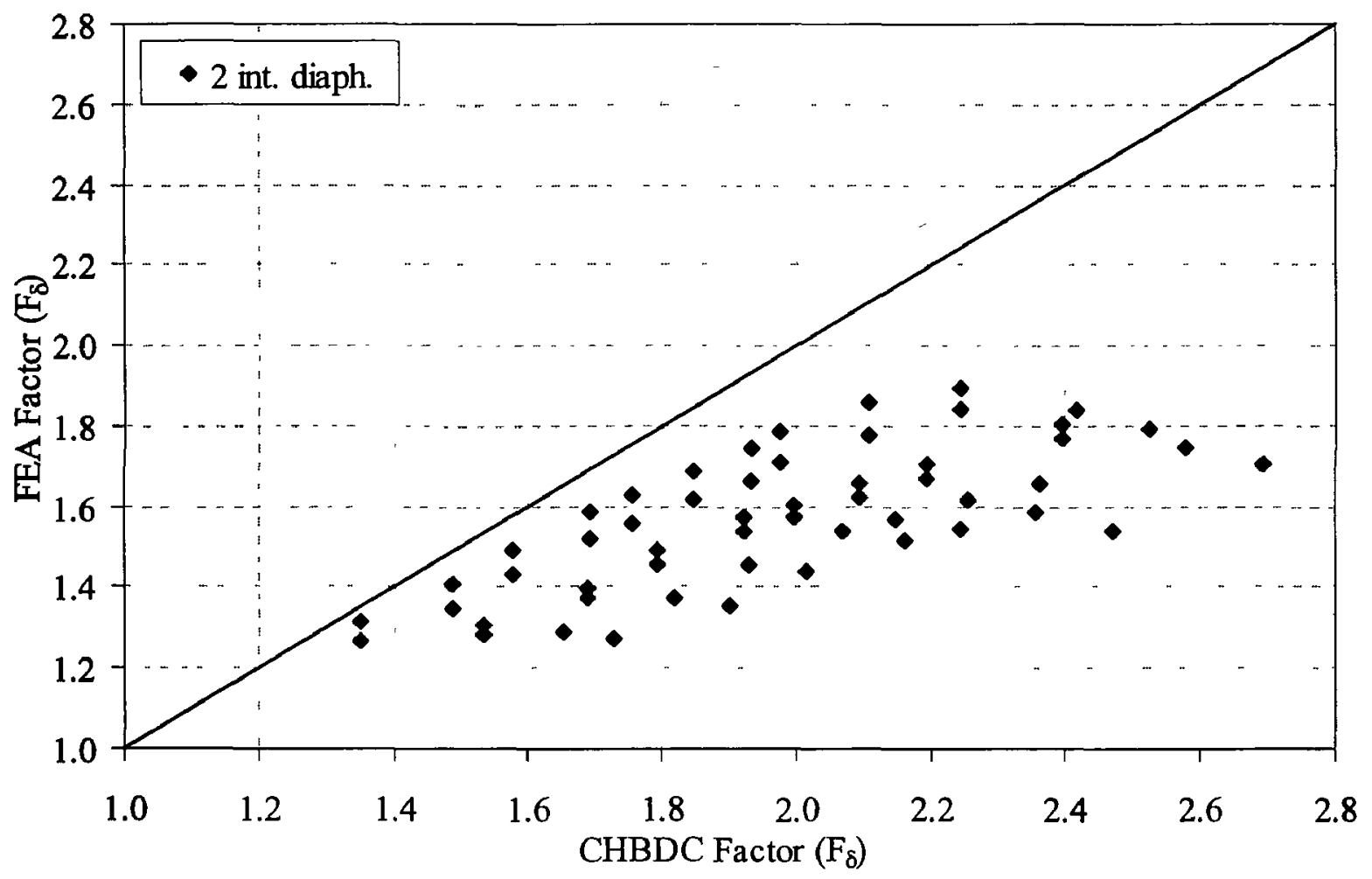

Figure 4.97 Comparison between deflection distribution factors of the exterior girder for FLS as obtained from FEA and CHBDC 


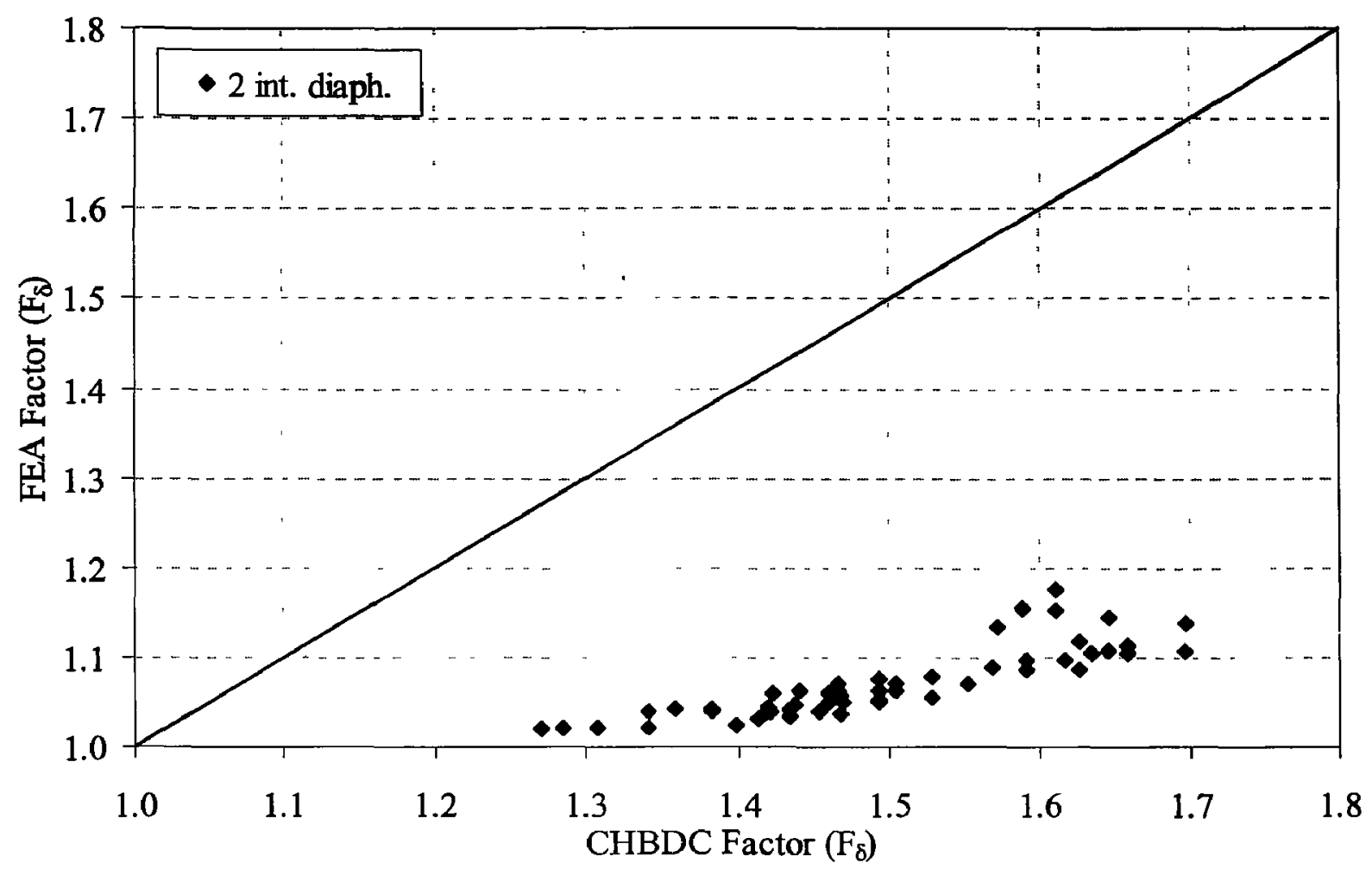

Figure 4.98 Comparison between deflection distribution factors of the interior girder as obtained from FEA and CHBDC

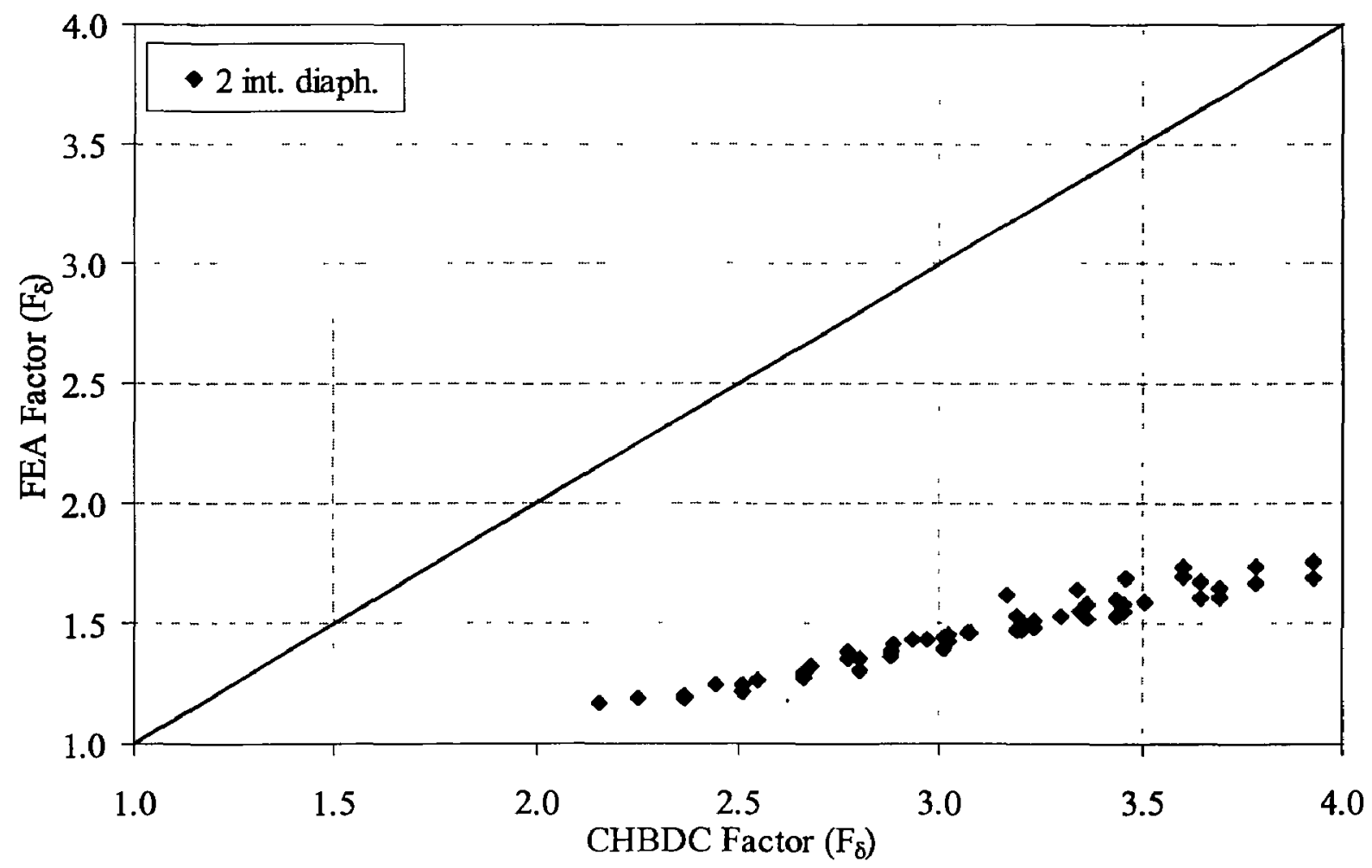

Figure 4.99 Comparison between deflection distribution factors of the interior girder for FLS as obtained from FEA and CHBDC 


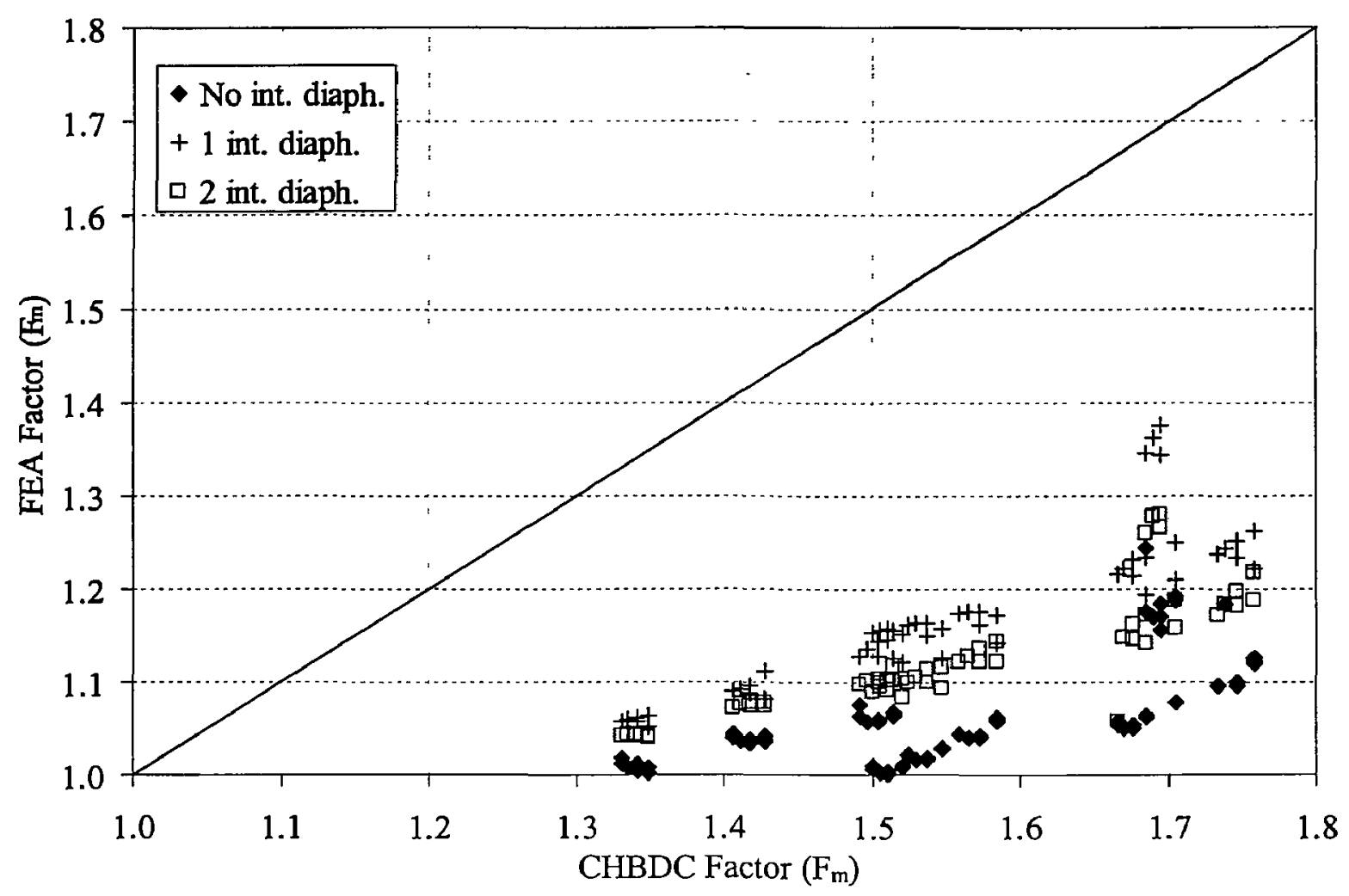

Figure 4.100 Comparison between moment distribution factors of the exterior girder as obtained from FEA and CHBDC

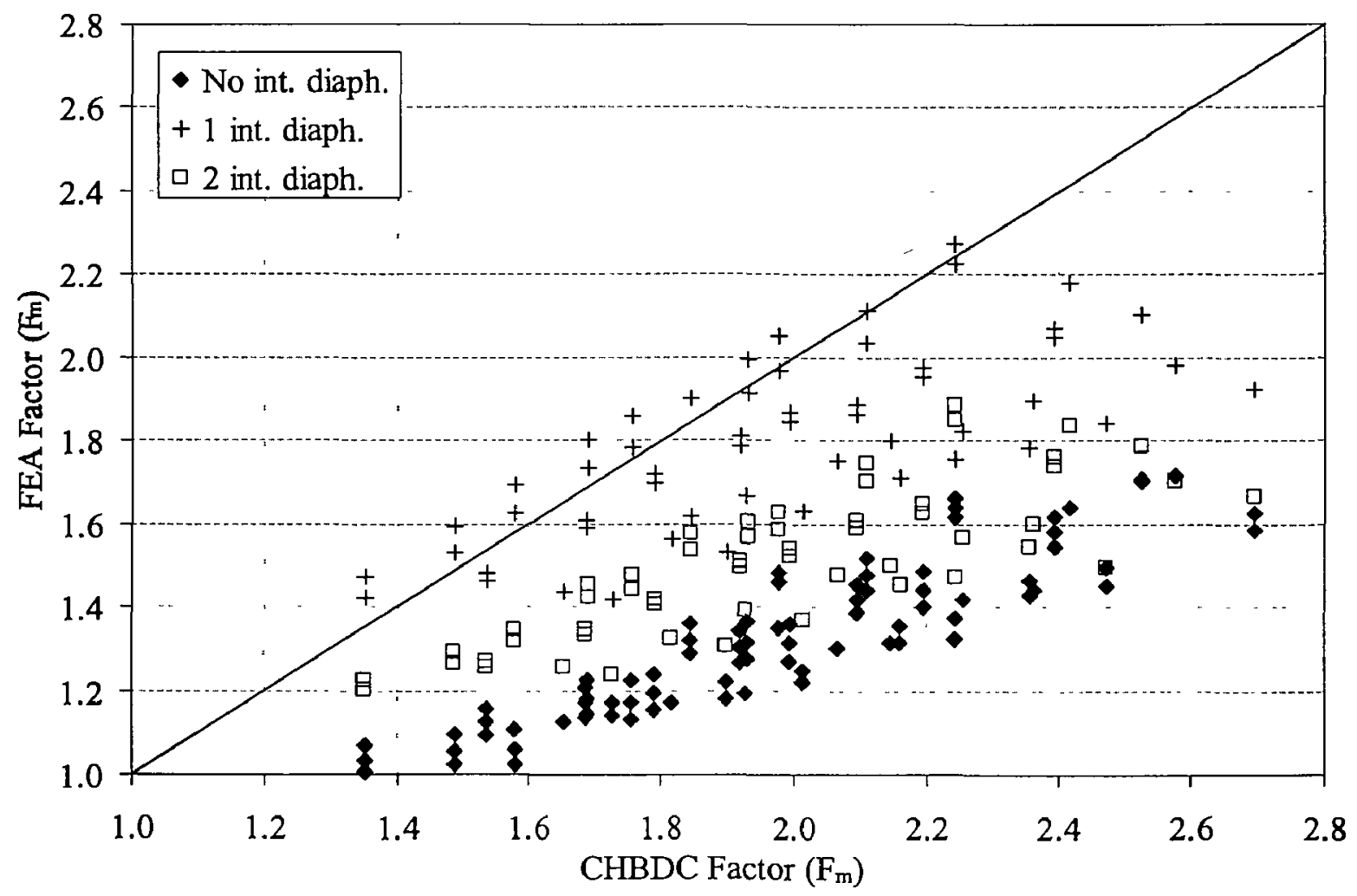

Figure 4.101 Comparison between moment distribution factors of the exterior girder for FLS as obtained from FEA and CHBDC 


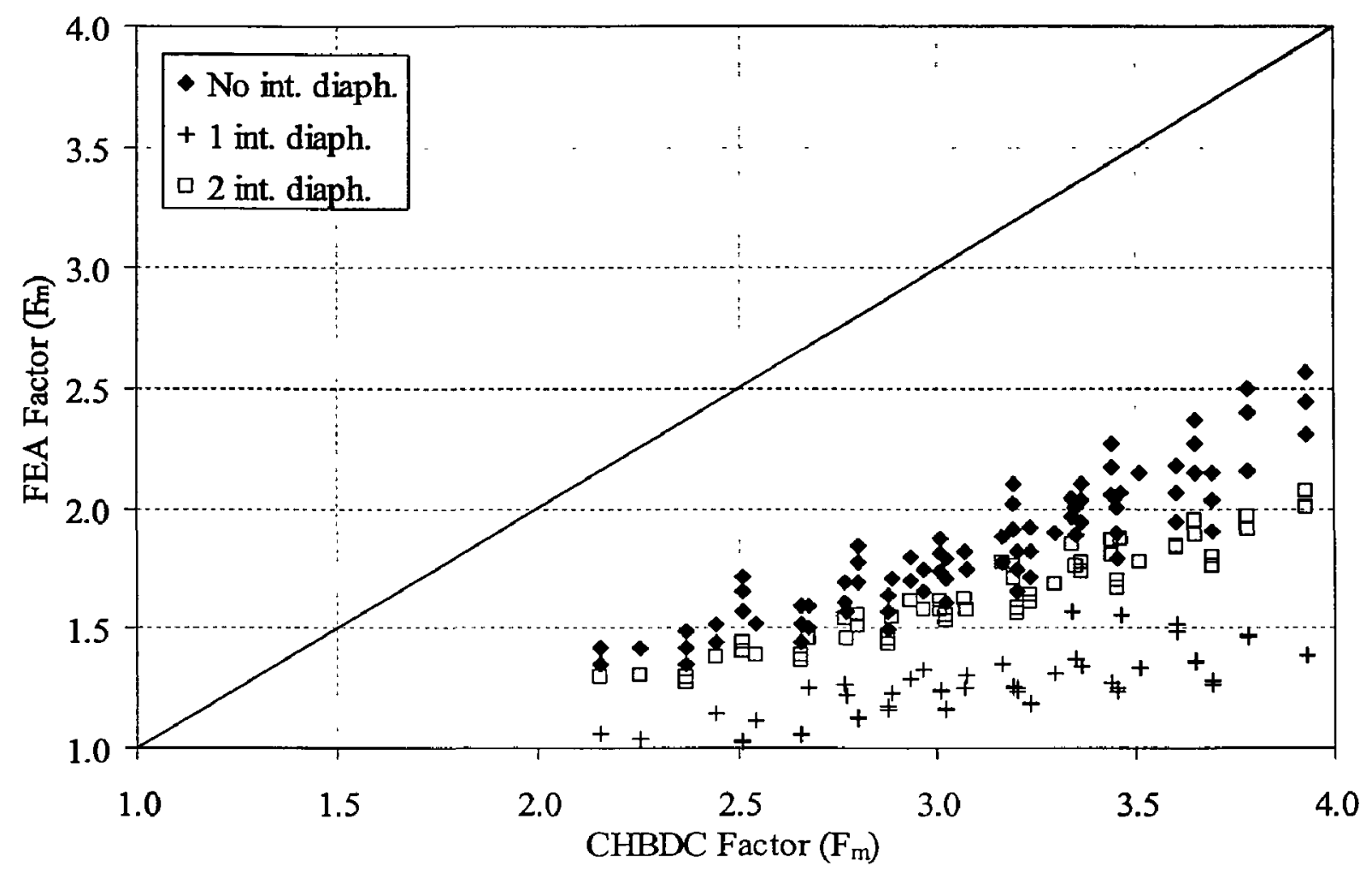

Figure 4.102 Comparison between moment distribution factors of the interior girder as obtained from FEA and CHBDC

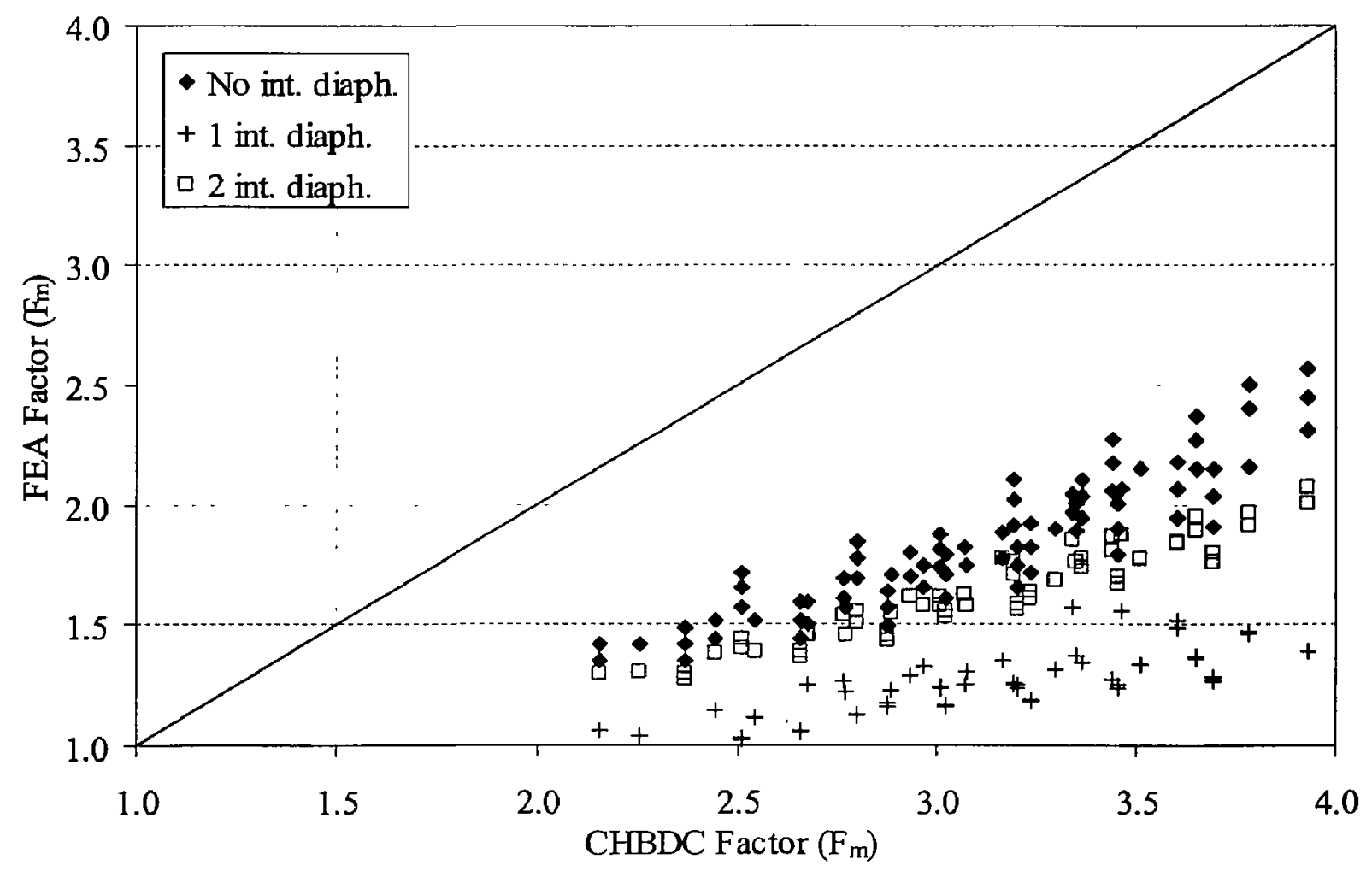

Figure 4.103 Comparison between moment distribution factors of the interior girder for FLS as obtained from FEA and CHBDC 


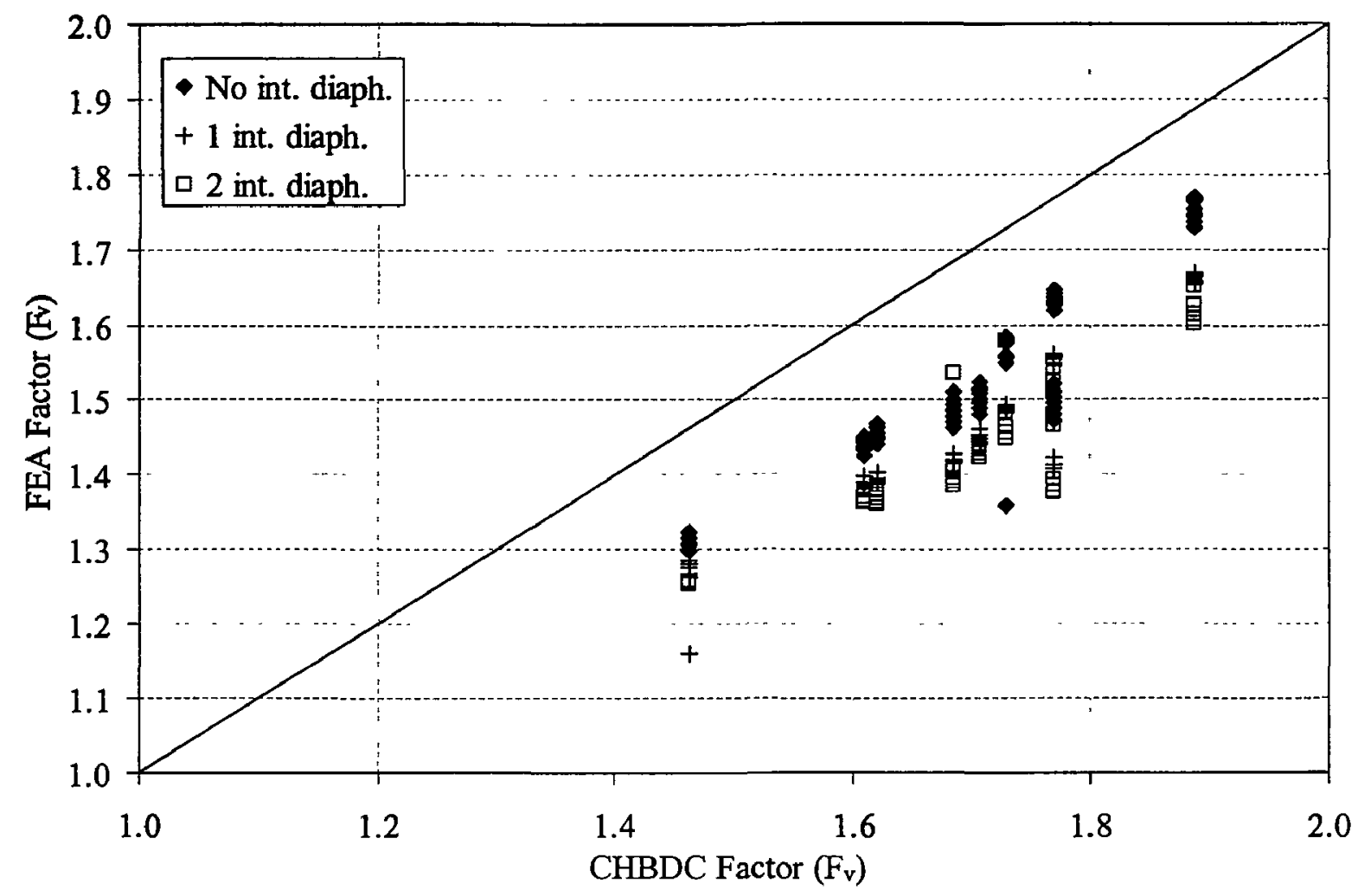

Figure 4.104 Comparison between shear distribution factors of the exterior girder as obtained from FEA and CHBDC

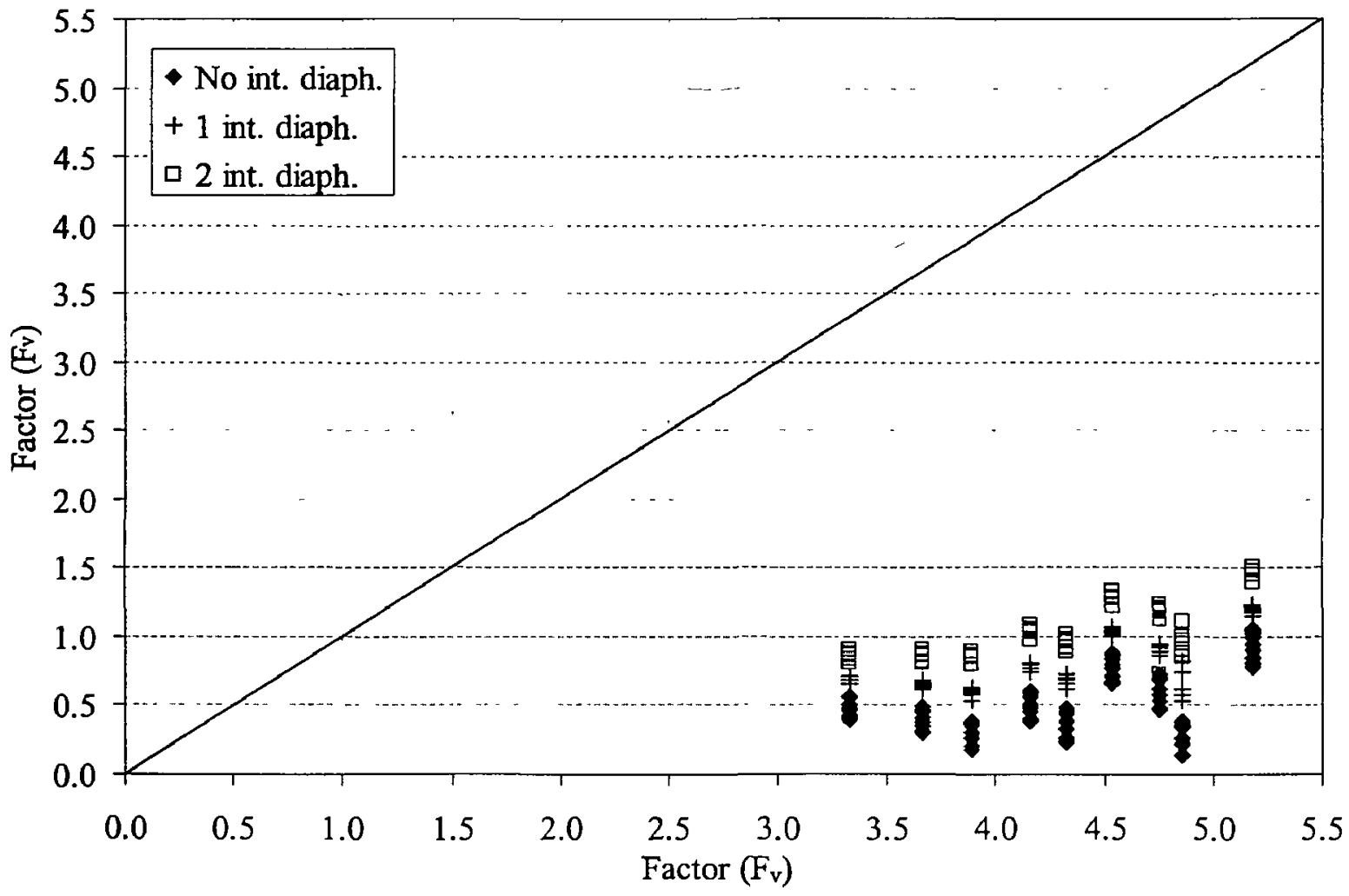

Figure 4.105 Comparison between shear distribution factors of the exterior girder for FLS as obtained from FEA and CHBDC 


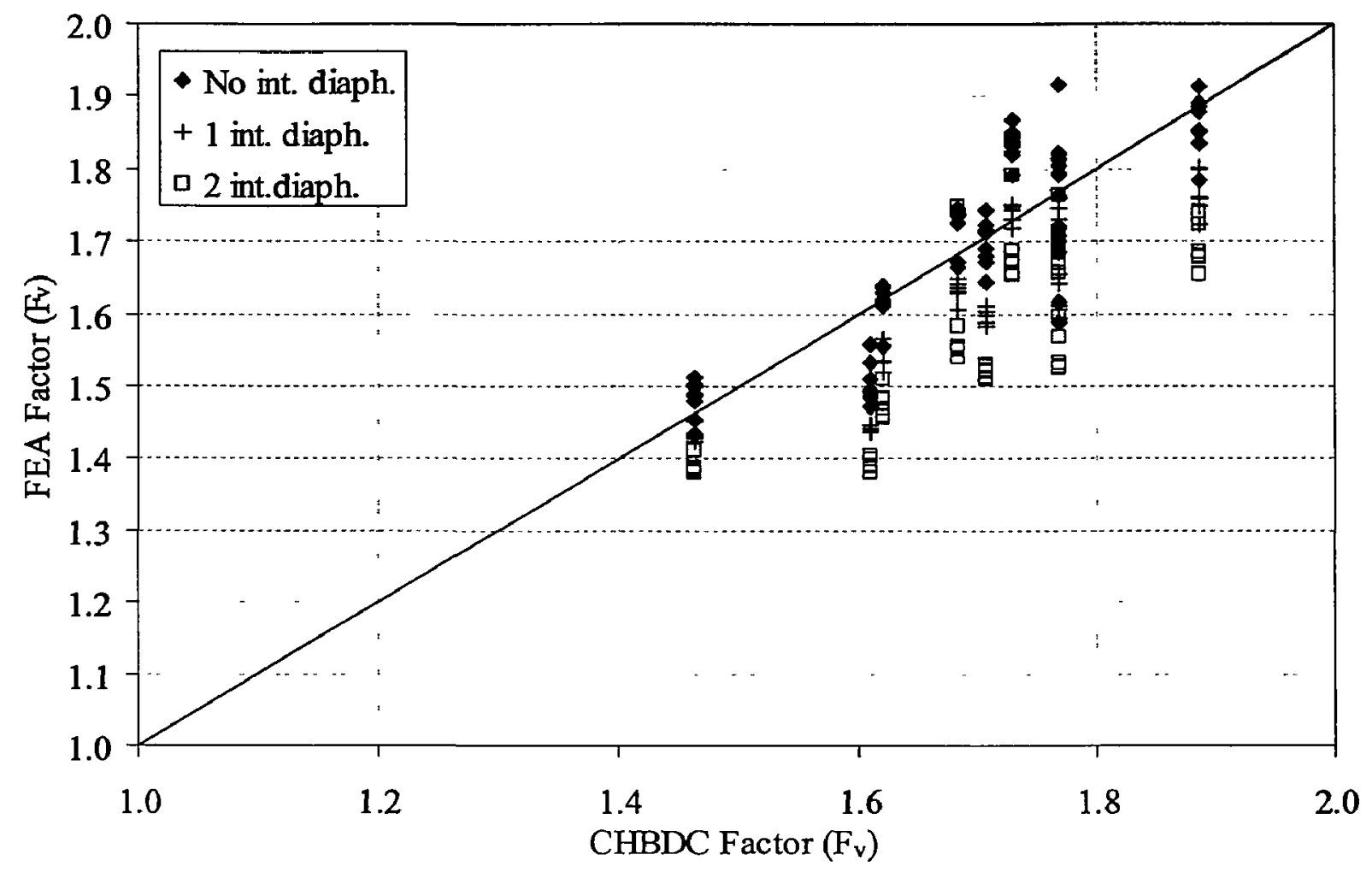

Figure 4.106 Comparison between shear distribution factors of the interior girder as obtained from FEA and CHBDC

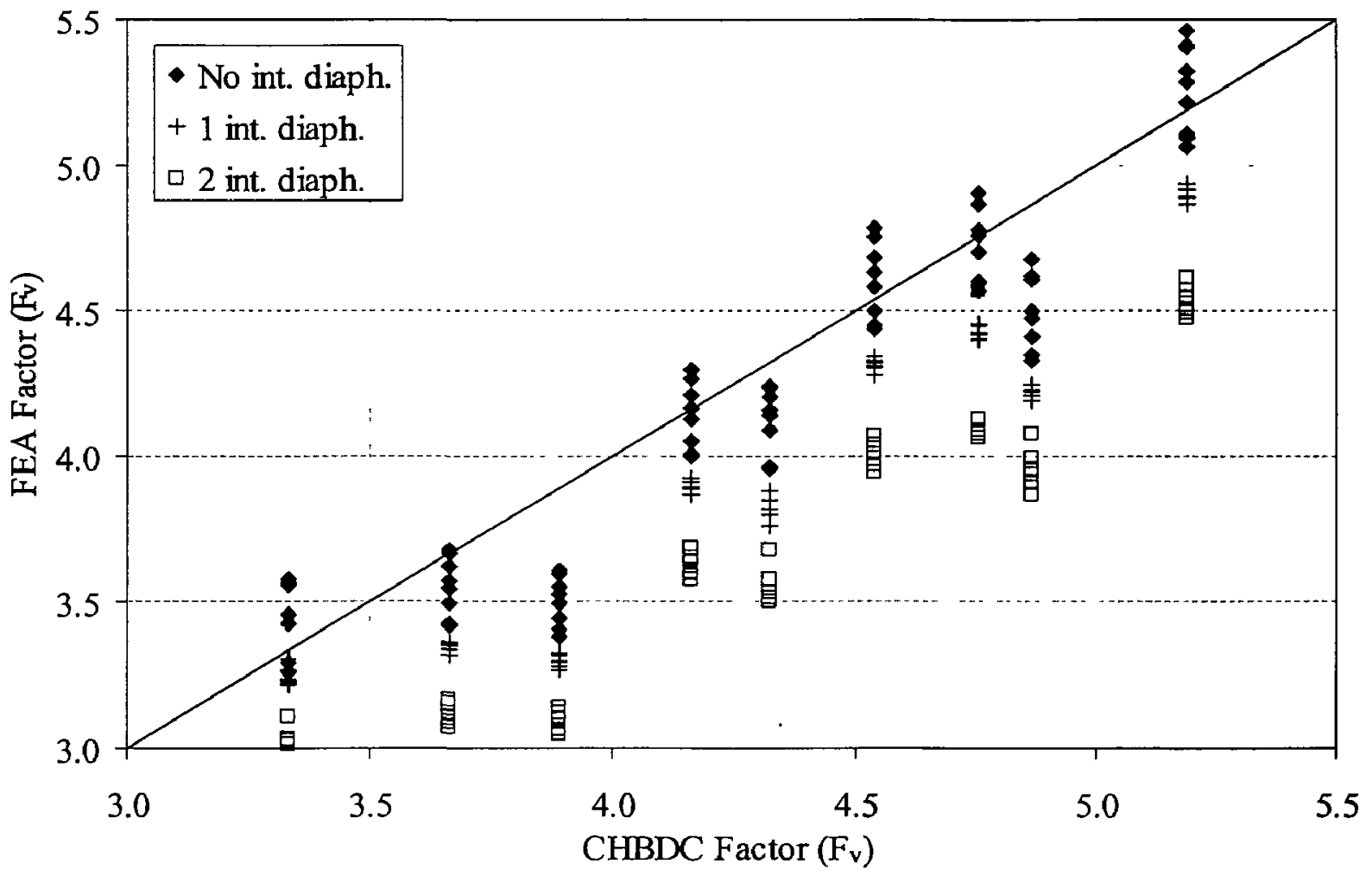

Figure 4.107 Comparison between shear distribution factors of the interior girder for FLS as obtained from FEA and CHBDC 


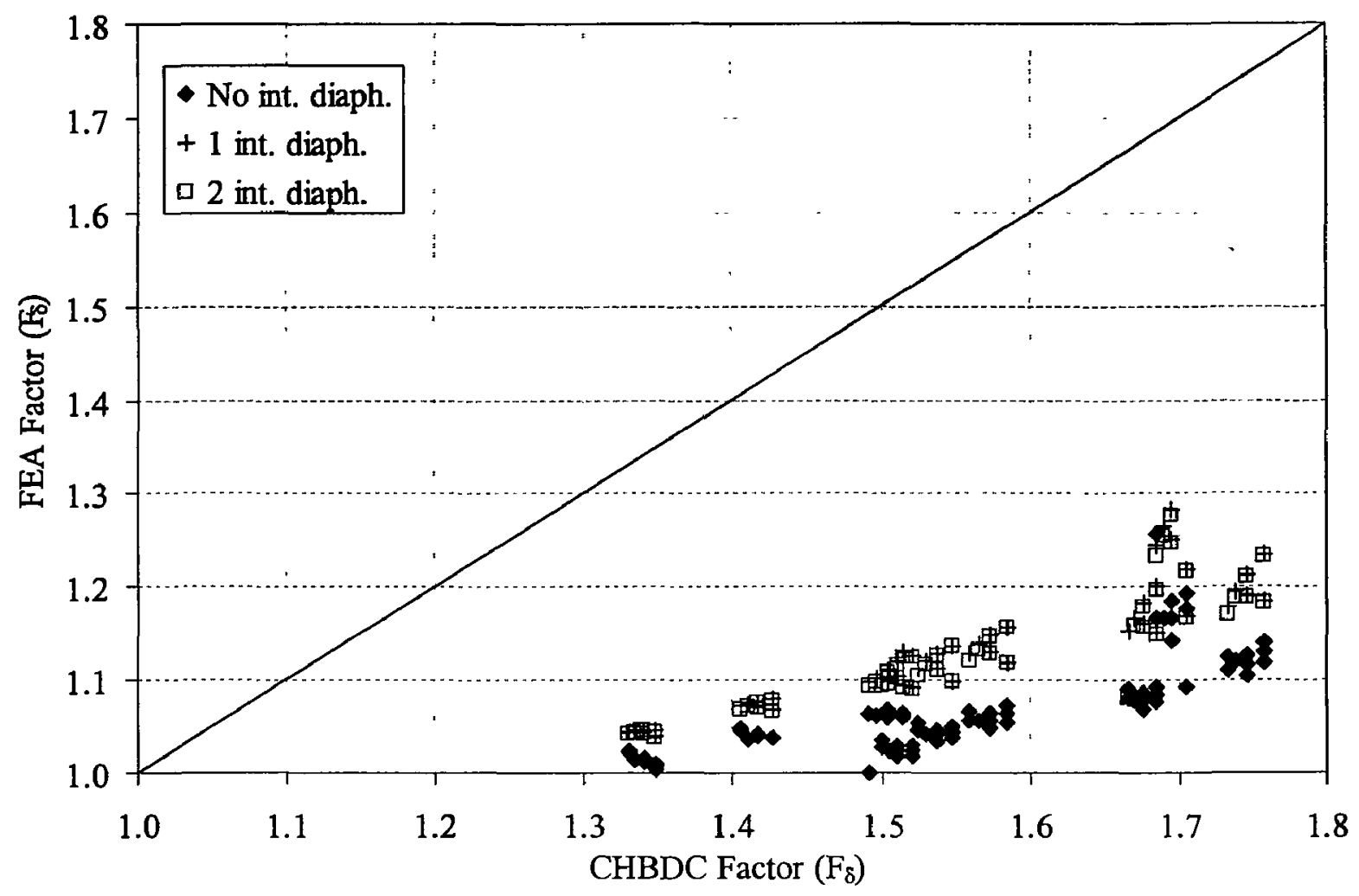

Figure 4.108 Comparison between deflection distribution factors of the exterior girder as obtained from FEA and CHBDC

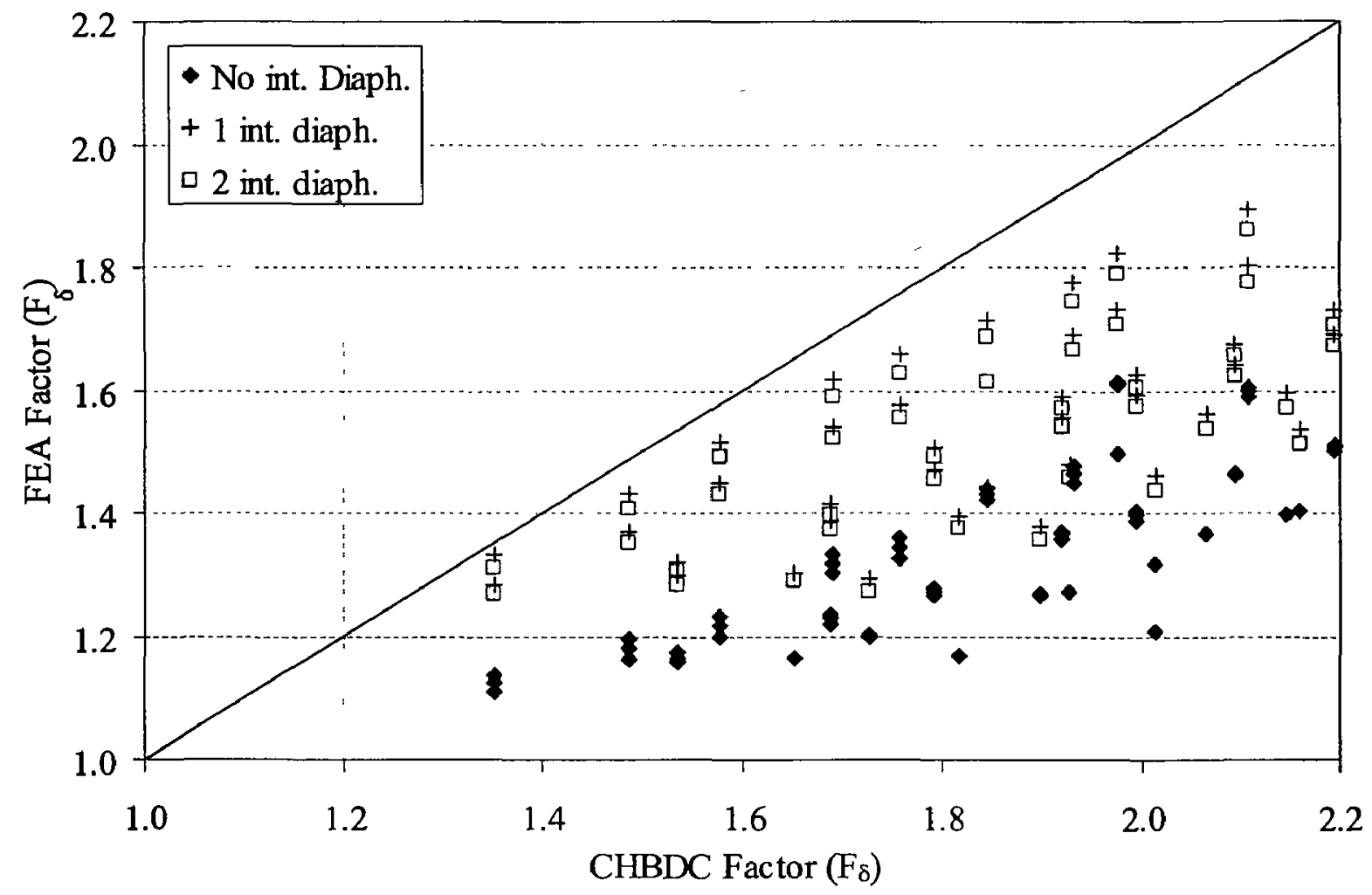

Figure 4.109 Comparison between deflection distribution factors of the exterior girder for FLS as obtained from FEA and CHBDC 


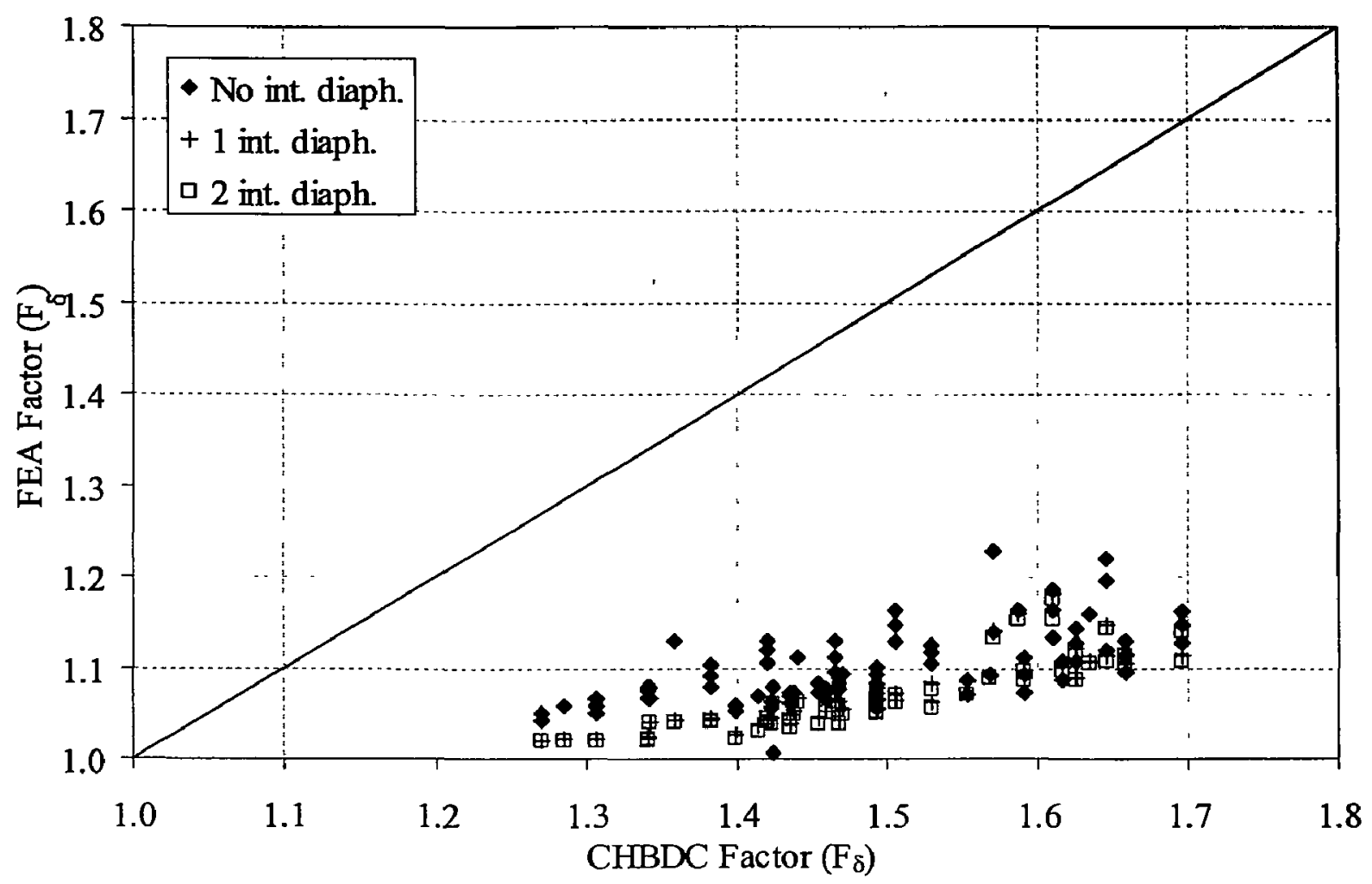

Figure 4.110 Comparison between deflection distribution factors of the interior girder as obtained from FEA and CHBDC

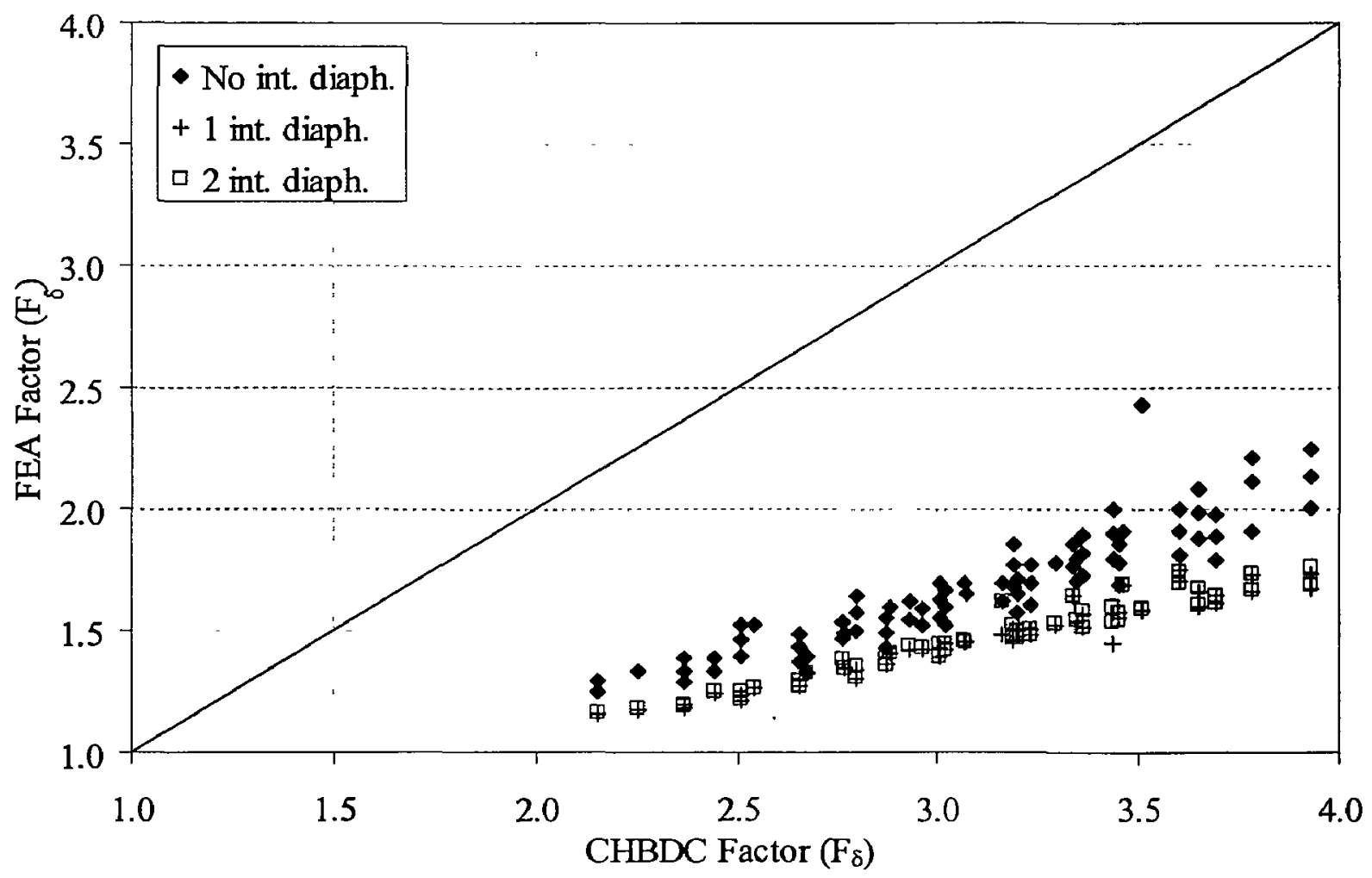

Figure 4.111 Comparison between deflection distribution factors of the interior girder for FLS as obtained from FEA and CHBDC 


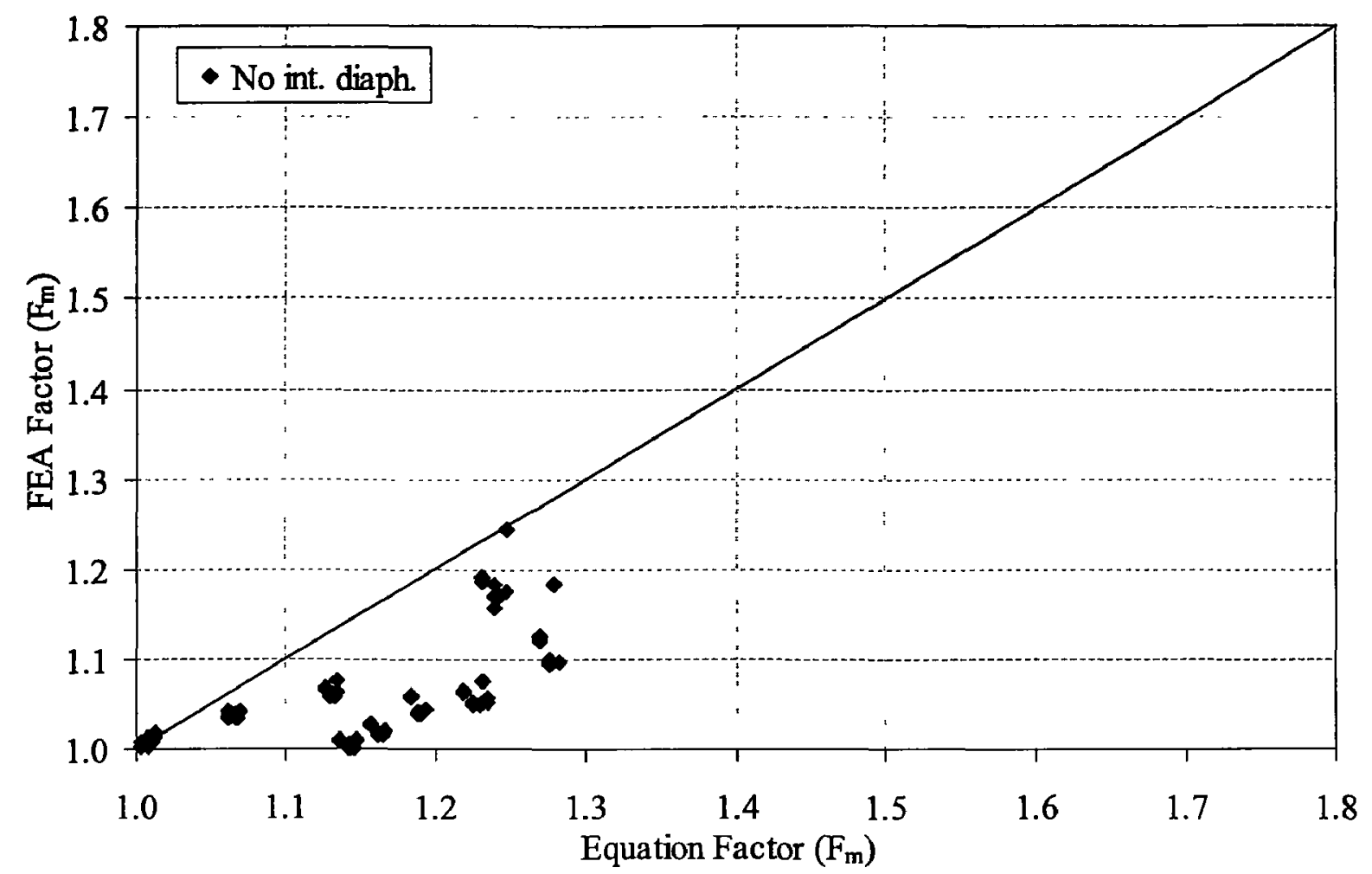

Figure 4.112 FEA results versus proposed equation for moment distribution factor of exterior girder

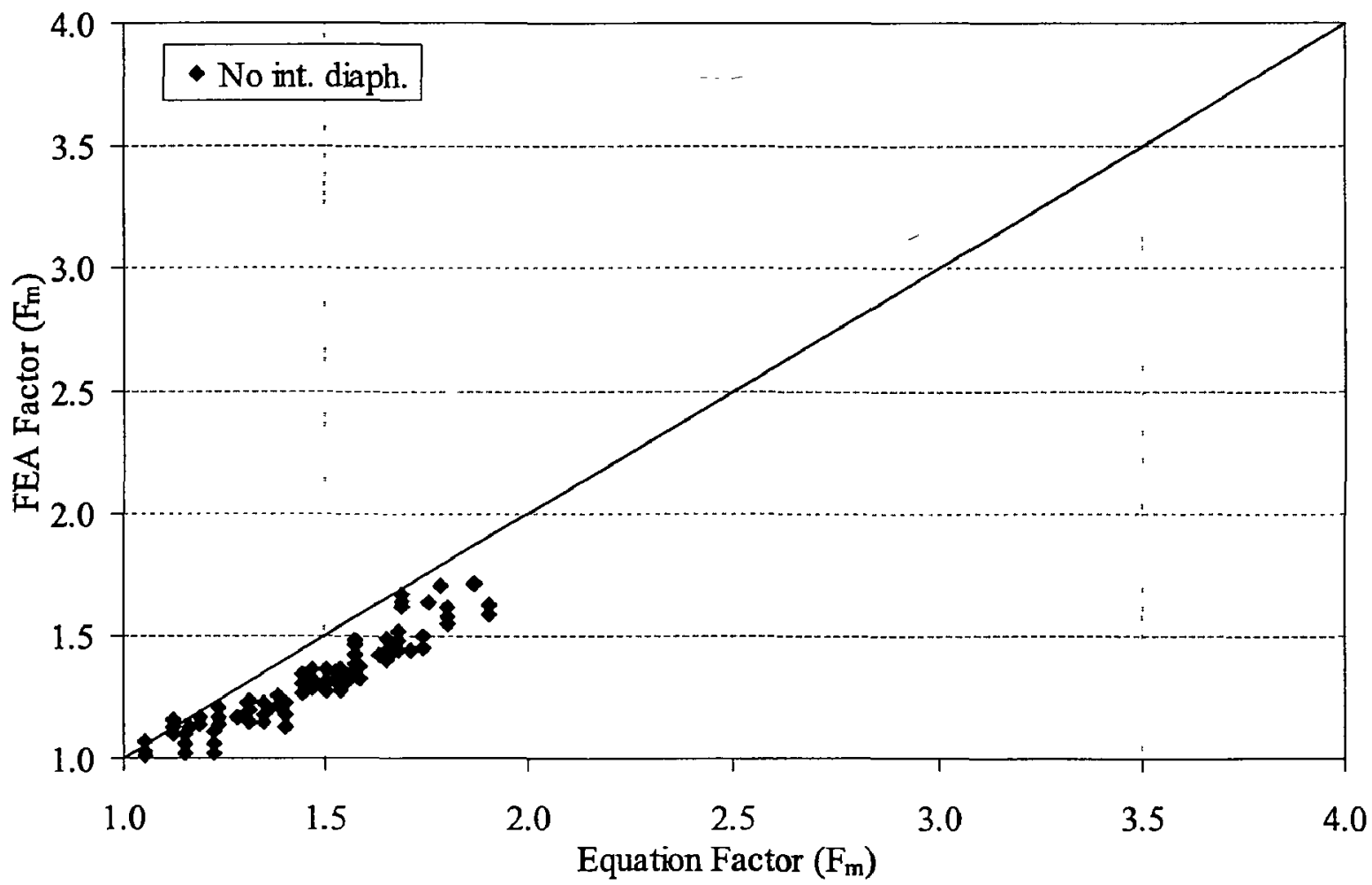

Figure 4.113 FEA results versus proposed equation for moment distribution factor of exterior girder for FLS 


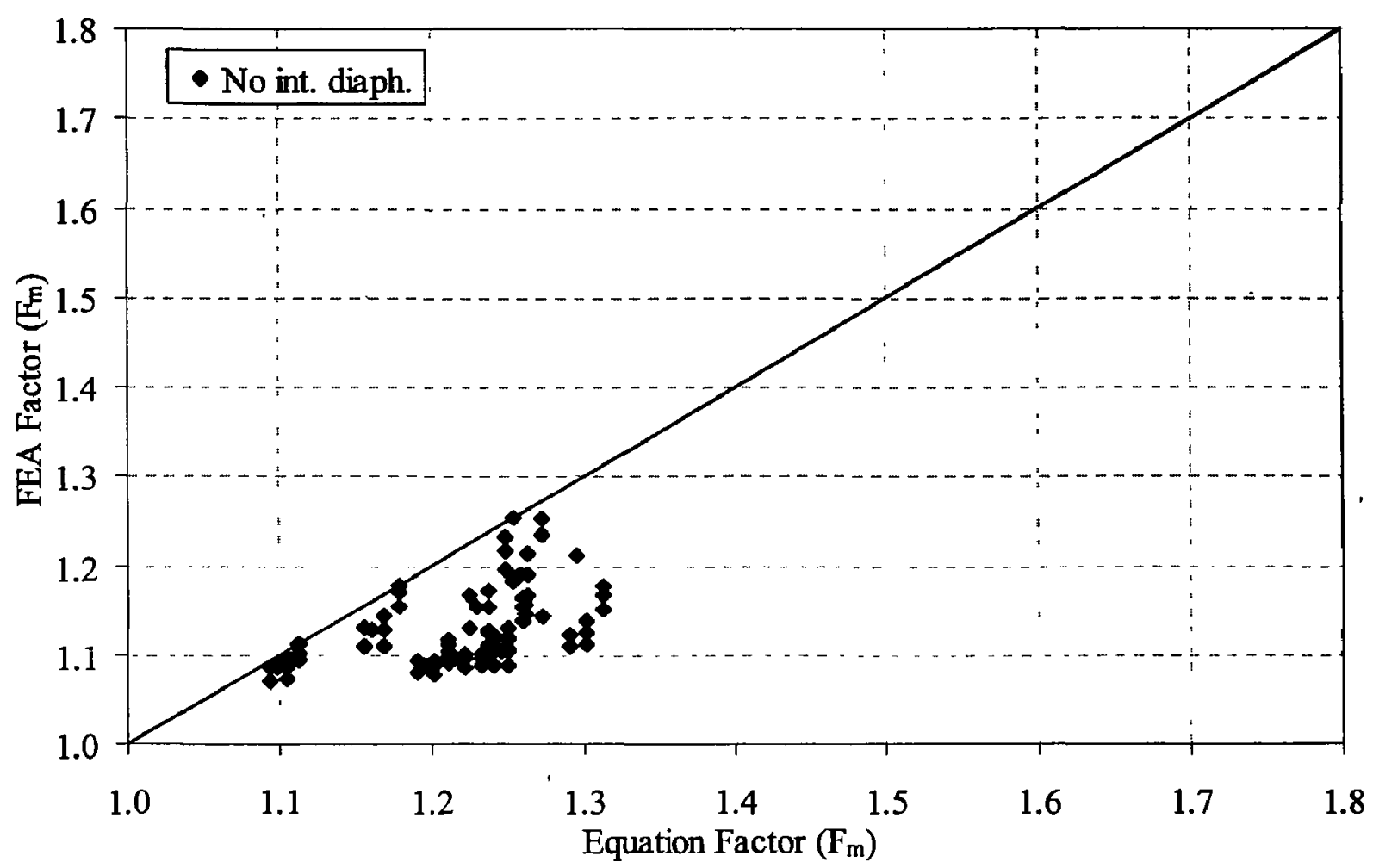

Figure 4.114 FEA results versus proposed equation for moment distribution factor of interior girder

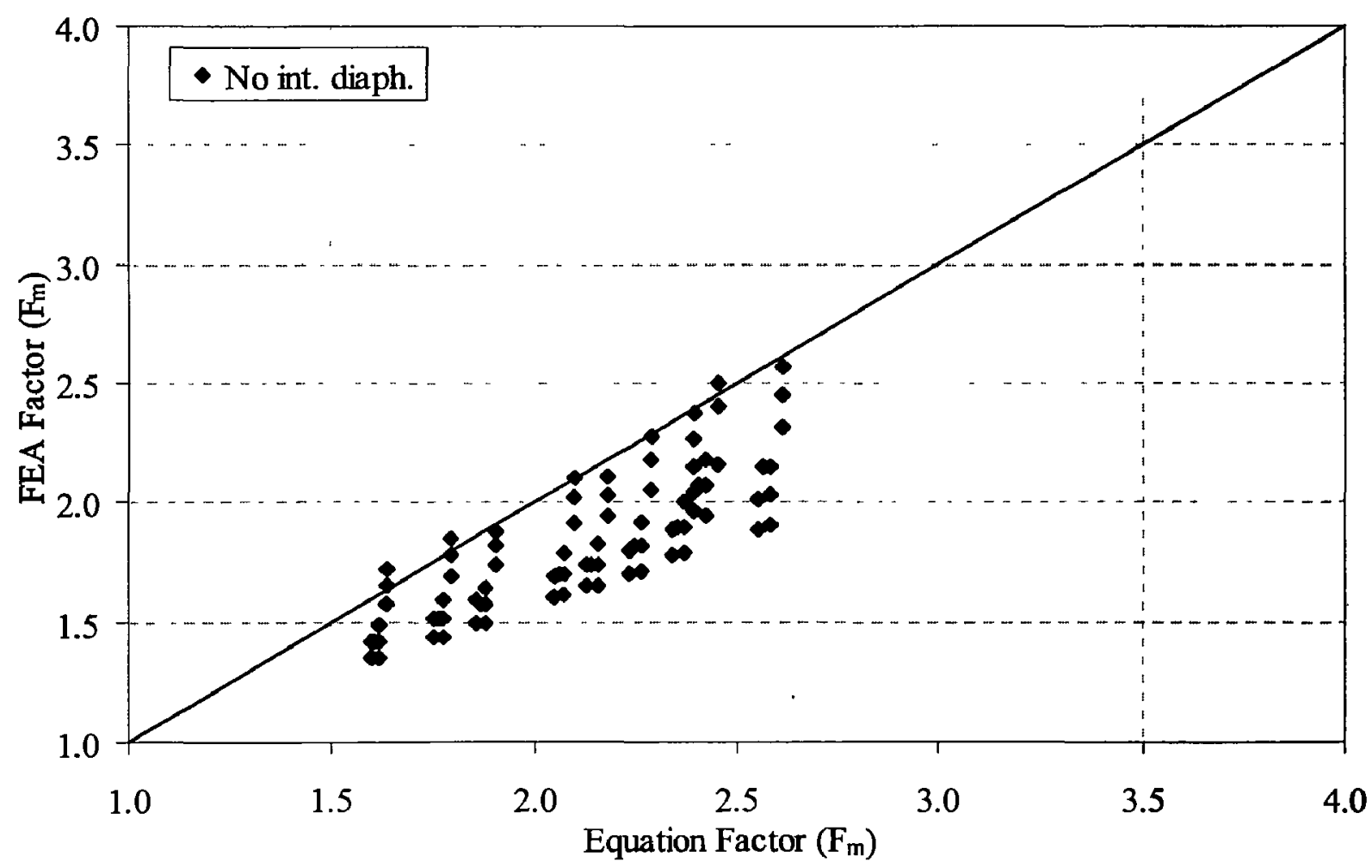

Figure 4.115 FEA results versus proposed equation for moment distribution factor of interior girder for FLS 


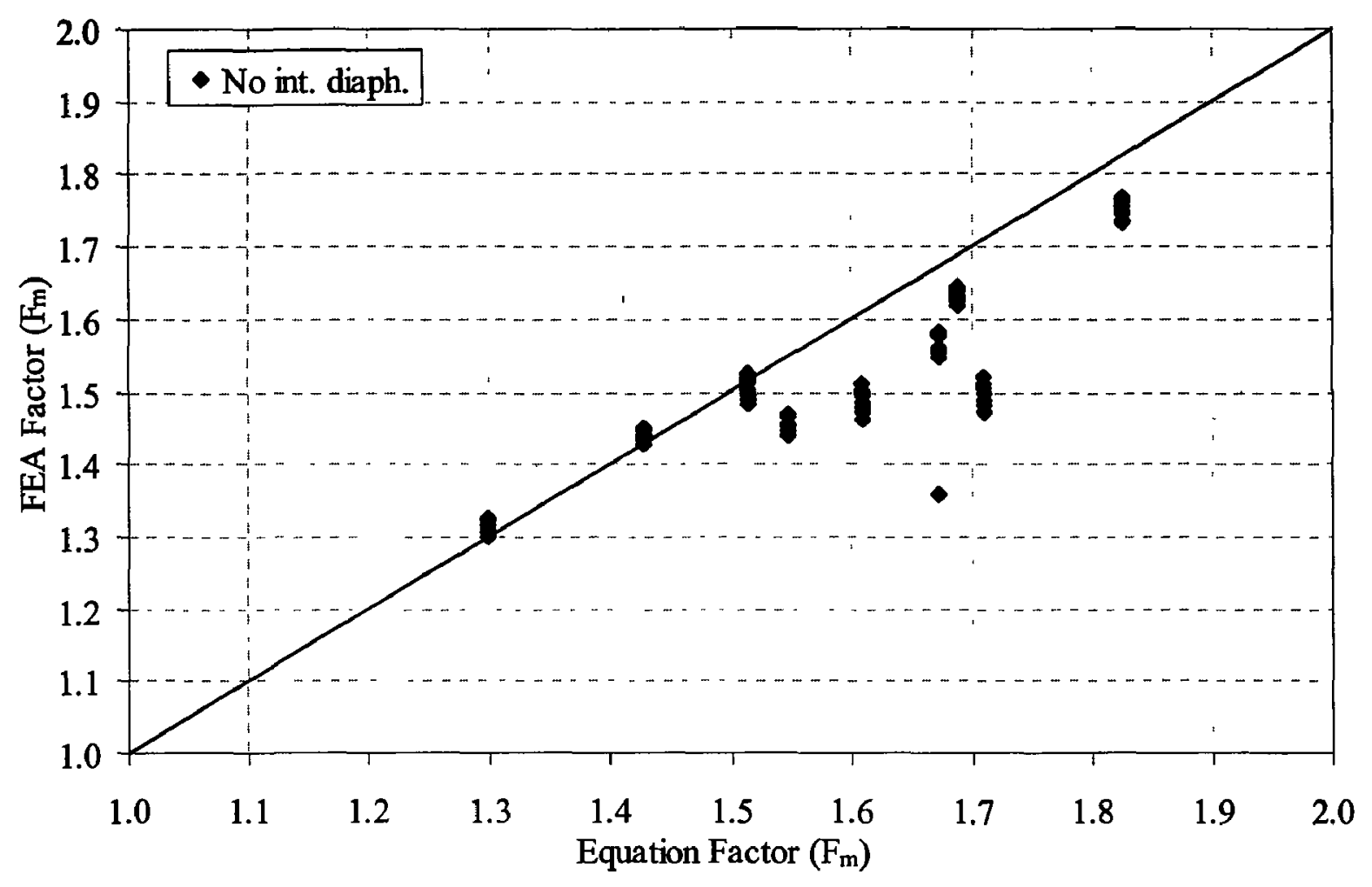

Figure 4.116 FEA results versus proposed equation for shear distribution factor of exterior girder

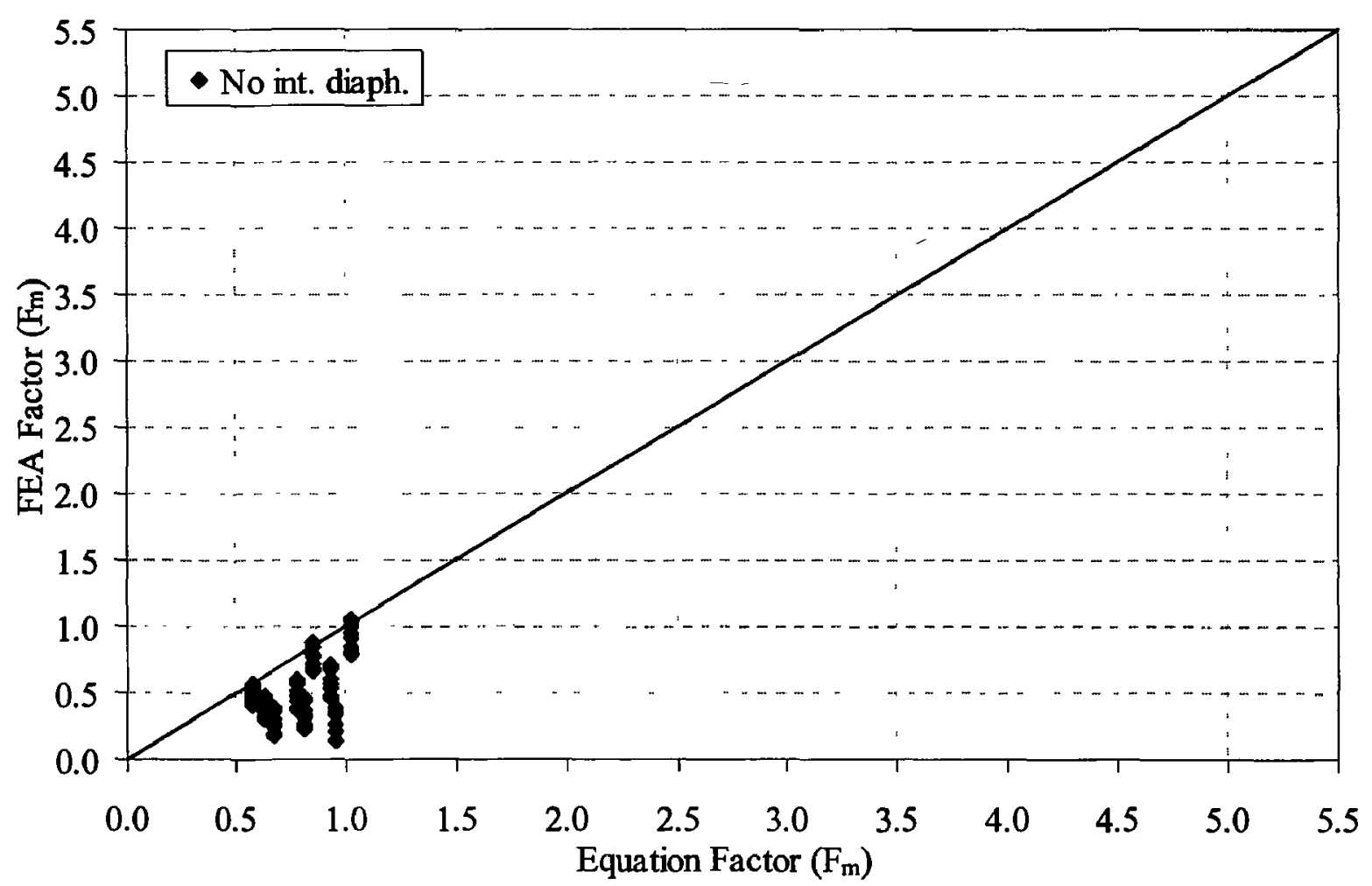

Figure 4.117 FEA results versus proposed equation for shear distribution factor of exterior girder for FLS 


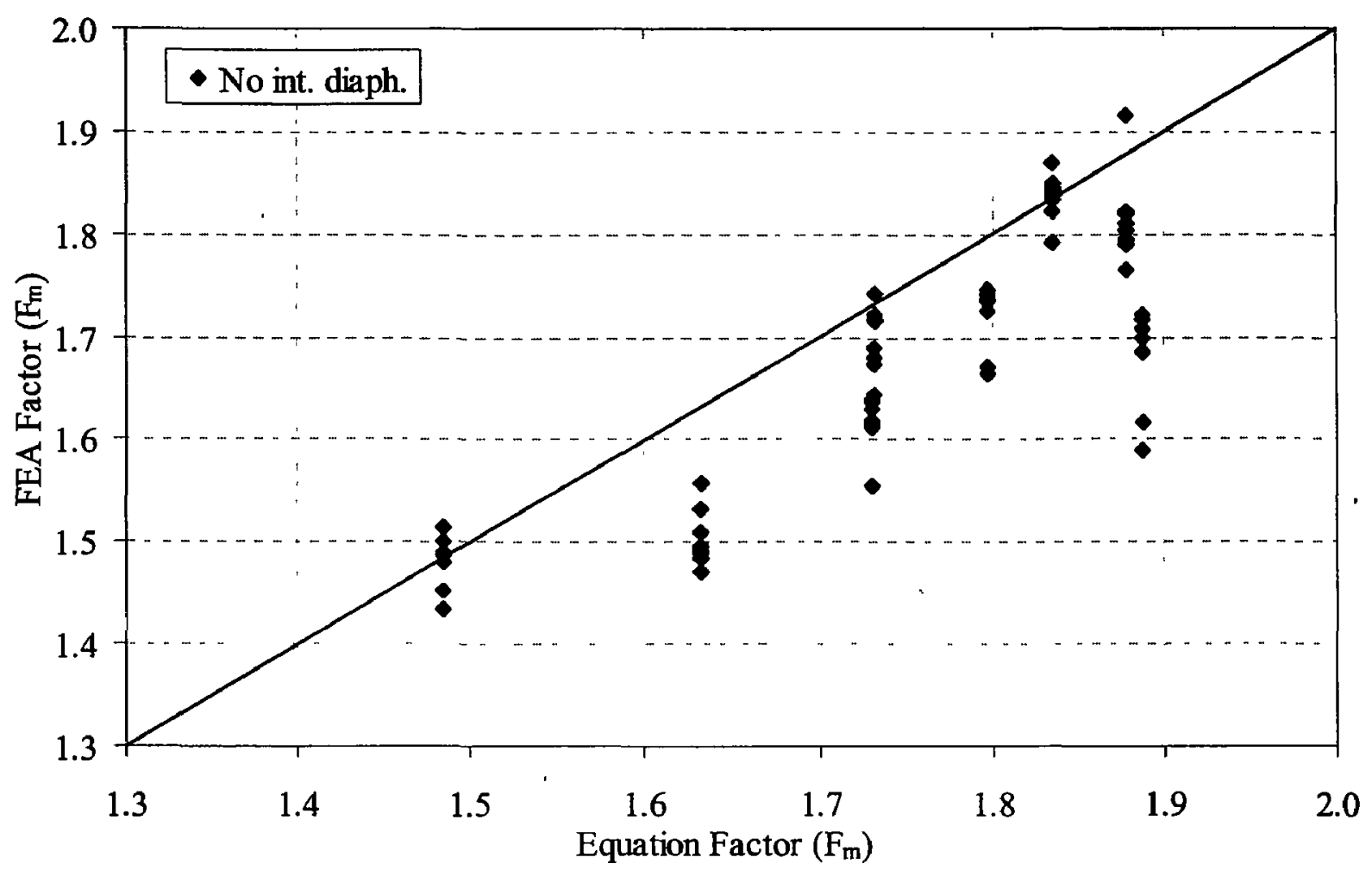

Figure 4.118 FEA results versus proposed equation for shear distribution factor of interior girder

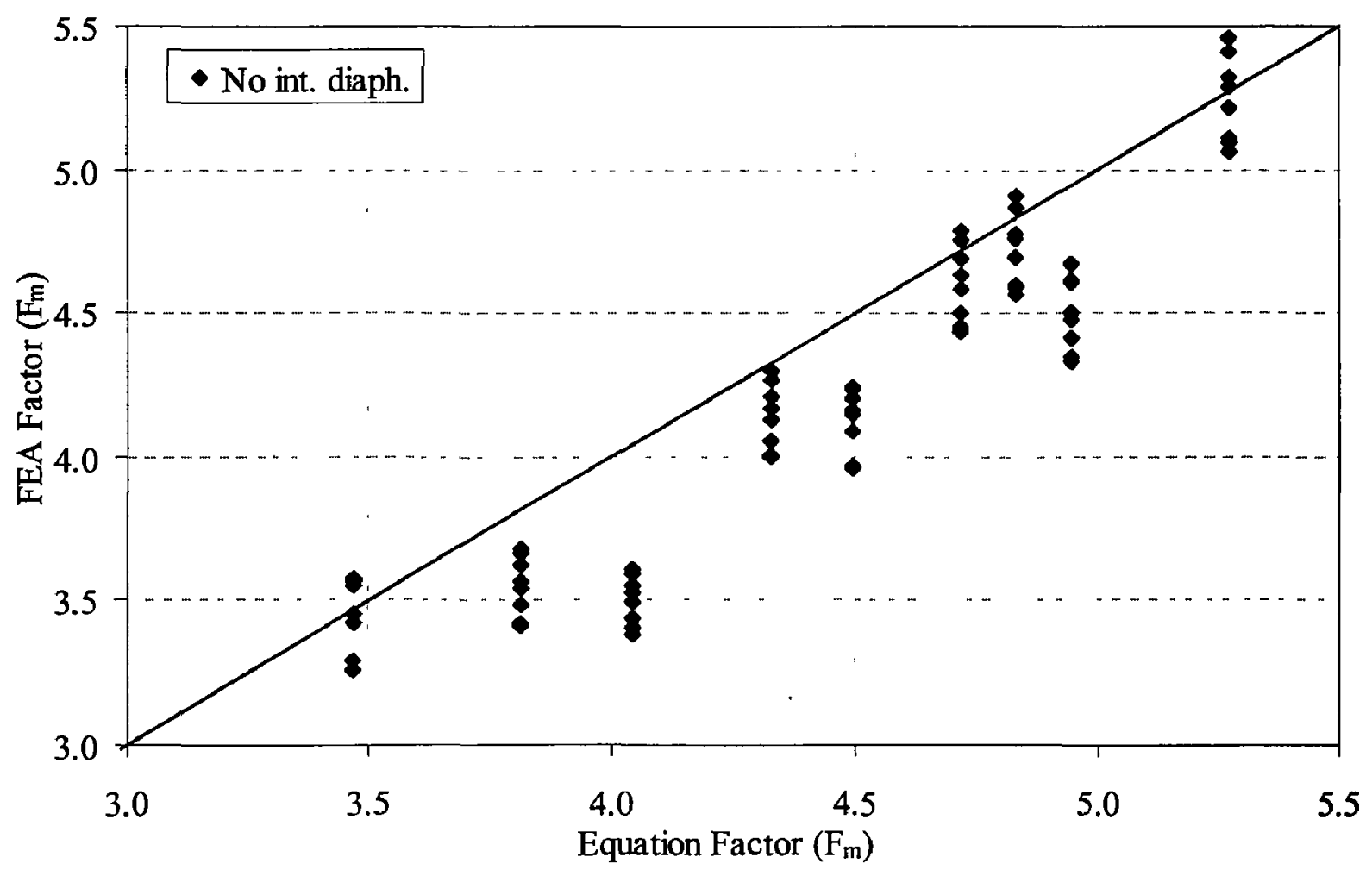

Figure 4.119 FEA results versus proposed equation for shear distribution factor of interior girder for FLS 


\section{APPENDLX A}

A - I. Input File For WF-CPCI 1600 Girder 30 m Span Bridge

With 6 girders, $2200 \mathrm{~mm}$ girder spacing and two intermediate diaphragms

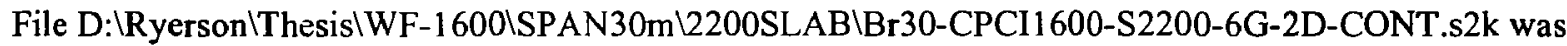
saved on $02 / 11 / 04$ at $22: 16: 20$

TABLE: "PROGRAM CONTROL"

Program Name=SAP2000 Version=8.1.2 ProgLevel=Nonlinear CurrUnits="KN, m, C"

; WF-CPCI 1600 GIRDERS 30M SPAN - 2200mm WIDTH - 6 GIRDERS

; CONCRETE RIGID DIAPHRAGMS AT SUPPORTS AND 2 INTERMEDIATE DIAPHRAGMS

; FULL CONNECTION BETWEEN GIRDER FLANGES

SYSTEM

$\mathrm{DOF}=\mathrm{ALL} \quad \mathrm{LENGTH}=\mathrm{M} \quad$ FORCE $=\mathrm{KN}$

JOINT

1

63

253

315

$1,63,1,1513,63$

;GIRDER WEB

2264

2326

2390

2452

$2264,2326,1,2390,63$

2516

2578

2642

2704

$2516,2578,1,2642,63$

2768

2830

2894

2956

$2768,2830,1,2894,63$

3020

3082

3146

3208

$3020,3082,1,3146,63$

3272

$\begin{array}{lll}X=0.0 & Y=0.0 & Z=1.3368 \\ X=31.000 & Y=0.0 & Z=1.3368 \\ X=0.0 & Y=2.2 & Z=1.3368 \\ X=31.000 & Y=2.2 & Z=1.3368 \\ X=0,31.000,0 & Y=0,0,13.2 & Z=1.3368\end{array}$

$\mathrm{X}=0.0$

$X=31.000$

$\mathrm{Y}=0.77$

$\mathrm{Y}=0.77$

$\mathrm{Y}=1.43$

$\mathrm{Y}=1.43$

$\mathrm{X}=0.0$

$X=0,31.000,0$

$\mathrm{Y}=0.77,0.77,1.43$

$\mathrm{Y}=2.97$

$\mathrm{Y}=2.97$

$\mathrm{Y}=3.63$

$\mathrm{Y}=3.63$

$X=0.0$

$\mathrm{Y}=2.97,2.97,3.63$

$Z=0.6684$

$\mathrm{Z}=0.6684$

$Z=0.6684$

$\mathrm{Z}=0.6684$

$\mathrm{Z}=0.6684$

$\mathrm{Z}=\mathbf{0 . 6 6 8 4}$

$Z=0.6684$

$\mathrm{Z}=0.6684$

$\mathrm{Z}=0.6684$

$\mathrm{Z}=0.6684$

$\mathrm{X}=0.0$

$\mathrm{Y}=5.17$

$\mathrm{Y}=5.17$

$Z=0.6684$

$X=31.000$

$\mathrm{Y}=5.83$

$\mathrm{Y}=5.83$

$\mathrm{Z}=0.6684$

$\mathrm{Z}=0.6684$

$\mathrm{Z}=0.6684$

$\mathrm{X}=0.0$

$\mathrm{Y}=5.17,5.17,5.83$

$\mathrm{Z}=0.6684$

$\mathrm{X}=0.0$

$Y=7.37$

$Y=7.37$

$\mathrm{Z}=0.6684$

$Z=0.6684$

$Z=0.6684$

$X=0.0 \quad Y=8.03$

$X=0.0 \quad Y=8.03$

$Z=0.6684$

$X=0,31.000,0$

$\mathrm{Y}=7.37,7.37,8.03$

$\mathrm{Z}=0.6684$

$\mathrm{X}=0.0$

$\mathrm{Y}=9.57$

$Z=0.6684$ 


\begin{tabular}{|c|c|c|c|}
\hline $3334, \quad x^{3}$ & $X=31.000$ & $Y=9.57$ & $Z=0.6684$ \\
\hline $3398 \quad$ '. & $X=0.0$ & $Y=10.23$ & $Z=0.6684$ \\
\hline 3460 & $X=0.0$ & $Y=10.23$ & $Z=0.6684$ \\
\hline $3272,3334,1,3398,63$ & $X=0,31.000,0$ & $Y=9.57,9.57,10.23$ & $Z=0.6684$ \\
\hline 3524 & $X=0.0$ & $Y=11.77$ & $Z=0.6684$ \\
\hline 3586 & $X=31.000$ & $\mathrm{Y}=11.77$ & $\mathrm{Z}=0.6684$ \\
\hline 3650 & $X=0.0$ & $Y=12.43$ & $Z=0.6684$ \\
\hline 3712 & $X=0.0$ & $\mathrm{Y}=12.43$ & $Z=0.6684$ \\
\hline $3524,3586,1,3650,63$ & $X=0,31.000,0$ & $Y=11.77,11.77,12.43$ & $Z=0.6684$ \\
\hline 4464 & $X=0.0$ & $Y=0.77$ & $Z=0.0$ \\
\hline 4526 & $X=31.000$ & $Y=0.77$ & $\mathrm{Z}=0.0$ \\
\hline 4590 & $X=0.0$ & $Y=1.43$ & $\mathrm{Z}=0.0$ \\
\hline 4652 & $X=0.0$ & $Y=1.43$ & $\mathrm{Z}=0.0$ \\
\hline $4464,4526,1,4590,63$ & $X=0,31.000,0$ & $Y=0.77,0.77,1.43$ & $\mathrm{Z}=0.0$ \\
\hline 4716 & $X=0.0$ & $Y=2.97$ & $\mathrm{Z}=0.0$ \\
\hline 4778 & $X=31.000$ & $Y=2.97$ & $\mathrm{Z}=0.0$ \\
\hline 4842 & $X=0.0$ & $Y=3.63$ & $Z=0.0$ \\
\hline 4904 & $X=0.0$ & $Y=3.63$ & $\mathrm{Z}=0.0$ \\
\hline $4716,4778,1,4842,63$ & $X=0,31.000,0$ & $Y=2.97,2.97,3.63$ & $\mathrm{Z}=0.0$ \\
\hline 4968 & $X=0.0$ & $Y=5.17$ & $\mathrm{Z}=0.0$ \\
\hline 5030 & $X=31.000$ & $Y=5.17$ & $\mathrm{Z}=0.0$ \\
\hline 5094 & $X=0.0$ & $Y=5.83$ & $Z=0.0$ \\
\hline 5156 & $X=0.0$ & $Y=5.83$ & $Z=0.0$ \\
\hline $4968,5030,1,5094,63$ & $X=0,31.000,0$ & $Y=5.17,5.17,5.83$ & $\mathrm{Z}=0.0$ \\
\hline 5220 & $X=0.0$ & $Y=7.37$ & $Z=0.0$ \\
\hline 5282 & $X=31.000$ & $Y=7.37$ & $Z=0.0$ \\
\hline 5346 & $X=0.0$ & $Y=8.03$ & $\mathrm{Z}=0.0$ \\
\hline 5408 & $X=0.0$ & $Y=8.03$ & $Z=0.0$ \\
\hline $5220,5282,1,5346,63$ & $X=0,31.000,0$ & $Y=7.37,7.37,8.03$ & $\mathrm{Z}=0.0$ \\
\hline 5472 & $X=0 \quad 0$ & $Y=9.57$ & $Z=0.0$ \\
\hline 5534 & $X=31.000$ & $\mathrm{Y}=9.57$ & $\mathrm{Z}=0.0$ \\
\hline 5598 & $X=0.0$ & $\mathrm{Y}=10.23$ & $Z=0.0$ \\
\hline 5660 & $X=0.0$ & $Y=10.23$ & $Z=0.0$ \\
\hline $5472,5534,1,5598,63$ & $X=0,31.000,0$ & $Y=9.57,9.57,10.23$ & $Z=0.0$ \\
\hline 5724 & $X=0.0$ & $Y=11.77$ & $\mathrm{Z}=0.0$ \\
\hline 5786 & $X=31.000$ & $Y=11.77$ & $Z=0.0$ \\
\hline 5850 & $X=0.0$ & $Y=12.43$ & $Z=0.0$ \\
\hline 5912 & $X=0.0$ & $Y=12.43$ & $\mathrm{Z}=0.0$ \\
\hline $5724,5786,1,5850,63$ & $X=0,31.000,0$ & $Y=11.77,11.77,12.43$ & $Z=0.0$ \\
\hline DIAPHRAGMS & & & \\
\hline 9001 & $X=0.5$ & $Y=1.1$ & $Z=1.3368$ \\
\hline 9021 & $X=0.5$ & $\mathrm{Y}=12.1$ & $Z=1.3368$ \\
\hline 9043 & $X=0.5$ & $Y=1.1$ & $\mathrm{Z}=0.0$ \\
\hline 9063 & $X=0.5$ & $Y=12.1$ & $Z=0.0$ \\
\hline $9001,9021,1,9043,21$ & $X=0.5$ & $Y=1.1,12.1,1.1$ & $Z=1.3368,1.3368,0$ \\
\hline 9101 & $X=30.5$ & $Y=1.1$ & $Z=1.3368$ \\
\hline & & 96 & \\
\hline
\end{tabular}




\begin{tabular}{|c|c|c|c|c|}
\hline \multicolumn{2}{|l|}{9121} & $X=30.5$ & $Y=12.1$ & $Z=1.3368$ \\
\hline \multicolumn{2}{|l|}{9143} & $X=30.5$ & $Y=1.1$ & $Z=0.0$ \\
\hline \multicolumn{2}{|c|}{9163} & $X=30.5$ & $Y=12.1$ & $\mathrm{Z}=0.0$ \\
\hline \multicolumn{2}{|c|}{$9101,9121,1,9143,21$} & $X=30.5$ & $Y=1.1,12.1,1.1$ & $\mathrm{Z}=1.3368,1.3368,0$ \\
\hline \multicolumn{2}{|l|}{9201} & $X=10.5$ & $Y=1.1$ & $\mathrm{Z}=1.3368$ \\
\hline \multicolumn{2}{|l|}{9221} & $X=10.5$ & $Y=12.1$ & $\mathrm{Z}=1.3368$ \\
\hline \multicolumn{2}{|l|}{9243} & $X=10.5$ & $Y=1.1$ & $\mathrm{Z}=0.0$ \\
\hline \multicolumn{2}{|l|}{9263} & $X=10.5$ & $Y=12.1$ & $\mathrm{Z}=0.0$ \\
\hline \multicolumn{2}{|c|}{$9201,9221,1,9243,21$} & $X=10.5$ & $Y=1.1,12.1,1.1$ & $\mathrm{Z}=1.3368,1.3368,0$ \\
\hline \multicolumn{2}{|l|}{9301} & $X=20.5$ & $Y=1.1$ & $\mathrm{Z}=1.3368$ \\
\hline \multicolumn{2}{|l|}{9321} & $X=20.5$ & $Y=12.1$ & $Z=1.3368$ \\
\hline \multicolumn{2}{|l|}{9343} & $X=20.5$ & $\mathrm{Y}=1.1$ & $\mathrm{Z}=0.0$ \\
\hline \multicolumn{2}{|l|}{9363} & $X=20.5$ & $Y=12.1$ & $Z=0.0$ \\
\hline \multicolumn{2}{|c|}{$9301,9321,1,9343,21$} & $X=20.5$ & $Y=1.1,12.1,1.1$ & $\mathrm{Z}=1.3368,1.3368,0$ \\
\hline \multicolumn{3}{|c|}{ PATTERN } & \multicolumn{2}{|c|}{ NAME=DEFAULT } \\
\hline \multicolumn{5}{|c|}{ RESTRAINTS } \\
\hline \multicolumn{2}{|c|}{$A D D=4465,4591,63$} & $\mathrm{DOF}=\mathrm{L}$ & & \\
\hline \multicolumn{2}{|c|}{$\mathrm{ADD}=4525,4651,63$} & $\mathrm{DOF}=$ & & \\
\hline \multicolumn{2}{|c|}{$\mathrm{ADD}=4717,4843,63$} & $\mathrm{DOF}=\mathrm{L}$ & & \\
\hline \multicolumn{2}{|c|}{$\mathrm{ADD}=4777,4903,63$} & $\mathrm{DOF}=$ & & \\
\hline \multicolumn{2}{|c|}{$\mathrm{ADD}=4969,5095,63$} & $\mathrm{DOF}=\mathrm{L}$ & & \\
\hline \multicolumn{2}{|c|}{$\mathrm{ADD}=5029,5155,63$} & $\mathrm{DOF}=$ & $-\ldots$ & \\
\hline \multicolumn{2}{|c|}{$\mathrm{ADD}=5221,5347,63$} & $\mathrm{DOF}=\mathrm{L}$ & & \\
\hline \multicolumn{2}{|c|}{$\mathrm{ADD}=5281,5407,63$} & $\mathrm{DOF}=$ & & \\
\hline \multicolumn{2}{|c|}{$\mathrm{ADD}=5473,5599,63$} & $\mathrm{DOF}=\mathrm{L}$ & & \\
\hline \multicolumn{2}{|c|}{$\mathrm{ADD}=5533,5659,63$} & $\mathrm{DOF}=$ & & \\
\hline \multicolumn{2}{|c|}{$\mathrm{ADD}=5725,5851,63$} & $\mathrm{DOF}=\mathrm{l}$ & & \\
\hline \multicolumn{2}{|c|}{$\mathrm{ADD}=5785,5911,63$} & $\mathrm{DOF}=$ & & \\
\hline CONSTRAIN" & & & & \\
\hline $\mathrm{NAME}=1$ & $\begin{array}{l}\text { TYPE }=E Q \\
\mathrm{ADD}=128,\end{array}$ & 8873 & & \\
\hline $\mathrm{NAME}=2$ & $\begin{array}{r}\text { TYPE }=E Q U \\
\text { ADD }=443,\end{array}$ & 8562 & & \\
\hline $\mathrm{NAME}=3$ & $\begin{array}{r}\text { TYPE }=\mathrm{EQU} \\
\mathrm{ADD}=758,\end{array}$ & 8251 & & \\
\hline $\mathrm{NAME}=4$ & $\begin{array}{r}\text { TYPE }=\text { EQU } \\
\text { ADD }=1073\end{array}$ & 3,7940 & & \\
\hline $\mathrm{NAME}=5$ & $\begin{array}{r}\text { TYPE }=\text { EQU } \\
\text { ADD }=1388\end{array}$ & 7,7629 & & \\
\hline $\mathrm{NAME}=6$ & $\begin{array}{r}\text { TYPE }=\text { EQU } \\
\text { ADD }=1703\end{array}$ & 1,7318 & & \\
\hline $\mathrm{NAME}=7$ & $\begin{array}{r}\text { TYPE}=E Q U \\
A D D=4528\end{array}$ & 4513 & & \\
\hline
\end{tabular}




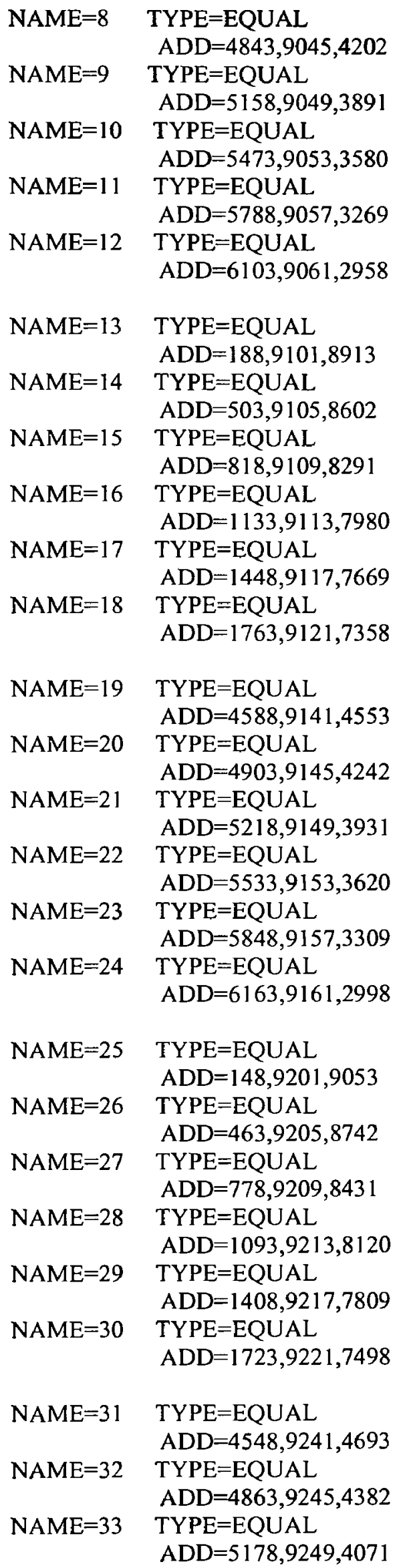




\begin{tabular}{|c|c|}
\hline $\mathrm{NAME}=34$ & $\begin{array}{l}\text { TYPE }=E Q U A L \\
\mathrm{ADD}=5493,9253,3760\end{array}$ \\
\hline $\mathrm{NAME}=35$ & $\begin{array}{l}\text { TYPE }=\text { EQUAL } \\
\mathrm{ADD}=5808,9257,3449\end{array}$ \\
\hline $\mathrm{NAME}=36$ & $\begin{array}{l}\text { TYPE }=\text { EQUAL } \\
\mathrm{ADD}=6123,9261,3138\end{array}$ \\
\hline NAME $=37$ & $\begin{array}{l}\text { TYPE }=\text { EQUAL } \\
\mathrm{ADD}=168,9301,9133\end{array}$ \\
\hline $\mathrm{NAME}=38$ & $\begin{array}{l}\text { TYPE }=\text { EQUAL } \\
\text { ADD }=483,9305,8822\end{array}$ \\
\hline $\mathrm{NAME}=39$ & $\begin{array}{l}\text { TYPE }=\text { EQUAL } \\
\text { ADD }=798,9309,8511\end{array}$ \\
\hline $\mathrm{NAME}=40$ & $\begin{array}{l}\text { TYPE }=\text { EQUAL } \\
\mathrm{ADD}=1113,9313,8200\end{array}$ \\
\hline $\mathrm{NAME}=41$ & $\begin{array}{l}\text { TYPE=EQUAL } \\
\mathrm{ADD}=1428,9317,7889\end{array}$ \\
\hline $\mathrm{NAME}=42$ & $\begin{array}{l}\text { TYPE }=\text { EQUAL } \\
\text { ADD }=1743,9321,7578\end{array}$ \\
\hline $\mathrm{NAME}=43$ & $\begin{array}{l}\text { TYPE }=\text { EQUAL } \\
\mathrm{ADD}=4568,9341,4773\end{array}$ \\
\hline $\mathrm{NAME}=44$ & $\begin{array}{l}\text { TYPE }=\text { EQUAL } \\
\mathrm{ADD}=4883,9345,4462\end{array}$ \\
\hline $\mathrm{NAME}=45$ & $\begin{array}{l}\text { TYPE }=\text { EQUAL } \\
\mathrm{ADD}=5198,9349,4151\end{array}$ \\
\hline NAME $=46$ & $\begin{array}{l}\text { TYPE }=\text { EQUAL } \\
\mathrm{ADD}=5513,9353,3840\end{array}$ \\
\hline $\mathrm{NAME}=47$ & $\begin{array}{l}\text { TYPE }=E Q U A L \\
\mathrm{ADD}=5828,9357,3529\end{array}$ \\
\hline $\mathrm{NAME}=48$ & $\begin{array}{l}\text { TYPE }=\text { EQUAL } \\
\mathrm{ADD}=6143,9361,3218\end{array}$ \\
\hline
\end{tabular}

MATERIAL

$\begin{array}{lllll}\text { NAME=CONC } & \begin{array}{l}\text { Type=ISO } \\ \mathrm{E}=27900000\end{array} & \begin{array}{l}\mathrm{M}=2.5 \\ \mathrm{U}=0.2\end{array} & \begin{array}{l}\mathrm{W}=24.5 \\ \mathrm{~A}=10.0 \mathrm{E}-6\end{array} & \text { IDES=C } \\ \text { NAME=CONC1 } & \begin{array}{l}\text { Type=ISO } \\ \mathrm{E}=27900000\end{array} & \begin{array}{l}\mathrm{M}=0.0 \\ \mathrm{U}=0.2\end{array} & \begin{array}{l}\mathrm{W}=0.0 \\ \mathrm{~A}=10.0 \mathrm{E}-6\end{array} & \text { IDES=C } \\ \text { NAME=REBAR } & \begin{array}{l}\text { Type=ISO } \\ \mathrm{E}=200000000\end{array} & \begin{array}{l}\mathrm{M}=7.85 \\ \mathrm{U}=0.3\end{array} & \begin{array}{l}\mathrm{W}=77.0 \\ \mathrm{~A}=12.0 \mathrm{E}-6\end{array} & \text { IDES=S } \\ \text { NAME=STEEL } & \begin{array}{l}\text { Type=ISO } \\ \mathrm{E}=200000000\end{array} & \begin{array}{l}\mathrm{M}=7.85 \\ \mathrm{U}=0.3\end{array} & \begin{array}{l}\mathrm{W}=77.0 \\ \mathrm{~A}=12.0 \mathrm{E}-6\end{array} & \text { IDES=S }\end{array}$

FRAME SECTION

$\begin{array}{llll}\text { NAME }=\text { SEC1 } & \text { MAT }=\text { REBAR } & \text { SH=R } & \mathrm{T}=0.012,0.3 \\ \text { NAME }=\text { SEC2 } & \text { MAT }=\text { STEEL } & \text { SH=L } & \mathrm{T}=0.150,0.150,0.015,0.015 \\ \text { NAME }=\text { SEC3 } & \text { MAT }=\text { CONC1 } & \text { SH=P } & \mathrm{T}=0.001\end{array}$

\section{FRAME}


; FALSE FRAME MEMBERS

50] $\mathrm{J}=1,2$

$\mathrm{GEN}=501,562,1$

$\mathrm{GEN}=501,687,62$

$\mathrm{GEN}=563,624,1$

$\mathrm{GEN}=625,686,1$

$\mathrm{GEN}=687,748,1$

$801 \mathrm{~J}=253,254$

$\mathrm{GEN}=801,862,1$

GEN $=801,987,62$

$\mathrm{GEN}=863,924,1$

GEN $=925,986,1$

$\mathrm{GEN}=987,1048,1$

$1101 \mathrm{~J}=505,506$

GEN $=1$ 101,1 162,1

$\mathrm{GEN}=1101,1287,62$

$\mathrm{GEN}=1163,1224, \mathrm{I}$

GEN $=1225,1286$, 1

GEN $=1287,1348,1$

1401

$\mathrm{J}=757,758$

$\mathrm{GEN}=1401,1462,1$

$\mathrm{GEN}=1401,1587,62$

$\mathrm{GEN}=1463,1524,1$

$\mathrm{GEN}=1525,1586,1$

$\mathrm{GEN}=1587,1648,1$

1701

$\mathrm{J}=1009,1010$

GEN $=1701,1762,1$

$\mathrm{GEN}=1701,1887,62$

GEN $=1763,1824,1$

$\mathrm{GEN}=1825,1886$, I

$\mathrm{GEN}=1887,1948,1$

2001

$\mathrm{J}=1261,1262$

$\mathrm{GEN}=2001,2062,1$

$\mathrm{GEN}=\mathbf{2 0 0 1}, \mathbf{2 2 4 9}, \mathbf{6 2}$

$\mathrm{GEN}=2063,2124, \mathrm{I}$

$\mathrm{GEN}=2125,2 \mathrm{I} 86,1$

$\mathrm{GEN}=2187,2248,1$

$\mathrm{GEN}=2249,2310,1$

SHELL SECTION

NAME $=$ SLAB
NAME$=$ WEB
NAME=BOTT
NAME=DIAPH

$\begin{array}{ll}\text { SEC }=\text { SEC3 } & \text { NSEG }=4 \\ \text { IINC }=1 & \text { JINC=1 } \\ \text { IINC }=63 & \text { JINC }=63 \\ \text { IINC }=1 & \text { JINC }=1 \\ \text { IINC }=1 & \text { JINC }=1 \\ \text { IINC }=1 & \text { JINC }=1\end{array}$

$\mathrm{SEC}=\mathrm{SEC} 3$

$\mathrm{NSEG}=4$

$\mathrm{JINC}=1$

JINC $=63$

$\mathrm{JINC}=1$

$\mathrm{JINC}=1$

IINC $=1 \quad$ JINC $=1$

$\begin{array}{ll}\text { SEC }=\text { SEC3 } & \text { NSEG }=4 \\ \text { IINC=1 } & \text { JINC }=1 \\ \text { IINC }=63 & \text { JINC }=63 \\ \text { IINC }=1 & \text { JINC }=1 \\ \text { IINC }=1 & \text { JINC }=1 \\ \text { IINC }=1 & \text { JINC }=1\end{array}$

$\mathrm{SEC}=\mathrm{SEC} 3$

$\mathrm{NSEG}=4$

$\mathrm{JINC}=1$

IINC $=63 \quad$ JINC $=63$

IINC $=1 \quad$ JINC $=1$

IINC $=1 \quad$ JINC $=1$

IINC $=1 \quad$ JINC $=1$

$\begin{array}{ll}\text { SEC }=\text { SEC3 } & \text { NSEG }=4 \\ \text { IINC }=1 & \text { JINC }=1 \\ \text { IINC }=63 & \text { JINC }=63 \\ \text { IINC }=1 & \text { JINC }=1 \\ \text { IINC }=1 & \text { JINC }=1 \\ \text { IINC }=1 & \text { JINC }=1\end{array}$

$\mathrm{SEC}=\mathrm{SEC} 3$

$\mathrm{NSEG}=4$

$\mathrm{JINC}=1$

$\mathrm{JINC}=63$

IINC $=63$

JINC $=1$

IINC $=1$

$\mathrm{JINC}=1$

$\begin{array}{ll}\text { IINC }=1 & \text { JINC }=1 \\ \text { IINC }=1 & \text { JINC }=1\end{array}$
$\mathrm{ANG}=0$

$\mathrm{ANG}=0$

$\mathrm{ANG}=0$

$\mathrm{ANG}=0$

$\mathrm{ANG}=0$

ANG $=0$
TYPE $=$ SHELL $\quad$ MAT $=$ CONC $\quad$ TH $=0.225$

TYPE $=$ SHELL $\quad$ MAT $=$ CONC $\quad T H=0.16$

TYPE $=$ SHELL $\quad$ MAT $=$ CONC $\quad$ TH $=0.293$

TYPE $=$ SHELL $\quad$ MAT $=$ CONC

$\mathrm{TH}=1.200$

SHELL ;TOP SLAB

$1 \quad \mathrm{~J}=1,2,64,65$

$\mathrm{SEC}=\mathrm{SLAB}$

$\mathrm{GEN}=1,62,1$

$\mathrm{JINC}=1$ 
249

497

745

993

1241
GEN $=1,187,62$

$\mathrm{GEN}=63,124,1$

GEN $=125,186,1$

GEN $=187,248,1$

$\mathrm{J}=253,254,316,317$

$\mathrm{GEN}=249,310,1$

$\mathrm{GEN}=249,435,62$

$\mathrm{GEN}=311,372,1$

$\mathrm{GEN}=373,434,1$

$\mathrm{GEN}=435,496,1$

$\mathrm{J}=505,506,568,569$

$\mathrm{GEN}=497,558,1$

$\mathrm{GEN}=497,683,62$

GEN $=559,620,1$

GEN $=621,682,1$

$\mathrm{GEN}=683,744,1$

$\mathrm{J}=757,758,820,821$

GEN $=745,806,1$

GEN $=745,931,62$

$\mathrm{GEN}=807,868,1$

$\mathrm{GEN}=869,930,1$

GEN $=931,992,1$

$\mathrm{J}=1009,1010,1072,1073$

GEN $=993,1054,1$

GEN $=993,1179,62$

$\mathrm{GEN}=1055,1116,1$

$\mathrm{GEN}=1117,1178,1$

GEN $=179,1240,1$

$\mathrm{J}=1261,1262,1324,1325$

GEN $=1241,1302,1$

$\mathrm{GEN}=1241,1427,62$

$\mathrm{GEN}=1303,1364,1$

$\mathrm{GEN}=1365,1426,1$

$\mathrm{GEN}=1427,1488,1$

;GIRDER

1800

1862

1924

1986

2100

2162
$\mathrm{J}=127,128,2327,2328$

$\mathrm{GEN}=1800,1861,1$

$\mathrm{J}=2327,2328,4527,4528$

$\mathrm{GEN}=1862,1923,1$

$\mathrm{J}=4464,4465,4527,4528$

GEN $=1924,1985,1$

$\mathrm{J}=4527,4528,4590,4591$

GEN=1986,2047,1

$\mathrm{J}=379,380,2579,2580$

$\mathrm{GEN}=2100,2161, \mathrm{l}$

$\mathrm{J}=2579,2580,4779,4780$

$\mathrm{GEN}=2162,2223,1$
$\mathrm{JINC}=63$

$\mathrm{JINC}=1$

$\mathrm{JINC}=1$

$\mathrm{JINC}=1$

$S E C=\$ L A B$

$\mathrm{JINC}=1$

$\mathrm{JINC}=63$

$\mathrm{JINC}=1$

$\mathrm{JINC}=1$

$\mathrm{JINC}=1$

$S E C=S L A B$

$\mathrm{JINC}=1$

$\mathrm{JINC}=63$

$\mathrm{JINC}=1$

$\mathrm{JINC}=1$

$\mathrm{JINC}=1$

$\mathrm{SEC}=\mathrm{SLAB}$

$\mathrm{JINC}=1$

JINC $=63$

$\mathrm{JINC}=1$

$\mathrm{JINC}=1$

$\mathrm{JINC}=1$

$\mathrm{SEC}=\mathrm{SLAB}$

$\mathrm{JINC}=1$

JINC $=63$

$\mathrm{JINC}=1$

$\mathrm{JINC}=1$

$\mathrm{JINC}=1$

$S E C=S L A B$

$\mathrm{JINC}=1$

JINC $=63$

$\mathrm{JINC}=1$

$\mathrm{J} 1 \mathrm{NC}=1$

$\mathrm{JINC}=1$

$S E C=W E B$

$\mathrm{JINC}=1$

$\mathrm{SEC}=\mathrm{WEB}$

$\mathrm{JINC}=1$

$\mathrm{SEC}=\mathrm{BOTT}$

$\mathrm{JINC}=1$

$\mathrm{SEC}=\mathrm{BOTT}$

$\mathrm{JINC}=1$

$\mathrm{SEC}=\mathrm{WEB}$

$\mathrm{J} 1 \mathrm{NC}=1$

$\mathrm{SEC}=\mathrm{WEB}$

$\mathrm{JINC}=1$ 


\begin{tabular}{|c|c|}
\hline 2224 & $\mathrm{~J}=4716,4717,4779,4780$ \\
\hline 2286 & $\begin{array}{l}\mathrm{GEN}=2224,2285,1 \\
\mathrm{~J}=4779,4780,4842,4843\end{array}$ \\
\hline & $\mathrm{GEN}=2286,2347,1$ \\
\hline 2400 & $\mathrm{~J}=631,632,2831,2832$ \\
\hline & GEN=2400,2461, 1 \\
\hline 2462 & $\mathrm{~J}=2831,2832,5031,5032$ \\
\hline & $\mathrm{GEN}=2462,2523,1$ \\
\hline 2524 & $\mathrm{~J}=4968,4969,5031,5032$ \\
\hline & GEN=2524,2585, 1 \\
\hline 2586 & $J=5031,5032,5094,5095$ \\
\hline & $\mathrm{GEN}=2586,2647,1$ \\
\hline 2700 & $J=883,884,3083,3084$ \\
\hline & $\mathrm{GEN}=2700,2761,1$ \\
\hline 2762 & $\mathrm{~J}=3083,3084,5283,5284$ \\
\hline & $\mathrm{GEN}=2762,2823,1$ \\
\hline 2824 & $\mathrm{~J}=5220,5221,5283,5284$ \\
\hline & $\mathrm{GEN}=2824,2885,1$ \\
\hline 2886 & $\mathrm{~J}=5283,5284,5346,5347$ \\
\hline & GEN=2886,2947, 1 \\
\hline 3000 & $\mathrm{~J}=1135,1136,3335,3336$ \\
\hline & $\mathrm{GEN}=3000,3061,1$ \\
\hline 3062 & $\mathrm{~J}=3335,3336,5535,5536$ \\
\hline & $\mathrm{GEN}=3062,3123,1$ \\
\hline 3124 & $\mathrm{~J}=5472,5473,5535,5536$ \\
\hline & $\mathrm{GEN}=3124,3185,1$ \\
\hline 3186 & $\mathrm{~J}=5535,5536,5598,5599$ \\
\hline & $\mathrm{GEN}=3186,3247,1$ \\
\hline 3300 & $\mathrm{~J}=1387,1388,3587,3588$ \\
\hline & $\mathrm{GEN}=3300,3361,1$ \\
\hline 3362 & $\mathrm{~J}=3587,3588,5787,5788$ \\
\hline & $\mathrm{GEN}=3362,3423,1$ \\
\hline 3424 & $\mathrm{~J}=5724,5725,5787,5788$ \\
\hline & $\mathrm{GEN}=3424,3485,1$ \\
\hline 3486 & $\mathrm{~J}=5787,5788,5850,5851$ \\
\hline & GEN=3486,3547, 1 \\
\hline
\end{tabular}

\author{
$\mathrm{SEC}=\mathrm{BOTT}$ \\ $\mathrm{JINC}=1$ \\ $\mathrm{SEC}=\mathrm{BOTT}$ \\ JINC $=1$ \\ SEC $=$ WEB \\ JINC $=1$ \\ SEC $=$ WEB \\ $\mathrm{JINC}=1$ \\ $\mathrm{SEC}=\mathrm{BOTT}$ \\ $\mathrm{JINC}=1$ \\ $\mathrm{SEC}=\mathrm{BOTT}$ \\ JINC $=1$ \\ SEC $=$ WEB \\ $\mathrm{JINC}=1$ \\ SEC $=$ WEB \\ $\mathrm{JINC}=1$ \\ $\mathrm{SEC}=\mathrm{BOTT}$ \\ $\mathrm{JINC}=1$ \\ $\mathrm{SEC}=\mathrm{BOTT}$ \\ $\mathrm{JINC}=1$ \\ $\mathrm{SEC}=$ WEB \\ $\mathrm{JINC}=1$ \\ $\mathrm{SEC}=\mathrm{WEB}$ \\ $\mathrm{JINC}=1$ \\ $\mathrm{SEC}=\mathrm{BOTT}$ \\ $\mathrm{JINC}=1$ \\ $\mathrm{SEC}=\mathrm{BOTT}$ \\ $\mathrm{JINC}=1$ \\ $\mathrm{SEC}=\mathrm{WEB}$ \\ $\mathrm{JINC}=1$ \\ $\mathrm{SEC}=\mathrm{WEB}$ \\ $\mathrm{J} 1 \mathrm{NC}=1$ \\ $\mathrm{SEC}=\mathrm{BOTT}$ \\ $\mathrm{JINC}=1$ \\ SEC $=$ BOTT \\ $\mathrm{J} 1 \mathrm{NC}=1$
}

; DIAPHRAGMS

$\begin{array}{lll}4001 & \mathrm{~J}=9001,9002,9022,9023 & \text { SEC=DIAPH } \\ 4041 & \mathrm{GEN}=4001,4020,1,4021,20 & \mathrm{JINC}=1,21 \\ & \mathrm{~J}=9101,9102,9122,9123 & \text { SEC=DIAPH } \\ & \text { GEN }=4041,4060,1,4061,20 & \mathrm{JINC}=1,21 \\ 4081 & \mathrm{~J}=9201,9202,9222,9223 & \\ & \text { GEN }=4081,4100,1,4101,20 & \text { SEC=DIAPH } \\ & \text { JINC=1,21 }\end{array}$




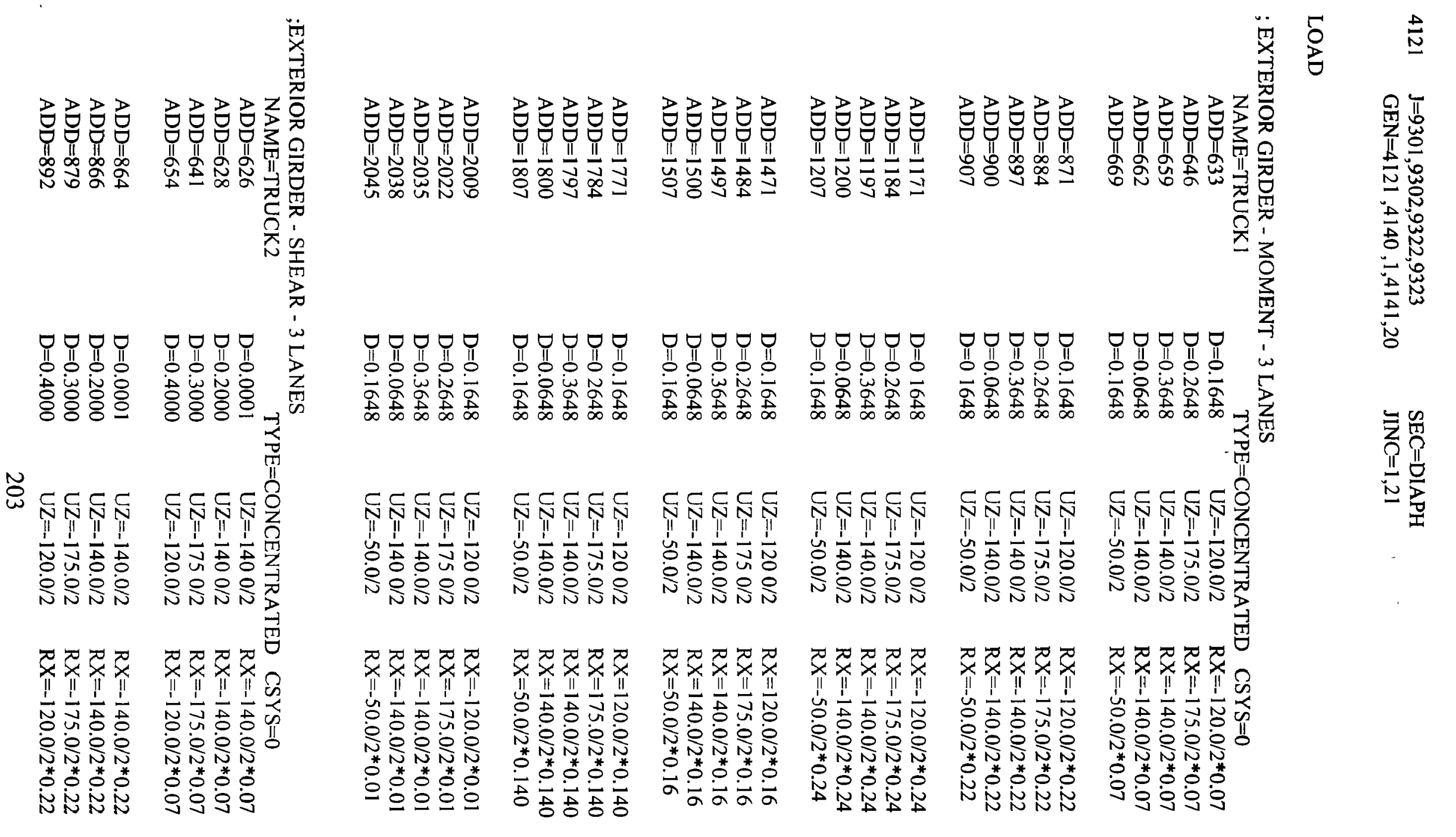




$\begin{array}{llll}\mathrm{ADD}=1164 & \mathrm{D}=0.0001 & \mathrm{UZ}=-140.0 / 2 & \mathrm{RX}=-140.0 / 2 * 0.24 \\ \mathrm{ADD}=1166 & \mathrm{D}=0.2000 & \mathrm{UZ}=-140.0 / 2 & \mathrm{RX}=-140.0 / 2 * 0.24 \\ \mathrm{ADD}=1179 & \mathrm{D}=0.3000 & \mathrm{UZ}=-175.0 / 2 & \mathrm{RX}=-175.0 / 2 * 0.24 \\ \mathrm{ADD}=1192 & \mathrm{D}=0.4000 & \mathrm{UZ}=-120.0 / 2 & \mathrm{RX}=-120.0 / 2 * 0.24 \\ & & & \\ \mathrm{ADD}=1464 & \mathrm{D}=0.0001 & \mathrm{UZ}=-140.0 / 2 & \mathrm{RX}=140.0 / 2 * 0.16 \\ \mathrm{ADD}=1466 & \mathrm{D}=0.2000 & \mathrm{UZ}=-140.0 / 2 & \mathrm{RX}=140.0 / 2 * 0.16 \\ \mathrm{ADD}=1479 & \mathrm{D}=0.3000 & \mathrm{UZ}=-175.0 / 2 & \mathrm{RX}=175.0 / 2 * 0.16 \\ \mathrm{ADD}=1492 & \mathrm{D}=0.4000 & \mathrm{UZ}=-120.0 / 2 & \mathrm{RX}=120.0 / 2 * 0.16 \\ & & & \\ \mathrm{ADD}=1764 & \mathrm{D}=0.0001 & \mathrm{UZ}=-140.0 / 2 & \mathrm{RX}=140.0 / 2 * 0.140 \\ \mathrm{ADD}=1766 & \mathrm{D}=0.2000 & \mathrm{UZ}=-140.0 / 2 & \mathrm{RX}=140.0 / 2 * 0.140 \\ \mathrm{ADD}=1779 & \mathrm{D}=0.3000 & \mathrm{UZ}=-175.0 / 2 & \mathrm{RX}=175.0 / 2 * 0.140 \\ \mathrm{ADD}=1792 & \mathrm{D}=04000 & \mathrm{UZ}=-120.0 / 2 & \mathrm{RX}=120.0 / 2 * 0.140 \\ & & & \\ \mathrm{ADD}=2002 & \mathrm{D}=0.0001 & \mathrm{UZ}=-1400 / 2 & \mathrm{RX}=-140.0 / 2 * 0.01 \\ \mathrm{ADD}=2004 & \mathrm{D}=0.2000 & \mathrm{UZ}=-140.0 / 2 & \mathrm{RX}=-140.0 / 2 * 0.01 \\ \mathrm{ADD}=2017 & \mathrm{D}=0.3000 & \mathrm{UZ}=-175.0 / 2 & \mathrm{RX}=-175.0 / 2 * 01 \\ \mathrm{ADD}=2030 & \mathrm{D}=04000 & \mathrm{UZ}=-120.0 / 2 & \mathrm{RX}=-120.0 / 2 * 0.01\end{array}$

; EXTERIOR GIRDER - MOMENT - 2 LÁNES

NAME $=$ TRUCK 3

$\mathrm{ADD}=633$

$\mathrm{ADD}=646$

$\mathrm{ADD}=659$

$\mathrm{ADD}=662$

$\mathrm{ADD}=669$

TYPE $=$ CONCENTRATED CSYS $=0$

$\mathrm{ADD}=871$

$\mathrm{ADD}=884$

$\mathrm{ADD}=897$

$\mathrm{ADD}=900$

$\mathrm{ADD}=907$

$\mathrm{D}=0.1648$

$\mathrm{D}=02648$

$\mathrm{UZ}=-120.0 / 2$

$\mathrm{RX}=-120.0 / 2 * 0.07$

$\mathrm{D}=0.3648$

$\mathrm{UZ}=-175.0 / 2$

$\mathrm{RX}=-175.0 / 2 * 0.07$

$\mathrm{UZ}=-140.0 / 2$

$\mathrm{RX}=-140.0 / 2 * 0.07$

$\mathrm{D}=0.0648$

$\mathrm{UZ}=-140.0 / 2$

$R X=-140.0 / 2 * 0.07$

$\mathrm{D}=0.1648$

$\mathrm{UZ}=-50 \quad 0 / 2$

$\mathrm{RX}=-50.0 / 2 * 0.07$

$\mathrm{ADD}=1171$

$\mathrm{ADD}=1184$

$\mathrm{D}=0.1648$

$U Z=-120.0 / 2$

$\mathrm{RX}=-120.0 / 2 * 0.22$

$\mathrm{D}=0.2648$

$\mathrm{UZ}=-175.0 / 2$

$R X=-175 \quad 0 / 2 * 0.22$

$\mathrm{D}=0.3648$

$U Z=-140 \quad 0 / 2$

$\mathrm{RX}=-140.0 / 2 * 0.22$

$\mathrm{D}=00648$

$U Z=-140.0 / 2$

$\mathrm{RX}=-140.0 / 2 * 0.22$

$D=0 \quad 1648$

$\mathrm{UZ}=-50.0 / 2$

$\mathrm{RX}=-50.0 / 2 * 0.22$

$\mathrm{ADD}=1197$

$\mathrm{D}=0.1648$

$\mathrm{UZ}=-120 \quad 0 / 2$

$\mathrm{RX}=-120.0 / 2 * 0.24$

$\mathrm{D}=0.2648$

$\mathrm{UZ}=-175.0 / 2$

$\mathrm{RX}=-175.0 / 2 * 0.24$

$\mathrm{ADD}=1200$

$\mathrm{D}=0.3648$

$\mathrm{UZ}=-140.0 / 2$

$\mathrm{RX}=-140.0 / 2 * 0.24$

$\mathrm{ADD}=1207$

$\mathrm{D}=00648$

$U Z=-140.0 / 2$

$\mathrm{RX}=-140.0 / 2 * 0.24$

$\mathrm{D}=0 \quad 1648$

$\mathrm{UZ}=-50.0 / 2$

$\mathrm{RX}=-50.0 / 2 * 0.24$

$\mathrm{ADD}=1471$

$\mathrm{D}=0.1648$

$U Z=-120.0 / 2$

$\mathrm{RX}=120.0 / 2 * 0.16$

$\mathrm{ADD}=1484$

$\mathrm{D}=0.2648$

$\mathrm{UZ}=-175.0 / 2$

$\mathrm{RX}=175.0 / 2 * 0.16$

$A D D=1497$

$\mathrm{D}=0.3648$

$\mathrm{UZ}=-140 \quad 0 / 2$

$\mathrm{RX}=140.0 / 2 * 0.16$

$\mathrm{ADD}=1500$

$U Z=-140.0 / 2$

$\mathrm{RX}=140.0 / 2 * 0.16$

$\mathrm{ADD}=1507$

$D=0.0648$

$U Z=-50.0 / 2$

$\mathrm{RX}=50.0 / 2 * 0.16$

;EXTERIOR GIRDER - SHEAR - 2 LANES

NAME $=$ TRUCK 4

$\mathrm{ADD}=626$

$\mathrm{ADD}=628$

$\mathrm{ADD}=641$

$\mathrm{ADD}=654$
TYPE $=$ CONCENTRATED CSYS $=0$

$\begin{array}{lll}D=0.0001 & \mathrm{UZ}=-140.0 / 2 & \mathrm{RX}=-140.0 / 2 * 0.07 \\ \mathrm{D}=0.2000 & \mathrm{UZ}=-140.0 / 2 & \mathrm{RX}=-140.0 / 2 * 0.07 \\ \mathrm{D}=0.3000 & \mathrm{UZ}=-175.0 / 2 & \mathrm{RX}=-175.0 / 2 * 0.07 \\ \mathrm{D}=0.4000 & \mathrm{UZ}=-120.0 / 2 & \mathrm{RX}=-120.0 / 2 * 0.07\end{array}$




$\begin{array}{llll}\mathrm{ADD}=864 & \mathrm{D}=0.0001 & \mathrm{UZ}=-140.0 / 2 & \mathrm{RX}=-140.0 / 2 * 0.22 \\ \mathrm{ADD}=866 & \mathrm{D}=0.2000 & \mathrm{UZ}=-140.0 / 2 & \mathrm{RX}=-140.0 / 2 * 0.22 \\ \mathrm{ADD}=879 & \mathrm{D}=0.3000 & \mathrm{UZ}=-175.0 / 2 & \mathrm{RX}=-175.0 / 2 * 0.22 \\ \mathrm{ADD}=892 & \mathrm{D}=0.4000 & \mathrm{UZ}=-120.0 / 2 & \mathrm{RX}=-120.0 / 2 * 0.22 \\ & & & \\ \mathrm{ADD}=1164 & \mathrm{D}=0.0001 & \mathrm{UZ}=-140.0 / 2 & \mathrm{RX}=-140.0 / 2 * 0.24 \\ \mathrm{ADD}=1166 & \mathrm{D}=0.2000 & \mathrm{UZ}=-140.0 / 2 & \mathrm{RX}=-140.0 / 2 * 0.24 \\ \mathrm{ADD}=1179 & \mathrm{D}=0.3000 & \mathrm{UZ}=-175.0 / 2 & \mathrm{RX}=-175.0 / 2 * 0.24 \\ \mathrm{ADD}=1192 & \mathrm{D}=0.4000 & \mathrm{UZ}=-120.0 / 2 & \mathrm{RX}=-120.0 / 2 * 0.24 \\ & & & \\ \mathrm{ADD}=1464 & \mathrm{D}=0.0001 & \mathrm{UZ}=-140.0 / 2 & \mathrm{RX}=140.0 / 2 * 0.16 \\ \mathrm{ADD}=1466 & \mathrm{D}=0.2000 & \mathrm{UZ}=-140.0 / 2 & \mathrm{RX}=140.0 / 2 * 0.16 \\ \mathrm{ADD}=1479 & \mathrm{D}=0.3000 & \mathrm{UZ}=-175.0 / 2 & \mathrm{RX}=175.0 / 2 * 0.16 \\ \mathrm{ADD}=1492 & \mathrm{D}=0.4000 & \mathrm{UZ}=-120.0 / 2 & \mathrm{RX}=120.0 / 2 * 0.16\end{array}$

; EXTERIOR GIRDER - MOMENT - 1 LANE

NAME $=$ TRUCK 5

$\mathrm{ADD}=633$

$\mathrm{ADD}=646$

$\mathrm{ADD}=659$

$\mathrm{ADD}=662$

$\mathrm{ADD}=669$

$\mathrm{ADD}=871$

$\mathrm{ADD}=884$

$\mathrm{ADD}=897$

$\mathrm{ADD}=900$

$\mathrm{ADD}=907$

\section{TYPE}

$\mathrm{D}=0.1648$

$\mathrm{D}=0.2648$

$\mathrm{D}=0.3648$

$\mathrm{D}=0.0648$

$\mathrm{D}=0.1648$

$\mathrm{D}=0.1648$

$\mathrm{D}=0.2648$

$\mathrm{D}=0.3648$

$\mathrm{D}=0.0648$

$\mathrm{D}=0.1648$
$E=$ CONCENTRATED CSYS $=0$

$\mathrm{UZ}=-120.0 / 2 \quad \mathrm{RX}=-120.0 / 2 * 0.07$

$\mathrm{UZ}=-175.0 / 2 \quad \mathrm{RX}=-175.0 / 2 * 0.07$

$\mathrm{UZ}=-140.0 / 2 \quad \mathrm{RX}=-140.0 / 2 * 0.07$

$\mathrm{UZ}=-140.0 / 2 \quad \mathrm{RX}=-140.0 / 2 * 0.07$

$\mathrm{UZ}=-50.0 / 2 \quad \mathrm{RX}=-50.0 / 2 * 0.07$

$\begin{array}{ll}\mathrm{UZ}=-120.0 / 2 & \mathrm{RX}=-120.0 / 2 * 0.22 \\ \mathrm{UZ}=-175.0 / 2 & \mathrm{RX}=-175.0 / 2 * 0.22 \\ \mathrm{UZ}=-140.0 / 2 & \mathrm{RX}=-140.0 / 2 * 0.22 \\ \mathrm{UZ}=-140.0 / 2 & \mathrm{RX}=-140.0 / 2 * 0.22 \\ \mathrm{UZ}=-50.0 / 2 & \mathrm{RX}=-50.0 / 2 * 0.22\end{array}$

; EXTERIOR GIRDER - SHEAR - 1 LANE NAME $=$ TRUCK 6 TYPE $=$ CONCENTRATED CSYS $=0$

$\mathrm{ADD}=626$

$\mathrm{ADD}=628$

$\mathrm{ADD}=641$

$\mathrm{ADD}=654$

$\mathrm{D}=0.0001$

$\mathrm{UZ}=-140.0 / 2$

$\mathrm{RX}=-140.0 / 2 * 0.07$

$\mathrm{D}=0.2000$

$\mathrm{UZ}=-140.0 / 2$

$\mathrm{RX}=-140.0 / 2 * 0.07$

$\mathrm{D}=0.3000$

$\mathrm{UZ}=-175.0 / 2$

$\mathrm{RX}=-175.0 / 2 * 0.07$

$\mathrm{D}=0.4000$

$\mathrm{UZ}=-120.0 / 2$

$\mathrm{RX}=-120.0 / 2 * 0.07$

$\mathrm{ADD}=864$

$\mathrm{D}=0.0001$

$U Z=-140.0 / 2$

$\mathrm{RX}=-140.0 / 2 * 0.22$

$\mathrm{ADD}=866$

$\mathrm{D}=0.2000$

$\mathrm{UZ}=-140.0 / 2$

$R X=-140.0 / 2 * 0.22$

$\mathrm{ADD}=879$

$\mathrm{D}=0.3000$

$\mathrm{UZ}=-175.0 / 2$

$\mathrm{RX}=-175.0 / 2 * 0.22$

$\mathrm{ADD}=892$

$\mathrm{D}=0.4000$

$U Z=-120.0 / 2$

$\mathrm{RX}=-120.0 / 2 * 0.22$

;INTERIOR GIRDER - MOMENT - 3 LANES

NAME $=$ TRUCK 7

$\mathrm{ADD}=809$

$\mathrm{ADD}=822$

$\mathrm{ADD}=835$

$\mathrm{ADD}=838$

$\mathrm{ADD}=845$

$\mathrm{ADD}=995$

$\mathrm{ADD}=1008$

$\mathrm{ADD}=1021$

$A D D=1024$

\section{TY}

$D=0.1648$
$D=0.2648$
$D=0.3648$
$D=0.0648$
$D=0.1648$

$\mathrm{D}=0.1648$

$D=0.2648$

$\mathrm{D}=0.3648$

$\mathrm{D}=0.0648$
YPE $=$ CONCENTRATED CSYS $=0$

$\begin{array}{cl}\mathrm{UZ}=-1200 / 2 & \mathrm{RX}=120.0 / 2 * 0.01 \\ \mathrm{UZ}=-175.0 / 2 & \mathrm{RX}=175.0 / 2 * 0.01 \\ \mathrm{UZ}=-140.0 / 2 & \mathrm{RX}=140.0 / 2 * 0.01 \\ \mathrm{UZ}=-140.0 / 2 & \mathrm{RX}=140.0 / 2 * 0.01 \\ \mathrm{UZ}=-50.0 / 2 & \mathrm{RX}=50.0 / 2 * 0.01 \\ \mathrm{UZ}=-120.0 / 2 & \mathrm{RX}=-120.0 / 2 * 0.140 \\ \mathrm{UZ}=-175.0 / 2 & \mathrm{RX}=-175.0 / 2 * 0.140 \\ \mathrm{UZ}=-140.0 / 2 & \mathrm{RX}=-140.0 / 2 * 0.140 \\ \mathrm{UZ}=-140.0 / 2 & \mathrm{RX}=-140.0 / 2 * 0.140 \\ 205 & \end{array}$




$\begin{array}{llll}\mathrm{ADD}=1031 & \mathrm{D}=0.1648 & \mathrm{UZ}=-50.0 / 2 & \mathrm{RX}=-50.0 / 2 * 0.140 \\ & & & \\ \mathrm{ADD}=1171 & \mathrm{D}=0.1648 & \mathrm{UZ}=-120.0 / 2 & \mathrm{RX}=-120.0 / 2 * 0.240 \\ \mathrm{ADD}=1184 & \mathrm{D}=0.2648 & \mathrm{UZ}=-175.0 / 2 & \mathrm{RX}=-175.0 / 2 * 0.240 \\ \mathrm{ADD}=1197 & \mathrm{D}=0.3648 & \mathrm{UZ}=-140.0 / 2 & \mathrm{RX}=-140.0 / 2{ }^{*} 0.240 \\ \mathrm{ADD}=1200 & \mathrm{D}=0.0648 & \mathrm{UZ}=-140.0 / 2 & \mathrm{RX}=-140.0 / 2 * 0.240 \\ \mathrm{ADD}=1207 & \mathrm{D}=0.1648 & \mathrm{UZ}=-50.0 / 2 & \mathrm{RX}=-50.0 / 2 * 0.240 \\ & & & \\ \mathrm{ADD}=1471 & \mathrm{D}=0.1648 & \mathrm{UZ}=-120.0 / 2 & \mathrm{RX}=120.0 / 2 * 0.160 \\ \mathrm{ADD}=1484 & \mathrm{D}=02648 & \mathrm{UZ}=-175.0 / 2 & \mathrm{RX}=175.0 / 2 * 0.160 \\ \mathrm{ADD}=1497 & \mathrm{D}=0.3648 & \mathrm{UZ}=-140.0 / 2 & \mathrm{RX}=140.0 / 2 * 0.160 \\ \mathrm{ADD}=1500 & \mathrm{D}=00648 & \mathrm{UZ}=-140.0 / 2 & \mathrm{RX}=140.0 / 2 * 0.160 \\ \mathrm{ADD}=1507 & \mathrm{D}=0.1648 & \mathrm{UZ}=-50.0 / 2 & \mathrm{RX}=50.0 / 2 * 0.160 \\ & & & \\ \mathrm{ADD}=1771 & \mathrm{D}=0.1648 & \mathrm{UZ}=-120.0 / 2 & \mathrm{RX}=120.0 / 2 * 0.140 \\ \mathrm{ADD}=1784 & \mathrm{D}=02648 & \mathrm{UZ}=-175.0 / 2 & \mathrm{RX}=175.0 / 2 * 0.140 \\ \mathrm{ADD}=1797 & \mathrm{D}=0.3648 & \mathrm{UZ}=-140.0 / 2 & \mathrm{RX}=140.0 / 2 * 0.140 \\ \mathrm{ADD}=1800 & \mathrm{D}=0.0648 & \mathrm{UZ}=-140.0 / 2 & \mathrm{RX}=140.0 / 2 * 0.140 \\ \mathrm{ADD}=1807 & \mathrm{D}=0.1648 & \mathrm{UZ}=-50.0 / 2 & \mathrm{RX}=50.0 / 2 * 0.140 \\ & & & \\ \mathrm{ADD}=2009 & \mathrm{D}=0.1648 & \mathrm{UZ}=-120.0 / 2 & \mathrm{RX}=-120.0 / 2 * 0.01 \\ \mathrm{ADD}=2022 & \mathrm{D}=0.2648 & \mathrm{UZ}=-175.0 / 2 & \mathrm{RX}=-175.0 / 2 * 0.01 \\ \mathrm{ADD}=2035 & \mathrm{D}=0.3648 & \mathrm{UZ}=-140.0 / 2 & \mathrm{RX}=-140.0 / 2 * 0.01 \\ \mathrm{ADD}=2038 & \mathrm{D}=00648 & \mathrm{UZ}=-140.0 / 2 & \mathrm{RX}=-140.0 / 2 * 0.01 \\ \mathrm{ADD}=2045 & \mathrm{D}=0.1648 & \mathrm{UZ}=-50.0 / 2 & \mathrm{RX}=-50.0 / 2 * 0.01 \\ & & & \end{array}$

;INTERIOR GIRDER - SHEAR - 3 LANES

NAME $=$ TRUCK 8

$\mathrm{ADD}=802$

$\mathrm{ADD}=804$

$\mathrm{ADD}=817$

$\mathrm{ADD}=830$

$\mathrm{ADD}=988$

$\mathrm{ADD}=990$

$\mathrm{ADD}=1003$

$\mathrm{ADD}=1016$

$\mathrm{ADD}=1164$

$\mathrm{ADD}=1166$

$\mathrm{ADD}=1179$

$\mathrm{ADD}=1192$

$\mathrm{ADD}=1464$

$\mathrm{ADD}=1466$

$\mathrm{ADD}=1479$

$\mathrm{ADD}=1492$

$\mathrm{ADD}=1764$

$\mathrm{ADD}=1766$

$\mathrm{ADD}=1779$

$\mathrm{ADD}=1792$

$\mathrm{ADD}=2002$

$\mathrm{ADD}=2004$
TYPE $=$ CONCENTRATED CSYS $=0$

$\begin{array}{lll}\mathrm{D}=0.0001 & \mathrm{UZ}=-140.0 / 2 & \mathrm{RX}=140.0 / 2 * 0.01 \\ \mathrm{D}=0.2000 & \mathrm{UZ}=-140.0 / 2 & \mathrm{RX}=140.0 / 2 * 0.01 \\ \mathrm{D}=0.3000 & \mathrm{UZ}=-175.0 / 2 & \mathrm{RX}=175.0 / 2 * 0.01 \\ \mathrm{D}=0.4000 & \mathrm{UZ}=-120.0 / 2 & \mathrm{RX}=120.0 / 2 * 0.01 \\ & & \\ \mathrm{D}=0.0001 & \mathrm{UZ}=-140.0 / 2 & \mathrm{RX}=-140.0 / 2 * 0.140 \\ \mathrm{D}=0.2000 & \mathrm{UZ}=-140.0 / 2 & \mathrm{RX}=-140.0 / 2 * 0.140 \\ \mathrm{D}=0.3000 & \mathrm{UZ}=-175.0 / 2 & \mathrm{RX}=-175.0 / 2 * 0.140 \\ \mathrm{D}=0.4000 & \mathrm{UZ}=-120.0 / 2 & \mathrm{RX}=-120.0 / 2 * 0.140 \\ & & \\ \mathrm{D}=00001 & \mathrm{UZ}=-140.0 / 2 & \mathrm{RX}=-140.0 / 2 * 0.240 \\ \mathrm{D}=0.2000 & \mathrm{UZ}=-1400 / 2 & \mathrm{RX}=-140.0 / 2 * 0.240 \\ \mathrm{D}=0.3000 & \mathrm{UZ}=-175.0 / 2 & \mathrm{RX}=-175.0 / 2 * 0.240 \\ \mathrm{D}=0.4000 & \mathrm{UZ}=-1200 / 2 & \mathrm{RX}=-120.0 / 2 * 0.240 \\ & & \\ \mathrm{D}=0.0001 & \mathrm{UZ}=-140.0 / 2 & \mathrm{RX}=140.0 / 2 * 0.160 \\ \mathrm{D}=0.2000 & \mathrm{UZ}=-140.0 / 2 & \mathrm{RX}=140.0 / 2 * 0.160 \\ \mathrm{D}=0.3000 & \mathrm{UZ}=-175.0 / 2 & \mathrm{RX}=175.0 / 2 * 0.160 \\ \mathrm{D}=0.4000 & \mathrm{UZ}=-120.0 / 2 & \mathrm{RX}=120.0 / 2 * 0.160 \\ & & \\ \mathrm{D}=0.0001 & \mathrm{UZ}=-140.0 / 2 & \mathrm{RX}=140.0 / 2 * 0.140 \\ \mathrm{D}=0.2000 & \mathrm{UZ}=-140.0 / 2 & \mathrm{RX}=140.0 / 2 * 0.140 \\ \mathrm{D}=0.3000 & \mathrm{UZ}=-175.0 / 2 & \mathrm{RX}=175.0 / 2 * 0.140 \\ \mathrm{D}=0.4000 & \mathrm{UZ}=-120.0 / 2 & \mathrm{RX}=120.0 / 2 * 0.140 \\ & & \\ \mathrm{D}=0.0001 & \mathrm{UZ}=-140.0 / 2 & \mathrm{RX}=-140.0 / 2 * 0.01 \\ \mathrm{D}=0.2000 & \mathrm{UZ}=-140.0 / 2 & \mathrm{RX}=-140.0 / 2 * 0.01 \\ & 206 & \\ & & \end{array}$




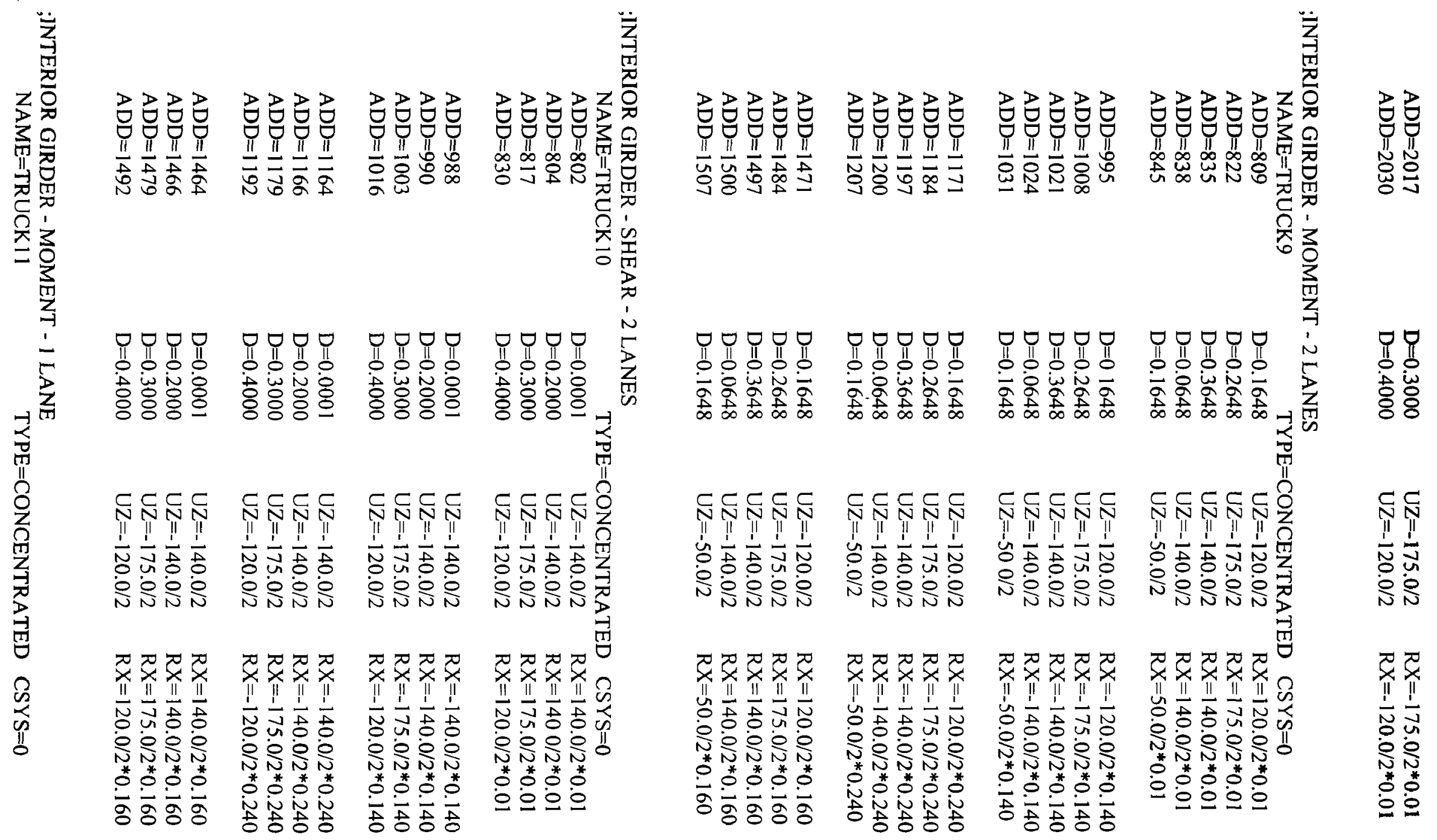




$\begin{array}{llll}\mathrm{ADD}=809 & \mathrm{D}=0.1648 & \mathrm{UZ}=-120.0 / 2 & \mathrm{RX}=120.0 / 2 * 0.01 \\ \mathrm{ADD}=822 & \mathrm{D}=0.2648 & \mathrm{UZ}=-175.0 / 2 & \mathrm{RX}=175.0 / 2 * 0.01 \\ \mathrm{ADD}=835 & \mathrm{D}=0.3648 & \mathrm{UZ}=-140.0 / 2 & \mathrm{RX}=140.0 / 2 * 0.01 \\ \mathrm{ADD}=838 & \mathrm{D}=0.0648 & \mathrm{UZ}=-140.0 / 2 & \mathrm{RX}=140.0 / 2 * 0.01 \\ \mathrm{ADD}=845 & \mathrm{D}=0.1648 & \mathrm{UZ}=-50.0 / 2 & \mathrm{RX}=50.0 / 2 * 0.01 \\ & & & \\ \mathrm{ADD}=995 & \mathrm{D}=0.1648 & \mathrm{UZ}=-120.0 / 2 & \mathrm{RX}=-120.0 / 2 * 0.140 \\ \mathrm{ADD}=1008 & \mathrm{D}=0.2648 & \mathrm{UZ}=-175.0 / 2 & \mathrm{RX}=-175.0 / 2 * 0.140 \\ \mathrm{ADD}=1021 & \mathrm{D}=0.3648 & \mathrm{UZ}=-140.0 / 2 & \mathrm{RX}=-140.0 / 2 * 0.140 \\ \mathrm{ADD}=1024 & \mathrm{D}=0.0648 & \mathrm{UZ}=-140.0 / 2 & \mathrm{RX}=-140.0 / 2 * 0.140 \\ \mathrm{ADD}=1031 & \mathrm{D}=0.1648 & \mathrm{UZ}=-50.0 / 2 & \mathrm{RX}=-50.0 / 2 * 0.140\end{array}$

;INTERIOR GIRDER - SHEAR - 1 LANE

NAME $=$ TRUCK 12

$\mathrm{ADD}=802$

$\mathrm{ADD}=804$

$\mathrm{ADD}=817$

$\mathrm{ADD}=830$

$\mathrm{ADD}=988$

$\mathrm{ADD}=990$

$\mathrm{ADD}=1003$

$\mathrm{ADD}=1016$

\begin{tabular}{lll}
\multicolumn{2}{c}{ TYPE $=$ CONCENTRATED CSYS $=0$} \\
$\mathrm{D}=0.0001$ & $\mathrm{UZ}=-140.0 / 2$ & $\mathrm{RX}=140.0 / 2^{*} 0.01$ \\
$\mathrm{D}=0.2000$ & $\mathrm{UZ}=-1400 / 2$ & $\mathrm{RX}=140.0 / 2^{*} 0.01$ \\
$\mathrm{D}=0.3000$ & $\mathrm{UZ}=-175.0 / 2$ & $\mathrm{RX}=175.0 / 2^{*} 0.01$ \\
$\mathrm{D}=0.4000$ & $\mathrm{UZ}=-120.0 / 2$ & $\mathrm{RX}=120.0 / 2 * 0.01$ \\
& & \\
$\mathrm{D}=0.0001$ & $\mathrm{UZ}=-140.0 / 2$ & $\mathrm{RX}=-140.0 / 2 * 0.140$ \\
$\mathrm{D}=0.2000$ & $\mathrm{UZ}=-1400 / 2$ & $\mathrm{RX}=-140.0 / 2^{*} 0.140$ \\
$\mathrm{D}=03000$ & $\mathrm{UZ}=-1750 / 2$ & $\mathrm{RX}=-175.0 / 2^{*} 0.140$ \\
$\mathrm{D}=0.4000$ & $\mathrm{UZ}=-120.0 / 2$ & $\mathrm{RX}=-120.0 / 2^{*} 0.140$
\end{tabular}

;EXTERIOR/INTERIOR GIRDER - FATIGUE MOMENT - 1 LANE

NAME $=$ TRUCK 13

$\mathrm{ADD}=871$

$\mathrm{ADD}=884$

$\mathrm{ADD}=897$

$\mathrm{ADD}=900$

$\mathrm{ADD}=907$

$\mathrm{ADD}=1171$

$\mathrm{ADD}=1184$

$\mathrm{ADD}=1197$

$\mathrm{ADD}=1200$

$\mathrm{ADD}=1207$
TYPE $=$ CONCENTRATED

$\begin{array}{lll}\mathrm{D}=0.1648 & \mathrm{UZ}=-120.0 / 2 & \mathrm{RX}=-120.0 / 2 * 0.25 \\ \mathrm{D}=0.2648 & \mathrm{UZ}=-175.0 / 2 & \mathrm{RX}=-175.0 / 2 * 0.25 \\ \mathrm{D}=0.3648 & \mathrm{UZ}=-1400 / 2 & \mathrm{RX}=-140.0 / 2 * 0.25 \\ \mathrm{D}=0.0648 & \mathrm{UZ}=-140.0 / 2 & \mathrm{RX}=-140.0 / 2 * 0.25 \\ \mathrm{D}=0.1648 & \mathrm{UZ}=-50.0 / 2 & \mathrm{RX}=-50.0 / 2 * 0.25\end{array}$

$\begin{array}{lll}\mathrm{D}=01648 & \mathrm{UZ}=-120.0 / 2 & \mathrm{RX}=120.0 / 2 * 0.15 \\ \mathrm{D}=0.2648 & \mathrm{UZ}=-175.0 / 2 & \mathrm{RX}=175.0 / 2 * 0.15 \\ \mathrm{D}=03648 & \mathrm{UZ}=-140.0 / 2 & \mathrm{RX}=140.0 / 2 * 0.15 \\ \mathrm{D}=0.0648 & \mathrm{UZ}=-1400 / 2 & \mathrm{RX}=140.0 / 2 * 0.15 \\ \mathrm{D}=01648 & \mathrm{UZ}=-500 / 2 & \mathrm{RX}=50.0 / 2 * 0.15\end{array}$

; EXTERIOR/INTERIOR GIRDER - FATIGUE SHEAR - 1 LANE

NAME $=$ TRUCK 14

$\mathrm{ADD}=864$

$\mathrm{ADD}=866$

$\mathrm{ADD}=879$

$\mathrm{ADD}=892$

$\mathrm{ADD}=\mathrm{I} 164$

$\mathrm{ADD}=1166$

$\mathrm{ADD}=1179$

$\mathrm{ADD}=1192$
TYPE $=$ CONCENTRATED CSYS $=0$

$\begin{array}{lll}D=00001 & \mathrm{UZ}=-1400 / 2 & \mathrm{RX}=-140.0 / 2 * 0.25 \\ \mathrm{D}=0.2000 & \mathrm{UZ}=-140.0 / 2 & \mathrm{RX}=-140.0 / 2 * 0.25 \\ \mathrm{D}=0.3000 & \mathrm{UZ}=-175.0 / 2 & \mathrm{RX}=-175.0 / 2^{*} 0.25 \\ \mathrm{D}=0.4000 & \mathrm{UZ}=-120.0 / 2 & \mathrm{RX}=-120.0 / 2 * 0.25\end{array}$

$\mathrm{D}=0.000 \mathrm{I}$

$\mathrm{UZ}=-140.0 / 2$

$\mathrm{UZ}=-140.0 / 2$

$\mathrm{UZ}=-175.0 / 2$

$\mathrm{UZ}=-120.0 / 2$
$\mathrm{RX}=140.0 / 2 * 0.15$

$\mathrm{RX}=140.0 / 2 * 0.15$

$\mathrm{RX}=175.0 / 2 * 0.15$

$\mathrm{RX}=120.0 / 2 * 0.15$ 


\begin{tabular}{llll} 
NAME $=$ TRUCK 15 & \multicolumn{3}{l}{ TYPE $=$ CONCENTRATED CSYS $=0$} \\
$\mathrm{ADD}=995$ & $\mathrm{D}=0.1648$ & $\mathrm{UZ}=-120.0 / 2$ & $\mathrm{RX}=120.0 / 2 * 0.025$ \\
$\mathrm{ADD}=1008$ & $\mathrm{D}=0.2648$ & $\mathrm{UZ}=-175.0 / 2$ & $\mathrm{RX}=175.0 / 2 * 0.025$ \\
$\mathrm{ADD}=1021$ & $\mathrm{D}=0.3648$ & $\mathrm{UZ}=-140.0 / 2$ & $\mathrm{RX}=140.0 / 2 * 0.025$ \\
$\mathrm{ADD}=1024$ & $\mathrm{D}=0.0648$ & $\mathrm{UZ}=-140.0 / 2$ & $\mathrm{RX}=140.0 / 2 * 0.025$ \\
$\mathrm{ADD}=1031$ & $\mathrm{D}=0.1648$ & $\mathrm{UZ}=-50.0 / 2$ & $\mathrm{RX}=50.0 / 2 * 0.025$ \\
& & & \\
$\mathrm{ADD}=1233$ & $\mathrm{D}=0.1648$ & $\mathrm{UZ}=-120.0 / 2$ & $\mathrm{RX}=-120.0 / 2 * 0.125$ \\
$\mathrm{ADD}=1246$ & $\mathrm{D}=0.2648$ & $\mathrm{UZ}=-175.0 / 2$ & $\mathrm{RX}=-175.0 / 2 * 0.125$ \\
$\mathrm{ADD}=1259$ & $\mathrm{D}=03648$ & $\mathrm{UZ}=-140.0 / 2$ & $\mathrm{RX}=-140.0 / 2 * 0.125$ \\
$\mathrm{ADD}=1262$ & $\mathrm{D}=00648$ & $\mathrm{UZ}=-140.0 / 2$ & $\mathrm{RX}=-140.0 / 2 * 0.125$ \\
$\mathrm{ADD}=1269$ & $\mathrm{D}=0.1648$ & $\mathrm{UZ}=-50.0 / 2$ & $\mathrm{RX}=-50.0 / 2 * 0.125$
\end{tabular}

;EXTERIOR/INTERIOR GIRDER - FATIGUE SHEAR 2ND CASE - 1 LANE NAME $=$ TRUCK $16 \quad$ TYPE $=$ CONCENTRATED CSYS $=0$

$\begin{array}{llll}\mathrm{ADD}=988 & \mathrm{D}=0.0001 & \mathrm{UZ}=-140.0 / 2 & \mathrm{RX}=140.0 / 2 * 0.025 \\ \mathrm{ADD}=990 & \mathrm{D}=0.2000 & \mathrm{UZ}=-140.0 / 2 & \mathrm{RX}=140.0 / 2 * 0.025 \\ \mathrm{ADD}=1003 & \mathrm{D}=0.3000 & \mathrm{UZ}=-175.0 / 2 & \mathrm{RX}=175.0 / 2 * 0.025 \\ \mathrm{ADD}=1016 & \mathrm{D}=0.4000 & \mathrm{UZ}=-120.0 / 2 & \mathrm{RX}=120.0 / 2 * 0.025 \\ & & & \\ \mathrm{ADD}=1226 & \mathrm{D}=0.0001 & \mathrm{UZ}=-140.0 / 2 & \mathrm{RX}=-140.0 / 2 * 0.125 \\ \mathrm{ADD}=1228 & \mathrm{D}=0.2000 & \mathrm{UZ}=-140.0 / 2 & \mathrm{RX}=-140.0 / 2 * 0.125 \\ \mathrm{ADD}=1241 & \mathrm{D}=0.3000 & \mathrm{UZ}=-175.0 / 2 & \mathrm{RX}=-175.0 / 2 * 0.125 \\ \mathrm{ADD}=1254 & \mathrm{D}=0.4000 & \mathrm{UZ}=-120.0 / 2 & \mathrm{RX}=-120.0 / 2 * 0.125\end{array}$

\section{OUTPUT}

ELEM $=$ SHELL TYPE $=$ FORCE LOAD $=*$

ELEM $=$ SHELL TYPE=STRESS LOAD $=*$

ELEM=FRAME TYPE $=$ JOINTF LOAD $=*$

END 
B - I. Distribution Factors for Bending Moment at Serviceability, Ultimate and Fatigue Limit States

\begin{tabular}{|c|c|c|c|c|c|c|c|c|c|c|c|c|c|c|}
\hline \multicolumn{7}{|c|}{ Bridge } & \multicolumn{4}{|c|}{$\begin{array}{c}\text { Distnbution Factors for Moment } \\
\text { at SLS and ULS }\end{array}$} & \multicolumn{4}{|c|}{$\begin{array}{c}\text { Distribution Factors for Moment } \\
\text { at FLS }\end{array}$} \\
\hline के & 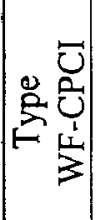 & 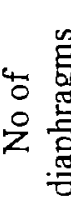 & 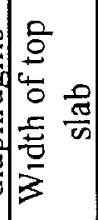 & $\frac{5}{3}$ & $\begin{array}{l}\frac{2}{2} \\
\frac{0}{0} \\
\frac{1}{50} \\
40 \\
0 \\
0 \\
\frac{0}{2}\end{array}$ & 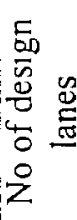 & \multicolumn{2}{|c|}{ Exterior Girder } & \multicolumn{2}{|c|}{ Interior Girder } & \multicolumn{2}{|c|}{ Extenor Girder } & \multicolumn{2}{|c|}{ Interior Girder } \\
\hline m & & & $\mathrm{mm}$ & $\mathrm{mm}$ & & & $\begin{array}{c}\text { Model } \\
\mathrm{F}_{\mathrm{m}}\end{array}$ & $\begin{array}{c}\text { CHBDC } \\
F_{m}\end{array}$ & $\begin{array}{c}\text { Model } \\
\mathrm{F}_{\mathrm{m}}\end{array}$ & $\begin{array}{c}\text { CHBDC } \\
\mathrm{F}_{\mathrm{m}} \\
\end{array}$ & $\begin{array}{c}\text { Model } \\
\mathrm{F}_{\mathrm{m}}\end{array}$ & $\begin{array}{c}\text { CHBDC } \\
F_{m}\end{array}$ & $\begin{array}{c}\text { Model } \\
F_{m}\end{array}$ & $\begin{array}{c}\text { CHBDC } \\
F_{n}\end{array}$ \\
\hline \multirow[t]{9}{*}{20} & \multirow[t]{9}{*}{1200} & \multirow[t]{9}{*}{0} & 2000 & 14000 & 7 & 3 & 1.07 & 1.51 & 1.19 & 1.51 & 1.11 & 1.58 & 1.74 & 3.01 \\
\hline & & & & 16000 & 8 & 4 & 1.03 & 1.55 & 1.09 & 1.49 & 1.22 & 1.76 & 1.95 & 3.36 \\
\hline & & & & 18000 & 9 & 5 & 1.08 & 1.71 & 1.14 & 1.65 & 135 & 1.98 & 2.16 & 3.78 \\
\hline & & & 2200 & 13200 & 6 & 3 & 1.04 & 1.43 & 1.15 & 1.42 & 1.10 & 1.49 & 1.69 & 2.80 \\
\hline & & & & 15400 & 7 & 4 & 101 & 1.52 & 1.11 & 147 & 122 & 1.69 & 1.92 & 3.19 \\
\hline & & & & 17600 & 8 & 5 & 1.06 & 1.68 & 1.14 & 1.63 & 1.36 & 1.93 & 2.15 & 3.65 \\
\hline & & & 2400 & 12000 & 5 & 3 & 1.01 & 135 & 1.09 & 1.34 & 1.07 & 1.35 & 1.57 & 251 \\
\hline & & & & 16800 & 7 & 4 & 106 & 1.58 & 1.15 & 1.53 & 1.36 & 1.85 & 2.05 & 3.44 \\
\hline & & & & 19200 & 8 & 5 & 1.12 & 176 & 1.15 & 1.70 & 152 & 2.11 & 2.31 & 3.93 \\
\hline \multirow[t]{9}{*}{20} & \multirow[t]{9}{*}{1200} & \multirow[t]{9}{*}{1} & \multirow[t]{3}{*}{2000} & 14000 & 7 & 3 & 113 & 151 & 105 & 1.51 & 1.62 & 1.58 & 1.25 & 3.01 \\
\hline & & & & 16000 & 8 & 4 & 1.13 & 1.55 & 105 & 1.49 & 178 & 1.76 & 1.35 & 3.36 \\
\hline & & & & 18000 & 9 & 5 & 1.21 & 1.71 & 1.10 & 165 & 197 & 1.98 & 1.47 & 3.78 \\
\hline & & & \multirow[t]{3}{*}{2200} & 13200 & 6 & 3 & 108 & 1.43 & 1.03 & 1.42 & 1.53 & 1.49 & 1.13 & 2.80 \\
\hline & & & & 15400 & 7 & 4 & 1.12 & 1.52 & 1.03 & 1.47 & 1.73 & 1.69 & 1.26 & 3.19 \\
\hline & & & & 17600 & 8 & 5 & 1.19 & 1.68 & 107 & 1.63 & 191 & 1.93 & 1.36 & 3.65 \\
\hline & & & \multirow[t]{3}{*}{2400} & 12000 & 5 & 3 & 1.05 & 1.35 & 100 & 1.34 & 142 & 1.35 & 1.03 & 2.51 \\
\hline & & & & 16800 & 7 & 4 & 114 & 1.58 & 106 & 1.53 & 162 & 185 & 1.27 & 344 \\
\hline & & & & 19200 & 8 & 5 & 1.22 & 1.76 & 110 & 1.70 & 203 & 2.11 & 1.39 & 3.93 \\
\hline \multirow[t]{9}{*}{20} & \multirow[t]{9}{*}{1200} & \multirow[t]{9}{*}{2} & \multirow[t]{3}{*}{2000} & 14000 & 7 & 3 & 1.10 & 1.51 & 1.11 & 1.51 & 132 & 1.58 & 1.58 & 3.01 \\
\hline & & & & 16000 & 8 & 4 & 109 & 1.55 & 1.07 & 1.49 & 144 & 176 & 1.74 & 3.36 \\
\hline & & & & 18000 & 9 & 5 & 1.16 & 1.71 & 1.14 & 1.65 & 1.59 & 1.98 & 1.91 & 3.78 \\
\hline & & & \multirow[t]{3}{*}{2200} & 13200 & 6 & 3 & 1.07 & 1.43 & 1.07 & 142 & 126 & 1.49 & 1.51 & 2.80 \\
\hline & & & & 15400 & 7 & 4 & 1.08 & 1.52 & 1.06 & 1.47 & 1.42 & 169 & 1.71 & 3.19 \\
\hline & & & & 17600 & 8 & 5 & 1.14 & 168 & 1.12 & 163 & 1.56 & 1.9 & 1.89 & 3.65 \\
\hline & & & \multirow[t]{3}{*}{2400} & 12000 & 5 & 3 & 1.04 & 1.35 & 1.05 & 134 & 1.20 & 1.35 & 140 & 2.51 \\
\hline & & & & 16800 & 7 & 4 & 1.12 & 1.58 & 109 & 1.53 & 1.54 & 1.85 & 1.81 & 3.44 \\
\hline & & & & 19200 & 8 & 5 & 119 & 1.76 & 114 & 1.70 & 170 & 2.11 & 2.00 & 3.93 \\
\hline 20 & 1400 & 0 & 2000 & 14000 & 7 & 3 & 1.07 & 1.51 & 1.22 & 1.51 & 106 & 1.58 & 1.82 & $3.0 \mathrm{I}$ \\
\hline & & & & 16000 & 8 & 4 & 103 & 1.55 & 1.10 & 1.49 & 117 & 1.76 & 2.04 & 3.36 \\
\hline & & & & 18000 & 9 & 5 & 1.19 & 1.71 & 1.23 & 1.65 & 148 & 1.98 & 2.40 & 3.78 \\
\hline & & & 2200 & 13200 & 6 & 3 & 1.04 & 1.43 & 1.17 & 1.42 & 1.05 & 1.49 & 1.78 & 2.80 \\
\hline & & & & 15400 & 7 & 4 & 1.01 & 1.52 & 1.11 & $1 . \overline{47}$ & 1.18 & 1.69 & 2.02 & 3.19 \\
\hline & & & & 17600 & 8 & 5 & 1.06 & 1.68 & 1.15 & 163 & 1.31 & 1.93 & 2.27 & 3.65 \\
\hline & & & 2400 & 12000 & 5 & 3 & 1.00 & 1.35 & 1.10 & 1.34 & 1.03 & 1.35 & 1.65 & 2.51 \\
\hline & & & & 16800 & 7 & 4 & 1.06 & 1.58 & 1.16 & 1.53 & 1.32 & 1.85 & 2.17 & 3.44 \\
\hline & & & & 19200 & 8 & 5 & 1.12 & 1.76 & 1.17 & 1.70 & 1.48 & 2.11 & 2.45 & 3.93 \\
\hline
\end{tabular}




\begin{tabular}{|c|c|c|c|c|c|c|c|c|c|c|c|c|c|c|}
\hline \multicolumn{7}{|c|}{ Bridge } & \multicolumn{4}{|c|}{$\begin{array}{c}\text { Distribution Factors for Moment } \\
\text { at SLS and ULS }\end{array}$} & \multicolumn{4}{|c|}{$\begin{array}{c}\text { Distribution Factors for Moment } \\
\text { at FLS }\end{array}$} \\
\hline 韋 & 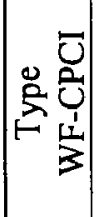 & 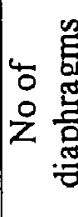 & 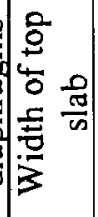 & 吾 & 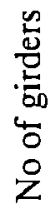 & 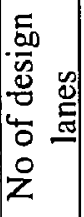 & \multicolumn{2}{|c|}{ Exterior Gırder } & \multicolumn{2}{|c|}{ Interior Gırder } & \multicolumn{2}{|c|}{ Exterior Girder } & \multicolumn{2}{|c|}{ Intenor Girder } \\
\hline $\mathrm{m}$ & & & $\mathrm{mm}$ & $\mathrm{mm}$ & & & $\begin{array}{c}\text { Model } \\
\mathrm{F}_{\mathrm{m}}\end{array}$ & $\begin{array}{c}\text { CHBDC } \\
F_{m}\end{array}$ & $\begin{array}{c}\text { Model } \\
\mathrm{F}_{\mathrm{m}}\end{array}$ & $\begin{array}{c}\text { CHBDC } \\
F_{m}\end{array}$ & $\begin{array}{c}\text { Model } \\
F_{m} \\
\end{array}$ & $\begin{array}{c}\text { CHBDC } \\
\mathrm{F}_{\mathrm{m}}\end{array}$ & $\begin{array}{c}\text { Model } \\
\mathrm{F}_{\mathrm{m}} \\
\end{array}$ & $\begin{array}{c}\text { CHBDC } \\
\mathrm{F}_{\mathrm{m}}\end{array}$ \\
\hline \multirow[t]{9}{*}{20} & \multirow[t]{9}{*}{1600} & \multirow[t]{9}{*}{0} & \multirow{3}{*}{2000} & 14000 & 7 & 3 & 1.06 & 1.51 & 1.23 & 1.51 & 1.02 & 1.58 & 1.88 & 3.01 \\
\hline & & & & 16000 & 8 & 4 & 1.03 & 1.55 & 110 & 1.49 & 1.13 & 1.76 & 2.11 & 3.36 \\
\hline & & & & 18000 & 9 & 5 & 1.19 & 1.71 & 1.25 & 1.65 & 146 & 1.98 & 2.50 & 3.78 \\
\hline & & & \multirow[t]{3}{*}{2200} & 13200 & 6 & 3 & 1.04 & 1.43 & 1.18 & 1.42 & 1.02 & 1.49 & 1.85 & 2.80 \\
\hline & & & & 15400 & 7 & 4 & 1.01 & 152 & 1.12 & 1.47 & 1.14 & 1.69 & 2.10 & 3.19 \\
\hline & & & & 17600 & 8 & 5 & 1.06 & 1.68 & 117 & 1.63 & 1.27 & 1.93 & 237 & 3.65 \\
\hline & & & \multirow[t]{3}{*}{2400} & 12000 & 5 & 3 & 100 & 135 & 1.11 & 1.34 & 1.01 & 1.35 & 1.72 & 251 \\
\hline & & & & 16800 & 7 & 4 & 1.06 & 1.58 & 1.16 & 1.53 & 1.29 & 1.85 & 2.27 & .44 \\
\hline & & & & 19200 & 8 & 5 & 1.13 & 1.76 & 1,18 & 1.70 & 1.44 & 2,11 & 2.57 & .93 \\
\hline \multirow[t]{9}{*}{20} & \multirow{9}{*}{1600} & \multirow[t]{9}{*}{1} & \multirow{3}{*}{2000} & 14000 & 7 & 3 & 116 & 151 & 1.06 & 1.51 & 1.69 & 158 & 1.24 & .01 \\
\hline & & & & 16000 & 8 & 4 & 1.16 & 1.55 & 1.06 & 1.49 & 1.86 & 1.76 & 1.34 & .36 \\
\hline & & & & 18000 & 9 & 5 & 125 & 171 & 1.12 & 1.65 & 2.05 & 1.98 & 1.47 & 3.78 \\
\hline & & & \multirow{3}{*}{2200} & 13200 & 6 & 3 & 1.11 & 1.43 & 1.03 & 1.42 & 1.59 & 1.49 & 1.12 & 2.80 \\
\hline & & & & 15400 & 7 & 4 & 1.15 & 1.52 & 1.04 & 1.47 & 1.80 & 1.69 & 1.25 & 3.19 \\
\hline & & & & 17600 & 8 & 5 & 1.23 & 1.68 & 1.09 & 1.63 & 1.99 & 1.93 & 1.36 & 3.65 \\
\hline & & & 2400 & 12000 & 5 & 3 & 1.06 & 135 & 1.00 & 1.34 & 147 & 1.35 & 103 & 2.51 \\
\hline & & & & 16800 & 7 & 4 & 1.17 & 1.58 & 1.07 & 1.53 & 1.90 & 185 & 1.27 & 344 \\
\hline & & & & 19200 & 8 & 5 & 1.26 & 1.76 & 112 & 170 & 2.11 & 2.11 & 1.39 & 3.93 \\
\hline 20 & 1600 & 2 & 2000 & 14000 & 7 & 3 & 1.12 & 1.51 & 1.11 & 1.51 & 1.35 & 1.58 & 1.61 & 3.01 \\
\hline & & & & \begin{tabular}{|l|}
16000 \\
\end{tabular} & 8 & 4 & 112 & 155 & 1.08 & 1.49 & 1.4 & 1.76 & 1.78 & 36 \\
\hline & & & & 18000 & 9 & 5 & 11 & 1.71 & 1.16 & 1.65 & 16 & 1.98 & 1.96 & .78 \\
\hline & & & 2200 & 13200 & 6 & 3 & 108 & 1.43 & 1.07 & 1.42 & 1.29 & 149 & 1.55 & 2.80 \\
\hline & & & & 15400 & 7 & 4 & 1.1 & 1.52 & 107 & 1.47 & 1.45 & 1.69 & 1.76 & .19 \\
\hline & & & & 17600 & 8 & 5 & 1.17 & 168 & 1.14 & 1.63 & 1.6 & 1.93 & 1.95 & 65 \\
\hline & & & 2400 & 12000 & 5 & 3 & 104 & 135 & 1.05 & 134 & 12 & 1.35 & 144 & 51 \\
\hline & & & & 16800 & 7 & 4 & 11 & 1.58 & 1.09 & 1.53 & 1.57 & 1.85 & 1.87 & 3.44 \\
\hline & & & & 19200 & 8 & 5 & 122 & 1.76 & 1.16 & 1.70 & 1.75 & 2.11 & 2.08 & 3.93 \\
\hline 25 & 1200 & 0 & 2000 & 14000 & 7 & 3 & 1.06 & 1.50 & 1.13 & 1.47 & 1.24 & 1.79 & 1.50 & 2.88 \\
\hline & & & & 16000 & 8 & 4 & 1.02 & 1.54 & 109 & 1.46 & 1.36 & 2.00 & 1.65 & 3.20 \\
\hline & & & & 18000 & 9 & 5 & 1.16 & 1.70 & 1.17 & 1.61 & 1.66 & 2.24 & 1.95 & 360 \\
\hline & & & 2200 & 13200 & 6 & 3 & 1.04 & 142 & 1.11 & 1.38 & 121 & 1.69 & 144 & 2.66 \\
\hline & & & & 15400 & 7 & 4 & 1.00 & 1.51 & 1.08 & 1.44 & 134 & 1.92 & 161 & 302 \\
\hline & & & & 17600 & 8 & 5 & 10 & 168 & 1.09 & 1.59 & 149 & 2.19 & 1.79 & 3.45 \\
\hline & & & 2400 & 12000 & 5 & 3 & 1.01 & 134 & 1.07 & 1.31 & 1.16 & 1.54 & 1.35 & 237 \\
\hline & & & & \begin{tabular}{|l|}
16800 \\
\end{tabular} & 7 & 4 & 104 & 1.57 & 1.11 & 1.49 & 1.45 & 2.09 & 1.71 & 3.23 \\
\hline & & & & 19200 & 8 & 5 & 110 & 1.75 & 1.11 & 1.66 & 1.62 & 2.39 & 1.91 & 3.69 \\
\hline 25 & 1400 & 0 & 2000 & 14000 & 7 & 3 & 1.06 & 1.50 & 1.15 & 1.47 & 1.19 & 1.79 & 1.57 & 2.88 \\
\hline & & & & 16000 & 8 & 4 & 1.02 & 1.54 & 1.10 & 1.46 & 1.31 & 2.00 & 174 & 3.20 \\
\hline & & & & 18000 & 9 & 5 & 117 & 170 & 1.19 & 1.61 & 1.64 & 2.24 & 207 & 3.60 \\
\hline & & & 2200 & 13200 & 6 & 3 & 104 & 142 & 1.13 & 1.38 & 1.17 & 1.69 & 1.52 & 2.66 \\
\hline & & & & 15400 & 7 & 4 & 100 & 151 & 1.09 & 144 & 130 & 1.92 & 1.71 & 3.02 \\
\hline & & & & 17600 & 8 & 5 & 1.05 & 1.68 & 1.10 & 1.59 & 1.44 & 2.19 & 1.90 & 3.45 \\
\hline & & & 2400 & 12000 & 5 & 3 & 1.01 & 1.34 & 1.09 & 1.31 & 1.12 & 1.54 & 1.42 & 2.37 \\
\hline & & & & 16800 & 7 & 4 & 104 & 1.57 & 1.12 & 1.49 & 1.42 & 2.09 & 1.82 & 3.23 \\
\hline & & & & 19200 & 8 & 5 & 1.10 & 1.75 & 1.13 & 1.66 & 1.58 & 2.39 & 2.03 & 3.69 \\
\hline
\end{tabular}




\begin{tabular}{|c|c|c|c|c|c|c|c|c|c|c|c|c|c|c|}
\hline \multicolumn{7}{|c|}{ Bridge } & \multicolumn{4}{|c|}{$\begin{array}{l}\text { Distribution Factors for Moment } \\
\text { at SLS and ULS }\end{array}$} & \multicolumn{4}{|c|}{$\begin{array}{l}\text { Distribution Factors for Moment } \\
\text { at FLS }\end{array}$} \\
\hline 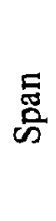 & 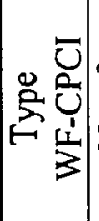 & 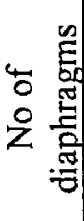 & $\begin{array}{l}\frac{0}{9} \\
\frac{2}{0} \\
\frac{0}{5} \\
\frac{5}{50} \\
3\end{array}$ & $\frac{\text { 点 }}{\frac{7}{3}}$ & 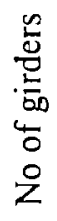 & 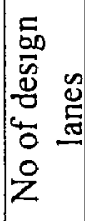 & \multicolumn{2}{|c|}{ Exterior Girder } & \multicolumn{2}{|c|}{ Interıor Girder } & \multicolumn{2}{|c|}{ Extenor Girder } & \multicolumn{2}{|c|}{ Interior Girder } \\
\hline $\mathrm{m}$ & & & $\mathrm{mm}$ & $\mathrm{mm}$ & & & $\begin{array}{c}\text { Model } \\
F_{m}\end{array}$ & $\begin{array}{c}\text { CHBDC } \\
\mathrm{F}_{\mathrm{m}}\end{array}$ & $\begin{array}{c}\text { Model } \\
\mathrm{F}_{\mathrm{m}}\end{array}$ & $\begin{array}{c}\mathrm{CHBDC} \\
\mathrm{F}_{\mathrm{m}}\end{array}$ & $\begin{array}{c}\text { Model } \\
F_{m}\end{array}$ & $\begin{array}{c}\mathrm{CHBDC} \\
\mathrm{F}_{\mathrm{m}}\end{array}$ & $\begin{array}{c}\text { Model } \\
\mathrm{F}_{\mathrm{m}}\end{array}$ & $\begin{array}{c}\text { CHBDC } \\
\mathrm{F}_{\mathrm{m}}\end{array}$ \\
\hline \multirow[t]{9}{*}{25} & \multirow[t]{9}{*}{1400} & \multirow[t]{9}{*}{1} & \multirow[t]{3}{*}{2000} & 14000 & 7 & 3 & 1.13 & 1.50 & 106 & 1.47 & 1.70 & 1.79 & 1.16 & 2.88 \\
\hline & & & & 16000 & 8 & 4 & 115 & 154 & 1.04 & 1.46 & 1.85 & 2.00 & 1.24 & 3.20 \\
\hline & & & & 18000 & 9 & 5 & 1.34 & 170 & 1.17 & 1.61 & 2.22 & 2.24 & 1.48 & 3.60 \\
\hline & & & \multirow[t]{3}{*}{2200} & 13200 & 6 & 3 & 109 & 1.42 & 1.03 & 1.38 & 1.59 & 1.69 & 1.05 & 2.66 \\
\hline & & & & 15400 & 7 & 4 & 1.15 & 1.51 & 1.03 & 144 & 1.79 & 1.92 & 1.16 & 3.02 \\
\hline & & & & 17600 & 8 & 5 & 1.21 & 1.68 & 1.07 & 159 & 1.95 & 219 & 1.24 & 3.45 \\
\hline & & & \multirow[t]{3}{*}{2400} & 12000 & 5 & 3 & 1.06 & 1.34 & 1.00 & 1.31 & 146 & 1.54 & 0.98 & 2.37 \\
\hline & & & & 16800 & 7 & 4 & 116 & 1.57 & 106 & 1.49 & 1.86 & 2.09 & 1.18 & 3.23 \\
\hline & & & & 19200 & 8 & 5 & 1.23 & 1.75 & 1.09 & 1.66 & 2.05 & 2.39 & 1.27 & 3.69 \\
\hline \multirow[t]{9}{*}{25} & \multirow[t]{9}{*}{1400} & \multirow[t]{9}{*}{2} & \multirow[t]{3}{*}{2000} & 14000 & 7 & 3 & 1.10 & 1.50 & 1.06 & 1.47 & 1.40 & 1.79 & 1.44 & 2.88 \\
\hline & & & & 16000 & 8 & 4 & 1.10 & 1.54 & 1.05 & 146 & 1.52 & 200 & 1.56 & 3.20 \\
\hline & & & & 18000 & 9 & 5 & 1.27 & 1.70 & 1.19 & 1.61 & 1.85 & 2.24 & 1.85 & 3.60 \\
\hline & & & \multirow[t]{3}{*}{2200} & 13200 & 6 & 3 & 1.07 & 1.42 & 1.04 & 1.38 & 1.33 & 169 & 1.37 & 2.66 \\
\hline & & & & 15400 & 7 & 4 & 1.09 & 1.51 & 1.04 & 1.44 & 1.49 & 1.92 & 1.53 & 3.02 \\
\hline & & & & 17600 & 8 & 5 & 1.15 & 1.68 & 1.09 & 1.59 & 1.63 & 219 & 1.67 & 3.45 \\
\hline & & & 2400 & 12000 & 5 & 3 & 1.04 & 134 & 1.02 & 1.31 & 1.26 & 1.54 & 1.28 & 2.37 \\
\hline & & & & 16800 & 7 & 4 & 1.12 & 1.57 & 1.06 & 1.49 & 1.59 & 209 & 1.61 & 3.23 \\
\hline & & & & 19200 & 8 & 5 & 1.18 & 175 & 111 & 1.66 & 1.74 & 239 & 1.76 & 3.69 \\
\hline 25 & 1600 & 0 & 2000 & 14000 & 7 & 3 & 1.06 & 150 & 117 & 1.47 & 1.15 & 1.79 & 1.64 & 2.88 \\
\hline & & & & 16000 & 8 & 4 & 1.02 & 154 & 1.10 & 1.46 & 1.27 & 2.00 & 1.82 & 3.20 \\
\hline & & & & 18000 & 9 & 5 & 1.18 & 1.70 & 1.21 & 161 & 161 & 2.24 & 2.18 & 3.60 \\
\hline & & & 2200 & 13200 & 6 & 3 & 103 & 142 & 114 & 1.38 & 113 & 1.69 & 1.59 & 2.66 \\
\hline & & & & 15400 & 7 & 4 & 100 & 1.51 & 1.10 & 1.44 & 1.26 & 1.92 & 1.79 & 3.02 \\
\hline & & & & 17600 & 8 & 5 & 1.05 & 168 & 1.12 & 159 & 140 & 2.19 & 2.00 & 3.45 \\
\hline & & & 2400 & 12000 & 5 & 3 & 100 & 1.34 & 1.10 & 1.31 & 1.10 & 1.54 & 1.49 & 2.37 \\
\hline & & & & 16800 & 7 & 4 & 104 & 1.57 & 1.13 & 149 & 1.39 & 209 & 1.92 & 3.23 \\
\hline & & & & 19200 & 8 & 5 & 110 & 1.75 & 1.14 & 166 & 1.54 & 239 & 2.15 & 3.69 \\
\hline 25 & 1600 & 1 & 2000 & 14000 & 7 & 3 & 1.14 & 1.50 & 1.06 & 1.47 & 1.72 & 179 & 1.17 & 2.88 \\
\hline & & & & 16000 & 8 & 4 & 1.16 & 154 & 105 & 1.46 & 1.87 & 2.00 & 1.25 & 3.20 \\
\hline & & & & 18000 & 9 & 5 & 1.38 & 170 & 119 & 1.61 & 228 & 2.24 & 1.52 & 3.60 \\
\hline & & & 2200 & 13200 & 6 & 3 & 1.10 & 142 & 103 & 1.38 & 1.61 & 1.69 & 1.06 & 2.66 \\
\hline & & & & 15400 & 7 & 4 & 1.16 & 1.51 & 103 & 144 & 181 & 1.92 & 1.17 & 3.02 \\
\hline & & & & \begin{tabular}{|l|}
17600 \\
\end{tabular} & 8 & 5 & 1.23 & 168 & 108 & 159 & 198 & 2.19 & 1.25 & 3.45 \\
\hline & & & 2400 & 12000 & 5 & 3 & 1.06 & 1.34 & 100 & 131 & 1.48 & 1.54 & 0.98 & 2.37 \\
\hline & & & & 16800 & 7 & 4 & 1.18 & 1.57 & 1.06 & 149 & 1.89 & 2.09 & 1.19 & 3.23 \\
\hline & & & & 19200 & 8 & 5 & 1.25 & 1.75 & 1.10 & 1.66 & 2.07 & 2.39 & 1.28 & 3.69 \\
\hline 25 & 1600 & 2 & 2000 & 14000 & 7 & 3 & 110 & 1.50 & 1.07 & 1.47 & 1.42 & 179 & 1.46 & 2.88 \\
\hline & & & & 16000 & 8 & 4 & 111 & 1.54 & 1.06 & 146 & 1.54 & 200 & 1.59 & 3.20 \\
\hline & & & & 18000 & 9 & 5 & 128 & 170 & 1.19 & 1.61 & 1.89 & 224 & 1.84 & 3.60 \\
\hline & & & 2200 & 13200 & 6 & 3 & 108 & 142 & 104 & 1.38 & 1.35 & 169 & 1.39 & 2.66 \\
\hline & & & & 15400 & 7 & 4 & 1.10 & 151 & 1.05 & 1.44 & 1.51 & 192 & 1.56 & 3.02 \\
\hline & & & & 17600 & 8 & 5 & 1.16 & 1.68 & 1.10 & 1.59 & 1.65 & 2.19 & 1.70 & 3.45 \\
\hline & & & 2400 & 12000 & 5 & 3 & 1.04 & 1.34 & 1.03 & 1.31 & 1.27 & 1.54 & 1.29 & 2.37 \\
\hline & & & & 16800 & 7 & 4 & 1.14 & 1.57 & 107 & 1.49 & 1.61 & 2.09 & 1.64 & 3.23 \\
\hline & & & & 19200 & 8 & 5 & 1.20 & 1.75 & 1.12 & 166 & 1.76 & 2.39 & 1.80 & 3.69 \\
\hline
\end{tabular}




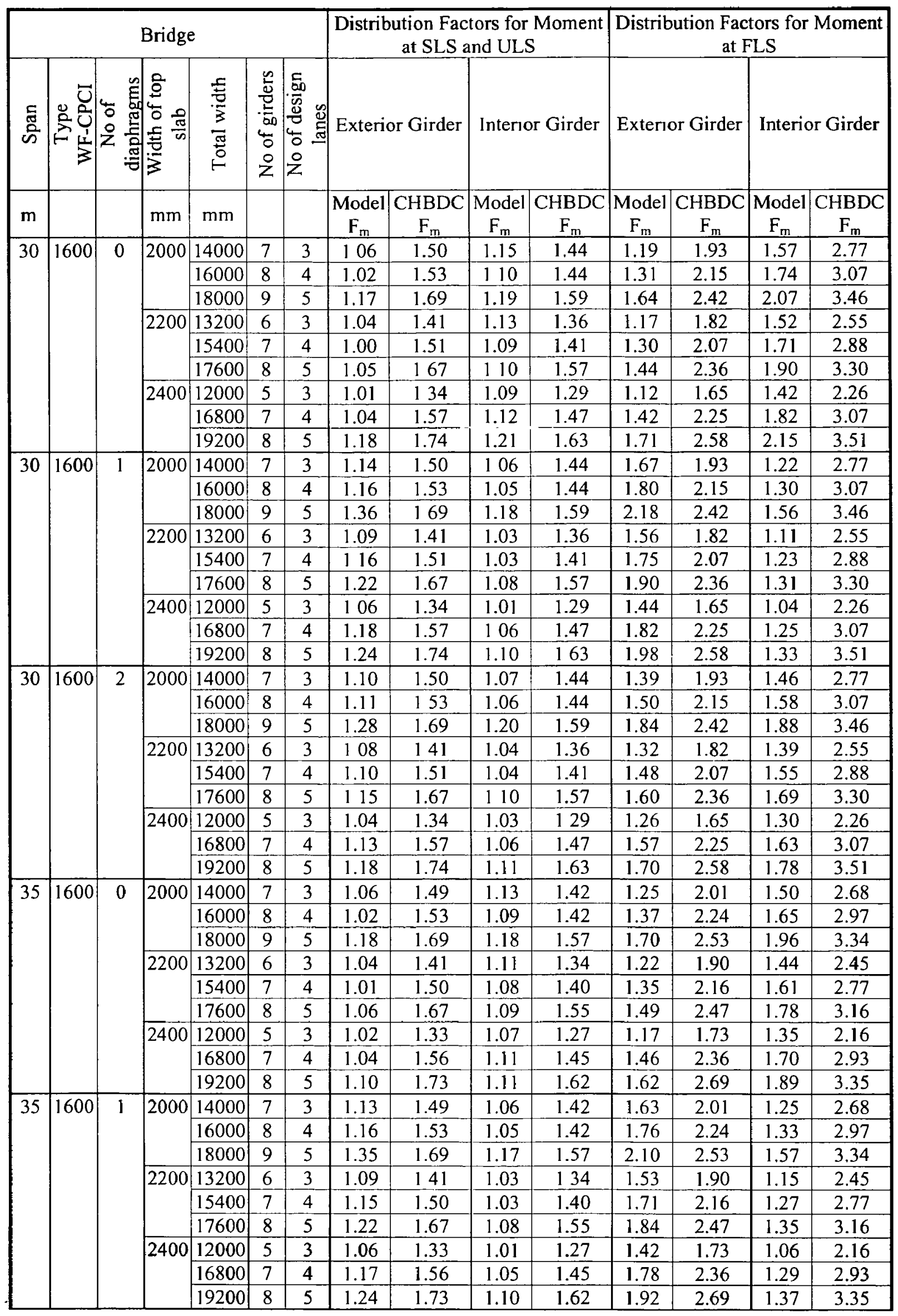




\begin{tabular}{|c|c|c|c|c|c|c|c|c|c|c|c|c|c|c|}
\hline \multicolumn{7}{|c|}{ Bridge } & \multicolumn{4}{|c|}{$\begin{array}{c}\text { Distribution Factors for Moment } \\
\text { at SLS and ULS }\end{array}$} & \multicolumn{4}{|c|}{$\begin{array}{c}\text { Distribution Factors for Moment } \\
\text { at FLS } \\
\end{array}$} \\
\hline 营 & 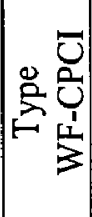 & 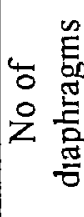 & 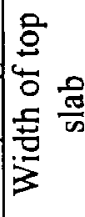 & $\frac{\text { 氮 }}{\frac{3}{3}}$ & 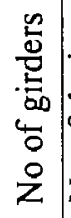 & 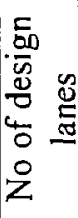 & \multicolumn{2}{|c|}{ Extenor Girder } & \multicolumn{2}{|c|}{ Interior Girder } & \multicolumn{2}{|c|}{ Exterior Girder } & \multicolumn{2}{|c|}{ Interior Girder } \\
\hline $\mathrm{m}$ & & & $\mathrm{mm}$ & $\mathrm{mm}$ & & & $\begin{array}{c}\text { Model } \\
F_{m}\end{array}$ & $\begin{array}{c}\mathrm{CHBDC} \\
\mathbf{F}_{\mathrm{m}} \\
\end{array}$ & $\begin{array}{c}\text { Model } \\
\mathrm{F}_{\mathrm{m}} \\
\end{array}$ & $\begin{array}{c}\text { CHBDC } \\
\mathrm{F}_{\mathrm{m}} \\
\end{array}$ & $\begin{array}{c}\text { Model } \\
\mathrm{F}_{\mathrm{m}}\end{array}$ & $\begin{array}{c}\mathrm{CHBDC} \\
\mathrm{F}_{\mathrm{m}} \\
\end{array}$ & $\begin{array}{c}\text { Model } \\
F_{m}\end{array}$ & $\begin{array}{c}\text { CHBDC } \\
\mathrm{F}_{\mathrm{m}} \\
\end{array}$ \\
\hline \multirow[t]{9}{*}{35} & \multirow[t]{9}{*}{1600} & \multirow[t]{9}{*}{2} & \multirow[t]{3}{*}{2000} & 14000 & 7 & 3 & 1.10 & 1.49 & 1.06 & 1.42 & 1.37 & 2.01 & 1.45 & 2.68 \\
\hline & & & & 16000 & 8 & 4 & 1.10 & 1.53 & 1.05 & 1.42 & 1.47 & 2.24 & 1.58 & 2.97 \\
\hline & & & & 18000 & 9 & 5 & 1.26 & 169 & 118 & 157 & 179 & 2.53 & 1.86 & 3.34 \\
\hline & & & \multirow[t]{3}{*}{2200} & 13200 & 6 & 3 & 107 & 141 & 1.04 & 1.34 & 1.31 & 1.90 & 1.38 & 2.45 \\
\hline & & & & 15400 & 7 & 4 & 1.09 & 1.50 & 1.04 & 1.40 & 1.46 & 2.16 & 1.54 & 2.77 \\
\hline & & & & 17600 & 8 & 5 & 1.06 & 1.67 & 109 & 1.55 & 1.49 & 247 & 1.78 & 3.16 \\
\hline & & & \multirow[t]{3}{*}{2400} & 12000 & 5 & 3 & 1.04 & 133 & 103 & 1.27 & 124 & 1.73 & 1.29 & 2.16 \\
\hline & & & & 16800 & 7 & 4 & 112 & 156 & 105 & 1.45 & 1.54 & 2.36 & 1.62 & 2.93 \\
\hline & & & & 19200 & 8 & 5 & 1.17 & 1.73 & 1.11 & 162 & 1.67 & 269 & 1.76 & 3.35 \\
\hline \multirow[t]{9}{*}{35} & \multirow[t]{9}{*}{1900} & \multirow[t]{9}{*}{0} & \multirow[t]{3}{*}{2000} & 14000 & 7 & 3 & 1.08 & 1.49 & 1.17 & 1.42 & 1.22 & 2.01 & 1.59 & 2.68 \\
\hline & & & & 16000 & 8 & 4 & 1.02 & 1.53 & 110 & 1.42 & 132 & 224 & 1.74 & 2.97 \\
\hline & & & & 18000 & 9 & 5 & 124 & 169 & 1.25 & 1.57 & 1.71 & 2.53 & 2.04 & 3.34 \\
\hline & & & \multirow[t]{3}{*}{2200} & 13200 & 6 & 3 & 1.04 & 141 & 113 & 1.34 & 1.18 & 1.90 & 1.52 & 2.45 \\
\hline & & & & 15400 & 7 & 4 & 1.01 & 1.50 & 1.09 & 1.40 & 1.31 & 2.16 & 1.70 & 2.77 \\
\hline & & & & 17600 & 8 & 5 & 1.05 & 1.67 & 1.11 & 1.55 & 1.45 & 2.47 & 1.88 & 3.16 \\
\hline & & & \multirow[t]{3}{*}{2400} & 12000 & 5 & 3 & 1.01 & 1.33 & 1.09 & 1.27 & 1.14 & 1.73 & 1.42 & 2.16 \\
\hline & & & & 16800 & 7 & 4 & 1.04 & 1.56 & 1.13 & 1.45 & 1.43 & 2.36 & 1.80 & 2.93 \\
\hline & & & & 19200 & 8 & 5 & 1.10 & 1.73 & 1.12 & 1.62 & 1.58 & 2.69 & 2.01 & 3.35 \\
\hline & & & & & & & & & & & & & & \\
\hline
\end{tabular}


B - II. Distribution Factors for Shear at Serviceability, Ultimate and Fatigue Limit States

\begin{tabular}{|c|c|c|c|c|c|c|c|c|c|c|c|c|c|c|}
\hline & & & Bridge & & & & Distnb & $\begin{array}{c}\text { ution Fac } \\
\text { at SLS }\end{array}$ & $\begin{array}{l}\text { tors for } \\
\text { and UL: }\end{array}$ & $\begin{array}{l}\text { Moment } \\
S\end{array}$ & Distrit & $\begin{array}{r}\text { sution } \mathrm{Fac} \\
\text { at } \\
\end{array}$ & $\begin{array}{l}\text { ctors for } \\
\text { FLS }\end{array}$ & Moment \\
\hline 产 & 总苍 & 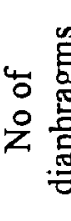 & 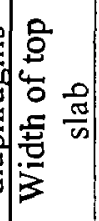 & $\frac{\sqrt{7}}{\frac{7}{0}}$ & 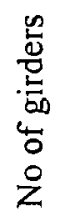 & 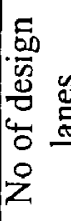 & Exterio & or Girder & Interic & or Girder & Exteri & or Girder & Interic & or Girder \\
\hline $\mathrm{m}$ & & & $\mathrm{mm}$ & $\mathrm{mm}$ & & & $\begin{array}{c}\text { Model } \\
\mathrm{F}_{\mathrm{y}}\end{array}$ & $\begin{array}{c}\text { CHBDC } \\
\mathbf{F}_{y}\end{array}$ & $\begin{array}{c}\text { Model } \\
F_{y}\end{array}$ & $\begin{array}{c}\text { CHBDC } \\
F_{y}\end{array}$ & Model & CHBDC & Model & $\begin{array}{c}\mathrm{CHBDC} \\
\mathrm{F}_{\mathrm{y}}\end{array}$ \\
\hline 20 & 1200 & 0 & 2000 & 14000 & 7 & 3 & 1.48 & 1.71 & 1.67 & 1.71 & 0.26 & 3.89 & 3.55 & 389 \\
\hline & & & & 16000 & 8 & 4 & 1.46 & 168 & 1.74 & 1.68 & 0.32 & 4.32 & 4.20 & 4.32 \\
\hline & & & & 18000 & 9 & 5 & 152 & 1.77 & 1.92 & 1.77 & 0.34 & 486 & 4.68 & 4.86 \\
\hline & & & 2200 & 13200 & 6 & 3 & 1.43 & 1.61 & 1.51 & 1.61 & 035 & 3.67 & 3.62 & 3.67 \\
\hline & & & & 15400 & 7 & 4 & 1.44 & 1.62 & 1.64 & 1.62 & 0.45 & 4.16 & 4.21 & 416 \\
\hline & & & & 17600 & 8 & 5 & 1.55 & 1.73 & 1.85 & 1.73 & 0.54 & 4.76 & 4.78 & 4.76 \\
\hline & & & 2400 & 12000 & 5 & 3 & 1.30 & 1.46 & 1.51 & 1.46 & 0.43 & 3.33 & 3.5 & 3.33 \\
\hline & & & & 16800 & 7 & 4 & 1.62 & 1.77 & 1.72 & 1.77 & 0.72 & 4.5 & 4.6 & 4.54 \\
\hline & & & & 19200 & 8 & 5 & 1.74 & 1.89 & 1.89 & 1.89 & 0.85 & 5.19 & 5.32 & 5.19 \\
\hline 20 & 1200 & 1 & 2000 & 14000 & 7 & 3 & 1.44 & 1.71 & 1.58 & 1.71 & 0.59 & 3.89 & 3.3 & 3.89 \\
\hline & & & & 16000 & 8 & 4 & 14 & 1.68 & 1.64 & & 0.69 & 4.3 & 3. & .32 \\
\hline & & & & 18000 & 9 & 5 & 1.47 & 1.77 & 1.81 & .77 & 0.74 & 486 & 4. & .86 \\
\hline & & & 2200 & 13200 & 6 & 3 & 138 & 1.61 & 1.45 & .61 & 0.63 & 3.67 & 3. & 67 \\
\hline & & & & 15400 & 7 & 4 & 1.39 & 1.62 & 1.57 & 1.62 & 0.77 & 4.16 & 3.8 & .16 \\
\hline & & & & 17600 & 8 & 5 & 1.49 & 1.73 & 1.75 & 1.73 & 089 & 4.76 & 4.41 & 4.76 \\
\hline & & & 2400 & 12000 & 5 & 3 & 1.26 & 1.46 & 1.45 & 1.46 & 066 & 3.33 & 330 & 333 \\
\hline & & & & 16800 & 7 & 4 & 1.56 & 1.77 & 1.66 & 1.77 & 102 & 4.54 & 4.32 & 4.54 \\
\hline & & & & 19200 & 8 & 5 & 1.67 & 1.89 & 180 & 189 & 118 & 5.19 & 4.89 & 5.19 \\
\hline 20 & 1200 & 2 & 2000 & 14000 & 7 & 3 & 1.44 & 1.71 & 152 & 1.71 & 079 & 3.89 & 312 & 3.89 \\
\hline & & & & 16000 & 8 & 4 & 1.41 & 1.68 & 1.58 & 1.68 & 0.91 & 4.32 & 3.68 & 4.32 \\
\hline & & & & 18000 & 9 & 5 & 1.47 & 1.77 & 1.76 & 1.77 & 100 & 4.86 & 4.08 & 4.86 \\
\hline & & & 2200 & 13200 & 6 & 3 & 1.3 & 1.6 & 140 & $1 . t$ & 0.81 & 3.67 & 3.1 & 3.67 \\
\hline & & & & 15400 & 7 & 4 & 1.39 & 1.62 & 1.51 & 1.6 & 0.97 & 4.16 & 3. & 4.16 \\
\hline & & & & 17600 & 8 & 5 & 148 & 1.73 & 1.69 & 1.7 & 1.12 & 4.76 & 4.13 & 4.76 \\
\hline & & & 2400 & 12000 & 5 & 3 & 1.25 & 1.46 & 1.41 & 1.4 & 0.80 & 3.33 & 3.1 & 3.33 \\
\hline & & & & 16800 & 7 & 4 & 1.54 & 1.77 & 1.60 & 1.77 & 1.21 & 4.54 & 4.04 & 4.54 \\
\hline & & & & 19200 & 8 & 5 & 165 & 189 & 1.74 & 1.89 & 1.40 & 519 & 4.57 & 5.19 \\
\hline 20 & 1400 & 0 & 2000 & 14000 & 7 & 3 & 149 & 1.71 & 1.71 & 1.71 & 0.20 & 3.89 & 3.59 & 3.89 \\
\hline & & & & 16000 & 8 & 4 & 1.47 & 168 & 175 & 1.68 & 0.26 & 4.32 & 4.24 & 4.32 \\
\hline & & & & 18000 & 9 & 5 & 1.47 & 1.77 & 180 & 1.77 & 0.13 & 4.86 & 4.61 & 486 \\
\hline & & & 2200 & 13200 & 6 & 3 & 143 & 1.61 & 1.56 & 1.61 & 0.32 & 3.67 & 3.67 & 367 \\
\hline & & & & 15400 & 7 & 4 & 1.45 & 1.62 & 1.64 & 1.62 & 0.40 & 4.16 & 4.27 & 4.16 \\
\hline & & & & 17600 & 8 & 5 & 1.56 & 1.73 & 1.84 & 1.73 & 0.48 & 4.76 & 4.87 & 4.76 \\
\hline & & & 2400 & 12000 & 5 & 3 & 1.31 & 1.46 & 1.50 & 1.46 & 0.41 & 3.33 & 3.58 & 3.33 \\
\hline & & & & 16800 & 7 & 4 & 1.63 & 1.77 & 1.72 & 1.77 & 0.68 & 4.54 & 4.75 & 4.54 \\
\hline & & & & 19200 & 8 & 5 & 1.74 & 1.89 & 1.88 & 1.89 & 0.80 & 5.19 & 5.41 & 5.19 \\
\hline
\end{tabular}




\begin{tabular}{|c|c|c|c|c|c|c|c|c|c|c|c|c|c|c|}
\hline \multicolumn{7}{|c|}{ Bridge } & \multicolumn{4}{|c|}{$\begin{array}{c}\text { Distribution Factors for Moment } \\
\text { at SLS and ULS }\end{array}$} & \multicolumn{4}{|c|}{$\begin{array}{c}\text { Distribution Factors for Moment } \\
\text { at FLS } \\
\end{array}$} \\
\hline \multirow{2}{*}{$\begin{array}{c}\frac{\tilde{T}}{0} \\
\text { n } \\
m\end{array}$} & \multirow[t]{2}{*}{ 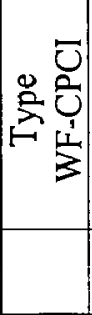 } & \multirow{2}{*}{ 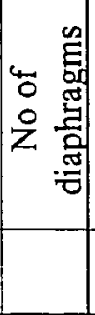 } & \multirow{2}{*}{$\begin{array}{l}\frac{0}{8} \\
\frac{ \pm}{0} \\
\frac{5}{5} \\
\frac{5}{5} \\
\\
m\end{array}$} & \multirow{2}{*}{ 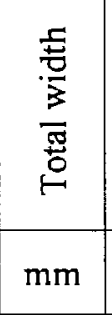 } & \multirow[t]{2}{*}{ 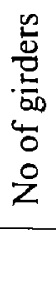 } & \multirow[t]{2}{*}{ 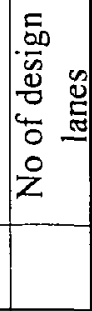 } & \multicolumn{2}{|c|}{ Exterior Girder } & \multicolumn{2}{|c|}{ Interior Girder } & \multicolumn{2}{|c|}{ Exterior Girder } & \multicolumn{2}{|c|}{ Interior Girder } \\
\hline & & & & & & & $\begin{array}{c}\text { Model } \\
F_{v}\end{array}$ & $\begin{array}{c}\text { CHBDC } \\
\mathrm{F}_{\mathrm{v}} \\
\end{array}$ & \begin{tabular}{|c|} 
Model \\
$\mathrm{F}_{\mathrm{v}}$ \\
\end{tabular} & $\begin{array}{c}\mathrm{CHBDC} \\
\mathrm{F}_{\mathrm{v}}\end{array}$ & \begin{tabular}{|c|} 
Model \\
$F_{v}$
\end{tabular} & $\begin{array}{c}\mathrm{CHBDC} \\
\mathrm{F}_{\mathrm{v}} \\
\end{array}$ & $\begin{array}{c}\text { Model } \\
F_{v}\end{array}$ & $\begin{array}{c}\text { CHBDC } \\
\mathrm{F}_{\mathrm{v}}\end{array}$ \\
\hline \multirow[t]{9}{*}{20} & \multirow[t]{9}{*}{1600} & \multirow[t]{9}{*}{0} & \multirow[t]{3}{*}{2000} & 14000 & 7 & 3 & 1.50 & 1.71 & 1.74 & 1.71 & 0.18 & 3.89 & 3.61 & 3.89 \\
\hline & & & & 16000 & 8 & 4 & 1.48 & 1.68 & 1.74 & 1.68 & 0.23 & 4.32 & 4.24 & 4.32 \\
\hline & & & & 18000 & 9 & 5 & 1.48 & 1.77 & 182 & 1.77 & 0.14 & 4.86 & 4.62 & 4.86 \\
\hline & & & 2200 & 13200 & 6 & 3 & 1.44 & 1.61 & 153 & 1.61 & 0.30 & 3.67 & 3.68 & .67 \\
\hline & & & & 15400 & 7 & 4 & 1.45 & 1.62 & 1.63 & 1.62 & 0.38 & 4.16 & 4.30 & .16 \\
\hline & & & & 17600 & 8 & 5 & 156 & 1.73 & 1.84 & 1.73 & 0.46 & 476 & 4.91 & .76 \\
\hline & & & 2400 & 12000 & 5 & 3 & 1.32 & 1.46 & 150 & 1.46 & 0.40 & 3.33 & 3.57 & 3.33 \\
\hline & & & & 16800 & 7 & 4 & 1.63 & 1.77 & 171 & 1.77 & 066 & 4.54 & 4.79 & 4.54 \\
\hline & & & & 19200 & 8 & 5 & 1.75 & 1.89 & 1.85 & 189 & 0.78 & 519 & 5.46 & 5.19 \\
\hline 20 & 1600 & 1 & 2000 & 14000 & 7 & 3 & 1.44 & 1.71 & 1.60 & 1.71 & 0.63 & 3.89 & 3.27 & 3.89 \\
\hline & & & & 16000 & 8 & 4 & 1.42 & 1.68 & 161 & 1.68 & 0.72 & 4.32 & 3.76 & 4.32 \\
\hline & & & & 18000 & 9 & 5 & 1.49 & 177 & 176 & 1.77 & 082 & 4.86 & 4.23 & 4.86 \\
\hline & & & 2200 & 13200 & 6 & 3 & 1.38 & 1.61 & 144 & 1.61 & 068 & 3.67 & 3.32 & 3.67 \\
\hline & & & & 15400 & 7 & 4 & 1.39 & 1.62 & 153 & 1.62 & 038 & 4.16 & 4.30 & 4.16 \\
\hline & & & & 17600 & 8 & 5 & 1.48 & 1.73 & 1.72 & 173 & 0.9 & 476 & 4.40 & 1.76 \\
\hline & & & 2400 & 12000 & 5 & 3 & 1.27 & 1.46 & 142 & 146 & 0.7 & 3.33 & 3.22 & .33 \\
\hline & & & & 16800 & 7 & 4 & 1.55 & 1.77 & 159 & 77 & 1.07 & 454 & 4.28 & .54 \\
\hline & & & & 19200 & 8 & 5 & 1.65 & 1.89 & 172 & 1.89 & 1.23 & 5.19 & 4.87 & 5.19 \\
\hline 20 & 1600 & 2 & 2000 & 14000 & 7 & 3 & 1.44 & 1.71 & 1.53 & 1.71 & 0.86 & 389 & 3.06 & .89 \\
\hline & & & & 16000 & 8 & 4 & 1.41 & 1.68 & 1.54 & 1.68 & 0.9 & $4 . \overline{32}$ & 3.51 & 4.32 \\
\hline & & & & 18000 & 9 & 5 & 148 & 1.77 & 1.71 & 1.77 & 110 & 4.86 & 3.96 & 4.86 \\
\hline & & & 2200 & 13200 & 6 & 3 & 137 & 161 & 139 & 161 & 0.88 & 3.67 & 3.09 & 3.67 \\
\hline & & & & 15400 & 7 & 4 & 1.37 & 1.62 & 146 & 1.62 & 1.04 & 4.16 & 3.60 & 4.16 \\
\hline & & & & 17600 & 8 & 5 & 147 & 1.73 & 166 & 173 & 1.20 & 4.76 & 4.09 & 4.76 \\
\hline & & & 2400 & 12000 & 5 & 3 & 1.26 & 1.46 & 139 & 146 & 0.88 & 333 & 3.00 & 3.33 \\
\hline & & & & 16800 & 7 & 4 & 152 & 1.77 & 153 & 1.77 & 1.29 & 4.54 & 3.97 & 4.54 \\
\hline & & & & 19200 & 8 & 5 & 163 & 1.89 & 165 & 1.89 & 1.48 & 5.19 & 4.50 & 5.19 \\
\hline 25 & 1200 & 0 & 2000 & 14000 & 7 & 3 & 150 & 1.71 & 165 & 1.71 & 0.37 & 389 & 3.44 & 3.89 \\
\hline & & & & 16000 & 8 & 4 & 1.49 & 1.68 & 173 & 1.68 & 0.46 & 4.32 & 4.09 & 4.32 \\
\hline & & & & 18000 & 9 & 5 & 149 & 1.77 & 177 & 77 & 0.3 & 4.86 & 4.41 & 4.86 \\
\hline & & & 2200 & 13200 & 6 & 3 & 1.44 & 1.61 & 148 & 1.61 & 0.4 & 3.67 & 3.4 & 3.67 \\
\hline & & & & 15400 & 7 & 4 & 146 & 1.62 & 161 & 1.62 & 0.57 & 416 & 4.05 & 4.16 \\
\hline & & & & 17600 & 8 & 5 & 136 & 1.73 & 230 & 1.73 & 0.6 & 4.76 & 4.60 & 4.76 \\
\hline & & & 2400 & 12000 & 5 & 3 & 131 & 146 & 143 & 146 & 0.51 & 3.33 & 3.42 & 3.33 \\
\hline & & & & 16800 & 7 & 4 & 163 & 177 & 170 & 177 & 0.84 & 454 & 4.50 & 4.54 \\
\hline & & & & 19200 & 8 & 5 & 1.76 & 189 & 189 & 189 & 1.00 & 519 & 5.11 & 5.19 \\
\hline 25 & 1400 & 0 & 2000 & 14000 & 7 & 3 & 1.51 & 1.71 & 169 & 1.71 & 0.30 & 3.89 & 3.50 & 3.89 \\
\hline & & & & 16000 & 8 & 4 & 1.49 & 1.68 & 174 & 1.68 & 0.38 & 432 & 4.14 & 4.32 \\
\hline & & & & 18000 & 9 & 5 & 150 & 1.77 & 179 & 1.77 & 0.27 & 4.86 & 4.48 & 4.86 \\
\hline & & & 2200 & 13200 & 6 & 3 & 145 & 1.61 & 149 & 1.61 & 0.41 & 3.67 & 3.54 & 3.67 \\
\hline & & & & 15400 & 7 & 4 & 1.46 & 162 & 162 & 1.62 & 0.51 & 4.16 & 4.13 & 4.16 \\
\hline & & & & 17600 & 8 & 5 & 1.58 & 1.73 & 1.83 & 1.73 & 0.62 & 4.76 & 4.70 & 4.76 \\
\hline & & & 2400 & 12000 & 5 & 3 & 1.32 & 1.46 & 1.48 & 1.46 & 0.48 & 3.33 & 3.45 & 3.33 \\
\hline & & & & 16800 & 7 & 4 & 1.64 & 1.77 & 1.70 & 1.77 & 0.79 & 4.54 & 4.58 & 4.54 \\
\hline & & & & 19200 & 8 & 5 & 1.76 & 1.89 & 1.88 & 1.89 & 0.94 & 5.19 & 5.22 & 5.19 \\
\hline
\end{tabular}




\begin{tabular}{|c|c|c|c|c|c|c|c|c|c|c|c|c|c|c|}
\hline \multicolumn{7}{|c|}{ Bridge } & \multicolumn{4}{|c|}{$\begin{array}{c}\text { Distribution Factors for Moment } \\
\text { at SLS and ULS } \\
\end{array}$} & \multicolumn{4}{|c|}{$\begin{array}{c}\text { Distribution Factors for Moment } \\
\text { at FLS }\end{array}$} \\
\hline $\begin{array}{l}\frac{5}{\pi} \\
\text { 号 }\end{array}$ & 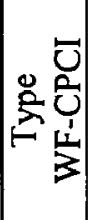 & 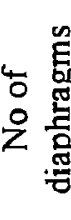 & 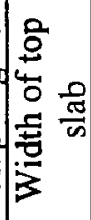 & $\frac{\text { 壱 }}{\frac{0}{3}}$ & 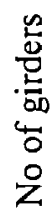 & 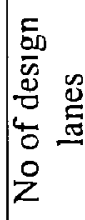 & \multicolumn{2}{|c|}{ Exterior Girder } & \multicolumn{2}{|c|}{ Interior Girder } & \multicolumn{2}{|c|}{ Exterior Girder } & \multicolumn{2}{|c|}{ Interior Girder } \\
\hline $\mathrm{m}$ & & & $\mathrm{mm}$ & $\mathrm{mm}$ & & & $\begin{array}{c}\text { Model } \\
F_{v}\end{array}$ & $\begin{array}{c}\mathrm{CHBDC} \\
\mathrm{F}_{\mathrm{v}}\end{array}$ & $\begin{array}{c}\text { Model } \\
F_{v}\end{array}$ & $\begin{array}{c}\mathrm{CHBDC} \\
\mathrm{F}_{\mathrm{v}}\end{array}$ & $\begin{array}{c}\text { Model } \\
\mathrm{F}_{\mathrm{v}}\end{array}$ & $\begin{array}{c}\text { CHBDC } \\
F_{v}\end{array}$ & $\begin{array}{c}\text { Model } \\
F_{v}\end{array}$ & $\begin{array}{c}\text { CHBDC } \\
F_{v}\end{array}$ \\
\hline \multirow[t]{9}{*}{25} & \multirow[t]{9}{*}{1400} & \multirow[t]{9}{*}{1} & \multirow[t]{3}{*}{2000} & 14000 & 7 & 3 & 1.45 & 1.71 & 1.59 & 1.71 & 0.61 & 3.89 & 3.28 & 3.89 \\
\hline & & & & 16000 & 8 & 4 & 1.42 & 1.68 & 1.65 & 1.68 & 0.70 & 4.32 & 3.85 & 4.32 \\
\hline & & & & 18000 & 9 & 5 & 1.41 & 1.77 & 1.72 & 1.77 & 0.61 & 4.86 & 4.21 & 4.86 \\
\hline & & & \multirow[t]{3}{*}{2200} & 13200 & 6 & 3 & 1.39 & 1.61 & 1.44 & 1.61 & 0.65 & 3.67 & 3.35 & 3.67 \\
\hline & & & & 15400 & 7 & 4 & 140 & 1.62 & 1.56 & 1.62 & 0.79 & 4.16 & 3.89 & 4.16 \\
\hline & & & & 17600 & 8 & 5 & 1.49 & 1.73 & 1.75 & 1.73 & 0.91 & 476 & 4.41 & 4.76 \\
\hline & & & \multirow[t]{3}{*}{2400} & 12000 & 5 & 3 & 1.16 & 1.46 & 1.43 & 1.46 & 0.69 & 3.33 & 3.26 & 3.33 \\
\hline & & & & 16800 & 7 & 4 & 1.56 & 1.77 & 164 & 1.77 & 1.04 & 4.54 & 4.31 & 4.54 \\
\hline & & & & 19200 & 8 & 5 & 1.67 & 189 & 1.80 & 1.89 & 1.21 & 5.19 & 4.89 & 5.19 \\
\hline \multirow[t]{9}{*}{25} & \multirow[t]{9}{*}{1400} & \multirow[t]{9}{*}{2} & \multirow[t]{3}{*}{2000} & 14000 & 7 & 3 & 1.44 & 1.71 & 1.51 & 171 & 0.87 & 3.89 & 3.05 & 3.89 \\
\hline & & & & 16000 & 8 & 4 & 1.54 & 168 & 1.75 & 1.68 & 0.99 & 4.32 & 3.58 & 4.32 \\
\hline & & & & 18000 & 9 & 5 & 1.39 & 177 & 1.66 & 1.77 & 0.94 & 4.86 & 3.90 & 4.86 \\
\hline & & & \multirow[t]{3}{*}{2200} & 13200 & 6 & 3 & 1.37 & 1.61 & 1.39 & 1.61 & 0.88 & 3.67 & 3.10 & 3.67 \\
\hline & & & & 15400 & 7 & 4 & 1.37 & 1.62 & 148 & 1.62 & 1.05 & 4.16 & 3.60 & 4.16 \\
\hline & & & & 17600 & 8 & 5 & 1.46 & 1.73 & 1.67 & 1.73 & 1.20 & 4.76 & 4.08 & 4.76 \\
\hline & & & 2400 & 12000 & 5 & 3 & 1.25 & 1.46 & 1.38 & 1.46 & 0.87 & 3.33 & 3.02 & 3.33 \\
\hline & & & & 16800 & 7 & 4 & 1.52 & 1.77 & 1.57 & 1.77 & 129 & 4.54 & 3.97 & 4.54 \\
\hline & & & & 19200 & 8 & 5 & 1.63 & 1.89 & 1.72 & 1.89 & 1.48 & 5.19 & $4 . \overline{49}$ & 5.19 \\
\hline 25 & 1600 & 0 & 2000 & 14000 & 7 & 3 & 1.52 & 1.71 & 1.72 & 1.71 & 0.27 & 3.89 & 3.52 & 3.89 \\
\hline & & & & 16000 & 8 & 4 & 1.50 & 1.68 & 1.74 & 1.68 & 0.33 & 4.32 & 4.16 & 4.32 \\
\hline & & & & 18000 & 9 & 5 & 1.50 & 1.77 & 1.81 & 1.77 & 0.21 & 4.86 & 4.50 & 486 \\
\hline & & & 2200 & 13200 & 6 & 3 & 1.45 & 1.61 & 1.50 & 1.61 & 0.38 & 3.67 & 3.57 & 3.67 \\
\hline & & & & 15400 & 7 & 4 & 1.47 & 1.62 & 1.61 & 1.62 & 0.48 & 4.16 & 4.17 & 4.16 \\
\hline & & & & 17600 & 8 & 5 & 1.58 & 1.73 & 1.82 & 1.73 & 0.58 & 4.76 & 4.76 & 4.76 \\
\hline & & & 2400 & 12000 & 5 & 3 & 1.32 & 1.46 & 1.49 & 1.46 & 0.47 & 333 & 3.45 & 3.33 \\
\hline & & & & 16800 & 7 & 4 & 1.65 & 1.77 & 1.69 & 1.77 & 0.76 & 4.54 & 4.63 & 4.54 \\
\hline & & & & 19200 & 8 & 5 & 177 & 1.89 & 1.85 & 1.89 & 0.90 & 5.19 & 5.28 & 5.19 \\
\hline 25 & 1600 & 1 & 2000 & 14000 & 7 & 3 & 145 & 1.71 & 1.60 & 1.71 & 0.61 & 3.89 & 3.29 & 3.89 \\
\hline & & & & 16000 & 8 & 4 & 1.42 & 168 & 1.63 & 1.68 & 0.70 & 4.32 & 3.80 & 4.32 \\
\hline & & & & 18000 & 9 & 5 & 141 & 1.77 & 1.73 & 1.77 & 0.62 & 4.86 & 4.19 & 4.86 \\
\hline & & & 2200 & 13200 & 6 & 3 & 139 & 1.61 & 1.44 & 1.61 & 0.67 & 3.67 & 3.33 & 3.67 \\
\hline & & & & 15400 & 7 & 4 & 1.39 & 162 & 1.54 & 1.62 & 0.80 & 4.16 & 3.89 & 4.16 \\
\hline & & & & 17600 & 8 & 5 & 1.49 & 173 & 1.73 & 1.73 & 0.92 & 4.76 & 4.42 & 4.76 \\
\hline & & & 2400 & 12000 & 5 & 3 & 1.27 & 146 & 1.43 & 1.46 & 0.71 & 333 & 3.23 & 3.33 \\
\hline & & & & 16800 & 7 & 4 & 1.55 & 177 & 1.61 & 1.77 & 1.06 & 454 & 4.30 & 4.54 \\
\hline & & & & 19200 & 8 & 5 & 166 & 1.89 & 1.76 & 1.89 & 1.22 & 5.19 & 4.89 & 5.19 \\
\hline 25 & 1600 & 2 & 2000 & 14000 & 7 & 3 & 143 & 171 & 1.51 & 171 & 0.89 & 3.89 & 3.05 & 3.89 \\
\hline & & & & 16000 & 8 & 4 & 140 & 168 & 1.55 & 168 & 1.01 & 432 & 3.50 & 4.32 \\
\hline & & & & 18000 & 9 & 5 & 139 & 1.77 & 1.67 & 177 & 0.97 & 4.86 & 3.87 & 4.86 \\
\hline & & & 2200 & 13200 & 6 & 3 & 137 & 1.61 & 1.38 & 161 & 0.91 & 3.67 & 3.07 & 3.67 \\
\hline & & & & 15400 & 7 & 4 & 1.37 & 162 & 1.46 & 1.62 & 1.08 & 4.16 & 3.58 & 4.16 \\
\hline & & & & 17600 & 8 & 5 & 1.45 & 1.73 & 1.66 & $1 . \overline{73}$ & 1.23 & 4.76 & 4.06 & 4.76 \\
\hline & & & 2400 & 12000 & 5 & 3 & 1.26 & 1.46 & 1.38 & 1.46 & 0.90 & 3.33 & 2.97 & 3.33 \\
\hline & & & & 16800 & 7 & 4 & 1.51 & 1.77 & 1.53 & 1.77 & 1.32 & 4.54 & 3.94 & 4.54 \\
\hline & & & & 19200 & 8 & 5 & 161 & 1.89 & 1.68 & 1.89 & 1.51 & 5.19 & 4.47 & 5.19 \\
\hline
\end{tabular}




\begin{tabular}{|c|c|c|c|c|c|c|c|c|c|c|c|c|c|c|}
\hline \multicolumn{7}{|c|}{ Bridge } & \multicolumn{4}{|c|}{$\begin{array}{c}\text { Distribution Factors for Moment } \\
\text { at SLS and ULS } \\
\end{array}$} & \multicolumn{4}{|c|}{$\begin{array}{c}\text { Distribution Factors for Moment } \\
\text { at FLS }\end{array}$} \\
\hline 范 & 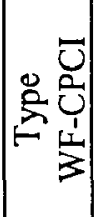 & 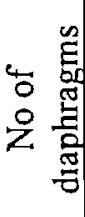 & 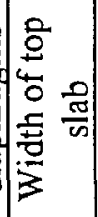 & 壱 & 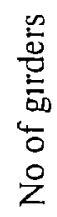 & 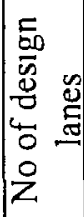 & \multicolumn{2}{|c|}{ Exterior Girder } & \multicolumn{2}{|c|}{ Intenor Girder } & \multicolumn{2}{|c|}{ Exterior Gırder } & \multicolumn{2}{|c|}{ Interior Girder } \\
\hline $\mathrm{m}$ & & & $\mathrm{mm}$ & $\mathrm{mm}$ & & & $\begin{array}{c}\text { Model } \\
F_{v}\end{array}$ & $\begin{array}{c}\mathrm{CHBDC} \\
\mathrm{F}_{\mathrm{v}}\end{array}$ & $\begin{array}{c}\text { Model } \\
\mathrm{F}_{\mathrm{v}}\end{array}$ & $\begin{array}{c}\text { CHBDC } \\
F_{v}\end{array}$ & $\begin{array}{c}\text { Model } \\
F_{v}\end{array}$ & $\begin{array}{c}\mathrm{CHBDC} \\
\mathrm{F}_{\mathrm{v}}\end{array}$ & $\begin{array}{c}\text { Model } \\
F_{v}\end{array}$ & $\begin{array}{c}\text { CHBDC } \\
F_{v}\end{array}$ \\
\hline \multirow[t]{9}{*}{30} & \multirow[t]{9}{*}{1600} & \multirow[t]{9}{*}{0} & \multirow[t]{3}{*}{2000} & 14000 & 7 & 3 & 1.51 & 171 & 1.69 & 171 & 0.30 & 389 & 3.50 & 3.89 \\
\hline & & & & 16000 & 8 & 4 & 149 & 1.68 & 1.74 & 168 & 0.38 & 4.32 & 4.14 & 4.32 \\
\hline & & & & 18000 & 9 & 5 & 1.50 & 1.77 & 1.79 & 1.77 & 0.27 & 486 & 4.48 & 4.86 \\
\hline & & & \multirow[t]{3}{*}{2200} & 13200 & 6 & 3 & 1.45 & 1.61 & 1.49 & 161 & 0.41 & 367 & 3.54 & 3.67 \\
\hline & & & & 15400 & 7 & 4 & 1.46 & 1.62 & 1.62 & 162 & 0.51 & 4.16 & 4.13 & 4.16 \\
\hline & & & & 17600 & 8 & 5 & 1.58 & 1.73 & 183 & 1.73 & 0.62 & 476 & 4.70 & 4.76 \\
\hline & & & \multirow[t]{3}{*}{2400} & 12000 & 5 & 3 & 1.32 & 146 & 148 & 1.46 & 0.48 & 3.33 & 3.45 & 3.33 \\
\hline & & & & 16800 & 7 & 4 & 1.64 & 177 & 1.70 & 1.77 & 0.79 & 4.54 & 4.58 & 4.54 \\
\hline & & & & 19200 & 8 & 5 & 186 & 189 & 1.91 & 189 & 1.04 & 5.19 & 5.41 & 5.19 \\
\hline \multirow[t]{9}{*}{30} & \multirow[t]{9}{*}{1600} & \multirow[t]{9}{*}{1} & \multirow[t]{3}{*}{2000} & 14000 & 7 & 3 & 1.45 & 1.71 & 1.60 & 1.71 & 0.58 & 389 & 3.31 & 3.89 \\
\hline & & & & 16000 & 8 & 4 & 142 & 1.68 & 1.64 & 1.68 & 0.66 & 432 & 3.81 & 4.32 \\
\hline & & & & 18000 & 9 & 5 & 1.41 & 1.77 & 1.75 & 177 & 0.58 & 4.86 & 4.22 & 4.86 \\
\hline & & & \multirow[t]{3}{*}{2200} & 13200 & 6 & 3 & 139 & 1.61 & 1.44 & 1.61 & 0.64 & 367 & 3.35 & 3.67 \\
\hline & & & & 15400 & 7 & 4 & 140 & 162 & 1.53 & 1.62 & 0.77 & 416 & 3.91 & 4.16 \\
\hline & & & & 17600 & 8 & 5 & 1.49 & 1.73 & 1.74 & 1.73 & 0.89 & 476 & 4.45 & 4.76 \\
\hline & & & 2400 & 12000 & 5 & 3 & 1.28 & 1.46 & 143 & 146 & 068 & 333 & 3.24 & 3.33 \\
\hline & & & & 16800 & 7 & 4 & 1.55 & 1.77 & 161 & 177 & 1.03 & 454 & 4.33 & 4.54 \\
\hline & & & & 19200 & 8 & 5 & 166 & 1.89 & 1.76 & 189 & 118 & 5.19 & 4.92 & 5.19 \\
\hline 30 & 1600 & 2 & 2000 & 14000 & 7 & 3 & 143 & 1.71 & 152 & 171 & 084 & 389 & 3.10 & 3.89 \\
\hline & & & & 16000 & 8 & 4 & 1.39 & 1.68 & 1.55 & 1.68 & 0.96 & 432 & 3.53 & 4.32 \\
\hline & & & & 18000 & 9 & 5 & 1.38 & 1.77 & 168 & 1.77 & 0.91 & 486 & 3.93 & 4.86 \\
\hline & & & 2200 & 13200 & 6 & 3 & 1.36 & 1.61 & 1.39 & 161 & 087 & 3.67 & 3.12 & 3.67 \\
\hline & & & & 15400 & 7 & 4 & 136 & 1.62 & 147 & 162 & 103 & 416 & 3.63 & 4.16 \\
\hline & & & & 17600 & 8 & 5 & 1.45 & 1.73 & 1.67 & 173 & 117 & 4.76 & 4.13 & 4.76 \\
\hline & & & $\widehat{2400}$ & 12000 & 5 & 3 & 126 & 146 & 1.39 & 146 & 086 & 333 & 3.02 & 3.33 \\
\hline & & & & 16800 & 7 & 4 & 1.51 & 1.77 & 1.53 & 1.77 & 128 & 454 & 4.01 & 4.54 \\
\hline & & & & 19200 & 8 & 5 & 1.61 & 189 & 1.69 & 189 & 146 & 5.19 & 4.55 & 5.19 \\
\hline 35 & 1600 & 0 & 2000 & 14000 & 7 & 3 & 151 & 171 & 1.68 & 1.71 & 0.39 & 389 & 3.38 & 3.89 \\
\hline & & & & 16000 & 8 & 4 & 150 & 168 & 1.67 & 168 & 047 & 432 & 3.96 & 4.32 \\
\hline & & & & 18000 & 9 & 5 & 1.51 & 1.77 & 1.80 & 1.77 & 0.3 & 4.86 & 4.35 & 4.86 \\
\hline & & & 2200 & 13200 & 6 & 3 & 1.44 & 1.61 & 147 & 1.61 & 0.4 & 367 & 3.43 & 3.67 \\
\hline & & & & 15400 & 7 & 4 & 1.46 & 1.62 & 155 & 162 & 0. & 416 & 4.0 & 4.16 \\
\hline & & & & 17600 & 8 & 5 & 1.58 & 1.73 & 1.79 & 173 & 0.7 & 4.76 & 4.5 & 4.76 \\
\hline & & & 2400 & 12000 & 5 & 3 & 1.32 & 1.46 & 145 & 146 & 056 & 333 & 3.29 & 3.33 \\
\hline & & & & 16800 & 7 & 4 & 1.64 & 1.77 & 1.62 & 1.77 & 088 & 454 & 444 & 4.54 \\
\hline & & & & 19200 & 8 & 5 & 1.76 & 1.89 & 1.78 & 1.89 & 1.05 & 5.19 & 5.06 & 5.19 \\
\hline 35 & 1600 & 1 & 2000 & 14000 & 7 & 3 & 1.46 & 1.71 & 1.61 & 1.71 & 0.54 & 389 & 3.33 & 3.89 \\
\hline & & & & 16000 & 8 & 4 & 1.43 & 1.68 & 1.63 & 168 & 0.62 & 4.32 & 3.82 & 4.32 \\
\hline & & & & \begin{tabular}{|l|}
18000 \\
\end{tabular} & 9 & 5 & 1.42 & 1.77 & 1.76 & 177 & 054 & 486 & 4.25 & 4.86 \\
\hline & & & $\overline{2200}$ & 13200 & 6 & 3 & 1.40 & 1.61 & 1.44 & 161 & 061 & 367 & 3.36 & 3.67 \\
\hline & & & & 15400 & 7 & 4 & 1.40 & 162 & 153 & 162 & 0.74 & 416 & 3.92 & 4.16 \\
\hline & & & & 17600 & 8 & 5 & 1.49 & 1.73 & 1.83 & 1.73 & 0.86 & 4.76 & 4.46 & 4.76 \\
\hline & & & 2400 & 12000 & 5 & 3 & 1.29 & 146 & 1.43 & 1.46 & 0.66 & 3.33 & 3.22 & 3.33 \\
\hline & & & & 16800 & 7 & 4 & 1.56 & 1.77 & 1.59 & 1.77 & 1.00 & 4.54 & 4.34 & 4.54 \\
\hline & & & & 19200 & 8 & 5 & 1.67 & 1.89 & 1.75 & 1.89 & 1.15 & 5.19 & 4.93 & 5.19 \\
\hline
\end{tabular}




\begin{tabular}{|c|c|c|c|c|c|c|c|c|c|c|c|c|c|c|}
\hline \multicolumn{7}{|c|}{ Bridge } & \multicolumn{4}{|c|}{$\begin{array}{c}\text { Distribution Factors for Moment } \\
\text { at SLS and ULS } \\
\end{array}$} & \multicolumn{4}{|c|}{$\begin{array}{c}\text { Distribution Factors for Moment } \\
\text { at FLS } \\
\end{array}$} \\
\hline $\begin{array}{l}\text { 范 } \\
\text { के }\end{array}$ & 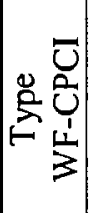 & 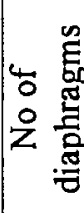 & 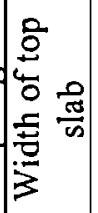 & $\begin{array}{l}\frac{5}{\frac{5}{5}} \\
\frac{\pi}{3} \\
\frac{\pi}{0} \\
\qquad\end{array}$ & 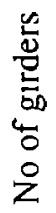 & 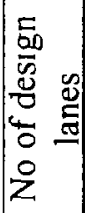 & \multicolumn{2}{|c|}{ Extenor Girder } & \multicolumn{2}{|c|}{ Interior Girder } & \multicolumn{2}{|c|}{ Exterior Girder } & \multicolumn{2}{|c|}{ Interior Girder } \\
\hline $\mathrm{m}$ & & & $\mathrm{mm}$ & $\mathrm{mm}$ & & & $\begin{array}{c}\text { Model } \\
F_{v}\end{array}$ & $\begin{array}{c}\text { CHBDC } \\
F_{v}\end{array}$ & $\begin{array}{c}\text { Model } \\
F_{v}\end{array}$ & $\begin{array}{c}\text { CHBDC } \\
F_{v}\end{array}$ & $\begin{array}{c}\text { Model } \\
F_{v}\end{array}$ & $\begin{array}{c}\text { CHBDC } \\
F_{v}\end{array}$ & $\begin{array}{c}\text { Model } \\
F_{v}\end{array}$ & $\begin{array}{c}\text { CHBDC } \\
F_{\mathrm{v}}\end{array}$ \\
\hline \multirow[t]{9}{*}{35} & \multirow[t]{9}{*}{1600} & \multirow[t]{9}{*}{2} & \multirow{3}{*}{2000} & 14000 & 7 & 3 & 1.42 & 1.71 & 1.53 & 1.71 & 0.79 & 3.89 & 3.14 & 3.89 \\
\hline & & & & \begin{tabular}{|l|}
16000 \\
\end{tabular} & 8 & 4 & 1.38 & 1.68 & 1.55 & 1.68 & 0.89 & 4.32 & 3.58 & 4.32 \\
\hline & & & & \begin{tabular}{|l|}
18000 \\
\end{tabular} & 9 & 5 & 138 & 1.77 & 170 & 1.77 & 084 & 4.86 & 4.00 & 486 \\
\hline & & & \multirow[t]{3}{*}{2200} & 13200 & 6 & 3 & 1.36 & 1.61 & 1.40 & 1.61 & 082 & 367 & 3.16 & 3.67 \\
\hline & & & & 15400 & 7 & 4 & 136 & 1.62 & 1.48 & 1.62 & 098 & 4.16 & 3.69 & 4.16 \\
\hline & & & & 17600 & 8 & 5 & 1.58 & 1.73 & 1.79 & 1.73 & 0.72 & 4.76 & 4.57 & 4.76 \\
\hline & & & \multirow[t]{3}{*}{2400} & 12000 & 5 & 3 & 1.26 & 1.46 & 1.39 & 1.46 & 0.84 & 3.33 & 3.03 & 3.33 \\
\hline & & & & 16800 & 7 & 4 & 1.51 & 1.77 & 1.53 & 1.77 & 1.22 & 4.54 & 4.07 & 4.54 \\
\hline & & & & 19200 & 8 & 5 & 1.60 & 189 & 1.68 & 189 & 1.39 & 5.19 & 4.61 & 5.19 \\
\hline \multirow[t]{9}{*}{35} & \multirow[t]{9}{*}{1900} & \multirow[t]{9}{*}{0} & \multirow[t]{3}{*}{2000} & 14000 & 7 & 3 & 1.52 & 171 & 1.72 & 1.71 & 0.36 & 3.89 & 3.40 & 3.89 \\
\hline & & & & 16000 & 8 & 4 & 1.51 & 1.68 & 1.67 & 1.68 & $04 \overline{4}$ & 4.32 & 3.96 & 4.32 \\
\hline & & & & 18000 & 9 & 5 & 1.52 & 177 & 1.82 & 1.77 & 0.35 & 4.86 & 4.33 & 4.86 \\
\hline & & & \multirow[t]{3}{*}{2200} & 13200 & 6 & 3 & 1.45 & 1.61 & 1.49 & 1.61 & 0.47 & 3.67 & 3.42 & 3.67 \\
\hline & & & & 15400 & 7 & 4 & 1.47 & 1.62 & 1.62 & 1.62 & 0.58 & 4.16 & 4.00 & 4.16 \\
\hline & & & & 17600 & 8 & 5 & 1.58 & 1.73 & 1.87 & 1.73 & 0.70 & 4.76 & 4.59 & 4.76 \\
\hline & & & \multirow[t]{3}{*}{2400} & 12000 & 5 & 3 & 1.32 & 1.46 & 1.49 & 1.46 & 0.56 & 3.33 & 3.26 & 3.33 \\
\hline & & & & 16800 & 7 & 4 & 1.64 & 1.77 & 1.59 & 1.77 & 0.87 & 4.54 & 4.45 & 4.54 \\
\hline & & & & 19200 & 8 & 5 & 1.77 & 1.89 & 1.84 & 1.89 & 1.03 & 5.19 & 5.10 & 5.19 \\
\hline & & & & & & & & & & & & & & \\
\hline
\end{tabular}


B - III. Distribution Factors for Deflection at Serviceability, Ultimate and Fatigue Limit States

\begin{tabular}{|c|c|c|c|c|c|c|c|c|c|c|c|c|c|c|}
\hline \multicolumn{7}{|c|}{ Bridge } & \multicolumn{4}{|c|}{$\begin{array}{c}\text { Distribution Factors for Moment } \\
\text { at SLS and ULS }\end{array}$} & \multicolumn{4}{|c|}{$\begin{array}{c}\text { Distribution Factors for Moment } \\
\text { at FLS }\end{array}$} \\
\hline क्ष & 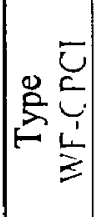 & 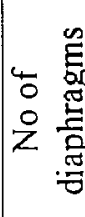 & 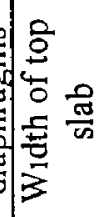 & $\frac{\text { 吾 }}{\frac{0}{3}}$ & 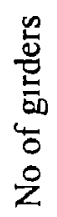 & 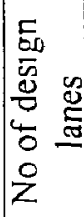 & \multicolumn{2}{|c|}{ Exterıor Girder } & \multicolumn{2}{|c|}{ Interior Girder } & \multicolumn{2}{|c|}{ Exterıor Girder } & \multicolumn{2}{|c|}{ Interior Girder } \\
\hline $\mathrm{m}$ & & & $\mathrm{mm}$ & $\mathrm{mm}$ & & & $\begin{array}{c}\text { Model } \\
\mathrm{F}_{\delta}\end{array}$ & $\begin{array}{c}\mathrm{CHBDC} \\
\mathrm{F}_{8} \\
\end{array}$ & $\begin{array}{c}\text { Model } \\
\mathrm{F}_{\delta}\end{array}$ & $\begin{array}{c}\mathrm{CHBDC} \\
\mathrm{F}_{8} \\
\end{array}$ & $\begin{array}{c}\text { Model } \\
F_{\delta}\end{array}$ & $\begin{array}{c}\mathrm{CHBDC} \\
\mathrm{F}_{\delta}\end{array}$ & $\begin{array}{c}\text { Model } \\
\mathrm{F}_{\delta}\end{array}$ & $\begin{array}{c}\text { CHBDC } \\
\mathrm{F}_{\delta} \\
\end{array}$ \\
\hline \multirow[t]{9}{*}{20} & \multirow[t]{9}{*}{1200} & \multirow[t]{9}{*}{0} & \multirow[t]{3}{*}{2000} & 14000 & 7 & 3 & 106 & 1.51 & 1.13 & 1.51 & 1.23 & 1.58 & 1.55 & 3.01 \\
\hline & & & & 16000 & 8 & 4 & 1.04 & 1.55 & 1.06 & 1.49 & 1.36 & 1.76 & 1.73 & 3.36 \\
\hline & & & & 18000 & 9 & 5 & 1.09 & 1.71 & 112 & 1.65 & 150 & 1.98 & 1.90 & 3.78 \\
\hline & & & \multirow[t]{3}{*}{2200} & 13200 & 6 & 3 & 104 & 1.43 & 1.11 & 142 & 1.19 & 1.49 & 1.50 & 2.80 \\
\hline & & & & 15400 & 7 & 4 & 1.02 & 152 & 1.08 & 147 & 1.33 & 169 & 1.68 & 3.19 \\
\hline & & & & 17600 & 8 & 5 & 1.08 & 1.68 & 1.11 & 1.63 & 1.48 & 1.93 & 1.88 & 3.65 \\
\hline & & & \multirow[t]{3}{*}{2400} & 12000 & 5 & 3 & 1.01 & 1.35 & 1.07 & 1.34 & 114 & 1.35 & 1.40 & 2.51 \\
\hline & & & & 16800 & 7 & 4 & 1.05 & 1.58 & 111 & 1.53 & 1.44 & 1.85 & 1.79 & 3.44 \\
\hline & & & & 19200 & 8 & 5 & 1.12 & 1.76 & 1.13 & 1.70 & 1.60 & 2.11 & 2.00 & 3.93 \\
\hline \multirow[t]{9}{*}{20} & \multirow[t]{9}{*}{1200} & \multirow[t]{9}{*}{1} & \multirow[t]{3}{*}{2000} & 14000 & 7 & 3 & 109 & 151 & 1.07 & 1.51 & 1.45 & 1.58 & 1.39 & .01 \\
\hline & & & & 16000 & 8 & 4 & 1.10 & 1.55 & 1.05 & 149 & 1.5 & 1.76 & 1. & .36 \\
\hline & & & & 18000 & 9 & 5 & 1.17 & 1.71 & 1.11 & 1.65 & 1.7 & 1.98 & 1.6 & .78 \\
\hline & & & \multirow[t]{3}{*}{2200} & 13200 & 6 & 3 & 1.07 & 1.43 & 1.04 & 142 & 1.37 & 1.49 & 1.3 & .80 \\
\hline & & & & 15400 & 7 & 4 & 1.09 & 1.52 & 1.04 & 147 & 1.54 & 169 & 1.46 & .19 \\
\hline & & & & 17600 & 8 & 5 & 1.15 & 1.68 & 1.09 & 163 & 1.69 & 193 & 1.60 & .65 \\
\hline & & & \multirow[t]{3}{*}{2400} & 12000 & 5 & 3 & 1.04 & 1.35 & 1.02 & 1.34 & 1.28 & 1.35 & 1.21 & 2.51 \\
\hline & & & & 16800 & 7 & 4 & 1.12 & 1.58 & 1.06 & 1.53 & 144 & 185 & 1.44 & 3.44 \\
\hline & & & & 19200 & 8 & 5 & 1.18 & 1.76 & 1.11 & 1.70 & 180 & 2.11 & 1.67 & 3.93 \\
\hline \multirow[t]{9}{*}{20} & \multirow[t]{9}{*}{1200} & 2 & 2000 & 14000 & 7 & 3 & 1.09 & 1.51 & 106 & 1.51 & 143 & 1.58 & 1.39 & 3.01 \\
\hline & & & & 16000 & 8 & 4 & 1.10 & 1.55 & 1.05 & 1.49 & 156 & 1.76 & 1.52 & 3.36 \\
\hline & & & & 18000 & 9 & 5 & 1.17 & 1.71 & 111 & 165 & 1.71 & 1.98 & 1.66 & 3.78 \\
\hline & & & 2200 & 13200 & 6 & 3 & 1.07 & 1.43 & 104 & 1.42 & 1.35 & 1.49 & 1.31 & 2.80 \\
\hline & & & & 15400 & 7 & 4 & 109 & 1.52 & 1.04 & 147 & 1.52 & 1.69 & 1.47 & 3.19 \\
\hline & & & & 17600 & 8 & 5 & 1.15 & 168 & 109 & 163 & 1.66 & 1.93 & 1.61 & 3.65 \\
\hline & & & 2400 & 12000 & 5 & 3 & 1.04 & 1.35 & 102 & 1.34 & 127 & 1.35 & 1.22 & 2.51 \\
\hline & & & & 16800 & 7 & 4 & & 1.58 & 1.06 & 1.53 & 16 & 1.85 & 1.53 & 3.44 \\
\hline & & & & 19200 & 8 & 5 & 1.18 & 1.76 & 111 & 1.70 & 1.78 & 2.11 & 1.68 & 3.93 \\
\hline 20 & 1400 & 0 & 2000 & 14000 & 7 & 3 & 1.06 & 1.51 & 115 & 1.51 & 1.22 & 1.58 & 1.63 & 3.01 \\
\hline & & & & 16000 & 8 & 4 & 1.04 & 1.55 & 107 & 1.49 & 134 & 1.76 & 1.81 & 3.36 \\
\hline & & & & 18000 & 9 & 5 & 1.18 & 1.71 & 120 & 1.65 & 161 & 1.98 & 2.11 & 3.78 \\
\hline & & & 2200 & 13200 & 6 & 3 & 1.04 & 1.43 & 1.12 & 1.42 & 118 & 1.49 & 1.57 & 2.80 \\
\hline & & & & 15400 & 7 & 4 & 1.02 & 1.52 & 1.08 & 1.47 & 1.32 & 1.69 & 1.77 & 3.19 \\
\hline & & & & 17600 & 8 & 5 & 1.09 & 1.68 & 1.13 & 1.63 & 1.46 & 1.93 & 1.99 & 3.65 \\
\hline & & & 2400 & 12000 & 5 & 3 & 1.01 & 1.35 & 1.07 & 1.34 & 1.12 & 1.35 & 1.46 & 2.51 \\
\hline & & & & 16800 & 7 & 4 & 1.06 & 1.58 & 1.12 & 1.53 & 1.43 & 1.85 & 1.90 & 3.44 \\
\hline & & & & 19200 & 8 & 5 & 1.13 & 1.76 & 1.15 & 1.70 & 1.60 & 2.11 & 2.13 & 3.93 \\
\hline
\end{tabular}




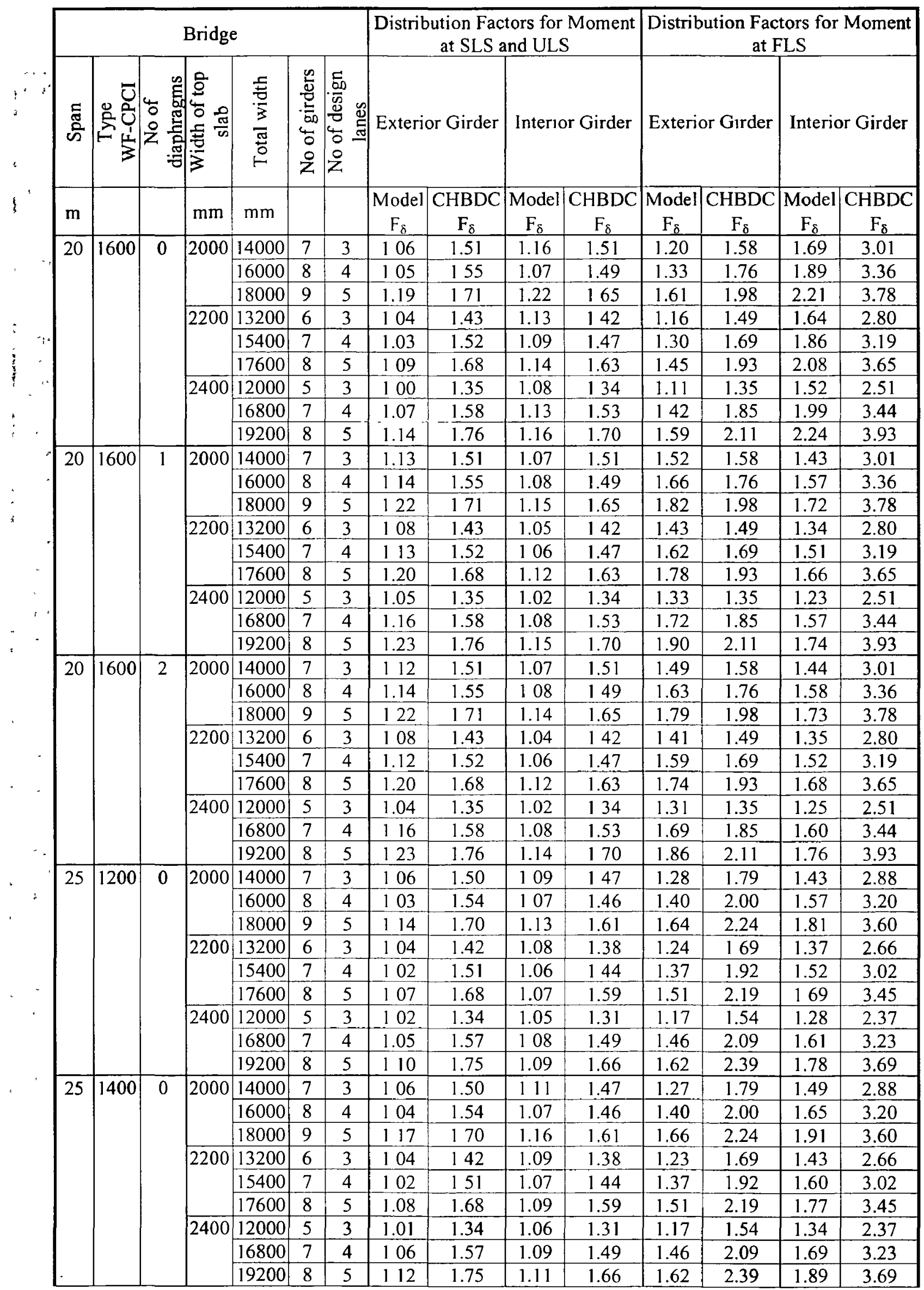




\begin{tabular}{|c|c|c|c|c|c|c|c|c|c|c|c|c|c|c|}
\hline \multicolumn{7}{|c|}{ Bridge } & \multicolumn{4}{|c|}{$\begin{array}{c}\text { Distribution Factors for Moment } \\
\text { at SLS and ULS } \\
\end{array}$} & \multicolumn{4}{|c|}{$\begin{array}{c}\text { Distribution Factors for Moment } \\
\text { at FLS }\end{array}$} \\
\hline \multirow{2}{*}{$\begin{array}{l}\text { क्ष̃ } \\
\text { क }\end{array}$} & \multirow[t]{2}{*}{ 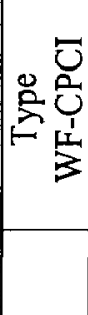 } & \multirow{2}{*}{ 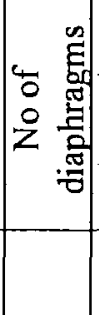 } & \multirow{2}{*}{ 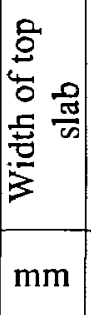 } & 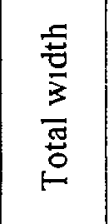 & \multirow[t]{2}{*}{ 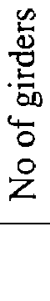 } & \multirow[t]{2}{*}{ 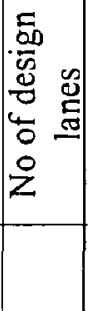 } & \multicolumn{2}{|c|}{ Exterior Girder } & \multicolumn{2}{|c|}{ Interior Girder } & \multicolumn{2}{|c|}{ Extenor Girder } & \multicolumn{2}{|c|}{ Interior Girder } \\
\hline & & & & $\mathrm{mm}$ & & & \begin{tabular}{|c|} 
Model \\
$\mathrm{F}_{\delta}$ \\
\end{tabular} & $\begin{array}{c}\mathrm{CHBDC} \\
\mathrm{F}_{\delta}\end{array}$ & $\begin{array}{c}\text { Model } \\
\mathrm{F}_{\delta} \\
\end{array}$ & $\begin{array}{c}\mathrm{CHBDC} \\
\mathrm{F}_{8} \\
\end{array}$ & $\begin{array}{c}\text { Model } \\
F_{\delta}\end{array}$ & $\begin{array}{c}\mathrm{CHBDC} \\
\mathrm{F}_{8}\end{array}$ & $\begin{array}{c}\text { Model } \\
\mathrm{F}_{\delta}\end{array}$ & $\begin{array}{c}\text { CHBDC } \\
\mathrm{F}_{\delta} \\
\end{array}$ \\
\hline \multirow[t]{9}{*}{25} & \multirow[t]{9}{*}{1400} & \multirow[t]{9}{*}{1} & \multirow{3}{*}{2000} & 14000 & 7 & 3 & 110 & 1.50 & 1.07 & 1.47 & 147 & 1.79 & 1.36 & 2.88 \\
\hline & & & & 16000 & 8 & 4 & 111 & 1.54 & 1.05 & 1.46 & 159 & 2.00 & 1.48 & 3.20 \\
\hline & & & & 18000 & 9 & 5 & 125 & 1.70 & 1.18 & 1.61 & 1.87 & 2.24 & 1.71 & .60 \\
\hline & & & 2200 & 13200 & 6 & 3 & 107 & 1.42 & 104 & 138 & 139 & 1.69 & 1.28 & .66 \\
\hline & & & & 15400 & 7 & 4 & 110 & 151 & 1.04 & 144 & 156 & 1.92 & 1.43 & 3.02 \\
\hline & & & & 17600 & 8 & 5 & 116 & 1.68 & 1.09 & 1.59 & 169 & 2.19 & 1.55 & 3.45 \\
\hline & & & 2400 & 12000 & 5 & 3 & 1.04 & 1.34 & 1.02 & 1.31 & 130 & 154 & 1.18 & 2.37 \\
\hline & & & & 16800 & 7 & 4 & 1.13 & 1.57 & 1.06 & 1.49 & 1.64 & 209 & 1.48 & 3.23 \\
\hline & & & & 19200 & 8 & 5 & 1.19 & 1.75 & 1.11 & 1.66 & 179 & 2.39 & 1.61 & 3.69 \\
\hline 25 & 1400 & 2 & 2000 & 14000 & 7 & 3 & 1.10 & 1.50 & 106 & 147 & 146 & 179 & 1.36 & 2.88 \\
\hline & & & & 16000 & 8 & 4 & 1.11 & 1.54 & 1.05 & 1.46 & 157 & 200 & 1.47 & 3.20 \\
\hline & & & & 18000 & 9 & 5 & 1.25 & 1.70 & 115 & 1.61 & 184 & 2.24 & 1.70 & 3.60 \\
\hline & & & 2200 & 13200 & 6 & 3 & 1.07 & 1.42 & 104 & 1.38 & 137 & $1 \overline{69}$ & 1.27 & 2.66 \\
\hline & & & & 15400 & 7 & 4 & 1.10 & 1.51 & 103 & 1.44 & 154 & 1.92 & 1.42 & .02 \\
\hline & & & & 17600 & 8 & 5 & 1.16 & 1.68 & 109 & 1.59 & 167 & 219 & 1.55 & .45 \\
\hline & & & 2400 & 12000 & 5 & 3 & 1.04 & 1.34 & 1.02 & 1.31 & 128 & 1.54 & 1.19 & 2.37 \\
\hline & & & & \begin{tabular}{|l|}
16800 \\
\end{tabular} & 7 & 4 & 1.13 & 1.57 & 1.05 & 1.49 & 162 & 209 & 1.48 & 3.23 \\
\hline & & & & 19200 & 8 & 5 & 119 & 175 & 1.10 & 1.66 & 177 & 2.39 & 1.61 & 3.69 \\
\hline 25 & 1600 & 0 & 2000 & 14000 & 7 & 3 & 1.07 & 1.50 & 1.13 & 1.47 & 127 & 1.79 & 1.55 & 2.88 \\
\hline & & & & 16000 & 8 & 4 & 1.05 & 1.54 & 1.08 & 1.46 & 139 & 200 & 1.71 & 3.20 \\
\hline & & & & 18000 & 9 & 5 & 1.18 & 1.70 & 1.19 & 1.61 & 1.67 & 2.24 & 2.00 & 3.60 \\
\hline & & & 2200 & 13200 & 6 & 3 & 104 & 1.42 & 1.10 & 1.38 & 122 & 169 & 1.48 & 2.66 \\
\hline & & & & 15400 & 7 & 4 & 103 & 1.51 & 1.07 & 1.44 & 136 & 192 & 1.67 & 3.02 \\
\hline & & & & 17600 & 8 & 5 & 109 & 168 & 1.11 & 1.59 & 1.50 & 2.19 & 1.86 & 3.45 \\
\hline & & & 2400 & 12000 & 5 & 3 & 101 & 1.34 & 1.07 & 1.31 & 1.16 & 154 & 1.38 & 2.37 \\
\hline & & & & 16800 & 7 & 4 & 1.06 & 157 & 110 & 1.49 & 1.46 & 209 & 1.77 & 3.23 \\
\hline & & & & 19200 & 8 & 5 & 113 & 1.75 & 113 & 166 & 1.62 & 239 & 1.98 & 3.69 \\
\hline 25 & 1600 & 1 & 2000 & 14000 & 7 & 3 & $\begin{array}{lll}1111 \\
\end{array}$ & 150 & 107 & 1.47 & 151 & 1.79 & 1.39 & 2.88 \\
\hline & & & & 16000 & 8 & 4 & 113 & 1.54 & 106 & 1.46 & $16 \overline{62}$ & 200 & 1.50 & 3.20 \\
\hline & & & & 18000 & 9 & 5 & 1.28 & 1.70 & 11 & 1.61 & 192 & 224 & 1.75 & 3.60 \\
\hline & & & \begin{tabular}{|l|}
2200 \\
\end{tabular} & 13200 & 6 & 3 & 1.08 & 1.42 & 1.05 & 1.38 & 16 & 169 & 1.2 & 2.66 \\
\hline & & & & 15400 & 7 & 4 & 1.12 & 1.51 & 1.05 & 144 & 159 & 1.92 & 1.45 & 3.02 \\
\hline & & & & 17600 & 8 & 5 & 118 & 1.68 & 110 & 159 & 173 & 2.19 & 1.57 & 3.45 \\
\hline & & & 2400 & 12000 & 5 & 3 & 105 & 1.34 & 1.02 & 131 & 132 & 1.54 & 1.20 & 2.37 \\
\hline & & & & 16800 & 7 & 4 & 115 & 1.57 & 107 & 1.49 & 167 & 209 & 1.50 & 3.23 \\
\hline & & & & 19200 & 8 & 5 & 121 & 1.75 & 112 & 1.66 & 183 & 2.39 & 1.64 & 3.69 \\
\hline 25 & 1600 & 2 & 2000 & 14000 & 7 & 3 & 111 & 1.50 & 1.07 & 1.47 & 149 & 1.79 & 1.39 & 2.88 \\
\hline & & & & 16000 & 8 & 4 & 1.13 & 1.54 & 1.06 & 146 & 161 & 200 & 1.50 & 3.20 \\
\hline & & & & 18000 & 9 & 5 & 1.28 & 1.70 & 1.18 & 161 & 190 & $2 \overline{24}$ & 1.74 & 3.60 \\
\hline & & & 2200 & 13200 & 6 & 3 & 1.08 & 142 & 104 & 1.38 & 140 & $1 \overline{69}$ & 1.29 & 2.66 \\
\hline & & & & 15400 & 7 & 4 & 112 & 151 & 104 & 144 & 157 & 1.92 & 145 & 3.02 \\
\hline & & & & 17600 & 8 & 5 & 1.18 & 1.68 & 1.10 & 1.59 & 1.71 & 2.19 & 1.58 & 3.45 \\
\hline & & & 2400 & 12000 & 5 & 3 & 105 & 1.34 & 1.02 & 1.31 & 1.31 & 1.54 & 1.20 & 2.37 \\
\hline & & & & 16800 & 7 & 4 & 1.15 & 1.57 & 1.06 & 149 & 166 & 2.09 & 151 & 323 \\
\hline & & & & 19200 & 8 & 5 & 1.21 & 1.75 & 1.11 & 1.66 & 180 & 2.39 & 1.64 & 3.69 \\
\hline
\end{tabular}




\begin{tabular}{|c|c|c|c|c|c|c|c|c|c|c|c|c|c|c|}
\hline \multicolumn{7}{|c|}{ Bridge } & \multicolumn{4}{|c|}{$\begin{array}{c}\text { Distribution Factors for Moment } \\
\text { at SLS and ULS }\end{array}$} & \multicolumn{4}{|c|}{\begin{tabular}{|c} 
Distribution Factors for Moment \\
at FLS \\
\end{tabular}} \\
\hline \multirow{2}{*}{$\begin{array}{c}\text { कू } \\
\text { के } \\
\mathrm{m}\end{array}$} & \multirow[t]{2}{*}{ 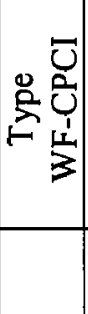 } & \multirow{2}{*}{ 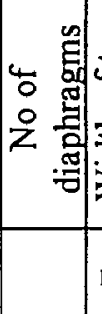 } & \multirow{2}{*}{$\begin{array}{l}\frac{0}{0} \\
\frac{0}{0} \\
\frac{5}{5} \\
\frac{5}{5} \\
0 \\
\mathrm{~mm}\end{array}$} & $\begin{array}{l}\frac{5}{5} \\
\frac{0}{3} \\
\frac{\pi}{0} \\
0\end{array}$ & \multirow[t]{2}{*}{$\begin{array}{l}0 \\
\frac{2}{2} \\
\frac{0}{2} \\
0+0 \\
0 \\
0 \\
0 \\
z\end{array}$} & \multirow[t]{2}{*}{ 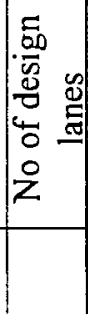 } & \multicolumn{2}{|c|}{ Exterior GIrder } & \multicolumn{2}{|c|}{ Interior Girder } & \multicolumn{2}{|c|}{ Exterior Girder } & \multicolumn{2}{|c|}{ Interior Girder } \\
\hline & & & & $\mathrm{mm}$ & & & $\begin{array}{c}\text { Model } \\
\mathrm{F}_{\delta}\end{array}$ & $\begin{array}{c}\text { CHBDC } \\
\mathrm{F}_{\delta}\end{array}$ & $\begin{array}{c}\text { Model } \\
F_{\delta}\end{array}$ & $\begin{array}{c}\mathrm{CHBDC} \\
\mathrm{F}_{\delta}\end{array}$ & $\begin{array}{c}\text { Model } \\
\mathrm{F}_{\delta}\end{array}$ & $\begin{array}{c}\text { CHBDC } \\
\mathrm{F}_{\delta}\end{array}$ & $\begin{array}{c}\text { Model } \\
F_{\delta}\end{array}$ & $\begin{array}{c}\mathrm{CHBDC} \\
\mathrm{F}_{\delta}\end{array}$ \\
\hline \multirow[t]{9}{*}{30} & \multirow[t]{9}{*}{1600} & \multirow[t]{9}{*}{0} & \multirow[t]{3}{*}{2000} & 14000 & 7 & 3 & 1.06 & 1.50 & 1.11 & 144 & 1.27 & 1.93 & 1.49 & 2.77 \\
\hline & & & & 16000 & 8 & 4 & 1.04 & 1.53 & 1.07 & 144 & 140 & 2.15 & 1.65 & 3.07 \\
\hline & & & & 18000 & 9 & 5 & 1.17 & 169 & I.16 & 1.59 & 1.66 & 2.42 & 1.91 & 346 \\
\hline & & & 2200 & 13200 & 6 & 3 & 1.04 & 1.41 & 1.13 & 1.36 & 1.17 & 1.82 & 1.52 & 2.55 \\
\hline & & & & 15400 & 7 & 4 & 1.02 & 1.51 & 107 & 1.41 & 1.37 & 2.07 & 1.60 & 288 \\
\hline & & & & 17600 & 8 & 5 & 1.08 & 1.67 & 1.09 & 1.57 & 1.51 & 2.36 & 1.77 & 3.30 \\
\hline & & & 2400 & 12000 & 5 & 3 & 1.01 & 1.34 & 1.06 & 1.29 & 117 & 1.65 & 1.34 & 2.26 \\
\hline & & & & 16800 & 7 & 4 & 1.06 & 1.57 & 1.09 & 1.47 & 1.46 & 2.25 & 1.69 & 307 \\
\hline & & & & 19200 & 8 & 5 & 1.49 & 1.74 & 1.48 & 1.63 & 2.19 & 2.58 & 2.43 & 351 \\
\hline 30 & 1600 & 1 & 2000 & 14000 & 7 & 3 & 1.10 & 1.50 & 107 & 1.44 & 1.48 & 1.93 & 1.35 & 2.77 \\
\hline & & & & 16000 & 8 & 4 & 1.12 & 1.53 & 105 & 1.44 & 1.60 & 2.15 & 1.46 & 307 \\
\hline & & & & 18000 & 9 & 5 & 1.26 & 1.69 & 1.16 & 1.59 & 1.87 & 2.42 & 1.69 & 346 \\
\hline & & & 2200 & 13200 & 6 & 3 & 1.07 & 1.41 & 1.04 & 1.36 & 1.40 & 1.82 & 1.26 & 2.55 \\
\hline & & & & 15400 & 7 & 4 & 1.11 & 1.51 & 1.04 & 1.41 & 156 & 2.07 & 1.41 & 2.88 \\
\hline & & & & 17600 & 8 & 5 & 1.17 & 1.67 & 1.09 & 1.57 & 1.69 & 2.36 & 1.52 & 3.30 \\
\hline & & & 2400 & 12000 & 5 & 3 & 1.05 & 1.34 & 1.02 & 1.29 & 1.30 & 1.65 & 1.18 & 2.26 \\
\hline & & & & 16800 & 7 & 4 & 114 & 1.57 & 1.05 & 1.47 & 1.64 & 2.25 & 1.46 & 3.07 \\
\hline & & & & 19200 & 8 & 5 & 1.19 & 1.74 & 1.11 & 1.63 & 1.77 & 2.58 & 1.58 & 3.51 \\
\hline 30 & 1600 & 2 & 2000 & 14000 & 7 & 3 & 1.10 & 1.50 & 1.06 & 1.44 & 1.46 & 1.93 & 1.35 & 277 \\
\hline & & & & 16000 & 8 & 4 & 112 & 1.53 & 1.05 & 1.44 & 1.57 & 2.15 & 1.46 & 307 \\
\hline & & & & 18000 & 9 & 5 & 1.26 & 1.69 & 1.15 & 1.59 & 184 & 2.42 & 1.68 & 3.46 \\
\hline & & & 2200 & 13200 & 6 & 3 & 1.07 & 1.41 & 104 & 1.36 & 1.37 & 1.82 & 1.27 & 255 \\
\hline & & & & 15400 & 7 & 4 & 1.10 & 1.51 & 103 & 141 & 1.54 & 2.07 & 1.41 & 288 \\
\hline & & & & 17600 & 8 & 5 & 1.16 & 1.67 & 109 & 1.57 & 1.66 & 2.36 & 1.53 & 3.30 \\
\hline & & & $\overline{2400}$ & 12000 & 5 & 3 & 1.04 & 1.34 & 1.02 & 1.29 & 1.29 & 1.65 & 1.18 & 2.26 \\
\hline & & & & 16800 & 7 & 4 & 1.13 & 1.57 & 1.05 & 147 & 162 & 2.25 & 1.46 & 3.07 \\
\hline & & & & 19200 & 8 & 5 & 1.19 & 1.74 & 1.10 & 1.63 & 1.75 & 2.58 & 1.59 & 3.51 \\
\hline 35 & 1600 & 0 & 2000 & 14000 & 7 & 3 & 107 & 1.49 & 1.08 & 142 & 1.32 & 2.01 & 1.39 & 2.68 \\
\hline & & & & 16000 & 8 & 4 & 1.05 & 1.53 & 1.06 & 1.42 & 144 & 2.24 & 1.52 & 2.97 \\
\hline & & & & 18000 & 9 & 5 & 1.17 & 1.69 & 1.14 & 157 & 170 & 2.53 & 1.76 & 3.34 \\
\hline & & & 2200 & 13200 & 6 & 3 & 1.05 & 1.41 & 1.07 & 1.34 & 127 & 1.90 & 1.33 & 2.45 \\
\hline & & & & 15400 & 7 & 4 & 1.03 & 1.50 & 105 & 140 & 140 & 2.16 & 1.47 & 2.77 \\
\hline & & & & 17600 & 8 & 5 & 1.08 & 1.67 & 107 & 155 & 1.54 & 2.47 & 1.62 & 316 \\
\hline & & & 2400 & 12000 & 5 & 3 & 1.02 & 1.33 & 104 & 127 & 120 & 1.73 & 1.25 & 216 \\
\hline & & & & 16800 & 7 & 4 & 1.06 & 1.56 & 1.07 & 145 & 1.49 & 2.36 & 1.54 & 2.93 \\
\hline & & & & 19200 & 8 & 5 & 1.11 & 1.73 & 1.09 & 1.62 & 164 & 2.69 & 1.70 & 3.35 \\
\hline 35 & 1600 & 1 & 2000 & 14000 & 7 & 3 & 1.10 & 1.49 & 1.06 & 1.42 & 1.46 & 2.01 & 1.33 & 2.68 \\
\hline & & & & 16000 & 8 & 4 & 1.11 & 1.53 & 1.04 & 142 & 157 & 2.24 & 1.43 & 2.97 \\
\hline & & & & 18000 & 9 & 5 & 1.24 & 1.69 & 114 & 157 & 1.83 & 2.53 & 1.64 & 3.34 \\
\hline & & & 2200 & 13200 & 6 & 3 & 1.07 & 141 & 104 & 134 & 1.38 & 1.90 & $1 . \overline{24}$ & 245 \\
\hline & & & & 15400 & 7 & 4 & 1.10 & 1.50 & 1.03 & 140 & 1.54 & 2.16 & 1.38 & 277 \\
\hline & & & & 17600 & 8 & 5 & 1.15 & 1.67 & 1.08 & 1.55 & 1.65 & 2.47 & 1.48 & 3.16 \\
\hline & & & 2400 & 12000 & 5 & 3 & 1.04 & 1.33 & 1.02 & 1.27 & 1.29 & 1.73 & 1.16 & 2.16 \\
\hline & & & & 16800 & 7 & 4 & 1.13 & 1.56 & 1.04 & 1.45 & 1.61 & 2.36 & 1.43 & 293 \\
\hline & & & & 19200 & 8 & 5 & 1.18 & 1.73 & 1.10 & 1.62 & 1.73 & 2.69 & 1.54 & 3.35 \\
\hline
\end{tabular}




\begin{tabular}{|c|c|c|c|c|c|c|c|c|c|c|c|c|c|c|}
\hline \multicolumn{7}{|c|}{ Bridge } & \multicolumn{4}{|c|}{$\begin{array}{c}\text { Distribution Factors for Moment } \\
\text { at SLS and ULS }\end{array}$} & \multicolumn{4}{|c|}{$\begin{array}{c}\text { Distribution Factors for Moment } \\
\text { at FLS } \\
\end{array}$} \\
\hline 营 & 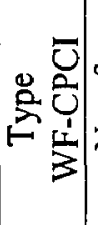 & 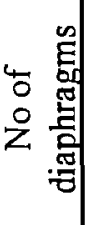 & 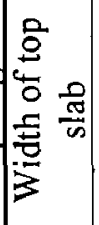 & 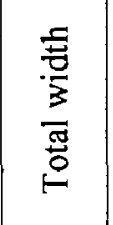 & 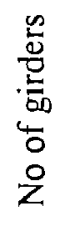 & 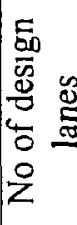 & \multicolumn{2}{|c|}{ Exterior Girder } & \multicolumn{2}{|c|}{ Interior Gırder } & \multicolumn{2}{|c|}{ Extenor Girder } & \multicolumn{2}{|c|}{ Interior Girder } \\
\hline $\mathrm{m}$ & & & $\mathrm{mm}$ & $\mathrm{mm}$ & & & $\begin{array}{c}\text { Model } \\
\mathrm{F}_{\delta} \\
\end{array}$ & $\begin{array}{c}\mathrm{CHBDC} \\
\mathrm{F}_{\delta} \\
\end{array}$ & $\begin{array}{c}\text { Model } \\
\mathbf{F}_{\delta} \\
\end{array}$ & \begin{tabular}{|c} 
CHBDC \\
$\mathrm{F}_{\delta}$ \\
\end{tabular} & $\begin{array}{c}\text { Model } \\
\mathrm{F}_{\delta} \\
\end{array}$ & $\begin{array}{c}\text { CHBDC } \\
\mathrm{F}_{\delta} \\
\end{array}$ & $\begin{array}{c}\text { Model } \\
\mathrm{F}_{\delta}\end{array}$ & \begin{tabular}{|c|c|} 
CHBDC \\
$\mathrm{F}_{\delta}$ \\
\end{tabular} \\
\hline \multirow[t]{9}{*}{35} & 1600 & 2 & 2000 & 14000 & 7 & 3 & 1.09 & 1.49 & 1.06 & 142 & 1.44 & 2.01 & 1.33 & 2.68 \\
\hline & & & & $\mathrm{I} 6000$ & 8 & 4 & 1.10 & 1.53 & 104 & 1.42 & 1.54 & 2.24 & 1.43 & 2.97 \\
\hline & & & & 18000 & 9 & 5 & 1.23 & 1.69 & 1.13 & 1.57 & 1.79 & 2.53 & 1.64 & 3.34 \\
\hline & & & 2200 & 13200 & 6 & 3 & 1.07 & 1.41 & 1.04 & 1.34 & 1.36 & 1.90 & 1.25 & 2.45 \\
\hline & & & & 15400 & 7 & 4 & 1.09 & 1.50 & 1.02 & 1.40 & 1.51 & 2.16 & 1.38 & 2.77 \\
\hline & & & & 17600 & 8 & 5 & 1.08 & 167 & 1.07 & 1.55 & 1.54 & 2.47 & 1.62 & 3.16 \\
\hline & & & 2400 & 12000 & 5 & 3 & 1.04 & 1.33 & 1.02 & 127 & 1.27 & 1.73 & 1.17 & 2.16 \\
\hline & & & & 16800 & 7 & 4 & 1.12 & 156 & 1.04 & 145 & 1.58 & 2.36 & 1.43 & 2.93 \\
\hline & & & & 19200 & 8 & 5 & 1.17 & 1.73 & 1.10 & 162 & 1.70 & 2.69 & 1.55 & 3.35 \\
\hline \multirow[t]{9}{*}{35} & 1900 & 0 & 2000 & 14000 & 7 & 3 & 0.98 & 1.49 & 1.01 & 142 & 121 & 2.01 & 1.33 & 2.68 \\
\hline & & & & 16000 & 8 & 4 & 1.05 & 1.53 & 1.06 & 142 & 1.44 & 2.24 & 1.59 & 2.97 \\
\hline & & & & 18000 & 9 & 5 & 1.26 & 1.69 & 1.23 & 157 & 1.73 & 2.53 & 1.86 & 3.34 \\
\hline & & & 2200 & 13200 & 6 & 3 & 1.05 & 141 & 1.08 & 1.34 & 1.27 & 1.90 & 1.38 & 2.45 \\
\hline & & & & 15400 & 7 & 4 & 1.04 & 1.50 & 1.06 & 140 & 1.40 & 2.16 & 1.54 & 2.77 \\
\hline & & & & 17600 & 8 & 5 & 1.09 & 1.67 & 1.09 & 1.55 & 1.54 & 2.47 & 1.70 & 3.16 \\
\hline & & & 2400 & 12000 & 5 & 3 & 1.02 & 1.33 & 1.05 & 1.27 & 1.20 & 1.73 & 1.29 & 2.16 \\
\hline & & & & 16800 & 7 & 4 & 1.07 & 1.56 & 1.08 & 3.45 & 1.50 & 2.36 & 1.62 & 2.93 \\
\hline & & & & 19200 & 8 & 5 & 1.12 & 1.73 & 1.11 & 1.62 & 1.65 & 2.69 & 1.79 & 3.35 \\
\hline & & & & & & & & & & & & & & \\
\hline
\end{tabular}


B - IV. Moment Distribution Factors for $13.2 \mathrm{~m}$ Width, 6-Girder, Bridges with Various Joint Spacing

\begin{tabular}{|c|c|c|c|c|c|c|c|c|c|c|c|}
\hline & \multicolumn{3}{|c|}{ Joint Spacing $(\mathrm{mm})$} & 0 & 500 & 1000 & 1500 & 2000 & 2500 & 3000 & 3500 \\
\hline Span & $\begin{array}{c}\text { Loaded } \\
\text { Lanes }\end{array}$ & $\begin{array}{l}\text { No of } \\
\text { Diaph }\end{array}$ & $\begin{array}{c}\text { Girder } \\
\text { No. }\end{array}$ & $F_{m}$ & $F_{m}$ & $F_{m}$ & $F_{m}$ & $F_{m}$ & $F_{m}$ & $\mathrm{~F}_{\mathrm{m}}$ & $F_{m}$ \\
\hline \multirow{6}{*}{20} & \multirow{6}{*}{1} & \multirow{6}{*}{0} & 1 & 1.021 & 0.870 & 0.857 & 0.853 & 0.853 & 0.854 & 0.856 & 0.857 \\
\hline & & & 2 & 1.848 & 2.098 & 2.126 & 2.137 & 2.146 & 2.147 & 2.147 & 2.148 \\
\hline & & & 3 & 1.492 & 1.571 & 1.579 & 1583 & 1.587 & 1.593 & 1.602 & 1.608 \\
\hline & & & 4 & 0.719 & 0529 & 0.502 & 0.491 & 0.484 & 0.480 & 0.477 & 0.475 \\
\hline & & & 5 & 0.471 & 0479 & 0.490 & 0.493 & 0.493 & 0492 & 0.490 & 0.488 \\
\hline & & & 6 & 0.430 & 0.453 & 0.447 & 0.443 & 0.437 & 0433 & 0.427 & 0.424 \\
\hline \multirow{6}{*}{20} & \multirow{6}{*}{1} & \multirow{6}{*}{1} & 1 & 1.601 & 1.620 & 1.621 & 1.619 & 1.620 & 1619 & 1.619 & 1.617 \\
\hline & & & 2 & 1.115 & 1.083 & 1.085 & 1.090 & 1.094 & 1.098 & 1.099 & 1.105 \\
\hline & & & 3 & 1.046 & 1.041 & 1.045 & 1051 & 1.055 & 1.060 & 1.067 & 1.066 \\
\hline & & & 4 & 0.995 & 1.036 & 1.041 & 1.045 & 1.048 & 1.051 & 1.053 & 1.055 \\
\hline & & & 5 & 0.698 & 0.683 & 0.678 & 0.675 & 0.672 & 0.670 & 0.667 & 0.665 \\
\hline & & & 6 & 0.418 & 0421 & 0.415 & 0409 & 0.401 & 0.394 & 0.387 & 0.381 \\
\hline \multirow{6}{*}{20} & \multirow{6}{*}{1} & \multirow{6}{*}{2} & 1 & 1.290 & 1272 & 1.271 & 1270 & 1270 & 1.271 & 1.271 & 1.271 \\
\hline & & & 2 & 1.549 & 1.573 & 1.577 & 1.579 & 1.583 & 1.581 & 1.579 & 1.578 \\
\hline & & & 3 & 1.245 & 1.260 & 1.264 & 1.269 & 1.272 & 1.279 & 1.289 & 1.295 \\
\hline & & & 4 & 0.804 & 0.788 & 0.788 & 0.789 & 0.790 & 0.791 & 0.792 & 0.793 \\
\hline & & & 5 & 0.623 & 0.632 & 0.631 & 0.630 & 0.628 & 0.626 & 0.624 & 0.621 \\
\hline & & & 6 & 0.467 & 0465 & 0.460 & 0.455 & 0.449 & 0.443 & 0.438 & 0.434 \\
\hline \multirow{6}{*}{20} & \multirow{6}{*}{2} & \multirow{6}{*}{0} & 1 & 1.006 & 0.995 & 0.999 & 1002 & 1.005 & 1.007 & 1.010 & 1.011 \\
\hline & & & 2 & 1.014 & 1.006 & 1.002 & 1002 & 1.002 & 1.003 & 1.005 & 1.006 \\
\hline & & & 3 & 0.970 & 1013 & 1017 & 1018 & 1.020 & 1020 & 1.019 & 1019 \\
\hline & & & 4 & 0.733 & 0764 & 0.769 & 0771 & 0772 & 0.774 & 0.777 & 0.778 \\
\hline & & & 5 & 0.432 & 0.365 & 0.354 & 0.348 & 0.344 & 0342 & 0.339 & 0.337 \\
\hline & & & 6 & 0.331 & 0.351 & 0.353 & 0.352 & 0.350 & 0.348 & 0.346 & 0.344 \\
\hline \multirow{6}{*}{20} & \multirow{6}{*}{2} & \multirow{6}{*}{1} & 1 & 1.113 & 1.110 & 1.110 & 1109 & 1.109 & 1.110 & 1.110 & 1.111 \\
\hline & & & 2 & 0.944 & 0.950 & 0953 & 0956 & 0.959 & 0.961 & 0.963 & 0.964 \\
\hline & & & 3 & 0.776 & 0775 & 0.778 & 0781 & 0.783 & 0786 & 0.787 & 0.790 \\
\hline & & & 4 & 0.658 & 0651 & 0.652 & 0653 & 0654 & 0.655 & 0.657 & 0.657 \\
\hline & & & 5 & 0.557 & 0.573 & 0.573 & 0.573 & 0.572 & 0.572 & 0.570 & 0.569 \\
\hline & & & 6 & 0.361 & 0.356 & 0.351 & 0.346 & 0.341 & 0.336 & 0.332 & 0.328 \\
\hline \multirow{6}{*}{20} & \multirow{6}{*}{2} & \multirow{6}{*}{2} & 1 & 1.068 & 1.068 & 1.068 & 1.068 & 1.069 & 1070 & 1.071 & 1.071 \\
\hline & & & 2 & 0.972 & 0.971 & 0.972 & 0974 & 0.975 & 0.977 & 0.979 & 0.980 \\
\hline & & & 3 & 0.877 & 0883 & 0.885 & 0887 & 0.888 & 0888 & 0.888 & 0.888 \\
\hline & & & 4 & 0.701 & 0.710 & 0.711 & 0.712 & 0.713 & 0715 & 0718 & 0.720 \\
\hline & & & 5 & 0.485 & 0478 & 0.476 & 0.475 & 0.474 & 0.473 & 0.471 & 0.470 \\
\hline & & & 6 & 0.379 & 0.381 & 0.378 & 0.375 & 0.371 & 0368 & 0.364 & 0.361 \\
\hline \multirow{6}{*}{20} & \multirow{6}{*}{3} & & 1 & 0.889 & 0838 & 0.835 & 0.833 & 0.834 & 0.829 & 0.825 & 0.823 \\
\hline & & & 2 & 1.199 & 1.308 & 1.319 & 1.324 & 1.324 & 1.331 & 1.338 & 1.342 \\
\hline & & 0 & 3 & 1.274 & 1.226 & 1.218 & 1.215 & 1.214 & 1.211 & 1.209 & 1.207 \\
\hline & & 0 & 4 & 1274 & 1227 & 1.220 & 1.218 & 1.217 & 1.215 & 1.214 & 1.214 \\
\hline & & & 5 & 1.199 & 1.302 & 1.313 & 1.315 & 1.318 & 1.315 & 1.313 & 1.311 \\
\hline & & & 6 & 0.889 & 0.847 & 0.844 & 0.844 & 0.843 & 0.847 & 0.851 & 0.854 \\
\hline
\end{tabular}




\begin{tabular}{|c|c|c|c|c|c|c|c|c|c|c|c|}
\hline \multicolumn{4}{|c|}{ Joint Spacing (mm) } & 0 & 500 & 1000 & 1500 & 2000 & 2500 & 3000 & 3500 \\
\hline Span & $\begin{array}{c}\text { Loaded } \\
\text { Lanes }\end{array}$ & $\begin{array}{l}\text { No of } \\
\text { Diaph }\end{array}$ & $\begin{array}{c}\text { Girder } \\
\text { No. }\end{array}$ & $F_{\mathrm{m}}$ & $F_{m}$ & $F_{m}$ & $\mathrm{~F}_{\mathrm{m}}$ & $\mathrm{F}_{\mathrm{m}}$ & $F_{m}$ & $F_{m}$ & $F_{m}$ \\
\hline \multirow{6}{*}{20} & \multirow{6}{*}{3} & \multirow{6}{*}{1} & 1 & 1.118 & 1.124 & 1121 & 1.116 & 1.112 & 1.108 & 1.102 & 1.100 \\
\hline & & & 2 & 1.072 & 1.046 & 1046 & 1.048 & 1.048 & 1.049 & 1.054 & 1.050 \\
\hline & & & 3 & 1.113 & 1.137 & 1.142 & 1.147 & 1.151 & 1.155 & 1.157 & 1.161 \\
\hline & & & 4 & 1.113 & 1.136 & 1.141 & 1.146 & 1.150 & 1.152 & 1.154 & 1.155 \\
\hline & & & 5 & 1.072 & 1.051 & 1051 & 1.052 & 1.054 & 1.055 & 1.054 & 1.057 \\
\hline & & & 6 & 1.118 & 1.126 & 1123 & 1118 & 1.114 & 1.110 & 1.110 & 1.104 \\
\hline \multirow{6}{*}{20} & \multirow{6}{*}{3} & \multirow{6}{*}{2} & 1 & 1.030 & 1.021 & 1018 & 1.014 & 1.012 & 1.006 & 1.000 & 0.995 \\
\hline & & & 2 & 1.158 & 1.180 & 1.181 & 1184 & 1.183 & 1.189 & 1.196 & 1.200 \\
\hline & & & 3 & 1.172 & 1.166 & 1167 & 1170 & 1.172 & 1.172 & 1.171 & 1.171 \\
\hline & & & 4 & 1.172 & 1.167 & 1.169 & 1172 & 1173 & 1.175 & 1.176 & 1.177 \\
\hline & & & 5 & 1.158 & 1.179 & 1.180 & 1.181 & 1.182 & 1180 & 1.177 & 1.175 \\
\hline & & & 6 & 1030 & 1.027 & 1.024 & 1.022 & 1.018 & 1020 & 1.022 & 1.023 \\
\hline \multirow{6}{*}{30} & \multirow{6}{*}{1} & \multirow{6}{*}{0} & 1 & 1.181 & 0.966 & 0.947 & 0.942 & 0942 & 0942 & 0.944 & 0.946 \\
\hline & & & 2 & 1.500 & 1.827 & 1.866 & 1.883 & 1.893 & 1.896 & 1.899 & 1.900 \\
\hline & & & 3 & 1.329 & 1.480 & 1.490 & 1.494 & 1.497 & 1.504 & 1.509 & 1.514 \\
\hline & & & 4 & 0.891 & 0.673 & 0.638 & 0.624 & 0.615 & 0.611 & 0.608 & 0.605 \\
\hline & & & 5 & 0.608 & 0.522 & 0.528 & 0.531 & 0.531 & 0.530 & 0.529 & 0.528 \\
\hline & & & 6 & 0.471 & 0.528 & 0.526 & 0.523 & 0.518 & 0513 & 0.508 & 0.505 \\
\hline \multirow{6}{*}{30} & \multirow{6}{*}{1} & \multirow{6}{*}{1} & 1 & 1.561 & 1.591 & 1.592 & 1.593 & 1.594 & 1.594 & 1.595 & 1.595 \\
\hline & & & 2 & 1.114 & 1.068 & 1.069 & 1.072 & 1.074 & 1.074 & 1.075 & 1.077 \\
\hline & & & 3 & 1.009 & 1.000 & 1004 & 1.005 & 1.008 & 1.012 & 1.012 & 1.011 \\
\hline & & & 4 & 0.969 & 1.013 & 1019 & 1.023 & 1.025 & 1029 & 1.031 & 1.031 \\
\hline & & & 5 & 0.755 & 0.744 & 0.741 & 0.738 & 0.736 & 0.734 & 0.733 & 0.732 \\
\hline & & & 6 & 0.513 & 0.513 & 0.507 & 0.501 & 0.495 & 0.489 & 0.483 & 0.478 \\
\hline \multirow{6}{*}{30} & \multirow{6}{*}{1} & \multirow{6}{*}{2} & 1 & 1.323 & 1.302 & 1301 & 1301 & 1.303 & 1.303 & 1.305 & 1.306 \\
\hline & & & 2 & 1.386 & 1.416 & 1420 & 1424 & 1.426 & 1.425 & 1.423 & 1.421 \\
\hline & & & 3 & 1.165 & 1.177 & 1.181 & 1182 & 1.185 & 1.191 & 1.197 & 1.201 \\
\hline & & & 4 & 0.863 & 0.841 & 0840 & 0841 & 0.840 & 0.842 & 0.842 & 0.842 \\
\hline & & & 5 & 0.692 & 0.701 & 0700 & 0699 & 0.697 & 0.695 & 0.693 & 0.691 \\
\hline & & & 6 & 0.557 & 0.556 & 0.551 & 0.546 & 0.541 & 0.537 & 0.532 & 0.529 \\
\hline \multirow{6}{*}{30} & \multirow{6}{*}{2} & \multirow{6}{*}{0} & 1 & 0.994 & 0.959 & 0.962 & 0.965 & 0968 & 0970 & 0.973 & 0.975 \\
\hline & & & 2 & 0.970 & 0.982 & 0.979 & 0.978 & 0979 & 0.979 & 0.980 & 0.981 \\
\hline & & & 3 & 0.896 & 0.965 & 0.971 & 0.974 & 0.975 & 0976 & 0.976 & 0.976 \\
\hline & & & 4 & 0.725 & 0.749 & 0.754 & 0.755 & 0.757 & 0.759 & 0.760 & $0.76]$ \\
\hline & & & 5 & 0.521 & 0.444 & 0.431 & 0424 & 0.420 & 0417 & 0.415 & 0.413 \\
\hline & & & 6 & 0382 & 0.397 & 0.399 & 0399 & 0397 & 0395 & 0.392 & 0.391 \\
\hline \multirow{6}{*}{30} & & & 1 & 1.086 & 1.087 & 1.087 & 1.087 & 1088 & 1.088 & 1.090 & 1.090 \\
\hline & & & 2 & 0.919 & 0.923 & 0.926 & 0.928 & 0930 & 0.931 & 0.932 & 0.933 \\
\hline & 2 & 1 & 3 & 0.767 & 0.763 & 0765 & 0.767 & 0.769 & 0.770 & 0.770 & 0.772 \\
\hline & & & 4 & 0.665 & 0659 & 0.659 & 0659 & 0.660 & 0.661 & 0.661 & 0.660 \\
\hline & & & 5 & 0.578 & 0.595 & 0.596 & 0.596 & 0595 & 0.595 & 0.594 & 0.593 \\
\hline & & & 6 & 0.423 & 0.418 & 0.413 & 0.409 & 0.405 & 0.401 & 0.397 & 0.395 \\
\hline & & & & & & & & & & & \\
\hline & & & & & & & & & & & \\
\hline & & & & & & & & & & & \\
\hline
\end{tabular}




\begin{tabular}{|c|c|c|c|c|c|c|c|c|c|c|c|}
\hline \multicolumn{4}{|c|}{ Joint Spacing (mm) } & \multirow{2}{*}{$\begin{array}{c}0 \\
F_{m}\end{array}$} & \multirow{2}{*}{$\frac{500}{F_{m}}$} & \multirow{2}{*}{$\frac{1000}{F_{m}}$} & \multirow{2}{*}{$\frac{1500}{F_{m}}$} & \multirow{2}{*}{$\frac{2000}{F_{\mathrm{m}}}$} & \multirow{2}{*}{$\frac{2500}{F_{m}}$} & \multirow{2}{*}{$\frac{3000}{F_{m}}$} & \multirow{2}{*}{$\frac{3500}{F_{m}}$} \\
\hline Span & $\begin{array}{c}\text { Loaded } \\
\text { Lanes }\end{array}$ & $\begin{array}{l}\text { No of } \\
\text { Diaph }\end{array}$ & $\begin{array}{c}\text { Girder } \\
\text { No. }\end{array}$ & & & & & & & & \\
\hline \multirow{6}{*}{30} & \multirow{6}{*}{2} & \multirow{6}{*}{2} & 1 & 1035 & 1.034 & 1.034 & 1.035 & 1.037 & 1.038 & 1.039 & 1.040 \\
\hline & & & 2 & 0.940 & 0.938 & 0.939 & 0.941 & 0.942 & 0.944 & 0.945 & 0.946 \\
\hline & & & 3 & 0.839 & 0.845 & 0.846 & 0.848 & 0.849 & 0.849 & 0.849 & 0.848 \\
\hline & & & 4 & 0697 & 0.705 & 0.706 & 0.707 & 0.707 & 0.709 & 0.711 & 0.712 \\
\hline & & & 5 & 0538 & 0.529 & 0.527 & 0.526 & 0.524 & 0.524 & 0.522 & 0.521 \\
\hline & & & 6 & 0440 & 0.443 & 0.440 & 0.437 & $0 . \overline{434}$ & 0.431 & 0.428 & 0.425 \\
\hline \multirow{6}{*}{30} & \multirow{6}{*}{3} & \multirow{6}{*}{0} & 1 & 0.856 & 0.796 & 0.793 & 0.793 & 0.792 & 0.790 & 0.788 & 0.787 \\
\hline & & & 2 & 1.028 & 1.109 & 1.120 & 1.123 & 1.125 & 1.130 & 1.132 & 1.135 \\
\hline & & & 3 & 1.108 & 1.094 & 1.086 & 1.083 & 1.082 & 1.080 & 1.079 & 1.078 \\
\hline & & & 4 & 1.108 & 1.093 & 1.086 & 1084 & 1.083 & 1.081 & 1.080 & 1.080 \\
\hline & & & 5 & 1.028 & 1.107 & 1.117 & 1.121 & 1.122 & 1.122 & 1.121 & 1.120 \\
\hline & & & 6 & 0856 & 0.802 & 0.799 & 0.797 & 0.797 & 0.800 & 0.802 & 0.803 \\
\hline \multirow{6}{*}{30} & \multirow{6}{*}{3} & \multirow{6}{*}{1} & 1 & 1.022 & 1.031 & 1.028 & 1.026 & 1024 & 1.020 & 1.018 & 1.017 \\
\hline & & & 2 & 0.966 & 0.944 & 0.944 & 0.943 & 0.943 & 0.944 & 0.943 & 0.942 \\
\hline & & & 3 & 0.972 & 0.989 & 0.993 & 0.997 & 0.999 & 1.002 & 1.003 & 1.004 \\
\hline & & & 4 & 0972 & 0.990 & 0.993 & 0.997 & 0.999 & 0.999 & 1.000 & 1.000 \\
\hline & & & 5 & 0.966 & 0.947 & 0.947 & 0.948 & 0.949 & 0.949 & 0.949 & 0.950 \\
\hline & & & 6 & 1.022 & 1.033 & 1.030 & 1.026 & 1.023 & 1.022 & 1.020 & 1.017 \\
\hline \multirow{6}{*}{30} & \multirow{6}{*}{3} & \multirow{6}{*}{2} & 1 & 0.957 & 0.948 & 0.945 & 0.944 & 0.942 & 0.939 & 0.935 & 0.933 \\
\hline & & & 2 & 1.014 & 1.032 & 1.033 & 1.033 & 1.034 & 1.037 & 1.040 & 1.043 \\
\hline & & & 3 & 1.023 & 1.017 & 1.018 & 1.019 & 1.020 & 1.020 & 1.019 & 1.018 \\
\hline & & & 4 & 1.023 & 1.017 & 1.019 & 1.021 & 1.022 & 1.023 & 1.023 & 1.024 \\
\hline & & & 5 & 1.014 & 1.032 & 1.033 & 1.034 & 1.034 & 1.032 & 1.031 & 1.029 \\
\hline & & & 6 & 0.957 & 0.952 & 0.949 & 0.947 & 0.945 & 0.947 & 0.948 & 0.949 \\
\hline
\end{tabular}


B - V. Deflection Lateral Distribution Factors for $13.2 \mathrm{~m}$ Width, 6-Girder, Bridges with Various Joint Spacing

\begin{tabular}{|c|c|c|c|c|c|c|c|c|c|c|c|}
\hline & \multicolumn{3}{|c|}{ Joint Spacing (mm) } & 0 & 500 & 1000 & 1500 & 2000 & 2500 & 3000 & 3500 \\
\hline Span & $\begin{array}{l}\text { Loaded } \\
\text { Lanes }\end{array}$ & $\begin{array}{l}\text { No of } \\
\text { Diaph }\end{array}$ & $\begin{array}{c}\text { Girder } \\
\text { No. }\end{array}$ & $\mathrm{F}_{\delta}$ & $\mathrm{F}_{\delta}$ & $\mathrm{F}_{\delta}$ & $\mathrm{F}_{\delta}$ & $F_{\delta}$ & $F_{\delta}$ & $F_{\delta}$ & $F_{\delta}$ \\
\hline \multirow{6}{*}{20} & \multirow{6}{*}{1} & \multirow{6}{*}{0} & 1 & 1.250 & 1.133 & 1.119 & 1.112 & 1.107 & 1.102 & 1.099 & 1.095 \\
\hline & & & 2 & 1.391 & 1.588 & 1615 & 1.629 & 1.640 & 1.648 & 1.656 & 1.661 \\
\hline & & & 3 & 1.232 & 1.328 & 1.338 & 1.344 & 1.351 & 1.356 & 1.363 & 1.368 \\
\hline & & & 4 & 0.909 & 0.787 & 0765 & 0.754 & 0.747 & 0.741 & 0.737 & 0.733 \\
\hline & & & 5 & 0.674 & 0.622 & 0623 & 0622 & 0.620 & 0.618 & 0.615 & 0.613 \\
\hline & & & 6 & 0.527 & 0555 & 0.554 & 0.551 & 0.548 & 0.546 & 0.543 & 0.541 \\
\hline \multirow{6}{*}{20} & \multirow{6}{*}{1} & \multirow{6}{*}{1} & 1 & 1.434 & 1430 & 1429 & 1429 & 1.429 & 1.429 & 1.429 & 1.429 \\
\hline & & & 2 & 1.335 & 1.344 & 1.347 & 1.351 & 1.354 & 1.357 & 1.360 & 1.362 \\
\hline & & & 3 & 1145 & 1.155 & 1.158 & 1.162 & 1165 & 1.168 & 1.171 & 1.174 \\
\hline & & & 4 & 0.898 & 0.901 & 0.901 & 0.902 & 0903 & 0.904 & 0.905 & 0.906 \\
\hline & & & 5 & 0.668 & 0.671 & 0.670 & 0.668 & 0666 & 0664 & 0.663 & 0.661 \\
\hline & & & 6 & 0.459 & 0.460 & 0.457 & 0.453 & 0.449 & 0.445 & 0.441 & 0.438 \\
\hline \multirow{6}{*}{20} & \multirow{6}{*}{1} & \multirow{6}{*}{2} & 1 & 1.407 & 1.402 & 1.402 & 1.401 & 1402 & 1402 & 1.402 & 1.402 \\
\hline & & & 2 & 1349 & 1.359 & 1.361 & 1.364 & 1367 & 1369 & 1.372 & 1.373 \\
\hline & & & 3 & 1.144 & 1.152 & 1155 & 1159 & 1162 & 1.165 & 1.169 & 1.172 \\
\hline & & & 4 & 0.881 & 0881 & 0.882 & 0.883 & 0884 & 0884 & 0.886 & 0.886 \\
\hline & & & 5 & 0.672 & 0.677 & 0676 & 0675 & 0673 & 0.672 & 0.670 & 0.669 \\
\hline & & & 6 & 0.479 & 0.481 & 0478 & 0.474 & 0471 & 0.467 & 0.463 & 0.460 \\
\hline \multirow{6}{*}{20} & \multirow{6}{*}{2} & \multirow{6}{*}{0} & 1 & 1.013 & 1.007 & 1.009 & 1.010 & 1.011 & 1.012 & 1.013 & 1.013 \\
\hline & & & 2 & 0.992 & 0.990 & 0.988 & 0.988 & 0988 & 0.989 & 0.990 & 0.991 \\
\hline & & & 3 & 0.921 & 0.955 & 0.958 & 0.960 & 0963 & 0.964 & 0.966 & 0.967 \\
\hline & & & 4 & 0719 & 0.743 & 0.748 & 0.750 & 0.751 & 0.752 & 0.753 & 0.754 \\
\hline & & & 5 & 0.476 & 0430 & 0421 & 0.416 & 0.412 & 0.409 & 0.405 & 0.403 \\
\hline & & & 6 & 0.355 & 0.368 & 0.370 & 0.369 & 0.368 & 0.367 & 0.365 & 0.364 \\
\hline \multirow{6}{*}{20} & \multirow{6}{*}{2} & \multirow{6}{*}{1} & 1 & 1.082 & 1.082 & 1082 & 1.082 & 1.083 & 1.084 & 1.085 & 1.085 \\
\hline & & & 2 & 0.960 & 0.963 & 0.964 & 0.966 & 0967 & 0.969 & 0.970 & 0.971 \\
\hline & & & 3 & 0.832 & 0.837 & 0.839 & 0.840 & 0842 & 0843 & 0.845 & 0.846 \\
\hline & & & 4 & 0.684 & 0.688 & 0.689 & 0690 & 0.690 & 0691 & 0691 & 0.692 \\
\hline & & & 5 & 0.526 & 0.527 & 0.526 & 0.525 & 0.524 & 0.523 & 0.523 & 0.522 \\
\hline & & & 6 & 0.379 & 0.379 & 0.377 & 0.375 & 0.373 & 0.370 & 0.368 & 0.366 \\
\hline \multirow{6}{*}{20} & \multirow{6}{*}{2} & \multirow{6}{*}{2} & 1 & 1072 & 1.073 & 1.073 & 1.073 & 1074 & 1.075 & 1.076 & 1.076 \\
\hline & & & 2 & 0.953 & 0.955 & 0.956 & 0958 & 0.959 & 0960 & 0.962 & 0.963 \\
\hline & & & 3 & 0.832 & 0.836 & 0.838 & 0839 & 0.840 & 0842 & 0843 & 0.844 \\
\hline & & & 4 & 0.684 & 0.689 & 0.690 & 0.691 & 0.691 & 0692 & 0.693 & 0.694 \\
\hline & & & 5 & 0.525 & 0.525 & 0.525 & 0.524 & 0523 & 0.522 & 0.521 & 0.521 \\
\hline & & & 6 & 0.391 & 0392 & 0.391 & 0.388 & 0386 & 0.384 & 0.381 & 0.380 \\
\hline \multirow{6}{*}{20} & \multirow{6}{*}{3} & & 1 & 0.950 & 0.917 & 0.914 & 0.911 & 0.909 & 0.906 & 0904 & 0.901 \\
\hline & & & 2 & 1.168 & 1.245 & 1.254 & 1.258 & 1.260 & 1263 & 1265 & 1.269 \\
\hline & & 0 & 3 & 1.239 & 1.209 & 1.204 & 1.202 & 1.202 & 1.201 & 1.201 & 1.200 \\
\hline & & 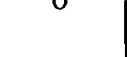 & 4 & 1.239 & 1.209 & 1.205 & 1.204 & 1204 & 1.204 & 1204 & 1.204 \\
\hline & & & 5 & 1.168 & 1.242 & 1.250 & 1.253 & 1.256 & 1.256 & 1.257 & 1.257 \\
\hline & & & 6 & 0.950 & 0.925 & 0.922 & 0.920 & 0.918 & 0.917 & 0.916 & 0.916 \\
\hline
\end{tabular}




\begin{tabular}{|c|c|c|c|c|c|c|c|c|c|c|c|}
\hline \multicolumn{4}{|c|}{ Joint Spacing (mm) } & \multirow{2}{*}{$\begin{array}{c}0 \\
F_{\delta}\end{array}$} & \multirow{2}{*}{$\begin{array}{c}500 \\
F_{\delta}\end{array}$} & \multirow{2}{*}{$\frac{1000}{F_{\delta}}$} & \multirow{2}{*}{$\frac{1500}{F_{\delta}}$} & \multirow{2}{*}{$\frac{2000}{F_{\delta}}$} & \multirow{2}{*}{$\frac{2500}{F_{\delta}}$} & \multirow{2}{*}{$\frac{3000}{F_{\delta}}$} & \multirow{2}{*}{$\frac{3500}{F_{\delta}}$} \\
\hline Span & $\begin{array}{l}\text { Loaded } \\
\text { Lanes }\end{array}$ & $\begin{array}{l}\text { No of } \\
\text { Diaph }\end{array}$ & $\begin{array}{c}\text { Girder } \\
\text { No. }\end{array}$ & & & & & & & & \\
\hline \multirow{6}{*}{20} & \multirow{6}{*}{3} & \multirow{6}{*}{1} & 1 & 1.074 & 1.072 & 1.070 & 1.068 & 1.066 & 1.064 & 1.062 & 1.060 \\
\hline & & & 2 & 1.121 & 1.127 & 1.128 & 1.129 & 1.130 & 1.130 & 1.131 & 1.132 \\
\hline & & & 3 & 1.147 & 1.152 & 1.154 & 1.157 & 1.158 & 1160 & 1.162 & 1.164 \\
\hline & & & 4 & 1.147 & 1.153 & 1.155 & 1.157 & 1.159 & 1161 & 1.163 & 1.165 \\
\hline & & & 5 & 1.121 & 1.129 & 1.130 & 1.131 & 1131 & 1.132 & 1.132 & 1.133 \\
\hline & & & 6 & 1.074 & 1.076 & 1.074 & 1.072 & 1071 & 1.069 & 1.067 & 1.066 \\
\hline \multirow{6}{*}{20} & \multirow{6}{*}{3} & \multirow{6}{*}{2} & 1 & 1.074 & 1.072 & 1.070 & 1.068 & 1.067 & 1.064 & 1.062 & 1.060 \\
\hline & & & 2 & 1.123 & 1.131 & 1.132 & 1133 & 1.134 & 1.135 & 1.137 & 1.138 \\
\hline & & & 3 & 1.141 & 1.144 & 1.146 & 1.148 & 1.150 & 1.152 & 1.153 & 1.155 \\
\hline & & & 4 & 1.141 & 1145 & 1.147 & 1.149 & 1.151 & 1.153 & 1.155 & 1.156 \\
\hline & & & 5 & 1.123 & 1.132 & 1.133 & 1.134 & 1.135 & 1.135 & 1.136 & 1.136 \\
\hline & & & 6 & 1.074 & 1.076 & 1.075 & 1.073 & 1.071 & 1.070 & 1.069 & 1.068 \\
\hline \multirow{6}{*}{30} & \multirow{6}{*}{1} & \multirow{6}{*}{0} & 1 & 1.250 & 1133 & 1.119 & 1.112 & 1.107 & 1.102 & 1.099 & 1.095 \\
\hline & & & 2 & 1.391 & 1.588 & 1.615 & 1.629 & 1.640 & 1648 & 1.656 & 1.661 \\
\hline & & & 3 & 1.232 & 1.328 & 1.338 & 1.344 & 1.351 & 1.356 & 1.363 & 1.368 \\
\hline & & & 4 & 0.909 & 0.787 & 0.765 & 0.754 & 0747 & 0.741 & 0.737 & 0.733 \\
\hline & & & 5 & $0.674^{\prime}$ & 0.622 & 0.623 & 0622 & 0.620 & 0.618 & 0.615 & 0.613 \\
\hline & & & 6 & 0.527 & 0.555 & 0.554 & 0.551 & 0.548 & 0.546 & 0.543 & 0.541 \\
\hline \multirow{6}{*}{30} & \multirow{6}{*}{1} & & 1 & 1.395 & 1.394 & 1.394 & 1.394 & 1.395 & 1.396 & 1.397 & 1.397 \\
\hline & & & 2 & 1.263 & 1.269 & 1.272 & 1.274 & 1.276 & 1.278 & 1.280 & 1.281 \\
\hline & & 1 & 3 & 1.099 & 1.105 & 1.108 & 1.110 & 1.112 & 1.114 & 1.116 & 1.118 \\
\hline & & 1 & 4 & 0.914 & 0.917 & 0.918 & 0.918 & 0.919 & 0.919 & 0.920 & 0.921 \\
\hline & & & 5 & 0.735 & 0738 & 0737 & 0.736 & 0.734 & 0.733 & 0.732 & 0.731 \\
\hline & & & 6 & 0.564 & $0 \overline{566}$ & 0.563 & 0.560 & 0.557 & 0.554 & 0.551 & 0.549 \\
\hline & & & 1 & 1.375 & 1.372 & 1.372 & 1.372 & 1.373 & 1.374 & 1.375 & 1.375 \\
\hline & & & 2 & 1.266 & 1.275 & 1.277 & 1279 & 1.281 & 1.282 & 1.284 & 1.285 \\
\hline 30 & & & 3 & 1.099 & 1.106 & 1.108 & 1.110 & 1.112 & 1.114 & 1.116 & 1.118 \\
\hline 30 & 1 & 2 & 4 & 0.908 & 0.908 & 0.909 & 0.909 & 0.910 & 0.910 & 0.910 & 0.911 \\
\hline & & & 5 & 0.739 & 0744 & 0743 & 0.742 & 0.741 & 0.740 & 0.738 & 0.737 \\
\hline & & & 6 & 0.581 & 0.583 & 0580 & 0.578 & 0575 & 0.572 & 0.569 & 0.567 \\
\hline & & & 1 & 0.993 & 0975 & 0976 & 0.976 & 0.977 & 0977 & 0.978 & 0.978 \\
\hline & & & 2 & 0.945 & 0.956 & 0955 & 0.955 & 0.955 & 0956 & 0.957 & 0957 \\
\hline 30 & 2 & 0 & 3 & 0.862 & 0.905 & 0.910 & 0.913 & 0.915 & 0.917 & 0.919 & 0.921 \\
\hline 30 & 2 & 0 & 4 & 0.717 & 0.733 & 0737 & 0.739 & 0740 & 0.741 & 0.743 & 0.744 \\
\hline & & & 5 & 0.550 & 0.507 & 0.498 & 0.493 & 0.489 & 0.486 & 0.483 & 0.481 \\
\hline & & & 6 & 0.424 & 0432 & 0432 & 0.432 & 0.430 & 0429 & 0.427 & 0.426 \\
\hline & & & 1 & 1.037 & 1.038 & 1.039 & 1.039 & 1.040 & 1.041 & 1.042 & 1.042 \\
\hline & & & 2 & 0.925 & 0.928 & 0.929 & 0.930 & 0.931 & 0.932 & 0.933 & 0.934 \\
\hline 30 & ? & 1 & 3 & 0.812 & 0.816 & 0.817 & 0.818 & 0.819 & 0.820 & 0.821 & 0.821 \\
\hline 30 & 2 & 1 & 4 & 0.691 & 0.695 & 0.695 & 0696 & 0696 & 0.696 & 0.697 & 0.697 \\
\hline & & & 5 & 0.568 & 0.570 & 0.569 & 0.568 & 0567 & 0.567 & 0.566 & 0.565 \\
\hline & & & 6 & 0.449 & 0.450 & 0.449 & 0.447 & 0445 & 0.443 & 0.441 & 0.440 \\
\hline & & & & & & & & & & & \\
\hline & & & & & & & & & & & \\
\hline & & & & & & & & & & & \\
\hline
\end{tabular}




\begin{tabular}{|c|c|c|c|c|c|c|c|c|c|c|c|}
\hline \multicolumn{4}{|c|}{ Joint Spacing (mm) } & 0 & 500 & 1000 & 1500 & 2000 & 2500 & 3000 & 3500 \\
\hline Span & $\begin{array}{c}\text { Loaded } \\
\text { Lanes }\end{array}$ & $\begin{array}{l}\text { No of } \\
\text { Diaph }\end{array}$ & $\begin{array}{c}\text { Girder } \\
\text { No. }\end{array}$ & $F_{\delta}$ & $\mathrm{F}_{\delta}$ & $\mathrm{F}_{\delta}$ & $\mathrm{F}_{\delta}$ & $\mathrm{F}_{\delta}$ & $\mathrm{F}_{\delta}$ & $\mathrm{F}_{\delta}$ & $\mathrm{F}_{\delta}$ \\
\hline \multirow{6}{*}{30} & \multirow{6}{*}{2} & \multirow{6}{*}{2} & 1 & 1.027 & 1.029 & 1.029 & 1.030 & 1.030 & 1.031 & 1.032 & 1.033 \\
\hline & & & 2 & 0.920 & 0.922 & 0.923 & 0.924 & 0.925 & 0.926 & 0.927 & 0.928 \\
\hline & & & 3 & 0.811 & 0815 & 0.816 & 0.817 & 0.818 & 0.819 & 0.819 & 0.820 \\
\hline & & & 4 & 0.693 & 0.697 & 0.697 & 0.698 & 0.698 & 0.698 & 0.699 & 0.699 \\
\hline & & & 5 & 0.570 & 0.571 & 0.570 & 0569 & 0.569 & 0.568 & 0.567 & 0.567 \\
\hline & & & 6 & 0.459 & 0.461 & 0.459 & 0458 & 0456 & 0.454 & 0452 & 0.451 \\
\hline \multirow{6}{*}{30} & \multirow{6}{*}{3} & \multirow{6}{*}{0} & 1 & 0.907 & 0874 & 0.870 & 0868 & 0.865 & 0.863 & 0.861 & 0.858 \\
\hline & & & 2 & 1.016 & 1.065 & 1.073 & 1.076 & 1078 & 1.080 & 1.082 & 1.084 \\
\hline & & & 3 & 1.069 & 1.065 & 1.061 & 1.061 & 1.061 & 1.061 & 1.061 & 1.061 \\
\hline & & & 4 & 1.069 & 1.065 & 1.062 & 1.061 & 1.061 & 1.062 & 1.062 & 1.062 \\
\hline & & & 5 & 1.016 & 1.064 & 1.071 & 1.074 & 1.076 & 1.077 & 1.077 & 1.078 \\
\hline & & & 6 & 0.907 & 0.878 & 0.875 & 0873 & 0871 & 0870 & 0869 & 0.869 \\
\hline \multirow{6}{*}{30} & \multirow{6}{*}{3} & \multirow{6}{*}{1} & 1 & 0.983 & 0.983 & 0.981 & 0.980 & 0.979 & 0.978 & 0.977 & 0.975 \\
\hline & & & 2 & 0.997 & 1.001 & 1.002 & 1.002 & 1.003 & 1.003 & 1.003 & 1.004 \\
\hline & & & 3 & 1.006 & 1.010 & 1.011 & 1.012 & 1.013 & 1.014 & 1.015 & 1.016 \\
\hline & & & 4 & 1.006 & 1.010 & 1.011 & 1013 & 1014 & 1.015 & 1.016 & 1.017 \\
\hline & & & 5 & 0.997 & 1.003 & 1003 & 1.004 & 1.004 & 1004 & 1.005 & 1.005 \\
\hline & & & 6 & 0.983 & 0.985 & 0.984 & 0983 & 0.982 & 0.981 & 0.981 & 0.980 \\
\hline \multirow{6}{*}{30} & \multirow{6}{*}{3} & \multirow{6}{*}{2} & 1 & 0.982 & 0.982 & 0.980 & 0.979 & 0.978 & 0.977 & 0.976 & 0.975 \\
\hline & & & 2 & 0.998 & 1.004 & 1.004 & 1.005 & 1.005 & 1.006 & 1.006 & 1.007 \\
\hline & & & 3 & 1.004 & 1.007 & 1.008 & 1.009 & 1.010 & 1.011 & 1.011 & 1.012 \\
\hline & & & 4 & 1.004 & 1.007 & 1.008 & 1.010 & 1.011 & 1012 & 1.012 & 1.013 \\
\hline & & & 5 & 0.998 & 1.005 & 1.006 & 1.006 & 1.006 & 1006 & 1.007 & 1.007 \\
\hline & & & 6 & 0.982 & 0.984 & 0.983 & 0.982 & 0.982 & 0.981 & 0.981 & 0.981 \\
\hline
\end{tabular}


B - VI. Shear Distribution Factors for $13.2 \mathrm{~m}$ Width, 6-Girder, Bridges with Various Joint Spacing

\begin{tabular}{|c|c|c|c|c|c|c|c|c|c|c|c|}
\hline \multicolumn{4}{|c|}{ Joint Spacıng (mm) } & 0 & 500 & 1000 & 1500 & 2000 & 2500 & 3000 & 3500 \\
\hline Span & $\begin{array}{l}\text { Loaded } \\
\text { Lanes }\end{array}$ & $\begin{array}{l}\text { No of } \\
\text { Diaph }\end{array}$ & $\begin{array}{c}\text { Girder } \\
\text { No. } \\
\end{array}$ & $\mathrm{F}_{\mathrm{v}}$ & $F_{v}$ & $\mathrm{~F}_{\mathrm{v}}$ & $F_{v}$ & $F_{v}$ & $F_{v}$ & $F_{v}$ & $F_{v}$ \\
\hline \multirow{6}{*}{20} & \multirow{6}{*}{1} & \multirow{6}{*}{0} & 1 & 0.300 & -0.030 & -0059 & -0.070 & -0.071 & -0.068 & -0.062 & -0.079 \\
\hline & & & 2 & 3.680 & 4.135 & 4.180 & 4196 & 4.195 & 4.188 & 4.174 & 4.196 \\
\hline & & & 3 & 2.558 & 2745 & 2.752 & 2.750 & 2.741 & 2.737 & 2.734 & 2.737 \\
\hline & & & 4 & -0.081 & -0496 & -0.551 & -0.569 & -0583 & -0.590 & -0.596 & -0.611 \\
\hline & & & 5 & -0.366 & -0298 & -0.263 & -0.250 & -0221 & -0.207 & -0.189 & -0.198 \\
\hline & & & 6 & -0.090 & -0056 & -0.059 & -0.056 & -0061 & -0.060 & -0.060 & -0.044 \\
\hline \multirow{6}{*}{20} & \multirow{6}{*}{1} & \multirow{6}{*}{1} & 1 & 0.686 & 0.561 & 0.551 & 0.544 & 0.542 & 0.541 & 0.541 & 0.530 \\
\hline & & & 2 & 3.312 & 3.454 & 3462 & 3464 & 3.459 & 3.451 & 3.438 & 3.451 \\
\hline & & & 3 & 2.259 & 2.359 & 2.361 & 2.361 & 2.356 & 2.357 & 2.360 & 2.355 \\
\hline & & & 4 & 0.031 & -0146 & -0.159 & -0.159 & -0.163 & -0.162 & -0.165 & -0.164 \\
\hline & & & 5 & -0.187 & -0.119 & -0102 & -0.095 & -0.074 & -0.063 & -0.049 & -0.055 \\
\hline & & & 6 & -0.101 & -0.109 & -0.113 & -0.114 & -0.120 & -0.123 & -0.125 & -0.116 \\
\hline \multirow{6}{*}{20} & \multirow{6}{*}{1} & \multirow{6}{*}{2} & 1 & 0.885 & 0797 & 0786 & 0.775 & 0.768 & 0.762 & 0.758 & 0.747 \\
\hline & & & 2 & 3.086 & 3.170 & 3176 & 3.179 & 3.177 & 3.173 & 3.164 & 3.175 \\
\hline & & & 3 & 2.127 & 2.210 & 2214 & 2.218 & 2.217 & 2.220 & 2.226 & 2.222 \\
\hline & & & 4 & 0.136 & 0.014 & 0008 & 0.012 & 0.009 & 0.010 & 0.008 & 0.012 \\
\hline & & & 5 & -0.112 & -0.066 & -0.053 & -0.048 & -0.028 & -0.018 & -0.006 & -0.013 \\
\hline & & & 6 & -0.121 & -0.126 & -0.132 & -0.136 & -0.143 & -0.148 & -0.151 & -0.144 \\
\hline \multirow{6}{*}{20} & \multirow{6}{*}{2} & \multirow{6}{*}{0} & 1 & 1.166 & 1.133 & 1133 & 1.134 & 1.134 & 1.134 & 1.134 & 1.132 \\
\hline & & & 2 & 1.366 & 1.338 & 1330 & 1.327 & 1323 & 1.323 & 1.322 & 1.319 \\
\hline & & & 3 & 1.461 & 1.539 & 1.541 & 1.537 & 1.531 & 1.522 & 1.511 & 1.516 \\
\hline & & & 4 & 0.796 & 0.877 & 0888 & 0.897 & 0.896 & 0.901 & 0.904 & 0.906 \\
\hline & & & 5 & -0.195 & -0.338 & -0351 & -0.359 & -0.349 & -0.346 & -0.340 & -0.351 \\
\hline & & & 6 & -0.094 & -0.049 & -0.041 & -0.035 & -0.036 & -0.034 & -0.032 & -0.022 \\
\hline \multirow{6}{*}{20} & \multirow{6}{*}{2} & \multirow{6}{*}{1} & 1 & 1270 & 1255 & 1253 & 1.250 & 1.248 & 1.245 & 1.242 & 1.238 \\
\hline & & & 2 & 1.317 & 1.296 & 1.293 & 1.291 & 1.289 & 1.289 & 1.290 & 1.290 \\
\hline & & & 3 & 1.353 & 1.382 & 1381 & 1.378 & 1.374 & 1.367 & 1.358 & 1.360 \\
\hline & & & 4 & 0.762 & 0.816 & 0821 & 0828 & 0.828 & 0.833 & 0.838 & 0.839 \\
\hline & & & 5 & -0.139 & -0.198 & $\begin{array}{lll}-0 & 198 \\
\end{array}$ & -0.198 & -0.186 & -0.181 & -0.174 & -0.179 \\
\hline & & & 6 & -0.064 & -0050 & -0050 & -0.049 & -0.052 & -0.054 & -0.055 & -0.049 \\
\hline \multirow{6}{*}{20} & \multirow{6}{*}{2} & \multirow{6}{*}{2} & 1 & 1.313 & 1.298 & 1294 & 1289 & 1.286 & 1.281 & 1.276 & 1.132 \\
\hline & & & 2 & 1.300 & 1283 & 1282 & 1281 & 1.280 & 1.281 & 1.283 & 1.319 \\
\hline & & & 3 & 1.297 & 1317 & 1.317 & 1316 & 1.313 & 1.308 & 1.301 & 1.516 \\
\hline & & & 4 & 0.747 & 0.789 & 0.794 & 0801 & 0802 & 0.808 & 0.813 & 0.906 \\
\hline & & & 5 & -0.092 & -0.131 & -0128 & -0.127 & -0.115 & -0.110 & -0.103 & -0.351 \\
\hline & & & 6 & -0.064 & -0.056 & -0059 & -0061 & -0065 & -0.067 & -0.070 & -0.022 \\
\hline \multirow{6}{*}{20} & \multirow{6}{*}{3} & & 1 & 0.367 & 0.162 & 0146 & 0.138 & 0.137 & 0.134 & 0.132 & 0.135 \\
\hline & & & 2 & 1.528 & 1.901 & 1938 & 1.955 & 1.963 & 1.975 & 1.984 & 1.980 \\
\hline & & 0 & 3 & 1.480 & 1.305 & 1284 & 1.274 & 1.267 & 1.256 & 1.246 & 1.248 \\
\hline & & 0 & 4 & 1.480 & 1310 & 1291 & 1.281 & 1.277 & 1.278 & 1.278 & 1.276 \\
\hline & & & 5 & 1.528 & 1.882 & 1.917 & 1.935 & 1.940 & 1.940 & 1.941 & 1.940 \\
\hline & & & 6 & 0.367 & 0.190 & 0.174 & 0.167 & 0.166 & 0.167 & 0.169 & 0.171 \\
\hline
\end{tabular}




\begin{tabular}{|c|c|c|c|c|c|c|c|c|c|c|c|}
\hline \multicolumn{4}{|c|}{ Joint Spacing (mm) } & \multirow{2}{*}{ 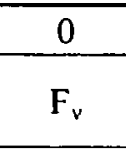 } & \multirow{2}{*}{$\frac{500}{F_{v}}$} & \multirow{2}{*}{$\frac{1000}{F_{v}}$} & \multirow{2}{*}{$\frac{1500}{F_{v}}$} & \multirow{2}{*}{$\frac{2000}{F_{v}}$} & \multirow{2}{*}{$\frac{2500}{F_{v}}$} & \multirow{2}{*}{$\frac{3000}{F_{v}}$} & \multirow{2}{*}{$\frac{3500}{F_{v}}$} \\
\hline Span & $\begin{array}{l}\text { Loaded } \\
\text { Lanes }\end{array}$ & $\begin{array}{l}\text { No of } \\
\text { Diaph }\end{array}$ & $\begin{array}{c}\text { Girder } \\
\text { No. }\end{array}$ & & & & & & & & \\
\hline \multirow{6}{*}{20} & \multirow{6}{*}{3} & \multirow{6}{*}{1} & 1 & 0.540 & 0.407 & 0.395 & 0.387 & 0.382 & 0375 & 0.368 & 0.369 \\
\hline & & & 2 & 1.471 & 1.708 & 1.725 & 1.735 & 1.740 & 1750 & 1.760 & 1.755 \\
\hline & & & 3 & 1.364 & 1.252 & 1.245 & 1.244 & 1.243 & 1.238 & 1.233 & 1.238 \\
\hline & & & 4 & 1.365 & 1258 & 1.253 & 1.252 & 1.253 & 1.260 & 1.264 & 1.265 \\
\hline & & & 5 & 1.471 & 1.694 & 1710 & 1.720 & 1.723 & 1.722 & 1.722 & 1.721 \\
\hline & & & 6 & 0.540 & 0.432 & 0421 & 0.412 & 0.408 & 0404 & 0.402 & 0.402 \\
\hline \multirow{6}{*}{20} & \multirow{6}{*}{3} & \multirow{6}{*}{2} & 1 & 0.613 & 0503 & 0.490 & 0.477 & 0.470 & 0.460 & 0.450 & 0.449 \\
\hline & & & 2 & 1.432 & 1620 & 1635 & 1.644 & 1.649 & 1.660 & 1.672 & 1.668 \\
\hline & & & 3 & 1.330 & 1242 & 1.241 & 1.244 & 1246 & 1.244 & 1.239 & 1.245 \\
\hline & & & 4 & 1330 & 1.249 & 1.249 & 1.252 & 1.255 & 1.263 & 1.269 & 1.271 \\
\hline & & & 5 & 1.432 & 1.609 & 1.622 & 1.631 & 1.636 & 1.636 & 1.638 & 1.635 \\
\hline & & & 6 & 0.613 & 0.526 & 0.514 & 0.502 & 0.494 & 0487 & 0.482 & 0.481 \\
\hline \multirow{6}{*}{30} & \multirow{6}{*}{1} & \multirow{6}{*}{0} & 1 & 0.441 & -0.036 & -0.073 & -0.080 & -0.074 & -0.067 & -0.057 & -0.107 \\
\hline & & & 2 & 3484 & 4127 & 4.185 & 4.196 & 4.184 & 4.168 & 4.146 & 4.227 \\
\hline & & & 3 & 2468 & 2.755 & 2.764 & 2.760 & 2.759 & 2.759 & 2.759 & 2.753 \\
\hline & & & 4 & 0.056 & -0.461 & -0528 & -0.540 & -0566 & -0.574 & -0.578 & -0.604 \\
\hline & & & 5 & -0.305 & -0325 & -0286 & -0.279 & -0.234 & -0.217 & -0.201 & -0.227 \\
\hline & & & 6 & -0.145 & -0060 & -0.063 & -0057 & -0069 & -0.069 & -0069 & -0.041 \\
\hline \multirow{6}{*}{30} & \multirow{6}{*}{1} & & 1 & 0641 & 0.436 & 0.428 & 0.431 & 0.440 & 0.447 & 0.455 & 0.420 \\
\hline & & & 2 & 3.350 & 3616 & 3.624 & 3.615 & 3.595 & 3.575 & 3.552 & 3.614 \\
\hline & & 1 & 3 & 2300 & 2429 & 2.429 & 2.423 & 2.424 & 2.426 & 2.428 & 2.405 \\
\hline & & 1 & 4 & 0.032 & -0.246 & -0266 & -0259 & -0.272 & -0.273 & -0.271 & -0.279 \\
\hline & & & 5 & -0.233 & -0.147 & -0122 & -0.120 & -0.083 & -0.070 & -0.056 & -0.073 \\
\hline & & & 6 & -0.089 & -0.087 & -0093 & -0.090 & -0.103 & -0105 & -0.107 & -0088 \\
\hline & & & 1 & 0.869 & 0755 & 0.750 & 0.750 & 0.753 & 0756 & 0.757 & 0.731 \\
\hline & & & 2 & 3.119 & 3.245 & 3.244 & 3234 & 3.216 & 3.199 & 3.182 & 3.232 \\
\hline 30 & 1 & 2 & 3 & 2.129 & 2223 & 2.224 & 2222 & 2.228 & 2.233 & 2.239 & 2.211 \\
\hline 30 & 1 & 2 & 4 & 0.116 & -0.047 & -0.053 & -0.042 & -0.052 & -0051 & -0.049 & -0.046 \\
\hline & & & 5 & -0.129 & -0.064 & -0044 & -0.044 & -0010 & 0002 & 0.014 & 0.000 \\
\hline & & & 6 & -0.104 & -0.112 & -0120 & -0.120 & -0135 & -0139 & -0.143 & -0.128 \\
\hline & & & 1 & 1.185 & 1.120 & 1121 & 1.124 & 1.126 & 1.127 & 1.127 & 1.122 \\
\hline & & & 2 & 1.367 & 1.357 & 1347 & 1341 & 1.338 & 1337 & 1.336 & 1.331 \\
\hline 30 & 2 & 0 & 3 & 1.419 & 1.537 & 1.540 & 1534 & 1523 & 1.512 & 1.499 & 1.523 \\
\hline 30 & 2 & U & 4 & 0.788 & 0873 & 0886 & 0901 & 0899 & 0904 & 0.910 & 0.900 \\
\hline & & & 5 & -0.146 & -0.327 & -0341 & -0356 & -0337 & -0332 & -0.326 & -0.345 \\
\hline & & & 6 & -0.113 & -0.061 & -0053 & -0044 & -0050 & -0048 & -0.047 & -0.032 \\
\hline & & & 1 & 1.251 & 1231 & 1.233 & 1.234 & 1.234 & 1.234 & 1.232 & 1.228 \\
\hline & & & 2 & 1.337 & 1.310 & 1303 & 1.298 & 1.296 & 1.296 & 1.296 & 1.293 \\
\hline 30 & 2 & 1 & 3 & 1.361 & 1.408 & 1.406 & 1.399 & 1.389 & 1.378 & 1.367 & 1.384 \\
\hline 50 & 2 & 1 & 4 & 0.758 & 0.825 & 0.831 & 0.843 & 0.842 & 0.847 & 0.854 & 0.842 \\
\hline & & & 5 & -0.135 & -0228 & -0.227 & -0.232 & -0.212 & -0205 & -0.197 & -0.208 \\
\hline & & & 6 & -0.072 & -0046 & -0.046 & -0.042 & -0.049 & -0.050 & -0.051 & -0.039 \\
\hline & & & & & & & & & & & \\
\hline & & & & & & & & & & & \\
\hline & & & & & & & & & & & \\
\hline
\end{tabular}




\begin{tabular}{|c|c|c|c|c|c|c|c|c|c|c|c|}
\hline \multicolumn{4}{|c|}{ Joint Spacing (mm) } & 0 & 500 & 1000 & 1500 & 2000 & 2500 & 3000 & 3500 \\
\hline Span & $\begin{array}{c}\text { Loaded } \\
\text { Lanes }\end{array}$ & $\begin{array}{l}\text { No of } \\
\text { Diaph }\end{array}$ & $\begin{array}{c}\text { Girder } \\
\text { No. }\end{array}$ & $F_{v}$ & $F_{v}$ & $F_{v}$ & $F_{v}$ & $F_{v}$ & $F_{v}$ & $F_{v}$ & $F_{v}$ \\
\hline \multirow{6}{*}{30} & \multirow{6}{*}{2} & \multirow{6}{*}{2} & 1 & 1.309 & 1.295 & 1.294 & 1.293 & 1.291 & 1.289 & 1.286 & 1.281 \\
\hline & & & 2 & 1.310 & 1.289 & 1.284 & 1.279 & 1.278 & 1.279 & 1.280 & 1.278 \\
\hline & & & 3 & 1.296 & 1.322 & 1.320 & 1.316 & 1307 & 1.299 & 1.289 & 1.304 \\
\hline & & & 4 & 0.740 & 0.789 & 0.794 & 0.806 & 0807 & 0.814 & 0.821 & 0.809 \\
\hline & & & 5 & -0.094 & -0.146 & -0.140 & -0.143 & -0.123 & -0116 & -0109 & -0.115 \\
\hline & & & 6 & -0.061 & -0.049 & -0.052 & -0.052 & -0.061 & -0.064 & -0.066 & -0.056 \\
\hline \multirow{6}{*}{30} & \multirow{6}{*}{3} & \multirow{6}{*}{0} & 1 & 0.351 & 0.132 & 0.116 & 0.110 & 0107 & 0105 & 0.102 & 0.110 \\
\hline & & & 2 & 1.330 & 1.686 & 1.723 & 1.739 & 1754 & 1764 & 1.776 & 1.753 \\
\hline & & & 3 & 1.318 & 1.176 & 1.155 & 1144 & 1130 & 1119 & 1.108 & 1.130 \\
\hline & & & 4 & 1.318 & 1.180 & 1.162 & 1.152 & 1.154 & 1154 & 1.154 & 1.142 \\
\hline & & & 5 & 1.330 & 1.669 & 1.703 & 1.719 & 1719 & 1.718 & 1.714 & 1.727 \\
\hline & & & 6 & 0.351 & 0.157 & 0.142 & 0136 & 0137 & 0.140 & 0.145 & 0.139 \\
\hline \multirow{6}{*}{30} & \multirow{6}{*}{3} & \multirow{6}{*}{1} & 1 & 0.463 & 0.319 & 0.310 & 0.306 & 0.302 & 0298 & 0.293 & 0.303 \\
\hline & & & 2 & 1.305 & 1.565 & 1.581 & 1.589 & 1.601 & 1.609 & 1.621 & 1.596 \\
\hline & & & 3 & 1.233 & 1.109 & 1.101 & 1.097 & 1.087 & 1.079 & 1.072 & 1.093 \\
\hline & & & 4 & 1.233 & 1.115 & 1.109 & 1.106 & 1111 & 1.115 & 1.118 & 1.105 \\
\hline & & & 5 & 1.305 & 1.551 & 1.566 & 1.573 & 1570 & 1.567 & 1.562 & 1.575 \\
\hline & & & 6 & 0.463 & 0.342 & 0.334 & 0.329 & 0330 & 0.331 & 0.334 & 0.328 \\
\hline \multirow{6}{*}{30} & \multirow{6}{*}{3} & \multirow{6}{*}{2} & 1 & 0.547 & 0.436 & 0.426 & 0.419 & 0411 & 0.404 & 0.397 & 0.406 \\
\hline & & & 2 & 1.273 & 1.468 & 1.480 & 1.487 & 1.500 & 1.509 & 1.519 & 1.494 \\
\hline & & & 3 & 1.180 & 1.088 & 1.085 & 1.085 & 1078 & 1.074 & 1.069 & 1.091 \\
\hline & & & 4 & 1.180 & 1.094 & 1.093 & 1.095 & 1102 & 1.109 & 1.113 & 1.102 \\
\hline & & & 5 & 1.273 & 1.457 & 1.467 & 1.473 & 1471 & 1.469 & 1.466 & 1.477 \\
\hline & & & 6 & 0.547 & 0.457 & 0.448 & 0.441 & 0.438 & 0.435 & 0.435 & 0.430 \\
\hline
\end{tabular}




\section{APPENDIX C}

C - I. Accuracy factors of Bending Moment, Deflection and Shear for Various Number of Elements in The Finite Element Model

\begin{tabular}{|c|c|c|c|}
\hline $\begin{array}{l}\text { No of } \\
\text { elements }\end{array}$ & $\begin{array}{l}\text { Max. moment } \\
\text { factor }\end{array}$ & $\begin{array}{c}\text { Max. } \\
\text { deflection } \\
\text { factor }\end{array}$ & $\begin{array}{l}\text { Max. shear } \\
\text { factor }\end{array}$ \\
\hline \multicolumn{4}{|c|}{ Longitudinal direction: } \\
\hline 20 & 0.976 & 0.998 & 1.004 \\
\hline 30 & 0.992 & 1.000 & 1.002 \\
\hline 40 & 0.994 & 1.000 & 1.001 \\
\hline 60 & 1.000 & 1.000 & 1.000 \\
\hline 120 & 1.009 & 1.003 & 1.007 \\
\hline \multicolumn{4}{|c|}{ Transverse direction: } \\
\hline 2 & $0 . \overline{998}$ & 0.997 & 0.994 \\
\hline 3 & 1.000 & 0.999 & 0.999 \\
\hline 4 & 1.000 & 1.000 & 1.000 \\
\hline 6 & 1.001 & 1.001 & 1.000 \\
\hline \multicolumn{4}{|c|}{ Vertical direction: } \\
\hline 1 & 0.992 & 0.997 & 0.995 \\
\hline 2 & 1.000 & 1.000 & 1.000 \\
\hline 3 & 1.008 & 1.003 & 1.000 \\
\hline 4 & 1.011 & 1.004 & 1.000 \\
\hline \multicolumn{4}{|l|}{ Diaphragm: } \\
\hline 1 & 1.003 & 1.006 & 0.999 \\
\hline 2 & 1.001 & 1.002 & 1.010 \\
\hline 3 & 1.002 & 1.005 & 1.005 \\
\hline 4 & 1.000 & 1.000 & 1.000 \\
\hline
\end{tabular}

Note: The results are for a bridge with $30 \mathrm{~m}$ span, $13.2 \mathrm{~m}$ width, 6 girders and $2.2 \mathrm{~m}$ girder spacing. 